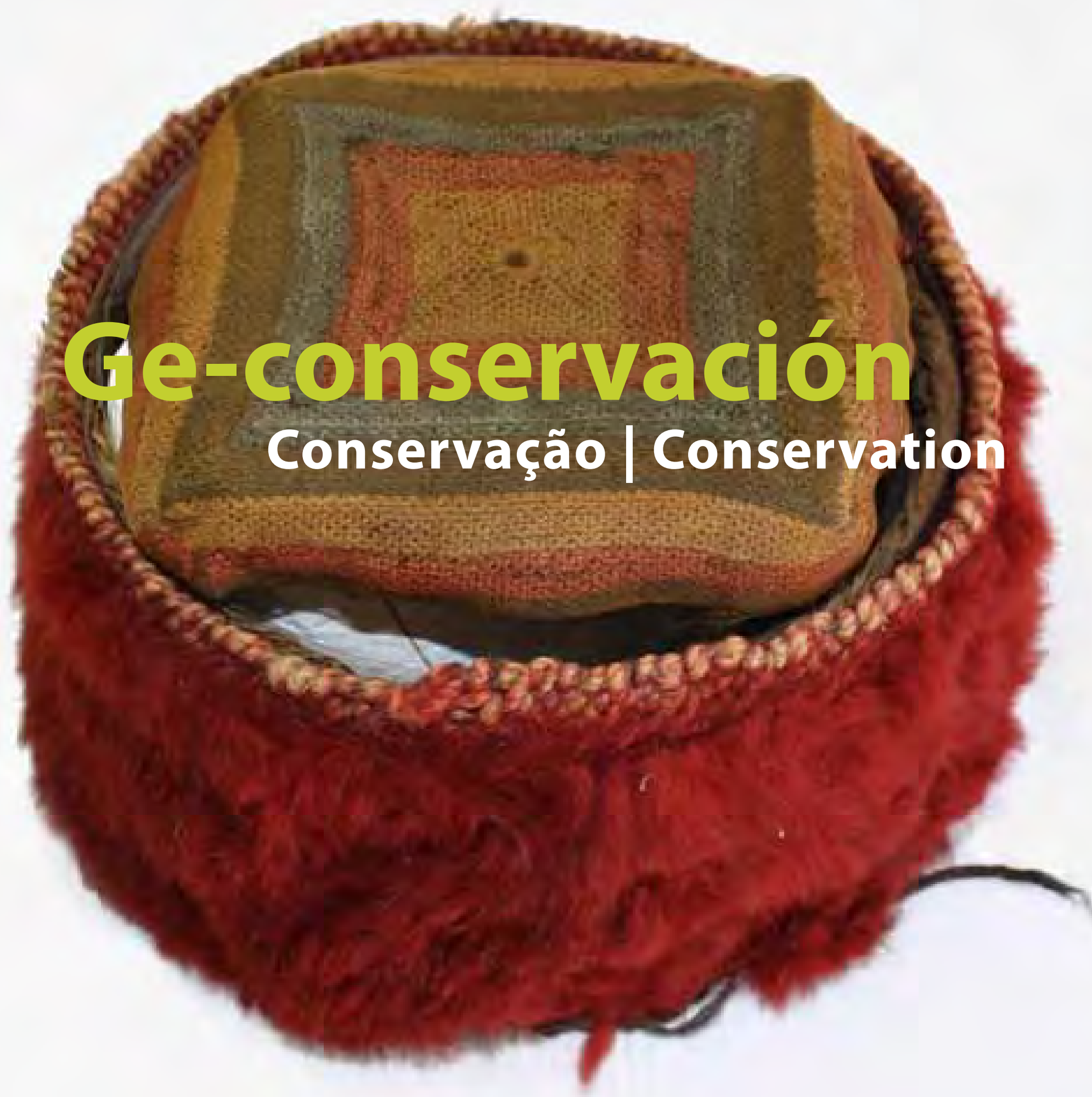




\section{Dirección Editorial:}

Consejo de Redacción:

\section{Secretaria de Edición:}

Revisores:

Webmaster GEIIC:

Diseño página web:

Maquetación:

Traducción:

Foto portada:
Rocío Bruquetas Galán y Ana Calvo Manuel

María Aguiar, Emilio Cano Ruíz, Emma García Alonso, Marisa Gómez González, Ana Laborde Marqueze, Emilio Ruiz de Arcaute Martínez, Margarita San Andrés Moya, Sandra Zetina Ocaña.

Ma Concepción de Frutos Sanz

Manuel Blanco Domínguez; Ana Calvo; Cristina Escudero Remirez; Ma Antonia García Rodríguez; Ma Isabel Herráez; Pilar Ineba; María López Rey; Domingo Marquina; Guadalupe Pinar; Ana Shoebel Orbea.

\section{Emma García Alonso}

Pepe Nieto PEZRED

Ma Concepción de Frutos Sanz y Emma García Alonso

María Aguiar

Totocado atacameño (Morales, 2012). ( 2014, Museo R.P. Gustavo Le Paige (I.I.A.M.), San Pedro de Atacama.

\section{ISSN: 1989-8568}

Esta publicación utiliza una licencia Creative Commons

Se permite compartir, copiar, distribuir y comunicar públicamente la obra con el reconocimiento expreso de su autoría y procedencia. No se permite un uso comercial de la obra original ni la generación de obras derivadas.

Esta revista utiliza Open Journal Systems, software libre de gestión y publicación de revistas desarrollando, soportado y libremente distribuido por el Public Knowledge Project bajo Licencia Pública General GNU.

\section{$=$ GRUPO ESPAÑOL de CONSERVACIÓN International Institute forConservation of historic and artistic works}

GE-conservación no se responsabiliza de la información contenida en los artículos ni se identifica necesariamente con ellas.

(c) La propiedad intelectual de los artículos pertenece a los autores, y los derechos de edición y publicación de este número son de Ge-conservación. Rogamos que en la difusión libre de los contenidos queden patentes los créditos de los autores y la procedencia.

El Grupo Español de Conservación es una asociación independiente afiliada a The International Institute for Conservation of Histtoric and Artistic Works, inscrita en el Registro Nacional de Asociaciones, Sección 1a, № 160.299. Sede: I.P.C.E. C/Greco, 428040 Madrid. Asociación Declarada de Utilidad Pública por Orden del Ministerio del Interior 3404/2009 (BOE 18-12-2009).

\section{Ge-conservación Conservaçãol Conservation}

\section{www.revista.ge-iic.com}

E-mail: revista@ge-iic.org

Revista indexada en: e-revist@s

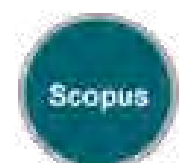

Universidad

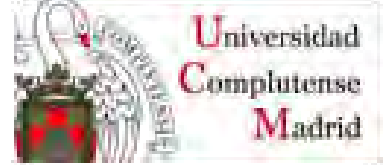

Biblioteca Complutense Catálogo Cisneucm 


\section{Índice}

Firmas invitadas y entrevista

Páginas

Historia de la Conservación Preventiva*. Parte II

Isabel M. García Fernández

Quinto aniversario de Intervención, Revista Internacional de Conservación, Restauración y Museología: una revisión retrospectiva y una visión prospectiva

Isabel Medina - González

De la memoria de los conservadores-restauradores contemporáneos a la "magdalena" de Proust". Conversaciones con Juan Carlos Pérez Ferrer y Jesús Serrano.

Por Ma Dolores Ruíz de Lacanal y Ana Calvo

\section{Artículos}

Caracterización de hongos aislados de mapas conservados en el Archivo Nacional de la República de Cuba

Manuel Alian Molina Veloso y Sofía Borrego Alonso

Conservación y restauración de un tocado atacameño del sitio Solcor-3, San Pedro de Atacama, norte de Chile

Carolina Morales-Nilo

Limpieza Ideal limpieza real en el patrimonio Arquitectónico

Manuel Ángel iglesias Campos

Pastas de relleno para reintegración volumétrica de esculturas en cera. Primeros resultados Nerea del Moral Aranza y Alicia Sánchez Ortiz

Diego Velázquez: Un retrato del natural de la Reina Isabel de Borbón

Carmen Garrído Pérez

\section{Reseñas de publicaciones}

Conservation in the Nineteenth Century

Reseña de Ana Calvo Manuel

La conservación preventiva de los bienes culturales

Reseña de Montaña Galán Caballero

The Renaissance Workshop: The Materials and Techniques of Renaissance Art

Reseña de Marisa Gómez

Policromía de Retablos en el Norte de España: Asturias, siglos XVII-XVIII

Reseña de Marisa Gómez

\section{Anexo:}

Comunicaciones en la Jornada sobre conservación de patrimonio. Rosa Ma Esbert "In Memoriam ". 16 de mayo de 2013. Oviedo.

Editoras: Ana Laborde y Diana Pardo 
Firmas invitadas y entrevista 


\title{
Historia de la Conservación Preventiva*. Parte II
}

\author{
Isabel M. García Fernández
}

Resumen: La segunda parte de la historia de la conservación preventiva comienza en 1990; esta etapa es mucho más corta que la primera, pero más prolífica en materiales, proyectos y publicaciones. Vamos a ver cómo desde sus inicios, la conservación preventiva ha ido cobrando protagonismo en todos los ámbitos relacionados con la preservación y uso del patrimonio.

En este artículo vamos a destacar los hitos fundamentales que han conseguido afianzar esta disciplina en los últimos 25 años y valorar su desarrollo en España.

Palabras clave: conservación preventiva, agentes de deterioro, evaluación de riesgos.

\section{History of Preventive Conservation*. Part II}

Abstract: The second part of the history of Preventive Conservation starts in 1990. This period is shorter but more prolific in materials, projects and publications. From the beginning, preventive conservation has been gaining relevance in all areas related to preservation and use of cultural heritage.

In this article we will underline the most important events occurred in the last 25 years, with special interest in the development of the discipline in Spain.

Key words: preventive conservation, deterioration agents, risk assessment.

\section{História da Conservação Preventiva*. Parte II}

Resumo: A segunda parte da história da conservação preventiva começa em 1990. Esta fase é muito mais curtado que a primeira, mas é mais prolífica em materiais, projetos e publicações. Veremos como, desde a sua criação, a conservação preventiva ganhou protagonismo em todas as áreas relacionadas com a preservação ea utilização do património.

Neste artigo, vamos destacar os marcos fundamentais que conseguiram reforçar esta disciplinanos últimos 25 anos, salientando o seu desenvolvimento em Espanha.

Palavras-chave: conservação preventiva, agentes de deterioração, avaliação de risco.

\section{Introducción}

Apuntábamos en la primera parte a la que llegábamos en la década de 1990, que es en ésta cuando realmente reconocemos el desarrollo espectacular de las teorías y técnicas de la conservación preventiva. Como expone Simon Lambert en un artículo recientemente publicado, "la historia de la conservación preventiva más antigua se caracteriza por la progresiva integración de la ciencia en el mundo de los museos y el fortalecimiento de la colaboración entre conservadores, restauradores y científicos"1; ${ }^{\prime 1}$ hemos visto que, desde finales de la Segunda Guerra Mundial, esto se ha ido produciendo en muchos países, pero veremos que en los últimos 25 años el avance ha sido espectacular. Asimismo hay que destacar la gran cantidad de publicaciones y referencias en medios electrónicos, que si por un lado son el reflejo del interés por esta disciplina, por otro, están dificultando la búsqueda de información útil y actualizada. 
En este artículo no pretendemos ser exhaustivos, sino intentar destacar los hitos importantes que han permitido el desarrollo y aplicación de la conservación preventiva en el mundo. Recordemos que ya en 2005 Rocío Bruquetas publicó un interesante artículo sobre la historia de esta disciplina; en él hacía referencia a los antecedentes para centrarse en el siglo XX, llegando hasta la década de 1990. Recientemente el Getty Conservation Institute ha publicado dentro de sus series Readings in Conservation [Lecturas en Conservación] el volumen número 6 dedicado a la conservación preventiva coordinado por Sarah Staniforth y titulado Historical Perspective of Preventive Conservation [Perspectiva histórica en conservación preventiva]. Recogemos pues el testigo para seguir narrando la rica historia de la conservación preventiva señalando que, en los últimos años se ha publicado la historia de su nacimiento y evolución en algunos países como Estados Unidos, Reino Unido o Italia. En este artículo, vamos a hacer especial hincapié en el caso español, donde la conservación preventiva ha tenido una aparición temprana, un desarrollo importante, encontrándose hoy en día de plena actualidad gracias a la puesta en marcha del Plan Nacional de Conservación Preventiva, su incorporación a las enseñanzas oficiales dentro del Espacio Europeo de Educación Superior y por su aplicación en instituciones que albergan bienes patrimoniales.

\section{La conservación preventiva en los últimos veinticinco años}

Uno de los primeros hechos destacables tuvo lugar en 1992: la celebración en París del III Coloquio internacional de ARAAFU [Association des Restaurateurs d'Art et d'Archaeologie de Formation Universitaire] considerada la primera reunión europea sobre conservación preventiva. Dos años más tarde, en 1994, del 12 al 16 de septiembre se celebró en Ottawa el Congreso del IIC organizado por el Canadian Conservation Institute [Instituto Canadiense de Conservación] (CCl/ICC); fue un evento muy significativo, ya que supuso un punto de inflexión en la aplicación de la disciplina. En la capital de Canadá se reunieron científicos, restauradores y profesionales para exponer los avances en materia científica y de aplicación en el campo de la conservación preventiva. El congreso comenzó con una gran polémica, ya que unas horas antes de su apertura se publicó en la prensa estadounidense un comunicado elaborado por los científicos del Conservation Analytical Laboratory [Laboratorio Científico de Conservación] (CAL), hoy Museum Conservation Institute perteneciente a la Institución del Smithsonian y uno de los más reconocidos del mundo en el campo de la restauración y la conservación preventiva. El manifiesto tenía por título "Work of Smithsonian Scientists Revises Guidelines for Climate Control in Museums and Archives" [El trabajo de los científicos del Smithsonian revisa las directrices del control climático en museos y archivos] y fue firmado por científicos destacados: Marion Mecklenburg, Charles Tumosa, David Erhardt y Mark McCormick. En el manifiesto se decía que las investigaciones que habían llevado a cabo estos científicos sobre valores de temperatura y humedad relativa para testar las propiedades físicas, mecánicas y químicas de los materiales comúnmente encontrados en museos determinaron que los objetos en museos podían tolerar, de manera segura, cambios o fluctuaciones mayores de temperatura y humedad relativa de lo que se creía hasta ahora. Esta evidencia podría ahorrar a los museos millones de dólares en equipamientos y mantenimiento para controlar las condiciones medioambientales: "con anterioridad las condiciones ideales para museos y archivos se habían fijado en $21^{\circ} \mathrm{C}$ y $50 \%$ de humedad relativa. Ahora Mecklenburg dice que puede existir hasta un 15\% de fluctuación de HR y una diferencia máxima de temperatura de $10{ }^{\circ} \mathrm{C}$." Estas afirmaciones crearon un gran desconcierto en la comunidad museística norteamericana, ya que como apuntaba Mecklenburg, hasta el $50 \%$ de los costes de construcción de nuevos museos y archivos provienen de la instalación de sistemas de refrigeración especializados "nuestra investigación muestra que esos sistemas especializados son innecesarios. La mayoría de los museos puede proteger de manera adecuada sus colecciones con tecnología utilizada en comercios, tales como los sistemas de refrigeración utilizados en carnicerías y otros negocios".

El final del comunicado contenía la esencia de lo que luego se expondría en el congreso desde varios puntos de vista y que se ha ido afianzando con el paso del tiempo dentro de la conservación preventiva; según estos científicos, su trabajo sirvió para definir los límites de tolerancia a las condiciones medioambientales de un gran número de materiales representados en las colecciones de los museos. McCormick-Goodhart dijo: "significa que no tenemos que estudiar cada objeto. Este es el gran paso adelante". Efectivamente esto fue así, la conservación preventiva permitía abrir la mente de los profesionales que se encargaban de la preservación de las colecciones en los museos, y en esta línea, algunas de las comunicaciones que se presentaron versaban sobre la elaboración de planes de conservación preventiva para museos en los que se exponía de manera sistemática cuáles eran los agentes de deterioro y las medidas de control. Entre ellas, hay que destacar la de Stefan Michalski "A systematic approach to preservation: description and integration with other museum activities" [Una estrategia sistemática para la preservación: descripción e integración con otras actividades del museo] y la de Robert Waller "Conservation risk assessment: a strategy for managing resources for preventive conservation" [La evaluación de riesgos en conservación: una estrategia para la gestión de recursos en conservación preventiva].

En 1994 también se publica Framework for the Preservation of Museum Collections Wall Chart [Marco para la Preservación de Colecciones Museísticas] del Instituto Canadiense de Conservación (CCI/ICC), que fue traducido al español ese mismo año por voluntarios de APOYO / Association for Heritage Preservation of the Americas [Asociación para la Preservación del Patrimonio de las Américas] a través de un acuerdo con el CCI/ICC. Fue concebido como un instrumento práctico para la elaboración de planes de con- 
servación preventiva que toda institución con colecciones significativas pudiera utilizar. Este póster o cartelón está basado en una publicación de 1992: A systematic approach to conservation (care) of museum collections with technical appendices, [una estrategia sistemática a la conservación (cuidado) de colecciones museísticas con apéndices técnicos] producida también por el $\mathrm{CCl}$ y planteada como manual. Dicha publicación describe las herramientas fundamentales de la metodología de la conservación preventiva, constituyendo la base de lo que posteriormente se desarrollará como evaluación de riesgos. En esta línea, junto a los estudios de uno de los pioneros en este campo, Robert Waller, tenemos que destacar el libro de Jonathan Ashley-Smith Risk Assessment for Object Conservation, producto de la investigación llevada a cabo durante el año 1994 y 1995 y respaldada en su dilatada carrera como restaurador jefe del Victoria and Albert Museum de Londres. En la introducción expone que entonces R. Waller le dijo que "no pensaba que la profesión estuviera preparada para una monografía sobre el tema"; es cierto que pasarían unos años para que se fueran asentando los conceptos de evaluación y gestión de riesgos.

Tanto las comunicaciones más representativas del congreso del IIC, como las publicaciones aparecidas en estos años planteaban que cada museo, de forma particular, debía desarrollar sus propias directrices y sus propios planes de conservación en los que se definieran las necesidades de infraestructura, equipamientos y los procedimientos a seguir por los trabajadores de la institución, aunque siempre dentro de la evidencia y pautas que han marcado las acciones de la conservación preventiva basadas en análisis y estudios científicos. Desde este momento se planteaba la necesidad de desarrollar un plan de actuación individualizado que implicase compromisos para la protección de las colecciones y su preservación.

La publicación de otro número monográfico de la revista Museum en 1999 dedicado a la conservación preventiva supuso la consolidación de las tendencias planteadas en el congreso de 1994 y desarrolladas los años posteriores. Este número contiene nueve artículos que abordan: el cambio que supone la conservación preventiva, su aplicación a nivel nacional y a ejemplos concretos, la función del restaurador y la formación en este campo -a la que se dedican varios artículos desde puntos de vista diferentes-; por último, se hace referencia al público, su educación y formación en la conservación preventiva. En el editorial se expone que:

De modo lento pero seguro, la expresión conservación preventiva se ha ido incorporando desde la década de los 70 al vocabulario cotidiano de los profesionales del museo. Nadie discute hoy este concepto, acuñado para responder a la convicción cada vez más clara de que la restauración de los objetos deteriorados no sirve para nada si no se modifican las condiciones causantes de ese deterioro, pero todavía debe integrarse como planteamiento general y fundamental en la práctica museística diaria. Esta expresión que

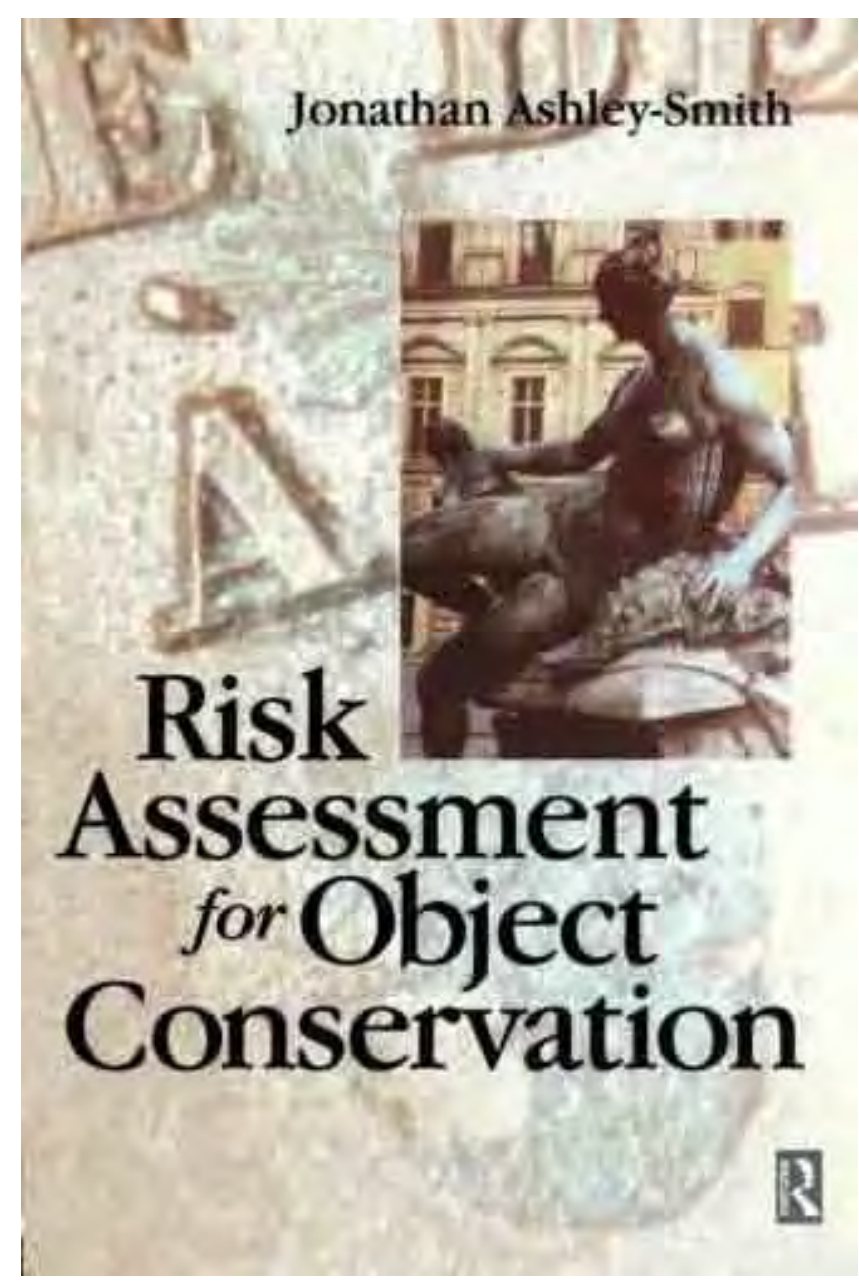

Figura 1. Portada del libro de Jonathan Ashley-Smith, 1999

implica las ideas básicas de anticipación y trabajo en equipo y la capacidad de considerar al museo como una entidad holística, ha invadido muchos métodos tradicionales de administración de los museos y de la formación profesional correspondiente [...] No es simplemente un método, una técnica o una orientación, sino que muchos la consideran hoy como un principio ético fundamental que sustenta la institución misma del museo. Para numerosos profesionales es el reflejo de un criterio de vuelta a lo esencial, ya que dirige una atención renovada hacia la auténtica razón de ser del museo: sus colecciones.

Gaël de Guichen, considerado como una de las figuras destacadas en la disciplina de la conservación preventiva, planteaba los objetivos ${ }^{2}$ de esta disciplina en términos muy claros (1999:5-6):

La conservación preventiva implica cambiar la antigua mentalidad para que el objeto de ayer se convierta en la colección de hoy, la sala en el edificio, el individuo en el equipo, el presente en futuro, los profesionales en el público en el más amplio sentido de la palabra, el secreto en comunicación, y el cómo en el por qué. 
Todo lo anterior se concreta en el intento de establecer un plan que establezca prioridades y defina responsabilidades, planteando que debe ser un proyecto que englobe a todos los que están implicados en el Patrimonio de una institución pública o privada, y que prevea la aplicación concertada de medidas directas e indirectas que han sido definidas con precisión y están encaminadas a prevenir las causas naturales y humanas del deterioro de las colecciones a fin de aumentar su esperanza de vida y garantizar la difusión del mensaje que contiene. Consiste, en definitiva,

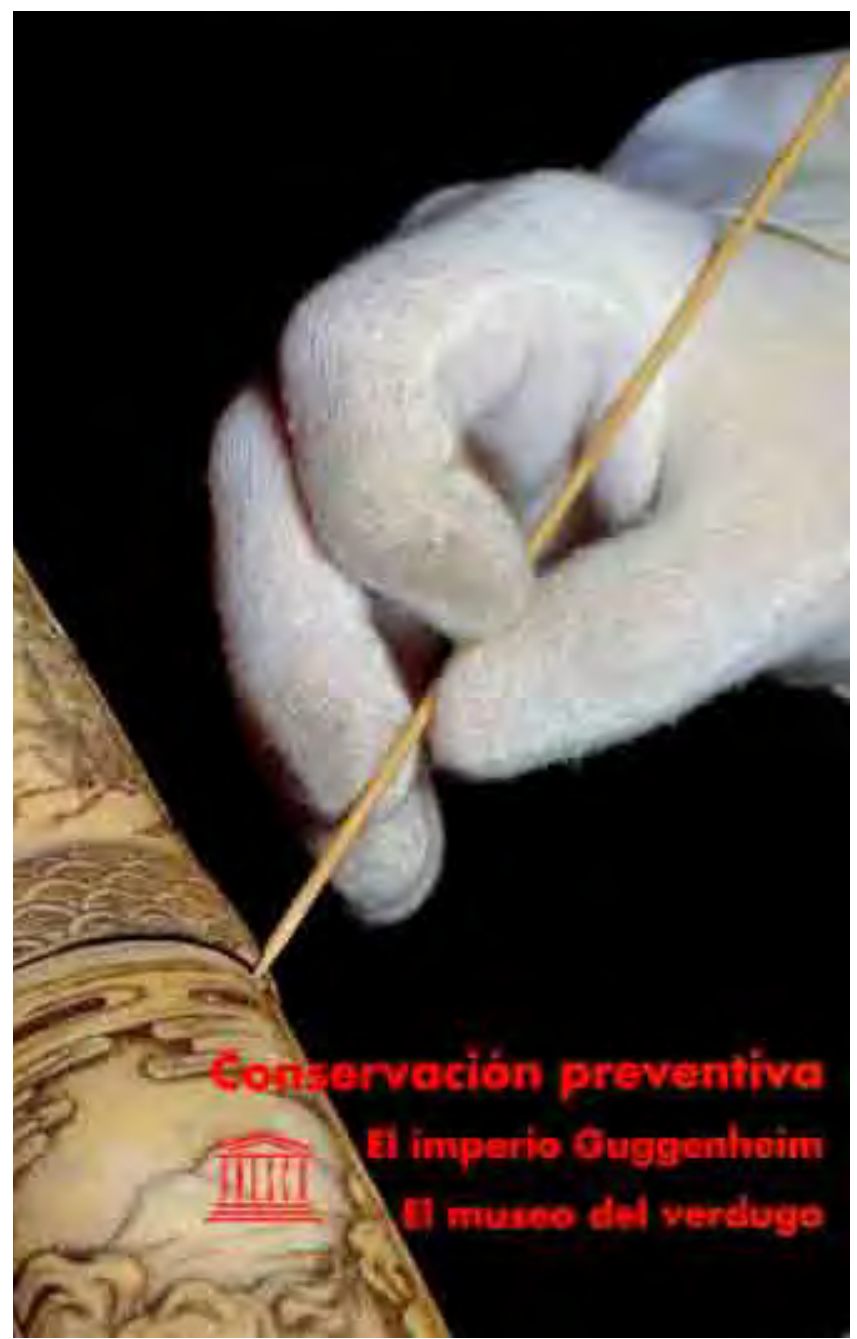

Figura 2. Portada de la revista Museum dedicada a la conservación preventiva, 1999.

en la creación y aplicación de sistemas óptimos para la exposición y almacén de objetos en museos, todo ello insertado en un plan de gestión de la institución que contenga bienes patrimoniales.

Marta de la Torre, que fue directora de Formación del Instituto Getty de Conservación y actualmente es miembro del Comité Asesor de Bienes Culturales de Estados Unidos y trabaja como asesora científica principal en el programa de UNESCO para el desarrollo de museos y cuidado de co- lecciones, ya dijo quince años atrás (1997:16) que:

La gran innovación de la conservación preventiva estará en que saca a la conservación de los talleres de los restauradores y la coloca en el centro de todas las actividades del museo. En este tipo de estrategia institucional la conservación se convierte en una responsabilidad compartida por todos los que trabajan en un museo. Una política efectiva de conservación preventiva requiere interés y buena voluntad institucional, pero también implica una sensibilización y la formulación adecuada de cada una de las partes implicadas.

Lo anterior comporta un cambio de mentalidad; prácticamente todas las decisiones que se toman en un museo se traducen en una serie de acciones que influyen en la conservación y muchas de ellas entran en el ámbito de la restauración. No obstante, la restauración ha dejado de tener prioridad dentro de las funciones del museo para convertirse en uno de los estadios dentro de los procesos que engloba la conservación.

El giro en el planteamiento de la conservación preventiva dejó patente por otra parte, que esta se ocupa de problemas muy complejos que implican a múltiples agentes y exigen el diseño de las estrategias más variadas. Se parte de que todos los materiales se deterioran y que la conservación preventiva está destinada a minimizar los daños que se producirán, ayudando a que la vida de esos materiales se alargue. A lo largo de las últimas dos décadas han aparecido numerosas definiciones, entre las que destacamos la del American Institute for Conservation (AIC) [Instituto Americano de Conservación] que en sus Guidelines for Practice [Normas para el ejercicio profesional] aprobadas en 1994, especifica que es la conservación preventiva y cuáles son las responsabilidades del profesional que se encarga de ella; de este modo se define como:

El sistema de mayor eficacia para promover la preservación a largo plazo de los bienes culturales. El profesional de la conservación deberá proporcionar normas para el uso y cuidado continuado de los diferentes objetos, así mismo proporcionará recomendaciones apropiadas sobre las condiciones ambientales para depósito/almacenaje y exhibición, y además estimulará el desarrollo de procedimientos adecuados para el manejo, embalaje y transporte ${ }^{3}$.

También enfatiza que "la conservación preventiva es un proceso continuo que acompaña la vida del bien patrimonial y no termina con el tratamiento de intervención".

Un aspecto fundamental que se introduce también en la década de 1990 es el de trabajo en equipo y su enfoque multidisciplinar; en este sentido, el ICCROM lideró un proyecto denominado Teamwork for Preventive Conservation Project en el que participaron once museos de nueve países europeos. En la justificación de su propuesta se plan- 
teaba que "el propósito de la conservación preventiva es reducir el deterioro y mantener la integridad de las colecciones en museos de manera asequible, para asegurar su disponibilidad para la sociedad actual y en el futuro". Se exponía que (2004:1):

La mejora en el cuidado de las colecciones no es solo un fin en sí mismo, sino que necesita lograrse de tal manera que permita el acceso público a la colección. Las tareas son tan amplias que es imposible hacerlas sin ayuda. Requieren la conciencia y la implicación de todos en el museo, un enfoque multidisciplinar a la conservación preventiva que puede lograrse gracias al trabajo en equipo.

En 2004 se publicaron los resultados del proyecto en forma de guía; ésta presenta un plan en cinco fases que tiene como fin la planificación y el desarrollo de equipos de trabajo, además de métodos para la creación de redes entre museos y otras instituciones que proporcionen el soporte adicional para las mejoras de conservación preventiva.

El siglo XXI comienza con una propuesta de la Comisión Europea dentro del Programa Raphael y que se denominó Hacia una Estrategia sobre Conservación Preventiva adoptada en la reunión celebrada en Vantaa (Finlandia) del 21 al 22 de septiembre de 2000 . Este documento reúne un conjunto de contribuciones realizadas por participantes de 24 países; en la exposición de motivos se decía que "los museos europeos han sido líderes en el desarrollo de la teoría y la práctica de la conservación preventiva: la gestión multidisciplinar para reducir la pérdida de patrimonio cultural en beneficio de la sociedad. La conservación preventiva es elemento primordial de cualquier política europea en materia de conservación del patrimonio".

Se establecieron cinco puntos estratégicos con sus correspondientes líneas de acción que constituyen el marco en el que los países deben trabajar: 1. Liderazgo: los gobiernos deben asumir el liderazgo en la preservación del patrimonio cultural y facilitar el desarrollo de estrategias y planes nacionales, 2. Planificación institucional: los museos deben incluir la conservación preventiva en la planificación institucional a largo plazo y utilizar metodologías acordes a este concepto, 3. Formación: todas las personas que tienen relación con las colecciones deben tener una formación adecuada y actualizada en el campo de la conservación preventiva, de acuerdo con su función y su responsabilidad, 4. Acceso a la información: todas las personas que tienen relación con el cuidado de colecciones deben tener conocimiento y acceso, de acuerdo con sus necesidades, a la información internacional sobre conservación preventiva, 5. El papel del público: el público debe conocer el concepto de conservación preventiva y participar en él. Se aboga por un proyecto conjunto europeo teniendo en cuenta los puntos citados y su desarrollo en sus correspondientes líneas de acción. May Cassar, en su discurso inaugural, recogido en el European Preventive Conservation Strategy Project (2001:38), incidía en el compro- miso de los agentes implicados en la conservación y decía que "la conservación preventiva es una responsabilidad compartida. Tiene que ver tanto con la gente, como con su interacción con las colecciones. Implica la aplicación de diferentes disciplinas en una causa común y a menudo requiere compromisos para lograr resultados más grandes, mejores y duraderos".

A comienzos del nuevo milenio, la conservación preventiva se seguía enfocando y aplicando a las colecciones que se encontraban fundamentalmente en museos; de este modo, el Consejo Internacional de Museos (ICOM) en su Código Deontológico de 2006 se referirá a que "la conservación preventiva es un elemento importante de la política de los museos y la protección de las colecciones. A los profesionales de los museos les incumbe la responsabilidad fundamental de crear y mantener un entorno adecuado para la protección para las colecciones almacenadas, expuestas o en tránsito, de las que están encargados".

Sin embargo, ya se iban viendo iniciativas respecto a su aplicación a otros bienes integrantes del patrimonio, como los inmuebles que contienen colecciones significativas, parajes naturales, históricos y culturales (incluyendo yacimientos arqueológicos y paleontológicos) y patrimonio inmaterial. Por otra parte, Dardes y Druzik (2000:4) del GCl, definían la conservación preventiva como“la gestión de las condiciones medioambientales en las que las colecciones son guardadas y almacenadas", planteaban que "gestionar el medio ambiente (o entorno)" se aplica ahora a todos los riesgos potenciales para las colecciones en los que entran, no solo parámetros tan conocidos como la temperatura o la HR, sino también, otros riesgos menos comunes (como desastres naturales); o el acceso, manipulación y uso de las colecciones por parte del personal del museo. Esta gestión supone planes a largo plazo donde se fijan las responsabilidades de cada agente implicado dentro de la institución. Como podemos comprobar, a la vez que el campo de la conservación preventiva se ampliaba, las voces de los profesionales que trabajaban en ella se iban uniendo con el propósito de clarificar y coordinar las acciones. Pues bien, muchas de ellas no se habían tenido en cuenta en el campo de la conservación. Estos autores destacan que cuando se publicó el libro Environmental Management de May Cassar en el Reino Unido en 1995 las necesidades medioambientales de las colecciones museísticas se posicionaron como prioridad para los gestores de museos.

Otra de las definiciones fundamentales ha sido elaborada por la European Confederation of Conservator-Restorers Organisations [Confederación Europea de Organizaciones de Conservadores-Restauradores] (ECCO), miembro asociado al ICCROM que agrupa a asociaciones profesionales de veintidós países europeos. Tiene como objetivo desarrollar y promover a un nivel práctico, científico y cultural la profesión del conservador-restaurador del patrimonio cultural para lo que ha confeccionado una serie de documentos: código ético y guías prácticas profesionales. La definición está recogida en el documento Professional 
Guidelines 2002, y en él se manifiesta que "la conservación preventiva consiste en las acciones indirectas para retardar el deterioro y prevenir los daños mediante la creación de las condiciones óptimas para la preservación del patrimonio cultural que sean compatibles con su uso social. La conservación preventiva también abarca la correcta manipulación, transporte, uso, almacenamiento y exposición. Además puede implicar la producción de facsímiles con el propósito de preservar el original".

Hay que enfatizar que la conservación preventiva no es un fin en sí misma, sino un medio para conseguir un fin; su éxito depende de siete aspectos fundamentales que sugieren un sentido de colectividad y apertura frente a la tradicional individualidad y conservadurismo. Estos aspectos han sido desarrollados por los profesionales que trabajan en el ICCROM siendo fruto de la experiencia de muchos años implicados en numerosos proyectos en todo el mundo. Indican el cambio de enfoque en la manera de concebir la conservación y son clave para asegurar la efectividad de sus procedimientos. Así, como hemos visto, se plantea que se debe pasar de pensar en objetos a pensar en colecciones, de salas a edificios, de individuo a equipo, de planes a corto plazo a otros a largo plazo, de secreto a público, de investigación a comunicación; y finalmente se apunta que hay que dejar de pensar en cómo se hace para pasar a saber por qué se hace.

Teniendo en cuenta lo anterior, hay que hacer mención a una definición basada en un amplio trabajo de recopilación y síntesis que se realizó desde el Comité para la Conservación del ICOM y se hizo pública en la XV Conferencia Trienal del ICOM-CC celebrada en Delhi en el 2008, concretando que la conservación preventiva abarca"todas aqueIlas medidas y acciones que tengan como objetivo evitar o minimizar futuros deterioros o pérdidas. Se realizan sobre el contexto o el área circundante al bien, o más frecuentemente un grupo de bienes, sin tener en cuenta su edad o condición. Estas medidas y acciones son indirectas- no interfieren con los materiales y estructuras de los bienes. No modifican su apariencia".

Al principio estas medidas y acciones, como hemos visto anteriormente, se identificaban con el estudio del medio ambiente en museos; es decir, con el control de los parámetros que conforman el clima en el interior de edificios, entre los que se encuentran la temperatura, la humedad relativa, la luz y los contaminantes. En la actualidad, gracias a las propuestas que se han ido haciendo, -algunas de las cuales hemos destacado-, el campo se ha ampliado abarcando a todos los agentes que tienen alguna influencia sobre la supervivencia de los objetos. En total hablamos de nueve o diez agentes según la clasificación hecha por los distintos autores. Aparte de los cuatro ya citados se contemplan cinco agentes que a lo largo de la historia han causado un grado mayor de daño, dando lugar a la pérdida irrecuperable de muchos objetos y obras de arte; nos referimos al fuego, al agua, a las plagas, a las llamadas "fuerzas físicas directas" y a un grupo en el que se incluyen el robo, el vandalismo y la negligencia.

El grupo de trabajo de conservación preventiva dentro del Consejo Internacional de museos-Comité para la Conservación (ICOM-CC) es uno de los mejores indicadores sobre las investigaciones que se están llevando a cabo sobre esta disciplina en la primera década del siglo; así sus miembros trabajan sobre diversos temas que se han ampliado en cada propuesta trienal, algunos de los resultados se han presentado en las reuniones periódicas del Comité para la Conservación. De 2002 a 2005 se ocupaban de la iluminación y el control del clima, el control del biodeterioro, el cuidado de las obras de arte en tránsito, la preparación para catástrofes y efectos y control de los contaminantes. Estos temas se ampliaron y especializaron de 2005 a 2008, dividiéndose en distintos grupos: el grupo A. Medioambiente, incluía: iluminación, clima (Ta y HR), actividad biológica (biodegradación), anoxia y contaminantes, grupo $B$. Gestión de riesgos: metodología, mitigación, clasificación (de colecciones / de tipos de riesgos), cuantificación y predicción, grupo C. Mecánica: modelos, manipulación y transporte, y grupo D. Materiales: sostenibilidad de los materiales utilizados en la construcción, capas de protección, depósitos de contaminantes y filtros. Otros subgrupos en cada tema incluían: sostenibilidad, herramientas, colaboración (networks) y directrices; y buenas prácticas. De 2008 a 2011 se ampliaron todavía más los temas de investigación; de este modo en el grupo A, en contaminantes, se especializaron las investigaciones para incluir: partículas sólidas, contaminantes industriales, materiales utilizados en construcción y depósitos; y filtros; en el $B$, dentro de gestión de riesgos, se añadió la desvinculación o descuido (marcado y siglado de objetos); el grupo C cambió el nombre a fuerzas físicas, incluyendo también los edificios, visitantes, choques y vibraciones, y se añadió otro nuevo grupo, el $\mathrm{E}$, de seguridad en el que se incluía planes de emergencia, recuperación de colecciones, fuego, agua (inundaciones, infiltraciones), robo y vandalismo. En otras tendencias se contempla también la colaboración entre profesionales y compartir resultados con otros grupos de investigación.

En este repaso por los hechos más significativos en la historia de la conservación preventiva hay que hacer referencia a que desde hace unos años dentro de esta disciplina se ha ido concretando una nueva corriente que apuesta por la denominada gestión de riesgos; esta ya se había planteado en los años ochenta, aunque se había desestimado su aplicación, fundamentalmente por la falta de datos registrados sobre la frecuencia y extensión de la incidencia de los agentes de deterioro en las colecciones del museo. En 1996 Suzanne Keene publicó el libro Managing Conservation in Museums que respaldaba la implementación de la gestión de riesgos; en ese libro hablaba de que cada vez existen más presiones por parte de los gobiernos para aplicar criterios de rentabilidad a todas las actividades de las instituciones públicas, lo que está forzando a los museos a adoptar formas de gestión empleadas por otras entidades o empresas. Existen muchas publicaciones sobre gestión de riesgos y sus métodos de aplicación basados fun- 
damentalmente en modelos y fórmulas cuantitativas. No obstante, no todas son aplicables a la conservación. Keene planteaba que el análisis del coste-beneficio o coste-efectividad se encuentra obstaculizado en la actualidad por la escasez de datos sobre la relación directa entre el entorno y el deterioro. Los análisis de riesgos, los objetivos en las jerarquías establecidas según el valor o significación de los bienes ayudan a identificar lo que es deseable conservar y a establecer prioridades, que es, en definitiva, el objetivo de la conservación. Respecto a la gestión de riesgos y su aplicación en la segunda edición de su libro en 2002, se refería directamente a los planteamientos de Michalski y Waller que empezaron a desarrollar en los años 90.

Desde 2005 tres instituciones de referencia como son el ICCROM, el CCl y el ICN (nos referimos al Instituto de Conservación y Restauración en Roma, el Instituto Canadiense de Conservación y el Instituto de Conservación de los Países Bajos, este último se incorporó a la Agencia Holandesa de Patrimonio Cultural (RCE) en 2011) colaboran juntas para desarrollar y difundir el enfoque de la gestión de riesgos en el campo de la conservación del patrimonio. Este planteamiento se está posicionando como una herramienta útil para la toma de decisiones en conservación, ya que ofrece una metodología que incorpora conocimientos del campo de la gestión de riesgos y los datos recogidos en el desarrollo de las disciplinas de la conservación y la restauración que permiten identificar los riesgos, evaluarlos, estimar su incidencia, establecer prioridades y aplicar los métodos más adecuados a cada circunstancia. Coordinados por el ICCROM, ofrecen varios cursos de formación a lo largo del año con el nombre de "reduciendo riesgos para el patrimonio cultural" dirigidos a los profesionales involucrados en la preservación del patrimonio que posean experiencia práctica en este campo, algunos de estos cursos se pueden seguir en línea (on-line) ${ }^{4}$.

Por otra parte, hay que volver a hablar de la ampliación del objeto de la conservación preventiva que no se ocupa solo del patrimonio encontrado en los museos, sino también del patrimonio natural, sitios históricos, yacimientos arqueológicos y paleontológicos, inmuebles con colecciones significativas, patrimonio industrial, científico, tecnológico y etnográfico; así como el patrimonio inmaterial. Todo este patrimonio ha de ser objeto de un plan de conservación individualizado que tenga en cuenta el contexto donde se encuentra e integre la problemática de todos sus componentes. Se trata de abrir aún más nuestra mente y enfrentarnos a nuevos retos adaptando herramientas que ya se han desarrollado para la conservación de colecciones en museos, bibliotecas y archivos.

\section{La conservación preventiva en España}

En lo que respecta a la conservación preventiva en España, se puede apuntar que ya desde comienzos de la década de 1990 empezaron a surgir cursos de formación, jornadas, congresos y publicaciones, fruto del interés que ya desper- taba esta disciplina en nuestro país. Hay que destacar que con anterioridad existían muy pocos textos en español que abordaran la conservación preventiva y todo lo que conlleva. El entonces Ilamado Instituto de Conservación y Restauración de Bienes Culturales (ICRBC) organizó durante varios años cursos de conservación preventiva, manipulación, transporte y embalaje de bienes culturales y se convirtió en una institución de referencia.

En 1992 tuvo lugar el Simposio Internacional y Primer Congreso Mundial sobre Preservación y Conservación de Colecciones de Historia Natural en el Museo Nacional de Ciencias Naturales del 10 al 15 de mayo de 1992, éste acabó con la aprobación de unas resoluciones que resumían las propuestas para la conservación de este tipo de colecciones que se entregaron a la UNESCO. Se publicaron tres volúmenes que recogían variadas e interesantes aportaciones, muchas de ellas tenían que ver con la conservación preventiva. En el volumen 1, se agrupan las comunicaciones presentadas que versaron sobre la función y gestión de las colecciones de historia natural y también se abordaron aspectos como la exposición y la educación; el volumen 2 , se dedicó a la conservación y preservación de estas colecciones y el 3, a los temas de actualidad, iniciativas y direcciones futuras sobre preservación y conservación de colecciones de historia natural.

En el ámbito nacional, también en 1992, en el IX Congreso de Conservación y Restauración de Bienes Culturales se empiezan a presentar ponencias sobre conservación preventiva 5 . A partir del XI Congreso de 1996 se crea el grupo de Conservación Preventiva (llamado conservación preventiva y técnicas analíticas) coordinado por Eduardo Porta. Se publicó en esta ocasión un gran número de artículos, 24 en total, entre los que se incluían proyectos de conservación preventiva en archivos y museos, como el Museo Nacional de Arte Romano e incluso en otras instituciones patrimoniales, como la catedral de Barcelona. En el siguiente congreso, el XII, celebrado en 1998, se presentaron 9 comunicaciones, algunas sobre conservación y restauración del patrimonio en parajes naturales; y en posteriores congresos se siguieron presentando interesantes ponencias sobre conservación preventiva.

Además de los cursos organizados por el ICRBC, hay que hablar también de los cursos sobre Patrimonio Histórico organizados por la Universidad de Cantabria; en el VII celebrado en julio-agosto de 1996 que llevaba por título la conservación preventiva: clave para la preservación del patrimonio, se presentaron ponencias de destacados profesionales de este campo. En la ponencia inaugural de José $M^{a}$ Losada Aranguren "La conservación preventiva hoy: el marco de referencia" introducía el curso y exponía que la conservación preventiva es "entendida como un conjunto de acciones tendentes a garantizar la conservación de los bienes culturales mediante el control de su entorno inmediato y la implantación de adecuados programas de mantenimiento" y dejaba claro que la prevención es la mejor forma de conservación ${ }^{6}$. Al año siguiente el curso tuvo por 
título Conservación y restauración del patrimonio mueble: el porvenir del pasado en el que se abordaba también cuestiones de conservación preventiva en diferentes ámbitos. En 1996 también se celebró el I Curso de Otoño de la Universidad de Cádiz en Jerez de la Frontera con el título "La conservación del patrimonio histórico-artístico. Técnicas y métodos". En éste se presentó la ponencia conservación preventiva de las obras de arte de Salvador Rovira Lloréns; en ella explicaba claramente qué es la conservación preventiva cuáles eran los factores ambientales y cómo influyen en los distintos materiales que componen la obra de arte $^{7}$. En 1998, la Fundación del Patrimonio Histórico Español de Castilla y León organizó un Simposio Internacional con el título la conservación como factor de desarrollo en el siglo XXl; la segunda jornada estuvo dedicada a la conservación del futuro y a la importancia de la conservación preventiva ${ }^{8}$.

Por otro lado, es importante destacar la aparición del Instituto Andaluz de Patrimonio Histórico (IAPH) en 1989 y del Grupo Español del IIC (GEIIC) en 1996, que poco a poco se han ido convirtiendo en organizaciones de referencia. El GEIIC en 2002 organizó el primer congreso con el título "Conservación del Patrimonio: evolución y nuevas perspectivas" en Valencia, desde entonces se han celebrado 5 ediciones más dedicadas a diferentes temas. Además desde 2009 publica la revista Ge-conservación donde han aparecido ya varios artículos sobre conservación preventiva. Uno de los grupos de trabajo se denomina específicamente de conservación preventiva y según se presenta en la web "nace con la intención de ser una plataforma para crear y difundir estrategias de prevención en todos los ámbitos y niveles profesionales que están en contacto con los bienes culturales" y entre sus objetivos están el proponer "jornadas y mesas de debate, que ayuden a compartir las experiencias", y propiciar "la publicación y difusión de textos y guías a los profesionales y a los que quieran iniciarse en la búsqueda de herramientas útiles y materiales de apoyo para facilitar su trabajo" ${ }^{\prime 2}$. El IAPH fue configurando una sección pionera en Conservación Preventiva que ha prestado y sigue prestando sus servicios a instituciones con colecciones patrimoniales, en muchos de estos proyectos trabaja con otras instituciones de ámbito local y nacional.

Todavía en la década de 1990, otro de los hitos importantes fue la celebración del Coloquio Internacional sobre Conservación Preventiva de Bienes Culturales que tuvo lugar en Vigo del 22 al 24 de noviembre de 1996, y al que asistieron más de 400 personas; allí se puso de manifiesto como el interés por esta disciplina en nuestro país iba cuajando. Ya entonces se estaban implantando planes de conservación preventiva en instituciones que albergan bienes culturales, tal es el caso de los proyectos auspiciados y desarrollados por la Comunidad Valenciana (Vaillant, 1997).

Como hemos visto, la difusión de la conservación preventiva se estaba llevando a cabo en distintos foros; a finales de esta década, se apostó por publicaciones que la trataban desde un punto de vista global recopilando y resumiendo

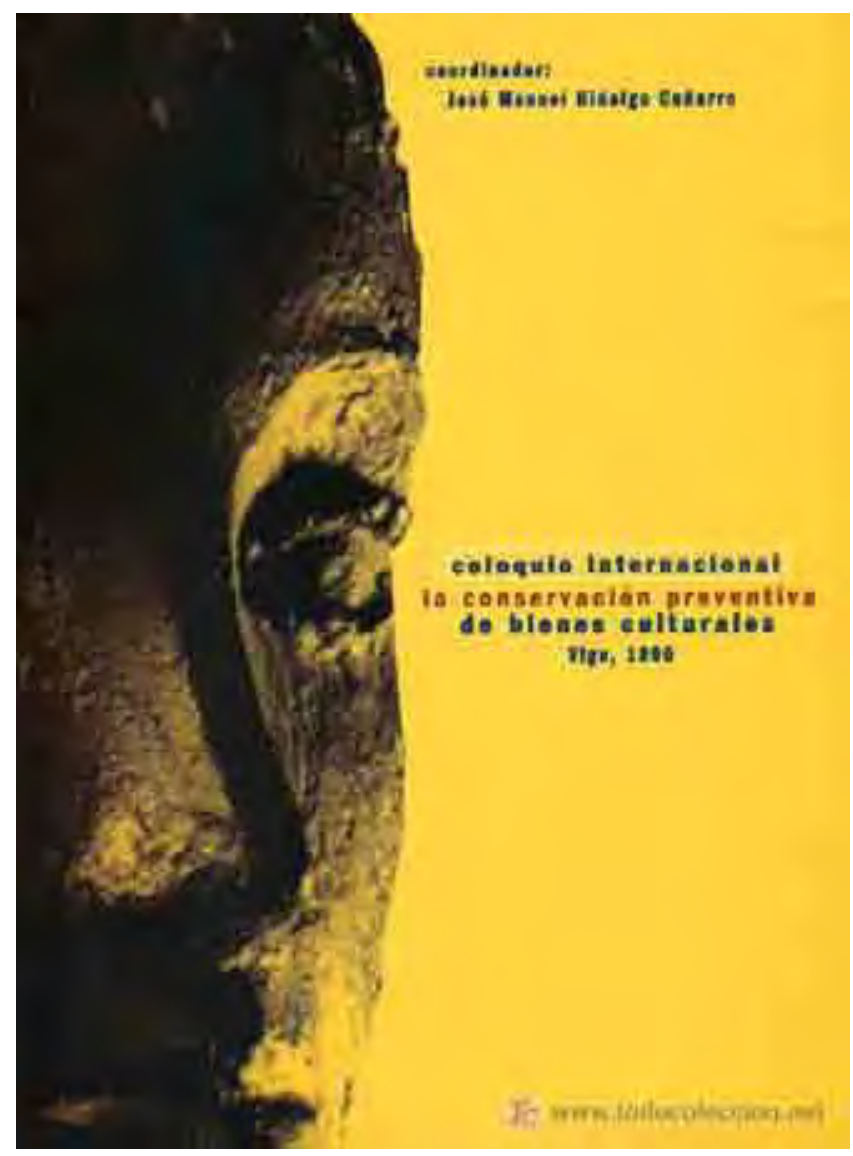

Figura 3. Portada de las Actas del Coloquio Internacional sobre Conservación Preventiva, 1997.

la información aparecida; de este modo, el artículo de Juan A. Herráez y Miguel A. Rodríguez de 1999“La conservación preventiva de las obras de arte" acometía la revisión de la conservación preventiva con sus antecedentes, su historia más reciente, los organismos vinculados, la conservación preventiva en España y la metodología de control de los factores ambientales. Desde un enfoque sistemático hay que destacar también los libros de María García Morales La conservación preventiva en los museos y de Isabel M. García Fernández La conservación preventiva y la exposición de objetos y obras de arte que, además de la recopilación de materiales sobre esta materia y su organización en bloques temáticos, están concebidos como manuales donde se puede encontrar la información práctica para abordar las diferentes tareas de la conservación preventiva ${ }^{10}$. Asimismo fue importante la celebración en $\mathbf{2 0 0 0}$ del VI Coloquio gallego de museos dedicado a la conservación preventiva.

En el siglo XXI, los textos en español se han multiplicado gracias al mayor conocimiento de esta disciplina en los países latinoamericanos; se han publicado artículos y manuales que están sirviendo de guía y apoyo a la aplicación de la conservación preventiva en colecciones de museos ${ }^{11}$. Hay que hacer referencia a la creación del Consorcio Latinoamericano de Conservación del Patrimonio Cultural que nació en 1997 para desarrollar la conservación preventiva en Latinoamérica, para ello se estableció una red entre paí- 
ses y profesionales con el objetivo de compartir información y recursos.

De vuelta en España, podemos decir que los temas de conservación preventiva han estado muy presentes, desde la aplicación en planes de conservación, sobre todo en archivos y bibliotecas ${ }^{12}$. También destacamos que en 2005 tuvieron lugar las Primeras Jornadas de Conservación Preventiva; entonces se reunieron en el Museo Guggenheim de Bilbao conservadores y restauradores de 15 instituciones (museos, universidad, fundaciones, centros de investigación); la segunda edición de este encuentro tuvo lugar dos años más tarde y se celebró en paralelo al seminario especializado sobre planes de emergencia para obras de $\operatorname{arte}^{13}$.

Los depósitos o almacenes también han sido objeto de consideración, la Revista de Museología publicó varios artículos en 2006 sobre los retos que presentan los almacenes en museos; nos referimos a los artículos de Paloma MuñozCampos "La conservación preventiva en los museos de artes decorativas. El reto del almacenamiento" y el de Mónica Redondo Álvarez, "La Conservación Preventiva y la Restauración. Un reto para el traslado del Museo del Ejército". También la Revista Museo de la Asociación Profesional de Museólogos de España le dedicó un número en 2011 con el título Entre bastidores: los equipamientos e instalaciones del museo y la Revista Digital del Comité Español del ICOM abordó esta cuestión en dos números. También la exposición y la conservación preventiva ha sido asunto de numerosos estudios y publicaciones. Destacamos la publicación Conservación preventiva y procedimientos en exposiciones temporales, un proyecto del GEIIC en colaboración con el Comité español del ICOM y la Fundación Duques de Soria que auspició dos encuentros profesionales entre España y México.

Pero no solo se alberga gran parte del patrimonio mueble en los museos, bibliotecas, archivos o en sus almacenes; sino también una parte importante se encuentra en lugares concebidos para el culto religioso. Los problemas de conservación que presentan han llevado a que en la actualidad la atención también se centre en estos recintos. Ejemplo de ello son las jornadas organizadas por el IPCE en 2009 o el Manual de conservación preventiva en recintos religiosos, volumen publicado por Instituto de Antropología e Historia de México en el año 2000.

Por otro lado, podemos destacar editoriales que han apostado por difundir la conservación preventiva; sirva de ejemplo la editorial de la Universidad Politécnica de Valencia, la editorial Síntesis y su colección de Patrimonio Cultural o la editorial Trea y su serie de Museología y Patrimonio que han publicado varios libros sobre aspectos relacionados con esta disciplina. Además en los manuales de museología se menciona y desarrolla la conservación preventiva como un capítulo fundamental en el funcionamiento de los museos.
También queremos enfatizar la labor de los diferentes institutos de conservación y restauración adscritos a las diferentes comunidades autónomas y otras instituciones locales que han llevado a cabo magníficos proyectos de conservación preventiva y siguen trabajando activamente en este campo. Por último, señalar la significativa labor desempeñada por individuos como Benoît de Tapol, referente internacional y nacional en el trabajo de aplicación de la conservación preventiva.

\section{El presente de la conservación preventiva}

El presente en buena medida se plantea desde el papel que juega el Instituto del Patrimonio Cultural de España (IPCE) como referente de esta disciplina en España ${ }^{14}$.

Hace tres años el Ministerio de Cultura, Educación y Deporte y el IPCE han puesto en marcha el Plan Nacional de Conservación Preventiva en España. El plan se desarrollará en diez años desde su aprobación en 2011, cuenta con tres fases: una primera fase dedicada al desarrollo organizativo de formación de la Comisión Técnica de Seguimiento y la definición de las pautas para su funcionamiento y coordinación. Una segunda en la que se abordarán los estudios, trabajos y documentos de referencia que permitan avanzar en la fijación de criterios y metodología; y en la última, se prevé la implementación de la conservación preventiva en proyectos e intervenciones en las que se materializará la adopción del trabajo teórico desarrollado en la fase anterior.

El plan se llevará a cabo de acuerdo con los principios de Vantaa y las Professional Guidelines [Directrices Profesionales] de ECCO en las que se establecen las líneas de actuación a nivel europeo. Así según reza en el documento aprobado en marzo de 2011:

La necesidad y oportunidad de un Plan Nacional de Conservación Preventiva (PNCP) se justifica por la importancia de la implantación de una estrategia de prevención como principio fundamental para la conservación del Patrimonio Cultural, y las carencias y dificultades existentes para su aplicación en algunas de sus manifestaciones.

De esta manera, el Plan Nacional de Conservación Preventiva se concibe como:

El instrumento necesario para la generalización de modelos organizativos, métodos de trabajo, criterios de actuación y protocolos o herramientas de gestión como principio fundamental para la conservación del patrimonio cultural y su mantenimiento de forma viable y sostenible en el tiempo. Todo ello teniendo en cuenta los recursos disponibles, la necesidad de compatibilizar el deseable uso y disfrute de los bienes culturales con su conservación, y la necesaria implicación de la sociedad en este objetivo. 
Este instrumento impulsado por el IPCE obedece a la necesidad de liderazgo institucional para generalizar una estrategia y una política de conservación del Patrimonio cultural, demandada por los profesionales e imprescindible con la estructura administrativa y el repaso de competencias en esta materia a nivel estatal (Herráez 2013:25). No solo es importante la difusión, sino el diseño y aplicación de metodologías de actuaciones en conservación preventiva y modelos de gestión de planes de conservación.

Para este plan se busca la participación y colaboración de todas las instituciones y agentes implicados en el diseño de pautas y líneas de actuación, que sirvan de referencia para abordar las dificultades que plantea la conservación del patrimonio de una manera sistemática, armonizada y eficiente. Todo ello en consonancia con lo que hemos visto a nivel internacional.

En el Plan Nacional de conservación preventiva de España dentro de las líneas de actuación entran las propuestas de estudios e investigación con la definición de modelos metodológicos e instrumentos de implantación, propuestas de proyectos piloto de conservación preventiva, propuestas de difusión y propuestas de formación ${ }^{15}$; en estas últimas se ha planteado la definición y desarrollo de líneas prioritarias de formación en conservación preventiva: "formación para profesionales en conservación-restauración que ayude a desarrollar capacidades para la elaboración de planes y trabajos de conservación preventiva en las distintas manifestaciones de los Bienes Culturales y formación en conservación preventiva para abordar las tareas de seguimiento, control de los riesgos de deterioro y mantenimiento de bienes inmuebles enfocada a la capacitación de equipos multidisciplinares de instituciones relacionadas con la conservación del patrimonio cultural". Ya se ha terminado el análisis de necesidades formativas en conservación preventiva en España con el objetivo de propiciar las actuaciones antes mencionadas. La formación se establece desde el Espacio Europeo de Educación Superior en universidades y escuelas superiores con grados en conservación y restauración donde existen asignaturas de conservación preventiva y programas de posgrado centrados en esta disciplina, también se ofrecen cursos desde el IPCE, que se afianza como institución de referencia y apoyo.

El Ministerio de Educación y Cultura a través de la Subdirección General de Museos Estatales también ha trabajado en planes de emergencia. En 2003 se creó un grupo de trabajo y, gracias a las sucesivas reuniones, incluidas las jornadas técnicas sobre protección de colecciones ante emergencias se llegó a publicar en 2008 una guía para elaborar y ejecutar planes de protección de colecciones en museos.

Finalmente, podemos citar el último número de la revista del Instituto de Patrimonio Cultural dedicada a la conservación preventiva que lleva por título: la conservación preventiva: revisión de una disciplina. En el primer artícu- lo, Gaël de Guichen (2013:15) afirma que “la conservación preventiva no ha sido una moda, sino que ha traído consigo un profundo cambio en el modo de trabajo", otros artículos hacen referencia a estudios e iniciativas impulsados desde el Plan Nacional de Conservación Preventiva.

Como conclusión podemos decir que la conservación preventiva goza de buena salud; desde su aparición se ha ido extendiendo sin pausa a todos los ámbitos que tienen relación con la preservación del patrimonio. La conciencia de la importancia de su aplicación está calando en la sociedad y se está convirtiendo en prioridad, no sólo a nivel nacional sino también europeo e internacional. Recordemos que a todos nos beneficia conservar el patrimonio y disfrutar de él con todas las garantías.

Terminamos con una frase de un buen amigo y referente en este campo "La conservación preventiva es políticamente incorrecta. A nadie le gusta oír lo que esta mal" (Rainiero)

Nota: Probablemente nos hemos dejado muchas referencias en el camino, pido disculpas por no poder reflejar la riqueza y variedad de iniciativas y materiales que se han producido en los últimos años y, que sin duda, seguirán apareciendo sin pausa; estamos alcanzando en España un gran nivel profesional, fruto del gran trabajo que se ha ido realizando estos últimos años.

*Texto basado en el capítulo Qué es la conservación preventiva incluido en el libro Conservación preventiva de bienes culturales publicado por Alianza, en Madrid, 2013. El texto se ha modificado y ampliado en buena medida para incluir la conservación preventiva en España.

\section{Notas}

[1] El artículo "The Early History of Preventive Conservation in Great Britain and the United States (1850-1950)" [La historia antigua de la conservación preventiva en Gran Bretaña y los Estados Unidos] pone de manifiesto como en el mundo anglosajón en una centuria van a tener lugar hechos fundamentales que favorecieron el desarrollo de lo que más tarde se llamaría conservación preventiva. Este autor también publicó en 2010 “Italy and the history of preventive conservation" [Italia y la historia de la conservación preventiva] donde examina los dos momentos fundamentales de la historia de la conservación en Italia y que resultaron fallidos a la hora de integrar la conservación preventiva dentro de las políticas culturales; estamos hablando de la famosa Comisión Franceschini (1964) y el plan piloto para la conservación programada del patrimonio cultural de Umbría (1976).

[2] Gaël de Guichen fue subdirector general del Centro Internacional de Estudios de Conservación y Restauración de los Bienes Culturales (ICCROM) de Roma hasta 2001 y en la actualidad sigue ligado a la institución como consejero, es también el Director Científico del Programa de conservación preventiva y régimen de acceso de la Cueva de Altamira. [Disponible en http://www. conservation-us.org/docs/default-source/about-us/guidelines- 
for-practice-in-spanish.pdf?sfvrsn=2]

[3] En el Código Ético aprobado también en 1994 recogía la misma idea en el punto VIII que "El profesional de la conservación reconocerá su responsabilidad en cuanto a la conservación preventiva, esforzándose en limitar daños o deterioros a los bienes culturales, proporcionando normas para su uso y cuidado continuado, recomendando las condiciones ambientales adecuadas para su depósito/almacenaje y exhibición, y estimulando procedimientos adecuados para su manejo, embalaje y transporte".

[4] Del 28 al 30 de noviembre de 2012 se celebró en Amersfoort, Países Bajos, la Reunión Internacional Reducing Risks to Heritage organizada por la Rijksdienst voor het Cultureel Erfgoed, el ICCROM y el CCI. En 2014 tuvo lugar el curso de 3 semanas Reducing Risk to Collections en Tianjin, China; la experiencia de las siete ediciones anteriores aseguró su éxito.

[5] Destacamos la dedicada investigación en conservación preventiva en este caso enfocada a las colecciones en papel Sánchez Hernampérez, Arsenio (1992). "Los programas de investigación en la conservación preventiva de las colecciones de papel: una propuesta metodológica" en Libro del IX Congreso de Conservación y Restauración de Bienes Culturales Sevilla, 17, 18, 18 y 20 de septiembre de 1992, Sevilla: Secretaría del IX Congreso de Conservación y Restauración de Bienes Culturales, 768-782.

[6] Estas ponencias se publicaron en el primer volumen de estos cursos. Las ponencias estuvieron a cargo de José Ma Losada Aranguren, María José Alonso López, Vicente Viñas Torner, José Antonio Buces Aguado, Andrés Carretero Pérez, Juan Antonio Herráez Ferreiro y Benoît de Tapol. Se incluyó la conservación preventiva del patrimonio arqueológico y etnográfico. En 2009 en el XX Curso se recoge la una ponencia que relaciona la arqueología y la conservación preventiva, correspondencia que va a ser tratada de manera sistemática en los últimos años.

[7] Curso coordinado por María Dolores López de la Orden; las otras ponencias estaban centradas en técnicas y métodos de análisis de los bienes que componen patrimonio desde el punto de vista de la datación, materiales constitutivos y estados de conservación.

[8] Al simposium estuvieron invitados importantes personalidades de Europa, Norteamérica y España, en la segunda jornada destacó la ponencia de Stefan Michalski “El papel de la conservación preventiva".

[9] Entre los cursos, seminarios y encuentros internacionales organizados con otras instituciones académicas y museísticas y empresas, podemos destacar el curso "Sobre Exposiciones Temporales y Conservación del Patrimonio" celebrado del 5 al 8 de abril de 2005 en la Facultad de Geografía e Historia de la UCM. El I Seminario organizado por el GE-IIC, CTS y el Museo Nacional Centro de Arte Reina Sofía "Reflexiones sobre Conservación Preventiva: Planificación, competencias y aplicaciones" impartido por Gäel de Guichen, Benoit de Tapol y Laura Ceballos el 14 de noviembre de 2008 y el II Seminario organizado con la Universidad Complutense de Madrid y el Museo Nacional del Prado
“Evaluación de riesgos medioambientales en las colecciones: ¿se aclimatan los objetos?" impartido por Stefan Michalski y celebrado los días 7 y 8 de mayo de 2009.

[10] Este libro se ha revisado y actualizado a tenor de los avances que se han producido en esta disciplina y se ha publicado en la editorial Alianza en 2013 con el título La conservación preventiva de bienes culturales.

[11] Recientemente la Gaceta de los Museos publicada por el Instituto Nacional de Arte e Historia de México dedicó un número a la conservación preventiva (n56 agosto-noviembre 2013).

[12] Desde la publicación de 1992 de Arsenio Sánchez "Los programas de investigación en la conservación preventiva de las colecciones de papel: una propuesta metodológica" se han publicado numerosos trabajos se centran en este patrimonio, ver Isabel Argerich Fernández (et al.) (2010): Conservación preventiva y plan de gestión de desastres en archivos y bibliotecas.

[13] Ver ponencias presentadas al seminario Planes de emergencia para Museos. Hacia una conservación preventiva integral. [Disponible en http://www.guggenheim-bilbao.es/la-coleccion/ conservacion/] y también Implantación de un plan de conservación preventiva: desarrollo e implantación de un plan integral de prevención desarrollado en el Museo Guggenheim [disponible en http://www.guggenheim-bilbao.es/src/uploads/2012/09/ plan prevencion.pdf]

[14] El Instituto de Conservación y Restauración de Bienes Culturales cambió su nombre en 2008 a Instituto del Patrimonio Cultural de España (IPCE); es una subdirección general adscrita a la Dirección General de Bellas Artes y Bienes Culturales y de Archivos y Bibliotecas del Ministerio de Educación, Cultura y Deporte, y su cometido es la investigación, conservación y restauración de los bienes que conforman el Patrimonio Cultural (según información recogida en su web: ipce.mcu.es).

[15] Se han previsto la publicación de varios textos como apoyo a la formación, entre ellos, la Guía para la Elaboración de Planes de Conservación Preventiva y el Manual para el seguimiento, análisis y control de las condiciones ambientales.

\section{Bibliografía}

ALTIERI SÁNCHEZ, J. y MOLINA GARCÍA, J. (1996). “Conservación preventiva en el Museo Nacional de Arte Romano" en XI Congreso de Conservación y Restauración de Bienes Culturales: Castellón, 3, 4, 5 y 6 de octubre de 1996, Castellón: Diputación Provincial de Castellón, 51-58.

ARGERICH FERNÁNDEZ, I. (ET AL.) (2010). Conservación preventiva y plan de gestión de desastres en archivos y bibliotecas. Hidalgo Brinquis, María del Carmen (Coord. Científica); Muiña Álvarez, Iolanda (ed.), Madrid: Ministerio de Cultura, Secretaría General Técnica.

American Institute for Conservation (1994): Guidelines for Prac- 
tice.http://www.conservation-us.org/about-us/core-documents/ guidelines-for-practice\#.U1Vn81V vps [consulta: 5/4/2014]

ARAAFU (1992). La Conservation Préventive. Libro de Actas del III Coloquio Internacional La conservation préventive: colloque sur la conservation-restauration des biens culturels celebrado en París 8, 9 y 10 de octubre de 1992, París: ARAAFU.

ASHLEY-SMITH, J. (1999). Risk Assessment for Object Conservation. Oxford; Boston: Butterworth-Heinemann.

ARISTEGUI ANDUIZA, B. \& SANZ LÓPEZ DE HEREDIA, A. (2004). "Implantación de un plan de conservación preventiva", Akobe: restauración y conservación de bienes culturales = ondasun enartapen eta berriztapena, 5:29-32.

BRUQUETAS GALÁN, R. (2005). La conservación preventiva: una nueva profesión con una vieja historia. En Curso Sobre Exposiciones Temporales y Conservación del Patrimonio [Recurso electrónico]: del 5 al 8 de abril de 2005, Madrid: Grupo Español IIC.

CANADIAN CONSERVATION INSTITUTE (1994). Framework for the Preservation of Museum Collections Wall Chart. Ottawa: Canadian Heritage / CCl.

- (1992). A Systematic Approach to the Conservation (Care) of Museum Collections, Ottawa: Canadian Conservation Institute, Mayo.

CASSAR, M. (1995). Environmental Management. Guidelines for museums and galleries. Londres: Museums \& Galleries Commission with Routledge.

-(2001). Opening address en ICCROM et al. (2001) European Preventive Conservation Strategy Project. A Project Report, Vantaa: EVTEK, 38-49.

CONSEJO NACIONAL PARA LA CULTURA Y LAS ARTES (2000). Normas básicas para la conservación preventiva de los bienes culturales en museos México D.F.: Consejo Nacional para la Cultura y las Artes.

CONSEJO NACIONAL PARA LA CULTURA Y LAS ARTES (2000). Manual de conservación preventiva de bienes culturales en recintos religiosos / Consejo Nacional para la Cultura y las Artes, Instituto Nacional de Antropología e Historia, Coordinación Nacional de Restauración de Patrimonio Cultural. México D.F.: Consejo Nacional para la Cultura y las Artes.

CONSEJO INTERNACIONAL DE MUSEOS (ICOM) (2006). Código de deontología para los museos. París: Consejo Internacional de Museos (ICOM).

CULUBRET WORMS, B.; ET AL (2008). Guía para un plan de protección de colecciones ante emergencias, Madrid: Ministerio de Cultura. Secretaría General Técnica. Centro de publicaciones.

DARDES, K. y DRUZIK, J. (2000). “Managing the Environment. An Update on Preventive Conservation", The Getty Conservation Institute Newsletter, 15, 2: 4-9.
DE LA TORRE, M. (1997). “Estrategias de conservación preventiva: el papel del restaurador/conservador" en Actas del Coloquio Internacional sobre Conservación de Bienes Culturales, Vigo: Diputación Provincial de Pontevedra, 13-18.

EUROPEAN COMMISSION (2000). Hacia una Estrategia Europea sobre Conservación Preventiva. Adoptada en la reunión de Vantaa 21-22 de septiembre de 2000. PC Start- Raphael Programme. European Commission.

FERNÁNDEZ, C.; ARECHAVALA, F.; MUÑOZ-CAMPOS, P.; TAPOL, B. DE (2008). Conservación preventiva y procedimientos en exposiciones temporales. Madrid: Grupo Español del IIC, Fundación Duques de Soria.

GARCÍA FERNÁNDEZ, I. M. (1999). La conservación preventiva y la exposición de objetos y obras de arte, Murcia: Editorial KR.

GARCÍA MORALES, M. (2000). La conservación preventiva en los museos. Teoría y práctica, Santa Cruz de Tenerife: Organismo Autónomo de Museos y Centros (OAMC).

GRUPO ESPAÑOL IIC (2005).Curso Sobre Exposiciones Temporales y Conservación del Patrimonio [Recurso electrónico]: del 5 al 8 de abril de 2005, Madrid: Grupo Español IIC.

GUICHEN, GAËL DE (1999). “La conservación preventiva: ¿simple moda pasajera o cambio transcendental?" Museum Internacional, 201 vol. LI, 1: 4-6.

HERRÁEZ FERREIRO, J. A. y RODRÍGUEZ LORITE, M. A. (1999). La conservación preventiva de las obras de arte Madrid: Arbor, 645 Septiembre 1999, 141-156.

HERRÁEZ FERREIRO, J. A. (2013). “El Plan Nacional de Conservación Preventiva", Patrimonio Cultural de España, 7: 25-31.

ICOM CE DIGITAL 03 (2011). Almacenes de museos. Espacios internos, propuestas para su organización. Madrid, ICOM- Comité Español.

ICOM CE DIGITAL 04 (2011). Colecciones en depósito. Experiencias en reservas nacionales e internacionales. Madrid, ICOM-Comité Español.

LAMBERT, S. (2010). "The Early History of Preventive Conservation in Great Britain and the United States (1850-1950)", CeROArt, http://ceroart.revues.org/3765 [consulta 21/4/2014].

- (2010)."Italy and the history of preventive Conservation", CeROArt, http://ceroart.revues.org/1707 [consulta 21/4/2014].

LOSADA ARANGUREN, J. M. (1997). “Conservación preventiva hoy: el marco de referencia" en Actas de los VII Cursos Monográficos sobre el Patrimonio Histórico: (Reinosa, julio-agosto 1996), José Manuel Iglesias Gil (ed.), Santander: Universidad de Cantabria, Servicio de Publicaciones; Reinosa: Ayuntamiento, 121-130.

MICHALSKI, S. (1994). "A Systematic Approach to Preservation: 
Description and Integration with Other Museum Activities" en Preventive Conservation: Practice, Theory and Research: Preprints of the Contributions to the Ottawa Congress12-16 Septiembre. Londres: International Institute for Conservation of Historic and Artistic Works, 8-11.

-(1998). "El papel de la conservación preventiva" en el Simposium Internacional La conservación como factor de desarrollo en el siglo XXI. Valladolid: Fundación del Patrimonio Histórico de Castilla y León, 147-157.

MUÑOZ-CAMPOS, P. (2006). “La conservación preventiva en los museos de artes decorativas. El reto del almacenamiento", RdM. Revista de Museología: Publicación científica al servicio de la comunidad museológica, 36: 124-134.

PUTT, N. y SLADE, S. (2004). Teamwork for Preventive Conservation. Roma: ICCROM International Centre for the Study of the Preservation and Restoration of Cultural Property.

REDONDO ÁlVAREZ, M. (2006). "La Conservación Preventiva y la Restauración. Un reto para el traslado del Museo del Ejército", RdM. Revista de Museología: Publicación científica al servicio de la comunidad museológica, 37: 220-229.

ROVIRA LLORENS, S. (1997). "Conservación preventiva de las obras de arte" en I Cursos de Otoño de la Universidad de Cádiz en Jerez de la Frontera. La conservación del patrimonio históricoartístico: técnicas y métodos, María Dolores López de la Orden (coord.), Ayuntamiento de Jerez y Universidad de Cádiz, Servicio de Autoedición e impresión, 7-21.

SÁNCHEZ HERNAMPÉREZ, A. (1992). “Los programas de investigación en la conservación preventiva de las colecciones de papel: una propuesta metodológica" en Libro del IX Congreso de Conservación y Restauración de Bienes Culturales Sevilla, 17, 18, 18 y 20 de septiembre de 1992, Sevilla: Secretaría del IX Congreso de Conservación y Restauración de Bienes Culturales, 768-782.

SMITHSONIAN INSTITUTION PRESS OFFICE (1994). "Work of Smithsonian Scientists Revises Guidelines for Climate Control in Museums and Archives" en Abbey Newsletter, 18: 4-5 http://cool. conservation-us.org/byorg/abbey/an/an18/an18-4/an18-405. html[consultado: 27/3/2014]

STANIFORTH, S. (ED). (2013). Historical Perspectives on Preventive Conservation. Los Angeles: Getty Conservation Institute.

VAILLANT, M. (1997). Informe sobre proyecto piloto de conservación preventiva para instituciones valencianas que atesoran bienes culturales. Valencia: Consellería de Cultura, Generalitat Valenciana.

VAILLANT CALLOL, M., VALENTÍN RODRIGO, N. Y DOMÉNECHCARBÓ, M.T. (EDS) (2003). Una mirada hacia la conservación pre- ventiva del patrimonio cultural, Editorial de la UPV, Valencia.

VV.AA. (1992). Libro del congreso = Congress book: basado en el Simposio Internacional y Primer Congreso Mundial sobre Preservación y Conservación de Colecciones de Historia Natural, celebrado en Madrid del 10 al 15 de Mayo de 1992. Vol.1, Sesiones del Primer Congreso Mundial y comunicaciones sobre función y gestión de las colecciones de historia natural / editores Fernando Palacios, Carmen Martínez, Barbara Thomas. Vol.2, Comunicaciones sobre la situación, preservación y conservación de colecciones de historia natural / editores Fernando Palacios, Carmen Martínez, Barbara Thomas. Vol. 3, Temas de actualidad, iniciativas y direcciones futuras sobre preservación y conservación de colecciones de historia natural / editores Carolyn L. Rose, Stephen L. Williams y Julio Gisbert. Madrid: Dirección General de Bellas Artes y Archivos, Ministerio de Cultura.

VV.AA. (1997). Actas del Coloquio Internacional sobre Conservación Preventiva de Bienes Culturales, Vigo, 22-24 de noviembre de 1996 Hidalgo Cuñarro, José Manuel (coord.), Vigo: Diputación Provincial de Pontevedra, Servicio de publicaciones.

VV.AA. (1997). Actas del VIII Cursos Monográficos sobre el Patrimonio Histórico. (Reinosa, julio-agosto 1997), José Manuel Iglesias Gil (ed.), Santander: Universidad de Cantabria, Servicio de Publicaciones; Reinosa: Ayuntamiento.

VV.AA. (2000). Coloquio Galego de Museos. A conservación preventiva / VI Coloquio Galego de Museos, Museo de Belas Artes da Coruña, 27-28-29 xaneiro de 2000. Santiago de Compostela: Consello Galego de Museos.

VV.AA. (2011). XIV Jornadas de Museología. Entre bastidores: los equipamientos e instalaciones del museo, Revista Museo, 16.

VV.AA. (2012). Conservación preventiva en lugares de culto. Actas de las Jornadas celebradas en el Instituto Cultural de España 25, 26 y 27 de marzo de 2009. Madrid: Ministerio de Educación Cultura y Deporte, Secretaría General Técnica, Subdirección General de Documentación y Publicaciones.

WALLER, R. (1994). "Conservation Assessment: A Strategy for Managing Resources for Preventive Conservation" en Preventive Conservation: Practice, Theory and Research: Preprints of the Contributions to the Ottawa Congress12-16 Septiembre. Londres: International Institute for Conservation of Historic and Artistic Works, $12-16$. 


\section{Isabel M. García Fernández}

Facultad de Bellas Artes

Universidad Complutense de Madrid

museoig@art.ucm.es

Isabel M. García Fernández es profesora titular de la Universidad Complutense de Madrid. Imparte docencia en la Facultad de Bellas Artes en el Departamento de Pintura y Restauración, en el Grado y Máster de Conservación y Restauración del Patrimonio Cultural. Pertenece al grupo de investigación 930420 Técnicas de Documentación, Conservación y Restauración del Patrimonio, validado por la ANEP y la UCM. Doctora en Geografía e Historia por la UCM, se especializó en museología y museografía (M.A. en San Francisco State University) y conservación preventiva (Beca de investigación en el Canadian Conservation Institute), disciplina que fue objeto de su tesis doctoral y de varios trabajos de investigación y publicaciones.

Artículo enviado el 22/05/2014 


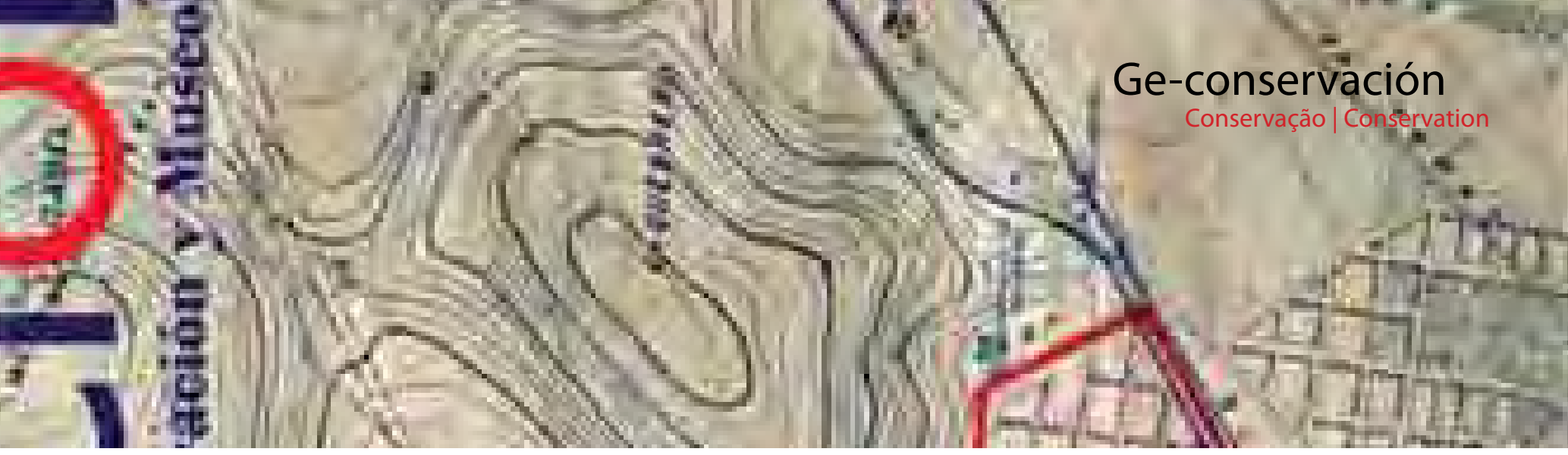

\title{
Quinto aniversario de Intervención, Revista Internacional de Conservación, Restauración y Museología: una revisión retrospectiva y una visión prospectiva
}

\author{
Isabel Medina - González
}

\begin{abstract}
Resumen: Con motivo del quinto aniversario de Intervención, Revista Internacional de Conservación, Restauración y Museología, publicación académica, arbitrada e indexada de la ENCRyM-INAH, se presenta una revisión retrospectiva de su desarrollo, con el fin de reflexionar sobre los avances logrados y los retos, a los que esta iniciativa editorial en plena consolidación se enfrenta en el presente. Con ello se busca discutir un tema paradójicamente poco analizado: la difusión del conocimiento en el campo patrimonial mediante medios escritos impresos que hoy en día experimentan su introducción a las plataformas electrónicas del internet. Se concluye con una visión prospectiva sobre el futuro de las publicaciones dedicadas a la conservación-restauración desde una perspectiva regional enfocada a Hispanoamérica.
\end{abstract}

Palabras claves: Conservación-restauración, editorial, revista, Intervención, Hispanoamérica.

\section{Quinto aniversario de Intervención, Revista Internacional de Conservación, Restauración y Mu- seología: una revisión retrospectiva y una visión prospectival}

\begin{abstract}
In the context of the fifth anniversary of Intervención, Revista Internacional de Conservación, Restauración y Museología academic, peer-reviewed and indexed periodical journal of ENCRyM-INAH--, this contribution presents an retrospective analysis of its development in order to promote reflection both on the goals already achieved by this fully consolidated editorial Project and on the challenges that it actually confronts. Such an approach serves to explore a topic that has hitherto poorly studied: knowledge dissemination in the heritage sector throughout written media that today experience its introduction in electronic platforms through the web. Finally, the author - Intervention chief-editor - concludes with a prospective insight on the future of conservation-restoration periodic journals from the standpoint of a regional perspective that focuses on Hispanic-America.
\end{abstract}

Key words: Conservation-restoration, editorial, periodical journal, Intervención, Hispanic-America.

\section{Quinto aniversário de Intervención, Revista Internacional de Conservação, Restauro e Museolo- gia: uma revisão retrospetiva e uma visão prospetiva}

Resumo: A propósito do quinto aniversário de Intervención, Revista Internacional de Conservação, Restauro e Museologia, publicação académica, arbitrada e indexada na ENCRyM-INAH, apresenta-se uma revisão retrospetiva da sua evolução, como objetivo de refletir sobre os avanços conseguidos e os desafios, com que esta iniciativa editorial, em plena consolidação, se depara atualmente. Com esta, procura-se discutir um tema, paradoxalmente, pouco analisado: a difusão do conhecimento no campo patrimonial a través dos meios escritos impressos que hoje em dia experimentam a sua introdução nas plataformas electrónicas da internet. Conclui-se com una visão prospetiva sobre o futuro das publicações dedicadas à conservação-restauro, a patir de uma perspetiva regional focada na Hispanoamérica.

Palavras-Chave: Conservação-restauro, editorial, revista, Intervenção, Hispanoamérica. 


\section{Introducción}

El año 2009, la Escuela Nacional de Conservación, Restauración y Museografía (ENCRyM), mundialmente conocida como el Centro Churubusco, del Instituto Nacional de Antropología e Historia (INAH), México, inició un proyecto editorial que culminaría, un año después, en la publicación del primer número de Intervención, Revista Internacional de Conservación, Restauración y Museología. A cinco años de ininterrumpida y puntual emisión, concretada en ya 10 números, y en el marco del 75 aniversario del INAH, vale la pena realizar una revisión retrospectiva sobre el desarrollo de este proyecto con el fin de cumplir un doble objetivo: por un lado, analizar lo logrado hasta el momento por un proyecto ya plenamente consolidado $y$, por otro, explicitar los retos a los que hoy se enfrenta. Esta exploración servirá para aproximar el análisis a un ámbito paradójicamente poco explorado en la literatura: la difusión del conocimiento en campo patrimonial por medios impresos que hoy experimentan una fundamental transición con su introducción a la plataformas electrónicos de acceso libre que ofrece el internet; proceso que indudablemente cambia los paradigmas de la producción y del impacto del quehacer intelectual en las disciplinas de la las humanidades. Finalmente, se propone una visión prospectiva sobre el futuro de Intervención en el marco del mundo editorial académico del campo patrimonial, la cual trasciende a una perspectiva regional con miras a la generación de una política editorial en Hispanoamérica.

\section{Devenir}

La historia de las publicaciones periódicas del sector patrimonial en el mundo, en Hispanoamérica y en México está por escribirse, lo cual explica la ausencia de un análisis sobre el desarrollo e impacto de la difusión científica en el ámbito profesional y formativo. Existen, sin embargo, algunos estudios parciales, destacando el elaborado --un año antes del surgimiento de Intervención--, por Linares (2008), el cual analiza el estado de situación de las publicaciones periódicas existentes en la última década del siglo XX y la primera del siglo XXI, con énfasis en aquellas dedicadas al área de conservación- restauración de bienes muebles. En este estudio, necesariamente selectivo, se describen y analizan doce iniciativas de publicaciones periódicas en materia de conservación-restauración de impacto significativo a escala nacional e internacional, incluyendo algunas memorias de series de coloquios y foros profesionales y de estudiantes. Es con base en este levantamiento general, se expone un censo parcial y en construcción de publicaciones periódicas tipo journal, con algunas adiciones representativas, fechas de fundación y de cese/vigencia.

Vale la pena hacer tres precisiones a este censo -insisto necesariamente parcial y en construcción--. Primero, su contenido mezcla publicaciones de diverso rango y alcance: desde aquellas de divulgación al público en general, boletines y gacetas de información de centros de trabajo, y aquellas de cierta estatura académica asentada en la ope- ración de una estructura editorial que vigila el desarrollo de procesos editoriales específicos -incluyendo de arbitraje por pares ciegos--, aseguran una calidad científica, excelencia generalmente certificada por la indexación. Así, como segundo punto, del universo presentado en la tabla, menos de una decena de publicaciones corresponden a la categoría académica, de éstas sólo un puñado articulan una misión de impacto internacional en términos tanto de procedencia de insumos como de distribución. En tercer lugar, es de subrayar que para el año 2009 no existían publicaciones de este último carácter en el ámbito de la conservación-restauración de México.

Desde su propia génesis, Intervención buscó llenar un vacío entre las publicaciones de alto rango académico internacional del campo patrimonial, vacante que ya tenía tintas de deuda histórica para un país, como México, con una larga y sólida tradición de formación y actuación profesional en el área de la conservación-restauración, cuyo principal agente protagonista ha sido el INAH.

La apuesta de Intervención, adicionalmente, se construyó intencional y programáticamente con fundamento en la diferencia de aproximación; es decir, creando una identidad no comparable con publicaciones de natalidad previa o contemporánea, un sello que aún se mantiene en la actualidad. En cierto sentido, el Comité Editorial de la Revista Intervención (CERI) formando por profesionales de distintas disciplinas e instituciones, decidimos no competir con lo existente, sino complementar e innovar: así se propuso generar una plataforma interdisciplinaria para la difusión, intercambio y debate de conocimiento y avances en los campos de la conservación, la restauración, museología, gestión y estudios del patrimonio cultural, abordaje que es congruente con el origen, actualidad y, en mi opinión, la natural evolución futura de la educación superior de la ENCRyM-INAH.

El diseño editorial, que comprendió un año, se articuló con base en una lógica de contenido que apuntada a una multivocalidad analítica: ello resultó en la formulación de tipos de contribuciones formuladas en secciones -Debate, Diálogos, Ensayo, Investigación, Informe, Reporte, Reflexión desde la Formación, Innovaciones, Escaparate, Semblanza, Desde el Archivo y Reseñas (de libro, de exposición, de evento académico), las cuales buscan concretar y explicitar las diversas formas de argumentación sobre el pensamiento, quehacer y reflexión en el campo patrimonial.

Otro factor programado con certidumbre desde el origen de Intervención fue el camino del proceso editorial académico, incluyente de fases de verificación y valoración por el equipo editorial núcleo (editor, coordinador editorial y asistente editorial) y el propio CERI a través de la figura de comisario, así como la instauración de procedimientos y formularios para el proceso de revisión anónimo por especialistas invitados a todas las postulaciones, el cual naturalmente se complementa con un mecanismo de pares ciegos para las secciones arbitradas, el cual ha significado 


\begin{tabular}{|c|c|c|c|}
\hline \multicolumn{4}{|c|}{$\begin{array}{l}\text { Censo representativo de publicaciones en materia de conservación-restauración } \\
\text { (basado en Linares } 2008 \text { y actualizado por autor) }\end{array}$} \\
\hline Nombre & Adscripción & Año de Fundación & Año de Vigencia \\
\hline Studies in Conservation & ICC, Reino Unido & 1952 & 2014 (Vigente) \\
\hline $\begin{array}{l}\text { Journal of the American Institute of } \\
\text { Conservation }\end{array}$ & AIC, EUA & 1960 & 2014 (Vigente) \\
\hline ICCROM Newspaper & ICCROM, Italia & 1974 & 2014 (Vigente) \\
\hline Pátina & ESCRBC, España & 1985 & 2014 (Vigente) \\
\hline GCI Newsletter & GCl, EUA & 1986 & 2014 (Vigente) \\
\hline Khurana & Privada, México & 1990 & 1993 \\
\hline Apoyo, Apoyoonline & $\begin{array}{c}\text { Asociación para la Conservación } \\
\text { del Patrimonio Cultural, Argentina y } \\
\text { EUA. }\end{array}$ & 1990 & 2014 (Vigente) \\
\hline Imprimatura & Imprimatura A.C, México & 1993 & 1998 \\
\hline México en el Tiempo & INAH, México & 1994 & 2001 \\
\hline Correo del Restaurador & INAH, México & 1996 & 2008 \\
\hline Conserva & CNCR, Chile & 1997 & 2014 (Vigente) \\
\hline ICON News & ICON, Reino Unido & 2005 & 2014 (Vigente) \\
\hline News in Conservation & ICC, Reino Unido & 2007 & 2014 (Vigente) \\
\hline ECR Estudos de Conservação e Restauro & Universidad Católica Portuguesa & 2008 & 2014 (Vigente) \\
\hline Ge- Conservación & Grupo Español, IIC, España & 2008 & 2014 (Vigente) \\
\hline Intervención & ENCRyM-INAH, México & 2010 & 2014 (Vigente) \\
\hline Boletín CR & CNPC-INAH, México & 2013 & 2014 (Vigente) \\
\hline
\end{tabular}

la creación de una cartera de árbitros nacionales e internacionales. En este respecto vale la pena señalar que la ingeniería del proceso de revisión no solo buscó introducir la evaluación o arbitraje — que hasta el momento era prácticamente ausente en las publicaciones del ámbito de la conservación-restauración en México-, sino también eliminar el prejuicios sobre su naturaleza en una comunidad científica relativamente pequeña, para entonces proporcionar certidumbre sobre su consecución tanto objetiva como cooperativa. Así, la revisión se ha convertido en un agente que no sólo avala, sino facilita la optimización de la calidad académica de las postulaciones en particular, y con ello, la correspondiente a la revista en general.
Adicionalmente, se estableció que el proceso de corrección de estilo a las postulaciones no sólo fuese realizado por un especialista habituado con el lenguaje profesional del área patrimonial, sino que sus propuestas fuesen avaladas por el equipo editorial núcleo y miembros del CERI familiarizados con el tema de la contribución, ello para asegurar que las optimizaciones en forma no afectarán el fondo de la expresión de las distintas disciplinas y especialidades del ámbito patrimonial. Cabe señalar que las versiones de corrección de estilo son certificadas por los autores como parte de un seguimiento riguroso donde también se suscriben y documentan fases de dictamen, aceptación, cesión de derechos patrimoniales y visto bueno de galeradas 


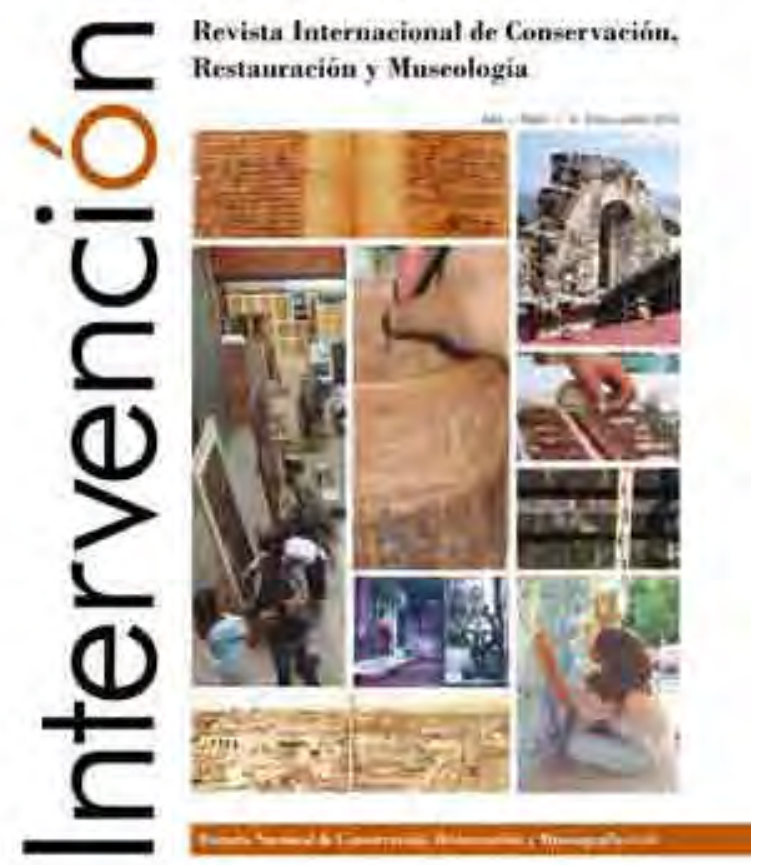

Figura 1. Portada del número inaugural de Intervención, Revista Internacional de Conservación, Restauración y Museología que salió a prensa en el año 2010. (Cortesía: ENCRyM-INAH, 2014).

como parte de una maquinaria de formalización editorial.

Siendo un producto editorial del INAH, Intervención cuidó generar una armónica y respetuosa colaboración intrainstitucional, que concatenara los procesos de producción académica realizados en la ENCRyM-INAH INAH con aquellos subsecuentes relativos a la maquetación e impresión. Así desde el número fundacional, estos últimos procesos son realizados en conjunto con la Coordinación de Difusión del INAH, particularmente por la Subdirección de Publicaciones Periódicas, bajo el mando un agente que se ha vuelto un colaborador clave en la concreción editorial, el Sr. Benigno Casas, quien hoy es el editor responsable de Intervención.

Los procesos de producción editorial académica y de publicación de Intervención han sido sujetos a continua revisión y ajuste en los últimos cinco años con el fin de mejorar su consecución y asegurar su transparencia. Esta evolución que es en gran parte responsable de la publicación en tiempo y forma de ya 9 números ha sido posible no sólo gracias a las ideas y motivación del grupo editorial núcleo y del CERI, sino también al cobijo de la certeza del financiamiento proporcionado por el presupuesto de la ENCRYM-INAH, bajo la dirección de la Lic. Liliana Giorguli y su equipo administrativo. A ello se debe sumar la colaboración de miembros de la secciones de diseño, informativa y difusión de la ENCRyM-INAH, quienes realizan tareas esenciales para la verificación, ajuste y conformación de los contenidos gráficos de la propia revista, para su distribución en México y en el extranjero, así como para su promoción a través de Ferias de publicaciones nacional e internacionales y diversos medios de comunicación impresos y electrónicos, incluyendo los generados por enlaces con las secciones de medios y prensa e informática del INAH. Es de notar que cada uno de estos procesos cuenta con procedimientos específicos que se ensamblan con la cadena de producción académica, de publicación y acciones de difusión propia de la ENCRyM-INAH, por lo que su logística y puesta en marcha involucra una serie de colaboradores, cuyo trabajo ha sido esencial para buen desempeño del proyecto editorial de Intervención.

\section{Alcances}

Hasta el momento se han publicado - en tiempo y forma- diez números de Intervención tanto en formato impresocomo en diversas plataformas electrónicas. A la publicación de esta reseña, con salida de prensa del último, se ha cumplido la meta de 5 años de continua y puntual aparición de nuestra revista. En este sentido, el presente es un momento de celebración para el CERI que se suma a los festejos del 75 aniversario del INAH. Al mismo tiempo, estos eventos significan a la editorial de Intervención una doble oportunidad para, por un lado, ponderar lo logrado $y$, por el otro, generar una auto-reflexión, ambos ejercicios que se justifican por un periodo de transformación significativa en el proyecto editorial, cuyos ejes de cambio merecen ser revisados en cuanto tanto a los beneficios que conllevan como de los retos que significan.

Empecemos por lo logrado. A lo largo de su vida, Intervención ha publicado casi 150 contribuciones, de las cuales un porcentaje considerable — sino mayoritario- corresponden al ámbito de la conservación-restauración, particularmente de bienes culturales muebles o inmuebles por destino, aunque varios refieren a las categorías más amplias o envolventes: colecciones, monumentos, sitios, paisaje y territorio. Los abordajes de estas contribuciones han cubierto aquellos de corte teórico-conceptual, jurídico normativo, histórico, metodológico, formativo $y$, fundamentalmente, práctico. La temporalidad temática ha cubierto desde la época precolombina, el periodo histórico (Virreinal), los tiempos modernos y la era contemporánea, predominando, el primero y con balances en los restantes. Algunas contribuciones han referido al ámbito inmaterial, aunque se han enfatizado aquellas que refieren a intervenciones sobre entidades patrimoniales materiales, incluyendo las tipologías, en orden de abundancia, de obra mural, escultura en piedra, metales, cerámica, instrumentos musicales, fotografía, pintura de caballete y tabla, y en menor proporción, textiles, documentos, artes aplicadas, y otros. Se han reseñado cuatro libros y dos eventos académicos, mientras que se han presentado semblanzas de dos instituciones y cuatro programas de actuación y 
formación profesional, todos ellos referentes del campo de la conservación-restauración nacional e internacional. Entre éstos también destacan las retrospectivas a dos revistas hermanas, una chilena y otra española - Conserva (CNCR 2013) y, recientemente, Ge-Conservación-(GEIIC en prensa)— , artículos que han servido para unir lazos institucionales, ya sea en forma de cooperación en la emisión de convocatorias y noticias de salida de prensa, intercambio en la producción de contribuciones y formación de enlaces bibliotecarios. Con ello, Intervención ha cumplido las expectativas iniciales de consolidarse como un órgano de divulgación del conocimiento en material patrimonial (cfr. Manzanilla 2010: 4).

Las ambiciones de Intervención en su doble carácter interdisciplinario e internacional --cualidades explicitadas en su subtítulo-- se han cumplido cabalmente. Cada uno de los números publicados cuenta con contribuciones derivadas de distintas aproximaciones disciplinarias, y en ya varios casos, se han publicado obras que son, de hecho, el resultado de la cooperación profesional, o bien, que muestran híbridos teóricos, metodológicos y de praxis tras-disciplinar. En el ámbito de las procedencia de la producción académica cabe señalar que Intervención ha publicado contribuciones de México, Chile, Colombia, Argentina, España, Reino Unido, Italia y Estados Unidos. Aunque gran parte de las adscripciones de los autores han sido institucionales — con predominancia obvia a la ENCRyM y al INAH — también se han manifestado organizaciones no gubernamentales y voces privadas. De esta manera, Intervención ha articulado su papel como plataforma de difusión e intercambio entre la comunidad nacional e internacional en el campo patrimonial (Cfr. Manzanilla 2010:4).

La dimensión nacional e internacional de nuestra publicación también se ha consolidado en su recepción: Intervención es distribuida no sólo en instancias claves, museos nacionales y los diversos Centros INAH donde se ejerce la conservación, restauración y museología institucional, sino también en organizaciones externas públicas de relevancia en dichos campos. Asimismo, se envían volúmenes a instituciones de formación y actuación profesional claves del sector patrimonial tanto en nuestro país en el resto del mundo, ello con la finalidad de ampliar la cobertura a la comunidad global mediante abstracts y keywords en lengua anglo-sajona, así como publicaciones, ya sea completas en ingles, o bien bilingües inglés-español.

Teniendo un tiraje determinado a 1000 ejemplares --con porcentajes dispuestos para la distribución antes descrita, agradecimientos para autores y revisores, y adquisición por donativo tanto en la biblioteca de la ENCRyM como en puntos de venta en las tiendas INAH-- no es de sorprender que desde fechas tempranas Intervención buscó incrementar su visibilidad por medios cibernéticos. Así, desde el primer número de Intervención, un compilado de sus contenidos en formato PDF se han hecho accesibles en el sitio web de la ENCRyM-INAH (ENCRyM 2014a) Esta primera transición a la plataforma digital se vio reforzada a partir el

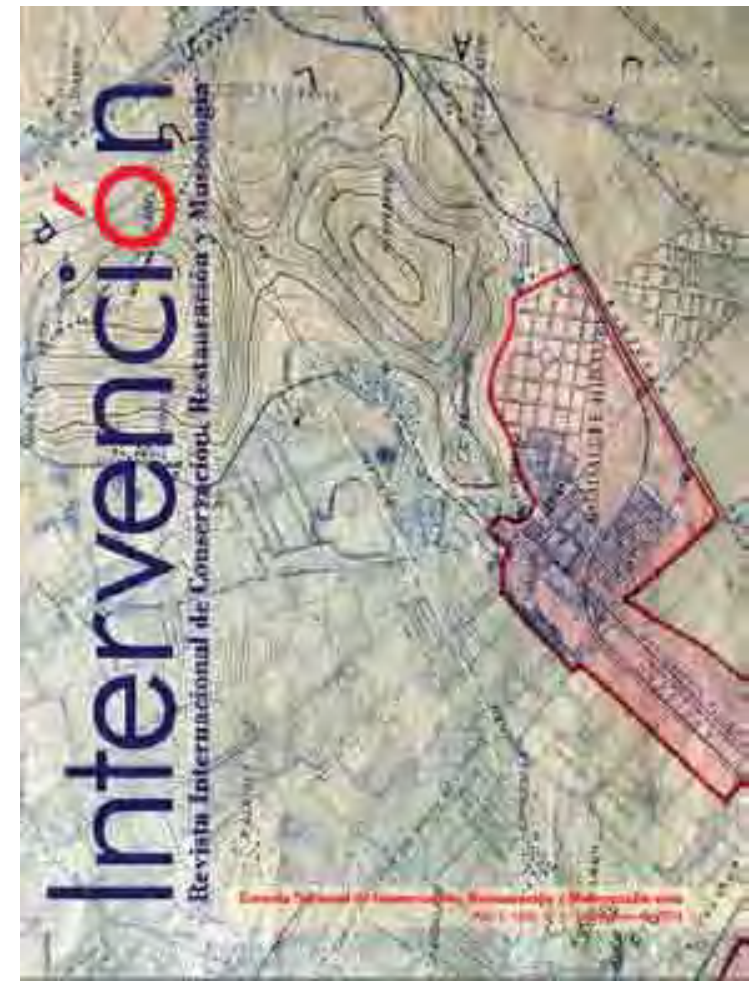

Figura 2. Portada del número 9 de Intervención, Revista Internacional de Conservación, Restauración y Museología (Cortesía: ENCRyM-INAH, 2014).

segundo número de Intervención con la integración, también de números completos en PDF, en la biblioteca virtual del INAH (BV INAH 2014) donde se publicitan un número considerable de publicaciones periódicas institucionales, siendo la nuestra la única en el sector de conservación y restauración.

La inserción de Intervención en ambas plataformas ha probado éxito en términos de incremento de visibilidad, un factor de ponderación de impacto. Datos del inicio de este año indican que un porcentaje considerable de visitas a la página de le ENCRyM corresponden a accesos a Intervención y que, de hecho, esta publicación sirve de ancla para que los usuarios visiten el resto del sitio de la escuela. Biblioteca virtual INAH, adicionalmente, reporta cifras de visita por número que, al día de hoy, duplican, triplican, cuatriplican, quintuplican y septuplican la cifra del tiraje impreso (BV-INAH 2014). Esta inicial etapa de transición a medios digitales, sumada a la voluntad de generar un proyecto innovador en materia de publicaciones en el INAH, llevó a Intervención en el año 2012 a publicarse en la plataforma de acceso libre --el Open Journal System-- en un formato de contribuciones individuales que permite búsqueda de contenidos por metadatos (Intervención 2014). Hoy en día, como resultado del esfuerzo del núcleo editorial no sólo se cuenta con todos los números de Intervención en el OJS, sino también, a partir del número 8, con la publicación de la emisión actual en medios digitales previa a la salida de imprenta, ello como parte de un portal de publi- 
caciones electrónicas de la ENCRyM (ENCRyM 2014b).

La transición de Intervención al uso del gestor editorial del OJS se catalizó con la integración de nuestro proyecto editorial el Índice de Revista de Científicas del Consejo Nacional de Ciencia y Tecnología (CONACYT) a finales del 2013, siendo ésta la segunda revista del INAH en ser merecedora de este reconocimiento. Hoy en día, contamos con nuevas Directrices Editoriales, un sistema editorial con procesos adaptados, transparentes y mejorados de revisión, así como una cartera de árbitros de más de 150 personas de distintas nacionalidades. Asimismo, en coincidencia con los impulsos institucionales en materia de publicaciones electrónicas --particularmente en la construcción con la mediateca-se busca crear mecanismos certeros de trabajo para que otros proyectos editoriales se sumen a la plataforma OJS con host y dominio institucionales (Intervención en proceso). En el caso de Intervención, estos son pasos que se complementan con los esfuerzos de integración a SCIELO-México y la suscripción a otros sistemas de indexación, aspectos que son materia de análisis en cuanto a la evolución futura del proyecto editorial.

\section{Evolución}

El campo editorial de las publicaciones periódicas académicas en el ámbito de las humanidades en México, está en un momento de profundas transformaciones hacia prácticas ya plenamente establecidas en el área científica, sobretodo en países de tradición anglo-sajona. Aunado a

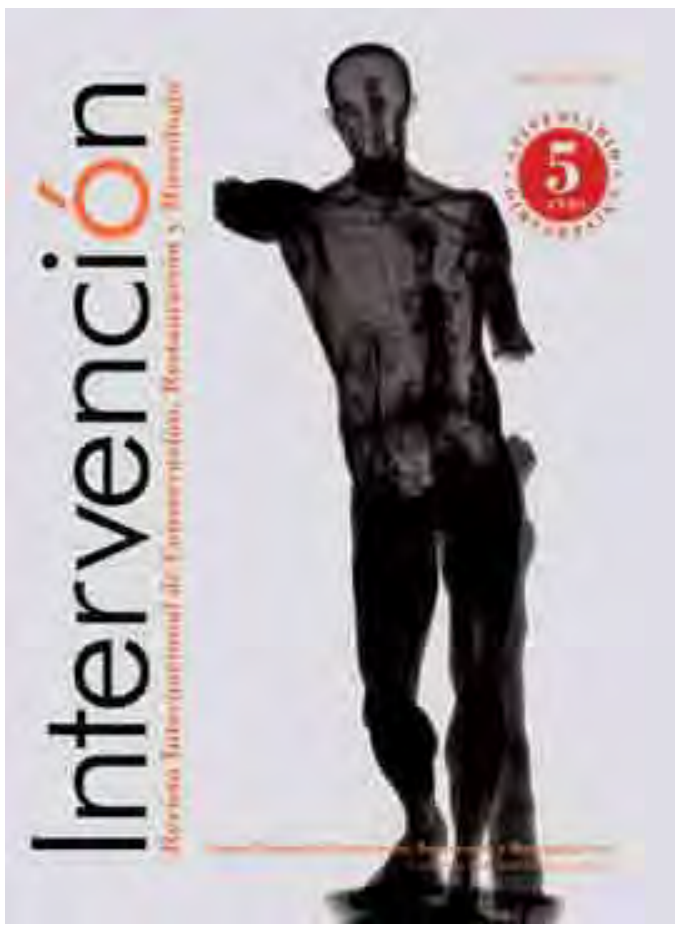

Figura 3. Portada del número 10 de Intervención, Revista Internacional de Conservación, Restauración y Museología (Cortesía: ENCRyM-INAH, 2014). la integración a sistemas de acceso cibernético libre, repositorios electrónicos, evaluación de impacto por cosecha de datos por citación, etc., que significan un nuevo lenguaje editorial, el ámbito de las publicaciones en materia de patrimonio se enfrenta a nuevos retos. Por un lado, es un mundo más diversificado y amplio: el espectro editorial se ha enriquecido por publicaciones configuradas desde el inicio en la plataforma electrónica: ejemplos como el español de GE-Conservación (GEIIC 2014) y el portugués de ECR (ECR 2014) son muestras de este paso evolutivo, que ya complementan la trayectoria de publicaciones impresas de gran trayectoria como Conserva, Studies in Conservation, Pátina, Apoyo, que ya cuentan con sus propios sitios en la web y sistemas de publicación electrónica por metadatos. Intervención siendo un proyecto editorial joven ha sido capaz de mantener el ritmo de la adaptación y tomar algún rumbo innovador, y ello se debe, en gran parte a la capacidad de auto-crítica que precede y genera renovación. Así, en los últimos años, hemos identificado áreas de oportunidad de crecimiento. Una de ellas, es la necesidad de confirmar un paso hacia la publicación bilingüe, e incluso trilingüe, con la integración de los idiomas portugués y francés. Asimismo, es evidente que nuestro proyecto requiere de consolidar su equipo editorial núcleo con personal que diseñe estrategias de difusión. Al mismo tiempo, será importante consolidar el paso al pleno uso del gestor editorial en el host institucional, proyecto que podría, en calidad de producto piloto, generar certezas para la suma de otras publicaciones periódicas del INAH. Tras seis años de trabajo también se vislumbran cambios en la estructura y contenido del equipo editorial. Estos cambios se generarán paralelamente aquellos de orden organizativo al interior de la ENCRyM-INAH. Lo cierto es que el proyecto editorial de Intervención requerirá mantener y renovarse responsabilidad en la medida de su ganada relevancia: hasta el momento, no se cuenta con ninguna revista académica en el campo patrimonial análoga a Intervención en Hispanoamérica. Desde la posición actual, significa un crecimiento sin perder lo ganado, incluyendo la publicación puntual de los números y la conservación de la calidad lograda. Se trata de un reto de grandes oportunidades, especialmente en vista de una nueva iniciativa, apenas en confección en la ENCRyM-INAH, bajo coordinación de quien suscribe que ha sido denominada Red de Publicaciones de Patrimonio (RIPP), un nódulo cibernético que pretende unir en un solo sistema accesos a los proyectos editoriales de la región hispanoamericana. Este marco demanda no sólo una reflexión de la historia y actualidad de las publicaciones en materia de patrimonio en diversas escalas, sino un análisis sobre las futuras posibilidades de trabajo a nivel global: un promisorio paso de evolución.

\section{Referencias}

BV-INAH (2014). Biblioteca Virtual INAH. Restauración y Conservación, página oficial web: http://www.bibliotecavirtual.inah.gob.mx/restauracion-y-conservacion [consul- 
ta 04.07.2014]

ENCRyM (2014a) ENCRyM-INAH, página oficial web: http:// www.encrym.edu.mx [consulta 04.07.2014]

ENCRyM (2014b). Portal de Publicaciones de la ENCRyMINAH, página oficial web: http://www.publicaciones-encrym.org/[consulta 04.07.2014]

ECR (2014). ECR - estudos de conservação e restauro, página official web. http://citar.ucp.pt/ecr/ES/index.php [consulta 04.07.2014]

GEIIC (2014). Ge-Conservación, página oficial web, OJS. http://www.ge-iic.com/ojs/index.php/revista [consulta 04.07.2014]

GEIIC (en prensa). Semblanza sobre la Revista Ge-Conservación, Intervención, Revista Internacional de Conservación, Restauración y Museología 10
Intervención (2014a). Intervención, Revista Internacional de Conservación, Resturación y Museología, página oficial web OJS, http://www.publicaciones-encrym.org/gestion/ index.php/intervencion. [consulta 04.07.2014]

Intervención (2014b). Intervención. Revista Internacional de Conservación, Restauración y Museología, página oficial web, dominio institucional, OJS, http://www.revistas.inah. gob.mx/index.php/intervencion [consulta 04.09.2014]

LINARES, P. (2008). La importancia de la difusión del conocimiento: análisis d las publicaciones periódicas enfocadas a la conservación y restauración generadas en México. Tesis de licenciatura en restauración, México, ENCRyM-INAH.

MANZANILLA, L. (2010). “Comentarios en torno a la presentación de la Revista Intervención", Intervención, Revista Internacional de Conservación, Restaución y Museología 2: 4-7

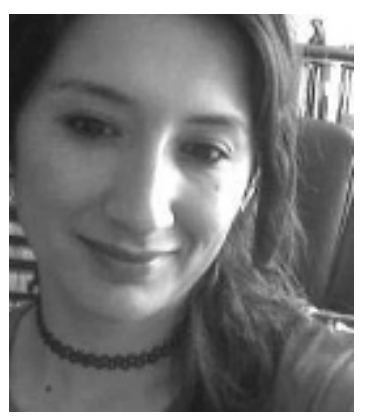

Isabel Medina-González ENCRyM-INAH, México ismedin@gmail.com

Licenciada en restauración de bienes muebles (Escuela Nacional de Conservación, Restauración y Museografía [ENCRyM], Instituto Nacional de Antropología e Historia [INAH], México), maestra en gestión de patrimonio arqueológico (University of York, Reino Unido), doctora en arqueología, especialidad en estudios de patrimonio cultural y museos (University College London [UCL], Reino Unido). Desde 1993, ha sido restaurador del INAH y trabajado en iniciativas de conservación, restauración, investigación, gestión y formación profesional en materia de patrimonio cultural en la Coordinación Nacional de Conservación del Patrimonio Cultural (CNCPC-INAH, México), el Museo Nacional de las Culturas (MNC-INAH, México) y la ENCRyM-INAH. Desde el 2009 es profesor-investigador de tiempo completo de la ENCRyM-INAH tanto en la licenciatura en restauración como en la maestría de conservación y resturación de bienes culturales inmuebles. Ha sido galardonada con el Premio al Joven Americanista (2000), Honorary Fellow del Institute of Archaeology (UCL, Reino Unido) y Profesor de Perfil Deseable (Programa del Mejoramiento del Profesorado [PROMEP], Secretaría de Educación Pública [SEP], México). Forma parte de Sistema Nacional de Investigadores (SNI). Desde el año 2009, es la editora de Intervención, Revista Internacional de Conservación, Restauración y Museología. 


\title{
De la memoria de los conservadores-restauradores contempo- ráneos a la "magdalena" de Marcel Proust. Conversaciones con Juan Carlos Pérez Ferrer y Jesús Serrano Rodríguez.
}

\author{
Por Ana Calvo Manuel y María Dolores Ruiz de Lacanal.
}

En el año 2013 el Premio Nacional de Restauración se otorgó a dos conservadores-restauradores por el proyecto de intervención en el Oratorio de San Felipe Neri, en Cádiz, y a un conservador-restaurador de la Biblioteca Nacional por su trayectoria profesional.

Con entusiasmo el Grupo Español del IIC celebró el reconocimiento a la profesión con una doble entrevista y publicó la primera, a Arsenio Sánchez Hernampérez con el título "De Sarajevo a los brioches de María Antonieta. Conversaciones con Arsenio Sánchez Hernampérez", en la revista digital Ge-conservación. La segunda, esta que tiene en sus manos, con el título "De la memoria de los conservadores-restauradores contemporáneos a la magdalena de Proust. Conversaciones con Juan Carlos Ferrer y Jesús Serrano Rodríguez", tiene vocación de entrevista y de documental.

La idea inicial fue hacer una presentación de los profesionales, sus trayectorias y actividades, y de alguna manera reflejar el trabajo ligado a los ámbitos laborales, aquel en la Biblioteca Nacional y estos en relación a sus proyectos en general o en particular con el monumento gaditano. Sin embargo, la riqueza de matices y las reflexiones que Arsenio Sánchez Hernampérez, dejó en su entrevista en el papel, aportando una de las visiones críticas contemporáneas más importante de la restauración en España, dio pie a que la segunda, aspirara a ser, más que una entrevista, un documento de la memoria de los conservadores-restauradores españoles contemporáneos.

Al fin y al cabo, la necesidad de encontrar la manera de hacer este archivo de la memoria, entendido como archivo oral contemporáneo, podría comenzarse por los Premios Nacionales de Restauración y continuar posteriormente con los profesionales de instituciones públicas, archivos, bibliotecas, museos, institutos... La oportunidad de hacer una entrevista, con sus valiosas opiniones y comentarios, suscitaba una reflexión: el olvido de la memoria de tantos y tantos profesionales de la conservación y restauración, que dejaron sus huellas en el patrimonio cultural, que velaron por su mantenimiento, que hicieron informes, estudiaron e investigaron los más variados materiales y casos, y a los que se ha ido olvidando poco a poco.

GEIIC - Reflexión en voz alta. ¿Es el Tiempo el gran conservador o realmente es el gran devorador de los bienes culturales? ¿Es nuestro aliado o nuestro enemigo?

J.C.P.F. - ¿Aliado o enemigo...? Ambas cosas. Aunque uno de nuestros papeles sea retrasar el menoscabo que el tiempo causa en los bienes culturales, también es el que permite su conservación. Una paradoja, la destrucción y la conservación. Digamos que tiende caprichosamente a deshacer lo que antes permitió que el hombre hiciera.

J.S. - No creo que exista una respuesta excluyente para tus reflexiones, aunque sin el Tiempo como parte del proceso creativo del arte no tendría razón de ser nuestra profesión. Estaremos de acuerdo en que cuando un artista concluye una obra de arte, ésta continúa evolucionando gracias a las pequeñas huellas que el paso del tiempo deja en ella, al igual que nosotros, envejece y cambia su fisonomía sin perder su identidad. Nosotros no somos los "esteticistas" que la intentan mantener joven... sino los que la cuida como superviviente que es.

La historia es algo lejano, impersonal, sin embargo la memoria es algo próximo, propio, entrañable, necesa- 
rio. Efectivamente la historia no es la memoria, y nuestra memoria queda en el monumento, invisible pero diferenciable, discernible... Nuestra memoria está guardada en los monumentos que hemos restaurado.

El Tiempo, hábil devorador de la memoria de tantas y tantas personas de nuestro ámbito, no ha sido menos certero con los profesionales y lo cierto es que si contar la historia de la profesión, ha sido una búsqueda de huellas, documentos y registros, entre vacíos y lagunas, difíciles de restaurar, hacer un archivo oral, documental, actual, es un gran reto para la profesión.

¿Por qué no hacerlo? Si el Tiempo es hábil, más lo es el hombre, creador de estratagemas, generador de archivos para conservar la memoria, constructor de museos que guardan sus conocimientos y su legado, de bibliotecas inmensas, como la Biblioteca Nacional en la que trabaja Arsenio Sánchez Hernampérez; además, están los monumentos, las pinturas y retablos, los documentos, en donde invisible, pero diferenciable, dejaron su huella los restauradores.

Recuerdo que en un Congreso en Florencia, se hablaba ya de la propiedad intelectual del restaurador. Pero estaría bien hacer un archivo, bien oral o digital, de aquellos, que dan forma a la profesión, que la configuran y la ejercen, y de esa manera construimos una memoria de la profesión.

No creo que sea una cuestión personal, sino profesional. Habría que crear un Archivo para la Memoria de la propia conservación y restauración de los bienes culturales, y protegerlo frente al olvido, para no tener siempre que empezar de nuevo hablando sobre el desarrollo y evolución de la profesión, sobre cómo ha pasado de ser artesano a un profesional. Una cosa está clara, los premios nacionales de restauración marcan el nombre de unas personas, que destacan en la profesión y serán recordadas por su carácter ejemplar, por su excelencia, un referente en la Historia de la profesión.

Insisto en que la entrevista sea también un documental, es decir, un ejercicio de la antropología, con imágenes e interpretaciones etnográficas, que descubra que el archivo de los conservadores-restauradores, recoge además de vuestras palabras, una manera de pensar y de hacer, un reflejo de una formación y unas costumbres de la sociedad, además de una manera de entender la profesión.

\section{GEIIC- Quizás seamos los buscadores de supervi- vientes. ¿Vamos a contar la historia o vamos a con- servar la memoria? ¿Conservará la historia vuestro nombre por un Premio Nacional?}

J.C.P.F. - En un sentido lato, memoria e historia son sinónimos. Pero si con Pierre Nora entendemos por memoria "el recuerdo de un pasado vivido o imaginado» $y$ por historia «una construcción siempre problemática e incompleta de aquello que ha dejado de existir, pero que dejó rastros", puede entonces asomar el conflicto que con precisión planteáis en vuestra pregunta: «¿Vamos a contar la historia o vamos a conservar la memoria?». Al profano esta distinción quizá le parezca una disgresión ajena a la conservación y restauración de bienes culturales, pero no es así. En nuestro campo también se da ese encuentro, o desencuentro, entre lo "afectivo o emotivo» y el "análisis crítico».

Veámoslo con un ejemplo. En muchos aspectos, Sevilla sigue siendo vivamente barroca y el oro, por tanto, también sigue siendo en la memoria de sus habitantes y visitantes el exponente de lo suntuario. Por eso, cuando alguien visita el palacio mudéjar del Real Alcázar se encuentra oro y más oro decorando paredes y techos... Pero aquellos artífices medievales aquí nunca emplearon panes de ese metal: esos revestimientos áureos provienen de reparaciones, modificaciones o adecentamientos posteriores. Aparece entonces la disyuntiva entre mantener el oro que tan bien refleja el lujo que de un sitio así se espera (atender a la Memoria, podríamos decir) o recuperar los revestimientos primitivos, originales (apelar a la Historia) este dilema siempre se resuelve estudiando cada caso detenidamente.

En suma, quizá una de las funciones del restaurador sea lograr tender a que memoria e historia no se opongan entre sí sino que se complementen.

En cuanto a si conservará la historia nuestro nombre por un Premio Nacional... María Dolores, Ana, esa pregunta os la devuelvo. Por vuestro trabajo, labor docente y publicaciones (que tantos consultamos frecuentemente) vais muy por delante en ese camino. Así pues, hagámoslo al revés, decidnos vosotras si la labor del restaurador (trabajar para que la historia material perviva) tiene algún sitio en ella, en la Historia.

J.S. - Creo que ambos conceptos deben coexistir sin que uno colapse al otro, la Historia como disciplina científica ceñida a la recopilación de los actos humanos, es muchas veces reinterpretada interesadamente para formar una memoria, que es un concepto mas emotivo y menos estricto en su justificación, pero a su vez mas fácil de transmitir y contagiar. Conservemos la Historia y contagiemos la Memoria.

\section{GEIIC- Pero ¿Conservará la historia vuestro nombre por un Premio Nacional?}

J.S. - Para nada. Cualquier restaurador cuando comienza su formación es consciente de que es un aliado en la sombra de los bienes culturales, que si son obras de arte hará todo lo posible por mantenerla lo mas fiel a como fue creada, pero que nunca seremos parte de ella. La Historia conserva los nombres de los artistas y creadores, pero nosotros no estamos en ese entorno, ya que trabajamos con las creaciones de otros. Es mi opinión y como tal puede ser errónea. 
¿Los restauradores opinan que su memoria queda en el monumento? Nos gustaría saber algo más sobre la relación entre los monumentos y los conservadoresrestauradores de bienes culturales. El restaurador y el monumento.

Juan Carlos Pérez Ferrer ha trabajado durante muchos años en el Alcázar, un monumento declarado Patrimonio de la Humanidad, en el corazón de Sevilla, que ha sido constantemente intervenido, en un proceso de aquellos que Antón Capitel comparaba con un paño de Penélope.

Jesús Serrano ha trabajado muchos años en uno de los monumentos o parajes arqueológicos más significativos del legado islámico, el conjunto de Medina Azahara en Córdoba.

Y ambos han trabajo en esta ocasión en el Oratorio San Felipe Neri, en Cádiz, un bien de interés cultural que guarda a su vez la memoria de una constitución, que a su vez guarda la memoria de un acuerdo de convivencia; que a su vez guarda la memoria de muchas desavenencias, desastres y conflictos armados.

Como lo importante es el Patrimonio Cultural y no el profesional prefieren hablar del yacimiento de Medina Azahara, del Alcázar de Sevilla o del Oratorio de San Felipe Neri, antes que de ellos mismos, de sus vidas y sus trabajos, porque lo son los monumentos y se sienten privilegiados de haber estado ahí, en esos momentos, en esos proyectos relevantes.

GEIIC- ¿Cómo se relaciona un conservador-restaurador con un monumento? Normalmente los restauradores trabajan con bienes muebles, ¿Qué ocurre cuando se trata de un inmueble? Es entonces inevitable la combinación arquitecto-restaurador ¿Cómo se lleva esta relación?

J.C.P.F. - La relación con un monumento empieza por el estudio: recopilar qué se sabe de él. Pero también «La propia obra de arte es el mejor documento». Por eso, el restaurador debe comprobar todo lo publicado, mediante la observación directa y también a la luz de los recursos científicos actuales. $Y$ actualizar e interpretar esa información atendiendo a historiadores, químicos, biólogos, aparejadores y arquitectos, filólogos... Cuando se actúa así, con un enfoque sistemático y multidisciplinar, siempre se obtienen buenos resultados. Por ejemplo, cuando restauramos el portalón medieval de la Media Naranja (Salón de Embajadores) del Alcázar de Sevilla leímos que todos los autores daban por alerce la madera empleada. Y así pudo haber quedado. Pero al traducir la epigrafía en árabe (nasjí) tallada en madera que orla las hojas descubrimos que la madera era "una partida noble que fue traída de la apreciada madera de ciprés». Y así también podría haber quedado si no hubiésemos hecho un estudio morfológico que reveló que la madera no era ni alerce ni el valorado por incorruptible ciprés sino un resinoso pinastro.
De forma aislada, así contado, esto no pasa de ser una curiosidad, pero es la suma de esas indagaciones lo que finalmente nos procura una idea cabal de la obra, de sus problemas y de la mejor restauración.

En cuanto a la relación entre el arquitecto y el restaurador... el restaurador no puede pretender que otros le entiendan si él no hace lo propio por los demás. En las restauraciones de envergadura que se ejecutan en inmuebles, en las rehabilitaciones, entran muchos oficios y disciplinas, intereses distintos, plazos de ejecución que no se deben estorbar entre sí... Pero cuando el equipo humano se aplica siempre concurre un mismo afán: hacer las cosas bien. Así pues, el buen restaurador es el que se sale con la suya satisfaciendo a todos ¿Difícil? Sí. ¿Imposible? ¡Qué va, en absoluto!

En este sentido, la relación con el arquitecto del Oratorio de San Felipe Neri, Francisco Torres, fue muy fructífera. Fructífera y agradable; es una persona de la que se pueden aprender muchas cosas, no sólo de arquitectura.

J.S. - En los años que llevo en la profesión, he ido recorriendo un camino al que me ha llevado la necesidad del continuo aprendizaje y que me obliga a marcarme constantemente nuevos retos. ¿Por qué te digo esto? Pues porque mi relación con el monumento es evolutiva y por lo tanto, todavía no la tengo definida, y espero que siga así. Como todos los restauradores de mi generación, empecé aprendiendo en un taller con obras de caballete y escultura policromada, pero al poco tiempo me di cuenta que si bien era un trabajo gratificante, a mi me resultaba insuficiente, así que abrí un poco mas mi círculo de actuación y me metí de lleno en el mundo de los yacimientos arqueológicos, pero no solo en la restauración de tal o cual pieza, sino en la conceptualización de los mismos, en entender los problemas del yacimiento y sus posibilidades de musealización. En otro círculo más externo, me sentí muy cómodo actuando en la rehabilitación de edificios históricos, en los que no existe un solo elemento a restaurar, sino que confluye una variedad de ellos que deben seguir coexistiendo. Cada vez que se planteaba cualquier intervención peregrina que pudiese necesitar el conocimiento de un restaurador, allí estaba yo levantando la mano, así he podido aprender a relacionarme con muchos otros profesionales que intervienen en el patrimonio aunque de manera esporádica y que me han enriquecido notablemente. De esta forma he dirigido obras tan "normales" como extraer y trasladar un árbol fosilizado de 300 millones de años y $25 \mathrm{~m}$ de longitud; extraer, reubicar y musealizar un horno romano excavado en el terreno, de 26 Tn de peso; extraer, reubicar y musealizar un yacimiento romano de mas de $4500 \mathrm{~m} 2$.

Bueno para no alargarme, en un principio mi relación con el "monumento" era la existente en el cuadro sobre el que trabajaba, ahora es difícil acotar donde empieza y donde termina el monumento. 
GEIIC - ¿Pero cómo se lleva la relación entre el restaurador y otros profesionales del patrimonio?

J.S. - Cómo te he comentado antes, llevo muchos años relacionándome con otros profesionales y entre ellos, claro está, destacan los arquitectos. Sinceramente te digo que salvo casos muy puntuales he tenido y mantengo una excelente relación con todos ellos.

En el caso de San Felipe Neri, el haber contado con Francisco Torres como Director, ha contribuido notablemente al éxito de los trabajos de restauración.

Si el técnico que trabaja en patrimonio es un buen profesional, enseguida se verá absorbido por la obra que tiene en sus manos y dejará de lado cualquier impulso de utilizar ésta como soporte de sus creaciones, donde digo técnico se puede decir restaurador, arquitecto, ingeniero, ....

La formación en la Facultad de Bellas Artes de Sevilla, la dirección de una empresas de restauración, el trabajo en equipo, los materiales, los andamios y las facturas, el tiempo y los plazos, los criterios y las autoridades competentes ¿Todo ello forma parte de la profesión del restaurador?, y asimismo, forma parte de la profesión: la humedad, el calor, la degradación de la piedra, las termitas o el papel, es decir, la materia y su degradación; pero también comprender las mentalidades que cambian de gusto y comprender a la sociedad, que quiere, a veces con urgencia cambiar el paisaje, cambiar los monumentos, cambiar de color la fachada, y tú estás ahí, intentando frenar su presente, limitar sus acciones, aliándote con una imagen del monumento en el pasado, y dejándolo congelado, mientras, la vida sigue, la gente vive ya de otra manera, piensa de otra manera, hacen monumentos de otra manera... Y tú le dices, no esto es como un animal en extinción... y lo tratas como tal, con mucho cuidado.

GEIIC- ¿Qué más forma parte de la profesión? Forma parte también los términos y los conceptos, los materiales, los procedimientos. Los usamos y nos parecen siempre igual, pero no es cierto, los vamos ajustando con el tiempo; por ejemplo, en la nueva edición en la que estoy trabajando de Materiales, técnicas y procedimientos. De la A a la Z estoy cambiado muchas entradas $y$ he introducido otras nuevas $y$, sobre todo, muchas definiciones, productos $y$ procesos que han aparecido recientemente.

J.C.P.F. - Sí, sí, ya lo creo que todo eso forma parte. $Y$ también en ocasiones reclamar el pago. No obstante, nuestra profesión tiene un desempeño muy distinto si perteneces a la Administración o si optas, como fue mi caso, por la actividad privada.

Si me permitís el chascarrillo, cuando terminé la carrera quise saber cómo sería su ejercicio libre, cómo sería mi futuro profesional. De aquellas pesquisas recuerdo una que sobradamente se ha cumplido: "Te espera la vida del turronero (de pueblo en pueblo, de feria en feria...)». En su vertiente privada es una profesión muy sacrificada por la disponibilidad a la que obliga; la maleta siempre tiene que estar lista, digamos. Pero aún siendo movida es también una vida que vale la pena.

J.S. - Estás definiendo mi profesión, pero creo que no define plenamente la profesión del restaurador. Tengo muchos colegas que no saben desglosar el IVA de una factura y sin embargo son excelentes restauradores. Quizás lo que pasa es que los que antes éramos raras avis, los que queríamos trabajar por libre y comernos el mundo, ahora nos hemos convertido en mayoría, aunque sea empujados por las circunstancias.

Yo me encuentro muy a gusto en este ambiente de problemas añadidos a la restauración, porque creo que todo es enriquecedor y siempre estoy dispuesto a levantar la mano y ampliar mi círculo.

De conservador a conservador, de restaurador a restaurador... Hay edificios que han pasado de conservador a conservador, de restaurador a restaurador y tiro porque me toca, como el caso del Alcázar de Sevilla, actuaciones constructivas y de restauración, como se recoge en las fuentes documentales existentes en el Archivo del Real Alcázar de Sevilla, algunas excepcionales o con carácter urgente y otras para darle la unidad de estilo, como diría Violet le Duc..., inspectores, aparejadores, arquitectos, que fueron manteniendo las cerrajerías, la carpintería, las azoteas y los cristales, las yeserías, los cierros acristalados, las cerámicas, los muros y yesos, los artesonados. Allí hay presupuestos y certificaciones de obras e intervenciones, y de esa manera tienes la impresión de que tú también como restaurador estas ahí, en ese archivo, y vives en esa red invisible que es el tiempo y dejas memoria.

Hablemos de la buena y la mala praxis. En el Alcázar de Sevilla también hubo y se recogió en los archivos, la mala praxis, de hecho, se nombró a un restaurador del edificio, "para salvar del abandono y hacer desaparecer las huellas asoladora de bárbaras restauraciones"... por ello, es importante, la buena praxis y distinguirla de la mala praxis. Dar un premio de restauración es precisamente revalidar la buena praxis. No todo está bien, y además no es una cuestión de gusto.

\section{GEIIC— ¿Qué opinais?}

J.C.P.F. - El gran hallazgo de la restauración moderna, por encima de que lo que se añada en las intervenciones se diferencie del original conservado, 0 , incluso, de que los materiales o sustancias empleados sean estables, es que la restauración sea reversible. En lo nuestro, de nada serviría que algo fuese discernible o estable si no fuera reversible, si no pudiésemos enmendar o revertir nuestra intervención. Una restauración que no distinguiese los justificados 

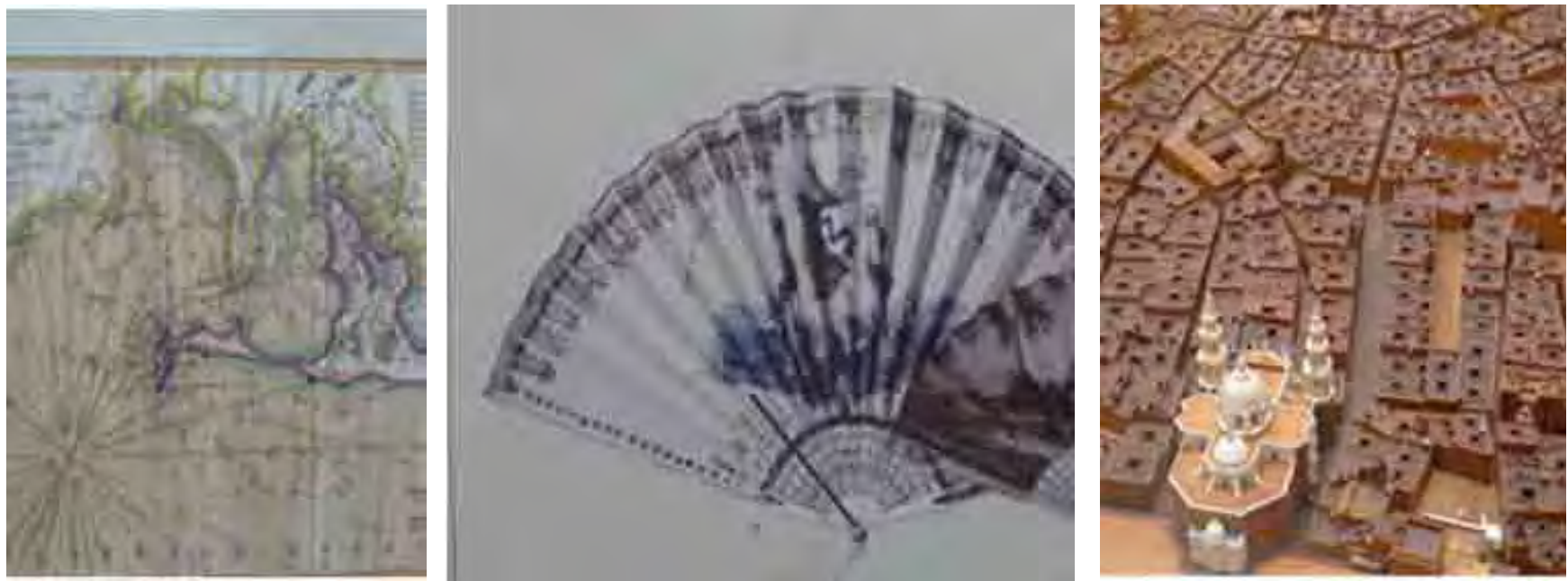

Figs. 1, 2 y 3. Imagen de un plano de Cádiz antiguo, un abanico y la maqueta de Cádiz. Museo de las Cortes de Cádiz.

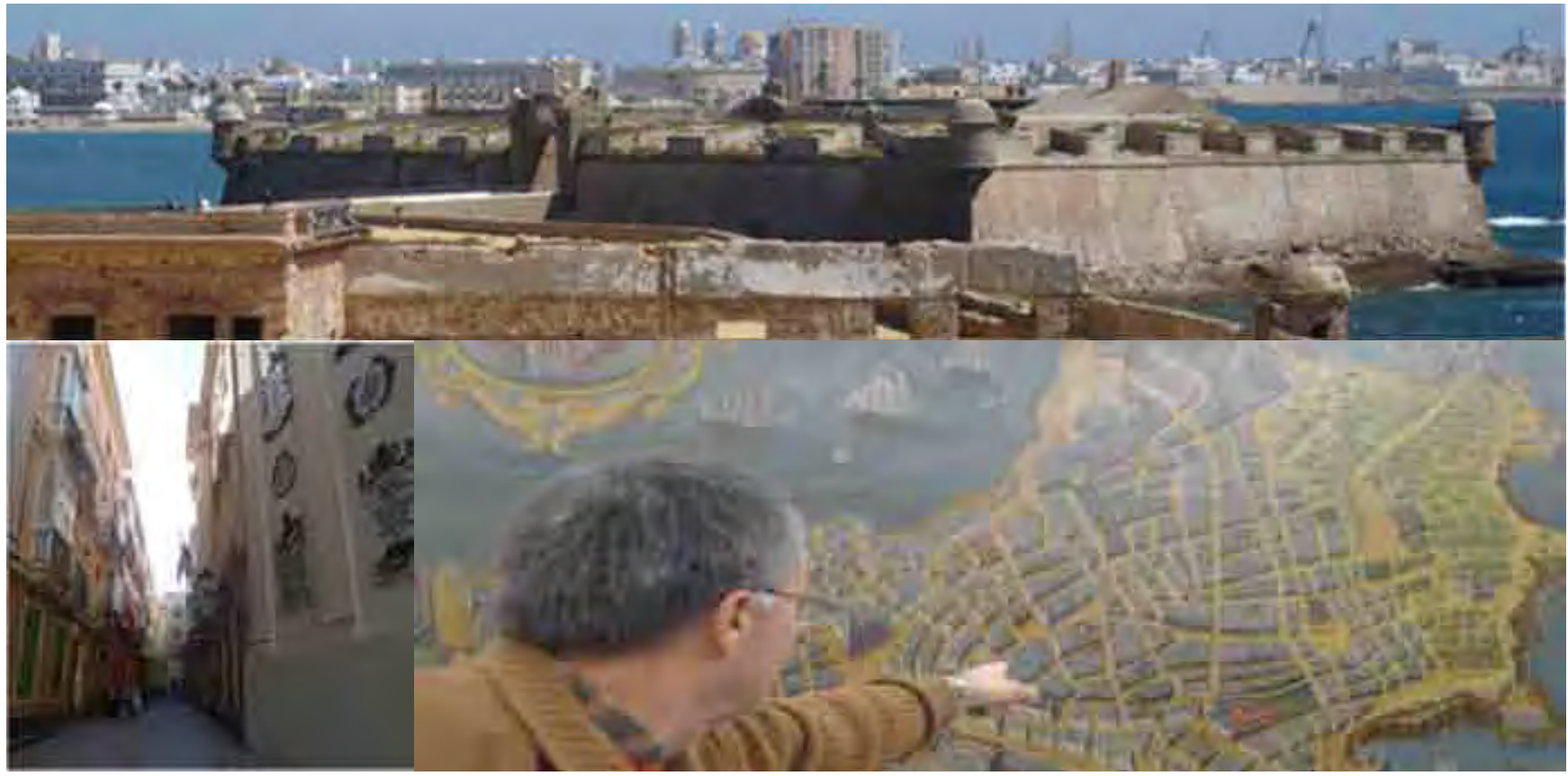

Figs. 4, 5 y 6. Baluarte de Santa Catalina, fachada exterior del Oratorio San Felipe Neri e imagen de un plano de la ciudad conservado en el Museo de las Cortes de Cádiz.

añadidos sería mala. Una intervención en la que no se hubiesen empleado materiales estables sería mala. Pero una restauración que fuese irreversible no sería mala, sería pésima y para siempre.

J.S. - En una comunidad en la que lo "bonito" se valora más que lo correcto, en la que todavía se critican intervenciones porque no brilla el oro, el que se premie una intervención concienzudamente meditada para no caer en el escaparatismo, es todo un espaldarazo a nuestra profesión.

Hablemos del proyecto del Oratorio de San Felipe Neri. Es un proyecto que comprende desde la ciudad al mo- numento y desde el abanico que se guarda en una vitrina del museo, pasando por el propio oratorio, por su cripta, o sus placas conmemorativas, como también el patrimonio intangible que supone el rescate de cartas, documentos, nombres...

El proyecto de mejora de "Los Lugares del Doce", y concretamente el proyecto de rehabilitación de San Felipe Neri, es en este sentido un proyecto integral.

La realización de este proyecto en el marco español, que empezaba a acusar la crisis, no fue sino una apuesta por comprender la conservación y restauración de los bienes culturales en un sentido contemporáneo, cons- 
ciente de que se requiere del apoyo y la estima social para revalidar, mantener y seguir transmitiendo los valores y bienes del legado español. El apoyo de las ciudades latinoamericanas a los proyectos de conservación y restauración, amplió el ámbito nacional al internacional, y no dudamos de que bien orientado, este núcleo o centro de acción cultural pueda ser con el tiempo, un registro cultural de interés para otras comunidades, entendiendo que esos bienes culturales son transmisores de valores intangibles, que hacen alusión a la conquista por el hombre de unos valores, como son la soberanía popular o la libertad de prensa. El propio monumento podría funcionar como la magdalena de Proust, es decir, despertando la memoria, pero desgraciadamente, este tipo de memoria no es automático, tenemos que hacer el esfuerzo de "recordar" ¡Ojalá algún día, esos valores intangibles y aquellos bienes culturales que son su memoria sean Patrimonio de la Humanidadi

En el momento en que se estaba interviniendo en el Oratorio de San Felipe Neri, la ciudad de Cádiz, estaba siendo intervenida en muchos sentidos y direcciones. Todos los tipos de patrimonios, tanto mueble, como inmueble, tanto industrial, como documental, etc. Era una intervención integral de la ciudad, algo espectacular. El monumento a las Cortes, las casas miradores que fueron realizadas en el siglo XVII o XVIII para vigilar desde las azoteas la llegada de los barcos de "las Indias" y que han perdido su función, pero que han dotado a Cádiz, de esa imagen o rostro de ciudad del mar, de ciudad del transporte marítimo, de comercio indiano. También se llevaron a cabo restauraciones en los baluartes y en las murallas, en los espigones y los sistemas defensivos del siglo XVIII... es decir, desde pequeños objetos como un abanico, pasando por edificios, defensas, arquitectura civil, todos son cultura, todos son bienes culturales, todos son manifestaciones culturales.

\section{GEIIC - Contadnos un poco todo esto...}

J.C.P.F. - Si nos ceñimos a la recuperación del patrimonio, la inversión para la celebración del Bicentenario de la Constitución Española de 1812, bautizada popularmente como La Pepa, corrió de alguna forma la misma suerte que la azarosa aplicación y vigor de la propia Constitución que se conmemoraba.

Política y técnicamente el plan era ambicioso y estaba muy
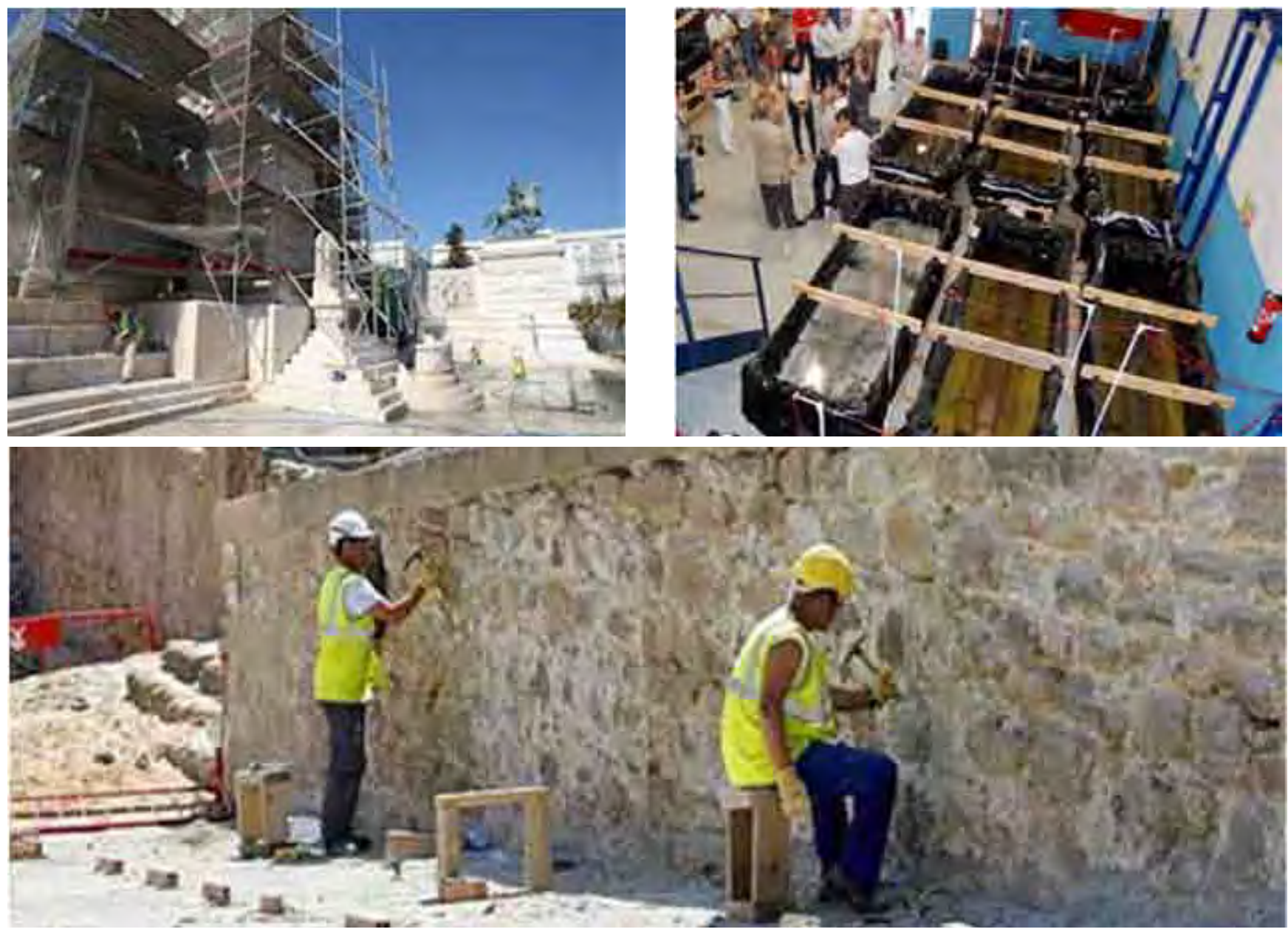

Figs. 7, 8 y 9. Trabajos de rehabilitación del Monumento a las Cortes de Cádiz, trabajos de restauración de cañones y reparación de paños de muralla. 
bien ideado. $Y$ con todas las Administraciones implicadas y de acuerdo, cosa que no es frecuente. Pero se cruzó la crisis. Desde luego, si comparamos la intención primera con lo que finalmente se ejecutó vemos que las intervenciones fueron menos que las anunciadas inicialmente.

Pero que, pese a los avatares mencionados, el proyecto e intervención de los bienes muebles del Oratorio se resolviese exitosamente tiene un porqué, unos antecedentes. En Andalucía hay un par de precedentes donde se lograron articular complejas y vastas intervenciones multidisciplinares. Me refiero, en primer lugar en el tiempo, a la rehabilitación del Monasterio de Santa María de las Cuevas, también conocido como Monasterio de la Cartuja, como parte de la Exposición Universal de Sevilla de 1992 y, en segundo lugar, al Programa Andalucía Barroca, de la Junta de Andalucía, que también fue un proyecto global y continuado en el tiempo (2007-2010), para la recuperación de series completas de bienes culturales de diversa naturaleza y que como sabéis también recibió el Premio Nacional en el año 2009.

En esas intervenciones a las que se refiere Juan Carlos Pérez Ferrer, tanto Jesús Serrano como él tuvieron responsabilidades en los equipos de restauración de Pintura Mural y de Piedra, respectivamente, durante la rehabilitación del área monacal, fabril y de la Capilla de Afuera del Monasterio de la Cartuja de Sevilla. En el Programa de Andalucía Barroca, Juan Carlos dirigió la restauración del imponente retablo mayor de Nuestra Señora de la Oliva, obra del genial Alonso Cano, en Lebrija (Sevilla), y también los retablos mayores de la Iglesia de San Lorenzo en Cádiz y de la Catedral Vieja de Cádiz; y Jesús, la Capilla del Sagrario en la Iglesia de San Mateo, Lucena (Córdoba), una de las más significativas obras arquitectónicas de esta tipología del barroco andaluz.

\section{GEIIC- ¿Estáis de acuerdo?}

J.S. - Estás definiendo lo que pudo haber sido y no fue. Desgraciadamente, un importante número de actuaciones en la ciudad se vieron afectadas por la crisis económica y por lo tanto reducida su inversión o simplemente eliminada. No obstante sí es cierto que, al margen de la inversión, sí se ha llevado a cabo un plan global de actuaciones en toda la ciudad de Cádiz y su zona de influencia, de manera que la relación existente entre los visitantes y el monumento al que antes hacías referencia, fuese en toda la ciudad y no solo en tal o cual edificio.

Se hicieron alianzas interprofesionales, porque fue un proyecto integral, con muchas especialidades: arqueólogos, historiadores, y un gran proyecto para el turismo, en los que hubo mucha profesionalidad y creatividad; también los periodistas colaboraron e hicieron un gran trabajo; recuerdo que se editaron libros y se rescataron de los archivos legajos, anuncios, etc.

En el campo de las letras se escribieron libros sobre la
Constitución, sobre las políticas liberales y los pactos sociales y salieron a relucir las mentalidades. Para ellos, el Tiempo gran devorador, podía encontrar una alianza o un pacto entre la Historia y la Memoria, a través de la Gran Carta o documento que es la propia Constitución. Confiaron en el registro de un documento, y en las paredes del monumento dejaron sus nombres en lápidas de mármol preparadas para evitar el olvido.

El monumento del Oratorio se conserva y se restaura no por razones monumentales, arqueológicas o artísticas, sino porque es memoria. Es el documento histórico más evidente de la Constitución de 1812, porque allí se firmó y conserva la memoria de un acontecimiento cultural, la primera constitución. Al final te das cuenta de que se conserva y se restaura no por razones estéticas, arqueológicas o monumentales.

\section{GEIIC— ¿Por qué restaurar y para quién?}

J.C.P.F. - Como resulta imposible justificar directamente lo que debería ser un principio, casi un axioma, intentaré hacerlo indirectamente mediante una pregunta retórica: ¿Hace falta argumentar por qué hay que conservar el legado que al menos en parte nos explica quiénes somos? y ¿Para quién? Pues para todo aquel que quiera saber quién es, es decir, para todos. En otras palabras, si las sociedades más estables conservan bien su patrimonio cultural por algo será. Y por algo será también que son las sociedades más estables.

J.S. - Vuelve a salir la memoria. Creo que todos necesitamos de excusas sencillas y emotivas que nos agrupen para conseguir un fin, si encima el fin es la recuperación del patrimonio, bien venido sea. Viva la Pepa, el Foro de Barcelona, la Expo del 92, o cualquier otro argumento que nos haga vivir con ilusión la recuperación de un convento abandonado, un palacio en ruinas o la colección olvidada de las Hermanas de clausura, porque con esto volvemos a darle vida a esa memoria.

Volviendo al Archivo contemporáneo de restauradores. Hemos leído la entrevista a Arsenio Sánchez Hernampérez, y compartimos con él la idea de que hay que ser capaces de hilar en el puente del tiempo, unas redes capaces de unir el presente con el pasado y orientar nuestros pasos en el futuro.

Quizás nos llevan los aires de grandeza, o delirios de grandeza, y solo debemos plantear abiertamente, la necesidad de hacer un Archivo de Conservadores-Restauradores, no ya histórico, como se ha realizado en algunos trabajos de investigación, sino un archivo oral, capaz de atrapar, aquellas manifestaciones culturales como es la propia conservación y restauración de los bienes culturales.

Para cerrar la entrevista, $M^{a}$.D.R.L. defiende de nuevo la idea. Piensa de nuevo en voz alta: la Historia, no es un 


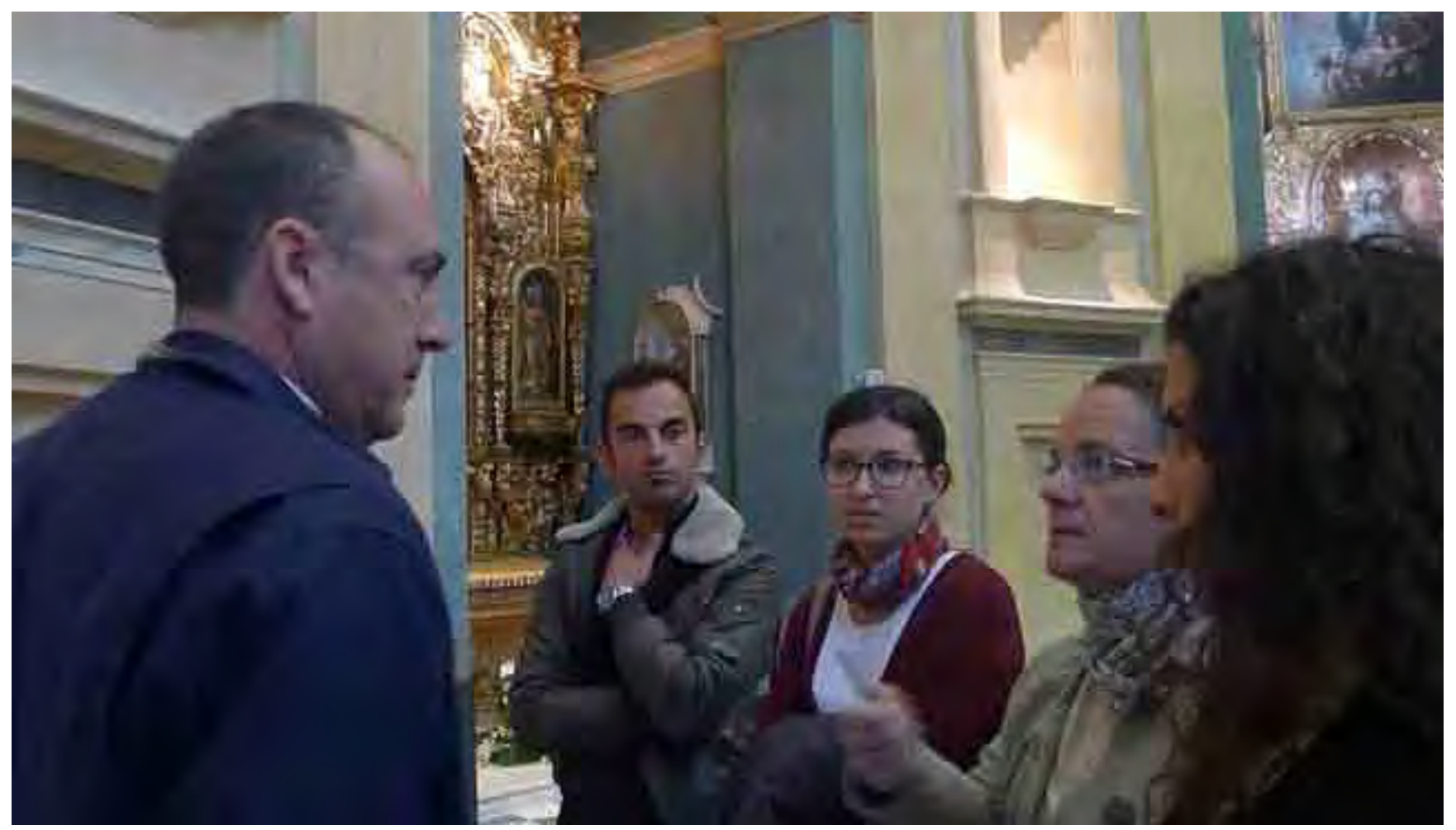

Entrevistando a Jesús Serrano

documento muerto, sino el material que nos permite comprender nuestra identidad y un saber trabajar con el pasado, como material de nuestros sueños contemporáneos, para trazar el proyecto de futuro. También A.C. interviene: Podríamos plantearlo como un grupo de trabajo al GEIIC.

Las personas, como recurso humano, son la mayor riqueza, el mayor e importante patrimonio de una nación..., las personas son las que llevan la carga del conocimiento a cuestas, las que practican los procesos y los transmiten a las siguientes generaciones, son las que actúan, piensan y transforman las disciplinas... los profesionales...

\section{Ana Calvo}

Facultad de Bellas Artes, Universidad Complutense de Madrid. UCM

\section{María Dolores Ruiz de Lacanal}

Facultad de Bellas Artes, Universidad de Sevilla. US

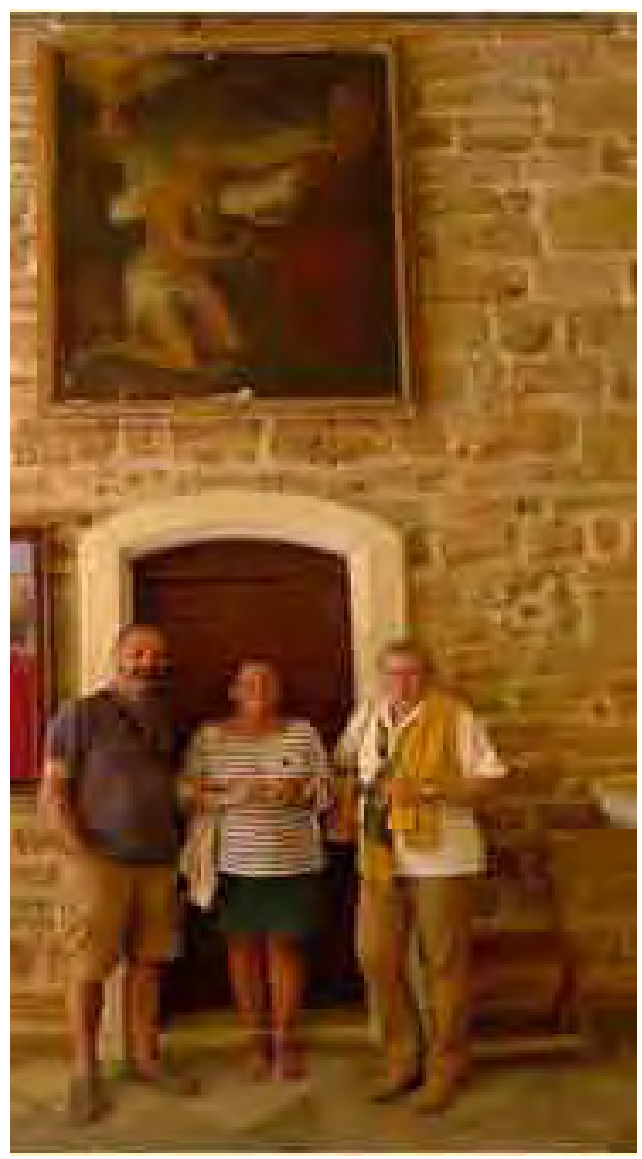

Ana y $\mathrm{M}^{\mathrm{a}}$ Dolores junto a Juan Carlos Pérez Ferrer 
Artículos 


\title{
Caracterización de hongos aislados de mapas conservados en el Archivo Nacional de la República de Cuba
}

\author{
Alian Molina Veloso y Sofía Borrego Alonso
}

Resumen: Los microorganismos, principalmente los hongos filamentosos (mohos), generan problemas en archivos, bibliotecas y museos provocando el biodeterioro de las colecciones. Estos efectos son más acusados en países de clima tropical debido a la influencia de las altas temperaturas y humedad relativa. Los objetivos de este estudio fueron caracterizar la concentración fúngica en cinco mapas conservados en la Mapoteca del Archivo Nacional de Cuba y determinar el potencial biodeteriorante de los hongos aislados. La toma de muestra se realizó mediante la técnica del hisopado en forma aséptica. Se determinó cualitativamente la actividad celulolítica, amilolítica, proteolítica así como la excreción de pigmentos y de ácidos orgánicos. Se detectó una concentración fúngica media de 622 ufc. $\mathrm{cm}^{-2}$, además de especies que constituyeron nuevos hallazgos en soportes documentales para el Archivo Nacional de Cuba. Los hongos degradaron la celulosa, el almidón y la gelatina además de excretar ácidos orgánicos y pigmentos.

Palabras clave: hongos filamentosos, biodeterioro, actividad celulolítica, mapas, soportes documentales

\section{Characterization of fungi isolated from maps preserved in the National Archives of the Republic of Cuba}

\begin{abstract}
Microorganisms, mainly filamentous fungi (molds), create problems in archives, libraries and museums causing biodeterioration. These deterioration effects increase in tropical climates countries due to the influence of high temperatures and relative humidity. The aims of this study were to characterize the fungal concentration in five maps stored in the map library of the National Archives of Cuba and to determine the biodeterioration potential of the isolated fungi. The maps sampling was performed using the swabbing technique. The cellulolytic, amylolytic and proteolytic activities, as well as the excretion of pigments and organic acids, were qualitatively determined. The mean value of fungal concentration detected was $622 \mathrm{cfu} . \mathrm{cm}^{-2}$ and, in addition, new fungal species were found on the documentary supports of the National Archives of Cuba. Cellulose, starch and gelatin were degraded by the isolated fungi and pigments and organic acids showed to be excreted.
\end{abstract}

Key words: filamentous fungi, biodeterioration, cellulolytic activity, maps, documentary supports.

\section{Caracterização de fungos isolados em mapas conservados no Arquivo Nacional da República de Cuba}

Resumo: Os microorganismos, principalmente os fungos filamentosos (bolores) originam problemas em arquivos, bibliotecas e museus, provocando a bio deterioração das colecções. Estes efeitos são mais visíveis nos países de clima tropical devido à influência das altas temperaturas e humidade relativa. Os objectivos deste estudo foram a caracterização da concentração fúngica de cinco mapas conservados na Mapoteca do Arquivo Nacional da República de Cuba e a determinação do potencial de bio deterioração dos fungos isolados. A recolha de amostras realizou-se segundo a técnica de cotonete em forma asséptica. Determinou-se, qualitativamente, as atividades celulolítica, amilolítica, proteolítica, assim como a excreção de pigmentos e ácidos orgânicos. Detectou-se uma concentração fúngica média de 622 ufc.cm-2, para além de novas espécies encontradas em suportes documentais no Arquivo Nacional de Cuba. Os fungos degradaram a celulose, o amido e a gelatina, para além de excretar pigmentos e ácidos orgánicos.

Palavras-chave: fungos filamentosos, bio deterioração, atividade celulolítica, mapas, suportes documentais. 


\section{Introducción}

Los microorganismos, principalmente los hongos filamentosos (mohos), generan grandes problemas en los archivos, bibliotecas y museos provocando un serio daño a las colecciones. Estos efectos son mayores en países de clima tropical debido a la influencia de las altas temperaturas y humedad relativa en las poblaciones microbianas (Borrego 2009:67-124). Como es bien sabido, el biodeterioro se define como todo aquel cambio indeseable en las propiedades de un material originado por la actividad vital de los organismos (Hueck 1965). A la forma específica de biodeterioro causada por el desarrollo de microorganismos se le denomina microbiodeterioro (Borrego 2009:67-124; Villalba y Malagón 2011). El microbiodeterioro afecta a materiales que pueden formar parte de los diferentes soportes tales como: madera, papel, textiles, cuero, material fotográfico, pinturas, y adhesivos empleados para las encuadernaciones, entre otros (Vaillant et al. 2004:145-149). Los soportes utilizados para la elaboración de mapas y planos no están exentos de dicho fenómeno.

Parte de la riqueza documental que atesora el Archivo Nacional de la República de Cuba la integran colecciones de mapas, planos y croquis cuyo número asciende a 40000, siendo los originales más antiguos de los siglos XVII y XVIII. Estas colecciones poseen un valor arquitectónico, científico e histórico que se considera de valor patrimonial.

Los hongos filamentosos tienen significación especial dentro de los agentes causantes del biodeterioro por ser capaces de vivir en una amplia variedad de ambientes. La mayoría lo hacen, preferentemente, en lugares húmedos aunque algunas especies son resistentes a las condiciones de sequedad (Valentín 2004 y 2010; Rojas 2012). Por otro lado, su gran versatilidad metabólica, sumado al hecho de que excretan al medio las enzimas o complejos enzimáticos que hidrolizan los sustratos de los que se nutren, les permite degradar una gran variedad de los mismos incluso sin entrar en contacto físico con ellos (Magalhães y Milages 2008; Cappitelli y Sorlini 2010:45-59). Las principales alteraciones que los hongos provocan a los soportes documentales son: la degradación enzimática de la celulosa y de las proteínas, la excreción de ácidos y pigmentos, así como la acción mecánica sobre el material (Martínez 2003; Valentín 2010; Borrego y García 2011). Las investigaciones micológicas realizadas en ambientes interiores en Cuba, hasta la fecha, se han centrado en los géneros y especies más comunes $y$, de éstos, se conocen un limitado número de características. Por tanto, una caracterización más completa es un paso primordial para la adecuada conservación de los objetos (Rojas 2010).

Otras propiedades importantes de los hongos están relacionadas con su potencial patogénico, es decir, la capacidad que tienen algunas especies para provocar enfermedades al hombre que está en contacto con ellos (Nevalainen y Morawska 2009:89-123; Haleem y Mohan 2012). En varias investigaciones realizadas en archivos y bibliotecas, se ha

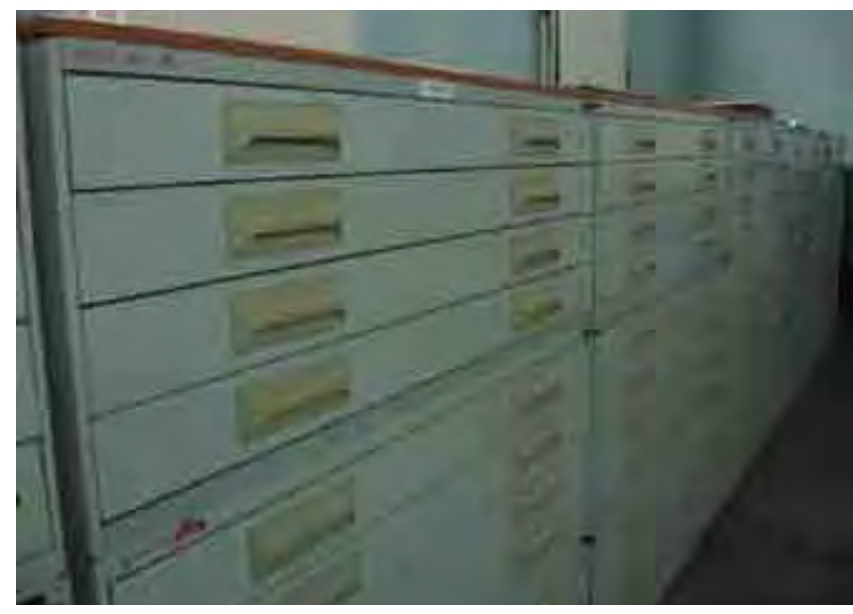

Figura 1. Planeros horizontales de gavetas donde se conservan los mapas en la Mapoteca.

demostrado que estos agentes son la causa de muchas enfermedades profesionales y patologías situacionales (Valliant 1996; Florian 2003).

Teniendo en cuenta estos aspectos, los objetivos propuestos en este trabajo han sido caracterizar la contaminación fúngica en cinco mapas conservados en la Mapoteca del Archivo Nacional de Cuba y determinar el potencial biodeteriorante de los hongos aislados.

\section{Materiales y métodos}

\section{Características del depósito estudiado}

La Mapoteca del Archivo Nacional de la República de Cuba es un depósito que se caracteriza por su gran tamaño, siendo sus dimensiones las siguientes (largo $\mathrm{x}$ ancho $\mathrm{x}$ altura, $\mathrm{m}): 15.2 \times 6.2 \times 2.5 \mathrm{~m}$. El local cuenta con un total de 195 metros lineales de mapas, planos y privilegios de invención, que en su mayoría están elaborados sobre papel de distintos tipos, aunque hay algunos en tejido de algodón y seda. Los mapas se conservan en planeros horizontales de gavetas [figura 1]. Durante los días en los que se realizó este estudio (época de lluvia, julio del 2010), el sistema de climatización llevaba dos semanas averiado y el local se ventilaba de forma natural.

Medición de temperatura (T) y humedad relativa (HR) en el momento del muestreo microbiológico

Aunque desde hace varios años, es habitual la medición y registro de la temperatura (T) y humedad relativa (HR) dos veces al día en todos los depósitos del archivo (10:00 a.m. y 3:00 p.m.), durante la colecta de las muestras microbiológicas, se realizó una medición suplementaria empleando un termohigrómetro digital (TH PEN 8709, China). 


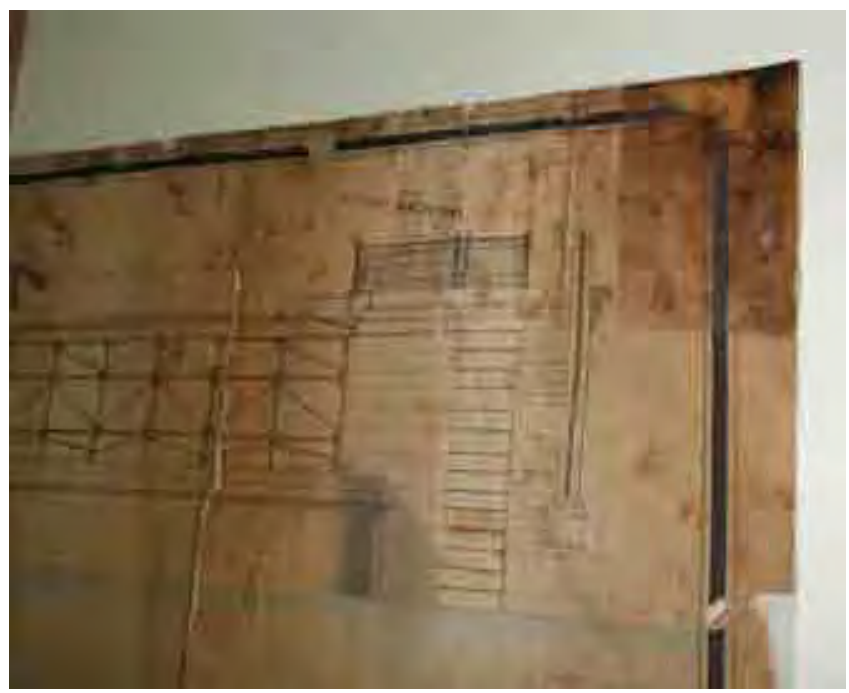

Figura 2. Mapa en soporte papel con crecimiento fúngico.

\section{Muestreo microbiológico de mapas}

Se seleccionaron cinco mapas al azar que presentaban signos de crecimiento fúngico no activo en su superficie [figura 2]. Se midieron los mapas analizados y las zonas muestreadas. La toma de muestra se realizó mediante la técnica del hisopado en forma aséptica (Pinzari et al. 2010). Posteriormente el hisopo se sumergió en un tubo que contenía $1 \mathrm{ml}$ de agua destilada estéril, se agitó bien la muestra a intervalos durante 45 minutos. Luego se hicieron diluciones seriadas y se sembró a profundidad en placas de $110 \mathrm{~mm}$ empleando el medio de cultivo Agar Malta (AM) (BIOCEN, Cuba) suplementado con $\mathrm{NaCl}$ (7.5\%) (Rojas et al. 2002). Las placas se incubaron invertidas durante 5 días a $30^{\circ} \mathrm{C}$ debido a las condiciones climáticas en Cuba.

Determinación de la concentración de los hongos en los mapas muestreados

Concluida la incubación, se realizó el conteo de unidades formadoras de colonia para poder determinar la concentración microbiana, expresada en unidades formadoras de colonias por $\mathrm{cm}^{2}$ de superficie (ufc. $\mathrm{cm}^{-2}$ ).

\section{Identificación de las cepas aisladas}

Se realizó el aislamiento y la purificación de las diferentes cepas de hongos que crecieron en las placas utilizadas para los diferentes muestreos. Para la identificación taxonómica de hongos hasta nivel de género se tomaron en cuenta las características culturales y morfológicas observadas al microscopio óptico o estereoscopio según resultó conveniente. Dichas características se determinaron a partir de colonias de cada aislado, obtenidas por inoculación en AM. La observación de las características morfológicas se llevó a cabo a través del montaje de microcultivos según la técnica de Casadesús y Rojas (1981), así como me- diante preparaciones en fresco y semipermanentes con lactofenol; asimismo, para la observación de estructuras hialinas se utilizó lactofenol-azul algodón (Booth 1971). La ubicación en géneros de los hongos imperfectos de los aislados se realizó de acuerdo con los criterios de Kendrick y Carmichael (1973) y Barnett y Hunter (1998).

Las especies ubicadas en los géneros Aspergillus, Penicillium y Eurotium se identificaron siguiendo los procedimientos sugeridos por Klich y Pitt (1994) y Pitt (2000); estas metodologías están basadas primeramente en los caracteres morfológicos y también en características fisiológicas como son las relaciones agua-temperatura, la pigmentación y el grado de desarrollo de las colonias en ciertos medios.

Determinación de la frecuencia relativa (FR) de los hongos aislados en los mapas

Este análisis se realizó de acuerdo a Esquivel et al. 2003) y Saleh (2007) donde:

$n^{\circ}$ demateriales en que se detecta un género o especie

$\mathrm{FR}=100$

$\mathrm{n}^{\circ}$ total de materiales analizados

Determinación de la producción de ácido por los hongos aislados

Se realizaron suspensiones de esporas de las cepas de hongos aisladas y se sembraron en un caldo de cultivo cuya composición salina para 1 litro es: nitrato de sodio 2 $\mathrm{g}$; fosfato de potasio $1 \mathrm{~g}$; sulfato de magnesio $0.5 \mathrm{~g}$; sulfato ferroso $0.01 \mathrm{~g}$ y cloruro de potasio $0.5 \mathrm{~g}$. Como fuente de carbono se utilizó glucosa al $1 \%$, el pH se ajusto a 7 y se adicionó $0.3 \mathrm{~g}$ de rojo fenol como indicador de acidificación del medio (reactivos, casa comercial MERCK). Los cultivos se incubaron a $30^{\circ} \mathrm{C}$ por 3 días y posteriormente se midió el $\mathrm{pH}$ del medio de cultivo con la ayuda de un potenciómetro (PACITRONIC MV 870, USA) (Borrego et al. 2010 a).

Determinación cualitativa de la capacidad celulolítica y la producción de pigmentos por los hongos

Con el objetivo de determinar el poder degradativo de la celulosa y la producción de pigmentos por parte de las cepas fúngicas aisladas, se cultivaron en tubos con cuña que contenían un medio de cultivo de composición salina similar al empleado anteriormente, además de agar 20g; el pH del medio se ajustó a 5.5. Como fuente de carbono se empleó en un caso una tira de papel de filtro (Whatman No. 1, Inglaterra) de 4,8 cm de largo por $1 \mathrm{~cm}$ de ancho (donde además se observó la producción de pigmentos), y en el otro celulosa cristalina (1\%). Como control se empleó glucosa $1 \%$. Los cultivos se incubaron a $30^{\circ} \mathrm{C}$ durante 21 
días (Borrego et al. 2010 a).

\section{Determinación de la actividad proteolítica de los hongos}

La actividad proteolítica cualitativa fue determinada a través de la hidrólisis de la gelatina en tubos de cultivo implementando una modificación al método de Abrusci (2005), que fue referido por Borrego et al (2010 a). Cada aislado fue inoculado por punción en el medio cuya composición salina para 1 litro es: nitrato de sodio $2 \mathrm{~g}$; fosfato de potasio $1 \mathrm{~g}$; sulfato de magnesio $0.5 \mathrm{~g}$ y sulfato ferroso $0.01 \mathrm{~g}$. Se adicionó gelatina a razón de $120 \mathrm{~g}$. $^{-1}$ y se ajusto el pH a 7.2. Los tubos inoculados fueron incubados por 7 días a $30^{\circ} \mathrm{C}$. Posteriormente fueron incubados a $4^{\circ} \mathrm{C}$ por 1 hora. Una reacción positiva muestra un medio líquido, en cambio la reacción negativa muestra el medio sólido aún después de agitar. Se evidencia la reacción de hidrólisis por la liquefacción del medio al agitar los tubos.

\section{Determinación de la actividad amilolítica de los hongos ais- lados}

La actividad amilolítica cualitativa fue determinada a través de la hidrólisis del almidón en placas (Borrego et al. 2010 a). Cada aislado fue inoculado por punción invertida en placas de $110 \mathrm{~mm}$ con un medio de composición salina por litro similar al empleado anteriormente, agar $20 \mathrm{~g}$ y utilizando como fuente de carbono almidón soluble $5 \mathrm{~g} . \mathrm{I}^{-}$ 1). Después de incubar durante 7 días a $30^{\circ} \mathrm{C}$ se vertieron sobre cada placa de cultivo $5 \mathrm{ml}$ de solución del reactivo Lugol. La presencia de una zona incolora alrededor de las colonias fue tomada como indicador de hidrólisis positiva

\section{Resultados y discusión}

Caracterización microbiana de los hongos aislados de los mapas

Se detectaron diferentes concentraciones de contaminación fúngica en los cinco mapas estudiados [tabla 1] obteniéndose concentraciones que oscilaron entre 200 y 1766 ufc.cm ${ }^{-2}$ para una media de 622 ufc. $\mathrm{cm}^{-2}$. La alta T y HR detectadas en este local $\left(29.5^{\circ} \mathrm{C}\right.$ y $67.5 \%$, respectivamente) ha favorecido el mantenimiento de hongos viables sobre los soportes, lo cual puede resultar devastador si aumentaran aun más la T y la HR del entorno. Se conoce que a una HR de $65 \%$ y a una $\mathrm{T}$ mayor de $20^{\circ} \mathrm{C}$ el contenido de humedad del papel puede aumentar de un $8-10 \%$ y por tanto favorecer el desarrollo fúngico (Pinzari et al. 2006). Por otra parte, también se sabe que los propágulos de hongos sobre cualquier tipo de sustrato almacenado constituyen un peligro potencial para la correcta conservación de materiales (Portnoy et al. 2004; Molina 2012). Una forma de bajar la carga microbiana e impedir un futuro brote fúngico que biodeterioraría a los mapas, sería realizar una limpieza profunda de los materiales por aspiración, además de man- tener las condiciones de temperatura y humedad relativa adecuadas para la conservación de estos soportes documentales, que se refieren en la Resolución No. 41 (2009) del Ministerio de Ciencia, Tecnología y Medio Ambiente (CITMA). Esto último se logra mediante el reestablecimiento de la climatización del local que cumple con las características técnicas establecidas en dicha resolución.

De la superficie de los mapas muestreados se aislaron 11 colonias de hongos filamentosos diferentes, el $100 \%$ de ellas fueron clasificadas como hongos mitospóricos pertenecientes a los géneros Aspergillus y Penicillium, orden Moniliales, familia Moniliaceae. El género Aspergillus, donde se ubicaron el $73 \%$ de las colonias detectadas, predominó sobre Penicillium (27\%). Al comparar estos resultados con los obtenidos por otros autores coinciden en que los géneros con mayor predominio encontrados en soportes documentales son Aspergillus y Penicillium, si bien aparecen uno más que otro indistintamente en diferentes estudios (Rojas 2010; Michaelsen et al. 2010; Borrego et al. 2010 a; Borrego y García 2011; Guiamet et al. 2011; Rojas et al. 2012; Manente et al. 2012; Molina 2012). En estudios anteriores realizados en este mismo depósito y período del año, los resultados coinciden solo de forma parcial, al ser los géneros Aspergillus y Penicillium en ese orden los que mostraron mayores prevalencias (Guiamet et al. 2011). Sin embargo, se detectaron en aquel momento además de los géneros mencionados, Talaromyces helicus (teleomorfo de Penicillium). Aspergillus y Penicillium son géneros que comúnmente se encuentran en ambientes interiores de regiones con clima cálido y templado (Borrego y Perdomo 2012). Su prevalencia sobre los soportes pudiera deberse a que son colonizadores primarios de los sustratos ya que pueden desarrollarse a bajos valores de actividad de agua (aw) (aw < 0.8) a diferencia de otros géneros fúngicos, como por ejemplo Alternaria y Cladosporium, que requieren valores de aw entre 0.8 y 0.9 (Nielsen 2003).

Se realizó la identificación taxonómica hasta nivel de especie de todos los aislados y se calculó la frecuencia relativa (FR) de cada una de ellos [tabla 2]. De todas las especies identificadas, destacaron algunas por diversas razones, tales como: ser referenciadas por varios autores como frecuentes en ambientes de archivos y bibliotecas, por su importancia como agentes biodeteriorantes y por ser causantes de afecciones a la salud humana.

Del género Aspergillus se identificaron 6 especies, de las cuales $A$. niger resultó la especie de mayor $\mathrm{FR}$ en los mapas analizados (80\%), seguido de $A$. flavus y A. caespitosus, ambas con un $60 \%$ de FR. Los dos primeros son citados por varios autores como hongos frecuentemente aislados en múltiples sustratos como papel, tela, cartón y lana; además de ser las especies dentro del género con mayor predominio en ambientes interiores de forma general (Lugauskas et al. 2003; Lignell 2008; Rojas 2010 y Rojas et al 2012). La especie $A$. niger se ha planteado como un gran productor de celulasas y hemicelulasas además de estar considerado, al igual que $A$. flavus, como un patógeno oportunista cau- 
sante de aspergillosis e infecciones pulmonares en personas inmunocomprometidas (De Hoog et al. 2000:470; Villena y Gutiérrez - Correa 2003; Gautam et al. 2011; Haleem y Mohan 2012).

Las tres especies del género Penicillium: P. citrinum, $P$. fellutanum y $P$. waksmanii mostraron frecuencias de aparición de un $40 \%$ las dos primeras y un $20 \%$ la tercera. Es importante destacar que $P$. citrinum está citado en la literatura científica como una especie predominante en soportes de papel y textil (Borrego et al. 2008; Rojas 2010). Es un hongo de gran importancia para la salud al ser referido como el causante de infecciones en tracto urinario, pulmones y en casos de keratitis (De Hoog et al. 2000:823). En estudios realizados anteriormente, en este mismo local por García (1997) P. citrinum y P. fellutanum ya fueron detectados en el aire, sin embargo, en el caso de $P$. waksmanii constituye el primer registro para Cuba en archivos.

\section{Capacidad biodeteriorante de las cepas fúngicas aisladas en} la Mapoteca

La capacidad biodeteriorante de las cepas aisladas en la Mapoteca se determinó con las pruebas fisiológicas realizadas a cada una de ellas, detectándose de forma general gran actividad hidrolítica de la celulosa y el almidón, además de acidificar el medio y producir diversos pigmentos.

La caracterización fisiológica [tabla 3] mostró que el 100\% de las cepas de hongos fueron capaces de crecer, en mayor o menor medida, a expensas del papel de filtro como única fuente de carbono (celulosa amorfa de más fácil asimilación), mientras que un $91 \%$ de ellas utilizaron la celulosa cristalina (de más difícil asimilación). Asimismo, el $40 \%$ de estos hongos excretaron diferentes pigmentos sobre el papel, abarcando colores desde el amarillo hasta el pardo intenso, pasando por tonos rojizos. También se evidenció que todas las cepas produjeron ácidos pues propiciaron una disminución significativa del pH del medio de cultivo. La degradación del almidón y la licuefacción de la gelatina se constataron en todas las cepas. Dentro de los hongos aislados, Aspergillus caespitosus 1 y A. ornatus resultaron ser potentes degradadores de la celulosa, el almidón y la gelatina.

Si se analiza el poder degradativo de todas las cepas aisladas, se evidencia no sólo que las especies de Aspergillus fueron las que predominaron sino que también son las de mayor poder degradativo de los componentes del papel y los textiles, tales como la celulosa, el almidón y la gelatina. Resultados similares han sido publicados por otros autores (Borrego et al. 2010 a; Guiamet et al. 2011; Rojas et al. 2012). La evaluación de las cepas aisladas permitió confirmar que Aspergillus y Penicillium son géneros con un potencial enzimático muy amplio, resultado que está en correspondencia con los obtenidos por otros autores (Villalba et al. 2004; Villalba y Malagón 2011; Rojas 2010).

Además de las actividades enzimáticas que se evidenciaron en este estudio, hay que señalar que varios representantes de estos géneros son productores de otras enzimas como catalasas, lipasas, quitinasas y pectinasas, capaces de degradar o modificar materiales que forman parte de los documentos (Mycota, 2013). Cuando crecen sobre el papel degradan todos sus componentes y principalmente su fuente carbonada, la celulosa (Sterflinger 2010). En la mayoría de las especies evaluadas se evidenció de forma cualitativa, la actividad celulasa en papel de filtro concretamente, la que se define como actividad global del complejo enzimático que incluye endoglucanasas, exoglucanasas y $\beta$-glucosidasa (Magalhães y Milages 2008; Cappitelli y Sorlini 2010:47). Rojas (2010) ha resaltado la elevada actividad de endoglucanasas de $A$. flavus y $A$. niger respecto a diferentes tipos de papel. Diversas especies obtenidas en este estudio demostraron gran actividad celulolítica entre ellas $A$. flavus, $A$. niger y $A$. oryzae; a este respecto, en la literatura especializada, se ha reconocido ampliamente este potencial (Lugauskas et al. 2003; Borrego et al. 2008; Borrego et al. 2010 a; Rojas 2010; Sterflinger 2010). Asimismo, se han detectado otras con similar poder degradativo tales como A. caespitosus. De los tres aislados del género Penicillium destacó por su actividad celulolítica $P$. citrinum.

\begin{tabular}{clcc} 
No. & Título & Soporte & ufc.cm ${ }^{-2}$ \\
1 & Reparto la prosperidad, San Francisco de Paula & Papel sobre textil & 418 \\
\hline 2 & Parque residencial Alturas del Vedado & Papel sobre textil & 500 \\
\hline 3 & Plano de silos para maíz & Papel & 226 \\
\hline 4 & Parcelación de la finca de San José & Papel & 200 \\
\hline 5 & Plano del ferrocarril de Júcaro & Papel & 1766 \\
\hline
\end{tabular}

Tabla 1. Concentración fúngica en los 5 mapas analizados 
De forma general todos los aislados produjeron ácidos orgánicos, lo que se evidenció con la acidificación del medio de cultivo. Varios autores han citado que Aspergillus niger y A. flavus producen ácido oleico, linoléico, palmítico, esteárico y cítrico (Dai et al. 2004); A. niger por su parte, también produce ácido oxálico (Santhiya y Ting 2005). En este ensayo las cepas de $A$. flavus y $A$. niger mostraron los valores de $\mathrm{pH}$ más bajos de todos los aislados ( $\mathrm{pH}<4.5)$. La acidificación provocada por estos colonizadores primarios del papel y los textiles que conforman los mapas y planos, es un factor importante en el envejecimiento de dichos soportes $y$, por otra parte, puede contribuir a crear las condiciones idóneas para el desarrollo de otros hongos filamentosos y levaduras, que en su inmensa mayoría son microorganismos acidófilos (Borrego 2009:67-124). Valentín (2010) aisló de materiales orgánicos e inorgánicos diferentes especies de Aspergillus, además, la autora refirió que las especies de este género pueden excretar amilasas, celulasas, glucosa oxidasa, ácido cítrico, láctico, fumárico y málico, que provocan manchas de diferentes colores, degradación y acidificación de una gran variedad de soportes. Todo lo antes expuesto permite considerar a este género fúngico de importancia para el biodeterioro de soportes documentales.

En lo que respecta a la producción de pigmentos, las cepas de ambos géneros (Aspergillus y Penicillium) destacaron por mostrar una gama de pigmentos difusivos en el medio, además de evidenciarse sobre la tira de papel de filtro utilizada para probar la actividad celulolítica. De los dos aislados de $A$. flavus evaluados en este trabajo, uno produjo pigmentos, resultado que coincide con los obtenidos por otros autores (Borrego et al. 2010 b), en tanto que la otra cepa no lo hizo. Esto demuestra la diversidad metabólica que puede existir entre diferentes cepas de una misma especie, aún cuando se han aislado de un mismo ecosistema, y enfatiza la necesidad de realizar los aislamientos aparejados a un análisis fisiológico, que sea representativo de la cantidad de colonias de un mismo tipo morfológico. Según lo planteado por Rehnstrom y Free (1997) y Rosas y Casadevall (1997), A. niger produce melanina y otros tipos de pigmentos, esto coincide con los resultados obtenidos para la cepa evaluada en este trabajo que produjo pigmentos de color pardo.

Del género Penicillium resultó significativa la producción de pigmento de color amarillo por parte del aislado de $P$. citrinum; este resultado coincide con lo planteado por Pitt (2000). De forma general, se evidenció que los hongos pueden provocar alteraciones cromáticas debido a manchas de diferentes colores, tonalidades y texturas, producto de la excreción de pigmentos y el crecimiento micelial, dañando de esta forma la estética de los documentos sobre los que se desarrolla. Los hongos, a diferencia de las bacterias, están considerados los organismos de mayor importancia como agentes biodeteriorantes de la materia orgánica, pues además de producir enzimas extracelulares, las hifas ejercen presión mecánica sobre el soporte produciéndole debilitamiento (Magalhães y Milages 2008; Cappitelli y Sorlini 2010:45-59).

La actividad amilolítica se evidenció en todas las cepas aisladas puesto que el almidón es un polímero que es asimilado de forma relativamente fácil por la mayoría de los microorganismos. Aunque el ensayo realizado fue cualitativo, los géneros Aspergillus y Penicillium se encuentran citados en la literatura científica como buenos degradadores del almidón (Rojas et al. 2009).

\begin{tabular}{llc}
\multicolumn{1}{c}{ Especies } & Mapas en los que fue hallado & FR (\%) \\
Aspergillus flavus & $1,2,5$ & 60 \\
\hline Aspergillus alliaceus & 3 & 20 \\
\hline Aspergillus caespitosus & $2,4,5$ & 80 \\
\hline Aspergillus niger & $2,3,4,5$ & 40 \\
\hline Aspergillus ornatus & 3,4 & 40 \\
\hline Aspergillus oryzae & 1,5 & 40 \\
\hline Penicillium citrinum & 1,4 & 40 \\
\hline Penicillium fellutanum & 1,3 & 20 \\
\hline Penicillium waksmanii & 4 & 40 \\
\hline
\end{tabular}

Tabla 2. Hongos aislados en los planos muestreados. 


\begin{tabular}{|c|c|c|c|c|c|c|}
\hline & Degradación & de celulosa & $\begin{array}{l}\text { Producción } \\
\text { de ácidos }\end{array}$ & & $\begin{array}{l}\text { Actividad } \\
\text { amilolítica }\end{array}$ & $\begin{array}{l}\text { Actividad } \\
\text { proteolítica }\end{array}$ \\
\hline Cepa & $\begin{array}{l}\text { Crecimiento } \\
\text { en papel de } \\
\text { filtro }\end{array}$ & $\begin{array}{l}\text { Crecimiento } \\
\text { en celulosa } \\
\text { cristalina }\end{array}$ & $\mathrm{pH}$ & $\begin{array}{l}\text { Producción } \\
\text { de pigmento }\end{array}$ & $\begin{array}{c}\text { Degradación } \\
\text { de almidón }\end{array}$ & $\begin{array}{l}\text { Licuefacción } \\
\text { de la gelatina }\end{array}$ \\
\hline Aspergillus alliaceus & $+/-$ & - & 5.70 & - & + & + \\
\hline Aspergillus caespitosus 1 & +++ & +++ & 6.05 & - & + & + \\
\hline Aspergillus caespitosus 2 & $+/-$ & + & 5.99 & - & + & + \\
\hline Aspergillus flavus 1 & +++ & $+/-$ & 4.35 & + & + & + \\
\hline Aspergillus flavus 2 & ++ & ++ & 5.23 & - & + & + \\
\hline Aspergillus niger & ++ & + & 3.85 & + & + & + \\
\hline Aspergillus ornatus & +++ & +++ & 6.40 & + & + & + \\
\hline Aspergillus oryzae & + & $+/-$ & 6.27 & - & + & + \\
\hline Penicillium citrinum & ++ & ++ & 4.62 & + & + & + \\
\hline Penicillium fellutanum & $+/-$ & $+/-$ & 4.75 & + & + & + \\
\hline Penicillium waksmanii & + & + & 4.42 & - & + & + \\
\hline
\end{tabular}

Tabla 3. Pruebas fisiológicas cualitativas realizadas a los aislados de los 5 mapas.

+++ : Indica crecimiento abundante, ++ : indica crecimiento moderado, $+:$ indica crecimiento pobre, también es indicativo de la presencia de pigmento, degradación de almidón y degradación de gelatina. +/- : indica crecimiento muy pobre, -: indica NO crecimiento, NO producción de pigmento y NO degradación de almidón y NO degradación de gelatina.

De igual forma, la actividad proteolítica se manifestó en el $100 \%$ de los hongos analizados. En este sentido, el género Aspergillus, es destacado en la literatura especializada; así Rojas et al. (2009) y Rojas (2010) mencionan su alta actividad proteolítica, aunque es menor que la amilolítica. Obviamente, los hongos que muestran actividad amilolítica y/o proteolítica resultan de suma importancia para el biodeterioro, sobre todo cuando se trata de material documental, puesto que muchos pegamentos y aditivos utilizados en las encuadernaciones tienen almidón y proteínas entre sus componentes principales (Valentín 2004; Rojas et al. 2009). Además, existen materiales documentales antiguos realizados en pergamino, de naturaleza proteolítica,que pudieran verse afectados seriamente.

\section{Conclusiones}

La concentración de propágulos fúngicos viables detectada en la superficie de cinco mapas presentó un valor medio de 622 ufc.cm ${ }^{-2}$, lo que constituye un peligro potencial para el biodeterioro de los mismos. Todos los hongos aislados mostraron actividad degradativa de diferentes sustratos. Las especies Aspergillus caespitosus, A. flavus, A. niger,
A. oryzae y $P$. citrinum presentaron las mayores actividades enzimáticas cualitativas para degradar celulosa, almidón y gelatina, además de excretar pigmentos y ácidos. El conjunto de estos resultados pone de manifiesto su amplio potencial biodeteriorante que puede afectar severamente los mapas. Constituyeron nuevos registros para el Archivo Nacional de Cuba las especies A. ornatus, Aspergillus alliaceus y $P$. waksmanii.

\section{Agradecimientos}

Los autores agradecen el apoyo financiero concedido por el Programa de Ayuda para los Archivos de Iberoamérica (ADAI), proyecto $146 / 2008$.

\section{Bibliografía}

BARNETT, H.L.; HUNTER, B.B. (1998). Illustrated Genera of Imperfect Fungi, Fourth. 4th. Ed .APS. Press. The American Phytopathological Society. USA, $218 \mathrm{p}$.

BOOTH, C. (1971). Introduction to General Methods. p84. En Meth- 
ods in Microbiology. Vol 4. Edied by C. Booth. Academia Press, London and New Cork. 795 p.

BORREGO, S. (2009). Factores externos que influyen en el deterioro del patrimonio documental. En: Conservación preventiva en archivos y bibliotecas. Bergaglio C., Pené M. (eds). 1 ra. Ed. La Plata: Instituto Cultural de la Provincia de Buenos Aires, pp. 67-124.

BORREGO, S., GARCIA, M. (2011). “Comportamiento de la concentración microbiana aérea en la Fototeca del Archivo Nacional de Cuba". Revista CENIC Ciencias Biológicas, 42: 61-67.

BORREGO, S., GUIAMET, P., GOMEZ DE SARAVIA, S., BATTISTONI, P., GARCIA, M., LAVIN, P., PERDOMO, I. (2010 a). "The quality of air at archives and the biodeterioration of photographs". International Biodeterioration and Biodegradation, 64: 139-145.

BORREGO, S., PERDOMO, I. (2012). “Aerobiological investigations inside repositories of the National Archive of the Republic of Cuba". Aerobiología, 28:303-316

BORREGO, S., PERDOMO, I.,GUIAMET, P., GOMEZ, S. (2010 b). "Study of the microbial concentration in the air in repositories of the National Archive of Cuba". AUGMDOMUS, 1:114-133.

BORREGO, S., PONS, V., PERDOMO, I. (2008). “La contaminación microbiana del aire en dos depósitos del Archivo Nacional de la República de Cuba". Revista CENIC Ciencias Biológicas, 39: 63-69.

CAPPITELLI, F., SORLINI, C. (2010). Papers and Manuscripts. En: Cultural heritage microbiology: Fundamental studies in conservation science. Eds. Ralph Mitchell \& Christopher J. McNamara. ASM Press, Washington, DC.

CASADESÚS, L., ROJAS, T. (1981). Micología Manual Práctico. Ed. MES.99 $\mathrm{p}$

DAI, Z., MAO, X., MAGNUGSON, J., LASURE, L. (2004). " Identification of genes associated with morphology in Aspergillus niger by using suppression subtractive hybridization". Applied and Environmental Microbiology, 70: 2474-2485.

DE HOOG, G.S., GUARRO, G., GENE, J. FIGUERAS, M.J. (2000). Atlas of clinical fungi. 2nd ed. (Eds): Deiana, P., Fatichenti, F., Farris, G.A., Mocquot, G., Lodi, R., Todesco, R. and Cecchi. Universidad Rovira I Virgili Reus, España.

ESQUIVEL, PP., MANGIATERRA, M.., GIUSIANO, G., SOSA, M.A. (2003). " Microhongos anemofilos en ambientes abiertos de dos ciudades del nordeste argentino ". Boletín Micológico, 18: 21 - 28

FLORIAN, M.L.E. (2003). “The four components of biodeterioration and of preservation of our collective memory". In: International Symposium: a choice and strategies for preservation of a collective memory. Dobbiaco, Toblach, Italy. Disponible en:_<http://www. uin-muenster.de/Forum-Bestandserhaltung/kons-restaurierung/ sch florian.shtml>

GARCIA, T. (1997). “Consideraciones sobre la microbiota de la Ma- poteca del Archivo Nacional". Trabajo de diploma. Facultad de Biología. Universidad de la Habana.

GAUTAM, A.K., SHARMA, S., AVASTHI, S., BHACLAURIA, R. (2011). "Diversity, pathogenicity and toxicology of Aspergillus niger: An important spoilage fungi". Research Journal of Microbiology, 6: 270-280.

GUIAMET, P., BORREGO, S. LAVIN, P. PERDOMO, I. GOMEZ, S. (2011). "Biofouling and biodeterioration in materials stored at the Historical Archive of the Museum of La Plata, Argentine and at the National Archive of the Republic of Cuba". Colloids and Surfaces $B$ : Biointerfaces, 85: 229-234.

HALEEM, A., MOHAN, S. (2012). "Fungal pollution of indoor environment and its management". Saudi Journal of Biological Science, $19,405-426$.

HUECK, H.J. (1965). "The biodeterioration of materials as part of hydrobiology". Materials and organism, vol. 1, pp. 5-34.

KENDRICK, B. W., CARMICHAEL, J. W. (1973). Hyphomycetes. Chapter 10. The Fungi. An advanced Treatise. Volume IVA. (Ed). G.C. Ainsworth. Institute Kew, Surrey, England.

KLICH, M.A.; PITT, J.I. (1994). A laboratory guide to the common Aspergillus species and their teleomorphs. Commonwealth Scientific and Industrial Research Organization. $116 \mathrm{p}$

LIGNELL, U. (2008). “Characterization of microorganisms in indoor environments", Publications of the National Public Health Institute, ISBN 978-951-740-770-0; 978-951-740-771-7 (pdf-version) ISSN 0359-3584; 1458-6290 (pdf-version) <http://www.ktl.fi/por$\mathrm{tal} / 4043>$

LUGAUSKAS, A., LEVINSKAITE, L., PECIULYTE, D. (2003). “Micromycetes as deterioration agents of polymeric material". International Biodeterioration and Biodegradation, 52: 233-242.

MAGALHÃES, P.O., MILAGRES, A.M.F. (2008). "Importância das celulases produzidas por basidiomicetos causadores de podridão branca na biodegradação de lignocelulosicos". Microbiologia in foco, 2: 4-12.

MANENTE, S., MICHELUZ, A., GANZERLA, R., RAVAGNAN, G., GAMBARO, A. (2012). "Chemical and biological characterization of paper: A case study using a proposed methodological approach". International Biodeterioration and Biodegradation, 74: 99-108.

MARTINEZ, P. (2003). “Determinación de la acidez producida por hongos contaminantes en bienes culturales". Boletín Patrimonio y Desarrollo, 9: 3-4.

MICHAELSEN, A., PIÑAR, G., PINZARI, F. (2010). "Molecular and microscopical investigation of the microflora inhabiting a deteriorated Italian manuscript dated from the thirteenth century". Microbial Ecology, 60:69- 80. 
biente interior de la Mapoteca del Archivo Nacional de la República de Cuba y del biodeterioro de mapas." Trabajo de diploma, Facultad de Biología, Universidad de la Habana.

MYCOTA (2013). "Fungal Contaminants of Cultural Heritage". Access by species. <http://mycota-crcc.mnhn.fr/site/genre. php?lang=eng $>$. [ consulta: 5/11/2013].

NEVALAINEN, A., MORAWSKA, L. (eds). (2009). "Biological Agents in Indoor Environments". Assessment of Health Risks. Work conducted by a WHO Expert Group between 2000-2003. <http:// www.ilaqh.qut.edu.au/Misc/BIOLOGICAL_AGENTS_2009.pdf.>

NIELSEN, K.F., (2003). "Mycotoxin production by indoor molds". Fungal Genetics and Biology 39: 103 - 117.

PINZARI, F., MONTANARI, M., MICHAELSEN, A., PIÑAR, G. (2010). "Analytical protocols for the assessment of biological damage in historical documents". COALITION, No.19:6-13.

PINZARI, F., PASQUARIELLO, G., DE MICO, A. (2006). “Biodeterioration of paper. A SEM study of fungal spoilage reproduced under controlled conditions". Macromol. Symp. 238: 57-66.

PITT, J.I. (2000). A laboratory guide to common Penicillium species. Food Science Australia. 3rd ed. $196 \mathrm{p}$.

PORTNOY, J. M., BARNES, C. S., KENNEDY, K. (2004). “Sampling for indoor fungi". Journal of Allergy and Clinical Immunology, 113: 189-198.

REHNSTROM, A.L., FREE, S. J. (1997). “The isolation and characterization of melanin deficient mutants of Monilia fructicola". Physiology and Molecular Pathology, 49: 321-330.

Resolución No. 41 (2009). “Lineamientos para la conservación de las fuentes documentales. Ministerio de Ciencia Tecnología y Medio Ambiente (CITMA)", Gaceta oficial 9 de mayo 2009. <http:// www.gacetaoficial.cu/pp.193>

ROJAS, J. A., CRUZ, C., MIKAN, J.F., VILLALBA, L.S., CEPERO DE GARCIA, M.C., RESTREPO, S. (2009). "Isoenzyme characterization of proteases and amylases and partial purification of proteases from filamentous fungi causing biodeterioration of industrial paper". International Biodeterioration and Biodegradation, 63:169-175.

ROJAS, T. I. (2010). “Diversidad fúngica en ambientes exteriores de áreas urbanas de ciudad de La Habana y sus potencialidades en el biodeterioro". Tesis presentada en opción al grado científico de Doctor en Ciencias Biológicas. Universidad de la Habana. Facultad de Biología.

ROJAS, T. I., AIRA, M. J., BATISTA, A., CRUZ, I.L. y GONZALEZ, S. (2012). "Fungal biodeterioration in historic buildings of Havana Cuba". Grana, 51:1, 44-51.
ROJAS, T.I., MARTINEZ, E., GOMEZ, Y., ALVARADO, Y. (2002). “Airborne spores of Aspergillus species in cultural institutions at $\mathrm{Ha}$ vana University". Grana, 41: 190e-193e.

ROSAS, A. L., CASADEVALL, A. (1997). "Melanization effects susceptibility of Cryptococcus neoformans to heat and cold. FEMS". Microbiology Letters, 153: 265-272.

SALEH, A. (2007). "Studies on Fungal Communities Associated whit Litter of Plant Cover at Al-Taif Province, Saudi Arabia". Met. Env. \& Arid Land Agric. Sci, 18: 2, pp: 87-98.

SANTHIYA, D., TING, Y. P. (2005). "Bioleaching of spent refinery proccessing catalyst using Aspergillus niger with high-yield oxalic acid". Journal of Biotechnology. 116: 171-184.

STERFLINGER, K., 2010. Review. Fungi. "Their role in deterioration of cultural heritage". Fungal Biology Reviews, 24: 47-55.

VAILLANT, M. (1996). "A work aimed to Project the health of the documental heritage conservators". International Conference on Conservation and Restoration of Archive and Library Materials. Preprints. Erice. 22- 29 April, p. 137-142.

VAILLANT, M., DOMENECH, M.T., VALENTIN, N. (2004). Una mirada hacia la conservación preventiva del patrimonio cultural. 1era Ed. Universidad Politécnica de Valencia, Valencia. pp.322.

VALENTIN, N. (2004). "El biodeterioro de materiales orgánicos". Jornadas Monográficas Prevención del biodeterioro en archivos y bibliotecas. Instituto del Patrimonio Histórico Español. 14-15 junio. pp.84-89.

VALENTIN, N. (2010). "Microorganisms in museum collections". COALITION, 19:2-5.

VILLALBA, L.S., MALAGON, A. (2011). "Biodeterioro de la fuente de Lavapatas, parque arqueológico de San Agustín-Huila. Colombia". Revista Ge-conservación, 2: 65-80.

VILLALBA, L.S., MIKAN, J.F., SANCHEZ, J. (2004). "Actividades hidrolíticas y caracterización isoenzimáticas de poblaciones microbianas aisladas del patrimonio documental en el Archivo General de Colombia". Nova Publicación Científica, 2: 50-57.

VILLENA, G.K., GUTIÉRREZ-CORREA, M. (2003). "Biopelículas de Aspergillus niger para la producción de celulasas: algunos aspectos estructurales y fisiológicos". Revista Peruana de Biología, 10: 78-87. 


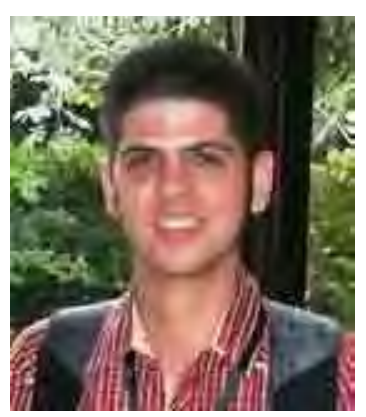

\section{Alian Molina Veloso}

Archivo Nacional de la República de Cuba

alian@arnac.cu, alian_molina@mail.com

Licenciado en Microbiología de la Universidad de La Habana, Cuba. Especialista del Laboratorio de Conservación Preventiva del Archivo Nacional de La República de Cuba. Realiza investigaciones en el campo de la Microbiología, la Aerobiología de interiores y el Biodeterioro documental. Todos estos temas vinculados con la conservación de patrimonio documental y la calidad de ambiente interior en archivos y otras instituciones patrimoniales.

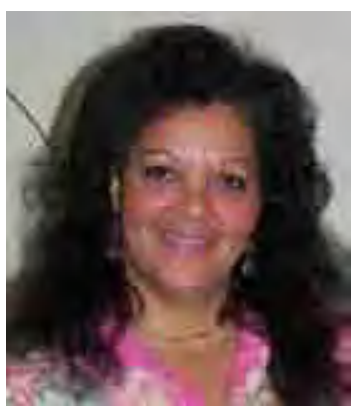

\section{Sofía Flavia Borrego Alonso}

Archivo Nacional de la República de Cuba

sofia@arnac.cu, sofy.borrego@gmail.com, sofia.borrego@rediffmail.com

Jefa del Laboratorio de Conservación Preventiva del Archivo Nacional de la República de Cuba es licenciada en Microbiología, Doctora en Ciencias Biológicas, Investigadora Auxiliar y Profesora Titular. Investiga en las líneas de: Conservación preventiva del patrimonio documental, biodeterioro de soportes documentales y aerobiología de interiores. Dirige varios proyectos de investigaciones nacionales e internacionales y ha dirigido proyectos de colaboración con instituciones científicas y de conservación en Argentina, España, Colombia y Venezuela. Ha impartido cursos y conferencias sobre conservación preventiva del patrimonio cultural en Cuba y en el extranjero (Argentina, Colombia, México, República Dominicana y Venezuela). Ha presentado más de 70 trabajos en eventos nacionales e internacionales y posee más de 40 publicaciones científicas en revistas nacionales e internacionales.

Artículo enviado el 06/05/2013

Artículo aceptado el 29/05/2014 


\title{
Conservación y restauración de un tocado atacameño del sitio Solcor-3, San Pedro de Atacama, norte de Chile
}

\author{
Carolina Morales-Nilo
}

Resumen: En la colección de tocados cefálicos prehispánicos asociados a contextos funerarios del Instituto de Investigaciones Arqueológicas y Museo R.P. Gustavo Le Paige (I.I.A.M.), San Pedro de Atacama, existe un tocado atacameño poco usual conformado por una banda afelpada y un casquete cuadrado. El presente artículo expone los procesos de documentación, diagnóstico y tratamiento de conservación aplicado a este tocado atacameño, procedente del fardo funerario de un individuo de la tumba 112 del sitio Solcor 3 , asociado a la fase de influencia del estado Tiwanaku en San Pedro de Atacama.

Palabras clave: Tocado Prehispánico; San Pedro de Atacama; Solcor-3; Conservación; Textil.

\section{Conservation and restoration of an atacamenian headdress of the Solcor-3 site, San Pedro de Atacama, northern Chile}

\begin{abstract}
In the collection of Prehispanic headdresses associated to funerary contexts of the Instituto de Investigaciones Arqueológicas y Museo R.P. Gustavo Le Paige (I.I.A.M.), San Pedro de Atacama, an unusual Atacamenian specimen constituted by a velvet band and a square crown was found. The present article describes the documentation, diagnostic and conservation treatment applied to this headdress, recovered from the funerary bundle of an individual from tomb 112 of the Solcor-3 site, associated with the Tiwanaku state influence in San Pedro de Atacama.
\end{abstract}

Key words: Prehispanic headdress; San Pedro de Atacama; Solcor-3; Conservation; Textile.

\section{Conservação e restauro de um toucado Atacameno do sítio Solcor-3, São Pedro de Atacama, Norte do Chile}

Resumo: Na colecção de toucados cefálicos pré-hispânicos associados a contextos funerários do Instituto de Investigações Arqueológicas, existe um toucado Atacameno pouco usual constituído por uma banda felpuda e um gorro quadrado. O presente artigo apresenta os processos de documentação, diagnóstico e tratamento de conservação aplicado a este toucado Atacameno, procedente do espólio funerário do individuo da tumba 112 do sítio Solcor-3, associado à fase de influência do estado Tiwanaku, em São Pedro de Atacama.

Palavras-chave: toucado pré-histórico, São Pedro de Atacama, Solcor-3; Conservação; Têxtil 
Introducción: Gorros con superficie afelpada o similivelours

El tocado ha representado uno de los elementos más distintivos entre las diferentes piezas del traje andino. Sobre la base de investigaciones arqueológicas, Berenguer (2006:63) afirma que: "La variabilidad en los atuendos no es sino la propia diversidad de las sociedades andinas, vista a través de una de sus manifestaciones culturales más expresivas. La cabeza - como el punto más prominente y visible del cuerpo- constituyó el lugar privilegiado para expresar mucho de esta diversidad. "Vestir" la cabeza fue un recurso simbólico para señalar importantes distinciones en el campo político, social, económico, étnico y de género". Este hecho se replica en las sociedades prehispánicas del norte de Chile donde la extrema aridez ambiental del Desierto de Atacama ha permitido la conservación y recuperación de las prendas de vestir procedentes de ajuares funerarios.

El repertorio de tocados en el área atacameña fue señalado por Latcham (1938) en su trabajo sobre las culturas arqueológicas del Desierto de Atacama indicando, entre otros hallazgos, gorros policromos semiesféricos con superficie similar al terciopelo, también conocidos como simili-velours. De acuerdo a D'Harcout (citado en Latcham 1938: 285) esta clase de tocado se encuentra desde el lago Titicaca hasta el norte de Chile y el sur del Perú, donde los dos centros de influencia cultural habrían sido Tiwanaku e Ica-Nazca. En cuanto a la técnica, se menciona que para generar una superficie aterciopelada se elabora un tejido de fondo neutro hecho a aguja en técnica de anudado en el que se incorporan hebras- gruesas y poco torcidas- que conforman el pelo. Estas mechas policromas se agregan al tejido en el momento en que se forma y se cierra el nudo a modo de herradura para luego cortarlas a un largo de 4 ó 5 mm (Latcham 1938: 285-286).

En la misma línea de estudio, Lindberg (1963) observa los tejidos y adornos de ajuares funerarios de los sitios arqueológicos Quitor 2, 5 y 6 de San Pedro de Atacama, identificando una clase de tocado como tipo mohair con forma de fez turco. La autora describe la técnica de confección como una superficie anudada de lana fina tejida en forma circular en la que se entrelazan mechones de piel de vicuña de $5 \mathrm{~cm}$ en cada nudo (Lindberg 1963: 198).

Otra variante formal en la técnica de inserción de mechas en tocados atacameños es observada por Rojas y Hoces de la Guardia (2000: 227) )[Figura 1] para el gorro que es parte del ajuar funerario de un individuo del sitio Coyo Oriente ( No 5382.2). Las investigadoras describen a la pieza como "un hermoso gorro rojo afelpado sobre la cabeza, de estructura base en trenzado vegetal y una capa exterior en anillado y mecha..." (Rojas y Hoces de la Guardia 2000: 227) [Figura 1]. Es significativo señalar que, entre las tres prendas textiles que envolvían el cuerpo de este hombre atacameño, las autoras destacan la túnica exterior como un tejido muy fino y de una riqueza técnica e iconográfica única que harían referencia a una cultura foránea, de modo que la pren- da habría sido creada para un personaje de alta jerarquía (Rojas y Hoces de la Guardia 2000: 231). Estos antecedentes contextuales son significativos en el marco del presente trabajo ya que el tocado del individuo de Coyo Oriente comparte varios rasgos técnicos con el objeto de estudio.

Otra referencia de textiles tradicionales con superficies

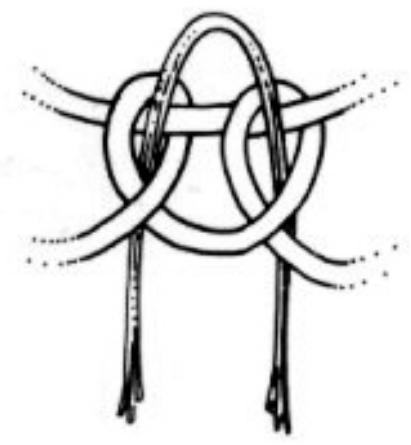

Figura 1. Ilustración de la técnica de malla anillada simple con incorporación de pelo (Bravo 1993).

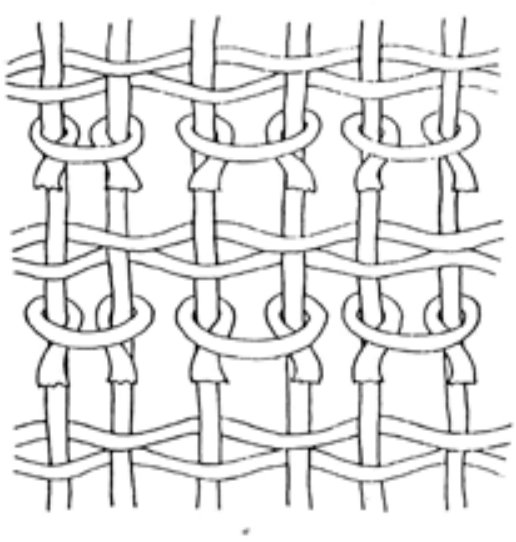

Figura 2. llustración de nudo turco o simétrico (Harris 2004).
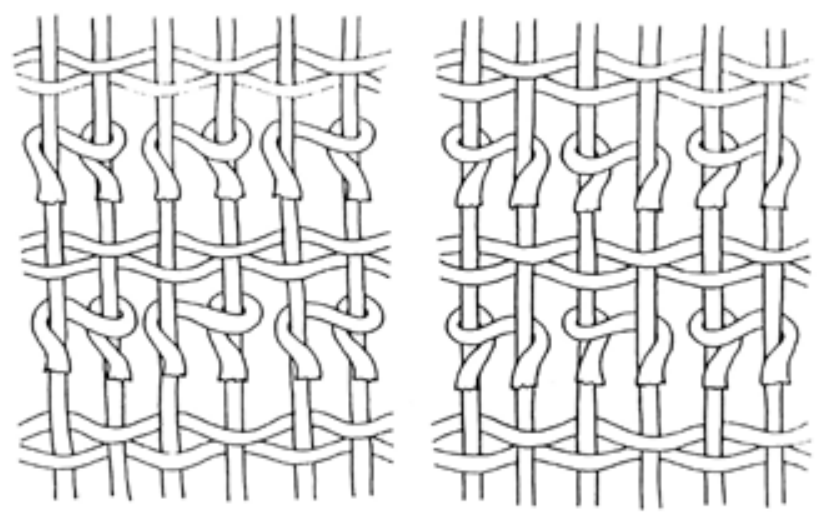

Figura 3. Ilustración de nudo persa o asimétrico (Harris 2004). 
afelpadas se relaciona con la confección de alfombras en Oriente. Estas fueron tejidas en una franja que corresponde desde España y norte de África hasta India y China y muchas de las sociedades tejedoras de alfombras estuvieron vinculadas al Islam en alguna etapa importante de su historia. Estos objetos tuvieron diversos usos, ya sea para cubrir murallas y pisos, como alfombras de oración, sillas de montar, bolsas y cojines (Harris 2004:28).

Las alfombras de pelo están hechas con pequeñas mechas que se sujetan a la urdimbre de una estructura de base a través de nudos generando una superficie densa. Los nudos más conocidos son el simétrico o nudo Turco [Figura 2] y el asimétrico o nudo Persa [Figura 3].

Sin embargo, las alfombras de pelo se diferencian técnicamente del tocado en estudio tanto por sus estructuras textiles de base como por la manera en que se insertan los pelos a esta estructura. Respecto a este tema, Seiler-Baldinger (1994: 105) expone una gran diversidad de técnicas de ornamentación clasificadas de acuerdo a la técnica del tejido de base, entre las que se mencionan tejidos de malla, tapicería, faz de urdimbre, gasa vuelta, entre otros.

\section{Banda cefálica afelpada con casquete cuadrado}

\section{Descripción general}

El gorro de la tumba 112 de Solcor-3 presenta dos estructuras independientes: por un lado está la banda cefálica, conformada por una estructura cilíndrica interior de trenzado vegetal de 14 cabos [Figura 4] y por una cinta exterior de textura afelpada tejida en anillado simple con hilo estructural y mecha roja de $1 \mathrm{~cm}$ de largo [Figuras $5 a$ y $5 \mathrm{~b}$ ]. El diámetro de esta banda cilíndrica disminuye en su parte superior, pasando de $57 \mathrm{~cm}$ en la base a $50 \mathrm{~cm}$ en la cúspi-

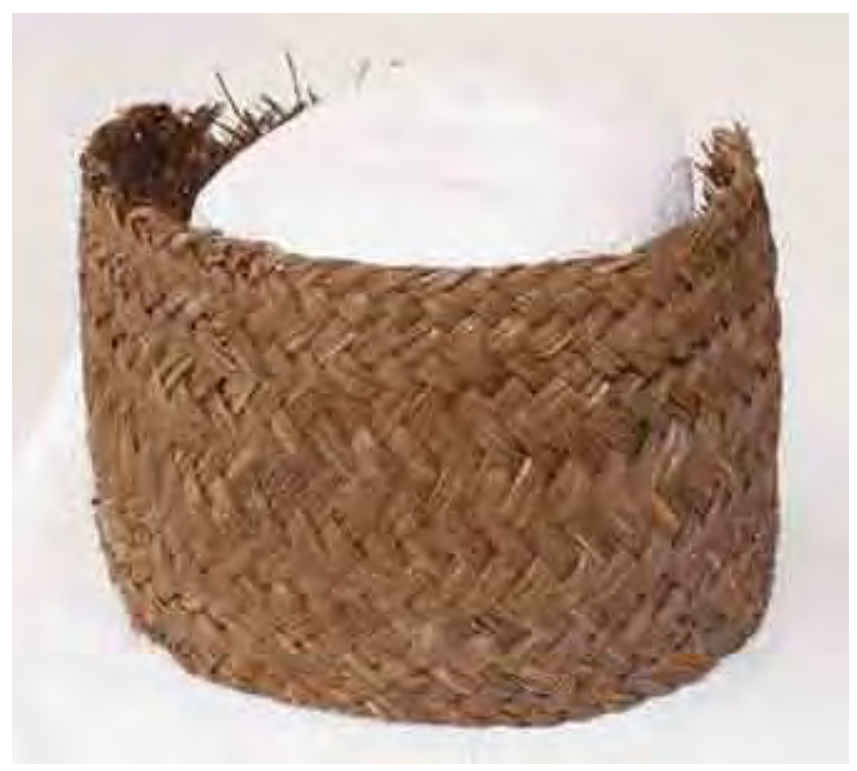

Figura 4. Estructura interior de la banda cefálica compuesta por un trenzado vegetal de 14 cabos (Morales, 2012).

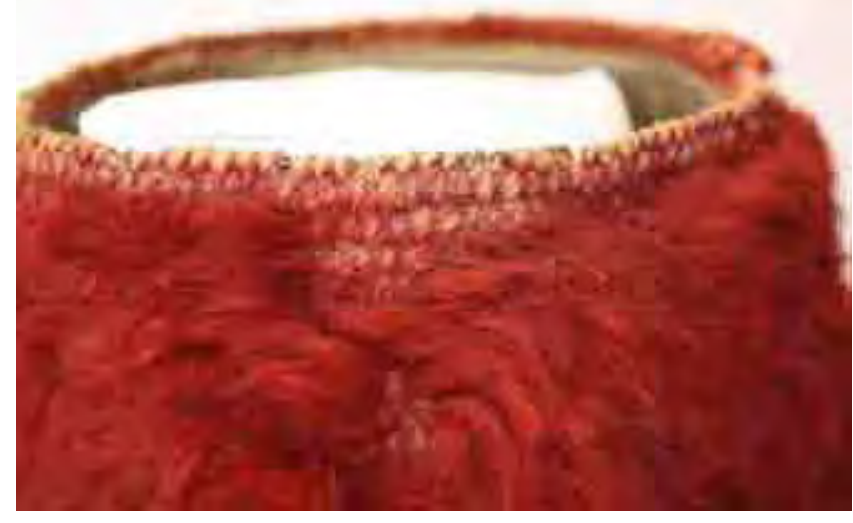

Figura 5a. Detalle del borde de la banda afelpada (Morales, 2012).

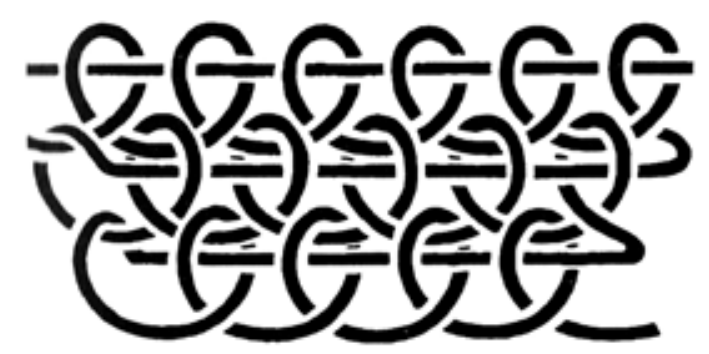

Figura 5b. llustración del tejido de base de la banda afelpada: malla anillada simple con hilo estructural (Seiler-Baldinger, 1994).

de, con una altura de 10,5 cm. En una intervención anterior realizada en el año 2006, el cintillo vegetal fue consolidado por anverso y reverso con una película de Mylar@ (tereftalato de polietileno) a través de puntadas.

Por otra parte, el gorro consta de un tejido de fibra de camélido policromo de $14 \times 14 \mathrm{~cm}$ confeccionado en anudado (nudo de doble enlace simétrico) y configurado por siete cuadrados concéntricos que generan los siguientes campos de colores (desde el centro hacia los bordes): amarillo ocre, rosa, celeste, verde musgo, amarillo ocre, rosa y verde musgo [Figura 6]; este tejido fue montado sobre una almohadilla de tela durante el tratamiento de restauración en el 2006. Al analizar la progresión del tejido se registró que en los cuatro cuadrados interiores las aristas aumentan en $2 \mathrm{~cm}$; en los dos siguientes, en 1,5 cm; y en el último, más externo, en $1 \mathrm{~cm}$. Además, se observó que a partir del cuarto cuadrado se tejen nudos adicionales en los vértices de modo que se generan pequeñas puntas, lo que podría sugerir que habría una similitud con la técnica de confección de los gorros de cuatro puntas frecuentes en enterramientos del extremo norte de Chile (Sinclaire 1998; Berenguer 2006 ). La terminación de la orilla del casquete se realiza con una corrida de anudado en color amarillo ocre. Esta fina superficie textil - con una densidad de 36 nudos por $\mathrm{cm}^{2}$ - fue encapsulada entre dos soportes de crepelina amarillo ocre en la restauración anterior. Al interior del embalaje que contiene el gorro se encuentran también fragmentos de plumas rojas, levemente decoloradas. En el marco del presente estudio, se encontraron otros 


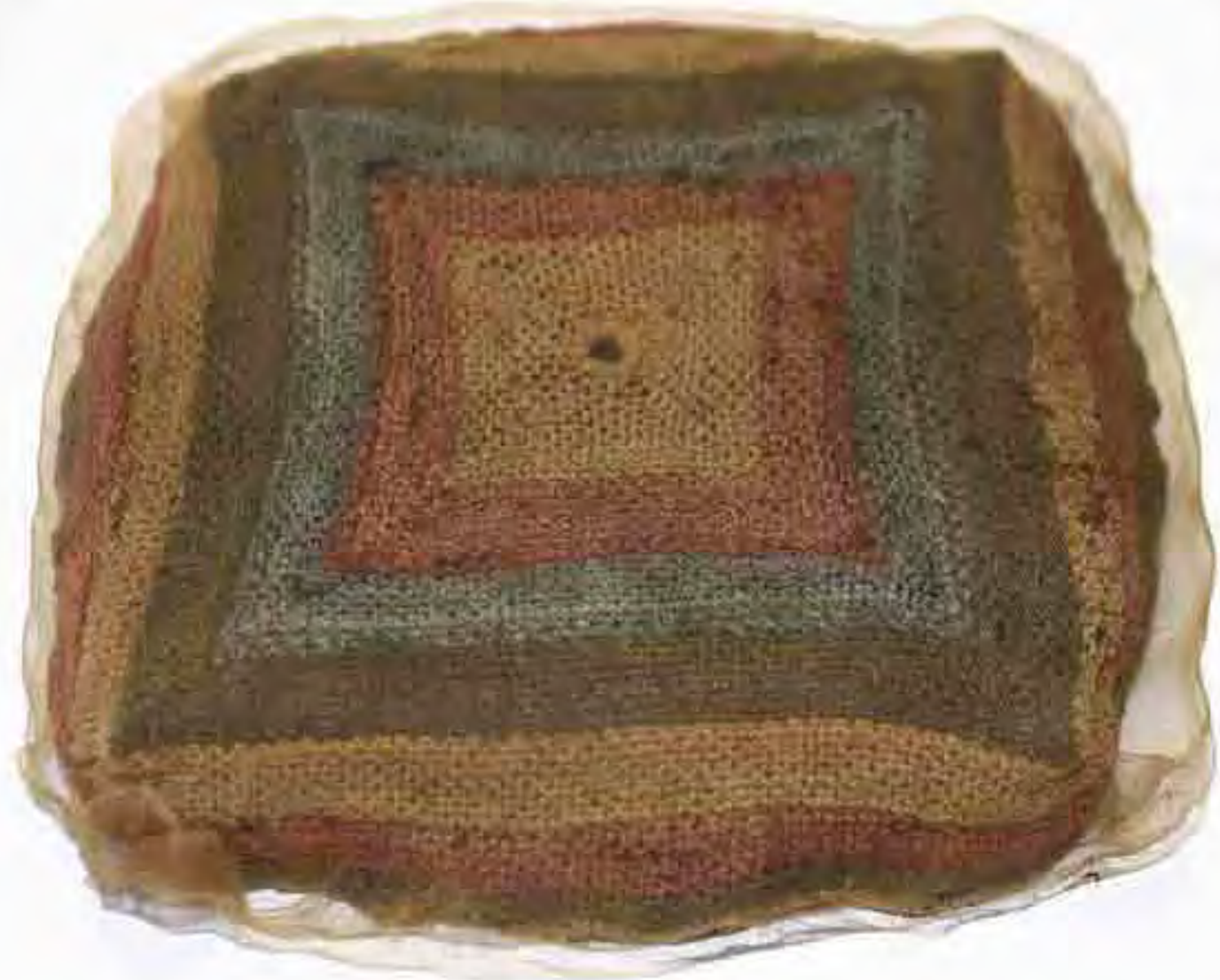

Figura 6. Casquete tejido en malla anudada con diseño de cuadrados concéntricos (Morales 2012).

fragmentos de atados de plumas rojas y blancas también asociados a la tumba 112 [Figura 7].

El proceso de documentación de la pieza en estudio fue fundamental para dilucidar dos cuestiones principales: indagar por qué las estructuras de banda afelpada y cas-

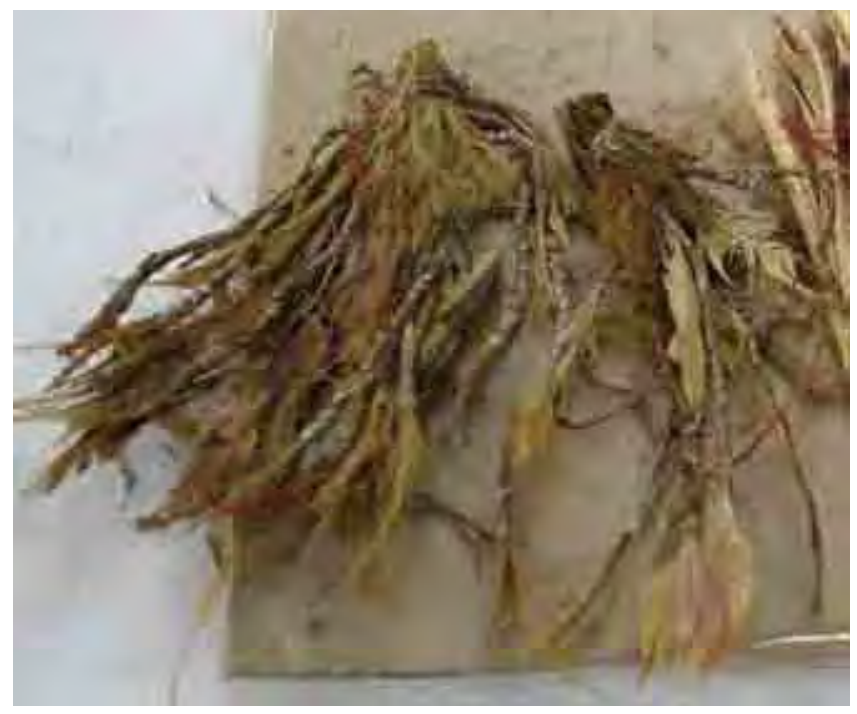

Figura 7. Detalle de fragmentos de atados de plumas asociados al tocado (Morales, 2012). quete se encontraban separadas y, en paralelo, cuál habría sido la forma original de la banda en función de un casquete evidentemente cuadrado. Para lo anterior se recopiló documentación arqueológica acerca del individuo de la tumba 112 del sitio Solcor-3 para lo cual se contactó a investigadores y otros integrantes de tal excavación. Del mismo modo, se revisaron las fichas asociadas al objeto facilitadas por la Unidad de Conservación del I.I.A.M.

\section{Documentación}

Solcor-3, ubicado en los límites del ayllu ${ }^{1}$ de Solcor, es uno de los más grandes cementerios prehispánicos utilizados durante el Horizonte Medio en San Pedro de Atacama. En 1983, Bravo y Llagostera dirigen las excavaciones del sitio encontrando 153 cuerpos distribuidos en 93 tumbas (Bravo y Llagostera 1986: 323) que fueron ampliadas posteriormente a 117 tumbas (Llagostera et al. 1988: 70). El cementerio estuvo en uso durante los años 400-900 d.C., observándose dos fases de ocupación: una pre-Tiwanaku y otra posterior, que muestra evidencia de la influencia Tiwanaku (Llagostera et al. 1988). Los objetos tiwanakotas encontrados en Solcor-3 están vinculados principalmente al complejo alucinógeno, que para este sitio, se caracteriza por "(...) una bolsa textil que contiene una tableta, un tubo, una cucharilla, y una o dos bolsas de cuero con los polvos alucinógenos" (Llagostera et al. 1988: 72). 


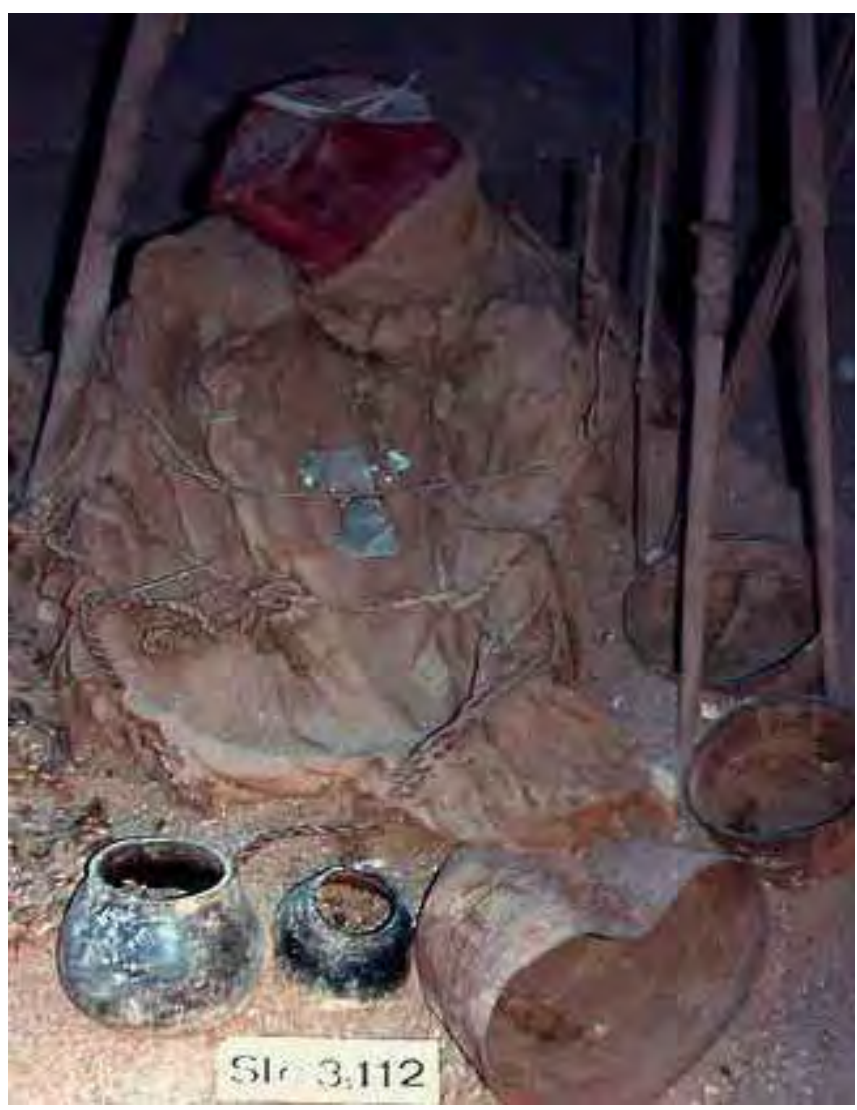

Figura 8a. Individuo de la tumba 112 en el sitio Solcor-3.

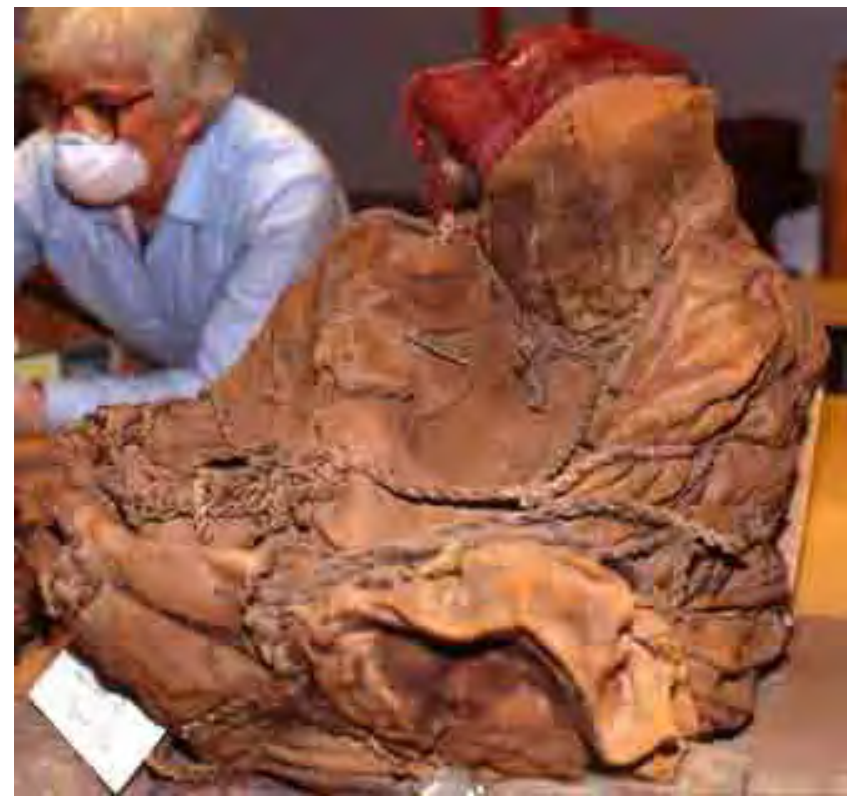

Figura 8b. Individuo de la tumba 112 traslado al I.I.A.M. Detalle del tocado rojo sobrepuesto al fardo funerario.

La tumba 112 del sitio Solcor-3 pertenece a la fase de influencia Tiwanaku. Se identifica el cuerpo como de un individuo probablemente varón por la presencia de arco y hacha entre sus ofrendas. La descripción del ajuar funerario

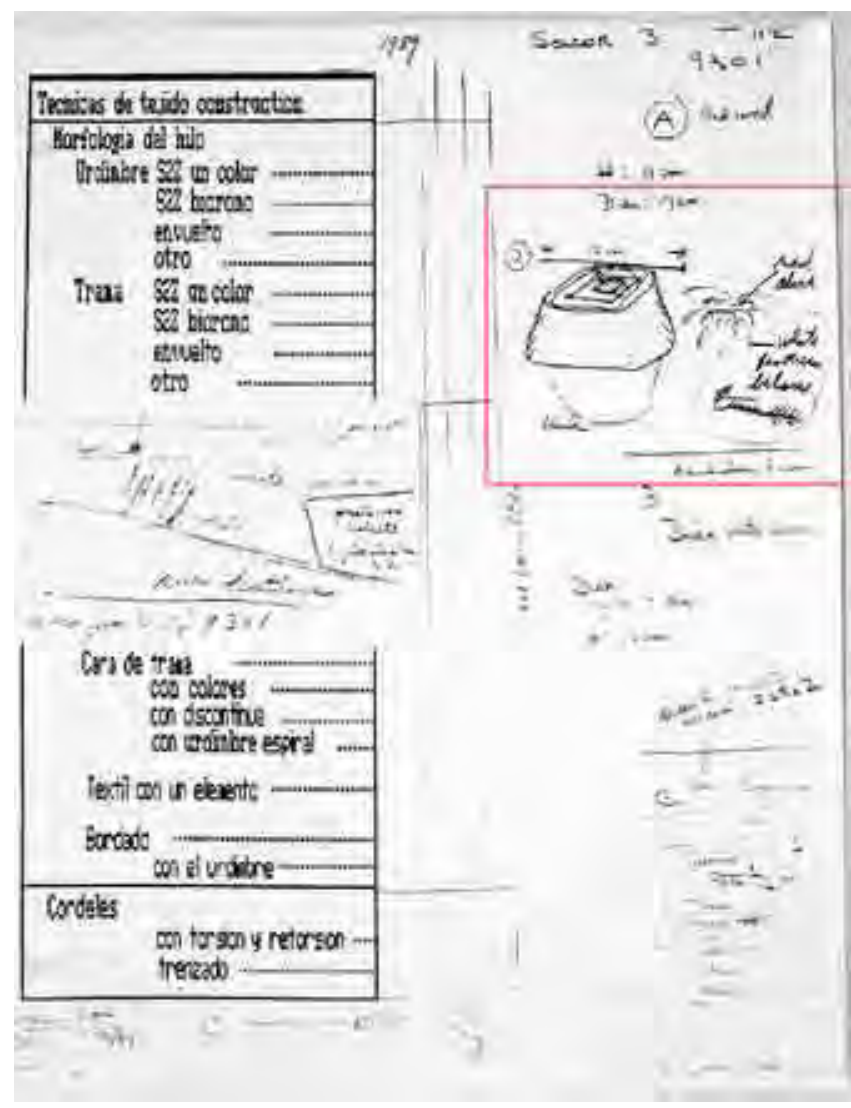

Figura 9. Ficha técnica del tocado elaborada por Barbara Conklin en 1989 (Registro I.I.A.M.).

se centra en el equipo psicotrópico y en otros artefactos como tres canastos y dos vasijas ovoides, sin indicar detalles acerca de los atuendos de la momia (Llagostera et al. 1988: 101).

A partir de la comunicación con los arqueólogos responsables de la excavación en Solcor-3 (Llagostera y Torres, com. personal, 2012) se accedió al registro visual del cuerpo ${ }^{2}$ en sitio y una vez que éste fue trasladado al laboratorio de la Unidad de Conservación del I.I.A.M. [Figuras 8a y 8b]. Si bien la fotografía del momento de su hallazgo da cuenta de un tocado volumétrico con aristas marcadas, es necesario considerar que su forma podría haberse alterado producto de las condiciones de entierro. Las escasas imágenes recopiladas no permiten distinguir el casquete con claridad ya que son tomas frontales del objeto; sin embargo, evidencian el desprendimiento de plumas rojas y blancas desde la copa del gorro.

En la búsqueda de información contextual de la tumba 112 se revisó el libro de registros del I.I.A.M. en el que se hace mención a la banda roja afelpada y su estructura vegetal, pero los autores no describen el casquete policromo. Para contrastar lo anterior, se consultó a un miembro del equipo de excavación de la tumba 112 (Tomás Cruz, com. personal, 2012) quien recordó que, efectivamente, el casquete le pertenecía a la banda afelpada roja, lo que se confirmaría más adelante a través de la revisión de nuevos datos. 
Otro documento que proporcionó importantes antecedentes acerca de los atributos formales y materiales del objeto de estudio es la ficha técnica realizada por la investigadora Barbara Conklin en 1989 [Figura 9]. En ella, se ilustra un tocado de base trapezoidal con una superficie afelpada coronado por un tejido cuadrado de lana de camélido que presenta siete cuadrados concéntricos con la misma secuencia de colores descrita previamente. La autora esquematiza también el modo como se incorporan las plumas de suri sobre el casquete, detallando que las plumas rojas van por encima de las blancas. En 2003, la arqueóloga Carolina Agüero desarrolla una nueva ficha técnica del artefacto en la que clasifica la pieza como un gorro fez afelpado, es decir, sugiere un volumen que reduce su diámetro en la parte superior al igual que un cono truncado.

El informe de restauración del tocado en estudio realizado en 2006 sería un documento clave para entender tanto aspectos originales de manufactura como las alteraciones presentes en la pieza. A partir del registro fotográfico del objeto previo a dicha intervención se comprobó nuevamente que la banda cefálica estaba coronada por un casquete policromo; aún más, se observaron los hilos desprendidos que aparentemente unían la banda cefálica al casquete [Figura 10]. En cuanto al estado de conservación, el mencionado informe reporta las siguientes alteraciones y deterioros: deformación estructural, suciedad de polvo y sales, sustancias proteicas en la superficie, pérdida en la estructura vegetal y desprendimiento de la copa. Se informa también acerca del tratamiento de restauración aplicado de acuerdo a los siguientes procedimientos: 1) desinfección en cámara fría por 48 horas, 2) aspirado y barrido con

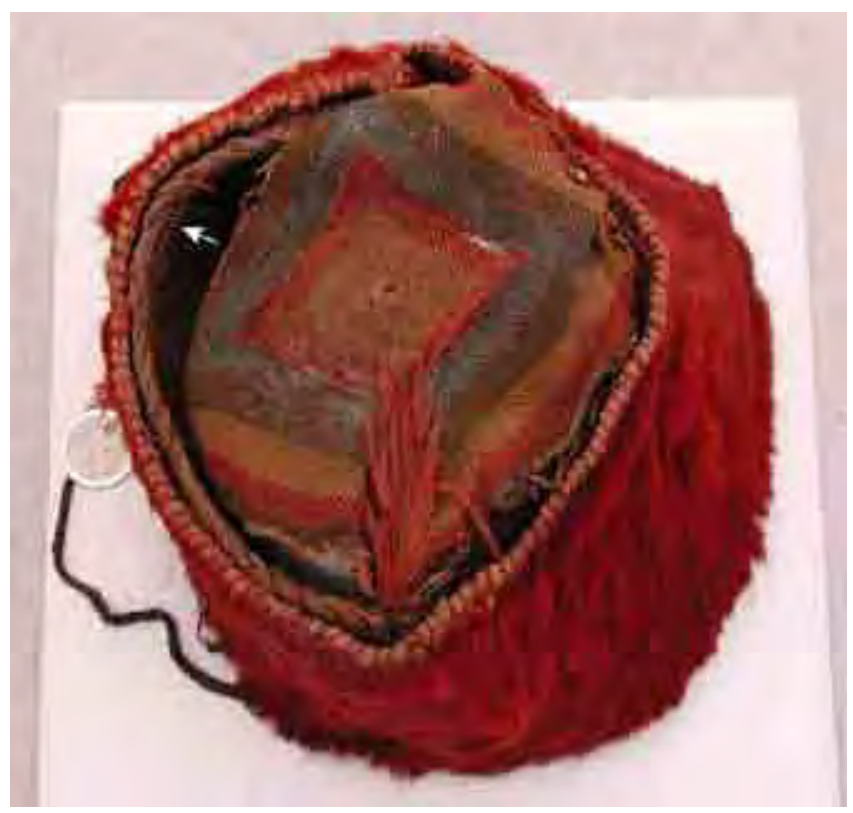

Figura 10. Registro fotográfico previo intervención realizada en 2006. Detalle de los hilos desprendidos que unían las estructuras del gorro (Registro I.I.A.M.).

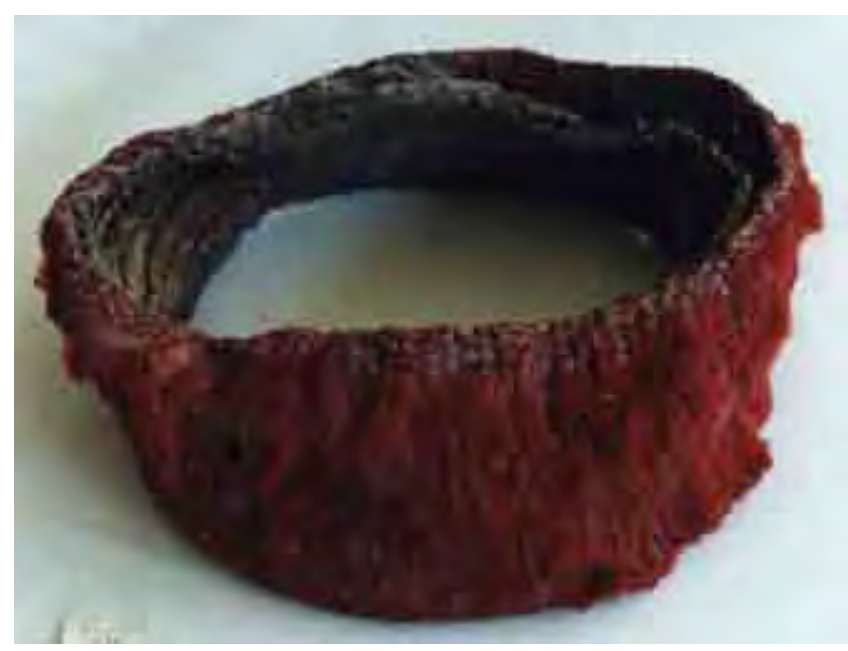

Figura 11a. Gorro Coyo Oriente № 5382.2 (Hoces de la Guardia 2000).

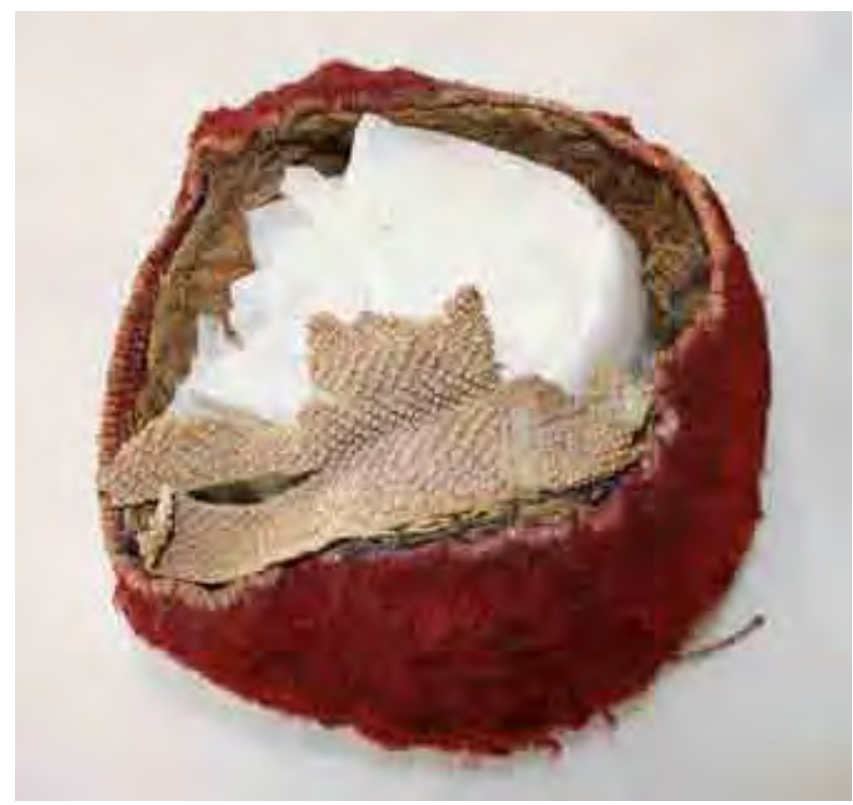

Figura 12a. Gorro Coyo Oriente № 3934. Banda cefálica afelpada con fragmento de casquete (Morales 2012).

pinceles, 3) lavado de la copa en solución desmineralizada y jabón neutro, 4) secado sobre molde con forma original (4 puntas), 5) humidificación por tres días para recuperar la forma original, 6) consolidación del casquete con soporte de crepelina y 7) consolidación del tejido vegetal con una solución de Paraloid@ (copolímero de metil metacrilato y butil acrilato) ${ }^{3}$ en acetona, y encapsulamiento entre láminas de Mylar@.

Con el fin de identificar un patrón formal de esta clase de tocado se buscaron especímenes similares al gorro de la tumba 112 de Solcor-3 en la colección. De un universo de 143 piezas se reconocieron dos gorros del sitio Coyo Oriente con atributos afines: el № 5382.2, mencionado anteriormente, y el No 3934. 


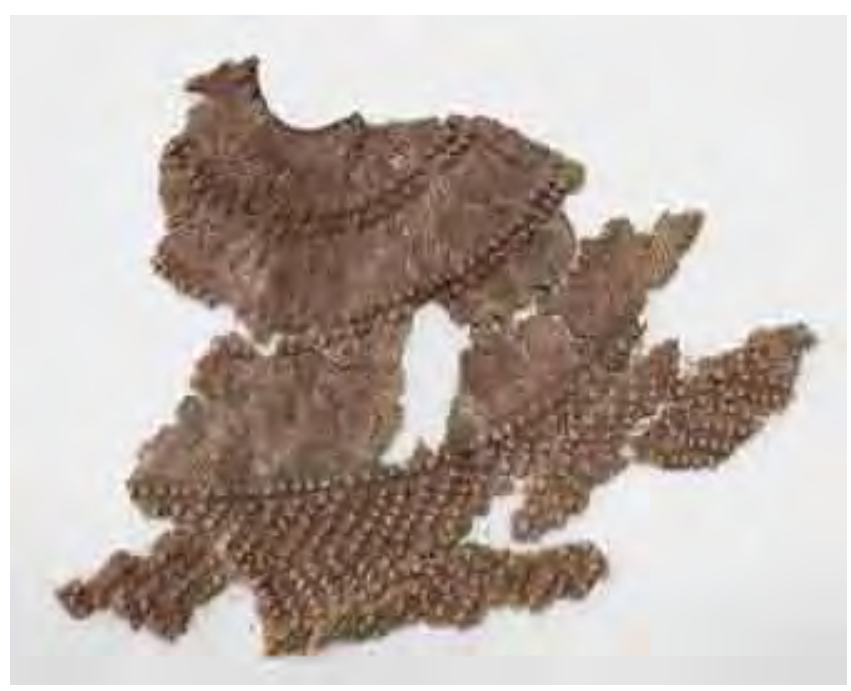

Figura 12b. Detalle del casquete circular tejido en anillado simple. Gorro Coyo Oriente № 3934 (Morales 2012).

El primero consta de una banda afelpada roja con estructura vegetal interior circular levemente deformada [Figura 11a]. El segundo gorro es igualmente interesante ya que permite proponer una relación formal entre la banda cefálica y el tejido que la corona; en este caso, el casquete presenta una superficie circular tejida en anillado simple que coincide con una banda cefálica cilíndrica, hoy deformada [Figuras 12a y 12b]. Por lo tanto, los gorros Solcor 3, tumba 112 y Coyo Oriente № 3934 son ejemplares de las dos variantes registradas para esta clase de tocado definida por la técnica de confección del casquete: el anudado (knotting) o el anillado simple (looping). Lo anterior constata la misma diferenciación observada por Oakland (1994: 111) para el tipo de gorros con cintillo y casquete.

Finalmente, es interesante notar que los casquetes tejidos en técnica de anudado en los gorros con cintillo y casquete son octogonales, lo que hace suponer que los tejedores han buscado una solución para que este tejido se adapte a la circunferencia del cintillo, ya que el anudado, a diferencia del anillado simple, no permite obtener formas circulares.

A partir de la documentación recopilada y anteriormente expuesta, se concluye que en el contexto sistémico, las estructuras del gorro en estudio - banda cefálica y casquete- estaban unidas. Además, se sugiere que la forma de la banda cefálica habría sido levemente trapezoidal de modo que hubiera coincidido en su perímetro superior con el casquete cuadrado. Estas características del tocado, técnica y morfológica, pretenden ser recuperadas en el supuesto de que fueron alteradas por la intervención realizada en el año 2006.

\section{Análisis del Estado de Conservación}

La pieza de estudio se encuentra estable y está adecuada- mente embalada. Sin embargo, se observan las siguientes alteraciones en el actual diagnóstico:

\section{Alteración superficial}

1.1. Adherencias superficiales: presencia de polvo en la superficie afelpada exterior y, en mayor concentración, en las láminas de Mylar@ que consolidan el cintillo vegetal interior. La acumulación de polvo sobre el textil es abrasivo, penetra en las fibras y las corroe, además de favorecer el crecimiento de insectos (Comité Nacional de Conservación Textil 2002).

1.2. Pérdida de componentes: este deterioro se identifica en el desprendimiento total de las plumas que decoraban el tocado. De éstas, se encontraron fragmentos de los atados de plumas rojas y blancas cuya única información acerca de la técnica de manufactura se encuentra en la ficha técnica elaborada por Barbara Conklin en 1989.

\section{Alteración estructural}

2.1. La separación de las estructuras textiles que conforman el tocado- banda cefálica y casquete- no permiten visualizar la pieza en su totalidad. Esta fragmentación genera la incertidumbre de que el casquete efectivamente le pertenezca a la banda.

2.2. El cintillo vegetal interior presenta un $25 \%$ de faltante lo que debilita estructuralmente la banda cefálica.

2.3. La fragilidad de las fibras textiles está presente tanto en las fibras proteicas como en las celulósicas. Para el primer caso, la oxidación de las fibras de camélido del casquete se hace evidente a través del amarilleamiento de la superficie. En el segundo caso, es notorio el resecamiento y el brillo de las fibras vegetales del cintillo interior de la banda cefálica, cuyo deterioro se potenció luego de la aplicación de Paraloid@. Los efectos descritos son avalados por los trabajos de Kronkright y de Tworek (citados en Norton 1990: 237). El primer autor señala que algunas resinas sintéticas provocan cambio de color y rigidez en los objetos de cestería; el segundo informa que el Paraloid B-72 (resina acrílica), el Revacryl 452 (dispersión acrílica coloidal) y el Methocel A4C (pasta de metilcelulosa) generan cambios de color y textura.

\section{Alteración visual}

3.1. Se observan dobleces y arrugas en los vértices interiores del casquete producto del acomodo del tejido sobre una almohadilla estructural. Asimismo, el casquete presenta cortes y pequeños faltantes en el tejido anudado.

3.2. El soporte de crepelina ocre usado para consolidar la superficie anversa del casquete intensifica el efecto de 


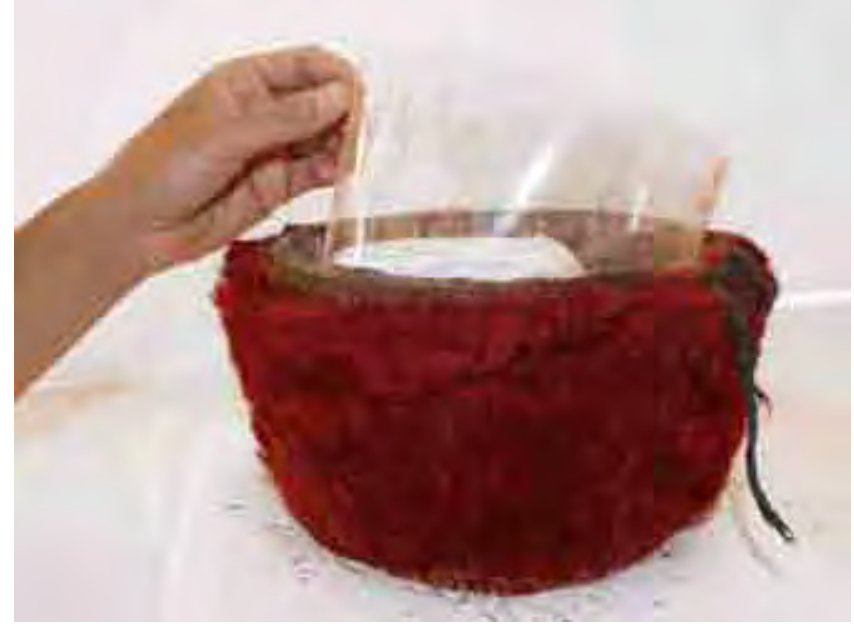

Figura 13. Retiro de las láminas de Mylar para evitar la adherencia del polvo en suspensión en la pieza (Morales 2012).

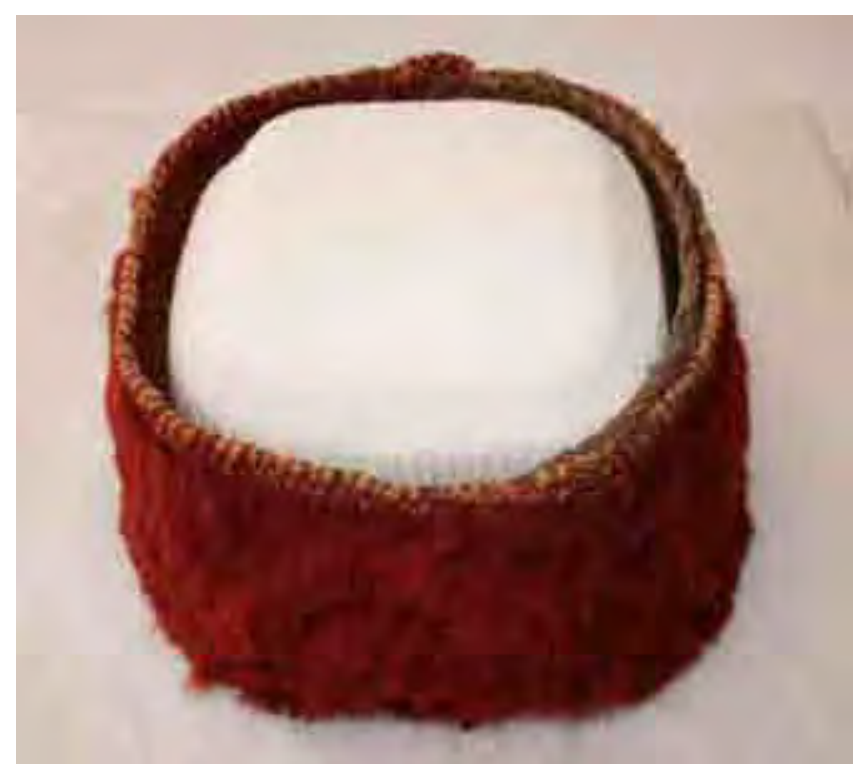

Figura 14. Instalación de un molde de Ethafoam ligeramente trapezoidal al interior de la banda cefálica. (Morales 2012).

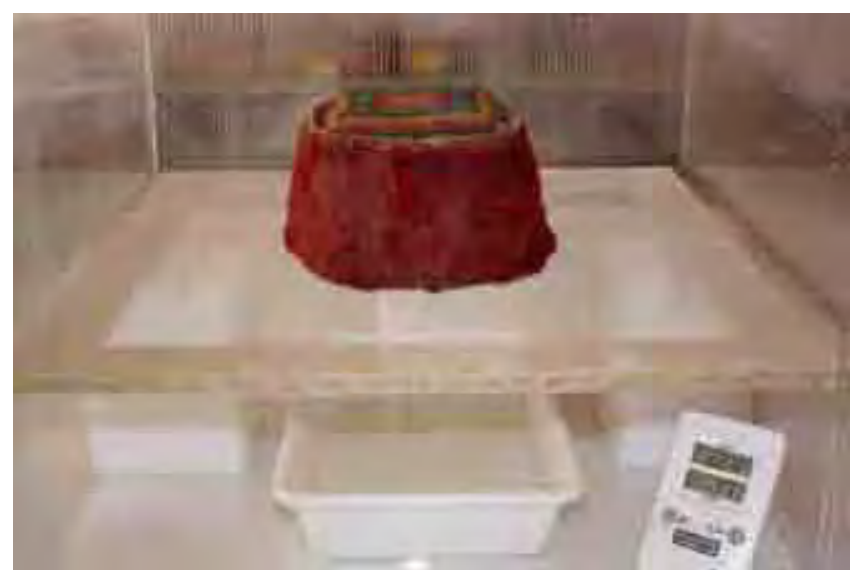

Figura 15. Ingreso de la pieza con el molde interior a la cámara de humificación (Morales 2012). amarilleamiento de las fibras de camélido producto de la oxidación, y genera una cierta distorsión de los colores actuales del textil.

Según lo expuesto en la documentación y en el análisis del estado de conservación, se propone un tratamiento orientado a: 1) evaluar los soportes incorporados al artefacto en la restauración anterior, eliminando o reemplazando aquellos que se consideren inadecuados, evitando alterar la estabilidad de la pieza, 2) hidratar las fibras textiles de la pieza para recuperar la forma original de sus partes y 3) unir el casquete a la banda cefálica para restituir la legibilidad estética del objeto.

\section{Tratamiento de Restauración}

Como medida previa a la intervención se retiraron muestras de fibras de camélido de la banda cefálica (hilado de la estructura anillada y vellón rojo de la superficie afelpada) y del casquete (hilados de color rojo, azul, verde y ocre), y muestras de fibras vegetales de la trenza plana para análisis posteriores en laboratorio (identificación de colorantes orgánicos e identificación de fibras).

\section{Retiro de soportes}

Se retiró el soporte de crepelina ocre del anverso del casquete ya que éste no permitía apreciar los colores actuales de la superficie del tejido. Este procedimiento no interfirió con la estabilidad del casquete ya que se mantuvo la crepelina de la cara reversa.

Asimismo, se retiraron las capas de Mylar@ del cintillo vegetal de la banda cefálica debido a que este plástico es electrostático y atrae el polvo en suspensión que se acumula con facilidad en climas áridos como el de San Pedro de Atacama. [Figura 13].

\section{Confección de molde}

Luego de la aspiración con baja succión de la banda afelpada y del casquete con el fin de retirar la suciedad superficial se confeccionó un molde de espuma de polietileno (Ethafoam $\odot$ ) levemente trapezoidal, con el contorno inferior $7 \mathrm{~cm}$ mayor que el contorno superior. Se forró el soporte con un jersey tubular de algodón para evitar roces de la superficie del molde con el gorro, y se instaló al interior de la banda cefálica [Figura 14].

\section{Humidificación}

Se ingresó la pieza montada sobre el molde de Ethafoam@ y el casquete sobrepuesto a la banda afelpada a una cámara de humidificación de policarbonato usando una bandeja de agua destilada como fuente de humedad [Figura 15]. Se cerró la cámara por dos días. Luego de ese período, en el que las fibras fueron humectadas a través del vapor del agua destilada, se fijó el casquete al soporte de Ethafoam® 


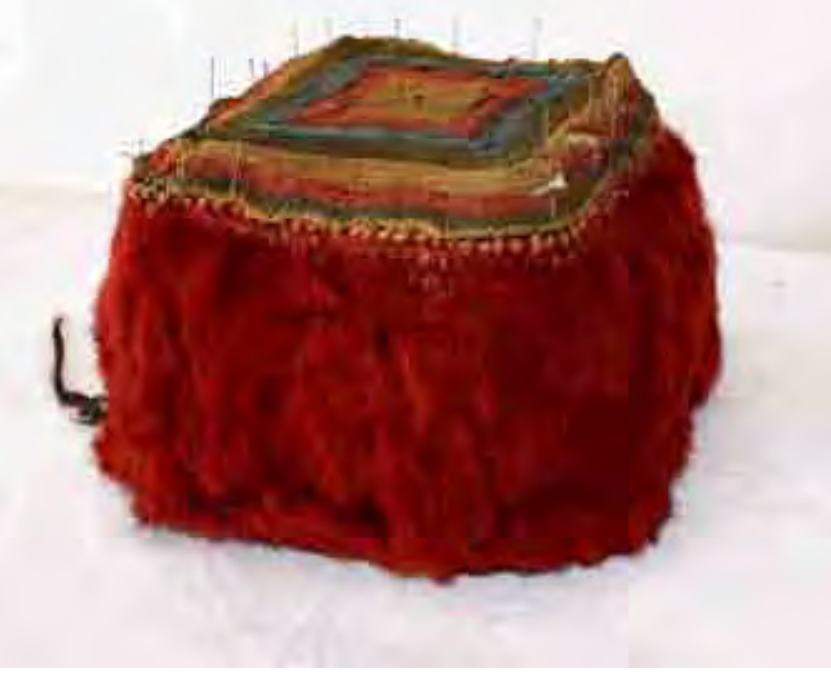

Figura 16. Fijación de la superficie del casquete al molde a través de alfileres entomológicos galvanizados (Morales 2012).

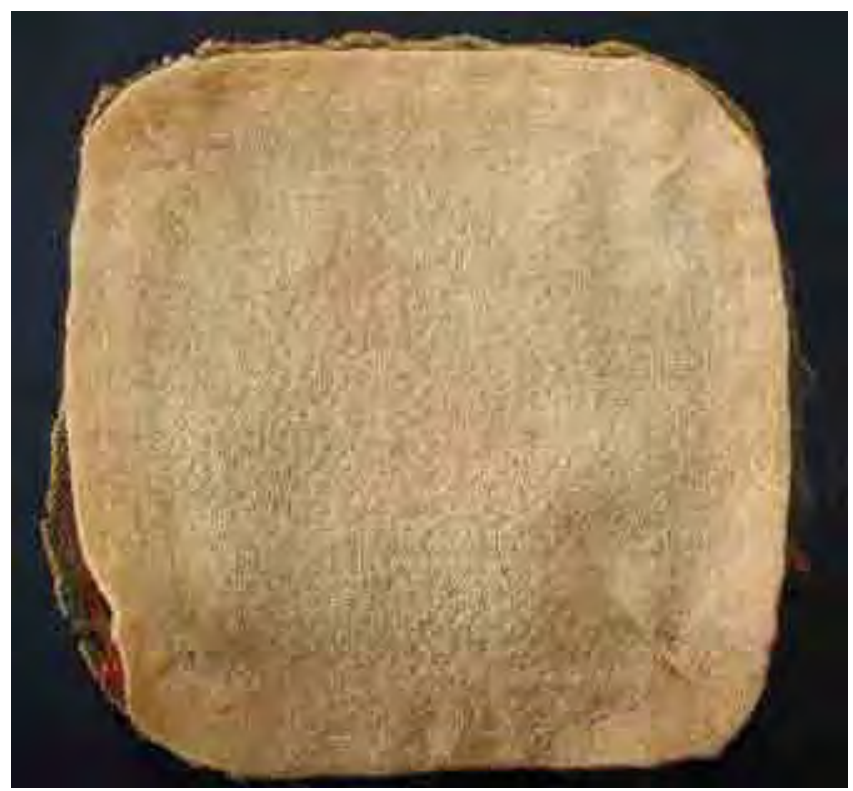

Figura 17. Soporte de etamina de lana fijado al casquete previo consolidación (Morales 2012).

usando alfileres entomológicos galvanizados ( $\left.\mathrm{N}^{\circ} 0\right)$ [Figura 16]. Se colocaron pequeñas almohadillas de espuma forrada en malla tubular de algodón para rellenar las esquinas interiores del tejido y así insinuar la prolongación de los vértices en forma de cuatro puntas. Luego se reingresó la pieza por dos días adicionales a la cámara, rociando previamente sus paredes con agua destilada ${ }^{4}$. En el quinto día, se retiró la bandeja de agua desde la cámara para que el gorro se secara lentamente durante otros dos días al interior de la cámara y así evitar que las fibras textiles sufrieran estrés a causa de los cambios bruscos en la humedad
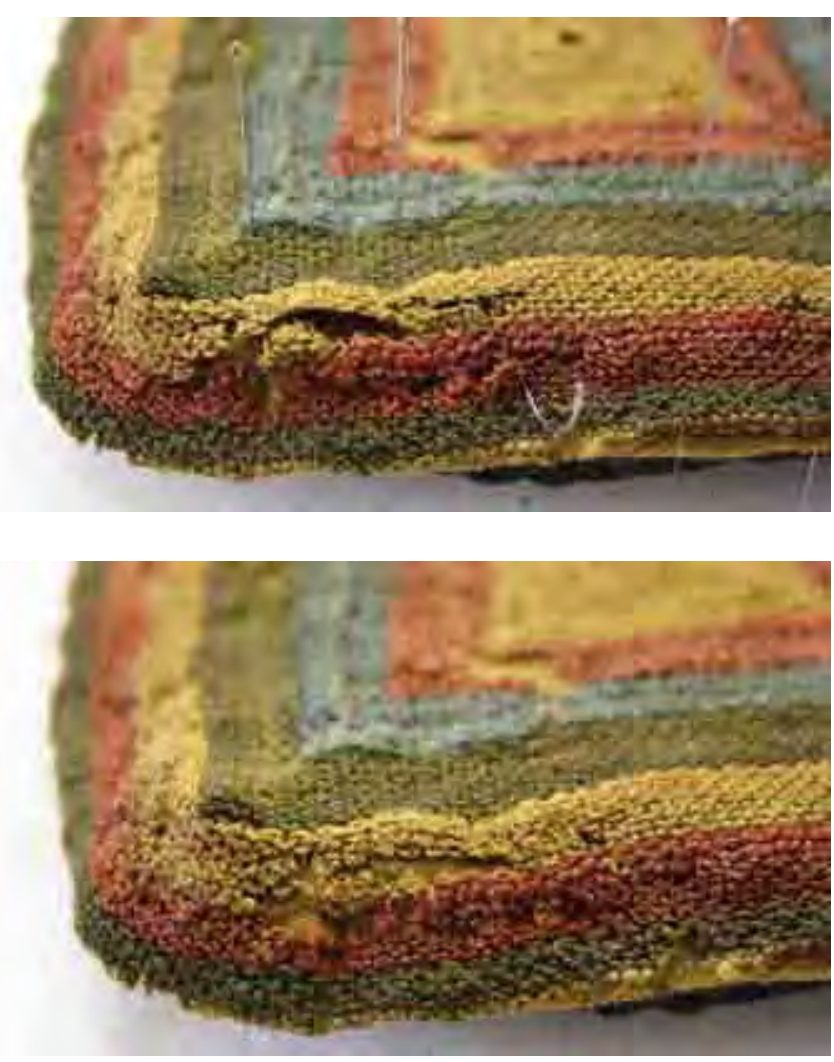

Figura 18a y b. Antes y después de consolidación del casquete a través de puntadas de couching (Morales 2012).

relativa, conllevando eventuales daños mecánicos en el material textil. Para lo anterior, se consideró la recomendación de Tímár-Balázsy (1999) en relación con el lavado de textiles históricos, quien señala que para retener la flexibilidad obtenida en las fibras lo óptimo es un ambiente con humedad relativa del $55 \%$ durante el secado.

El proceso de humidificación otorgó una forma ligeramente trapezoidal a la banda afelpada, lo que permitió que el perímetro del casquete se adaptara a los bordes de la banda.

\section{Consolidación}

Con el fin de reforzar la estructura del casquete y reintegrar las áreas faltantes era necesario incorporar un soporte en la cara reversa. Para esto se usó un tejido de lana en ligamento de tela (etamina de lana de $80 \mathrm{~g}$ ) ya que tanto la densidad como el ligamento del tejido se ajustaban a las características de la superficie textil original. Se hicieron pruebas de teñido con colorantes reactivos Lanaset $\odot$ mediante mezcla de tricromía, optando finalmente por el color amarillo ocre ya que generaba un fondo neutro para la reintegración cromática. Una vez teñido, se realizaron pinzas en las esquinas del soporte de manera que éste se adaptara a la forma del casquete cuadrangular y se fijaron ambos tejidos a través de puntadas de hilván [Figura 17]. Luego, se desprendieron progresivamente las puntadas diagonales de la restauración anterior para reemplazarlas 


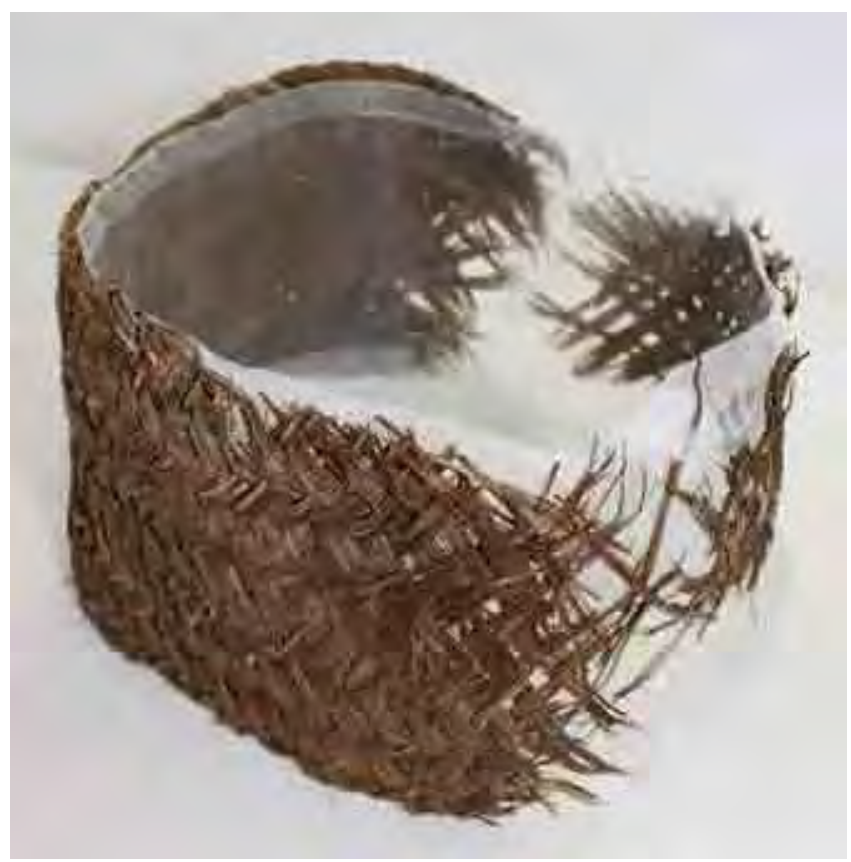

Figura 19. Consolidación del cintillo vegetal a un soporte de crepelina mediante puntadas con hilo de seda (Morales 2012).

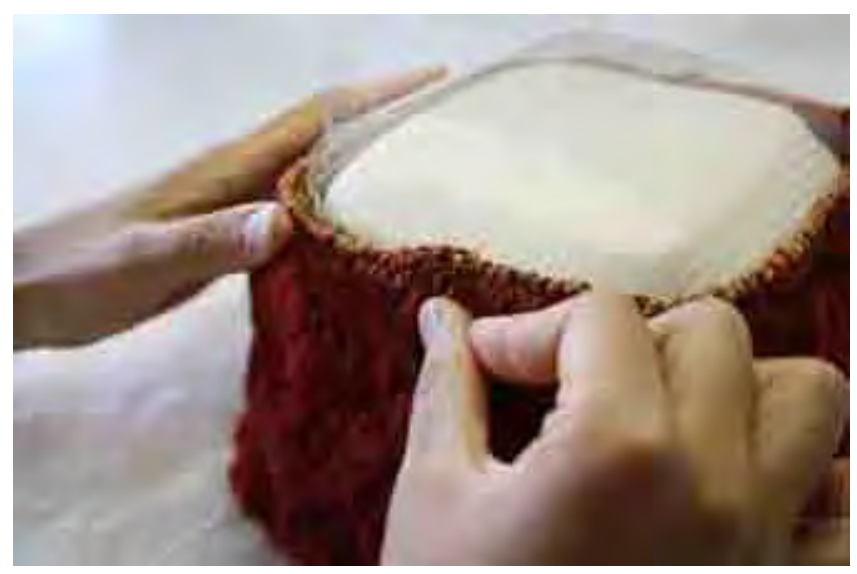

Figura 20. Unión entre las estructuras de la banda cefálica a través de puntadas con hilo de seda (Morales 2012).

por costuras de couching debido a que esta técnica es más efectiva para soportar la superficie textil, además de generar una superficie más plana. De este modo, se consolidaron las áreas faltantes y los cortes mediante puntadas de couching con aguja quirúrgica curva Kalt No1 e hilo de seda color tostado. Durante este proceso fue necesario el apoyo de una lupa ya que el tejido anudado presenta una superficie muy fina. El resultado luego de la consolidación fue una superficie textil más regular y sin arrugas en las puntas [Figura 18a y 18b].

En cuanto a la consolidación del cintillo interior de la banda cefálica se buscó un material adecuado que reemplazara el Mylar@. El nuevo soporte debiera permitir contener las fibras vegetales altamente friables sin alterar la apa- riencia del material relativo al oscurecimiento y brillo de la superficie (Norton 1990: 235). Se tomó en consideración la opción de un tratamiento sin solventes sugerido por Norton (1990: 239) quien propone el uso de un soporte de crepelina de seda o Stabiltex@ (crepelina de poliéster). De este modo, se consolidó el cintillo vegetal a una banda de crepelina de seda mediante puntadas diagonales en los perímetros superior e inferior de la estructura [Figura 19]. El área del cintillo que presentaba mayor desprendimiento de material fue reforzado con puntadas adicionales para fijar los cabos desprendidos de la trenza vegetal. Este procedimiento se realizó con la mínima manipulación posible debido al resecamiento que presentaban las fibras del entramado.

\section{Unión de estructuras}

Una vez que la banda vegetal fue consolidada se adhirió al cintillo afelpado con costuras en los bordes superior e inferior [Figura 20]. Luego, se unió el casquete a ambas estructuras de la banda a través de puntadas diagonales con hilo de seda doble. Para lo anterior, se estableció un patrón de $1,5 \mathrm{~cm}$ de distancia en función de pequeños agujeros observados en el borde del tejido anudado que se interpretaron como marcas de la costura original.

Finalmente, se realizó el registro fotográfico del resultado final obtenido [Figuras 21a y b].

\section{Conclusiones}

El presente trabajo generó un debate crítico entre arqueólogos y conservadores del I.I.A.M. en torno a la propuesta de tratamiento para la pieza en estudio, convirtiendo la instancia de intervención en una oportunidad para articular los distintos actores que habían participado en los procesos de excavación y posterior conservación de la pieza. La recopilación de documentos que registraron los antecedentes históricos y clínicos del artefacto - fichas técnicas, informes de restauración, registros fotográficos - así como la observación de especímenes similares en la colección aportaron información primordial que permitió fundamentar el tratamiento de restauración.

En esta búsqueda de recopilar datos para el análisis técnico y formal del tocado en discusión se sugiere el estudio de referentes artefactuales de otras colecciones del subárea Circumpuneña (suroeste de Bolivia, Región de Antofagasta en Chile y el Noroeste argentino) en las que podrían, eventualmente, encontrarse objetos textiles afines debido a los vínculos existentes entre poblaciones prehispánicas de estas regiones. Éstas compartieron el empleo de la técnica de mallas anilladas y redes anudadas que en los Andes alcanzó una gran diversidad de variantes según la densidad, la dirección y el tipo de enlace o nudo utilizado para tejer bolsas, redes de pesca y tocados. Es por ello que aunque comparten la técnica de la incorporación de pelos a un tejido de base, los textiles andinos se diferencian de 

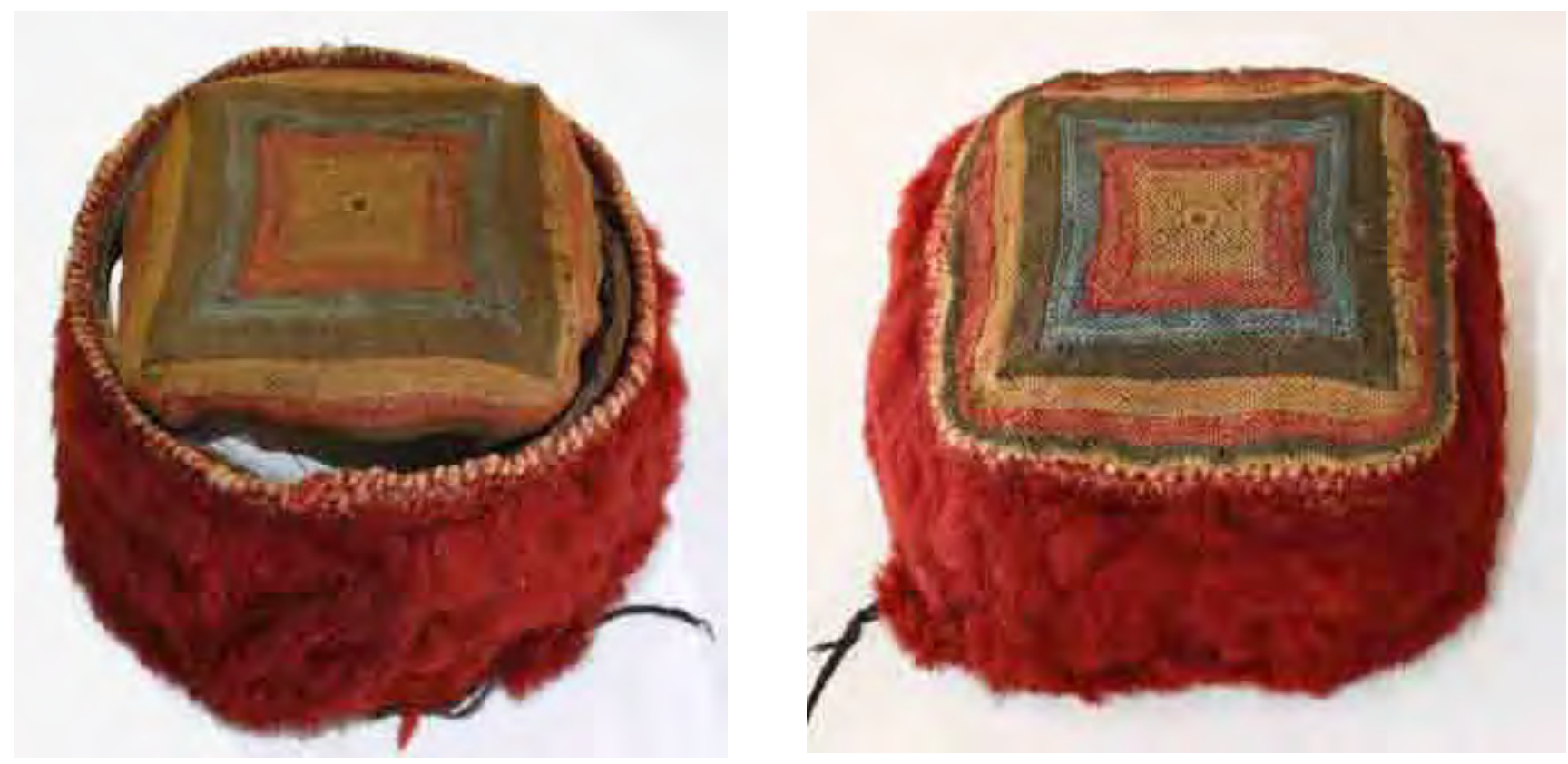

Figuras 21 a y b. Registro fotográfico antes y después de la intervención (Morales 2012).

los orientales en cuanto fueron tejidos con agujas y no en el telar haciendo uso de fibras de camélido.

En cuanto al tratamiento de restauración, se priorizó el respeto a la autenticidad del tocado, por lo que se dedicó un tiempo importante a reflexionar sobre las soluciones que permitieran restituir la legibilidad del artefacto. Además, la intervención anterior generó un aprendizaje en cuanto al uso de materiales de conservación inadecuados para el ambiente árido de San Pedro de Atacama, por ejemplo, el uso del Mylar $^{\circledast}$ para encapsular estructuras textiles y la aplicación de Paraloid ${ }^{\circledR}$ como consolidante de fibras de composición celulósica ya que favorece los cambios de color, brillo y rigidez de las fibras.

Finalmente, este trabajo significó un aporte en cuanto se restauró uno de los tres gorros representativos de una clase que se caracteriza por una banda cefálica anillada con mechas rojas y un cintillo interior vegetal, permitiendo que pudiera ser exhibido en una eventual muestra museográfica de tocados atacameños.

\section{Notas}

[1] Unidades territoriales pertenecientes a un conjunto de individuos relacionados por lazos de parentesco y/o económicos.

[2] El registro fotográfico del individuo estuvo a cargo de WiIliam Conklin (Torres, com. personal, 2012).

[3] No se especifica el tipo de Paraloid usado.

[4] Los valores de H.R. registrados en este proceso se caracterizaron por una progresión y descenso constantes, con una H.R. máxima observada de $93 \%$

\section{Agradecimientos}

El presente trabajo contó con el apoyo del proyecto PIA-CONICYT Anillo ACT No 096 (http://www.cienciaymemoria.cl) y del Instituto de Investigaciones Arqueológicas y Museo R.P. Gustavo Le Paige.

Mis agradecimientos a Hermann M. Niemeyer del Laboratorio de Química Ecológica de la Universidad de Chile por la permanente orientación en torno a los análisis científicos de la pieza y a Maeva Schwend por la asesoría continúa e indispensable respecto al tratamiento de restauración realizado.

A ambos, Hermann y Maeva, agradezco también la revisión del presente manuscrito. A todo el equipo de la Unidad de Colecciones y Conservación del I.I.A.M., en especial a Arturo Torres y a Helena Horta por la permanente colaboración en las actividades involucradas en este proyecto.

\section{Bibliografía}

BERENGUER, J. (2006). Gorros del Desierto. Santiago de Chile: Museo Chileno de Arte Precolombino.

BRAVO, L. y LLAGOSTERA, A. (1986). "Solcor 3: Un aporte al conocimiento de la cultura San Pedro. Período 500 al 900 d.C.." En Chungara 16-17: 323-332.

BRAVO, M. (1993). "Análisis técnico de cinco gorros atacameños". En Identidad y Prestigio en Los Andes. Gorros, turbantes y diademas. Museo Chileno de Arte Precolombino. Santiago, Chile: 76-82. 
HARRIS, J. (2004). 5.000 years of Textiles. Washington: Smithsonian Books.

LATCHAM, R. (1938). Arqueología de la Región Atacameña. Santiago: Universidad de Chile.

LINDBERG, I. (1963). “Tejidos y adornos de los cementerios Quitor 2, 5 y 6 de San Pedro de Atacama". En Revista Universitaria, XLVIII: 195-202.

LLAGOSTERA, A., TORRES, M.C., y COSTA, M.A. (1988). “El complejo psicotrópico en Solcor-3, (San Pedro de Atacama)". En Estudios Atacameños 9: 67-106.

COMITÉ NACIONAL DE CONSERVACIÓN TEXTIL (2002). Manual de conservación preventiva de textiles. Proyecto catastro del patrimonio textil chileno. Santiago de Chile: Comité Nacional de Conservación Textil. Dirección de Bibliotecas Archivos y Museos . Fundación Andes.

OAKLAND, A. (1994). "Tradición e innovación en la prehistoria andina de San Pedro de Atacama" . En Estudios Atacameños 11: 109-120.
NORTON, R. (1990). “Conservation of artifacts made from plant materials". En The conservation of artifacts made from plant materials, Getty Trust Publications: Getty Conservation Institute. California: 195-285.

ROJAS, A.M. y HOCES DE LA GUARDIA, S. (2000). "Coexistencia y diversidad técnica, textural y formal en los textiles de un fardo perteneciente al sitio Coyo de San Pedro de Atacama". En Chungara, 32 (2): 227-233.

SEILER-BALDINGER, A. (1994). Textiles: A classification of techniques. Bathurst, Australia: Crawford House Press.

SINCLAIRE, C. (1998). “Los gorros de cuatro puntas de la colección arqueológica Manuel Blanco Encalada: tipología y secuencia para el Valle de Azapa, Arica". En Boletín del Comité Nacional de Conservación Textil 3: 169-00.

TÍMÁR-BALÁZSY, A. (1999). "Drying behaviour of fibres". Proceedings of the ICOM Committee for Conservation Triennial Meeting (12th), Lyon, 661-666.

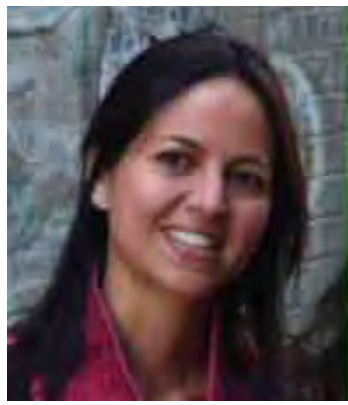

\section{Carolina Morales-Nilo}

Diseñadora, Pontificia Universidad Católica de Chile

Postítulo en Restauración del Patrimonio Cultural Mueble, Universidad de Chile

carolimorales@gmail.com

Ha sido asesora como diseñadora gráfica y textil en proyectos de investigación FONDECYT en la línea de "Tecnologías textiles precolombinas de los Andes" apoyada por la Escuela de Diseño de la Pontificia Universidad Católica de Chile y el Museo Chileno de Arte Precolombino. Se ha formado en la conservación y restauración de bienes muebles realizando pasantías en el Área de Conservación del Museo Chileno de Arte Precolombino (Santiago) y en el Museo R.P. Gustavo Le Paige (San Pedro de Atacama), dirigiéndolas al área del patrimonio textil etnográfico y arqueológico.

Artículo enviado el 10/08/2013

Artículo aceptado el 07/07/2014 


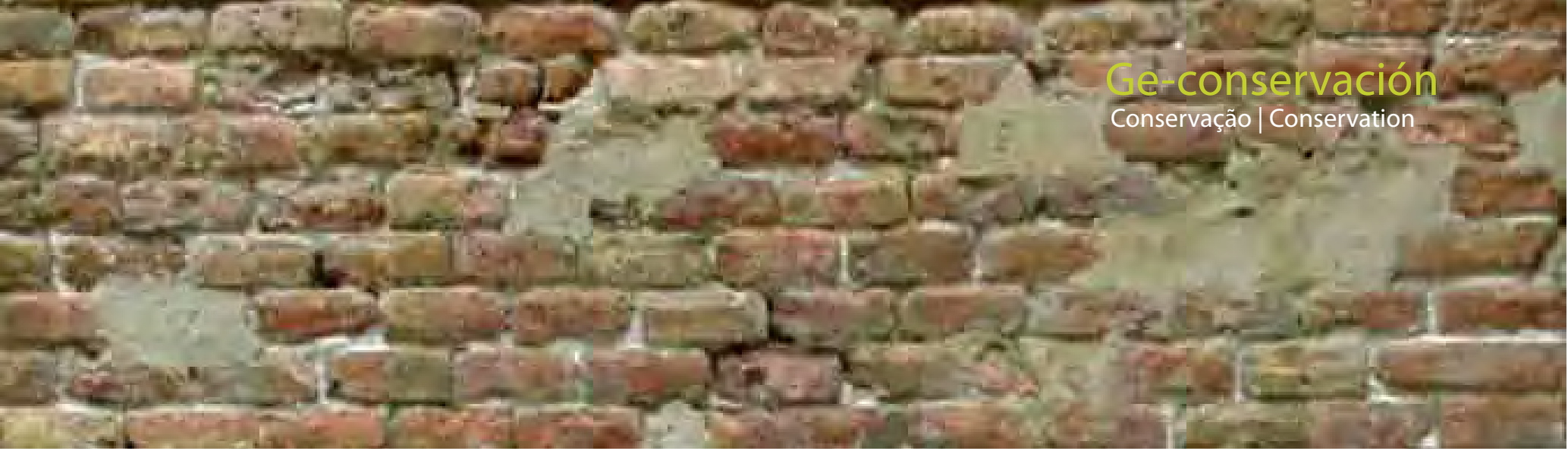

\title{
Limpieza ideal y limpieza real en Patrimonio Arquitectónico
}

\author{
Manuel Ángel Iglesias Campos
}

\begin{abstract}
Resumen: El concepto actual de limpieza refleja la evolución que la conservación-restauración ha tenido durante el siglo XX. Gracias al desarrollo de las ciencias y a la formación de los conservadores-restauradores se le ha ido añadido añadiendo un carácter científicotécnico - limpieza ideal - y se ha profesionalizado la intervención - limpieza real - . En este trabajo, a partir de la definición de limpieza en Patrimonio Arquitectónico y de determinados preceptos implícitos al tratamiento (estética, conservación, catas previas, evaluación, etc.), se analiza la normativa específica en la materia para comprobar su vigencia y adaptación a las necesidades reales de intervención. Tras plantear diversas cuestiones sobre el tratamiento se puede concluir que, si bien el estudio científico de las catas previas de limpieza es algo habitual, no se ha determinado cómo plantear un seguimiento efectivo de los trabajos según los baremos establecidos en dichos estudios.
\end{abstract}

Palabras clave: limpieza, normativa, evaluación, catas previas, conservación-restauración.

\section{Ideal Cleaning and Actual Cleaning in Architectural Heritage}

Abstract: The current concept of cleaning reflects the evolution of conservation-restoration during the twentieth century. Due to science development and conservators-restorers' academic training a scientifictechnical basis has been added — ideal cleaning — and a professional status to the intervention has been given - actual cleaning - In this paper, from the definition of Architectural Heritage cleaning and from certain treatment implicit concepts (aesthetic, conservation, previous tests, evaluation, etc.), the specific standards of this area are reviewed to verify its validity and adaptation to the requirements of an actual intervention. After considering several questions about cleaning it can be concluded that, although the scientific study of previous cleaning tests is a common practice, it has not been determined how to set up an effective monitoring of the work in accordance to the established scales in these studies.

Key words: cleaning, standards, evaluation, previous tests, conservation-restoration.

\section{Limpeza ideal e limpeza real em Património Arquitectónico}

Resumo: $\mathrm{O}$ atual conceito de limpeza reflete a evolução que a conservação e restauro teve durante o século XX. Graças ao desenvolvimento das ciência se à formação dos conservadores-restauradores, foi-se ganhando um caráter científico-técnico — limpeza ideal — e foi-se profissionalizando a intervenção — limpeza real —. Neste trabalho, a partir da definição de limpeza em Património Arquitectónico e de determinados preceitos implícitos ao tratamento (estético, conservação, testes de limpeza prévios, avaliação, etc), analisam-se as normativas específicas da matéria para comprovar a sua vigência e sua adaptação às necessidades da intervenção atual. Depois de colocar diversas questões sobre o tratamento, pode concluir-se que, embora o estudo científico dos testes de limpeza seja algo comum, não está determinado como se deve fazer um seguimento efetivo dos trabalhos, de acordo com os parâmetros estabelecidos nesses estudos.

Palavras-chave: limpeza, normas, avaliação, testes de limpeza prévios, conservação-restauro. 


\section{Introducción}

La forma de entender la limpieza en la actualidad es fruto de la evolución que ha tenido la conservación-restauración a lo largo del siglo XX al beneficiarse del desarrollo científico y de la formación de los conservadores-restauradores como garantes de los trabajos (ECCO 2002; AA.VV. 2000; ICOM 1984; Brandi y de Angelis d'Ossat 1972; AA.VV. 1931). Se le ha añadido un carácter científico-técnico - limpieza ideal - y se ha profesionalizado la intervención - limpieza real ${ }^{-1}$.

Pero, ¿todas las disciplinas científicas, técnicas o profesionales implicadas en el Patrimonio Arquitectónico han asumido estos cambios? Los arquitectos han atendido en sus proyectos a determinados criterios deontológicos de la restauración; los científicos han centrado sus investigaciones en las necesidades reales de la intervención; el conservador-restaurador ha asumido un papel destacado entrando en un campo regido por principios, principalmente económicos, diferentes a los que le eran habituales; las constructoras que gestionan los trabajos, cuentan con conservadores-restauradores para determinados tratamientos.

Aparentemente, todo parece funcionar. Pero, por la manera de adjudicar la mayoría de proyectos y por los baremos de valoración normalmente establecidos al otorgar estas contratas $¿$ Todas las intervenciones se adecuan realmente a los criterios establecidos por los organismos responsables del Patrimonio Arquitectónico?, ¿Son estos criterios mesurables según los protocolos de calidad consensuados en otras ramas de la construcción?

Aparte de consideraciones legislativas y administrativas de gestión y control de las intervenciones por parte de los organismos responsables, parece necesario establecer una metodología clara con la que determinar el tratamiento que permita al conservador-restaurador, y a los responsables de la obra, implantar un seguimiento preciso durante toda la intervención. A pesar de lo complejo que resulta definir el procedimiento de limpieza de los diferentes materiales de un monumento por la variedad de depósitos superficiales o manchas, y la diversidad de estados de conservación que pueden tener, desde hace años existen normas y recomendaciones, nacionales e internacionales, que abordan la cuestión.

En este trabajo, a partir de la definición de limpieza en el contexto actual de intervención en Patrimonio Arquitectónico, y del análisis de determinados conceptos relacionados con el tratamiento se revisan las normas existentes en la materia para comprobar si pueden ayudar a determinar la calidad de una limpieza y asegurar el seguimiento de los trabajos dentro de los valores establecidos en un proyecto y en un estudio previo. Ciencia, criterio, normalización, profesionalización,... son paradigmas inherentes al tratamiento que no siempre coexisten en la limpieza real.

\section{Limpieza}

Semánticamente, el término limpieza aparece vinculado a su verbo: limpiar. Limpiar significa quitar la suciedad o inmundicia de algo, hacer que un lugar quede libre de lo que es perjudicial en él, y, quitar imperfecciones o defectos (Real Academia Española s.a.). También existe una relación evidente entre limpieza e higiene, entendida como el aseo de viviendas, lugares públicos y poblaciones (Real Academia Española s.a.).

Los monumentos se limpian por diferentes razones, y una de ellas es porque se renuevan o embellecen al considerarse que una superficie limpia es mejor (Andrew 1992: 63). Por tanto, uno de los argumentos para limpiar un monumento es estético, ya que cambia su apariencia y la de su entorno.

Esto ha sido así desde antiguo. En la Edad Media, en el centro de Italia, las ciudades tenían normas para mantener la armonía visual de sus edificios y asegurar una representación positiva; entre 1625 y 1775, las iglesias de Roma se encalaban cada 25 años para celebrar los Años Santos, relacionando limpieza con celebración de acontecimientos (Koller 2000: 6). A mitad del siglo XIX, en París, existía una recomendación que pedía a sus habitantes conservar las fachadas de los edificios cada diez años (Vergès-Belmin y Bromblet, 2000: 234)².

En otros casos, la preocupación higienista y estética favoreció que se utilizasen determinados materiales constructivos. Así, por ejemplo, durante el siglo XIX en Inglaterra, se intentaba solucionar el problema de la contaminación utilizando materiales que retienen menos la suciedad y son más fáciles de limpiar como el ladrillo, la cerámica vidriada, el mármol o el vidrio (Ashurst 1994: 70). También se protegía el material, y en el mismo periodo, los estucos de la fachadas de Londres se cubrían con pintura al óleo para tratar de conservarlos (Brimblecombe 1992: 56).

Estas breves referencias, de las muchas existentes, muestran la preocupación que ha existido desde siempre sobre el aspecto de los edificios y monumentos al ser símbolos de un determinado lugar ${ }^{3}$.

Pero frente a la reflexión estética, al término limpieza se le añade el concepto de conservación. Ashurst (1994: 1) define su necesidad no solo por motivos estéticos sino para asegurar una mejor conservación de los materiales. Torraca (1995: 2-3) refiere también la conservación del material y la comprensión de la imagen, y lo plantea como un proceso que al eliminar sustancias dañinas intenta detener o minimizar la degradación, permite la observación del estado real del sustrato y facilita la aplicación de los tratamientos necesarios en otras etapas de intervención. Torsello (1995: 9-18) habla de limpieza como un resultado más que como un procedimiento, y la relaciona con acciones de sustraer, de sacar la suciedad y lo impuro de un objeto. 
Plantea reflexiones habituales al tratamiento: qué quitar, cómo, hasta dónde, etc.; así como, cuál es la finalidad y el porqué de la limpieza. Quaresima, Pasanisi y Scarsella (1995: 179) indican que la limpieza representa una fase particularmente importante y delicada ya que debe prever la eliminación de lo que es dañino para el material y debe garantizar el respeto a la estratigrafía histórica que caracteriza a cada monumento. El IPCE (AA.VV. 2013: 63-67) define como principal objetivo de la limpieza la conservación y preservación del bien cultural mediante la eliminación de la suciedad y de todos aquellos productos y elementos ajenos al soporte capaces de generar daño y/o impedir el reconocimiento del objeto, facilitando su preparación para posteriores tratamientos cuando estos sean necesarios.

En resumen, con una limpieza se intentan eliminar los depósitos superficiales y las manchas que son o pueden ser dañinas para la conservación de un material ${ }^{4} \mathrm{o}$ impiden su reconocimiento, debiendo garantizar el respeto a las diferentes etapas históricas que lo definen, y facilitando a su vez, la aplicación de los tratamientos que pueden ser necesarios en otras etapas de la intervención. A lo que hay que añadir que, como premisa principal, no debe provocar alteración de las superficies tratadas.

Se entiende, por tanto, que con la limpieza solo se debería eliminar lo que produce alteración físico-química. Pero como la estética final acostumbra a ser determinante, por ser la forma de presentar el monumento, durante la intervención se decidan, quizás, retirar algunos depósitos no perjudiciales para potenciar un momento determinando, un tratamiento concreto o porque han perdido su funcionalidad (aspectos que se deben evaluar individualmente para cada situación ${ }^{5}$ ).

La limpieza se muestra, de este modo, como un tratamiento no exento de riesgos, con diferentes planteamientos estéticos, técnicos o científicos, y en el que se realiza una modificación irreversible en el monumento. Y, como en la mayoría de los casos puede ser necesaria, se debe evitar alterar el sustrato y documentar todo el proceso como testimonio de los diferentes estratos que se retiran.

Como es sabido, estos requerimientos indican que la limpieza es una de las etapas más delicadas y que requiere un seguimiento muy preciso debido a su carácter irreversible, siendo normalmente la primera operación que se realiza. $Y$ al ser un proceso relacionado con la acción de sustraer, se necesita definir claramente el límite de la actuación.

Se perfila así, la reiterada necesidad de una fase previa de estudio con la que conocer la evolución histórica del monumento, las características de los materiales y de sus alteraciones (y de sus interrelaciones), así como, la realización de pruebas de limpieza, de su evaluación según procedimientos científicos y de la valoración crítica de los resultados según las exigencias de cada intervención.

Pero, debido a la variabilidad de situaciones que se suelen encontrar en un monumento, ¿estos estudios previos contemplan el seguimiento posterior en obra de los resultados?

\section{Evolución}

Las reuniones técnicas que se organizaron regularmente entre 1960-1980 son muestra del interés científico y de la colaboración que ha ayudado a la transformación del concepto de limpieza en Patrimonio Arquitectónico (Laurenzi Tabasso y Simon 2006: 68). La conservación-restauración de materiales constructivos evolucionó junto con las ciencias afines - historia, geología, biología, química, física, etc. - para comprender cómo se forman los diferentes depósitos superficiales, ya sean de alteración o de uso, y su interacción con los sustratos. Asimismo, el desarrollo de técnicas de análisis cada vez más precisas ha permitido un conocimiento mayor de lo que se necesita retirar para determinar y evaluar los resultados del tratamiento, y de cómo la limpieza puede afectar a los materiales.

Estos cambios han favorecido también el desarrollo de nuevas técnicas y nuevos equipos que facilitan al conservador-restaurador el control necesario en estas intervenciones. Las técnicas se han diversificado, y su combinación es normalmente el planteamiento habitual para conseguir los mejores resultados según el material y la suciedad a retirar.

De manera genérica, las técnicas de limpieza aconsejadas en la actualidad, y ya desde 1980, son: las limpiezas con agua nebulizada o con productos químicos aplicados en forma de apósito, las limpiezas mecánicas manuales como la microproyección de abrasivos a baja presión, y las limpiezas con láser. Existen otras menos usuales en obra basadas en la aplicación de ultrasonidos, y algunas tentativas en el uso de sistemas criogénicos, por el momento sin demasiado éxito. Se han ido descartando poco a poco limpiezas agresivas con agua a presión, con vapor de agua, con chorro de arena o con agentes químicos comerciales por la falta de control que suponen (Tabla 1) aunque en ocasiones, y por negligencia en la inspección de los trabajos, se siguen empleando.

Cada una de las técnicas actualmente aceptadas presenta también ventajas e inconvenientes, y unos parámetros de aplicación que se necesitan controlar (AA.VV. 2010). Aunque los métodos seleccionados sean selectivos y graduables, la complejidad de las variables de aplicación hace que no estén libres de efectos secundarios, por lo que su estudio y compresión ayuda a seleccionar el procedimiento más apropiado para cada caso concreto y su protocolo de aplicación.

Pero, ¿estos aspectos técnicos de los métodos de limpieza se han establecido en un protocolo detallado y de fácil seguimiento para todos los técnicos implicados en la intervención? 


\begin{tabular}{|l|l|l|l|}
\hline Mecanismo Efectividad genérica & Técnicas aconsejadas & Técnicas desaconsejadas \\
\hline
\end{tabular}

Permiten retirar depósitos superficiales que no han pene-

Métodos físicos. trado en la textura porosa del material.
Limpieza láser.

Limpieza mecánica manual.

Proyección-microproyección Limpieza con proyección a de abrasivos a baja presión. alta presión.

Limpieza por ultrasonidos.
Métodos mecánicos y físi- perficiales que no han peneco-mecánicos. material.

$\begin{array}{lll} & \begin{array}{l}\text { Permiten la limpieza de depó- } \\ \text { sitos solubles en el medio. }\end{array} & \begin{array}{l}\text { Limpieza con agua y cepillado. } \\ \text { Limpieza con agua nebulizada, }\end{array} \\ \text { Métodos químico-físicos } & \begin{array}{l}\text { Pueden actuar a cierta pro- } \\ \text { con disolventes no reacti- }\end{array} & \begin{array}{l}\text { vandidad. } \\ \text { vos (agua principalmente). }\end{array} \\ & \begin{array}{l}\text { Necesitan de una acción me- } \\ \text { cánica para eliminar residuos } \\ \text { disueltos. }\end{array} & \begin{array}{l}\text { Proyección-microproyección } \\ \text { de abrasivos a baja presión en }\end{array} \\ & \text { húmedo. }\end{array}$

Limpieza con agua a presión. Limpieza con vapor de agua.
Permiten la limpieza de depósitos solubles en el medio. Pueden actuar a cierta profundidad.

Necesitan de una acción mecánica para eliminar residuos disueltos.
Apósitos con diferentes agentes químicos de limpieza con formulaciones conocidas. Resinas de intercambio iónico.
Limpieza con agentes ácidos o alcalinos (químicos comerciales).
Métodos químico-físic
con agentes reactivos. 
ra sintética los métodos de limpieza que se consideran aceptados para superficies escultóricas, para paramentos exteriores no esculpidos sin particular concepción estética y los tratamientos para la vegetación. En el punto 4.1 recoge, además, unos estudios mínimos con los que evaluar el tratamiento.

La norma E1857-97-2004 (ASTM International 2004) recoge los procedimientos para la selección y evaluación de las técnicas de limpieza, indicando que en las superficies artísticas se precisa la supervisión de especialistas. Además de reseñar las diferentes técnicas con sus ventajas e inconvenientes - no aparece el láser - , establece la necesidad de las catas previas y la de determinar el procedimiento de ejecución y el de evaluación.

La norma BS 8221-1:2012-Part 1 (British Standards Institution 2012) recoge también los procedimientos para la selección y la evaluación de las diferentes técnicas, explicando brevemente los materiales constructivos más comunes y los riesgos que puede suponer cada tipo de limpieza. Recoge la necesidad de establecer tanto la competencia del contratista y la cualificación de los operarios asignados para llevar a cabo el trabajo propuesto, como la de los supervisores, que deben tener un conocimiento exhaustivo sobre los materiales y los procesos de limpieza.

En España, como referencia para los tratamientos de limpieza, existe el documento del IPCE (AA.VV. 2013: 63-67) ${ }^{8}$ y las recomendaciones AENOR (2009) ${ }^{9}$. El documento del IPCE contempla todos los procesos de intervención sobre materiales pétreos en Patrimonio Histórico, entre ellos la limpieza, y analiza los requisitos previos, las consideraciones y recomendaciones, y los diversos sistemas. Los documentos sobre limpieza de AENOR, estructurados en seis informes, se ocupan de los materiales constructivos en general, indicando que en el caso de edificios históricoartísticos se necesita extremar el seguimiento. El primero de estos informes recoge consideraciones generales y los cinco restantes se ocupan de los métodos más habituales, detallando los principios de actuación y los factores a controlar en cada uno de ellos - agua, mecánicos, láser, químico con aplicación en forma de solución y químico con aplicación en forma de apósitos - (Iglesias Campos et al. 2007; Iglesias Campos 2007).

Aparte de estas normas generales, existe una concreta sobre la limpieza láser (UNI 2006). Quizás por ser más específica, presenta un desarrollo en el que se establece de manera precisa un procedimiento y unas técnicas de evaluación.

Entre los grupos de trabajo sobre normalización, además de los organismos nacionales, existe la comisión europea CEN/TC 346 sobre Patrimonio Cultural (Cen-European Committee for Standardization 2009). Su objetivo es el de normalizar la terminología, los métodos de experimentación y análisis, la caracterización de materiales, los procesos de deterioro y las técnicas para la conservación, restau- ración y mantenimiento en bienes muebles e inmuebles. Dentro de los diferentes grupos de trabajo, y en concreto del WG3 - Evaluación de métodos y productos para trabajos de conservación -, existe un subgrupo - WI 011 - que tiene previsto encargarse de la limpieza con el fin de redactar futuros documentos que regulen los métodos de ensayo y análisis, tanto en laboratorio como in situ, para evaluar las metodologías de intervención ${ }^{10}$ (Fassina 2013: 8-26; Fassina 2006: 23). Todos los documentos normativos, recomendaciones o guías existentes en la actualidad siguen una línea similar en su desarrollo: objetivo, referencias, terminología, caracterización del sustrato y de la suciedad, criterios y técnicas de limpieza. Todos plantean aproximaciones generales y similares al problema porque recogen y sintetizan la bibliografía existente sobre el tema hasta el momento de su publicación; y todos consideran la necesidad de realizar catas previas y su evaluación posterior para definir el tratamiento.

Pero en este último aspecto es, quizás, donde más adolecen de especificidad. Si bien es complejo determinar el procedimiento de limpieza para los diferentes materiales de un monumento por la variedad de suciedades y de estados de conservación que pueden existir, en cambio, para su evaluación, donde según la técnica se pueden prever los posibles daños, no se llegan a concretar unos estudios que faciliten la información mínima necesaria para su valoración.

Todas las normativas refieren la necesidad de trabajos en laboratorio. La BS 8221-1:2012-Part 1 (BSI 2012) habla además de realizar mediciones colorimétricas y la Normal 20/85 (Commissione Normal-CNR-ICR 1986: 17) enumera procedimientos que incluyen medidas de color, absorción de agua, rugosidad y sales solubles, entre otros. Aun así, estos procedimientos de evaluación, resultan muchas veces difíciles de aplicar en obra o están pensados para unos estudios previos que no contemplan el seguimiento posterior.

Pero, ¿no sería necesario que se normalizasen también unas evaluaciones in situ que garantizasen la idoneidad de los procedimientos durante el proceso de intervención?

\section{Catas previas}

La definición de limpieza, su irreversibilidad, sus riesgos y sus requerimientos técnicos, reafirman la necesidad de realizar unas catas previas, evaluadas posteriormente, para determinar los tratamientos más apropiados para cada caso concreto ${ }^{11}$.

Se muestra así la necesidad de estudiar la limpieza según los procedimientos habituales de las ciencias experimentales en las que, para reproducir un ensayo, se precisan mantener constantes los parámetros que han intervenido en su consecución. Y esto se plantea, además, porque frecuentemente en el estudio preliminar de cualquier limpie- 

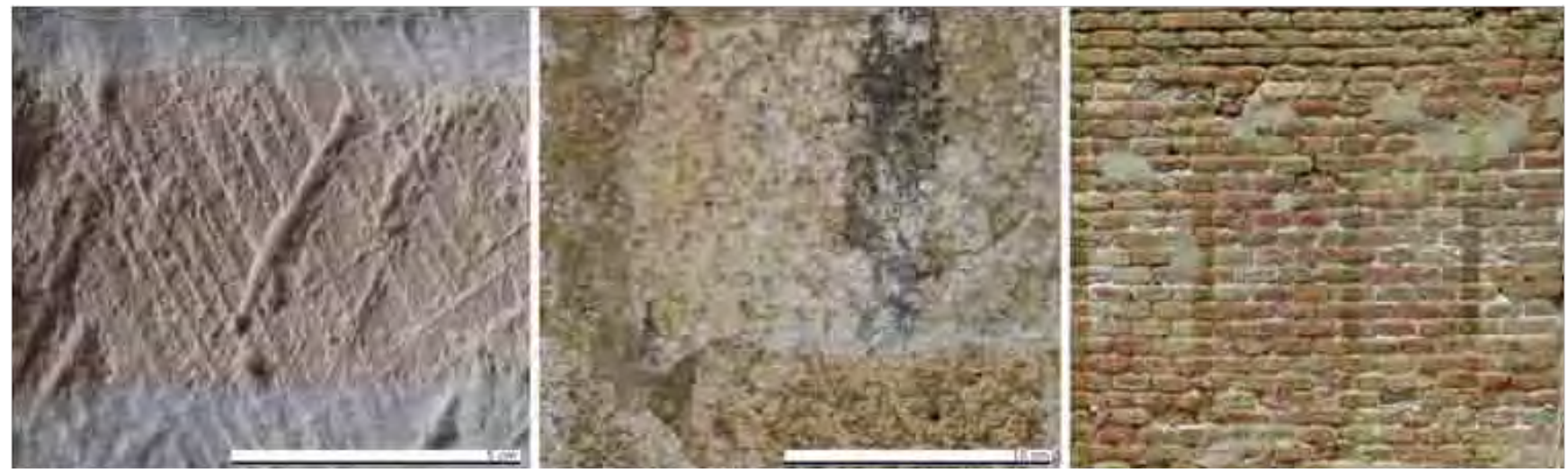

Figura 1. Catas previas. Eliminación de encalados - caliza micrítica- (izquierda), retirada de revestimientos - enlucido pintado - (centro) y limpieza de depósitos superficiales de suciedad compactada - ladrillo manual - (derecha). (M.A. Iglesias Campos)

za - catas previas como ensayo científico - las pruebas y la ejecución del trabajo suelen realizarlas equipos diferentes.

Metodológicamente, como ya es sabido y aunque no sea siempre así en la realidad, antes de proceder con los ensayos de limpieza, se necesita estudiar la historia del monumento para comprender su evolución ${ }^{12}$. El estudio de su situación actual, incluyendo materiales constructivos, alteraciones, depósitos naturales, depósitos artificiales, y sus relaciones, facilita datos relevantes para seleccionar los métodos de limpieza y para determinar críticamente los depósitos artificiales que tienen o no relevancia en el conjunto de la obra según las exigencias de cada intervención ${ }^{13}$.

A partir de estos informes que definen los parámetros del material y de la suciedad se seleccionan los métodos a ensayar, porque de los datos que se obtienen, algunas técnicas podrían descartarse desde el principio. Estas pruebas, realizadas preferentemente en obra o en laboratorio, donde se aplicarán de forma similar a la que se utilizará en el monumento (Iglesias-Campos, García Fortes y Prada Pérez, 2014; Iglesias-Campos, 2014), facilitan una información que agiliza el trabajo de los diferentes equipos implicados en la intervención.

Las catas en obra permiten, además, visualizar el grado la limpieza que se intenta conseguir, y su tamaño se relaciona con la superficie donde se realizan. Así, en un volumen escultórico tenderán a ser lo más pequeñas posibles y, en un paramento, deberán tener un tamaño que permita observar el aspecto final, incluyendo los morteros de junta [Figura 1]. Esta metodología permite también establecer unas zonas de referencia en obra que sirven de guía para comprobar que los trabajos se ejecutan según lo determinado en los estudios. Así, si en algún momento no se consigue el mismo acabado - por defecto o exceso - el responsable de la limpieza podrá consensuarlo con el resto de los técnicos antes de continuar.

Evidentemente, las limpiezas ensayadas no se podrán re- producir con la misma exactitud en toda la superficie del monumento ya que estas catas, por previas, se acostumbran a realizar en las partes bajas del monumento al no poder acceder a su totalidad. Aun así, su estudio permite establecer un rango de valores seguros con los que reducir el riesgo del tratamiento, aunque es aconsejable su revisión una vez iniciada la obra.

Al principio de este apartado, se ha relacionado cata previa y ensayo científico porque en ambos se necesitan mantener constantes los parámetros que han intervenido en su consecución; y durante el desarrollo, se han referido unos estudios previos con los que se definen los parámetros del material y de la suciedad - lo que indica que el protocolo se ha establecido -.

Pero, ¿se han determinado detalladamente los parámetros propios de cada técnica que han de tenerse en cuenta para definir y reproducir el tratamiento y su protocolo de ejecución?

\section{Evaluación}

Se ha reiterado la necesidad de evaluar las catas previas para comprobar que no se han producido modificaciones físico-químicas en el material, y determinar la inocuidad y efectividad de la limpieza.

Habitualmente, y la mayoría de la veces por falta de presupuesto, las evaluaciones se hacen en obra mediante un análisis visual de los técnicos implicados. Estas valoraciones suelen ser parciales ya que, para determinar un tratamiento como inadecuado, el daño suele ser muy evidente - pérdida de material, pátina, policromía, etc. -. En algunos casos se suelen completar con observaciones con lupa, microscopio portátil o macrofotografía que, aunque más precisas, proporcionan datos cualitativos parciales.

En obra también se pueden comparar medidas de dureza, de rugosidad, de color y brillo, de absorción de agua 

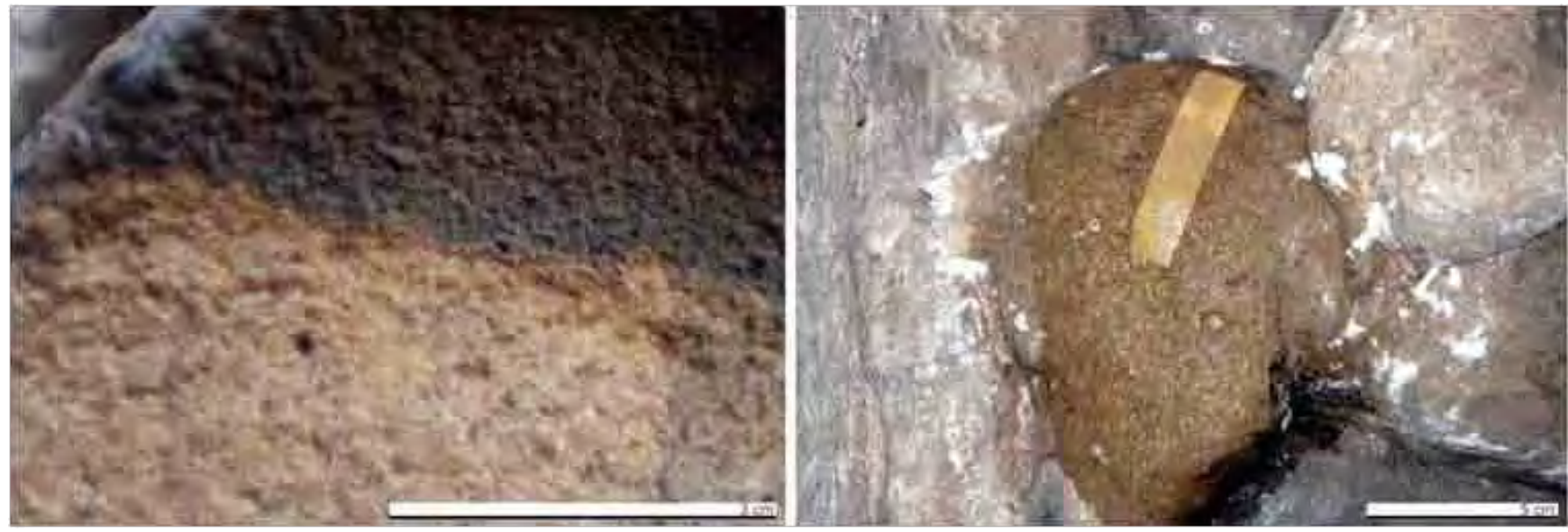

Figura 2. Evaluación in situ. Macrofotografía de cata de limpieza láser (izquierda) y evaluación de variaciones de pH mediante tiras reactivas tras limpieza química con apósitos (derecha). (M. Á. Iglesias Campos)
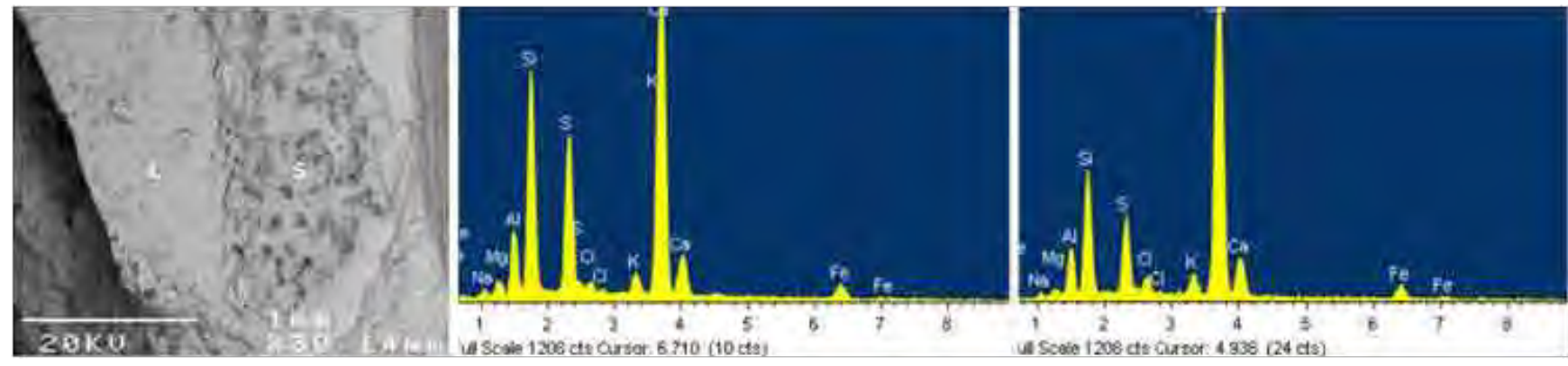

Figura 3. Imagen SEM-BSEI (Scanning Electron Microscopy-Back Scattered Electron Image) de cata de limpieza: zona tratada - L - y sin tratar - S - (izquierda). Espectros SEM-EDX (Scanning Electron Microscopy-Energy Dispersive X-ray spectroscopy). Disminución de los principales elementos de una costra negra sobre sustrato carbonatado (centro) en comparación con la zona tratada y limpia (derecha). (M. Á. Iglesias Campos)

por capilaridad, de $\mathrm{pH}$ y de sales solubles (AA.VV. 2003: 71; Vergès-Belmin y Bromblet 2000: 270), valores que añaden información a los registros visuales. A pesar de la falta de precisión, su ventaja radica en el hecho de no necesitar muestra [Figura 2].

En laboratorio, y a partir de muestra, las técnicas y los equipos de evaluación son diversos y se puede determinar con elevada precisión los efectos del tratamiento. El microscopio estereoscópico y el microscopio óptico petrográfico permiten interpretar estratigrafías, estudiar comparativamente los cambios morfológicos en la superficie y comprobar el grado de eliminación de la suciedad. Estos datos se pueden profundizar y corroborar con estudios más detallados mediante microscopia electrónica de barrido SEM-EDX (Scanning Electron Microscopy-Energy Dispersive X-ray spectroscopy), con la que además de obtener imágenes de elevada resolución, se pueden estudiar los cambios que se han producido con el tratamiento al comparar la composición elemental de la superficie [Figura 3].

Otras técnicas, como la difracción de rayos X - XRD (X-ray Diffraction) - para conocer la composición de las capas de suciedad o del sustrato, o la espectroscopia de infrarrojo - FTIR (Fourier Transform Infrared Spectroscopy) - para ana- lizar cambios en compuestos orgánicos e inorgánicos y en las fases minerales, ayudan a comprender en profundidad las modificaciones que con la limpieza se han producido.

La necesidad cada vez mayor de evaluaciones in situ que reduzcan la toma de muestras, ha favorecido en los últimos años el desarrollo, y en algún caso la comercialización, de instrumental con el que obtener información sobre las transformaciones superficiales provocadas por la limpieza (Weinhold et al. 2007), a la vez que se investigan metodologías y protocolos que permitan profundizar en las valoraciones (Papadakis, Loukaiti y Pouli 2010; Delegou et al. 2008; Kapsalas et al., 2007; Moropoulou et al. 2007). Existen también equipos portátiles con técnicas no destructivas o semidestructivas que permiten analizar, monitorizar y obtener datos precisos sobre el tratamiento (Blanco Domínguez 2010). Aun así, la evolución y el desarrollo de estos aparatos es lento; sus costes, elevados; y muchas veces resultan difíciles de manipular en superficies verticales; factores, todos ellos, que restringen su empleo.

Por tanto, y según la información que se necesite, las técnicas de análisis disponibles son numerosas, pero la necesaria racionalización en la evaluación de la limpieza, por coste y por tiempo, debe de basarse en comprobar el estado 
del material antes y después del tratamiento para verificar que no se ha provocado o favorecido su alteración. La lógica indica que, al igual que las limpiezas, las técnicas de evaluación deben de utilizarse de manera gradual, de las más sencillas a las más complejas, hasta obtener la información que valide o invalide el tratamiento.

Una vez evaluadas las pruebas de limpieza se dispone de información sobre cómo determinados tratamientos han actuado en una superficie de pequeño tamaño según los parámetros seleccionados para el ensayo, tan pequeña como sea la muestra analizada.

Pero, ¿se ha establecido cómo llevar el control del tratamiento durante la limpieza general del monumento, y a poder ser, sin un coste excesivo?

\section{Conclusiones}

Desde hace años, aunque dependiendo de la entidad del monumento, en las intervenciones en Patrimonio Arquitectónico se realiza una fase previa de estudio según procedimientos científicos que documenta la evolución histórica, los materiales, las alteraciones y su interrelación, y donde se evalúan las catas previas de limpieza. La información que se obtiene es fundamental para definir la intervención - limpieza ideal -.

Estos datos, sin embargo, son representativos de evaluaciones puntuales a partir de muestra de pequeño tamaño, y no se acostumbra a plantear un seguimiento posterior en obra - limpieza real -. Así, en la mayoría de las intervenciones, y al no contemplarse económicamente en las partidas presupuestarias, el conservador-restaurador tiene que asumir la idoneidad del tratamiento a partir de su observación visual, su conocimiento y su experiencia, sin contar con todo el apoyo deseable.

Partiendo de un planteamiento científico que valide las premisas metodológicas y críticas de la intervención, y debido a las características del Patrimonio Arquitectónico, sería necesario llevar un seguimiento experimental que verificase las modificaciones realizadas en el tratamiento para ajustarlo a la variabilidad de estados de conservación que suelen existir. Esta metodología, en cambio, supondría un coste que ni la intervención por cuantía y tiempo, ni el Patrimonio Arquitectónico por cantidad de muestra, se pueden permitir; ya que a pesar de existir técnicas de evaluación in situ, no se suelen utilizar ni en la limpieza ideal ni en la real por su escasa disponibilidad o por la inversión necesaria.

Del mismo modo, a pesar de considerarse necesario el estudio del tratamiento, no existe una normativa, recomendación o protocolo, que especifique qué parámetros de las técnicas de limpieza se deben detallar por su influencia en el proceso, ni qué estudios mínimos documentan e informan de los resultados. Existe, por tanto, la necesidad de establecer una metodología de ensayo y evaluación que sintetice los preceptos de la limpieza ideal - ensayos y evaluaciones de carácter experimental - y las necesidades de la limpieza real - aplicación y seguimiento de la intervención con un coste asumible - y que establezca un protocolo detallado para todos los técnicos implicados en la intervención.

La solución más realista, por el momento, es que el conservador-restaurador recoja y cuantifique en memorias pormenorizadas y contempladas económicamente en las partidas de obra, los parámetros del tratamiento, y analice las superficies con técnicas fácilmente disponibles, y de bajo coste, que eviten o reduzcan la toma de muestras, con el objetivo de documentar todo el proceso para consultas y revisiones posteriores. Su formación y experiencia son determinantes para obtener el resultado más adecuado, ya que cualquier método de limpieza en manos inexpertas, al igual que una limpieza sin documentar, supone un riesgo para el monumento.

Y esto plantea también la necesidad de establecer normativamente la competencia del contratista y la cualificación de los supervisores y operarios que intervienen en la obra, que deberían de tener un amplio conocimiento sobre los materiales y procedimientos de limpieza que aplican, así como, del modelo de memoria que se debería entregar.

Los comentarios, preguntas y conclusiones, que en este caso se refieren a la limpieza por ser el tratamiento estudiado en el trabajo, bien podrían extrapolarse al resto de intervenciones (rejuntado, reintegración/reposición de volúmenes, consolidación, protección, etc.) que se realizan en el Patrimonio Arquitectónico.

\section{Notas}

[1] Con limpieza ideal y limpieza real se pretende reflejar la dualidad que existe en la mayoría de las intervenciones. Con limpieza ideal no se quiere, ni se intenta, indicar la existencia de un modelo perfecto y aplicable a cualquier intervención, sino que hace referencia a un tratamiento analizado, estudiado, razonado, y por tanto, objetivamente recomendable.

[2] Estas anotaciones muestran también la vinculación apuntada entre limpieza e higiene.

[3] Actitud que perdura en la actualidad. Basta con revisar las intervenciones que se realizan para la celebración de un acontecimiento relevante o las recomendaciones municipales de acabado en fachadas restauradas que, en esencia, mantienen el mismo carácter propagandístico.

[4] El término material o material constructivo se emplea en este trabajo con un significado amplio e incluye materiales constructivos naturales, artificiales conglomerados y artificiales térreos, independientemente de su uso y función en la obra, y los recubrimientos cromáticos y pátinas naturales y/o artificiales que 
pudieran existir (que serían, en este caso, los materiales a limpiar).

[5] Estas decisiones sobre el mantenimiento o la retirada de determinados depósitos superficiales para presentar públicamente el edificio, aunque actualmente meditadas en la mayoría de los casos, suponen una cierta subjetividad de criterio y una vinculación a las tendencias conceptuales del momento, aspectos que, tanto el desarrollo científico como el normativo pretende objetivar.

[6] Aun así, una vez que la norma está establecida y las empresas la consideran importante para la calidad de su trabajo, puede convertirse en exigencia de mercado.

[7] No se considera norma porque no está avalada por un Organismo Normalizador reconocido, que en su caso sería UNI.

[8] En este documento —revisión, actualización y ampliación del anterior (AA.VV. 2003)—, además de establecerse los criterios de intervención, se incluye una detallada descripción y clasificación de los indicadores de deterioro en materiales pétreos.

[9] Aunque aquí solo se citan las normas publicadas por AENOR relativas a la limpieza, este organismo ha publicado en los últimos años diferentes documentos normativos sobre diagnóstico y conservación del patrimonio cultural (AA.VV. 2013: 104-105).

[10] El WG3 del CEN/TC 346 está redactando recomendaciones sobre los sistemas de evaluación de los diferentes métodos de limpieza para materiales inorgánicos porosos y sobre la limpieza láser (AA.VV. 2013: 77), y el WG2 - Materiales constituyentes del patrimonio cultural - ha publicado algunas normas sobre métodos de análisis con las que caracterizar y evaluar el estado de conservación de materiales inorgánicos (Fassina 2013: 15-17) que pueden ser de utilidad para comparar modificaciones provocadas por determinados tratamientos de limpieza.

[11] De todos modos, el estudio de estos ensayos previos, cuya necesidad está ampliamente aceptada por todas las partes implicadas en la intervención, es una realidad que solo suele materializarse en contadas excepciones porque, en muchos casos, los estudios previos de limpieza se realizan de forma paralela a la intervención sin el tiempo necesario y suficiente para profundizar en los resultados.

[12] En esta etapa es muy importante recoger la información sobre tratamientos anteriores de limpieza, y especialmente los tratamientos químicos por los residuos que pudieran haber quedado en el material.

[13] La práctica habitual de cartografiar materiales y alteraciones, y en este caso exclusivamente los depósitos superficiales, permite visualizar de manera global los cambios cromáticos que reflejan la existencia de suciedades, cuantificar la superficie afectada y establecer los diferentes grados de deterioro. Esta documentación gráfica, junto con los resultados de los estudios previos, permite comprender además cómo se ha ensuciado el monumento para prevenir o reducir el reensuciamiento posterior a la intervención.

\section{Bibliografía}

AA.VV. (2013). Proyecto Coremans: Criterios de intervención en materiales pétreos. Madrid: Secretaría General Técnica. Centro de Publicaciones. Ministerio de Educación, Cultura y Deporte. $<$ https://sede.educacion.gob.es/publiventa/descargas.action?f codigo $=14516$ C \&codigoOpcion $=1>$. [consulta 08/03/2014].

AA.VV. (2010). La tecnología láser y otros métodos de limpieza y restauración de materiales pétreos. Gisbert Aguilar, J. (ed.). Documentos para la caracterización y restauración del patrimonio histórico. Cuadernos Arbotante n 1. Zaragoza: Libros Pórtico.

AA.VV. (2003). "Criterios de intervención en materiales pétreos: conclusiones de las Jornadas celebradas en febrero de 2002 en el IPHE". Bienes Culturales: Revista del Instituto del Patrimonio Histórico Español, 2: 1-34 <http://ipce.mcu.es/pdfs/CriteriosMaterialesPetreos.pdf $>$. [consulta 25/11/2013].

AA.VV. (2000). Carta de Cracovia 2000. Principios para la conservación y restauración del patrimonio construido. <http://www.ge-iic. com/files/Cartasydocumentos/Carta_de_Cracovia.pdf $>$. [consulta $25 / 11 / 2013]$

AA.VV. (1931). Carta de Atenas. <http://www.ge-iic.com/files/Cartasydocumentos/ 1931cartadeatenas.pdf>. [consulta 25/11/2013].

AENOR (2009). UNE 41806-1:2009 IN a UNE 41806-5-2:2009 IN. Conservación de edificios. Limpieza de elementos constructivos. Partes 1 a 5-2.

AENOR (2002). Normalización. <http://www.aenor.es/aenor/normas/normas/normalizacion.asp >. [consulta 25/11/2013]

ANDREW, C. (1992). "Towards an aesthetic theory of building stone". En Stone cleaning and the nature, soiling and decay mechanisms of stone, London: Donhead Publishing, 63-81.

ASHURST, N. (1994). Cleaning historic buildings. Vol. 1. Substrates, soiling and investigation. London: Donhead Publishing.

ASTM INTERNATIONAL. (2004). E1857-97(2004). Standard guide for selection of cleaning techniques for masonry, concrete and stucco surfaces.

BLANCO DOMÍNGUEZ, M. (2010). "Caracterización de tratamientos de limpieza en materiales pétreos". En La tecnología láser y otros métodos de limpieza y restauración de materiales pétreos. Documentos para la caracterización y restauración del patrimonio histórico. Cuadernos Arbotante n 1. Gisbert Aguilar, J. (ed.). Zaragoza: Libros Pórtico, 15-27.

BRANDI, C.; DE ANGELIS D'OSSAT, G. (1972). Carta del Restauro. <http://www.ge-iic.com/files/ Cartasydocumentos/Carta_del_ restauro.pdf>. [consulta 25/11/2013].

BRIMBLECOMBE, P. (1992). "A brief history of grime: accumulation and removal of soot deposits on buildings since the 17th century". En Stone cleaning and the nature, soiling and decay mechanisms of stone, London: Donhead Publishing, 53-62.

BRITISH STANDARDS INSTITUTION (2012).BS 8221 - 1:2012. Code of practice for cleaning and surface repair of buildings; Part 1 Cleaning of natural stones, brick, terracotta and concrete.

CEN-EUROPEAN COMMITTEE FOR STANDARDIZATION (2009). CEN/TC 346. Conservation of cultural property. <http://www.cen. eu/CEN/Sectors/TechnicalCommitteesWorkshops/CENTechnical- 
Committees $/$ Pages/TCStruc.aspx ? param $=411453 \&$ title $=$ CEN\%2F TC+346>. [consulta 25/11/2013].

CIRUJANO, C.; SCHOEBEL, A. (2005). "Calidad en la conservación y restauración del patrimonio artístico". En II Congreso del GEIIC. Investigación en Conservación y Restauración, Barcelona: Universidad de Barcelona, 481-484.

COMMISSIONE NORMAL. CNR-ICR. (1986). Normal 20/85. Interventi conservativi.

DELEGOU, E.T.; AVDELIDIS, N. P.; KARAVITI E.; MOROPOULOU A. (2008). "NDT\&E techniques and SEM-EDS for the assessment of cleaning interventions on Pentelic marble surfaces". X-Ray Spectrometry, 37, 4: 435-443.

ECCO (2002). Directrices profesionales: la profesión y su código ético. <http://www.ge-iic.com/files/ Cartasydocumentos/2002_directrices_\%20profesionales_de_ecco_la_profesion_y_su_codigo_etico.pdf>. [consulta 25/11/2013].

ENCORE (2012). European Network for Conservation-Restoration Education. <http://www.encore-edu.org/>. [consulta 25/11/2013].

FASSINA, V. (2013). "The activity of CEN TC 346-Conservation of Cultural Heritage". Ge-conservación, 5, 8-26. <http://ge-iic.com/ ojs/index.php/revista/article/view/194/pdf>. [consulta 08/03/2014].

FASSINA, V. (2006). "CEN/TC 346. Conservation of cultural property". En Jornada Técnica: Informe AENOR de diagnóstico de edificios para la intervención en el patrimonio arquitectónico. Madrid: RECOPAR-ETSAM, 12-23. <http://www.aq.upm.es/Departamentos/Construccion/recopar/v2/es2/docs/ev_0306.pdf>. [consulta 25/11/2013].

ICOM (1984). El conservador-restaurador: una definición de la profesión. <http://www.ge-iic.com/files/Cartasydocumentos/1984_El_conservador-restaurador_una_definicion_de_la_ profesion.pdf>. [consulta 25/11/2013].

IGLESIAS CAMPOS, M.; AZORÍN LÓPEZ, V.; SÁNCHEZ DE ROJAS, M.I.; FRÍAS ROJAS, M. (2008). Hacia una normalización de la limpieza de fachadas de edificios. En Actas de la III Bienal de Restauración Monumental. Sobre la des-restauración, Sevilla: Junta de Andalucía, Consejería de Cultura, Academia del Partal, 265-271.

IGLESIAS CAMPOS, M.; AZORÍN LÓPEZ, V.; GARCÍA PASCUA, N.; SÁNCHEZ DE ROJAS, M.I.; FRÍAS ROJAS, M. (2007). Limpieza de superficies exteriores de elementos constructivos: proyecto de norma AENOR. En Jornada J3. CEMCO RECOPAR. Limpieza de superficies exteriores de elementos constructivos. Madrid: (IETCC) Instituto de Ciencias de la Construcción Eduardo Torroja, I.1-I.24.

IGLESIAS CAMPOS, M. (2007). Técnicas de intervención para la limpieza de fachadas: proyecto de informe AENOR. En Jornada J3. CEMCO RECOPAR. Limpieza de superficies exteriores de elementos constructivos. Madrid: (IETCC) Instituto de Ciencias de la Construcción Eduardo Torroja, II.1-II.13
IGLESIAS-CAMPOS, M.Á.; GARCÍA FORTES, S.; PRADA PÉREZ, J.L. (2014). "Influence of projection angle in sandblasting cleaning on detrictic stone materials in Architectural Heritage". Materiales de Construcción. 64(314): e021.

IGLESIAS-CAMPOS, M.Á. (2014). “Effects of mechanical cleaning by manual brushing and abrasive blasting on lime render coatings on Architectural Heritage". Materiales de Construcción. 64(316): e039.

KAPSALAS, P.; MARAVELAKI-KALAITZAKI, P.; ZERVAKIS, M.; DELEGOU E.T.; MOROPOULOU A. (2007). “Optical inspection for quantification of decay on stone surfaces". NDT \& E International, 40, 1:2-11.

KOLLER, M. (2000)."Surface cleaning and conservation". The Getty Conservation Institute Newsletter, 15, 3: 5-9. <http://www.getty. edu/conservation/publications_resources/newsletters/pdf/ v15n3.pdf>. [consulta 25/11/2013].

LAURENZI TABASSO, M.; SIMON, S. (2006). “Testing methods and criteria for the selection/evaluation of products for the conservation of porous building materials". Reviews in Conservation, 7 : 67-82.

MOROPOULOU, A.; DELEGOU, E.T.; VLAHAKIS V.; KARAVITI E. (2007). "Digital processing of SEM images for the assessment of evaluation indexes of cleaning interventions on Pentelic marble surfaces". Materials Characterization, 58, 11-12: 1063-1069.

PAPADAKIS, V.; LOUKAITI, A.; POULI, P. (2010). "A spectral imaging methodology for determining on-line the optimum cleaning level of stonework". Journal of Cultural Heritage, 11, 3: 325-328.

QUARESIMA, R.; PASANISI, A.; SACARSELLA, C. (1995). “Patine di ossalati e croste nere: indicazioni su possibili interventi conservativi". En La pulitura delle superficie dell'architettura, Sciencia e Beni Culturali XI. Padova: Librería Progetto Editore, 179-186.

REAL ACADEMIA ESPAÑOLA (s.a) Diccionario de la lengua española. <http://rae.es/recursos/diccionarios/ drae>. [consulta 25/11/2013].

TORRACA, G. (1995). “La pulitura delle facciate in pietra: necessità della conservazione e immagine del monumento". En La pulitura delle superficie dell'architettura, Sciencia e Beni Culturali XI. Padova: Libreria Progetto Editore, 1-7.

TORSELLO, B. P. (1995). “La pulitura delle superfici: alcune domande e una reflessione". En La pulitura delle superficie dell'architettura, Sciencia e Beni Culturali XI. Padova: Libreria Progetto Editore, 9-18. UNI (2006). Beni Culturali. Materiali lapidei naturali ed artificiali. Pulitura con tecnologia laser. UNI 11187.

VERGÈS-BELMIN, V.; BROMBLET, P. (2000). “Le nettoyage de la pierre". Monumental. Revue scientifique et technique des Monuments Historiques, 220-273.

WEINHOLD W.P.; WORTMANN A.; DIEGELMANN C.; PUMMER E.; 
PASCUA N.; BRENNAN Th.; BURKHARDT R.; GORETZKI L. (2007). "Optosurf measurement tecnhology for use on surfaces of historic buildings and monuments cleaned by laser". En Lasers in the Conservation of Artworks. Lacona VI, Berlin Heidelberg: Springer, 593-599.

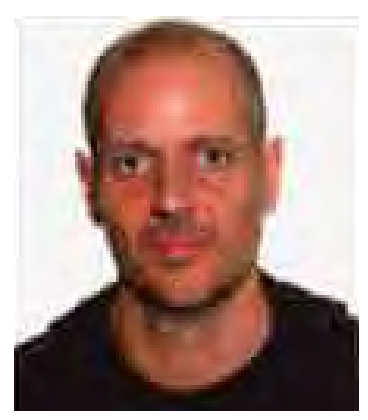

\section{Manuel Ángel Iglesias Campos}

Facultat de Belles Arts (Universitat de Barcelona)

Pau Gargallo, 4

08028 Barcelona

934034076

Doctor en Conservación-Restauración por la Universidad de Barcelona. Actualmente es profesor de la Secció de Conservació-Restauració de la Facultat de Belles Arts (Universitat de Barcelona) y colabora como docente en diferentes Másteres, Postgrados y cursos profesionales sobre conservación del Patrimonio Histórico. Su línea de investigación se centra en el tratamiento de materiales del Patrimonio Arquitectónico y Monumental.

Artículo enviado el 6/12/2013

Artículo aceptado el 21/04/2014 


\title{
.
}

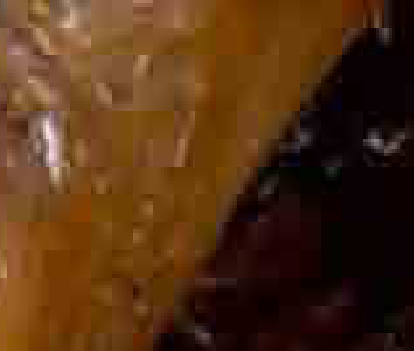

\section{Pastas de relleno para reintegración volumétrica de esculturas en cera. Primeros resultados experimentales}

\author{
Nerea del Moral y Alicia Sánchez Ortiz
}

Resumen: La conservación de esculturas en cera supone un gran reto para el restaurador al tratarse de un material que presenta diversas dificultades derivadas tanto de sus propiedades físicas como de sus procesos de envejecimiento natural. Con el tiempo, los propios materiales adicionados a la cera para la preparación de las pastas de modelar sufren transformaciones químicas que ocasionan un aumento de la fragilidad en este tipo de objetos. Este hecho unido a la acción de agentes de degradación externos, sobre todo cambios bruscos de temperatura en el ambiente expositivo, puede conllevar la formación de micro-fisuras y grietas, y en grado extremo la existencia de fracturas y pérdidas del material, haciendo necesario efectuar tratamientos de reintegración en las zonas dañadas.

Este trabajo muestra los primeros resultados obtenidos tras someter a estudio ciertas características físicas de la cera, a fin de desarrollar un método científico de intervención en lagunas. Se ha partido de ocho posibles pastas de relleno para analizar sus intervalos de fusión y su comportamiento tras ser sometidas a envejecimiento artificial, con el objetivo de encontrar una pasta idónea para la restauración de los modelos anatómicos en cera de la colección Javier Puerta de la Universidad Complutense de Madrid. Los resultados que se exponen podrían ser aplicables a otras colecciones de ceroplástica y/o esculturas en cera.

Palabras clave: reintegración, ceroplástica, protocolo de investigación, pasta cerosa, envejecimiento artificial, intervalo de fusión.

\section{Filler dough for volumetric reintegration of wax sculptures. First experimental result.}

Abstract: The preservation of wax sculpture is a great challenge for the conserver because it's a material that has serious difficulties a arising from both its physical properties and its processes of natural aging. After the passage of time, materials added to the wax to prepare modelling pastes undergo chemical alterations that makes these objects more fragile. This, combined with external degradation agents, specially severe temperature changes, at the exposition environment, can encourage the appearance of micro-fissures and cracks, and in severe cases fractures or material loss, making neccesary the reintegration of the damaged areas.

This paper presents our first experimental work to begging to develop a scientific methodology for the intervention of gaps in wax objects taken into account the physical characteristics of the material. We have selected eight different grouts pastes analyzing their stability and response to artificial aging and specific melting ranges, with the aim of finding a suitable paste for the restoration of the anatomical wax models of the Javier Puerta Collection of the Complutense University of Madrid. The results set forth may be applicable to other collections of ceroplastics and/or artifacts in wax.

Key words: reintegration, ceroplastics, research protocol, wax paste, accelerated aging, melting range.

\section{Massas de preenchimento para reintegração volumétrica de esculturas em cera. Primeiros re- sultados experimentais.}

Resumo: A conservação de esculturas em cera representa um grande desafio para o conservador-restaurador, ao tratar-se de um material que apresenta diversas dificuldades derivadas, tanto das suas propriedades como dos seus processos de envelhecimento natural. Com o passar do tempo, os próprios materiais adicionados à cera para a preparação das pastas de modelar, sofrem transformações químicas que causam um aumento da fragilidade neste tipo de objectos. Este facto, em conjunto com a acção dos agentes de degradação externos, sobretudo alterações bruscas de temperatura no ambiente expositivo, pode propiciar a formação de micro fissuras e 
de gretas e, em caso extremo, o aparecimento de fracturas e perdas de material, sendo necessário realizar tratamentos de reintegração nas áreas danificadas.

Este trabalho mostra os primeiros resultados obtidos depois de submeter a estudo determinadas características físicas da cera, com o objectivo de desenvolver um método científico de intervenção em lacunas. Partiu-se de oito possíveis pastas de preenchimento para analisar os seus intervalos de fusão e o seu comportamento, após serem submetidas a envelhecimento artificial, com o objectivo de encontrar uma pasta idónea para o restauro dos modelos anatómicos em cera da colecção Javier Puerta da Universidade Complutense de Madrid. Os resultados que se apresentam poderão ser aplicados a outras coleções cero-plásticas e/ou a artefactos de cera.

Palavras-chave: reintegração, cero-plástica, protocolo de investigação, pasta cerosa, envelhecimento artificial, intervalo de fusão.

\section{Introducción}

Dentro de la investigación sobre la ceroplástica ocupa un lugar destacado el conocimiento de las técnicas de elaboración de modelos anatómicos por los diferentes talleres europeos. A la escasez de documentos de época conservados al respecto, se suma el secretismo con el que trabajaron los artífices sus creaciones en estrecha colaboración con los anatomistas más prestigiosos del momento. Existen, a pesar de ello, escuetas descripciones en recetarios de época que permiten disponer de información sobre el tipo de ceras, resinas naturales, grasas animales, pigmentos y otros aditivos que se incorporaban a las pastas, así como breves anotaciones sobre las técnicas de manufactura ajustadas a los requerimientos del modelo a reproducir'. Parece que el recelo con el que los "cero-escultores" del siglo XVIII y principios del XIX protegieron su saber-hacer, mantiene su vigencia en

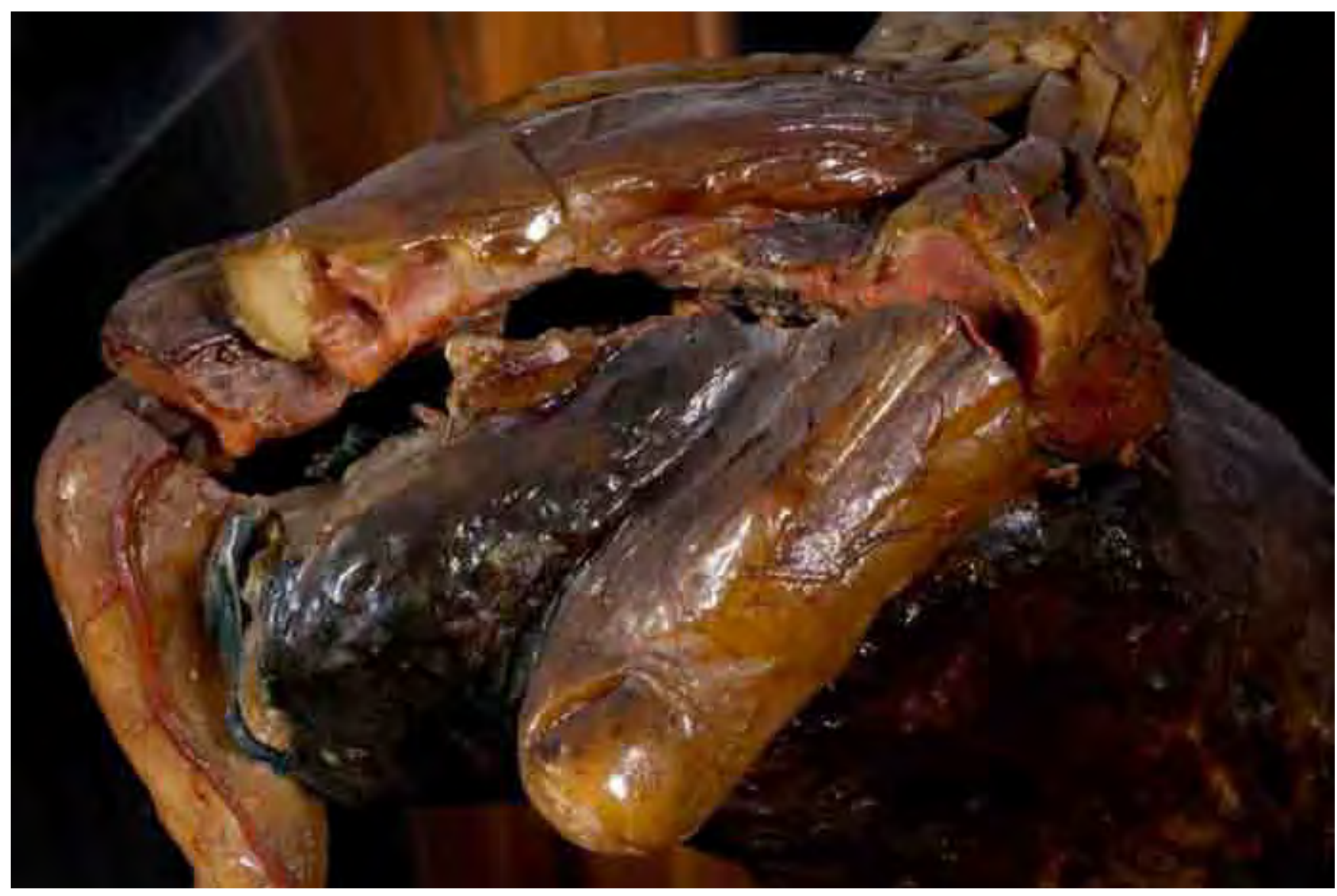

Figura 1. En esta mano se observa una rotura en los dedos con pérdida de materia lo que ha generado la aparición de una laguna volumétrica. Imagen de Luis Castelo. Modelo despellejado de tamaño natural de la colección del Museo de Anatomía Javier Puerta. UCM. Siglo XVIII. 


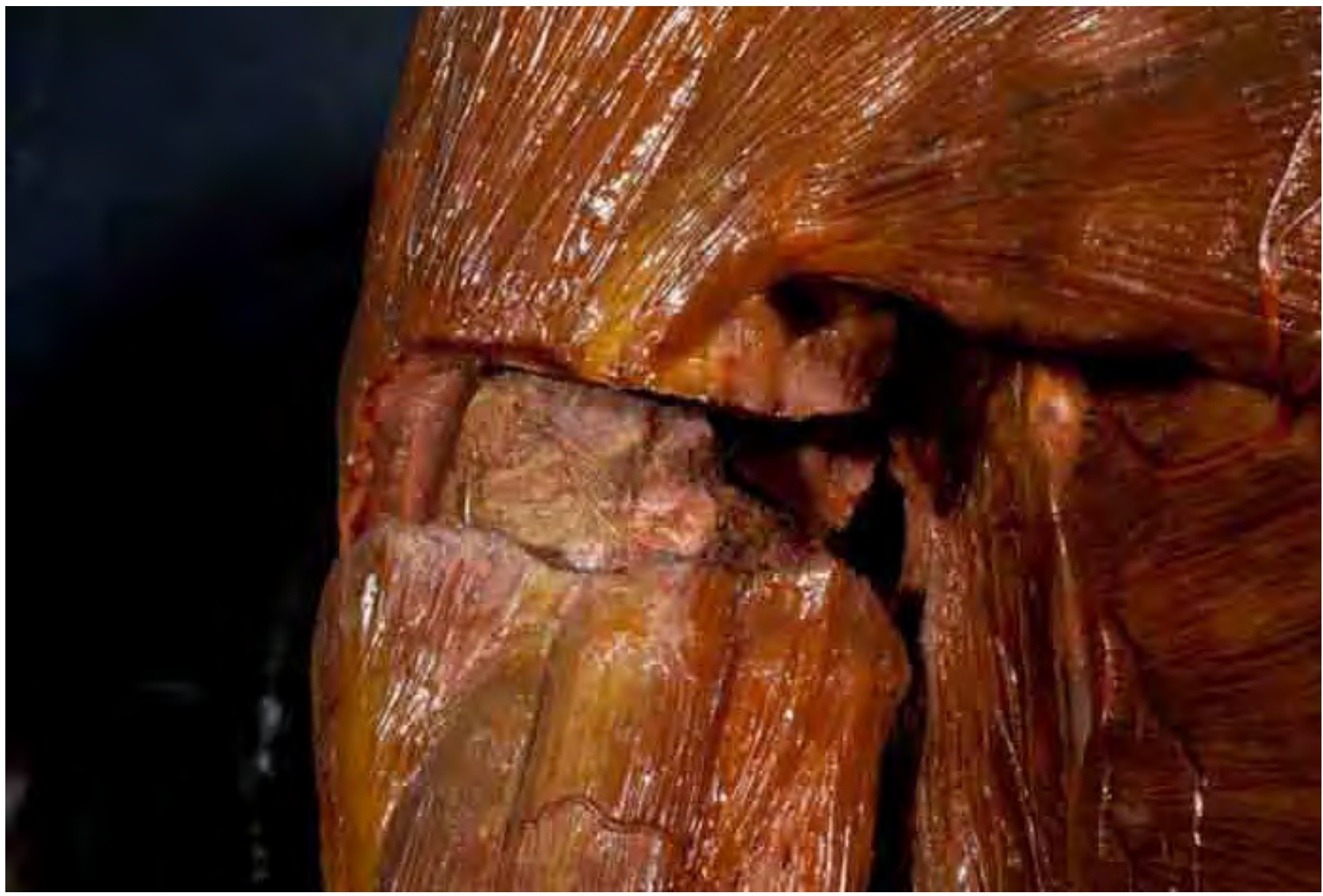

Figura 2. Debido a los procesos de dilatación y contracción, este modelo anatómico Colección Museo de Anatomía "Javier Puerta". UCM, muestra uno de los daños más frecuentes en esculturas de cera, concretamente fractura en una de las extremidades que compromete la correcta conservación de la pieza en esa zona debido a su propio peso. Imagen de Luis Castelo. Modelo despellejado de tamaño natural. Siglo XVIII.

el momento presente dentro del ámbito específico de la conservación de esta tipología de esculturas; apenas existen aclaraciones relativas a las pastas de relleno que se utilizan en tratamiento de lagunas y menos aún en lo referente a la metodología de aplicación ${ }^{2}$.

Los modelos en cera se comenzaron a elaborar en el siglo XVIII en gabinetes de anatomía vinculados a las cátedras de diversas universidades europeas y su finalidad era claramente docente. Con anterioridad a ellos había sido habitual recurrir al estudio del cuerpo humano a través de figurillas de pequeño tamaño talladas en marfil o hueso, órganos y cuerpos disecados por el método de la inyección de cera e ilustraciones de gran calidad. El estudio de la anatomía humana directamente sobre el cadáver estaba muy controlado tanto por la autoridad civil como por la religiosa. Ello unido a la escasez de cuerpos y a la falta de medios para su conservación llevo a que, a finales de la mitad del siglo XV, se incorporasen a los textos contenidos en los tratados médicos dibujos y grabados realizados por artistas que gozaban de gran reconocimiento en la época. Se trataba de una colaboración que durante siglos escultores y pintores realizaron conjuntamente y trabajando junto a los anatomistas dadas sus habilidades para plasmar por medio de diferentes técnicas el interior del cuerpo humano. Pero las ilustraciones anatómicas tenían limitaciones derivadas del soporte utilizado y pronto se buscaron alternativas tridimensionales. Tras probar primero con materiales como el marfil o la madera para elaborar los maniquíes se optó finalmente por la cera dada su gran capacidad de imitar con una increíble verosimilud la calidad de la piel y tejidos humanos. Concretamente en Madrid se crea, a finales del siglo XVIII, el Real Colegio de San Carlos. Tras dos siglos de historia y vicisitudes parte de la colección elaborada se salvaguarda hoy en el Museo de Anatomía Javier Puerta de la Facultad de Medicina de la UCM.

La cera de abejas es el constituyente principal de los modelos de esta colección, junto a una serie de aditivos que se incorporaban en diferentes cantidades a la masa inicial para hacer que la pasta se adecuase a las necesidades técnicas perseguidas por el escultor durante el proceso de ejecución de cada obra. Mecánicamente las propiedades de las pastas de cera han sufrido cambios debido a las dilataciones, reblandecimientos, migración del material y contracciones surgidas tanto por las reacciones químicas de los elementos integrantes como por 
la respuesta de éstos a las fluctuaciones bruscas del ambiente circundante, tornándose en el momento presente frágiles y quebradizas [Figura 1]. La presencia de plastificantes y endurecedores en su composición genera que la cera vaya cristalizándose. Al debilitarse el material constitutivo, cualquier desplazamiento o pequeño golpe en las piezas hace que quiebren, generándose roturas que normalmente conllevan una pérdida de material [Figura 2]. De ahí la necesidad de llevar a cabo un estudio sobre las pastas cerosas para reintegrar estas lagunas volumétricas. Estos modelos merecen toda nuestra atención por su singularidad técnica, su valor histórico dentro del campo de la anatomía y las calidades estéticas propias de cada figura, lo que las eleva a auténticas obras de arte a salvaguardar dentro del Patrimonio Cultural.

\section{Objetivo}

A partir de una pormenorizada investigación teórica sobre el tema (consultar nota 2), se han establecido unas premisas que han permitido dar paso a una experimentación enfocada a la obtención de un protocolo específico de actuación en reintegración tridimensional de ceras. A continuación se detallan los primeros experimentos que se han llevado a cabo en los inicios de la búsqueda de una pasta de relleno adecuada para los modelos de la colección de Ceroplástica del Museo de Anatomía Javier Puerta. Este trabajo será objeto de una segunda parte donde se mostrará la reintegración en maquetas con las pastas seleccionadas en esta primera investigación, con motivo de analizar experimentalmente su estabilidad, compatibilidad y "re-tratabilidad" frente a la pasta original de estos modelos anatómicos. Destacar que cada colección y pieza ceroplástica es particular en cuanto a pasta cerosa, materiales de composición, técnica de elaboración y proceso de envejecimiento, por lo que merece el estudio que se plantea a escala individual.

\section{Preliminares}

Como primer paso dentro del protocolo de reintegración volumétrica, se ha procedido a establecer temperaturas de seguridad de trabajo midiendo el intervalo de fusión de la pasta origen del modelo a restaurar para poder seleccionar materiales de relleno que no dañen la pieza. En el caso concreto de estudio que se ha seleccionado, se tomó una muestra de cera de una zona que no suponía un daño para el original. La muestra no debe pesar menos de 1 gramo (g) aproximadamente, para que la medida sea significativa. Se extrajo un fragmento de una rotura de un modelo anatómico que muestra la colocación de las manos en el momento del parto porque éste presentaba numerosas grietas y trozos desprendidos imposibles de adherir.

Se seccionó a bisturí con el fin de desmenuzarla para facilitar su proceso de fusión y se introdujo en una pe- queña probeta de punta de plástico transparente, con objeto de que la cera fundiera en su interior controlando visualmente el proceso. Se dispuso en una estufa de baño maría P. Selecta Univeba con agua desionizada. La temperatura del baño se controló con un termómetro de mercurio introducido en el mismo. El intervalo de fusión se determinó tomando medidas con un termómetro eléctrico de punta de platino. Se revistió su cánula y se insertó en la muestra de cera en fusión manteniendo un contacto continuo. El multímetro utilizado realiza las medidas indirectas en valores de resistencia que es preciso transformar en términos de temperatura de fusión. Para medirla se ha utilizado el método de las 4 puntas, que permite averiguar exactamente la resistencia Rt del elemento sensor de platino sin que influya en la lectura la resistencia de los cables. Un Pt-100 es un sensor de temperatura que consiste en un alambre de platino que a $0^{\circ} \mathrm{C}$ tiene una resistencia de 100 ohmios $(\Omega)$ y al aumentar la temperatura, también lo hace su resistencia eléctrica. Para medir las variaciones de resistencia se utiliza una sonda Pt-100 (de precisión $0.01^{\circ} \mathrm{C}$ ) y un multímetro Agilent $34401 \mathrm{~A}$ (de resolución $0.0001 \Omega$ ). La equivalencia entre los valores de resistencia medidos y la temperatura en ${ }^{\circ} \mathrm{C}$ se determina utilizando la ecuación (I) para la sonda Pt-100:

siendo, $\quad T=\frac{R_{t}-R_{0}}{a R_{0}}$

$$
\begin{aligned}
& \mathrm{T} \text { : temperatura }\left({ }^{\circ} \mathrm{C}\right) \\
& \mathrm{R}_{\mathrm{t}} \text { : resistencia en } \Omega \text { a } \mathrm{T}^{\circ} \mathrm{C} \\
& \mathrm{R}_{0} \text { : resistencia en } \Omega \text { a } 0^{\circ} \mathrm{C}(100 \Omega)
\end{aligned}
$$

a: coeficiente de temperatura de la resistencia, cuyo valor entre $0^{\circ} \mathrm{C}$ y $100^{\circ} \mathrm{C}$ es de $0.003850 \Omega \times(1 / \Omega) \mathrm{x}$ $\left(1 /{ }^{\circ} \mathrm{C}\right)$

Durante las 2:30 h. que duró el experimento se tomaron un total de 153 medidas de las que se seleccionaron los 52 valores de resistencia más significativos acompañados de la temperatura que les corresponde según (I).

El resultado del experimento indicó que el intervalo de fusión de la pasta original de la pieza problema es de 57 ${ }^{\circ} \mathrm{C}-85.5^{\circ} \mathrm{C}$, lo que significa que empieza a fundir a $57^{\circ} \mathrm{C}$ y su fusión transcurre hasta que termina de licuarse por completo a $85.5^{\circ} \mathrm{C}$. 


\begin{tabular}{|c|c|}
\hline Nombre & Cera de abejas natural \\
\hline Naturaleza & Natural animal. Segregada por las glándulas ceruminosas de la Apis mellifica \\
\hline Composición & $\begin{array}{l}\text { Ésteres de ácidos y alcoholes de largas cadenas, de 21-36 átomos de C, hidrocarburos sa- } \\
\text { turados }\end{array}$ \\
\hline Color & Amarillo claro a marrón claro \\
\hline Propiedades & $\begin{array}{l}\text { Buena plasticidad, cuerpo sólido a T ambiente, frágil a baja T, se reblandece por debajo } \\
\text { de los } 31^{\circ} \mathrm{C}\end{array}$ \\
\hline Solubilidad & $\begin{array}{l}\text { Insoluble en agua. Un poco soluble en alcohol frío. Soluble en alcohol caliente, hidrocar- } \\
\text { buros aromáticos (tolueno, xileno) y saturados }\end{array}$ \\
\hline Compatibilidad & $\begin{array}{l}\text { Se le pueden añadir cuerpos grasos y otras ceras (vegetales y minerales) formando inte- } \\
\text { resantes pastas de relleno }\end{array}$ \\
\hline Intervalo de fusión & $62-64^{\circ} \mathrm{C}$ (se reblandece a $30^{\circ} \mathrm{C}$ ) \\
\hline $\mathrm{Tg}$ & $31-33^{\circ} \mathrm{C}$ \\
\hline Índice de acidez & 17-24 (aumenta con el envejecimiento) \\
\hline Empresa suministradora & CTS \\
\hline Forma del producto & Pieza en bloque sólida \\
\hline
\end{tabular}

\begin{tabular}{cc}
\hline Nombre & Cera de carnauba \\
\hline Naturaleza & Natural vegetal. La exudan las hojas de la palmera Copernica cerifera \\
\hline Composición & $80 \%$ ésteres de ácidos grasos, 10-15\% alcoholes, 3-6\% ácidos, 1-3\% hidrocarburos \\
\hline Color & Amarillo grisáceo \\
\hline Propiedades & Alta dureza, frágil. Es resistente a los cambios de temperatura. Brillante. \\
\hline Solubilidad & En insoluble en disolventes a T ambiente, empieza a disolver a los $455^{\circ} \mathrm{C}$ \\
\hline Compatibilidad & Compatible con ceras animales, minerales y vegetales \\
\hline Intervalo de fusión & $84-91^{\circ} \mathrm{C}$ \\
\hline Tg & $49-51^{\circ} \mathrm{C}$ \\
\hline Índice de acidez & $17-24$ (aumenta con el envejecimiento) \\
\hline Empresa suministradora & $\mathrm{CTS}$ \\
\hline
\end{tabular}




\begin{tabular}{|c|c|}
\hline Nombre & Cera de candelilla \\
\hline Naturaleza & Natural vegetal. Segregada por el arbusto Euphorbia cerifera \\
\hline Composición & $\begin{array}{l}\text { Alrededor de } 50 \% \text { de hidrocarburos saturados lineales de } 31 \text { átomos de C, cantidad baja } \\
\text { de ésteres volátiles }\end{array}$ \\
\hline Color & Naranja \\
\hline Propiedades & $\begin{array}{l}\text { Dura y quebradiza por contener grandes cantidades de resina. Resistente a los cambios } \\
\text { de temperatura }\end{array}$ \\
\hline Solubilidad & $\begin{array}{l}\text { Insoluble en agua, poco soluble en alcohol, soluble en acetona, benceno, disulfuro de } \\
\text { carbono, éter de petróleo caliente, las esencias, los aceites, la trementina, el cloroformo } \\
\text { caliente y el tetracloruro de carbono }\end{array}$ \\
\hline Compatibilidad & Compatible con las ceras animales, vegetales y minerales \\
\hline Intervalo de fusión & $66-71^{\circ} \mathrm{C}$ \\
\hline $\mathrm{Tg}$ & $37-40^{\circ} \mathrm{C}$ \\
\hline Índice de acidez & 11-19 (ligeramente ácida) \\
\hline Empresa suministradora & CTS \\
\hline Forma del producto & Escamas \\
\hline
\end{tabular}

\begin{tabular}{cl}
\hline Nombre & Parafina \\
\hline Naturaleza & Natural. Extraída por destilación fraccionada del petróleo \\
\hline Composición & Hidrocarburos saturados lineales de 20-30 átomos de C \\
\hline Color & Blanco, aspecto translúcido \\
\hline Propiedades & Macrocristalina, dura, frágil, rígida, de fusión neta, no adhesiva y poco viscosa, inodora \\
\hline Solubilidad & Soluble en disolventes apolares como los hidrocarburos aromáticos y alifáticos \\
\hline Compatibilidad & Compatible con las ceras animales, vegetales y minerales \\
\hline Intervalo de fusión & $56-58{ }^{\circ} \mathrm{C}$ \\
\hline Tg & $34-40^{\circ} \mathrm{C}$ \\
\hline Índice de acidez & 0 (neutra) \\
\hline Empresa suministradora & CTS \\
\hline Forma del producto & Pieza en bloque sólido \\
\hline
\end{tabular}




\begin{tabular}{|c|c|}
\hline Nombre & Ceras microcristalinas tipo Cosmolloid $80^{\circledR}$ \\
\hline Naturaleza & Natural. Extraída por destilación fraccionada del petróleo \\
\hline Composición & $\begin{array}{l}\text { Hidrocarburos saturados de cadena lineal e hidrocarburos saturados ramificados y cícli- } \\
\text { cos, de } 41-50 \text { átomos de } C\end{array}$ \\
\hline Color & Blanco \\
\hline Propiedades & $\begin{array}{l}\text { Blanda, plástica, flexible, adhesiva, viscosa, tenaz. Más dura y resistente a las variaciones } \\
\text { climáticas que otras ceras naturales }\end{array}$ \\
\hline Solubilidad & $\begin{array}{l}\text { Insoluble en agua, poco soluble en alcohol, soluble en acetona, benceno, disulfuro de } \\
\text { carbono, éter de petróleo caliente, las esencias, los aceites, la trementina, el cloroformo } \\
\text { caliente y el tetracloruro de carbono; en general en hidrocarburos alifáticos y aromáticos }\end{array}$ \\
\hline Compatibilidad & Compatible con las ceras animales, vegetales y minerales \\
\hline Intervalo de fusión & $75-86^{\circ} \mathrm{C}$ \\
\hline $\operatorname{Tg}$ & $56-59^{\circ} \mathrm{C}$ \\
\hline Índice de acidez & 0 (neutra) \\
\hline Empresa suministradora & CTS \\
\hline Forma del producto & Perlas \\
\hline
\end{tabular}

\begin{tabular}{cl}
\hline Nombre & Polietilenglicol (PEG) \\
\hline Naturaleza & Polímero sintético \\
\hline Composición & Mezcla de hidrocarburos saturados e insaturados de 20-56 átomos de C o más \\
\hline Color & Blanco \\
\hline Propiedades & Puede presentarse líquido o más sólido a T ambiente (se le suele añadir alguna carga) \\
\hline Solubilidad & Soluble en agua \\
\hline Compatibilidad & Compatible con ceras animales, minerales y vegetales \\
\hline Intervalo de fusión & $110^{\circ} \mathrm{C}$ \\
\hline Tg & $-110^{\circ} \mathrm{C}$ \\
\hline Índice de acidez & 0 (neutra) no interacciona con otros materiales como el metal \\
\hline
\end{tabular}

Tabla 1. Principales propiedades de las ceras que se utilizan en el experimento. 
Establecer este dato es fundamental para poder investigar el tipo de pasta de reintegración que se vaya a utilizar en el tratamiento estético consistente en el relleno de la laguna, dado que si el intervalo de fusión de dicha mezcla supera al de la cera original existe una incompatibilidad entre los materiales, puesto que al fundir la pasta se estaría ocasionando un daño irreversible.

\section{Experimento}

\section{1.- Materiales:}

De acuerdo con las propiedades de las principales ceras que existen en el comercio (cera de abejas natural, cera de carnauba, cera de candelilla, parafina, ceras microcristalinas tipo Cosmolloid $80^{\circledR}$, ozoquerita y polietilenglicol (PEG) -las que se utilizan aparecen recogida en la tabla [Tabla 1]-, se comenzaron a establecer las bases de una metodología de actuación.

\section{2.- Consideraciones:}

Como punto de partida inicial y tras la consulta de fuentes documentales se tienen en cuenta los siguientes aspectos ya señalados por otros investigadores:

1.- La proporción de mezcla de dos componentes debe ser exclusivamente $2 / 3$ de cera de abejas y $1 / 3$ de otra cera (Besnainou, 1984: 56; Cordua et al, 2009).

2.- Todas las ceras son compatibles entre sí y sus mezclas son de gran reversibilidad (Besnainou, 1984: 56).

3.- No se aconseja reintegrar con mezclas de cera-resina, (por ejemplo las ya estudiadas de cera de abejas con colofonia o resina dammar). Las ceras carnauba y candelilla se decoloran adicionando parafina o con carbón activo (Besnainou, 1984: 71). Se decide descartar tanto la cera de carnauba como la de candelilla, solas, debido a su fuerte coloración.

4.- Al mezclar cera de abejas con una resina acrílica se produce una incompatibilidad que da como resultado una irreversibilidad, porque ambos elementos tienen un punto de fusión tan dispar que no es posible fundirlos conjuntamente (Besnainou, 1984: 56, 57).

5.- La cera de abejas pura o blanqueada, empleada sola, no muestra una buena estabilidad (Pradier, 2011: 112). A partir de los $40^{\circ} \mathrm{C}$ se observa una modificación física, comienzan a ablandarse y se deforman. Esto es debido a que sus temperaturas de transición vítrea y de fusión son relativamente bajas.

6.- Se elimina la ozoquerita y también el polietilenglicol, dado que ambos endurecen y se vuelven quebradizos con el envejecimiento (Pradier, 2011:112).
7.- Se aconsejan como materiales de relleno la cera Cosmolloid $80^{\circledR}$, la parafina $60-62$, la mezclas $2 / 3$ de Cosmolloid $80^{\oplus}+1 / 3$ parafina $50-52$, la mezcla $1 / 2$ Cosmolloid 80 $+1 / 2$ parafina 50-52 (Pradier, 2011: 112-117).

8.- En restauración arqueológica se viene utilizando para la reintegración volumétrica un compuesto de cera conocido como Integrante 76 , con el que se reconstruyen las pérdidas de materia en piezas antiguas. Estos datos pueden servirnos como punto de partida para otra posible pasta a estudiar. Es un producto que utiliza como base la cera virgen de abejas, como aglutinantes la parafina y la resina de colofonia y por último, óxido de zinc y yeso muy fino como materiales de carga inerte (Navarro Lizandra, 2005: 94).

\section{3.- Metodología:}

1.- Preparación de las muestras: Cada muestra se preparó pesando la proporción adecuada de cada cera en balanza de precisión Denver Instrument SI-234 (Max. $230 \mathrm{~g}, \mathrm{~d}=0,1 \mathrm{mg}$ ) en gramos (g) Posteriormente cada cera por separado se introdujo en un vaso de precipitados de Pyrex (resistente al calor) con el fin de introducirla en una estufa Selecta Mod. 200 (intervalo de temperatura de calentamiento hasta $200^{\circ} \mathrm{C}$ ) para que funda por completo a su intervalo de temperatura de fusión específico. Una vez fundidas las ceras, se mezclaron convenientemente éstas y se vertieron en un soporte de silicona desmoldable apto para el calentamiento de la muestra. Se obtuvieron así las ocho muestras que se proponen [Tabla 2].

2.- Los intervalos de fusión de cada muestra de pasta cerosa se determinaron de una manera experimental idéntica a la descrita con anterioridad para la pasta de cera original. Los resultados obtenidos para cada caso se muestran en la tabla [Tabla 2] una vez realizados los cálculos correspondientes. Cada medida se repitió 3 veces.

3.- Estudio experimental de envejecimiento artificial acelerado. Para continuar con la selección de pastas de relleno todas ellas fueron sometidas a una prueba de envejecimiento artificial.

Antes de comenzar el experimento se hicieron fotografías de la superficie expuesta de cada una de las 8 probetas, macroscópicas con cámara Reflex digital y microscópicas con una Lupa Binocular Leica MZ 12.5, 0.8X y 1.6X aumentos. El motivo es volver a fotografiarlas, bajo los mismos parámetros, al terminar la experimentación, para poder comparar los estados inicial y final de las mismas. Ello conducirá a determinar qué modificaciones sufren a niveles macroscópico y microscópico con el paso del tiempo.

Para ello las pastas de relleno se introdujeron en una cámara de radiación ultravioleta (UV). Concretamente se trata de una cámara de envejecimiento UV fabricada 


\begin{tabular}{|c|c|c|c|c|c|}
\hline & MATERIAL 1 & PROPORCIÓN & MATERIAL 2 & PROPORCIÓN & $\begin{array}{l}\text { INTERVALO DE } \\
\text { FUSIÓN MEDIDO }\end{array}$ \\
\hline MUESTRA 1 & Parafina 56/58 & 1 & & & $56-58^{\circ} \mathrm{C}$ \\
\hline MUESTRA 2 & Cosmolloid $80^{\circledR}$ & 1 & & & $52-82^{\circ} \mathrm{C}$ \\
\hline MUESTRA 3 & Cosmolloid $80^{\circledR}$ & $2 / 3$ & Parafina $56 / 58$ & $1 / 3$ & $51,9-62,3^{\circ} \mathrm{C}$ \\
\hline MUESTRA 4 & Cosmolloid $80^{\circledR}$ & $1 / 2$ & Parafina 56/58 & $1 / 2$ & $51,9-62,6^{\circ} \mathrm{C}$ \\
\hline MUESTRA 5 & $\begin{array}{l}\text { Cera de abejas virgen } \\
\text { amarilla }\end{array}$ & $2 / 3$ & Parafina 56/58 & $1 / 3$ & $43,2-64,9^{\circ} \mathrm{C}$ \\
\hline MUESTRA 6 & $\begin{array}{c}\text { Cera de abejas virgen } \\
\text { amarilla }\end{array}$ & $2 / 3$ & Cosmolloid $80^{\circledR}$ & $1 / 3$ & $62,1-69,5^{\circ} \mathrm{C}$ \\
\hline MUESTRA 7 & $\begin{array}{c}\text { Cera de abejas virgen } \\
\text { amarilla }\end{array}$ & $2 / 3$ & Candelilla & $1 / 3$ & $54,9-65,5^{\circ} \mathrm{C}$ \\
\hline MUESTRA 8 & $\begin{array}{c}\text { Cera de abejas virgen } \\
\text { amarilla }\end{array}$ & $2 / 3$ & Carnauba & $1 / 3$ & $63,1-69,9^{\circ} \mathrm{C}$ \\
\hline
\end{tabular}

Tabla 2. Pastas cerosas de partida y resultados de la medida de su intervalo de fusión. Estos rangos de fusión se midieron del mismo modo que se hizo para la cera original con una sonda Pt-100.

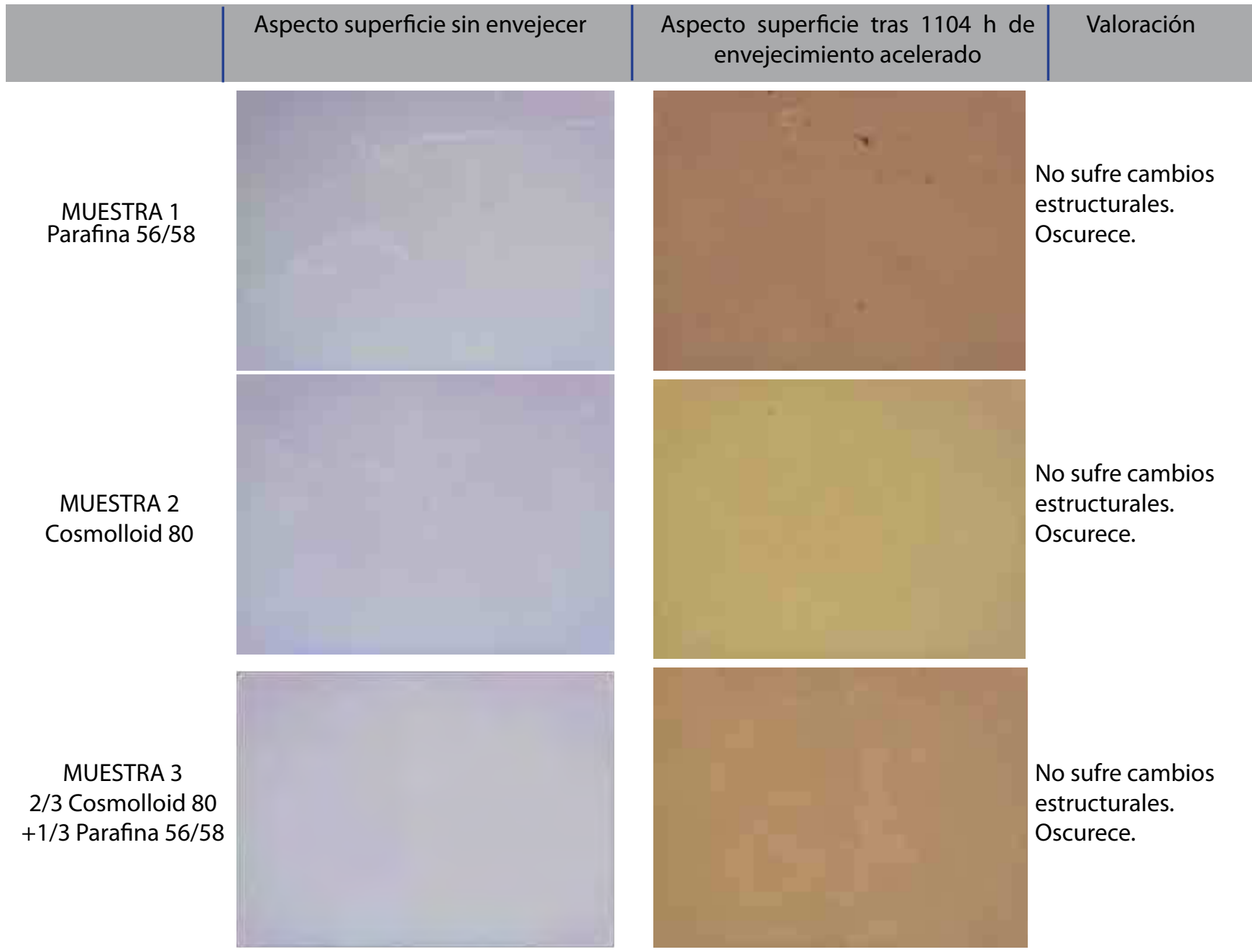


MUESTRA 4

$1 / 2$ Cosmolloid 80

$+1 / 2$ Parafina $56 / 58$

\section{MUESTRA 5}

2/3 Cera abeja virgen

$+1 / 3$ Parafina $56 / 58$

\section{MUESTRA 6}

2/3 Cera abeja virgen

$+1 / 3$ Cosmolloid 80

MUESTRA 7

2/3 Cera abeja virgen

$+1 / 3$ Candelilla

\section{MUESTRA 8}

2/3 Cera abeja virgen

$+1 / 3$ Carnauba
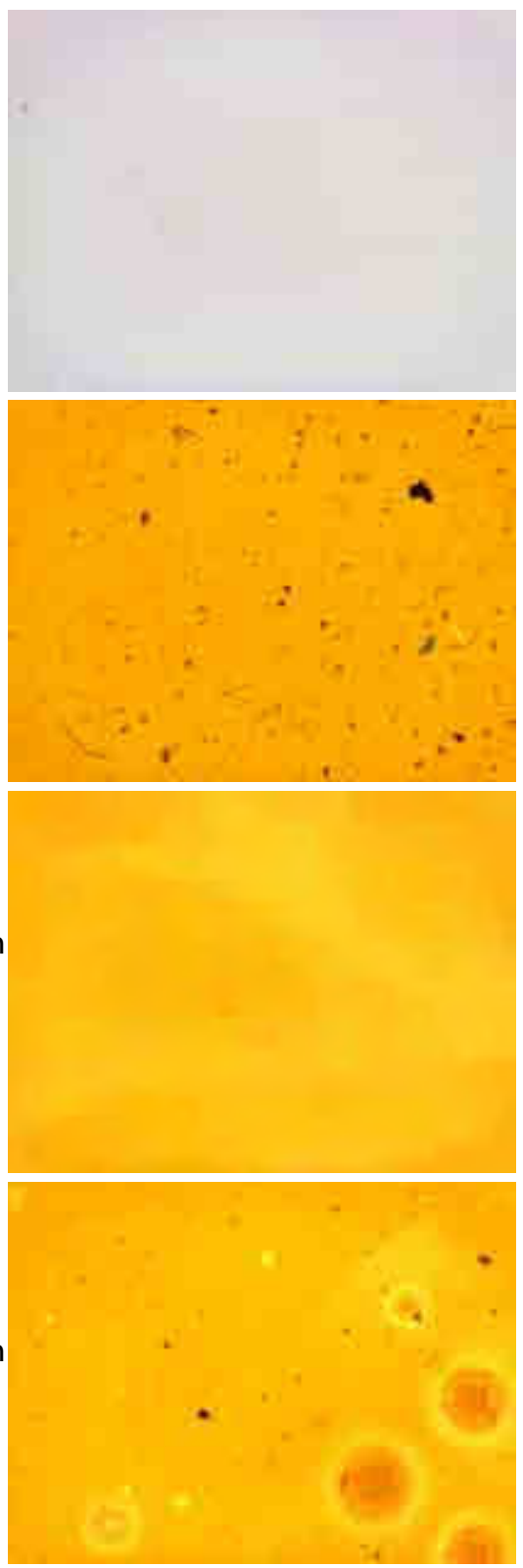

-

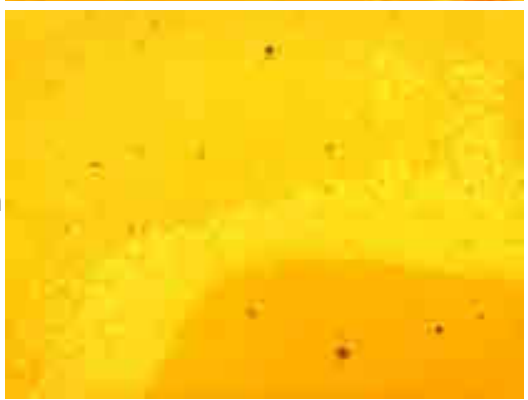

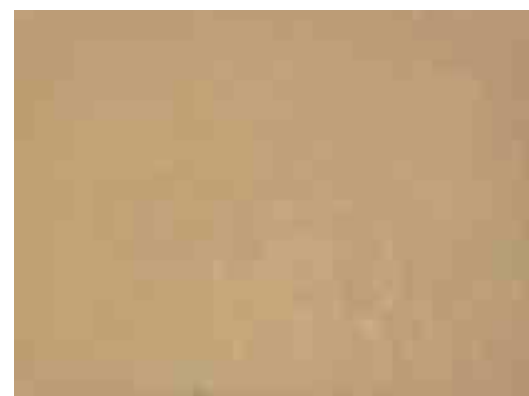

No sufre cambios

estructurales.

Oscurece.

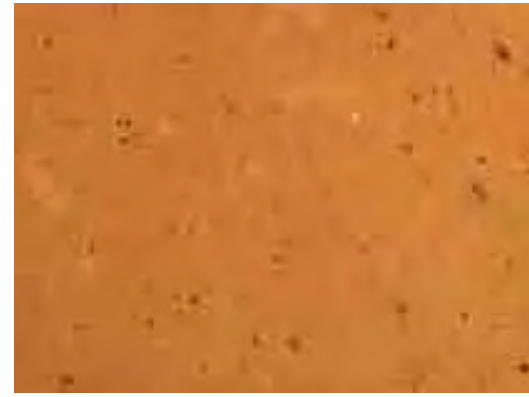

No sufre cambios estructurales.

Oscurece.

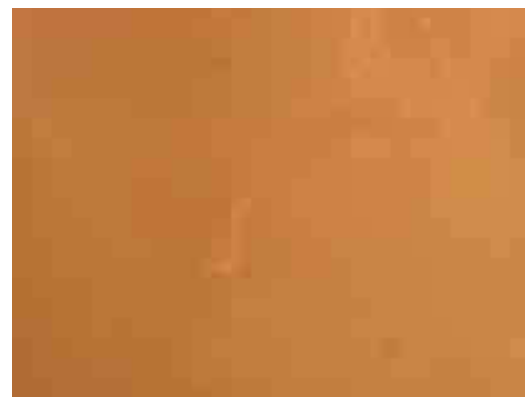

No sufre cambios estructurales.

Oscurece.

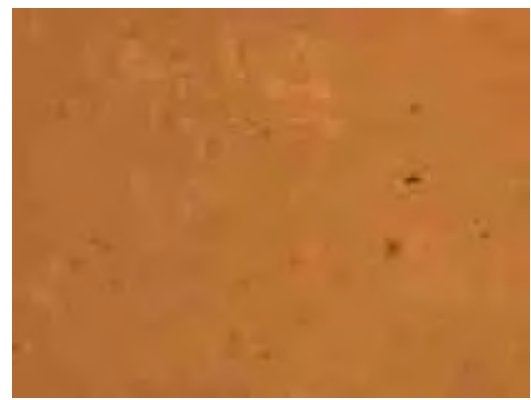

No sufre cambios estructurales.

Oscurece.

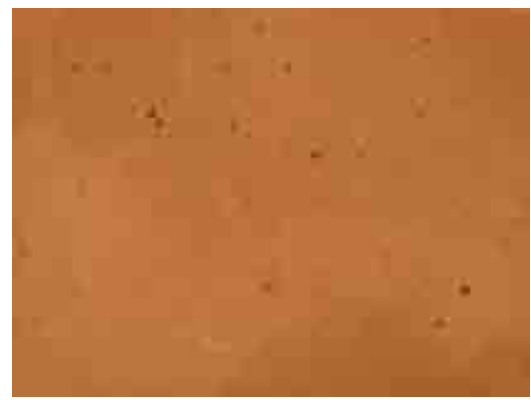

No sufre cambios estructurales.

Oscurece.

Tabla 3. Observaciones realizadas con lupa binocular Leica MZ 12 5,b 1,6x: se presenta una comparación de los cambios experimentados por cada muestra.

NOTA: Los posibles dibujos en superficie son irrelevantes porque se deben al proceso de secado; lo interesante es el cambio superficial de color. 


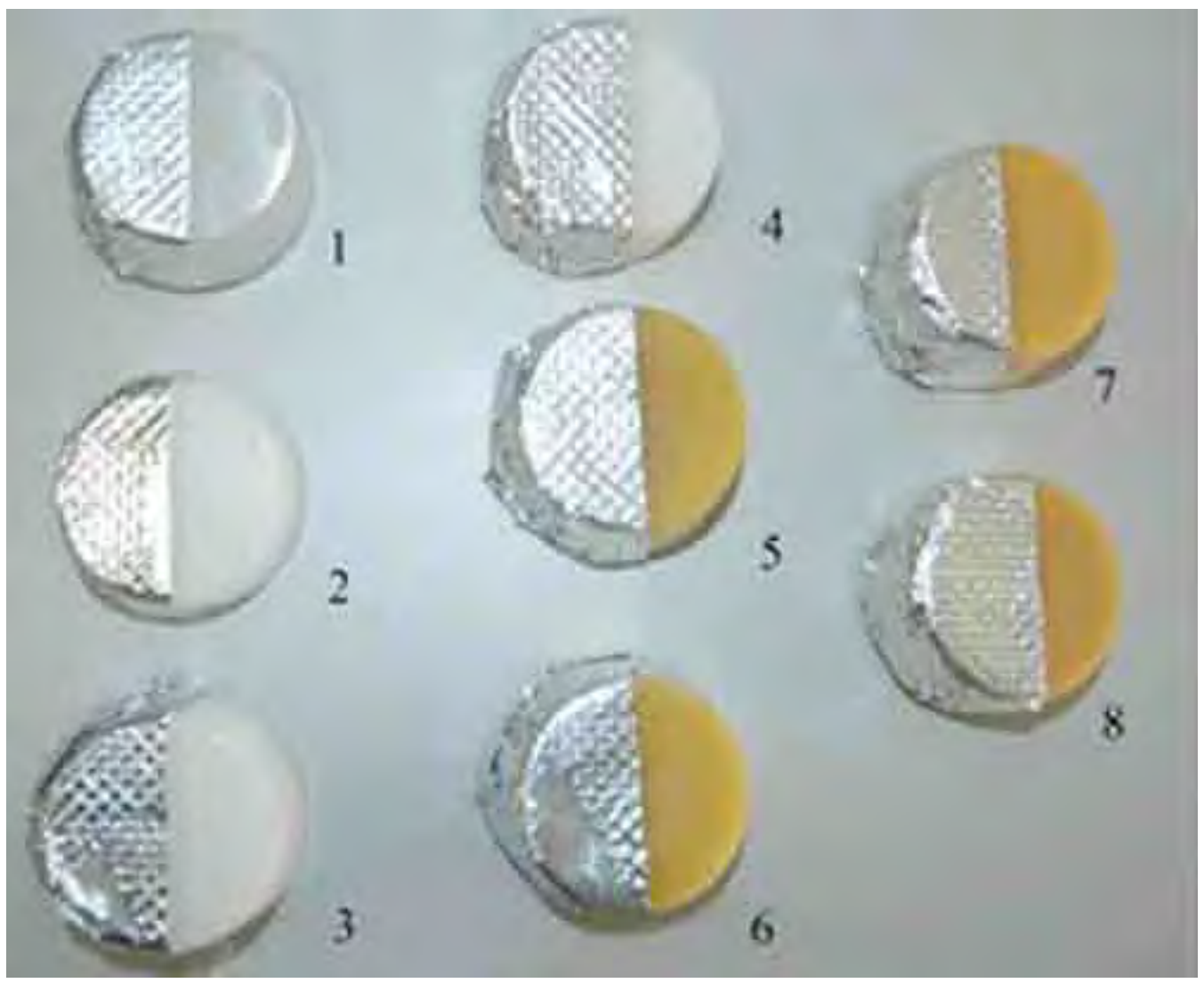

Figura 3. Conjunto de las ocho posibles pastas de reintegración preparadas para su introducción en la cámara de envejecimiento UV.
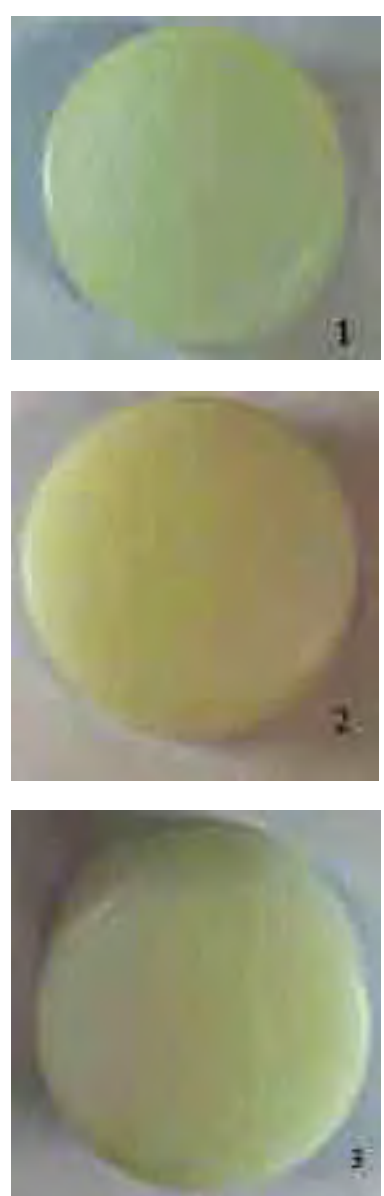
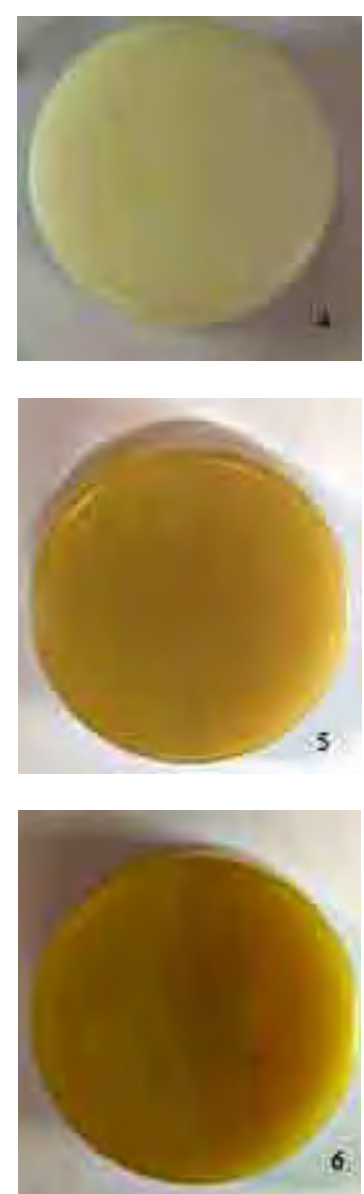
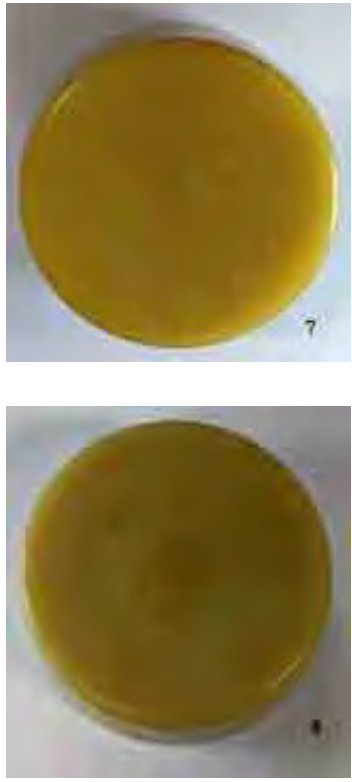

Tabla 4. Estado tras el envejecimiento realizado de las ocho pastas de reintegración. Obsérvese, como se ha indicado, que los cambios de color no son sustanciales a nivel macroscópico 
bajo la norma UNE 53-104-86. Presenta un carrusel de 4 tubos fluorescentes Ultraviolet-B TL 40W/12RS (Philips) con una distribución espectral de energía dentro del intervalo 260-390 nm, el máximo de emisión es de 0,80 W a $317 \mathrm{~nm}$, con una radiación incidente sobre la muestra de $0,081 \mathrm{~W} / \mathrm{m}^{2}$ medida a $340 \mathrm{~nm}$ a una distancia de $10 \mathrm{~cm}$. La humedad relativa (HR), constante en esta cámara, es un factor de degradación que no interesa porque las ceras y sus mezclas se muestran estables ante este agente externo (son materiales hidrófobos). Las condiciones de envejecimiento son: exposición constante a radiación UV y temperatura constante de $30^{\circ} \mathrm{C}-35^{\circ} \mathrm{C}$. Todas las muestras fueron sometidas a ciclos de $140 \mathrm{~h}$., fotografiadas $\mathrm{y}$ evaluadas a las 480 h. de envejecimiento y a las 1.104 h., considerado éste como el punto final del experimento.

A nivel microscópico lo más concluyente es que ninguna de las muestras sufre cambios físico/estructurales, sino sólo a nivel de color en superficie [Tabla 3]. Todas oscurecen pero hay cambios de tono que, a nivel macroscópico, son menos significativos [Tabla 4]. Todas las pastas han resultado ser materiales muy estables al envejecimiento en cuanto a su comportamiento mecánico.

A nivel macroscópico, para poder observar la variación que sufrían las maquetas al introducirlas en la cámara, una de sus mitades, en concreto la parte izquierda, se cubrió con un material resistente al calor [Fig. 3], aunque tras el experimento resultó algo penetrado por la radiación UV. No se observaron reblandecimientos ni cambios estructurales de superficie en ninguno de los ensayos, si bien se considera conveniente en el futuro llevar a cabo análisis químicos que permitan concretar estos resultados iniciales.

\section{Resultados y discusión}

A continuación se exponen los principales resultados alcanzados en el transcurso de esta investigación:

MUESTRA 1: se produce una considerable contracción y merma de la pasta cerosa al solidificarse. En estado sólido la pasta resulta maleable con las manos a temperatura ambiente.

MUESTRA 6: apenas se percibe retracción en la mezcla al endurecer.

MUESTRA 8: se produce una mínima contracción de la pasta cerosa al solidificar.

MUESTRAS 2, 3, 4, 5 y 7: a nivel macroscópico no se observó contracción aparente alguna.

Se considera necesario realizar un experimento de dilatación térmica que permita examinar con más precisión, a nivel macro y microscópico, las alteraciones resultantes de la retracción de cada pasta cerosa a fin de determinar si podrían ser utilizadas como material de relleno para tratamiento de lagunas volumétricas en objetos de cera.

Dado que la pasta de cera original tiene un intervalo de fusión de $57^{\circ} \mathrm{C}-85.5^{\circ} \mathrm{C}$ y se busca una pasta de relleno que tenga un intervalo de fusión inferior, de acuerdo con los resultados obtenidos en las medidas, se propone descartar la MUESTRA 2 (Cosmolloid 80 ${ }^{\circledR}$ ) dado que presenta un intervalo de fusión muy similar: $52{ }^{\circ} \mathrm{C}-82$ ${ }^{\circ} \mathrm{C}$, terminando de fundir a una temperatura excesivamente alta que haría peligrar la cera original; también se desaconseja la MUESTRA 8 ( $2 / 3$ cera de abejas virgen $+1 / 3$ carnauba) puesto que su intervalo de fusión: 63,1 ${ }^{\circ} \mathrm{C}-69,9{ }^{\circ} \mathrm{C}$ excede a la temperatura a la que comienza a fundir $\left(57^{\circ} \mathrm{C}\right)$ la cera original, con lo que podría provocar su fusión evitando la reversibilidad y dañando el modelo.

Una vez observado el proceso de enfriamiento y consiguiente solidificación de cada pasta estudiada, se considera conveniente analizar más en profundidad la MUESTRA 1 por la retracción superficial que sufre, dado que esto provocaría una merma en sentido vertical. Este problema podría solventarse aplicando el material por capas con una espátula térmica, comenzando a una temperatura $X$ adecuada y bajándola paulatinamente conforme nos aproximemos a la zona superior de la laguna. No se aprecia la misma tendencia a mermar en ninguna otra dirección, de lo que se deduce que tiende a contraer al entrar en contacto con el aire.

No se considera adecuada la MUESTRA 2 dado que sufre un amarilleamiento considerable con el paso del tiempo. Por su parte, las pastas 7 y 8 resultan ya inicialmente oscuras frente a la cera original, a pesar de no amarillear apenas. Tras el experimento de envejecimiento acelerado, se descartan la MUESTRA 6 y la MUESTRA 3, porque se observa un cambio de color excesivo.

\section{Conclusiones}

Los actuales criterios deontológicos de la profesión establecen como pauta a tener en cuenta en el tratamiento de lagunas, la conveniencia de seleccionar un material de relleno que se diferencie del original para hacer discernible la parte añadida. A fin de garantizar la compatibilidad y la estabilidad, se considera adecuado incorporar a la pasta de relleno alguno de los componentes originales. Los análisis químicos efectuados en los modelos anatómicos de la colección sometida a estudio indican que los escultores modificaron los componentes de las pastas para adaptarlas a las exigencias técnicas de cada elemento anatómico a reproducir. Aquellas esculturas que tienen deterioros a modo de roturas o pérdidas matéricas permiten comprobar cómo en la praxis de taller utilizaron distintas pastas cerosas, comenzando por una rojiza más dura que daba sostén, varias intermedias y terminando por una más translúcida y de color similar al de 
la piel o tejido a representar.

Una de las muestras que podría responder mejor, la MUESTRA 5, contiene además de $1 / 3$ de parafina con un punto de fusión entre 56/58, 2/3 de cera virgen de abejas, aproximándose en su composición a las pastas originales donde predomina la cera virgen blanqueada. Puede trabajarse con una pasta que incluya algún componente de la pasta original siempre que no sea exactamente igual ,sino solo similar. Los dos siglos trascurridos desde la creación de estas esculturas, hacen pensar que esto no sería un inconveniente dado que la cera envejecida muestra un estado que nada tiene que ver con la pasta original, que es maleable y pegajosa. Sin embargo, dado que la pasta de relleno ha de trabajarse y aplicarse a la laguna volumétrica en caliente es preferible que sea diferente para que tenga una plasticidad mayor (los modelos parecen cristalizados) a fin de rellenar bien toda la laguna.

Como la cera es un material que funde con calor dentro de un rango de temperaturas (al ser un material físicamente amorfo lo hace gradualmente), habrá que optar por una pasta de relleno con un intervalo de fusión inferior al de la pasta origen, para que el objeto de partida no sufra alteración estructural alguna. Por esta razón, previo a todo estudio de posibles materiales de relleno de una laguna volumétrica en un objeto de cera, se ha de medir el intervalo de fusión de la misma mediante la toma de muestra del material original para garantizar la seguridad de la pieza. También se medirá siempre el citado intervalo de cada una de las pastas de cera que se piense sea posible utilizar para la reintegración con la finalidad de rechazar aquéllas que no cumplan con esta premisa.

Respecto a la resina de colofonia se hicieron algunas pruebas experimentales tanto en estufa como al baño maría y se observó que tiene un punto de fusión dispar frente a la cera de abejas, de manera que si se utiliza combinada con ella para la preparación de la masilla, tiende a solidificar formándose un bloque semi-sólido que muestra dificultad para mezclarse por completo con el resto de los componentes. Si se aumenta la temperatura para conseguir que cera y resina fundan conjuntamente se llega a derretir la resina pero surgen dos grandes inconvenientes: se deja de trabajar con un intervalo de seguridad dado que ésta aumenta el intervalo de fusión de la pasta y la resina tiende a decantar al verterse la pasta. Por otra parte, endurece el material céreo al añadirla y es imprescindible que la pasta de reintegración tenga flexibilidad para adecuarse a los cambios bruscos de temperatura y a las contracciones y dilataciones que éstos generen. Se estima que la masilla de relleno debe mantener con el envejecimiento natural un cierto grado de elasticidad para que sea capaz de adaptarse a los posibles cambios dimensionales como respuesta de los materiales, tanto añadidos como originales, a las fluctuaciones de la temperatura ambiental. Este tipo de estudios experimentales será objeto de una próxima publicación.
Se descartan las ceras de carnauba y candelilla por su dureza y color oscuro. El que tengan una elevada dureza implica que, al utilizarlas para reintegrar estructuralmente, crearán una serie de posibles tensiones en la escultura que podrían provocar la formación de pequeñas grietas internas; asimismo, la tonalidad de las mismas, una vez seca la pasta, no es adecuada para realizar la posterior reintegración cromática dado que se parte de un tono de base muy oscuro. Se recomienda elegir una pasta de relleno siempre más clara que la original o de color natural similar que pueda ser coloreada desde la masa con la adición de pigmentos o retocada con colores en superficie, aplicando la regla de reintegración óptima de claro a oscuro y no a la inversa, para que el resultado sea visual y estéticamente limpio.

Las pastas de relleno que muestran un comportamiento mejor en relación a su intervalo de fusión frente al de la pasta original y a su proceso de envejecimiento son:

MUESTRA 1: Parafina con intervalo de fusión entre $56 / 58^{\circ} \mathrm{C}$

MUESTRA 3: $2 / 3$ Cosmolloid $80^{\circledR}+1 / 3$ parafina $56 / 58$

MUESTRA 4: $1 / 2$ Cosmolloid $80^{\oplus}+1 / 2$ parafina $56 / 58$

MUESTRA 5: $2 / 3$ cera de abeja virgen $+1 / 3$ parafina $56 / 58$

\section{Notas}

[1] DUHAMEL DU MONCEAU, H.L. (1777) Arte de cerero. Madrid: Imprenta Pedro Marín. BONELLS, J; LACABA, I. (1796) Curso completo de anatomía del cuerpo humano, Madrid: Imprenta de Sancha, 5 vols. LE NORMAND, L-S. (1836) Manuel du chandelier, du cirier et du fabricant de cire a cacheter, Paris: Lybrairie encyclopédique de Roret. LEBRUN, M. (1850) Nouveau manuel complet du moleur. París: Encyclopédie- Roret, 12. MARGIVAL, N. (1937) Cires, encaustiques, produits d'entretien. Nouvelle Coleccion des Recueils de Recettes Rationelles. París: Desforges.

[2] Se puede consultar al respecto la bibliografía siguiente: MURREL, V. J. (1971) "Some aspects of the conservation of wax models." Studies in Conservation: 95-109. BESNAINOU, D. (1984) Cire et cires: etude sur la composition, I'alteration, la restauration, la conservation des ouvres céroplastiques. París: Institut Francais de Restauration des Ouvres d'Art. FERNÁNDEZ BERENGUÉ, L.; PUGĖS DORCA, M.; ZARZOSO ORELLANA, A. (2001) La restauración de una Venus anatómica de cera. http://www.museudelamedicina.cat/pdf/venus.pdf

BECCHETI, L. (2007) “I sigili di una pergamena duecentesca conservata all'Archivio Segreto Vaticano. Intervento di restauro e conservacione." Kermes, 67-68: 35-41. GABBRIELLINI, C. et al. (2008) "Il restauro di un manufatto in cera del Museo di Anatomia Patologica di Firenze. II Busto di bambino hidrocefálico 
eseguito da Luigi Calamai nel 1831". OPD Restauro, 20: 227234. CORDUA, M. G. Et al. (2009) "Marvellous Horrors. Gaetano Zumbo's Unpublished Waxes alter Restoration". OPD Restauro, 21: 43-53. DAL FORNO, F. (2009) La ceroplastica anatomica e il suo restauro. Un nuovo uso Della TAC, una possibile attribuzione a G. G. Zumbo. Florencia: Nardini. PRADIER, I. (2011) A corps ouvert: étude et restauration d'une cire anatomique florentine de la fin du XVIIle siècle (Conservatoire dÁnatomie de Montpellier). Recherche sur les matériaux de comlement des objets en cire. Mémoire de fin d'études. Institut National du Patrimoine.

\section{Agradecimientos}

Estudios realizados con ayuda de una beca predoctoral FPI de la Universidad Complutense de Madrid, en calidad de becario con contrato de profesor ayudante en prácticas.

Las diversas pruebas experimentales han sido llevadas a cabo en el Laboratorio de Magnetobiología de la Prof. M. J. Azanza, Catedrática de Biología-Magnetobiología, en la Facultad de Medicina de la Universidad de Zaragoza. Para la supervisión de las medidas físicas se ha contado con la colaboración del Prof. A. del Moral, Catedrático de Física de la Materia Condensada en la Facultad de Ciencias de la misma Universidad.

El envejecimiento artificial de las maquetas se ha realizado en el Laboratorio de Química aplicada perteneciente a la Red de Laboratorios de Ciencia y Tecnología aplicadas a la Conservación del Patrimonio (RedLabPat), CEl, Campus Moncloa (UCM-UPM), con el apoyo de la Prof. Margarita San Andrés Moya.

\section{Bibliografia}

BECCHETI, L. (2007). “I sigili di una pergamena duecentesca conservata all'Archivio Segreto Vaticano. Intervento di restauro e conservacione". Kermes, 67-68: 35-41.

BESNAINOU, D. (1984). Cire et cires: étude sur la composition, I'altération, la restauration, la conservation des ouvres céroplastiques. Paris: Institut Français de Restauration des Ouvres d'Art.

BESNAINOU, D. (1987). "Conservation et Restauration". En Sculptures en cire de l'Ancienne Égypte à l'art abstrait, VVAA. Paris: RMN, 73-79.

BONELLS, J; LACABA, I. (1800). Curso completo de anatomía del cuerpo humano, Madrid: Imprenta de Sancha, 5 vols.

CORDUA, M. G.; LANTERNA, G., LOMBARDI, et. al. (2009). "MarveIlous Horrors. Gaetano Zumbo's Unpublished Waxes after Restoration". OPD Restauro, 21: 43-53.

DAL FORNO, F. (2009). La ceroplastica anatomica e il suo restauro. Un nuovo uso Della TAC, una possibile attribuzione a G. G. Zumbo. Florencia: Nardini.V
FERNÁNDEZ BERENGUÉ, L.; PUGÈS DORCA, M.; ZARZOSO ORELLANA, A. (2001). La restauración de una Venus anatómica de cera. http://www.museudelamedicina.cat/pdf/venus.pdf [2-112010]

GABBRIELLINI, C; NESI, G.; ROSSI, F. et. al. (2008). "Il restauro di un manufatto in cera del Museo di Anatomia Patologica di Firenze. II Busto di bambino hidrocefálico eseguito da Luigi Calamai nel 1831" OPD Restauro, 20: 227-234.

GABBRIELLINI, C.; NESI, G.; ROSSI, F. et. al. (2009). “The wax Collection at the Museum of Pathological Anatomy in Forence. Notes of historical events, on technical manufacture and treatments". OPD Restauro, 21: 29-41.

LEGORBURU ESCUDERO, M. P. (1995). Criterios sobre la reintegración de lagunas en obras de arte y transcendencia del estuco en el resultado final según su composición y aplicación. Tesis Doctoral. Bilbao: Universidad del País Vasco, Facultad de Bellas Artes, D. L.

MURREL, V. J. (1971). "Some aspects of the conservation of wax models". Studies in Conservation, 16, n 3: 95-109.

NAVARRO LIZANDRA, J. L. (2005). Maquetas, modelos y moldes: materiales y técnicas para dar forma a las ideas. Castelló de la Plana: Publicaciones de la Universidad Jaime I.

PRADIER, I. (2011). A corps ouvert: étude et restauration d'une cire anatomique florentine de la fin du XVIIle siècle (Conservatoire d'Anatomie de Montpellier) Recherche sur les matériaux de collement des objets en cire. Mémoire de fin d'études. Institut National du Patrimoine. 


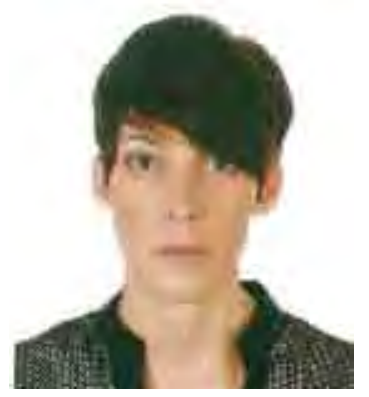

\author{
Nerea Del Moral \\ Licenciada en Bellas Artes \\ Universidad Complutense de Madrid. C/Greco 2, 28040. \\ nemoral@pdi.ucm.es./n_delmoral@yahoo.com
}

Premio Extraordinario de Licenciatura de la UCM curso 2007/08. Máster Oficial de Posgrado de la UCM en Conservación-Restauración y Exposición de Bienes Culturales. Becaria predoctoral con una Beca FPI de la UCM como profesor ayudante en prácticas.

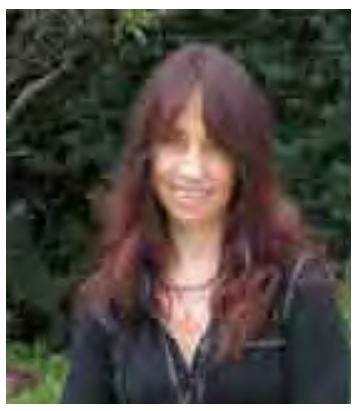

\author{
Alicia Sánchez Ortiz \\ Profesora Titular de la Facultad de Bellas Artes \\ Universidad Complutense de Madrid. C/Greco 2, 28040 \\ alicisan@ucm.es
}

Desde el año 1993 imparte docencia en las diversas titulaciones de Licenciatura, Grado y Máster en Conservación y Restauración del Patrimonio Cultural, así como en Programas de Doctorado y Títulos Propios de Magister, de la Facultad de Bellas Artes. Pertenece al Grupo de Investigación Investigación cromática: aspectos técnicos, formales y de significado en la expresión del color a través del arte (UCM930735). Ha dirigido y formado parte de varios proyectos de investigación relacionados con la conservación del patrimonio científicoartístico, destacando El arte de la ceroplástica anatómica: caracterización de materiales y metodología de actuación en conservación de colecciones de modelos anatómicos en cera (Museos anatómicos Facultad de Medicina (UCM) y Valladolid) (MICCIN HAR2009-10679) y La ceroplástica en veterinaria: documentación, caracterización de materiales y métodos de conservación-restauración en la colección Complutense (HAR2013-42460-P). Autora de libros, capítulos de libros, catálogos y actas de congresos, ha publicado también artículos de carácter científico en numerosas revistas. Conferenciante y ponente en congresos nacionales e internacionales dentro del campo del color y de la conservación. 


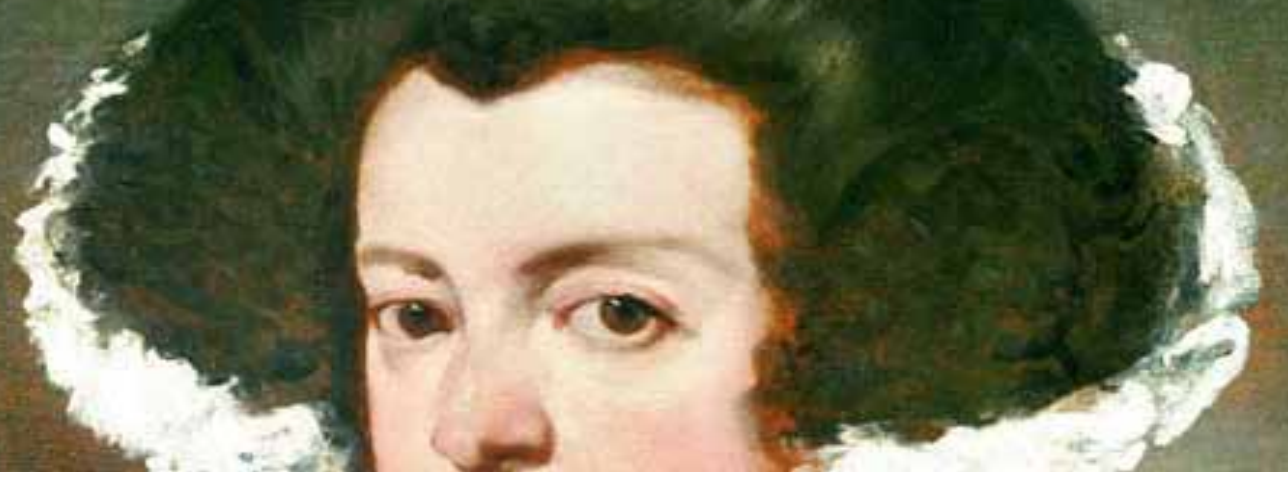

\section{Diego Velázquez: Un retrato del natural de la Reina Isabel de Borbón}

\section{Carmen Garrído Pérez}

Resumen: Entre las prácticas del pintor Diego Velázquez (Sevilla, 1599- Madrid, 1660), está la de realizar apuntes al óleo sobre lienzo "del natural", de aquellas personas de las que después haría retratos en otras dimensiones. En el catálogo de su obra existen esta clase de bocetos: rey Felipe IV, Infanta María Teresa o Baltasar Carlos. El de Isabel de Borbón que aquí se da a conocer viene a sumarse a los mencionados.

La inmediatez y la soltura técnica son las características más importantes de todos estos retratos, en los que el pintor ha centrado su trabajo en la captación del espíritu del personaje, de una manera que resulta más natural que las posteriores versiones que hará a partir de ellos. Debido a su finalidad, Velázquez se centra fundamentalmente en la cabeza, insinuando solamente otros detalles como el peinado, el posible atuendo o el fondo.

Todos los datos técnicos y estilísticos extraídos de este estudio de la Reina avalan la atribución al maestro sevillano.

Palabras clave: retrato de Isabel de Borbón; retrato de Velázquez; Estudio técnico de un retrato; autoría de Velázquez; boceto del natural.

\section{Diego Velázquez: A portrait of Queen Isabel de Borbón painted from life}

Abstract: One of the salient practices of Diego Velázquez (Sevilla, 1599- Madrid, 1660) was to make portrait oil studies from life of individuals that he would subsequently represent in other dimensions and formats. Among works of this type are portraits of king Philip IV, the Infanta María Teresa and the Infante Baltasar Carlos. The portrait sketch of queen Isabel de Borbón presented here is another such painting.

Immediacy and technical fluency count among the most important characteristics of these portraits; the painter has evidently concentrated his attention on capturing the "spirit" of the person and did so in a manner that appears more "natural" than subsequent versions of the image. Given the function of such images, Velázquez focuses almost exclusively on the head and merely implies details of the hairstyle, costume and the background.

The technical evidence and stylistic qualities of this study supports an attribution to the Sevillian master.

Key words: portrait of Elizabeth of Borbon; portrait of Velázquez; Technicalstudy of a portrait; Velázquezauthorship; sketch from life

\section{Diogo Velázquez: Um retrato do natural daRainha Isabel de Borbón}

Resumo: Resumo: Entre as práticas do pintor Diogo Velázquez (Sevilha, 1599- Madrid, 1660), figura a de realizar esboços a óleo sobre tela "do natural", daquelaspessoas de quemviria a fazer, mais tarde, retratos de outrasdimensões. No catálogo da sua obra existe esta classe de esbocetos: rei Filipe IV, Infanta Maria Teresa ou Baltasar Carlos. O de Isabel de Borbon que aqui se dá a conhecer, vem a somarse aos mencionados.

A imediatez e a soltura técnica são as características mais importantes de todos estes retratos, nos quais o pintor centrou o seutrabalhonacaptação do espírito da personagem, de uma forma que resulta mais natural que as versões posteriores que irá fazer, a partir 
destes. Tendoemconta a suafinalidade, Velásquez, centra-se fundamentalmente nacabeça, apenas insinuando outrosdetalhes, como o penteado, o eventual vestuárioou o fundo.

Todos os dados técnicos e estilísticos extraídos desteestudo sobre a rainhaatestam a atribuiçãoaomestresevilhano.

Palavras-chave: retrato de Isabel de Borbon; retrato de Velázquez; Estudotécnico de um retrato; autoria de Velázquez;esboceto do natural

La Reina Isabel de Borbón (1602-1644) fue la primera esposa del Rey de España Felipe IV (1605-1665), hijo del Rey Felipe III y de la Reina Margarita, cuyo reinado transcurrió entre los años 1621 y 1665 . Era hija de Enrique IV de Francia y de María de Medicis y se desposó en 1615 con Felipe IV, siendo aún Príncipe de Asturias, y por tanto heredero al Trono.

Aunque existen retratos de la Reina de otros pintores de la Corte como Rodrigo de Villadrando, Francisco Rizzi o Frans Pourbus, no son tantos los que conocemos actualmente pintados por Diego Velázquez. Hay pocas imágenes de ella que fueron repetidas, en ocasiones, varias veces por otros maestros menos dotados ${ }^{1}$. Tal vez, en esta escasez de representaciones pueda haber influido la idea transmitida por las crónicas sobre lo poco que le gustaba posar: "decía que no se dejaba retratar de buena gana" (Oliván 2012:1635; Doval 2009: 137-157).

El cuadro que aquí examinamos es un estudio de la cabeza de Isabel de Borbón (Óleo sobre lienzo, 73 x 59 cm), tomado del natural, de los que éste y otros pintores solían hacer como modelos del personaje antes de abordar la ejecución de la imagen definitiva (Fig.1). Bernardino de Pantorba en el año 1960 dio a conocer este prototipo en un cuaderniIlo, atribuyéndolo a Velázquez, y datándolo entre 1631-32, cuando la Reina tenía unos treinta años (Pantorba 1960).

La ejecución de retratos partiendo del boceto de la cabeza es un procedimiento que ya nos describe Francisco Pacheco, suegro de Velázquez, como punto de partida esencial para poder realizar posteriormente la pintura definitiva (Pacheco 1990). Este método tradicional fue empleado por grandes maestros de todos los tiempos, como por ejemplo los realizados por Goya entre mayo y junio de 1800 en Aranjuez para el Retrato de la familia de Carlos IV del Museo del Prado 2 . Para la toma de estos modelos, los personajes posaban, y de ahí el naturalismo que emerge de manera especial en estas representaciones. Como decía Sebastiano Ricci en un comentario sobre las pinturas religiosas, «el boceto es la obra terminada y el cuadro de altar la copia», lo que podría aplicarse igualmente al género del retrato.

Desde el principio, Velázquez siguió los consejos de Pacheco, y tenía «cohechado un aldeanillo aprendiz, que le servía como modelo en diversas acciones y posturas». Ya
Queen Isabel de Borbón (1602-1644) was the first wife of the King of Spain, Philip IV (1605-1665), son of King Philip III and Queen Margarita, who reigned from 1621 to 1665. The daughter of King Henry IV of France and Maria de Medici, Isabel married Philp IV in 1615 whilst he was still the Prince of Asturias and heir to the throne.

Although there are portraits of the Queen by other court painters such as Rodrigo de Villandrando, Francisco Ricci and Frans Pourbus, at the current time we know of very few painted by Velázquez. There are also a number of depictions of Isabel which were repeatedly copied by less capable artists '. Historical accounts suggest that the Queen did not enjoy sitting for her portrait - "it was said that she did not allow herself to be painted with any great desire." - and this may account for the scarcity of such representations (Oliván 2012:16-35; Doval 2009: 137-157).

The painting under examination here is a study of the head of Isabel de Borbón that has been painted from life (fig. 1; oil on canvas, $73 \times 59 \mathrm{~cm}$.). It is the type of study that Velázquez and other artists made as models before painting the finished portrait. In 1960, Bernardino de Pantorba published the picture in a pamphlet with an attribution to Velázquez and dated it to 1631-2, when the Queen was 30 years old. (Pantorba 1960)

The execution of a portrait based on a sketch of the sitter's head is a practice described by Francesco Pacheco, Velázquez's father-in-law, as an essential starting point in being able to complete the finished picture at a later time. (Pacheco 1990). This is a traditional procedure followed by great artists throughout the ages, such as the studies painted by Goya in Aranjuez between May and June 1800 for the Portrait of the Family of Charles V (Museo del Prado, Madrid)2. To create these models, the figures would pose in person for the artist; this direct encounter is reflected in the striking naturalism evident in such depictions. As Sebastiano Ricci said in an essay on religious paintings: "the bozzetto is the finished work and the altarpiece the copy" - a comment that could apply equally to the genre of portraiture.

From the beginning, Velázquez followed Pacheco's advice, and "hired a village apprentice, whom he used as a model in a variety of actions and poses." Even during his 


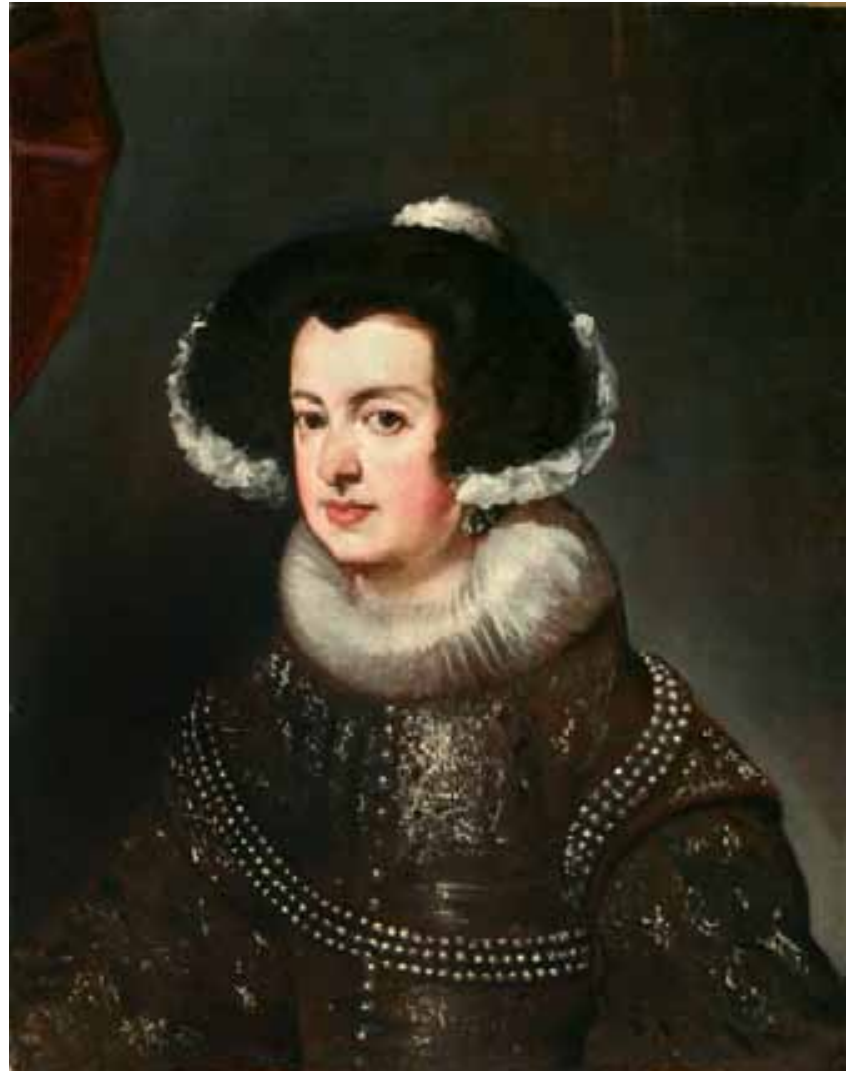

Figura 1. La Reina Isabel de Borbón. Colección particular.

en sus primeros años en la Corte, era tal su destreza en este sentido, que al comentarle el rey Felipe IV [...] «que no faltaba, quien dijese, que toda su habilidad se reducía a saber pintar una cabeza; a qué respondió: Señor, mucho me favorecen, porque yo no sé, que haya quien la sepa pintar», según cuenta Palomino en la biografía dedicada al pintor sevillano (Palomino 2008).

El examen de las imágenes radiográfica e infrarroja de la obra revelan el trabajo realizado por el pintor para la puesta en escena de la Reina, y la elaboración interna-externa necesaria para llevarla a cabo ${ }^{3}$. Este trabajo es el mismo, como se ha podido comprobar, al encontrado en muchas otras obras del autor ${ }^{4}$.

En primer lugar, sobre la preparación el artista marcó las líneas básicas de dibujo a fin de encajar la figura en el espacio, como se observa en el grueso trazo negro que bordea el peinado, en una ubicación superior a la que después se pintó. En el infrarrojo aparece esta línea por encima del adorno blanco que engalana su peinado (Fig.2). Otros trazos negros señalan el contorno de la cara, según vemos en el lateral derecho de la misma, bajando por el borde de la gola y marcando su límite en el lado contrario. Igualmente estas pinceladas de dibujo están en algunos perfiles del traje, en la manga izquierda al desplazarse hacia el exterior, y en la derecha, así como en torno al lugar por el que discurre el amplio diseño del adorno de las tres filas de perlas.

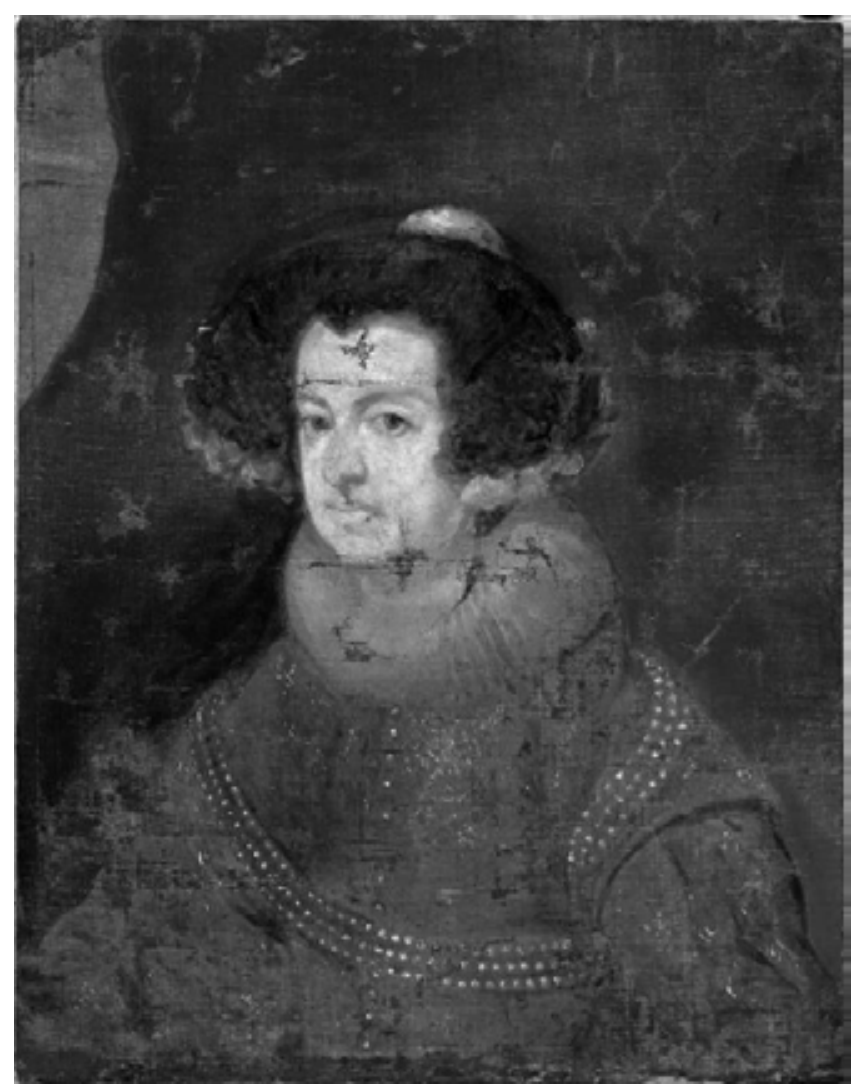

Figura 2. Imagen infrarroja del retrato.

early years at court, such was his ability in this regard that, according to Palomino in his biography of the artist, when King Philip IV commented that "... there are people who say that the essence of your skill is your ability to paint a face," Velázquez replied: "you favour me greatly, my Lord, because I do not know anyone who is able to do this." (Palomino 2008)

Examination of the x-radiograph and infra-red reflectogram of the portrait shows how the artist has established the subject on the canvas and the creative process employed in order to bring the portrait to completion ${ }^{3}$. As has been demonstrated, this process is the same as that found in many other works by Velázquez ${ }^{4}$.

The artist began by drawing the basic strokes to position the figure within the pictorial space, as can be seen in the broad black line around the top of the sitter's hair, showing too that this was originally higher than it was eventually painted. In the infra-red reflectogram, this line appears above the white net which adorns the hair (Fig. 2). Additional strokes of black define the outline of the face, as can be seen on the right side, running down the border of the ruff and marking its outer edges. Similarly, this brush drawing can be seen in some of the contours of the costume, and in both the right sleeve and left (as it turns towards the viewer), as well as the area occupied by the three strings of pearls. The shape 
También, de manera simplificada deja intuir la forma del vestido y los pliegues formados por la tela en su caída por la manga izquierda. A través de todos ellos, el maestro precisa las líneas del esquema general.

Las características del gesto y la grafía del somero dibujo se corresponden con los que Velázquez realiza habitualmente, tanto en sus cuadros acabados como en aquellos otros que al igual que éste son modelos para obras posteriores, según se constata en toda su carrera, por ejemplo el boceto para el Retrato de Baltasar Carlos a caballo del Museo del Prado que se conserva en la Galería Carrara (Bérgamo) o el también boceto de Felipe IV de última época del Museo del Prado, en el que el esquema de la creación artística sigue siendo el mismo (Fig. 3). Trazos de dibujo semejantes, aunque para prefijar detalles diferentes, son visibles directamente en obras sin terminar, como en el caso de la mano derecha del retrato de Hombre Joven (Pinacoteca de Múnich), o en el diseño de la escultura de la cabeza de Felipe IV en el retrato de Juan Martínez Montañés del Museo del of the dress and the folds in the fabric of the left sleeve are also sketched-in in the same abbreviated manner. In this way, the artist defined the overall composition of the portrait.

The graphic character of the summary preliminary drawing is consistent with Velazquez's usual practice, both in finished works and in preparatory sketches such as the present portrait. This can be seen in paintings from all stages of the artist's career, such as the bozzetto in the Accademia Carrara, Bergamo, for the Portrait of Baltasar Carlos on Horseback (Museo del Prado, Madrid) or the study for the late Portrait of Philip IV (also in the Prado), which follows the same creative process (fig. 3). Similar brush drawing, albeit to establish different details, is visible to the naked eye in unfinished works - see, for example, the right hand of the sitter in the Portrait of a Young Man (Alte Pinakothek, Munich), or the sketched sculpture of the head of Philip IV in the Portrait of Juan Martínez Montañés in the Museo del Prado (Ga-
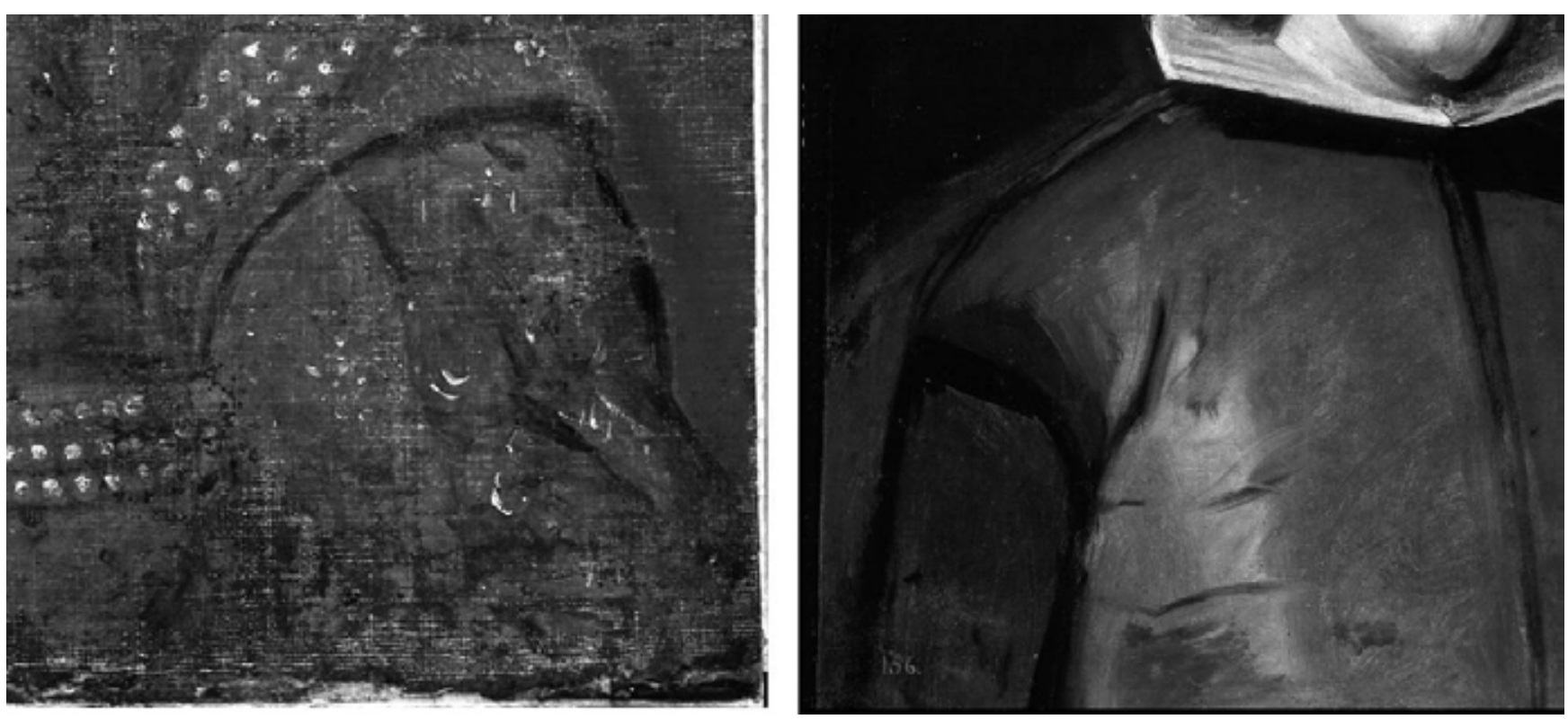

Figura 3. Comparación del dibujo de puesta en escena del retrato de la Reina con el retrato de Felipe IV, dos décadas posterior. Reflectografía infrarroja de la Reina y visible en blanco y negro del Rey.

\section{Prado (Garrido 1992).}

El infrarrojo también revela otras pinceladas negras, que, junto con las de color blanco, sugieren someramente los detalles decorativos del vestido, a la vez que nos permiten precisar un poco más la manera rápida y deshecha con la que Velázquez pintó el peinado de la Reina y algunas rectificaciones del cuello y del traje. Una imagen del cuadro, modificada con tratamiento digital a través de la saturación del color, completa esta información y ayuda a la interpretación de los dos documentos técnicos mencionados (Fig. 4). rrido 1992)

The infra-red image also reveals other brushstrokes of black which, along with brushstrokes in white, describe in an abbreviated fashion the decorative details of the sitter's dress. The reflectogram also allows us to observe more clearly the rapid, loose manner with which Velázquez has painted the hair and some of the changes he has made to the collar and costume. An image of the painting that has been digitally modified through colour saturation, and which can be compared to the x-ray and infra-red reflectogram, confirms these observations regarding the creative process (fig. 4). 


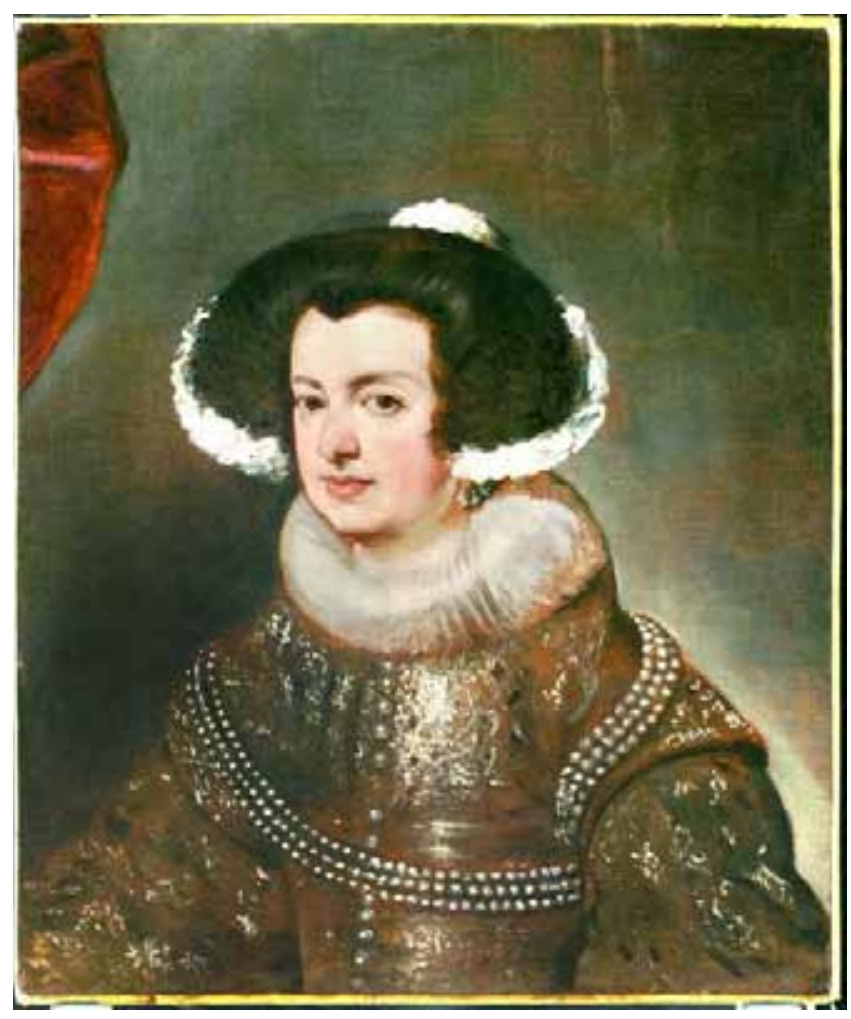

Figura 4. Imagen modificada con tratamiento digital.

La radiografía manifiesta el acusado contraste de la pintura con respecto al fondo, debido al proceso creativo del artista (Fig.5). Esta manera de trabajar es la que encontramos en las obras de sus etapas sevillana y madrileña. Después, poco a poco, las figuras se irán fundiendo con los fondos a causa del cambio que sufren los materiales empleados en las preparaciones de los lienzos, que pasan de la Tierra de Sevilla (de color ocre) usada en sus inicios, a la Tierra de Esquivias (de color naranja-rojizo) que se encuentra en sus primeros años de Madrid. Ambas carecen de radiopacidad frente a las que se hacen con albayalde como pigmento fundamental a partir de su primer viaje a Italia (1629-1631). El modelado de las figuras también irá cambiando, las capas de pintura serán cada vez más ligeras y el resultado radiográfico no será tan nítido, al ir ganando en la visión radiográfica el fondo óptico sobre la imagen definitiva (Garrido 1992).

El trazo superficial que marca el borde inferior del rostro en el lado izquierdo y el arranque del pincel que señala el límite del cuello al lado contrario, así como la luz más suave de la parte inferior de dicho cuello, revelan la grafía del pintor, que se ve reflejada incluso en obras muy posteriores como el boceto de la Infanta María Teresa del Metropolitan Museum (Colección Jules Bache, Nueva York). En este último o en el de la misma infanta conservada también en el Metropolitan (Colección Robert Lehman, Nueva York) el trazo de luz del inicio del cuello, en el lado derecho, se alarga en vertical dada

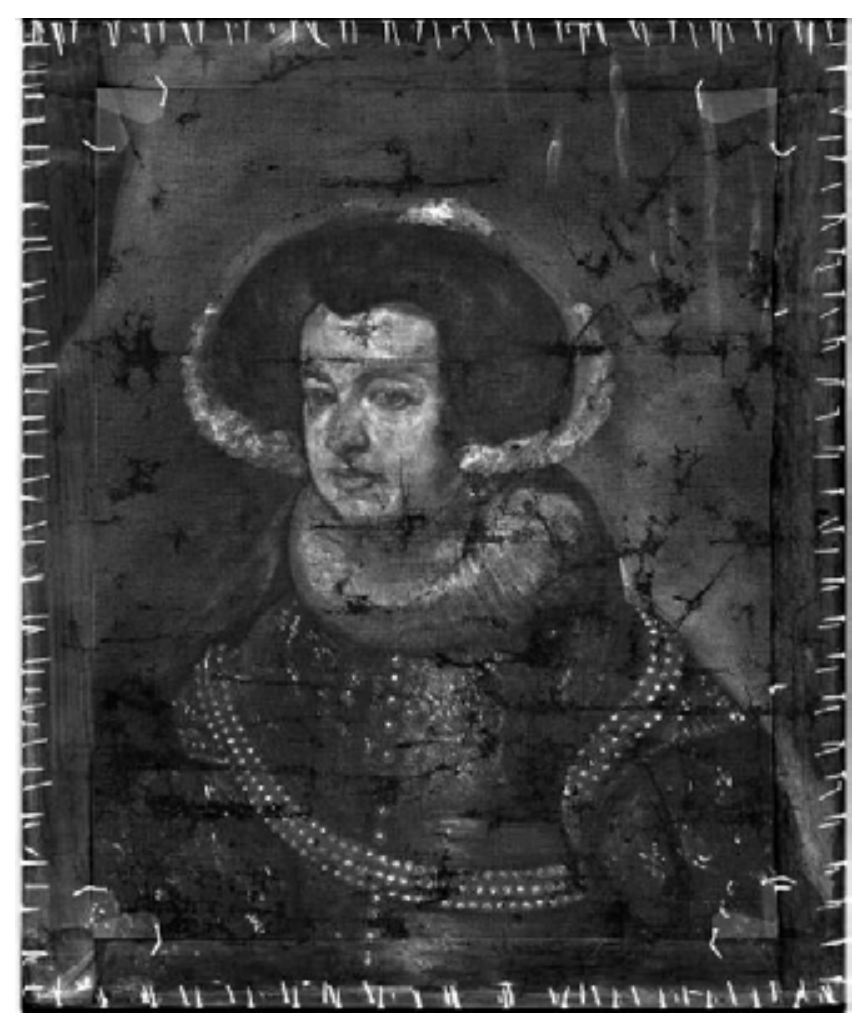

Figura 5. Radiografía general

The $x$-radiograph reveals the emphatic contrast between the figure and the background, which is the result of the artist's creative process (fig. 5). This way of working can also be found in paintings from Velázquez's Seville and Madrid periods. In later works, the figures tend to merge into the background because of the changes in the materials used to prepare the canvases - from the ochre of the 'Tierra de Sevilla' or 'Seville earth' ground used by the artist at the beginning of his career to the orange-red of the 'Tierra de Esquivias' or 'Esquivias earth' preparation found in the early Madrid works. Both of these types of ground lack the radiopacity of the grounds composed principally of lead white that Velázquez began to use on his first trip to Italy (162931). From this point, the modelling of the figures also begins to change; the layers of paint become progressively thinner such that the resultant $x$-ray image becomes less clear due to the increasing dominance of the background over the final image in the radiograph (Garrido 1992).

The topmost stroke of white that defines the lower edge of the face on the left side and the brushstroke indicating the line of the neck on the right, along with the softer lighting in the lower part of the neck, all reveal the hand of Velázquez. Such brushwork can also be seen in much later works by the artist, among them two preparatory studies for the Portrait of the Infanta María Teresa both in the Metropolitan Museum of Art, New York (Jules Bache collection and Robert Lehman collection), in which the stroke of light paint where the cheek meets the neck at the right hand side extends further upwards, in a more styli- 
su mayor estilización. En los cuellos de los personajes masculinos sucede algo similar: cuando quedan sin cubrir, dependiendo de si el cuello del retratado es corto o más largo, el arranque y desarrollo de estas pincela- zed manner. Something similar also occurs with the neck of the sitters in Velázquez's male portraits: when the neck is left exposed - depending on its length - the application and elaboration of the brushstrokes described above is the
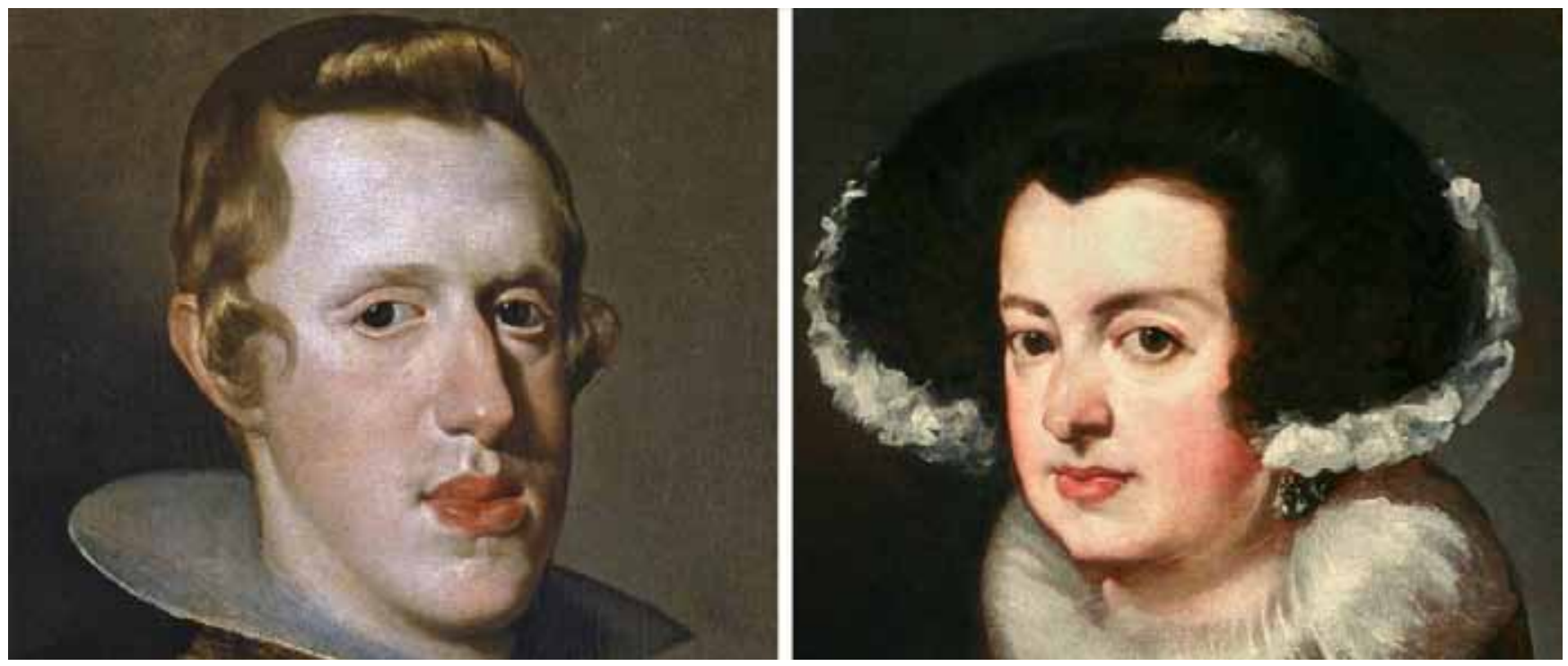

Figura 6. Comparación del retrato del rey Felipe IV con armadura con el de la Reina. El arranque de las pinceladas del inicio del cuello son similares, así como otros tratamientos de la superficie de la pintura.

das descritas son los mismos. (Fig.6)

La cabeza, por ser la zona más elaborada al tratarse de un estudio hecho del natural, está más empastada. El rostro se perfila respetando su lugar y encajándolo con el peinado según revela la radiografía. Este encaje va realizándose por aproximaciones del color, método que práctica Velázquez tanto en los retratos femeninos como en los masculinos, y en los personajes que integran sus composiciones, quedando siempre un pequeño espacio en el que el cabello queda más ligero sobre la carnación. Las capas de pintura más finas que cubren estos límites hacen que lo que se intuye en la imagen visible, en los documentos técnicos esté definido con mayor precisión, distinguiéndose la mancha o máscara inicial del rostro y su modelado posterior. En este modelado juega un papel muy importante la introducción de las luces a base de toques y trazos puntuales, como por ejemplo en los lacrimales, en los párpados y en las órbitas oculares, en donde el pincel se desliza con un ritmo circular, o bien mediante pinceladas más difusas en las mejillas y la frente, y toques menores en otras zonas a destacar de la cara. (Fig.7).

También es muy significativa la manera de hacer las sombras, que quedan enmarcadas por las luces que destacan con mayor intensidad en el documento radiográfico, práctica que encontramos en otros retratos y figuras pintadas por Velázquez. (Fig.8).

Otro recurso interesante es el de la ejecución del sombreado bajo la barbilla, la nariz o el hoyuelo de debajo de same (fig. 6).

There is a greater thickness of impasto in the face, since this is the most worked-up part of the portrait given that it is a study from life. As the x-ray reveals, the face is delineated within the space designated for it and fits closely under the hair - a fit achieved by the use of similar colours. This is a technique deployed by Velázquez in his portraits and in the figures in his larger compositions, where there is always a small area in which the hair is painted a little more thinly over the flesh tones. While thin layers of paint which cover the areas between the face and hair on the surface of the painting, the initial shape or silhouette of the face and its subsequent modelling can be seen more clearly in the $x$-ray and infra-red reflectogram. The use of highlights plays an important role in this modelling, ranging from precise dots and blobs of white in, for example, the lachrymals, eyelids and eyeballs, where the brush works in a circular movement, to broader strokes in the cheeks and forehead, and some smaller touches elsewhere that make the face stand out (fig. 7).

Also of great relevance is the way in which the shadows are formed, demarcated by the highlights which emerge more clearly in the $\mathrm{x}$-ray image, a feature we see in other portraits and figures painted by Velázquez. (fig. 8).

Equally significant is the execution of the shadows under the chin, nose and lower lip. Although they are 

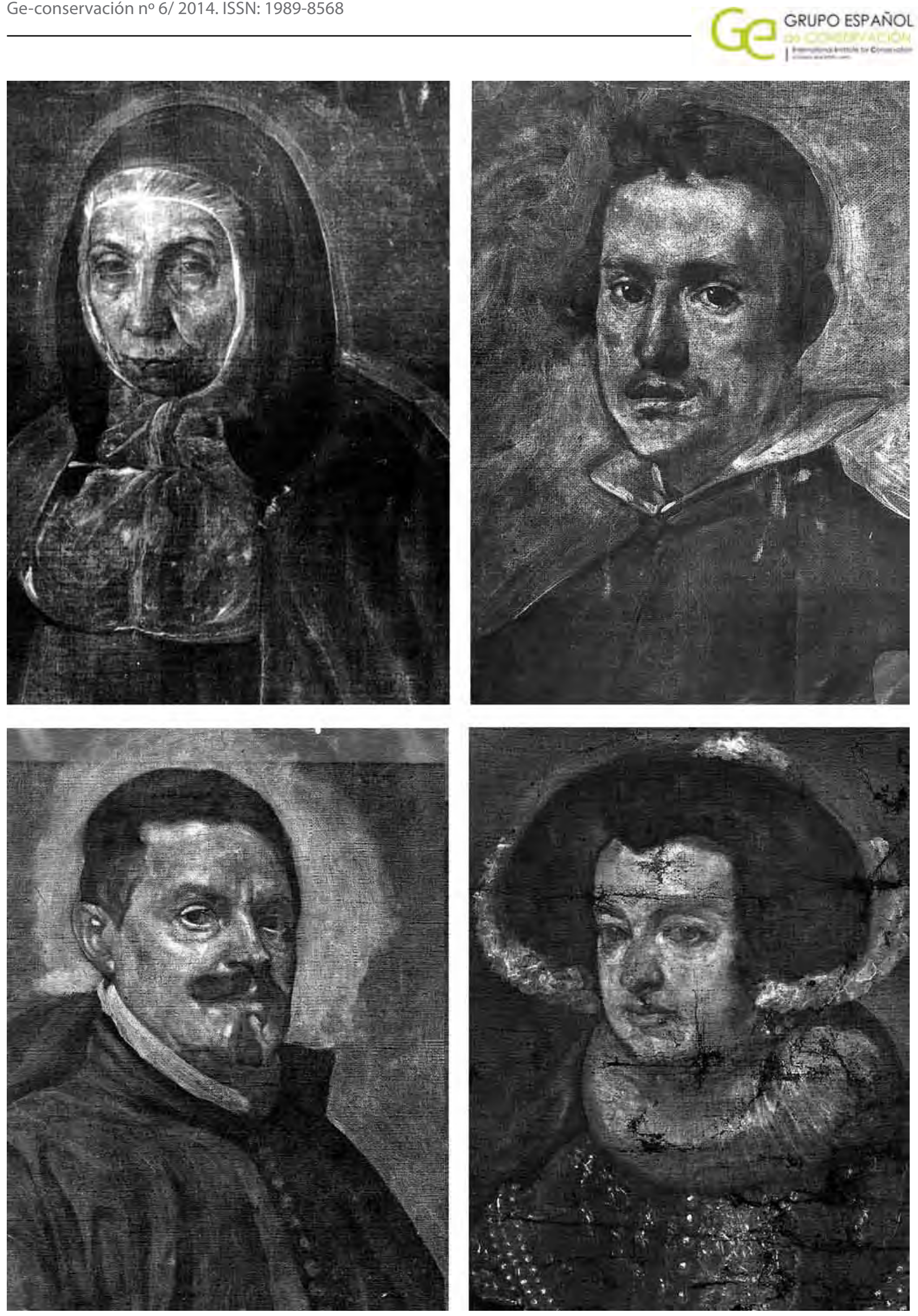

Figura 7. Detalles radiográficos de retratos de la década de los años veinte, cada uno con sus peculiaridades. En ellos destacan las diversas pinceladas introducidas por el pintor para resaltar las luces y los contornos. 


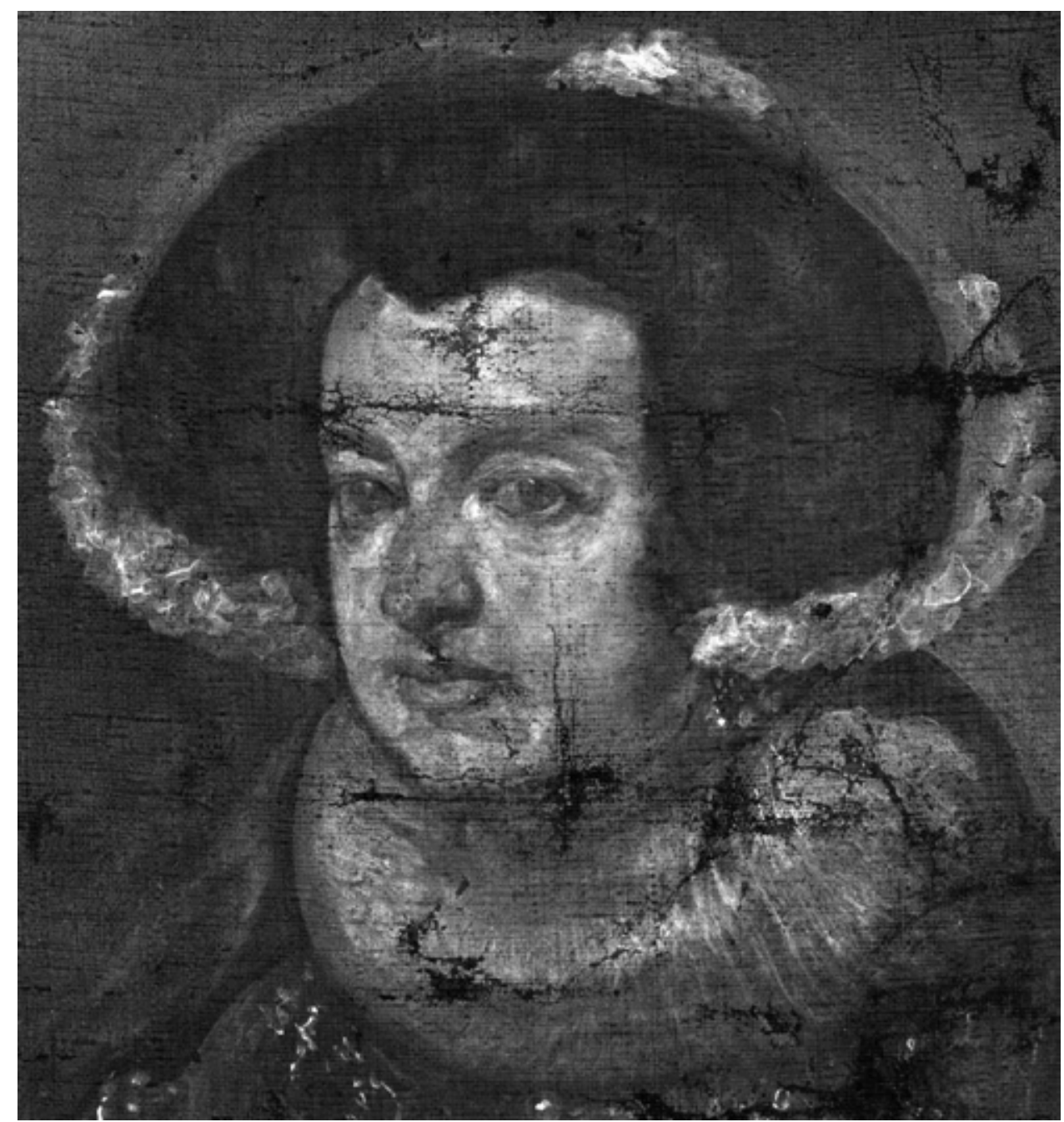

Figura 8. Detalle radiográfico de la cabeza de la Reina.
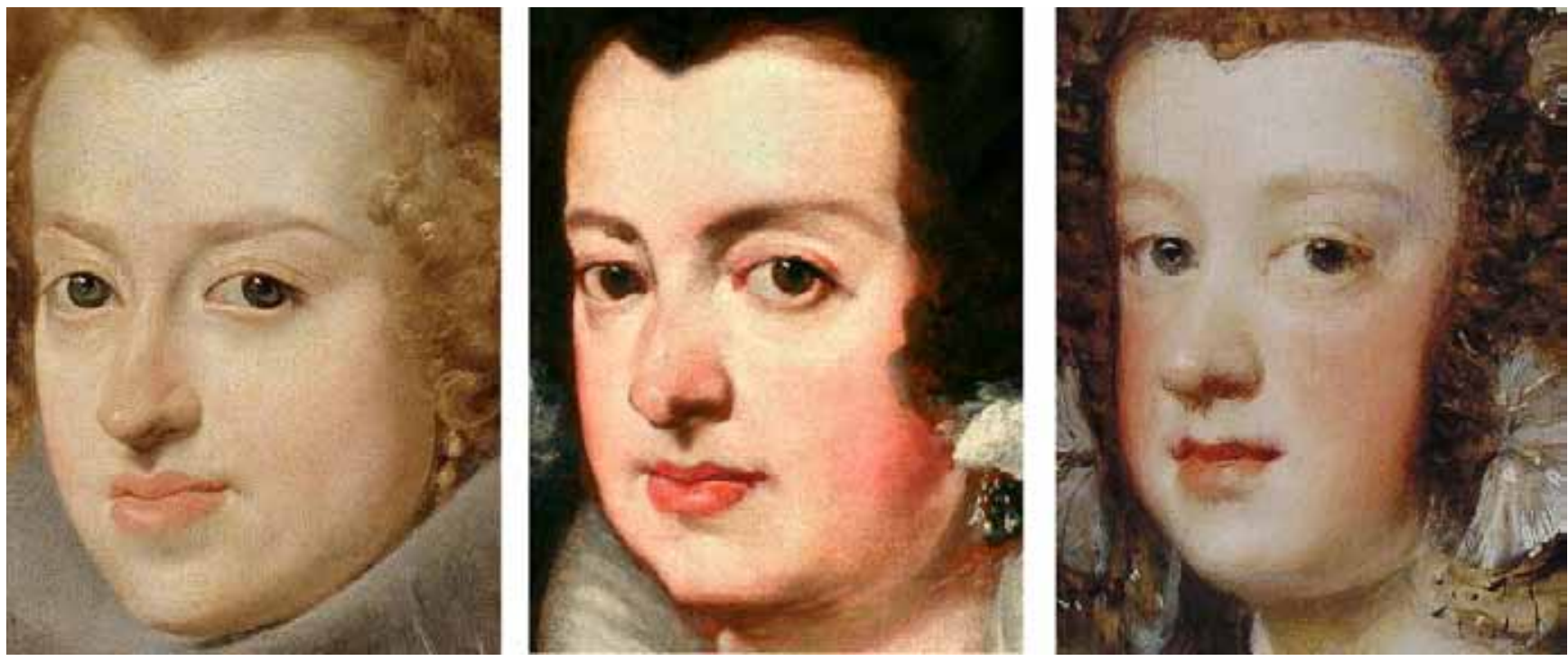

Figura 9. Comparación de los rostros de María de Hungría, Isabel de Borbón y María Teresa. Véanse las semejanzas de toques de luz (en los lagrimales, en la nariz en la boca o rodeando el ojo sobre la mejilla) y de sombra (en el cuello, bajo la nariz y la boca, etc.), el perfilado de la boca, los toques en las comisuras, el trazado en dos momentos de las cejas y el recto trazo que señala el perfil de la cara en el lado derecho, partiendo de debajo del ojo. En los tres casos, la manera de encajar el rostro y el pelo es muy parecida 
la boca; al igual que las demás sombras están pintadas de forma suave. A pesar de ello nos transmiten su existencia, sobre todo en el cuello, aunque esta es una zona menos terminada. Pero el efecto que producen resulta muy velazqueño (Fig.9).

El pintor ha captado con frescura la imagen y la expresión del rostro ya que, al ser un prototipo y estar tomado del natural, resulta más realista. Por otra parte, lo mismo que sucede en otras obras del pintor que quedaron en este nivel de acabado, el trabajo hecho hasta ese momento sugiere todos los detalles, y al contemplarlo a cierta distancia la idea de la representación se completa en nuestra retina, pareciendo terminado el conjunto.

En los modelos pintados por Velázquez para la ejecución de obras de mayor tamaño, por lo general retratos, ocurre algo semejante. Entre ellos se encuentran Maria de Austria, reina de Hungría (Museo del Prado), El Príncipe Baltasar Carlos (Gallería Carrara de Bergamo) (Garrido 1992), El retrato de una niña (The Hispanic Society of America, Nueva York), el de la Reina Mariana (Meadows Museum, Dallas), los dos antes mencionados de la Infanta María Teresa (Metropolitan Museum, Nueva York) o el de Felipe IV de busto (Museo del Prado, Madrid), de muy distintas dataciones a través de su carrera artística y con niveles de trabajo diferentes, a pesar de estar considerados todos como estudios del natural (Fig. 10). Al ser examinados de cerca se puede comprobar que no están "finitos", pero en la distancia todo se suma envolviendo la figura que nos parece terminada, ya que hasta el menor trazo indicativo de dibujo o realce nos permite imaginar cómo será el resultado final, al sugerirnos todos los detalles de la imagen. Por ser modelos, la cabeza es lo más trabajado por el artista para captar las facciones, la expresividad y el alma del personaje, mientras que en el inicio del cuello y el busto la pintura se va deshaciendo, ya que lo demás no le resulta necesario. Para el resto, no posa el personaje pues el pintor lo puedo componer libremente en el taller ${ }^{5}$.

Volviendo a los documentos técnicos, el borde derecho del rostro de la Reina esta perfilado dejando ver una fina línea rojiza que es debida al color de la imprimación, al igual que en todo el contorno de la cara y en el resto de la obra. En el centro bajo la gola, sobre la que Velázquez aplicó una base blanquecina y unos toques más intensos con albayalde para marcar los pliegues, esta imprimación queda al aire, aumentando su presencia en el lado izquierdo y hacia el fondo, como en la zona inferior.

En el traje se han superpuesto pequeños toques y pinceladas que insinúan las decoraciones y adornos de los realces bordados de la tela, y la imprimación juega, lo mismo que en el resto, como un color más que se suma al cromatismo general de la pintura, incluso con mayor presencia que los detalles sugeridos. En algunos de los painted quite softly like the shadows elsewhere in the portrait, they are nonetheless convincing, particularly in the neck even though this is a less finished area. However, the effect they produce is typical of Velázquez (fig. 9).

The artist has captured the features of the sitter and her facial expression with great immediacy, such that it appears more lifelike, as is to be expected in a prototype painted from life. On the other hand, as also occurs in other paintings by the artist that are brought to the same degree of completion that we see here, the work done up to this point already conveys all of the relevant details of the subject, and, when viewed from a certain distance, the image completes itself in the eye of the viewer and thus appears fully finished.

Something similar occurs in the studies painted by Velázquez for larger-scale compositions, which for the most part are portraits. These include the Portrait of María of Hungary (Museo del Prado, Madrid), Portrait of Prince Baltasar Carlos (Accademia Carrara, Bergamo) (Garrido 1992), Portrait of a Girl (The Hispanic Society of America, New York), Portrait of Queen Mariana (Meadows Museum, Dallas), Portrait of Philip IV, bust-length (Museo del Prado, Madrid) and the two previously discussed depictions of the Infanta María Teresa, both in the Metropoli$\tan$ Museum of Art, New York (fig. 10). Although they may all be considered studies from life, these works were painted at different points in the artist's career and executed to varying degrees of finish. When examined from close-up we can see that they are not 'finished', but from a distance everything comes together in the creation of the figure, such that it appears complete. Even the smallest stroke of the preliminary sketch or touch of light allows us to imagine what the final result will be, and in this way every detail of the subject is transmitted to the viewer. Because these works are studies, it is the head of the sitter that the artist has worked up most in order to capture the facial features, expressiveness and soul of the individual, whereas the base of the neck and the chest are painted more loosely, given that there is no need for anything more detailed here. For the rest of the portrait, the sitter did not pose for the artist, who could subsequently finish it in the studio ${ }^{5}$.

Returning to the technical analysis, one can see that the edge of the Queen's face is defined by a thin reddish line where the imprimatura has been left exposed. The same feature can be seen around the head and elsewhere in the painting. In the centre below the ruff, where Velazquez has applied a whitish base layer with some more emphatic strokes of lead white to define the pleats, the red of this priming layer has also been left uncovered, more so on the left side and towards the background, and likewise in the lower half of the picture.

In the costume, small overlapping strokes and touches of colour suggest the decorations and adornments of the embroidered trimmings of the fabric. The red of the imprimatura functions - as it does elsewhere - as another colour in the overall palette of the painting, but with greater emphasis in the specific areas described above. In some of the afore- 

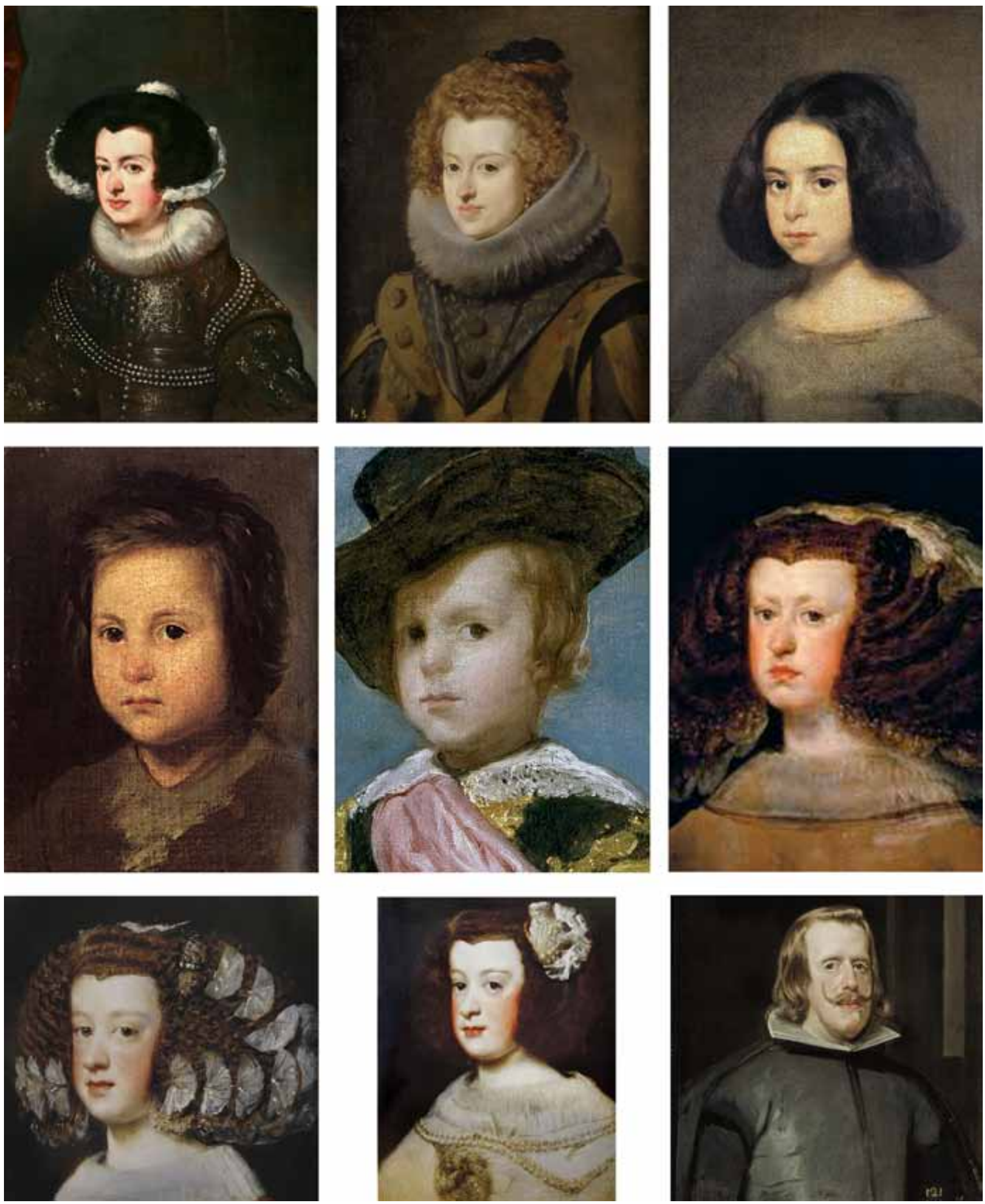

Figura 10. Obras consideradas como bocetos de Velázquez para pinturas de gran tamaño. 
estudios antes mencionados, por ejemplo en el del Retrato de niña de la Hispanic Society, sólo se sobrepone a este estrato de base los trazos de dibujo del patrón del vestido y algo de blanco manchado que sugiere una especie de muceta. De similar forma, en el Retrato de Baltasar Carlos de la Carrara o en el Felipe IV del Museo del Prado aparecen únicamente las líneas negras que delimitan los espacios de la forma del traje y unos toques de luces sobre el tono inicial de la tela. En otros bocetos, como el de la Reina María de Hungría, la gola y el vestido tienen una mayor definición, porque el pintor ha querido dotarle de un nivel de acabado mayor.

En la imagen forzada de color, antes mencionada, se constata la presencia de la tonalidad rojiza de la imprimación por todas partes, salvo en el rostro, por ser esta la zona más trabajada, como corresponde a un estudio previo. En la radiografía y en la reflectografía infrarroja también apreciamos su existencia en los contornos, en las zonas del traje menos decoradas y en el fondo del cuadro, porque al no tener pintura encima o sólo ligeras capas traslúcidas, aparece una línea, y zonas más oscuras, debido a la densidad diferente de la materia en esas partes del retrato. La complementariedad de las imágenes técnicas es fundamental para esta lectura.

La obra está pintada sobre un soporte de lienzo de tafetán que tiene, por $\mathrm{cm}^{2}, 9-10$ hilos en urdimbre por 7-8 pasadas en la trama. Los bordes de este soporte están cortados por el anverso, lo que no han permitido determinar la naturaleza de la tela. La reducción de la tela, tomada a través de la radiografía, está dentro de los parámetros de las empleadas por Velázquez en torno a la época de los primeros retratos del rey y de su hermano Don Carlos (1626-1628), así como de los estudiados en otras obras (Garrido 1992). Aunque el soporte haya sido cortado en los cuatro lados al reentelarse, las dimensiones del cuadro no debieron ser mucho mayores, ya que las ondas de tensión surgidas en todo el perímetro al ser clavado el lienzo sobre el bastidor original, se observan en la radiografía, especialmente en la parte superior.

En los cortes estratigráficos realizados, existe una preparación-imprimación que aparece en otras obras de la misma datación, en torno 1628 (Garrido 1992). En la escena de Los Borrachos del Museo del Prado, hay sólo esta única capa que le sirve al pintor tanto para preparar el lienzo tras encolarlo, según los métodos tradicionales, como para realizar el fondo óptico que sustentará la pintura. La presencia de un solo estrato ha sido encontrada también en el retrato de El inquisidor Don Sebastián de Huerta, recientemente redescubierto, y es de tonalidad anaranjada, igual que la empleada por Velázquez en sus obras de la etapa madrileña y descrita con la denominación de Tierra de Esquivias (óxidos de hierro mezclados con un poco de calcita, blanco de plomo y negro carbón con óleo como aglutinante)(Garrido 1992).

Los materiales de pintura empleados por Velázquez para la ejecución de este retrato son pocos y las mezclas muy sim- mentioned portrait studies, such as the Portrait of a Girl (The Hispanic Society of America, New York), lines sketching out the pattern of the clothing or strokes of white that suggest a cape are all that are painted over this base layer. Likewise in the Portrait of Prince Baltasar Carlos in the Accademia Carrara, Bergamo, and the Portrait of Philip IV, bust-length (Museo del Prado, Madrid), there are only black lines denoting the basic design of the costume and a few highlights applied to the priming layer. In other sketches, for example, in the Portrait of Queen María of Hungary (Museo del Prado, Madrid), the ruff and dress are more defined since the artist wanted to achieve a greater degree of finish.

In the digitally modified image of the portrait mentioned above, the reddish tonality of the priming layer is evident throughout, with the exception of the face since this is the most worked-up passage, as is to be expected in a preliminary study. In the x-ray and infra-red reflectogram, it can also be seen in the outlines, the less finished passages of the costume and the background of the portrait, and, since there is either no paint or just thin translucent glazes in these areas, one can see lines or darker areas because of the different density of material here. The concordance of the technical analyses in this regard is fundamental in our reading of the picture.

The portrait is painted on a taffeta canvas with a thread count of 9-10 threads per $\mathrm{cm}^{2}$ in the vertical direction and 7-8 in the horizontal. The edges of the canvas have been cut from the front, and as a result the original dimensions cannot be established. The thread count, which can be measured in the $x$-ray, is consistent with canvases used by Velázquez when he was working on his first portraits of the king and his brother Don Carlos (1626-1628), as has been seen in paintings studied elsewhere (Garrido 1992). Although the canvas was cut on all fours sides during relining, it cannot have been much larger since the cusping around the edges caused when it was placed on the original stretcher, is evident in the x-ray, particularly along the upper edge.

In the cross-sections taken, one can see a preparatorypriming layer that is found in other works from the same date, circa 1628 (Garrido 1992). In Los Borrachos or The Feast of Bacchus (Museo del Prado, Madrid), the artist has used just one such layer to prepare the canvas, after sizing it with glue in the traditional manner, to create the optical ground that will support the paint. There is also just a single preparatory layer in the recently rediscovered Portrait of the Inquisitor Don Sebastián de Huerta, and its reddish-orange tonality is the same as that used by Velázquez in works from his Madrid period. Known as 'Tierra de Esquivias' or 'Esquivias earth', it consists of iron oxide mixed with a little calcium carbonate, lead white and carbon black and bound with oil. (Garrido 1992).

In the present portrait, Velázquez has used only a few pigments, very simply mixed. This is typical of the artist who 
ples, hecho que es habitual en la obra del pintor, que con el dominio técnico que le caracteriza sabe crear una amplia gama cromática partiendo de lo esencial (Fig. 10). En muchas de las pinceladas blancas, el albayalde está aplicado directamente, como sucede en el tocado de este color en torno a su cabeza, en las zonas más luminosas de la gola y en los toques rápidos e igualmente lumínicos del traje y las perlas. De ahí su fuerte contraste radiográfico, ya que el pincel va más cargado de materia en aquellas zonas en las que hay que realzar la intensidad de la luz. Lo mismo sucede con el negro de origen orgánico en muchos de los trazos y toques dados en dicho tono en el peinado y en los elementos decorativos del vestido, aunque en este caso es la luz infrarroja la que los hace destacar, ya que carecen de respuesta radiográfica.

Existen en el cuadro otros dos elementos frecuentes en la obra de Velázquez que se observan con mayor nitidez en el documento radiográfico. El primero es el halo más claro que rodea la cabeza de la Reina, que queda al aire en ciertas zonas, y en otras se le superpone el tocado mediante toques rápidos que se van sumando, en los que el pincel juega en todas direcciones, creando un movimiento de gran belleza expresiva. Una zona de claridad también se crea a los lados del blanco cuello y en la caída del borde izquierdo del traje, por ser este lateral el que recibe mayor iluminación. Este recurso de clari- was capable of creating a broad palette of colours from quite basic elements - the result of the technical mastery that characterises his oeuvre (fig. 11). In many of the brushstrokes of white pigment, the lead white is applied directly, as can be seen in the headdress, in the brightest passages of the ruff and in the rapidly executed highlights of the costume and pearls. This creates a strong contrast in the x-ray since the brush is more heavily loaded in the areas that require greater highlighting. The same contrast can be seen with the organic black used for many of the dark lines and strokes in the hair and decorative elements of the dress, although in this instance it is the infra-red reflectogram that reveals this given the lack of radiopacity of the black.

The x-ray reveals more clearly two other features often found in works by Velázquez. The first is the 'halo' or circle of light around the Queen's head. In some sections, it is left exposed, whereas in others it is covered by the headdress, which is created through the build-up of rapid brushstrokes. Here the brush flows in every direction, creating a movement of great expressive beauty. There is a strip of light on either side of the white collar and also down the left edge of the costume, since this side is more strongly illuminated. This serves to create the illusion of space bet-
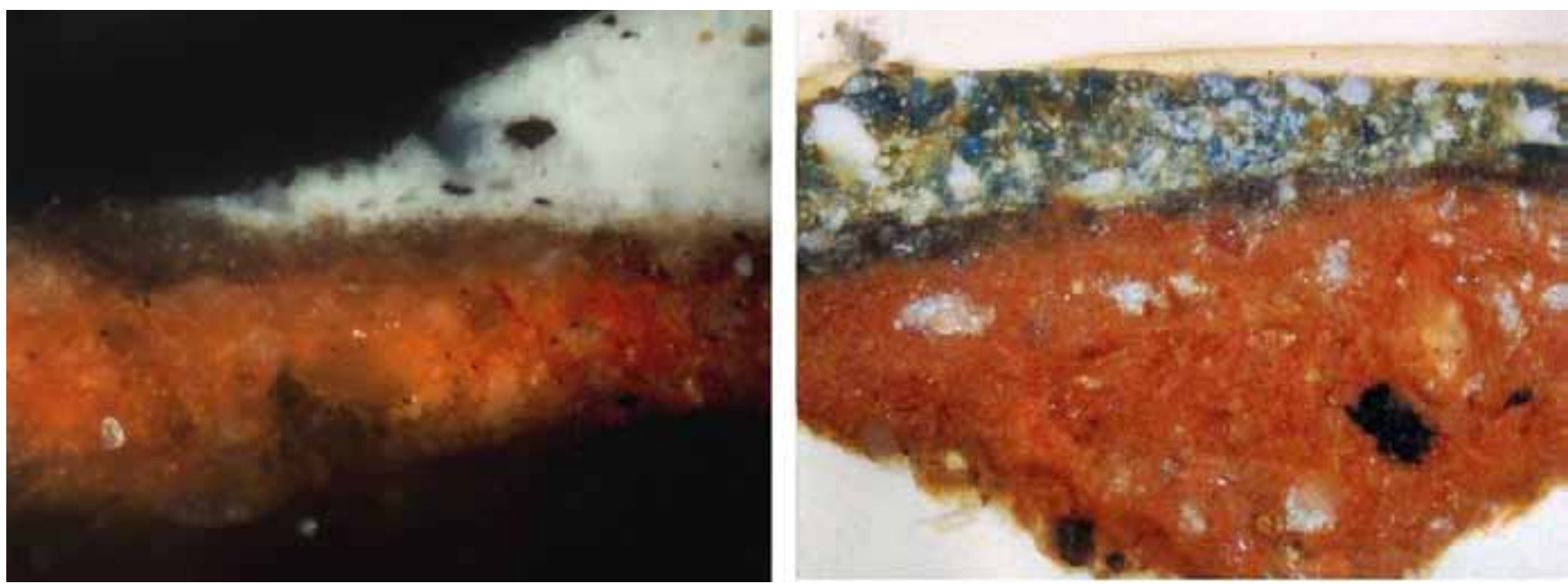

Figura 11. Cortes trasversales sobre micromuestras de pintura. A la izquierda, el de la Reina y a la derecha el de Los Borrachos

dad hace que se cree un efecto de espacio entre la figura y el fondo, que la hace salir hacia el exterior, mientras que la oscuridad hace profundizar la figura en el lado derecho. (Fig.11).

El segundo, es la limpieza o pruebas del color que aparecen sobre el ángulo superior derecho de este cuadro, práctica habitual en muchas de sus obras. En este caso, están dadas de similar forma y tienen una grafía semejante a las del retrato de La Venerable Madre Sor Jerónima de la Fuente o el Retrato del Infante Don Carlos, hermano del Rey, ambos en el Museo del Prado. En todos los casos están dispuestas en un lugar parecido, aunque también ween the sitter and background such that the figure advances towards the viewer, while the darkness on the right causes it to recede (Fig. 11)

The second distinctive feature of the present portrait is the series of brushstrokes in the upper right corner of the picture, where Velázquez has either cleaned his brush or tested colours, an habitual practice found in many of his paintings. The strokes found here are similar in form and in style to those in the Portrait of Venerable Mother Jerónima de la Fuente and the Portrait of the Infante Don Carlos, both in the Museo del Prado. In all three works, they are painted in the same place in the canvas, although the strokes 
aparecen de manera más individualizada. Al final quedan al descubierto o se traslucen a través de las ligeras capas de los fondos, al "trepar" hacia la superficie los tonos oscuros por la translucidez natural de su técnica, acentuada a través del tiempo y sumada al desgaste de los últimos estratos del color (Fig.12). themselves are quite individualized in appearance. In the end, they are either left uncovered or show through the thin glazes of the background, as the darker tones of the strokes rise to the surface - the result of the natural translucency of Velázquez's technique and a process which becomes more pronounced over time and with the thinning of the topmost glazes (fig. 12).
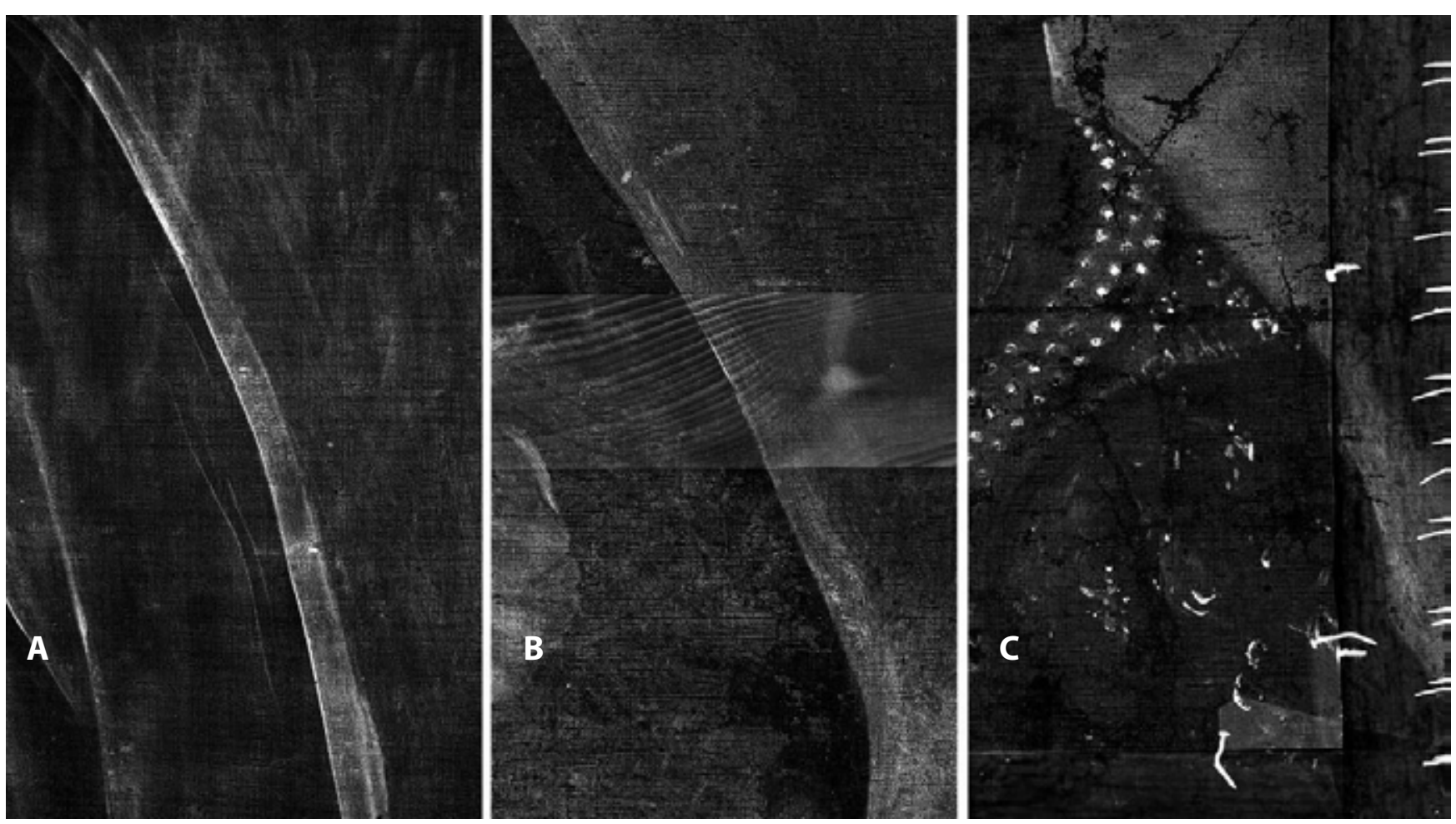

Figura 12. Halos en torno a las figuras: A: La Venerable Madre Sor Jerónima de la Fuente. Museo del Prado.; B: Don Sebastián de Huerta. Colección particular; C: Reina Isabel de Borbón.
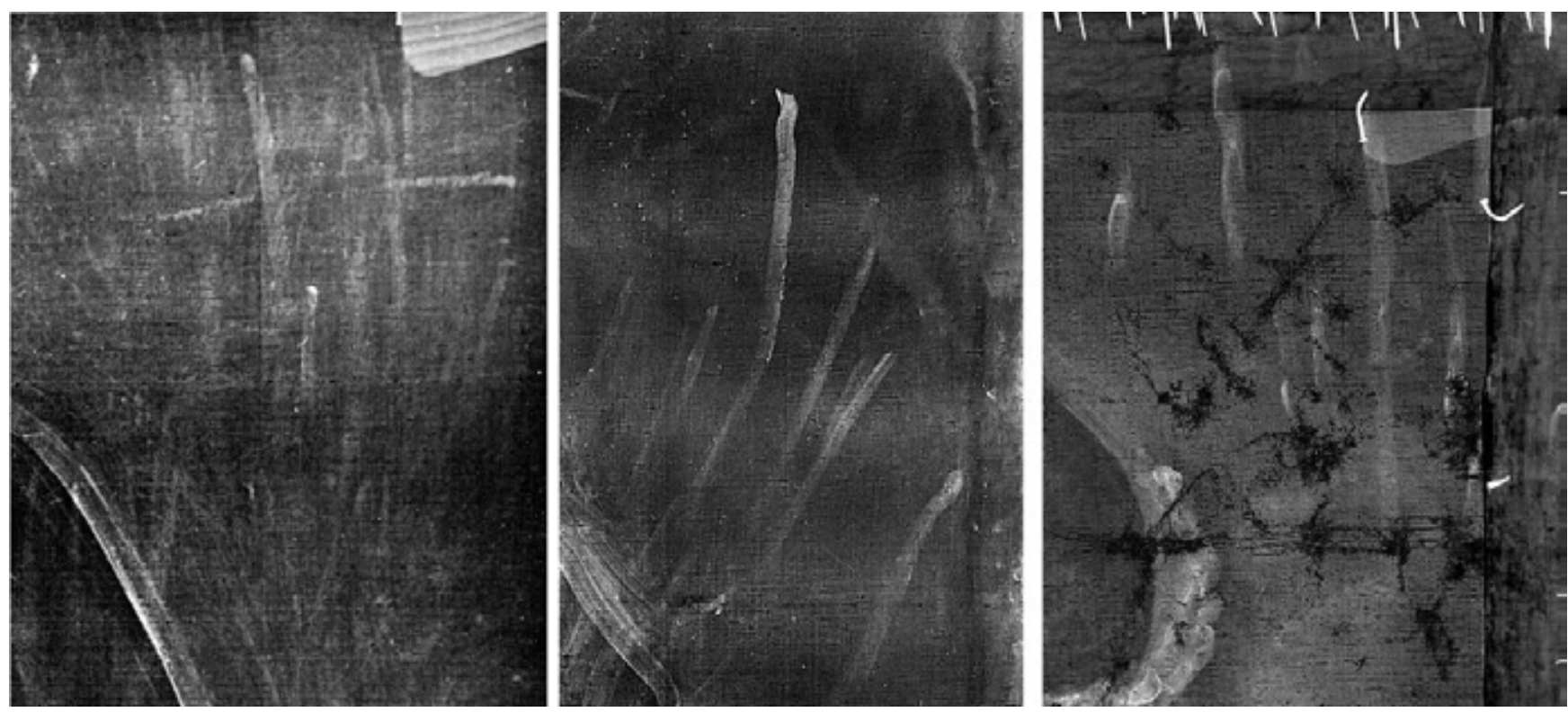

Figura 13. Limpieza o descarga de los pinceles: A: La Venerable Madre Sor Jerónima de la Fuente. Museo del Prado; B: El Infante Don Carlos de Austria. Museo del Prado; C: La Reina Isabel de Borbón 
La cortina colocada en el ángulo superior izquierdo está solamente insinuada, marcándose con un trazo de diseño negro su contorno, y con restregones del mismo pigmento las zonas internas del plegado. En los bordes de los pliegues que sobresalen, ha aclarado la laca roja con algo más de albayalde, pero estos trazos, como sucede en otras partes, son sólo un somero pincelado de la puesta en escena. Todo el contorno de esta cortina está iluminado, al igual que la figura, por medio de un halo blanquecino. En la fotografía publicada por Pantorba en 1960 no se observa este elemento, que estaba tapado por una restauración anterior, ya que en la radiografía se delimita el espacio reservado para ella desde el principio, y en la última restauración ha podido comprobarse la existencia del repinte.

La pintura ha sufrido pérdidas en el transcurso de su historia material. En la radiografía pueden verse con claridad, si bien, por fortuna, éstas no afectan de manera significativa a las partes fundamentales del rostro. Por las líneas horizontales que se marcan sobre el soporte, pensamos que la tela ha podido estar desclavada del bastidor y doblada, lo
The curtain in the upper left corner is just sketched in, its edge defined by a black outline with washes of the same pigment in the folds. Velázquez has lightened the red lake with lead white on the tops of the folds, but the strokes here give only a summary indication of the object they depict, as occurs elsewhere in the portrait. The full length of the curtain's edge is lit with a strip of whitish light, just like the figure itself. The curtain is not visible in the photograph of the portrait published by Pantorba in 1960, as it had been painted over in a previous restoration. In the x-ray, however, the space originally left for the curtain is clearly defined and the overpaint in this area was revealed in the recent restoration.

The painting has suffered some losses over time. These are clearly visible in the x-ray, although thankfully they do not significantly affect the most important passages of the face. The horizontal lines across the canvas suggest that in the past the painting might have been removed from its stretcher and folded, and this would have contributed
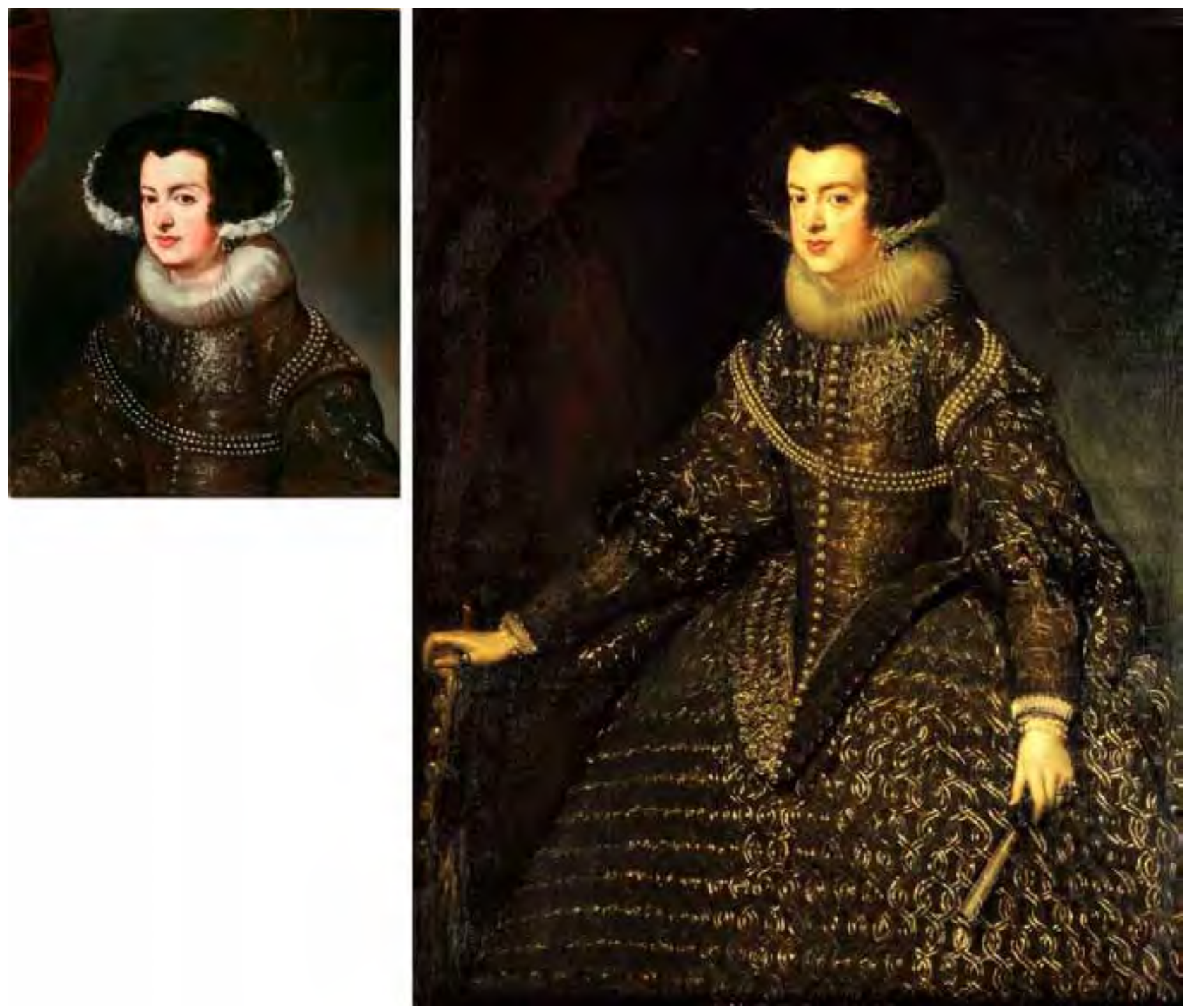

Figura 14. Comparación del boceto de la Reina con el retrato conservado en Viena 
que habría contribuido a los daños que revela. Actualmente, tras un proceso de restauración muy delicado y cuidado, la obra ha recobrado su esplendor, dejándonos ver en detalle la gran calidad que tiene ${ }^{6}$.

La técnica de ejecución del retrato, los materiales empleados y su forma de introducirlos reafirman, a nuestro parecer, la idea de que estamos ante un estudio de la Reina Isabel de Borbón, pintado por Diego Velázquez para la ejecución de otros retratos de Estado que se harían a partir de este modelo realizado del natural, en torno al año 1628, poco antes de su primer viaje a Italia. No se conserva ninguno de cuerpo entero de este momento, aunque es posible que se hiciese lo mismo que el del Rey, el de su hermano Don Carlos, el Conde-Duque o el de otros personajes relevantes de la Corte. Sí se conservan en cambio otros anteriores como el pintado por Villandrando y otros posteriores de Velázquez, además de gran número de copias de menor fortuna de este y otros modelos que realizarían pintores de la corte madrileña.

El que se estudia en este artículo pudo servir para el Retrato de lsabel de Borbón, de tres cuartos, conservado en Viena (Kunsthistorisches Museum, Viena), de mejor calidad que el del Rey con el que se le quiere emparejar, fechados habitualmente en torno a 1632. (Fig. 14). Las pinceladas de la cara y el cuello, así como el halo de luz lateral, o el toque de algunas partes de las decoraciones del vestido recuerdan la grafía y los recursos del pintor, con las diferencias existentes entre un boceto y un cuadro acabado, que pudo tener la participación de algún ayudante. (Fig. 15). to the damages seen. After an extremely careful and sensitive restoration, the portrait has recovered its original splendour, such that we can now see in detail the high quality of the painting. ${ }^{6}$

In the view of the present author, the technique of the portrait, the materials used and the way in which they are used, all confirm that the painting under examination is a study of Queen Isabel of Borbón, painted from life by Diego Velázquez around 1628, shortly before his first trip to Italy, as the model for other State portraits of the Queen. No full-length depiction of the Queen from this period is known, although it is possible that such a work was painted, as was indeed the case with the King, his brother Don Carlos, the Count Duke of Olivares and other figures from the Court. It is true, however, that there are earlier portraits of the Queen by Rodrigo de Villandrando and later ones by Velázquez himself, along with many lesser copies of the present composition and other depictions of the same sitter painted by artists active at the court in Madrid.

The painting under discussion here could have been the model for the three-quarter-length portrait of the Queen now in the Kunsthistorisches Museum, Vienna (fig. 14). Generally dated to c. 1632, it is of better quality than the portrait of the King Philip IV in the same museum with which it is paired. The brushstrokes in the face and collar, the strip of light along the left side figure and the execution of some of the costume decoration recall the brushwork and technique characteristic of the master, albeit allowing for the differences between a fully autograph study and a finished painting which may have involved the participation of an assistant (Fig. 15).
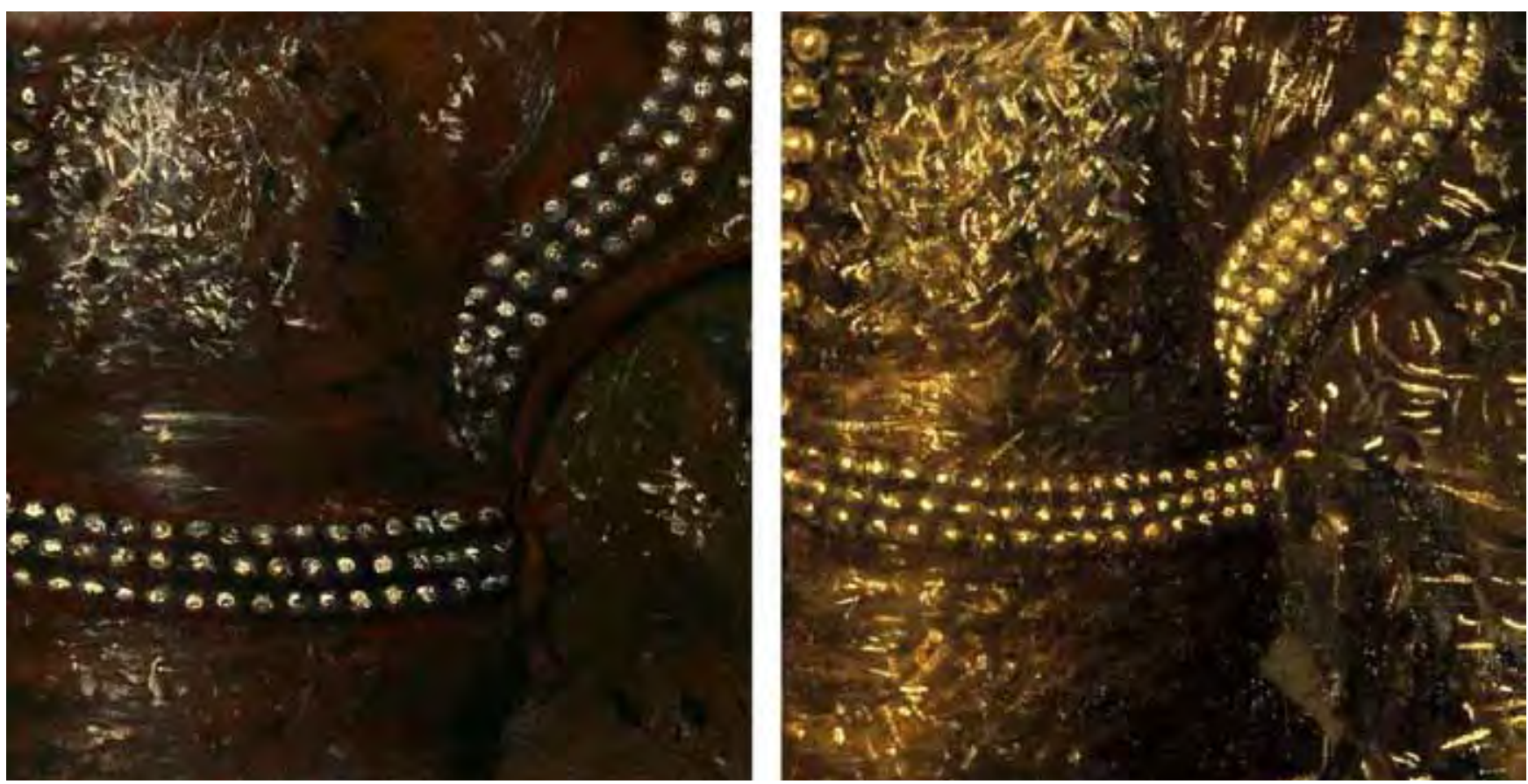

Figura 15. Comparación de las decoraciones de los vestidos de ambos retratos. En el prototipo destaca la simplicidad y limpieza del juego en los brillos de las pinceladas. 
En un retrato de la Reina de cuerpo entero (Col. Particular, Nueva York), pintado tras el viaje a Italia, y que estuvo colgado en el Palacio del Buen Retiro, el rostro se encuentra más idealizado, si bien su radiografía muestra que el punto de partida era una
In a full-length portrait of the Queen (Private Collection, New York; fig. 16) painted after Velázquez's trip to Italy and hung in the Palacio del Buen Ritiro, the face is more idealised, although the $x$-ray image shows that the starting point for the head -
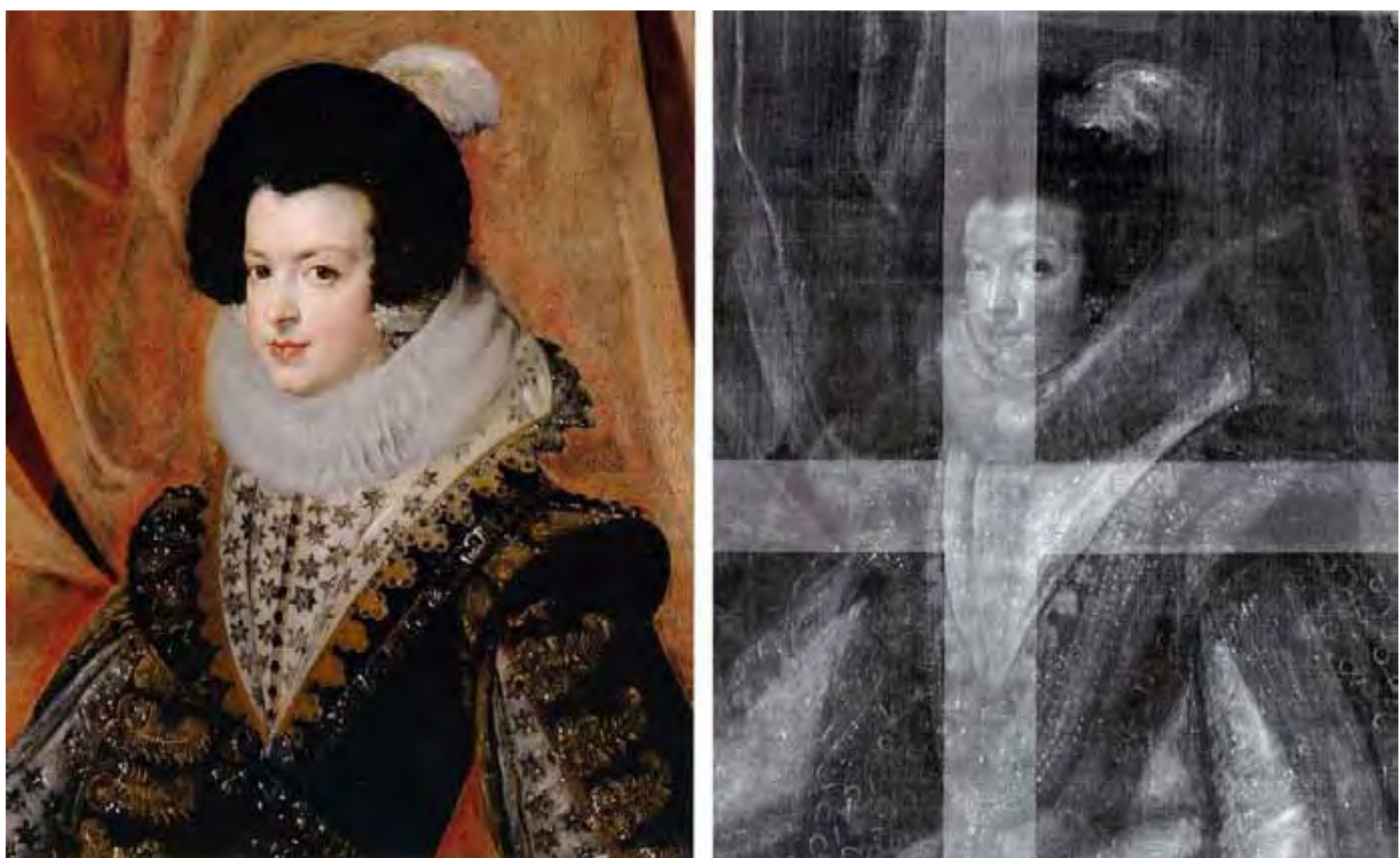

Figura 16. Detalle del retrato de la Reina Isabel de Borbón de una colección particular de New York. Imagen visible y radiográfica.
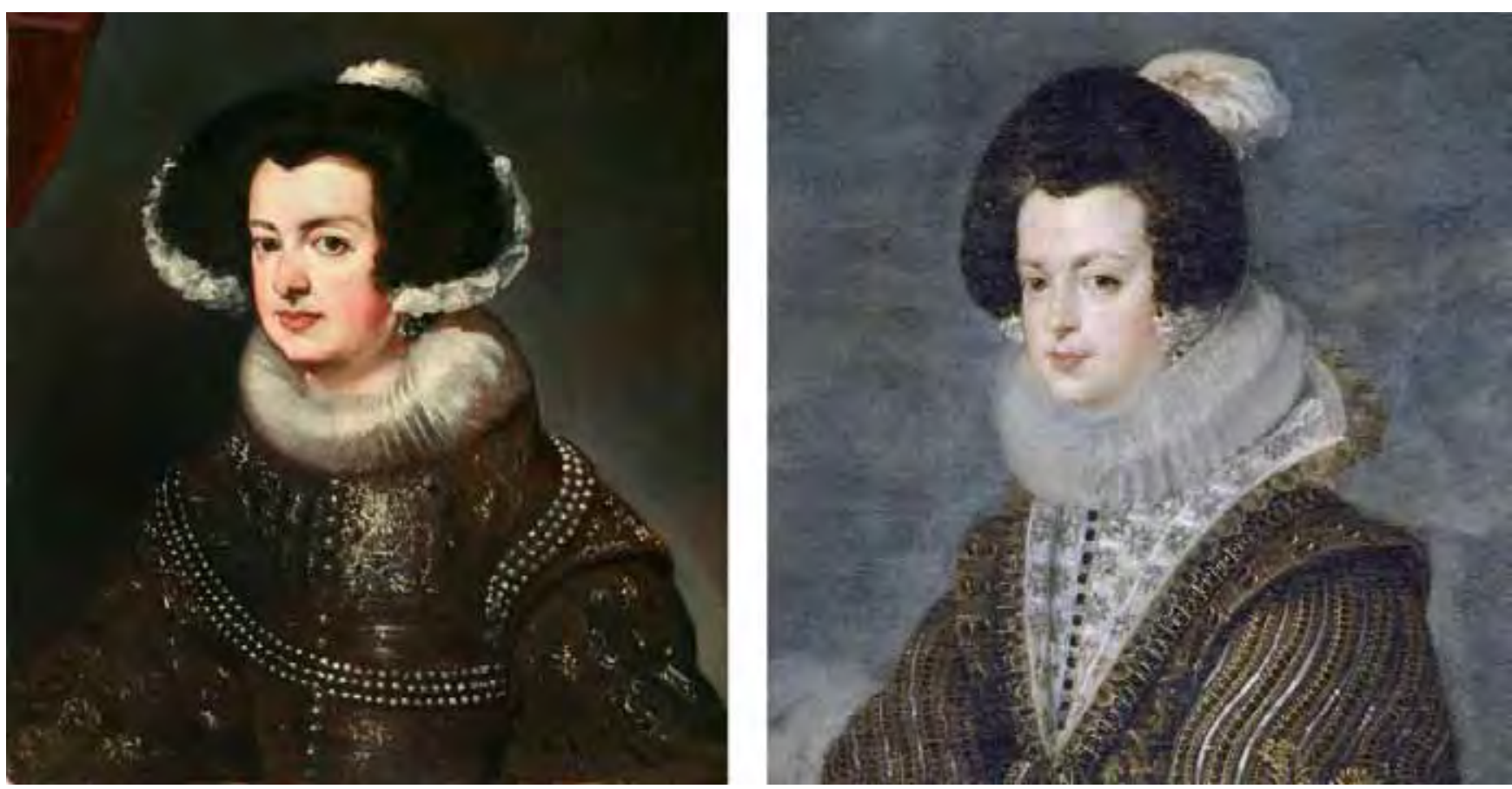

Figura 17. Comparación del boceto de la Reina con la cabeza del retrato ecuestre del Museo del Prado. 
imagen más cercana al boceto que ahora estudiamos, teniendo incluso el peinado semejante en altura. El tocado inicial de la parte superior es muy parecido (Grombie,1958). (Fig.16)

El último retrato de la Reina conservado es el ecuestre pintado para el Salón de reinos del Buen Retiro, ya de mitad de la década de los treinta, cuya cabeza, como otras partes del cuadro fue pintada por Velázquez, manifiesta una evolución técnica de los años transcurridos, así como una idealización aún mayor del rostro. (Fig. 17)

Este redescubrimiento es probablemente el primero y único ejemplo de un estudio del natural de Isabel de Borbón, y una incorporación importante al catálogo de la obra de Diego Velázquez, y claramente cubre un vacío en la producción del artista antes de su primer viaje a Italia.

\section{Notas:}

[1] Sobre este modelo, véase Mayer 1936, Lam. 180, № 477 y 477.

[2] De los personajes que aparecen en el cuadro del Prado, además de los Reyes, el Museo conserva cinco bocetos tomados del natural. Garrido 2002, 287-309.

[3] Los documentos técnicos y los exámenes analísticos del cuadro han sido realizados por el Dr. Nicholas Eastaugh y la Dra. Jilleen Nadolny de Art Access and Research, Londres, Analytical Report. Ref. AAR0215/11 de 25 noviembre 2011.

[4] Para el conocimiento de la técnica del pintor: Garrido, 1992, y Brown y Garrido 1998.

[5] Como sabemos por anécdotas contemporáneas: [...] «hecha que fue la cabeza, para lo restante del cuerpo, por no cansar a la dama, lo trajo a mi casa para acabarlo, que era de medio cuerpo [...]» (Martinez 1988, 211-212). Hecho referido a un retrato femenino pintado por Velázquez en la ciudad de Zaragoza.

[6] La restauración ha sido llevado a cabo por Simon Folkes, Londres. including the height of the coiffure - was closer to the present study. The initial brushstrokes in the hair are also very similar. (Grombie 1958) (Fig.16)

The final depiction of Isabel is the equestrian portrait executed for the Salon de Reinos in the Buen Retiro palace in the mid1630s The head of the sitter, painted along with other parts of the picture, by Velázquez, shows the development of the artist's technique in the intervening years and reveals an even greater idealisation of the face. (Fig. 17).

This rediscovered portrait is probably the first and only example of a study from life of Isabel de Borbón. As such it represents an important addition to the oeuvre of Diego Velázquez and fills a gap in the artist's production before his first trip to Italy.

Notes:

[1] For this model, see Mayer 1936, pl. 180, nos. 476 \& 477 .

[2] The museum has five studies painted from life for figures in the picture, in addition to those for the King and Queen. See Carmen 2002, 287-309.

[3] The technical analysis was done by Dr. Nicholas Eastaugh and Dra. Jilleen Nadolny of Art Access and Research, London (Analytical Report, Ref AAR0215/11, 25 November 2011).

[4] For studies on the artist's technique see Garrido, 1992, and Brown and Garrido 1998.

[6] As we know from contemporary accounts: “... he did the head but, so as not to tire the lady, he brought the picture, which was a half-length portrait, to my home to finish it ..." (Martinez 1988, 211-212.). This is in reference to a female portrait painted by Velázquez in Zaragoza.

[6] The restoration was done by Simon Folkes, London.

\section{Bibliografía:}

BROWN, J. y GARRIDO, C. (1998). La ténica del Genio. Yale University. Madrid: Ediciones Encuentro.

CROMBIE, T. (1958). "Isabella of Bourbon by Velázquez", Connoisseur, 141, 238-244.

DOVAL TRUEBA, M. del M. (2009). “Velázquez y los retratos de Isabel de Borbón", Boletín Museo e Instituto Camón Aznar. №103, 137-157.

GARRIDO, C. (1992). Velázquez técnica y evolución. Madrid. Museo del Prado.

GARRIDO PÉREZ, C. (2002). “Cómo se pintó el retrato de la Familia”, 
en Goya. La familia de Carlos IV. Ed. a cargo de Manuela B. Mena Marqués. Madrid: Museo Nacional del Prado, 287-309.

GARRIDO, C. (2004). “Puntualizaciones sobre algunos retratos de Diego Velázquez". Goya. Revista de Arte, n² 298: 4-24.

GARRIDO, C. (2013). "Velázquez y el Inquisidor”, Ars Magazine. Número 17, enero-marzo: 56-68.

MARTINEZ, J. (1988). Discursos practicables del novilísimo arte de la pintura. Madrid: Akal.

MAYER, A. L. (1936). Velázquez. A Catalogue Raisonné of the Pictures and Drawings. Londres, Faber and Faber, Limited.

OLIVÁN SANTALIESTRA, L. (2012). “Decía que no se dejaba retratar de buena gana". Modestia e invisibilidad de la reina Isabel de Borbón (1635-1644)", en Goya. № 338: 16-35.

PACHECO, F. (1990). El Arte de la Pintura [1649]. Madrid: Ed. Cátedra.

PALOMINO, A. (2008). Vida de Don Diego Velázquez de Silva [1724] Madrid, Ediciones AKAL.

PANTORBA, B. de (1960). Sobre un retrato de la reina Isabel de Borbón, Madrid.

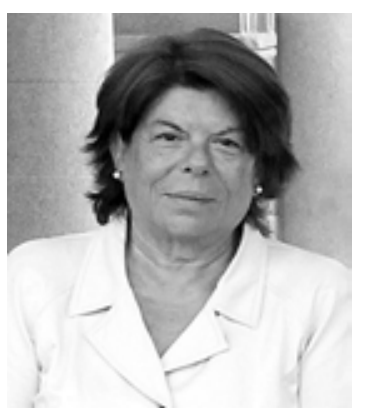

\section{Carmen Garrído Pérez}

carmengarridoperez@gmail.com

Doctora en Historia del Arte, especializada en la aplicación de los métodos de laboratorio para el estudio de la Historia del Arte, el conocimiento del proceso creativo de los artistas y las técnicas pictóricas, y los exámenes del estado material y la conservación de las obras.

Después de trabajar en el Laboratorio del Instituto de Conservación y Restauración de Madrid (actual IPCE) y en la Escuela de Restauración del mismo Centro, se incorporó en 1978 al Museo Nacional del Prado para llevar a cabo el montaje y el desarrollo del Gabinete de Documentación Técnica, del que ha sido responsable hasta 2013.

Entre sus más de ciento cincuenta publicaciones cabe destacar los libros de Velázquez: Técnica y Evolución (1992), Velázquez: La técnica del genio (1998) en colaboración con el profesor Jonathan Brown, El Bosco en el Museo del Prado: Estudio Técnico (2001) en colaboración con el profesor con Roger Van Schoute y otros profesores, Luis Meléndez. La serie de los bodegones del Príncipe de Asturias: Estudio Técnico (2004) con el profesor Peter Cherry. A finales de este año saldrá publicado su último libro, El Greco pintor. 


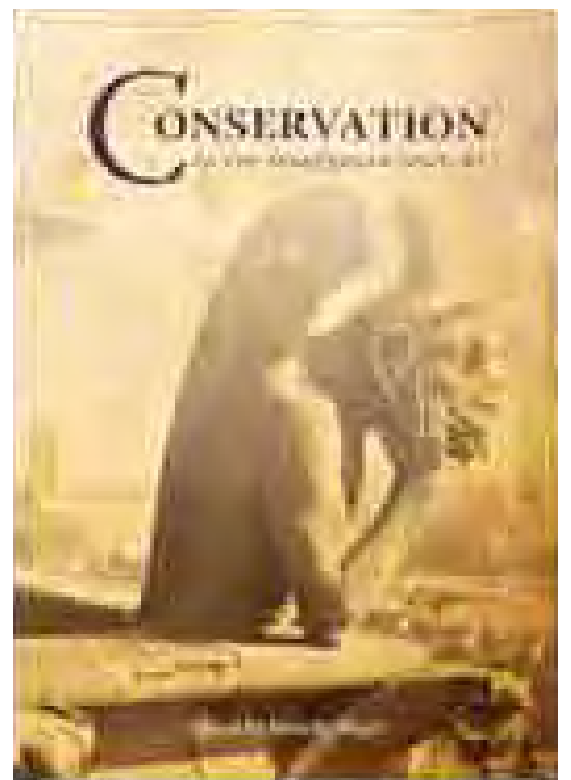

\section{Conservation in the Nineteenth Century}

\author{
Isabelle Brajer (ed.)
}

Archetype Publications in association with the National museet of Denmark and CATS (Centre for Art Technological Studies and Conservation), Copenhagen. London, 2013. 232 páginas, $220 \times 300 \mathrm{~mm}$.

ISBN: 978-1-904982-91-3.
Coordinado por Isabelle Brajer, este libro recoge las dieciocho conferencias presentadas en el congreso Conservation in the Nineteenth Century, celebrado en Copenhague, en mayo de 2013. Estas ponencias plantean cuestiones relacionadas con las tareas y técnicas llevadas a cabo por ciertos restauradores decimonónicos. Asimismo se estudian también tratamientos específicos, que han sido situados en su contexto histórico, con el fin de hacer más comprensibles las críticas y olvidos posteriores. Otra tanda de intervenciones aluden a la influencia de los avances científicos y al impacto y repercusión que tuvieron en los primeros tratados de restauración publicados, en aquel siglo, en diferentes países europeos. Predominan las cuestiones relacionadas con la pintura y la pintura mural, pero también son objeto de estudio la escultura policromada, el papel, los textiles, los instrumentos musicales y objetos de bronce, de cerámica griegos, y prehistóricos.

Aunque en el volumen no se dedica ningún comentario especializado a la figura de Viollet-le-Duc, destaca Isabelle Brajer que las referencias a sus teorías en un buen número de ponencias, prueban la influencia de sus criterios también en intervenciones de bienes muebles. Quizás por ello, de forma simbólica, se ha empleado en la portada del libro una imagen de las gárgolas que el célebre arquitecto-restaurador añadió a NotreDame de Paris. Y, en efecto, el interés por la antigüedad y por lo medieval, y el gusto por una contemplación estética de los objetos completos fue una de las más significativas características del XIX, llevándose a cabo reconstrucciones muy invasivas en todo tipo de intervenciones.
La búsqueda de rigor que predomina en la mayor parte de los trabajos se hace presente incluso cuando la falta de informes sobre los tratamientos, ha sido compensada con la aportación de recibos, notas de compra de materiales e inventarios de productos. Esta misma exigencia se percibe en los datos y contrastes facilitados por los análisis científicos.

Dado el extenso número de ponencias, una reseña de este tipo solo permite un somero recorrido meramente enunciativo por las mismas: Inicialmente, Mireille te Marvelde en su artículo -"Interpreting historical conservation terminology: cleaning' paintings in Dutch eighteenth- and nineteenth-century sources"- se centra en los problemas de terminología relacionada con la limpieza en esa época, incidiendo en los problemas planteados por la regeneración de los barnices.

Seguidamente, Cathleen Hoeniger en "Art, science and painting restoration in Napoleonic Italy, 1796-98", aporta una serie de documentos que muestran la elevada consideración que los profesionales franceses tenían de su superioridad científica. Y exigían por ello, que las obras fueran restauradas en Francia y no en Italia, aunque se enviasen historiadores a este último país para estudiar in situ los objetos artísticos.

Por otro lado Giorgio Bonsanti en “Raphael's Marriage of the Virgin in Milan and the restoration by Giuseppe Molteni (1858)", hace un interesante recorrido por el tratamiento llevado a cabo en esa maravillosa tabla por el restaurador Giuseppe Molteni. Estudiando su forma- 
ción, sus técnicas y principios; incluye, además, el informe que realizó sobre dicha obra.

Después, Matthew Hayes reflexiona sobre los tratamientos que exigían los traslados o transferencias de la pintura a otro soporte en el siglo XIX, en el trabajo "A higher reality, born of the mind: notes for a philosophy of transfer".

A la vida y obra de un restaurador de la época dedica su artículo Nicola Costaras "Richard Redgrave (18041888): first curator of paintings at the South Kensington Museum", que se señaló por incluir protecciones del reverso en los cuadros, colocar cristales por el anverso y prestar atención a los aspectos relacionados con la luz y las condiciones ambientales. Otro tanto hace Ann Hoenigswald en "Charles Chapuis: Degas' 'picture doctor' and painting restoration at the end of the nineteenth century". Este restaurador de Paris en sus etiquetas y facturas hacía notar el tipo de trabajos a los que se dedicaba: "rentoilage de tableaux, parquetage et marouflage".

A continuación, Bettina Achsel aborda el impacto y acogida que tuvo el manual de Giovanni Secco Suardo en el desarrollo de la conservación y restauración en el siglo XIX. Delphine Steyaert, por otro lado, trata de la conservación de las esculturas medievales en Bélgica en el siglo XIX y destaca la valoración de las mismas realizada por parte de la Comisión Real de Monumentos. Y Barbara Beckett aborda la técnica de la encáustica utilizada por el restaurador Franz Fernabach para sus intervenciones en pinturas murales en Alemania.

Sobre diferentes aspectos de las pinturas murales son los artículos: "Jacob Kornerup and the conservation of wall-paintings in nineteenth-century Denmark" de Susanne Ørum e Isabelle Brajer; "Documentation of medieval wall-paintings in Denmark and Germany in the nineteenth century and its impact on conservation and contemporaneous art" de Isabelle Brajer, Ursula Schädler-Saub y Susanne Ørum.

Christopher Sokolowski analiza la repercusión obtenida por un manual en Francia, "Bonnardot's Essai: a nineteenth-century restoration manual and its author". En la ponencia titulada "The test of time: nineteenthcentury innovations in paper fibre analysis", Debora D. Mayer, aborda las novedades en materia de análisis de las fibras del papel en el aquel siglo. Mientras que Maria Brunskog y Johanna Nilsson se refieren a la restauración de textiles planos "...ideological framework, ideas and treatment methods in Sweden before 1900".

Las intervenciones realizadas, en el siglo XIX, en una colección de instrumentos musicales del Musée de la Musique en Paris, constituyen la aportación de un gru- po de especialistas: Jean-Phillippe Echard, Justine Provino, Thierry Maniguet, Christine Laloue, Joël Dugot y Stephane Vaiedelich.

Otra especialidad es la tratada por Erik Risser y David Saunders, que dedican su artículo a la conservación y restauración del bronce pompeyano del Apolo Saettante del J. Paul Getty Museum. Y en otro campo incide Marie Svoboda que ha tratado de identificar las intervenciones de Raffaele Gargiulo en cuatro vasos cerámicos de la Apulia, investigación enmarcada en el proyecto The Apulian Vase Project del GCl. Finalmente, el último artículo de Helge Brinch Madsen et Jan Holme Andersen está dedicado a la preservación de objetos prehistóricos en Dinamarca entre 1807 y 1832.

A través, pues, de tan amplio recorrido, el lector puede encontrar y consultar una gran cantidad de datos muy valiosos para la profesión, tanto en materia de criterios, como de materiales y técnicas. Un libro destinado, por tanto, a convertirse en una referencia fundamental sobre la restauración europea en el siglo XIX.

Junto al anterior título, otras recientes publicaciones, en torno a la historia de la restauración, están enriqueciendo los conocimientos del pasado más inmediato de nuestra profesión, Se suman así nuevas informaciones valiosísimas tanto para los especialistas en restauración como para los interesados por las técnicas y materiales empleados en las obras artísticas. Entre ellas cabría señalar, en Francia, la de Noémie Étienne - La restauration des peintures à Paris, 1750-1815. Pratiques et discours sur la matérialité des oeuvres d'art, Presses universitaires de Rennes 2012-, o la dirigida por ella misma y Léonie Hénaut -L'Histoire à l'atelier. Restaurer les oeuvres d'art (XVIIle-XXIe siècles), Presses universitaires de Lyon 2012-, además de los volúmenes de la española Teresa Vicente Rabanaque -El restaurador de obras de arte en España durante los siglos XVIII y XIX. Nacimiento y reconocimiento de una profesión; y Del restaurador de obra de arte al conservador-restaurador de bienes culturales. La consolidación disciplinar y profesional de la restauración en España (siglos XX-XXI), Universitat Politécnica de València, Editorial UPV 2012-, por ejemplo.

Ana Calvo Manuel Universidad Complutense de Madrid 


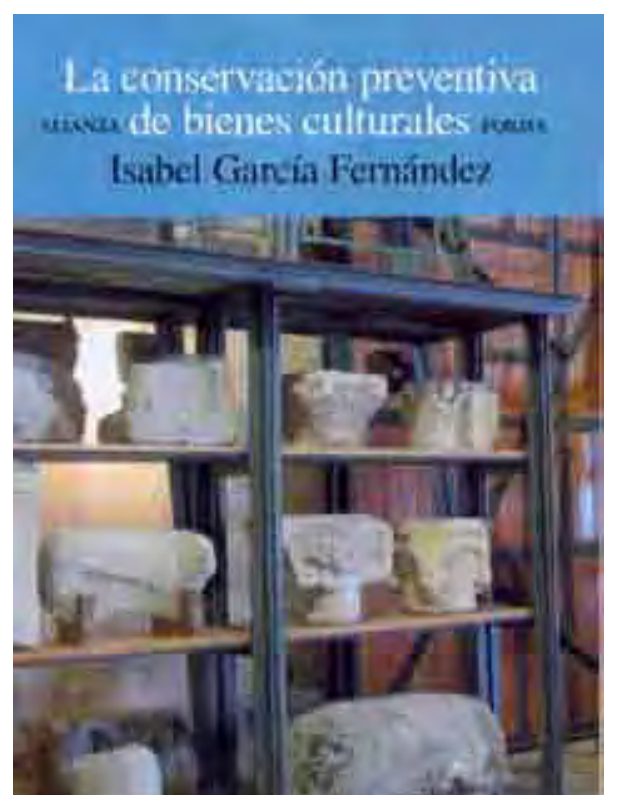

\section{La conservación preventiva de los bienes culturales}

\author{
Isabel García Fernández
}

\author{
Alianza Forma. Madrid, 2013 \\ 301 páginas, ilustraciones en blanco y negro, $18 \times 23 \mathrm{~cm}$.
}

ISBN: 978-84-206-7856-8
Con la garantía de la editorial Alianza Forma se presenta este nuevo texto titulado La conservación preventiva de los bienes culturales que su autora, Isabel García Fernández, de la Universidad Complutense de Madrid, propone como resultado de sus investigaciones después de más de veinte años dedicados al estudio de la denominada conservación preventiva. Tal y como ella misma apunta en la introducción del libro, éste responde a la necesidad de sistematización de estudios que sean de utilidad a las instituciones y profesionales en cuanto a la puesta en práctica de planes de conservación preventiva, de evaluación de los riesgos y del establecimiento de directrices adecuadas para el proyecto expositivo.

No sería justo decir que este reciente volumen es una nueva edición del antiguo La conservación preventiva y la exposición de objetos y obras de arte, que la misma autora publicó en 1999 fruto de sus estudios y experiencias en diferentes instituciones como ICC canadiense o el ICROM de Roma, ya que en catorce años el panorama de la conservación preventiva ha evolucionado mucho. Nuevos títulos se han sumado a los existentes, si bien estos suelen ser obras de carácter específico como las series de la editorial Trea sobre manifestaciones artísticas concretas o sobre aspectos diversos del patrimonio. Este libro supone, empero, un estudio general pero riguroso que recoge los avances, estudios y nuevos puntos de vista que se han ido desarrollando en los últimos quince años en el campo de la conservación preventiva y que, en algunas cuestiones, han supuesto un cambio de paradigma.
El libro se compone de seis capítulos, glosario de términos, bibliografía e índice analítico. El primero de ellos -"La conservación preventiva"- está dedicado precisamente a esclarecer el significado de ésta al tiempo que procura un repaso histórico exhaustivamente documentado sobre la evolución de la citada disciplina. Establece también las estrategias para la conservación de los bienes culturales, explicando cuál es el valor y el significado de las colecciones, y poniendo de manifiesto las propuestas que se han llevado a cabo en instituciones de otros países para categorizar los bienes culturales en función de ese valor-histórico, cultural, social, etc.- y de esta manera establecer jerarquías para actuar con un plan determinado en caso de riesgo para las colecciones.

Le sigue un segundo capítulo de eminente carácter práctico, "Aplicación de la conservación preventiva. La evaluación", donde se proponen los planes de conservación, la evaluación de los riesgos, el establecimiento de los estándares o directrices medioambientales, la evolución de este concepto a lo largo del tiempo y la importancia que ha supuesto para todos los profesionales dedicados a la conservación del patrimonio la concreción de los agentes de deterioro en una lista de solamente diez. En este capítulo se recogen también una relación de las evaluaciones y publicaciones más relevantes en el campo de la conservación preventiva de los últimos cuarenta años (desde 1975 a 2015), así como una cronología de los hechos más relevantes en la conservación preventiva (desde 1872 a 2012). 
Los siguientes capítulos se dedican a cuatro de los citados agentes de deterioro por ser todos ellos de tipo ambiental: la humedad relativa, la temperatura, la iluminación y las partículas contaminantes. El capítulo tercero se centra en las alteraciones y/o deterioros que pueden sufrir los objetos por su exposición a índices de humedad o de temperatura no adecuados o contraindicados y en la relación directa que se establece entre el clima exterior del museo o entidad y el interior. Por otra parte, aporta las estrategias de medición y control de la humedad y la temperatura, al tiempo que enseña a crear microclimas para la preservación de objetos en los museos, tanto por la utilización de métodos pasivos como el gel de sílice, como por los métodos activos, como pueden ser las unidades de climatización dependientes de la red eléctrica.

La compleja cuestión de la iluminación se desarrolla en el capítulo cuarto. En él que se explica qué es el espectro lumínico y se describen las distintas fuentes de luz utilizadas en las salas, almacenes o museos. Asimismo, se enumeran todos los procesos de deterioro causados por la luz en sus distintos espectros infrarrojo, ultravioleta y visible, y se proponen las estrategias para controlar y medir las radiaciones lumínicas, así como, reducir o minimizar los efectos irreversibles sobre los objetos o especímenes.

El capítulo quinto se centra en el último de los agentes ambientales, la contaminación. En él, se consignan y describen los distintos tipos de contaminantes que pueden afectar a los objetos, sus fuentes de emisión y las reacciones químicas que se producen en el seno de los objetos conservados. Seguidamente, se establecen los métodos de control de dichos contaminantes, que se llevan a cabo mediante la medición del aire y el posterior control de los agentes por medio del bloqueo o del filtrado, por mencionar sólo unos ejemplos.

Conjugando los dos grandes intereses que preocupan a la autora, se propone un último capítulo: "La conservación preventiva y el proceso expositivo". En él se recuperan y actualizan algunos de los aspectos tratados en Diseño de exposiciones. Concepto, instalación y montaje que Luis Alonso Fernández e Isabel García Fernández publicaron en esta misma editorial en 1999 y posteriormente actualizaron en 2010.

Finalmente el texto incluye un glosario de términos, y para terminar, una amplia y actualizada bibliografía de los temas tratados.

La formación internacional de la autora, su experiencia en el estudio de diversas colecciones, entre ellas las pertenecientes a la Universidad Complutense - de la que ella forma parte de su claustro docentey su dilatada carrera, han permitido producir este magnífico estudio del panorama internacional en el campo de la preservación del patrimonio.

Escrito en un lenguaje claro y directo, este libro puede ser de utilidad a conservadores, restauradores, historiadores, investigadores del patrimonio, estudiantes y en especial a todas las personas pertenecientes a instituciones, museos o entidades que custodian nuestros bienes culturales.

Montaña Galán Caballero

Universidad Complutense de Madrid 


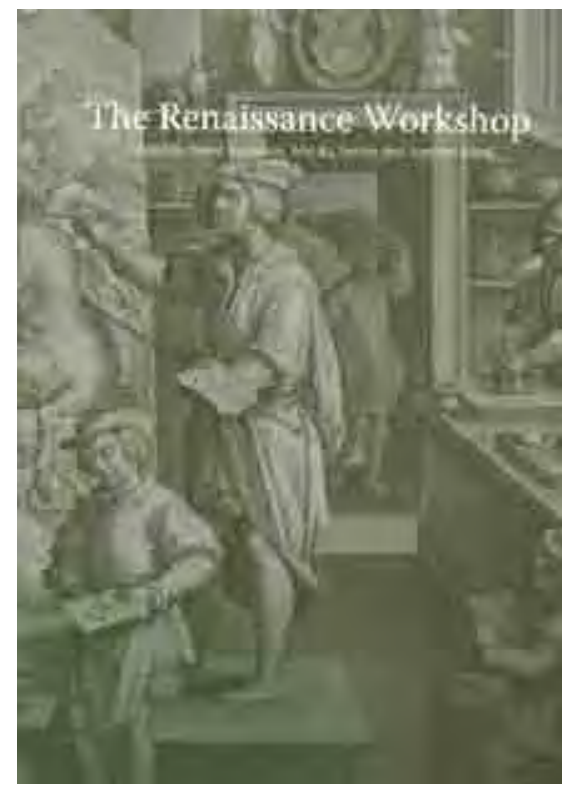

The Renaissance Workshop: The Materials and Techniques of Renaissance Art

\section{David Saunders, Marika Spring, Andrew Meek}

\author{
Publicado por: Archetype Publications Ltd.con The British Mu- \\ seum, The National Gallery, Charisma \\ London, 2013. 208 páginas, 297 x $210 \mathrm{~mm}$
}

ISBN: 9781904982937
El libro The Renaissance Workshop: The Materials and Techniques of Renaissance Art (El taller renacentista: Las materiales y las técnicas en el arte del Renacimiento) recoge la mayor parte de las comunicaciones y posters presentados en un congreso organizado en 1912 en el Museo Británico. Dicha compilación forma parte de las actividades del grupo de trabajo de difusión, patrocinadas por la plataforma europea CHARISMA (Cultural Heritage Advanced Research Infrastructures: Synergy for a Multidisciplinary Approach to conservation/restoration).

Las comunicaciones del congreso seleccionadas por CHARISMA, el Museo Británico o la Galería Nacional de Londres para esta publicación, presentan un excelente nivel en cuanto a la claridad de exposición, el interés del tema expuesto y el desarrollo de la metodología científica empleada en cada caso particular. Otro punto a tener en cuenta es la amplitud de técnicas artísticas afrontadas, que aportan una amplia visión sobre la magnitud del prodigioso fenómeno artístico que se produjo en el Renacimiento europeo.

Una parte importante de las comunicaciones del congreso se ocupa de estudiar las técnicas de iluminación de manuscritos, la pintura de retablos y murales, mayoritariamente en Italia, aunque también en España y Portugal. También hay ponencias sobre otros muchos objetos religiosos o suntuarios y decoraciones arquitectónicas, tales como esmaltes, crucifijos y otros objetos de orfebrería fabricados con metales y piedras preciosas. Hay artículos que incluyen recetas concernientes a la tecnología de fabricación de objetos artísticos, encontrados en manuscritos de época o descubren algunos elementos que intervienen en las primeras etapas del diseño de las obras de arte, como son la carta lúcida o, la punta de plomo. Por último, ciertos capítulos de la publicación tratan sobre un determinado autor de renombre. Un estudio singular es el que se refiere a los modelos anatómicos móviles sobre papel.

Los artículos de este volumen ilustran como los resultados obtenidos en los estudios técnicos, históricos y experimentales contribuyen a la comprensión de las prácticas del taller renacentista y las interrelaciones entre diferentes artistas y artesanos. Estos estudios proporcionan una visión vital de las prácticas artísticas de esta época.

El libro recoge también algunos aspectos asociados al talento artístico y la organización, incidiendo en las preocupaciones y la vida cotidiana de los que trabajaban dentro del taller, demostrando hasta qué punto resultan pertinentes los numerosos desafíos a los que se enfrentaban aquellos artistas y artesanos. Era necesario mantener un equilibrio entre la originalidad, la individualidad, el sentimiento y la sensatez, de tal forma que, el trabajo realizado resultara comercialmente rentable. La tentación de la repetición popularizada competía con el deseo de innovar. Por otro lado, los artistas trataban de hacer el mejor uso de los materiales más caros, debido a su escasez. Es posible, que para ello buscaran equilibrar los costes más bajos de los productos locales, con la carestía de las importaciones de los más valo- 
rados, por su mayor calidad o su exotismo.

En el Renacimiento, la intercomunicación de ideas y conocimientos alrededor de un mismo tema o de una estética común, atravesaba las fronteras nacionales y circulaba entre estudios e individuos. El examen de los materiales y las técnicas ha permitido establecer hipótesis sobre algunas de estas conexiones y profundizar en la transferencia de conceptos, prácticas y estilos regionales, tradicionales o innovadores.

Este congreso monográfico dedicado a estudios de los talleres renacentistas ha supuesto un avance en el conocimiento de las influencias y los contactos entre culturas y generaciones en los siglos XV y XVI en Europa.

El volumen se dirige a profesionales y expertos, tales como científicos, historiadores o restauradores vinculados al Patrimonio o incluso a estudiosos interesados por un mayor conocimiento de esta etapa de la Historia del Arte. Los textos van acompañados por imágenes y tablas de resultados que ilustran los aspectos más relevantes expuestos en cada apartado.

Marisa Gómez González

Instituto del Patrimonio Cultural de España 


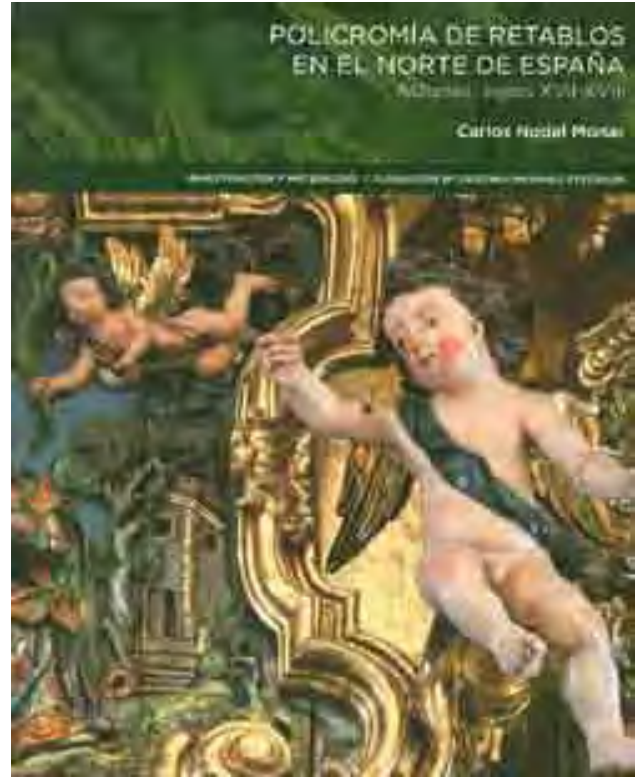

\section{Policromía de Retablos en el Norte de España: Astu- rias, siglos XVII-XVIII}

\section{Carlos Nodal Monar}

Investigación y Mecenazgo / Fundación Ma Cristina Masaveu Peterson Madrid, 2014

432 páginas, $310 \times 245 \mathrm{~mm}$

ISBN-10: 8461691342

ISBN-13: 9788461691340
El libro de Carlos Nodal titulado Policromía de Retablos en el Norte de España: Asturias, siglos XVII-XVIII es fruto de una Beca de Investigación en Arte, otorgada por la Fundación María Cristina Masaveu Peterson. La trayectoria curricular del autor, historiador, especialista en policromía de retablos y restaurador de bienes culturales, hacen que este trabajo haya sido concebido a partir de diversos enfoques que convergen en un conocimiento global de la policromía como tema a desarrollar, dentro de un ámbito territorial y temporal que corresponden al mayor desarrollo del barroco en la cornisa cantábrica.

El contenido de esta publicación se inicia definiendo la figura del pintor policromador asturiano, los distintos grados obtenidos en el aprendizaje del oficio, el trabajo en los talleres, las relaciones de los artistas entre sí y con los comitentes. En este sentido el autor aporta una nutrida documentación, relacionada con las condiciones exigidas en los contratos, tanto desde el punto de vista estilístico e iconográfico, como en lo referente a la forma de contratación, coste y materiales a emplear. El libro dedica los siguientes capítulos a proporcionar una breve ficha historiográfica de los principales maestros asturianos y sus antecedentes (desde finales del siglo XV), basada en la actividad profesional obtenida a partir de la recopilación de documentos de época.

La parte central recoge un apartado que narra la evolución estilística de la policromía de los retablos asturianos, los periodos que marcan su desarrollo y las obras más destacadas, haciendo especial hincapié en la descripción de sus características técnicas y relacionándo- las con las condiciones expresadas en los contratos y otros documentos de archivo.

Carlos Nodal completa el panorama histórico con una breve revisión de los tratados de pintura y dorado de los siglos XVII y XVIII. A continuación el autor complementa el capitulo documental anterior con un estudio pormenorizado de los materiales y las técnicas de la policromía, que incluyen la preparación del soporte y el aparejado, y todo el proceso necesario para lograr los distintos acabados superficiales de dorados y plateados, estofados, corlas y otras veladuras, encarnaciones, peleteados, relieves, postizos, etc.

El volumen concluye con dos apéndices. El primero de ellos aporta la transcripción de documentos entre los cuales cabe destacar varios contratos y condicionados, un convenio de colaboración por diez años entre un escultor y una carta de aprendizaje entre un pintor dorador y su discípulo. El apéndice gráfico recoge información ilustrada con numerosas imágenes de los motivos representados en un amplio número de retablos estudiados.

En su declaración de intenciones el autor expresa su deseo de dar a conocer la policromía asturiana, por considerar que siempre se le ha asignado un papel secundario en el estudio del retablo. También pretende establecer la relación de esta comarca, con toda la cornisa cantábrica y la meseta norte, ya que los artistas provenían de regiones limítrofes. 
La comprensión de la policromía es un punto de partida indispensable para potenciar la conservación y restauración de estas obras de creación arquitectónica, artística y artesanal. Muchos de los retablos asturianos de este periodo han pasado inadvertidos por sus exiguas condiciones de conservación. La divulgación del trabajo de investigación desarrollado en este proyecto constituye una herramienta fundamental para la consulta de restauradores, investigadores, académicos y docentes. La catalogación e inventariado de las obras, su posterior documentación científico-técnica, estudio histórico-artístico y análisis material, así como los apéndices documentales y gráficos completan el discurso del investigador en torno al maravilloso patrimonio retablístico asturiano.

\section{Marisa Gómez González}

Instituto del Patrimonio Cultural de España 


\section{Anexo:}

Comunicaciones en la Jornada sobre Conservación de Patrimonio. Rosa Ma Esbert "In Memoriam" -16 de mayo de 2013 


\section{Ge}

\section{JORNADA SOBRE}

\section{CONSERVACIÓN DEL PATRIMONIO}

\section{ROSA ESBERT IN MEMORIAM}
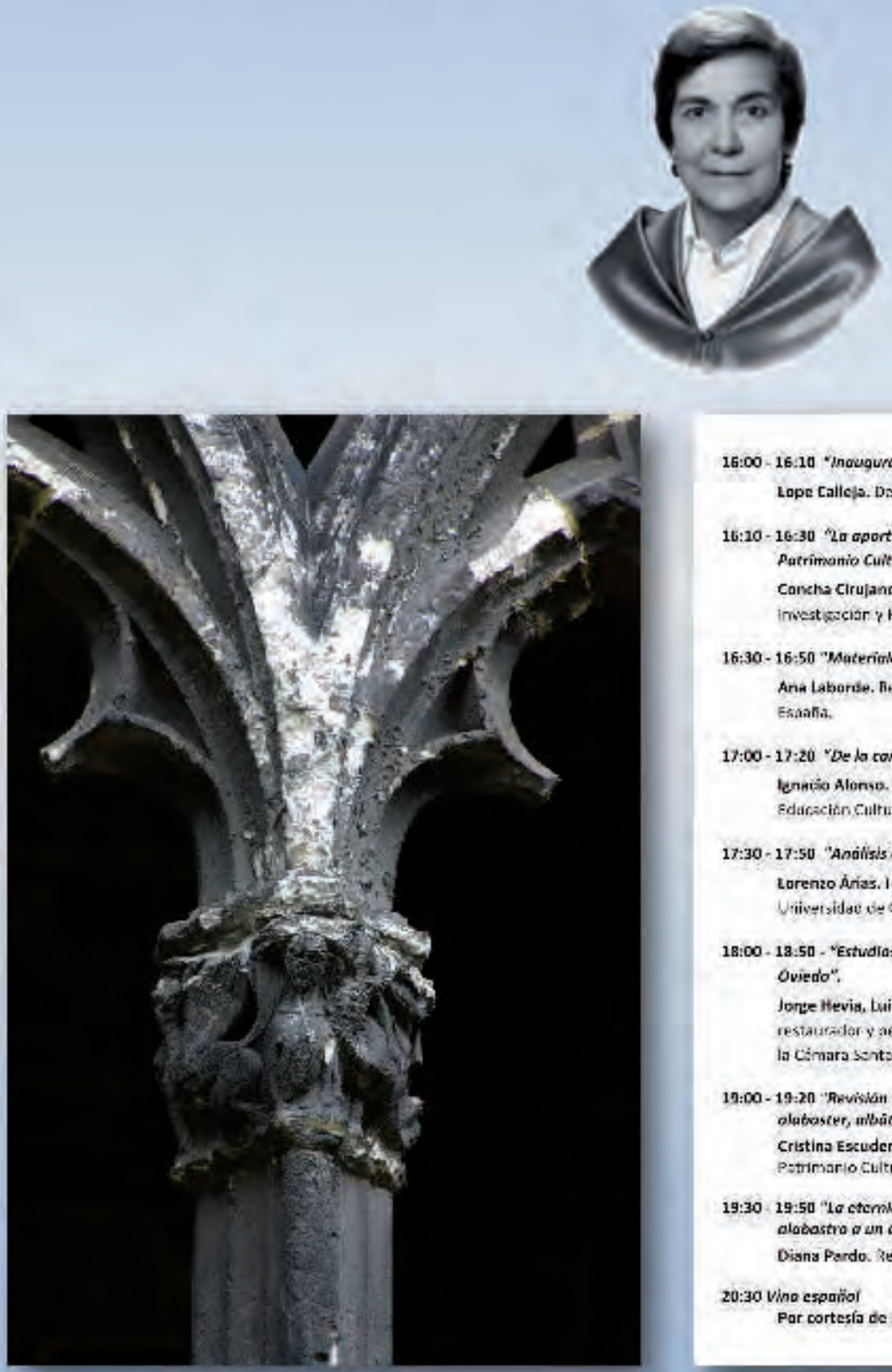

16:00 - 16:10 "Inouguración de las fornadas".

Lope Calleps. Decana tela Fasultad de Gcologia

16:10-16:30 2a aportación de Fasa Esbert al desarrollo cientifico de fa Conservarion del Patrimantio Cuitural en Españo"

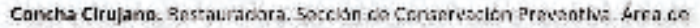

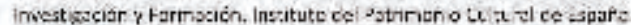

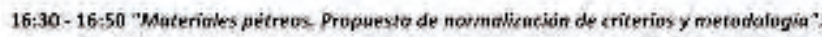

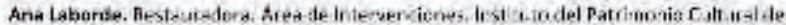
Exaskia.

17:00-17:20 "De la covartenizaciän al tratamiento"

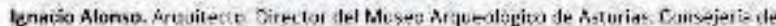

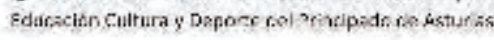

17:30 - 17:50 "Andilisis de los criterios de Kestouración en Ja cómara Santo en ei sialo XX" Lorenzo Ávias. llisteriacor. Prufaser litular. Up.o. de Histeria del Artey rosusizolopia. Vaiversidae de Qviedo.

18:00 - 13:50 - "Estudias campismentarlas petralagkes en la comara Santo de la cotcarol de Oviedo":

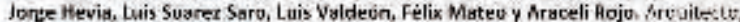

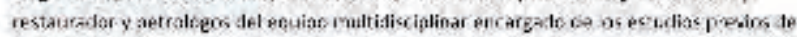
lacinara serts,

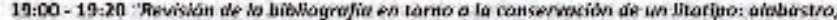
alaboseter, mbícre:

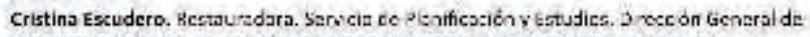
Patrinar lo Cultural, Consegeris de Culturn v Turisrya nelo Jurta ce Castils y Lotr.

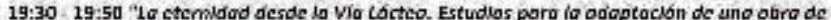
alabastro a un entorna sallino

Diana Pardo. Restauradora. Servicio de Restauratón ce la Eipatscitr Torai de $k$ ava.

20:30 Vine espoñol

Par corteś́a de ESFER CONSTRUCCIONES Y PROYECTOS S.

Jueves 16 de mayo de 2013 Aula A de la Facultad de Geología

\section{Entidades colaboradoras:}

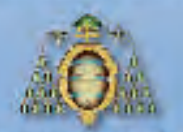

CALERSIDAD DE ONIFUO

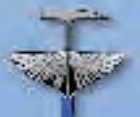

II
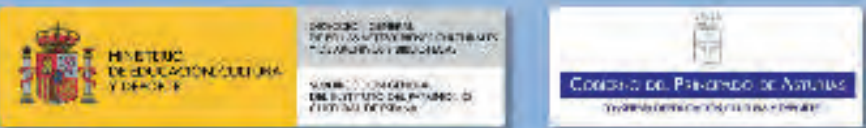

esfer 


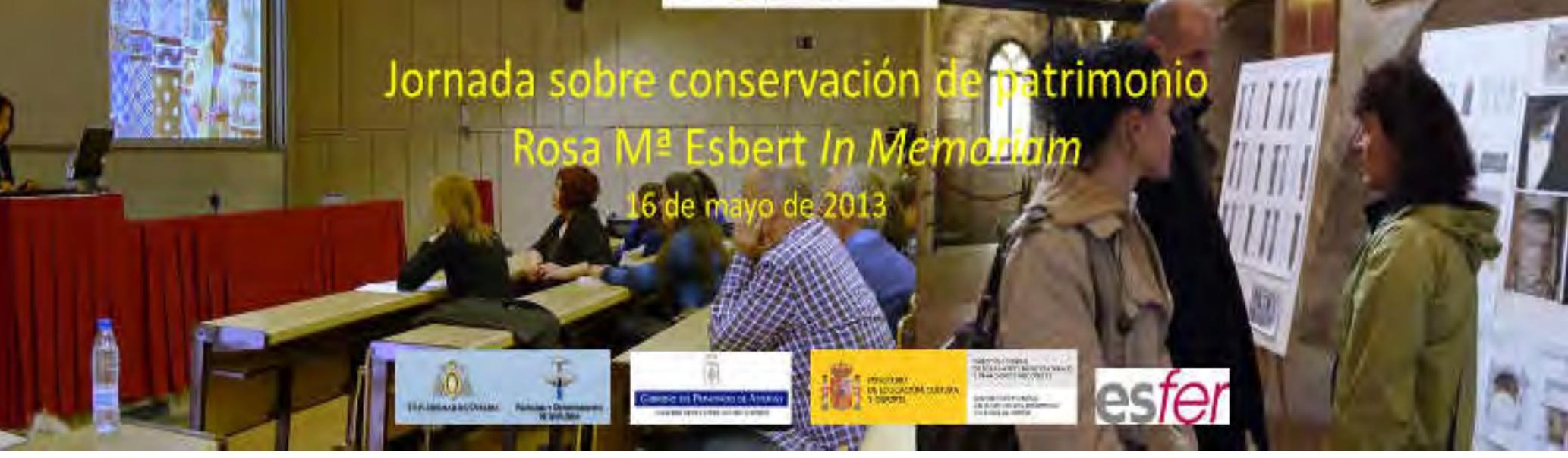

\title{
Caracterización y conservación de los materiales pétreos: Bibliografía del Grupo de Investigación de la Universidad de Oviedo.
}

\author{
Fco. Javier Alonso, Jorge Ordaz y Luis Valdeón.
}

\begin{abstract}
Resumen: Se presenta un inventario de publicaciones y documentos realizados por el "Grupo de Alteración" de la Universidad de Oviedo, dirigido por la profesora Rosa María Esbert, desde sus inicios a finales de los años 70. Los temas estudiados giran en torno a la caracterización, deterioro y conservación de los materiales pétreos utilizados en edificación, en especial en monumentos y patrimonio arquitectónico. Se recogen cronológicamente distintos tipos de documentos: libros y capítulos de libros, artículos de publicaciones periódicas, comunicaciones presentadas en congresos y documentos inéditos (memorias de investigación resultado de proyectos y contratos). Se indica cuales son actualmente de libre disposición en la red (normalmente las publicaciones periódicas), si bien todos ellos pueden consultarse en el Área de Petrología y Geoquímica (Departamento de Geología, Universidad de Oviedo).
\end{abstract}

Palabras clave: piedra, alteración, deterioro, durabilidad, conservación, restauración, monumentos, patrimonio.

\section{Characterization and conservation of stone materials: Bibliography of Research Group of Oviedo University.}

Abstract: An inventory of publications and documents made by the "Group of Alteration" from University of Oviedo, led by professor Rosa María Esbert, from its beginnings in the late '70s is shown. Topics studied include characterization, deterioration and conservation of stone materials used in building, especially in monuments and architectural heritage. Different types of documents are collected chronologically: books and book chapters, articles in periodicals, papers presented in congresses and unpublished documents (research reports from projects and contracts). Documents that are freely available at present on the net (usually periodicals) are showed, although all of them are available on the Area of Petrology and Geochemistry (Department of Geology, University of Oviedo).

Key words: stone, alteration, deterioration, durability, conservation, restoration, monuments, heritage.

\section{Introducción}

Rosa María Esbert llegó a la Universidad de Oviedo en el año 1972 y muy pronto empezó a trabajar en temas relacionados con la degradación y conservación de los materiales pétreos de edificación. A principios de los años 80 forma un equipo integrado fundamentalmente por petrólogos, profesores y estudiantes que realizan sus trabajos de licenciatura y de doctorado, y eventualmente por especia- listas en otras materias. Este equipo, denominado "Grupo de Caracterización petrofísica, durabilidad y conservación de materiales pétreos" o de forma abreviada "Grupo de Alteración" de Oviedo, está considerado uno de los pioneros en estos temas y se ha mantenido activo durante más de 30 años realizando proyectos de investigación nacionales, regionales y también internacionales, así como formando investigadores posteriormente consolidados y otros cuya memoria se va perdiendo. 
En este sentido y bajo la dirección de la profesora Esbert, el grupo estuvo formado desde sus inicios por los profesores Jorge Ordaz y Fco. Javier Alonso, con la participación más esporádica de otros profesores: Modesto Montoto, Luis M. Suárez del Río, Lope Calleja, Vicente Gómez y Ángel Rodríguez. Entre los principales investigadores se cuentan por orden cronológico: Dra. Rosa Marcos, Dr. Luis Valdeón. Dra. Carlota Grossi, Dra. Beatriz Menéndez, Dra. Beatriz Pérez, Dña. Mercedes Vázquez, Dra. Ángeles Pérez, D. José Alonso, Dr. Francisco Díaz-Pache, Dña. Araceli Rojo, Dr. Félix Mateos, Dra. Patricia Vázquez, Dra. Timea Kovács. Dña. Lucía Carrizo y Dña. Marta Fernández.

Entre los monumentos del patrimonio arquitectónico estudiados caben destacar (se señalan entre paréntesis los materiales pétreos más significativos) las catedrales de Oviedo (caliza de Piedramuelle y dolomía de Laspra), León (dolomía de Boñar y caliza del País), Murcia (calizas de Monte Guil y Mayayo), Almería (dolomías), Sevilla (calizas de Gilena, Espera, Utrera, Gandul, Puerto de Sta. María...), Seu Vella de Lleida (arenisca de Lérida y caliza de Vinaixa), Segovia (dolomías de Bernuy y Zamarramala), Palma de Mallorca (caliza de Santanyí, Marés blanco y Marés de Porreras), Burgos (calizas de Hontoria, Briviesca), Girona (caliza numulítica); los claustros de Santillana del Mar (arenisca) en Cantabria, San Juan de la Peña (arenisca) en Huesca, Santo Domingo de Silos (dolomía) y San Salvador de Oña (areniscas, calizas, dolomía) en Burgos; las iglesias de San Juan de los Caballeros (dolomías) en Segovia, San Pedro Mártir (granito) en Toledo, Sta. María de Castro Urdiales y Sta. María de Laredo (areniscas) en Cantabria, Sagrada Familia (granitos, areniscas, calizas, hormigón) en Barcelona; las fachadas de la Biblioteca Nacional (mármol) y del Museo del Prado (granito) en Madrid, la Pedrera (calizas de Garraf y Vilafranca), el teatro del Liceo (calizas, serpentinitas, gneis), el Eixample y el Palau de la Música (arenisca de Montjuït, ladrillos) en Barcelona, Presidencia del Gobierno Insular Canario (granito), Teatro Reina Victoria (arenisca de Igueldo) en San Sebastián, Palacio de Sobrellano de Comillas (arenisca) en Cantabria; monumentos prerrománicos asturianos Sta. María del Naranco, San Miguel de Lillo, San Julián de los Prados y Sta. Cristina de Lena, así como el palacio de los Duques del Parque (caliza de Piedramuelle y areniscas), el antiguo Hospicio Provincial y la iglesia de San Isidoro (caliza de La Granda) en Oviedo, palacio de Revillagigedo (arenisca de Villaviciosa) en Gijón, palacio Ferrera e iglesia de los Padres Franciscanos (arenisca de la Grandiella y dolomía de Bustiello) en Avilés; edificaciones del patrimonio catalán (areniscas de Folgueroles y El Figueró, calizas de Sant Vicenç y Manresa, dolomía de Tortosa), monumentos castellano-leoneses (areniscas de Villamayor y Quintanar, calizas del Páramo y Sepúlveda, adobes), otros monumentos (arenisca de Vitoria y Uncastillo; calizas de Santa Pudia, Cenia, Ámbar, Miel; mármoles de Macael, Tranco, Triana; serpentinitas Verde Guatemala y Verde indiano; granitos de Axeitos, Rosa Porriño, Rosavel, Grissal...)

En resumen, se ha estudiado una parte significativa del patrimonio arquitectónico español construido en piedra, con la esperanza de que estos documentos se incorporen al acerbo científico y cultural, y supongan una aportación en el ámbito de la conservación de los materiales pétreos.

\section{Relación de trabajos}

\section{8}

**ESBERT R.M., GRANDA J., ORDAZ J., y SUÁREZ DEL RÍO L.M. (1978). "Nota previa sobre la interpretación textural de la porosidad de algunas rocas graníticas de Galicia". Trabajos de Geología, 10: 173-181, Universidad de Oviedo.

ORDAZ J., ESBERT R.M. y SUAREZ DE RIO L.M. (1978). "A proposed petrographical index to define mineral and rock deterioration in granite rocks." En: Alteration et protection des monuments en pierre, UNESCO, RILEM, ICCROM, 16 p. Int. Symp. Deterioration and protection of stone monuments, Paris-1978.

1981

ESBERT R.M., ORDAZ J., ALONSO F.J. y ALBA J.M. (1981). “Petrographic and physical study of the building stones from León Cathedral (Spain)". En: The conservation of stone. II. Preprints of the contributions to the international symposium, Bologna, 27-30 October 1981, ICCROM, 285-298.

1982

**ESBERT R.M., MARCOS R.M. y ALONSO F.J. (1982). “La deterioración de las piedras de la catedral de Oviedo. $1^{\text {a }}$ Parte: Petrografía y porosidad características intrínsecas determinantes de la deterioración de sus rocas carbonatadas". Materiales de Construcción (CSIC), 185: 61-71

**ESBERT R.M., MARCOS R.M. (1982). "La deterioración de las pie-

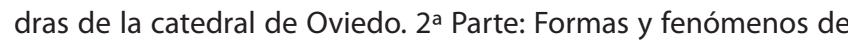
alteración". Materiales de Construcción (CSIC), 186: 79-88.

MARCOS R. (1982). Valoración del estado de alteración de los materiales pétreos de la catedral de Oviedo. Tesis de licenciatura, Departamento de Geología, Universidad de Oviedo.

\section{3}

**ORDAZ J. (1983). “Características físicas y alterabilidad de la piedra de Villamayor (Salamanca)". Materiales de Construcción (CSIC), 190-191: 85-95.

**ORDAZ J., ALONSO F.J. (1983). “Características del sistema poroso de la arenisca de Villamayor (Salamanca)". Trabajos de Geología 13: 83-92., Universidad de Oviedo.

VALDEÓN L. (1983). Estudio petrofísico y alterológico de las areniscas del palacio de Revillagigedo de Gijón. Tesis de licenciatura, Departamento de Geología, Universidad de Oviedo. 
**ESBERT R.M., VALDEÓN L. (1984). "Estudio petrofísico de las areniscas del Palacio de Revillagigedo de Gijón (Asturias)". Materiales de Construcción (CSIC), 34 (194): 61-72.

ESBERT R.M., ORDAZ J., ALONSO F.J. y VALDEÓN L. (1984). “Influencia de las características petrográficas en la durabilidad de areniscas utilizadas en monumentos". En: Congreso Español de Geología, Segovia-1984, Colegio Oficial de Geólogos, comunicaciones, T-II, 921-931. I.

MONTOTO M. et al. (1984). Evaluación del estado de alteración y alterabilidad de los materiales rocosos de las catedrales de León y Sevilla. Primer informe. Informe de proyecto, Departamento de Geología, Universidad de Oviedo.

ORDAZ J., ESBERT R.M., MONTOTO M., DE CASO F. y ALONSO F.J. (1984). "Estado de alteración y alterabilidad futura de la piedra de Villamayor de los monumentos salmantinos: interpretación petrográfica". En: Estudio sobre las alteraciones y tratamiento de la piedra de Villamayor. Caja de Ahorros y M.P. de Salamanca, 315419.

\section{5}

**ALONSO F.J., SUAREZ DEL RÍO L.M. (1985). "Velocidad de propagación de ondas en rocas carbonatadas". Trabajos de Geología, 15: 315-324. Universidad de Oviendo.

**ESBERT R.M., ORDAZ J. (1985). "Alterabilidad de la piedra monumental de Laspra". Trabajos de Geología , 15: 325-331. Universidad de Oviendo.

**ESBERT R.M., ORDAZ J. y VALDEÓN L. (1985). "Relaciones entre porosidad, contenido en arcillas y durabilidad de arenisca". Materiales de Construcción (CSIC), 35 (200): 15-22.

MONTOTO M. et al. (1985). Evaluación del estado de alteración y alterabilidad de los materiales rocosos de las catedrales de León y Sevilla. Segundo y tercer informe. Informe de proyecto, Departamento de Geología, Universidad de Oviedo.

**VALDEÓN L., ESBERT R.M. y MARCOS R.M. (1985). “La alveolización y otras formas de alteración desarrolladas sobre las areniscas del palacio de Revillagigedo de Gijón (Asturias)". Materiales de Construcción (CSIC), 35 (200): 41-48.

\section{6}

**ALONSO F.J. (1986). Caracterización petrofísica y alterabilidad de calizas y dolomías. Tesis doctoral, Departamento de Geología, Universidad de Oviedo.

ESBERT R.M. et al. (1986). Propuesta de restauración. Torre norte. Catedral de León. Informe de proyecto, Departamento de Geología, Universidad de Oviedo.

ESBERT R.M. et al. (1986). Estudio alterológico de los materiales pétreos del claustro de la colegiata de Santillana del Mar (Cantabria). Especial referencia al estado de degradación de sus capiteles.
Informe de proyecto, Departamento de Geología, Universidad de Oviedo.

ESBERT R.M., ORDAZ J., ALONSO F.J., GROSSI C. y DE LLANOS C. (1986). "Aplicación del S.E.M. en el control del tratamiento de materiales pétreos con consolidantes". En: XIV Reunión Bienal de Ia SEME, Congreso Nacional de Microscopía Electrónica, Ávila-1986. Colegio Universitario de Medicina 108-113.

GROSSI C.M. (1986). Ensayos de tratamiento en materiales rocosos de la catedral de Oviedo. Tesis de licenciatura, Departamento de Geología, Universidad de Oviedo.

MONTOTO M. et al. (1986). Evaluación del estado de alteración y alterabilidad de los materiales rocosos de las catedrales de León y Sevilla. Cuarto informe. Informe de proyecto, Departamento de Geología, Universidad de Oviedo.

VÁZQUEZ M. (1986). Estudio alterológico de las piedras utilizadas en algunos monumentos de Avilés. Tesis de licenciatura, Departamento de Geología, Universidad de Oviedo.

\section{7}

**ALONSO F.J., ESBERT R.M. y ORDAZ J. (1987). “Comportamiento hídrico de calizas y dolomías". Boletín Geológico y Minero (IGME), 98-4: 555-576.

ALONSO F.J., ESBERT R.M., ORDAZ J. y VALDEÓN L. (1987). “Ensayos de alterabilidad: revisión crítica del ensayo de cristalización de sales" . En: I Semana de la Calidad en la Edificación, Oviedo, Colegio Oficial de Aparejadores, comunicaciones, 607-616.

**ALONSO F.J., ORDAZ J. y ESBERT R.M. (1987). “Caracterización del sistema poroso de calizas y dolomías". Boletín Geológico y Minero (IGME), 98-2: 226-237.

**ALONSO F.J., ORDAZ J., VALDEÓN L. y ESBERT R.M. (1987). “Revisión crítica del ensayo de cristalización de sales". Materiales de Construcción (CSIC), 37 (206): 53-60.

ESBERT R.M. et al. (1987). Estudio del deterioro de las piedras de las fachadas del Museo del Prado en vistas a su conservación. Informe de proyecto, Departamento de Geología, Universidad de Oviedo.

ESBERT R.M. et al. (1987). Estado del deterioro de las piedras del frontón de la Biblioteca Nacional en vistas a su restauración. Informe de proyecto, Departamento de Geología, Universidad de Oviedo.

ESBERT R.M. et al. (1987). Caracterización petrofísica, petroquímica, mecánica y alterología de los materiales pétreos utilizados en el patrimonio monumental de Cataluña. Informe de proyecto, Departamento de Geología, Universidad de Oviedo.

ESBERT R.M. et al. (1987). Estudio del deterioro de las piedras de la Casa Milá (La Pedrera) en vistas a su limpieza y conservación. Informe de proyecto, Departamento de Geología, Universidad de Oviedo. 
**ESBERT R.M., GROSSI C. y MARCOS R.M. (1987). «Estudios experimentales sobre la consolidación y protección de los materiales calcáreos de la catedral de Oviedo. $1^{\text {a }}$ parte. (Laboratory studies on the consolidation and protection of calcareous materials in the Cathedral of Oviedo. Part I)". Materiales de construcción (CSIC), 37 (206): 17-25.

**ESBERT R.M., GROSSI C. Y MARCOS R.M. (1987). “Estudios experimentales sobre la consolidación y protección de los materiales calcáreos de la catedral de Oviedo. $2^{\text {a }}$ parte. (Laboratory studies on the consolidation and protection of calcareous materials in the Cathedral of Oviedo. Part I)". Materiales de Construcción (CSIC), 37 (208): 13-21.

ESBERT R.M., GROSSI C. Y MARCOS R.M. (1987). "Aplicación de consolidantes y protectores en materiales pétreos de edificación". En: I Semana de la Calidad en la Edificación, Oviedo, Colegio Oficial de Aparejadores, comunicaciones, 467-41.

GUTIÉRREZ M., ESBERT R.M. et al. (1987). Estudio geológico y alterológico de los materiales pétreos de San Juan de la Peña: Especial referencia a sus capiteles románicos. Informe de proyecto, Cátedra de Geología, Universidad de Zaragoza, Departamento de Geología, Universidad de Oviedo.

MONTOTO M. et al. (1987). Evaluación del estado de alteración y alterabilidad de los materiales rocosos de las catedrales de León y Sevilla. Quinto y sexto informe. Informe de proyecto, Departamento de Geología, Universidad de Oviedo.

MONTOTO M. et al. (1987). Evaluación del estado de alteración y alterabilidad de los materiales rocosos de las catedrales de León y Sevilla. Informe final. Informe de proyecto, Departamento de Geología, Universidad de Oviedo.

\section{8}

ESBERT R.M. et al. (1988). Caracterización petrofísica, petroquímica, mecánica y alterología de los materiales pétreos utilizados en la catedral de Murcia: Puerta de los Apóstoles y Capilla de los Junterones. Primera fase (materiales, alteración). Informe de proyecto, Departamento de Geología, Universidad de Oviedo.

ESBERT R.M. et al. (1988). Caracterización petrofísica, petroquímica, mecánica y alterología de los materiales pétreos utilizados en la catedral de Murcia: Puerta de los Apóstoles y Capilla de los Junterones. Informe final (tratamientos, durabilidad). Informe de proyecto, Departamento de Geología, Universidad de Oviedo.

ESBERT R.M. et al. (1988). Estudio de la piedra utilizada en las construcciones monumentales de Álava en vistas a su conservaciónrestauración. Informe de proyecto, Departamento de Geología, Universidad de Oviedo.

ESBERT R.M., GROSSI C.M., SUÁREZ DEL RÍO L.M., CALLEJA L., ORDAZ J. y MONTOTO M. (1988). «Acoustic emission generates in treated stones during loading". En: Ciabach J. (Co.), VIth Int. Congress on Deterioration and Conservation of Stone, Torun, Nicholas Copernicus University, Torun, ICRROM, 403-410.
**ESBERT R.M., ORDAZ J., ALONSO F.J., MONTOTO M., RUIZ DE ARGANDOÑA V.G., MARCOS R.M. y VALDEÓN L. (1988). “Caracterización petrofísica y alterabilidad de las piedras de la catedral de Sevilla. (Petrophysical caracterization and weatherability of stones of the Sevilla Cathedral)". Materiales de Construcción (CSIC), 38 (210): 5-23.

ESBERT R.M., ORDAZ J., MARCOS R.M. y VALDEÓN L. (1988). “Propiedades físicas a considerar en el deterioro de las rocas como materiales de construcción". Revista d'investigacions geológiques Universidad de Barcelona), 44-45: 303-311.

**ESBERT R.M., VÁZQUEZ M. y ALONSO F.J. (1988). “Petrografía, formas y procesos de alteración desarrollados en las piedras de algunos monumentos de Avilés (Asturias)". Boletín Geológico y Minero (IGME), 99-3: 432-443.

**MENÉNDEZ B., ORDAZ J. y ALONSO F.J. (1988). “Observación del sistema poroso de rocas carbonatadas al microscopio electrónico de barrido". Estudios Geológicos (CSIC), 44: 189-197.

**ORDAZ J., ESBERT R.M. (1988). “Glosario de términos relacionados con el deterioro de las piedras de construcción". Materiales de Construcción (CSIC), 30 (209): 39-45.

**ORDAZ J., ESBERT R.M. y ALONSO F.J. (1988). "Factores que condicionan la alteración de las areniscas de la colegiata de Santillana del Mar (Cantabria)". Geogaceta (SGE), 5: 56-57.

\section{9}

ALONSO F.J., VALDEÓN L., MARCOS R.M. y ESBERT R.M. (1989). "Propiedades físicas y durabilidad de rocas calcáreas utilizadas en la construcción". En: Simposio sobre Rocas Industriales y Ornamentales, Mieres.

ESBERT R.M. et al. (1989). Conservación de la fachada del hotel de la Reconquista (Oviedo): Diagnóstico de lesiones y sugerencias de tratamiento. Informe de proyecto, Departamento de Geología, Universidad de Oviedo.

ESBERT R.M. et al. (1989). Caracterización petrofísica y alterológica del material pétreo de los capiteles. Proyecto de conservación de los capiteles del monasterio de Santo Domingo de Silos. Informe de proyecto, Departamento de Geología, Universidad de Oviedo.

ESBERT R.M. et al. (1989). Conservación de los materiales graníticos del claustro real de San Pedro Mártir de Toledo. I Diagnóstico de lesiones y consideraciones generales referidas a su conservación. II Pruebas de tratamiento con consolidantes e hidrofugantes: resultados obtenidos. Informe de proyecto, Departamento de Geología, Universidad de Oviedo.

**ESBERT R.M., MARCOS R.M., ORDAZ J., MONTOTO M., SUÁREZ DEL RÍO L.M., RUIZ DE ARGANDOÑA V.G., CALLEJA L., ALONSO F.J. y RODRÍGUEZ REY A. (1989). “Petrografía, propiedades físicas y durabilidad de algunas rocas utilizadas en el patrimonio monumental de Catalunya (España)". Materiales de Construcción (CSIC), 39 (214): 37-47. 
ESBERT R.M., ORDAZ J., ALONSO F.J. y GROSSI C. (1989). “La contaminación ambiental y la formación de sales solubles en piedras monumentales". En: IV Reunión Nacional, Geología Ambiental y Ordenación del Territorio, Gijón.

VALDEÓN L. (1989). Comportamiento hídrico de dolomías, calizas y areniscas de las catedrales de León, Sevilla y Salamanca. Aplicabilidad a la conservación de rocas monumentales. Tesis doctoral, Departamento de Geología, Universidad de Oviedo.

\section{0}

ESBERT R.M. et al. (1990). Estudio de los materiales de cantería del ex-convento de Sta. Clara (Oviedo): Estado de deterioro y sugerencias para su conservación. Informe de proyecto, Departamento de Geología, Universidad de Oviedo.

ESBERT R.M. et al. (1990). Estudio de piedras y revocos de San Miguel de Lillo (Oviedo). Informe de proyecto, Departamento de Geología, Universidad de Oviedo.

**ESBERT R.M., GROSSI C.M., VALDEÓN L., ORDAZ J., ALONSO F.J. y MARCOS R.M. (1990). “Estudios de laboratorio sobre la conservación de la piedra de la catedral de Murcia. (Laboratory studies for stone conservation at the Cathedral of Murcia)". Materiales de Construcción (CSIC), 40 (217): 5-15.

ESBERT R.M., GROSSI C.M., VALDEÓN L., ORDAZ J., ALONSO F.J. y MARCOS R.M. (1990). "Studies for stone conservation at the cathedral of Murcia (Spain)". En: Zezza F. (Ed.), 1st Int. Symp. The Conservation of Monuments in the Mediterranean Basin, Cons. Nac. delle Recherche, Grafo Ed., Brescia, ICCROM, 437-441.

ESBERT R.M., MONTOTO M., SUÁREZ DEL RÍO L.M., RUIZ DE ARGANDOÑA V.G. y GROSSI C.M. (1990). "Mechanical stresses generated by crystallization of salts inside treated and non-treated monumental stones; monitoring and interpretation by acoustical emission/microseismic activity". En: Vandiver P.B., Druzink J. and Wheeler G.S. (Eds.), Materials Issues in Art and Archaeology II, MRS Procc. 185: 285-296.

HAMMECKER C. (1990). Etude de l'interaction de produits de consolidation Rhone-Poulenc sur des roches carbonatees mises en œuvre en Espagne. $1^{\circ}$ y $2^{\circ}$ Rapport. Informe de proyecto, Departamento de Geología, Universidad de Oviedo.

MONTOTO M., CALLEJA L., PÉREZ B. y ESBERT R.M. (1990). “Evaluation in situ of the state of deterioration of monumental stones by non-destructive ultrasonic techniques". En: Vandiver P.B., Druzink J. and Wheeler G.S. (Eds.), Materials Issues in Art and Archaeology II, MRS Proc. 185: 273-284.

**ORDAZ J., ESBERT R.M., ALONSO F.J., RUIZ DE ARGANDOÑA V.G. y RODRÍGUEZ REY A. (1990). "Petrophysical characterization and deterioration of the stones of "La Pedrera" (Barcelona, Spain)". En: Zezza F. (Ed.), 1st Int. Symp. The Conservation of Monuments in the Mediterranean Basin, Cons. Nac. delle Recherche, Grafo Ed., Brescia, ICCROM, 271-274.
ORDAZ J., ALONSO F.J. y ESBERT R.M. (1990). “Caracterización física de algunos adobes de Castilla-León (España). Physical characterization of adobes in Castilla-Leon (Spain)". En: 6th Int. Conference on the Conservation of Earthen Architecture, Adobe 90, Getty Conservation Institute Publ., Los Angeles (USA), 438-442.

VÁZQUEZ M., ESBERT R.M. y ALONSO F.J. (1990). “Estudio de contaminantes ambientales en superficies de rocas monumentales mediante SEM y EDAX". En: XVI Reunión Bienal de la SEME, Microscopía Electrónica 92, Universidad de Cádiz, 295-296.

\section{1}

ESBERT R.M. et al. (1991). Estudio del deterioro de los materiales pétreos de San Juan de los Caballeros (Museo Zuloaga, Segovia). Informe de proyecto, Departamento de Geología, Universidad de Oviedo.

**ESBERT R.M., GROSSI C., ORDAZ J. y ALONSO F.J. (1991). "La conservación de la piedra de la Casa Milá ("La Pedrera" de Gaudí, Barcelona): Pruebas preliminares". Boletín Geológico y Minero (IGME), 102-3: 446-454.

**ESBERT R.M., MARCOS R., ORDAZ J., MONTOTO M., ALONSO F.J., SUÁREZ DEL RÍO L.M., RUIZ DE ARGANDOÑA V.G., CALLEJA L. y RODRÍGUEZ REY A. (1991). “Petrografía, propiedades físicas y durabilidad de algunas rocas utilizadas en el patrimonio monumental de Cataluña, España ( $2^{a}$ parte) ${ }^{\prime}$. Materiales de Construcción (CSIC), 41 (222): 49-59.

*ESBERT R.M., MONTOTO M. y ORDAZ J. (1991).“La piedra como material de construcción: durabilidad, deterioro y conservación (Rock as a construction material: durability, deterioration and conservation)". Materiales de Construcción (CSIC), 41 (221): 61-73.

ESBERT R.M., VALDEÓN L.M., ORDAZ J., ALONSO F.J. y GROSSI C.M. (1991). "Ultrasonic velocity and humidity in monumental stones". En: Baer N.S., Sabbioni C. and Sors A.I. (Eds.), Science, Technology and European Cultural Heritage, Butterworth-Heinemen Publ., ICCROM, Bolonia 597-600.

HAMMECKER C. (1991). Etude de l'interaction de produits de consolidation Rhone-Poulenc sur des roches carbonatees mises en œuvre en Espagne. $3^{\circ}$ y $4^{\circ}$ Rapport. Informe de proyecto, Departamento de Geología, Universidad de Oviedo.

MONTOTO M., CALLEJA L., PÉREZ GARCÍA B., SUÁREZ DEL RÍO L.M., RUIZ DE ARGANDOÑA V.G., ESBERT R.M. y GROSSI C.M. (1991). "Non-destructive ultrasonic procedure to evaluate in situ the relative deterioration of monumental stones: preliminary results". En: Baer N.S., Sabbioni C. and Sors A.I. (Eds.), Science, Technology and European Cultural Heritage, Butterworth-Heinemen Publ., ICCROM, Bolonia 545-548.

\section{2}

ALONSO F.J., ORDAZ J., PÉREZ A. y ESBERT R.M. (1992). “Laboratory study of a treated dolostone subjected to thermal cycles". En: Delgado J., Henriques F. and Jeremias F.T. (Eds.), 7th. Int. Cong. 
Deterioration and Conservation of Stone, Laboratório Nacional de Engenharia Civil, Lisboa, V-2, 745-751.

DÍAZ-PACHE F. (1992). Técnicas instrumentales aplicadas al conocimiento de la penetración de consolidantes en rocas carbonatadas y sus efectos en el sistema poroso. Tesis de licenciatura, Departamento de Geología, Universidad de Oviedo.

ESBERT R.M. et al. (1992). Diagnóstico de lesiones y análisis de los productos de alteración de la piedra de construcción de la catedral de Palma de Mallorca. Informe de proyecto, Departamento de Geología, Universidad de Oviedo.

ESBERT R.M. et al. (1992). Deterioro y sugerencias de conservación de la piedra calcárea de las bóvedas de "Ses Voltes" (Palma de Mallorca). Informe de proyecto, Departamento de Geología, Universidad de Oviedo.

ESBERT R.M. et al. (1992). Caracterización petrofísica de algunas de las piedras de construcción empleadas en la catedral de Segovia. Informe de proyecto, Departamento de Geología, Universidad de Oviedo.

ESBERT R.M. et al. (1992). Identificación de la piedra utilizada en la catedral de Almería (monumento y cantera). Informe de proyecto, Departamento de Geología, Universidad de Oviedo.

ESBERT R.M. et al. (1992). Estudio de los espacios vacíos de cinco muestras de rocas de La Camocha (Gijón). Informe de proyecto, Departamento de Geología, Universidad de Oviedo.

ESBERT, R.M., DÍAZ-PACHE, F., GROSSI, C.M., ALONSO, F.J. y OR$D A Z$, J. (1992). "Incidencia de la contaminación en el deterioro y conservación de rocas monumentales españolas". En: Patrimonio Histórico Artístico y Contaminación. (Encuentro Europeo sobre el Patrimonio Histórico Artístico y Contaminación), Consorcio para la Organización de Madrid Capital Europea de la Cultura 163-167.

**ESBERT R.M., GARCÍA RAMOS J.C., NISTAL A.M., ORDAZ J., VALENZUELA M., ALONSO F.J. y SUÁREZ DE CENTI C. (1992). “EI proceso digital de imágenes aplicado a la conservación de la piedra monumental. Un ejemplo: Sta. María del Naranco (Oviedo)". Revista de Arqueología, 139: 7-11.

**ESBERT R.M., GROSSI C.M., ORDAZ J., ALONSO F.J., RUIZ L. y MARCOS R.M. (1992). “La conservación de la piedra de la fachada del antiguo Hospicio Provincial de Oviedo". En: Cong. Int. Rehabilitación del Patrimonio Arquitectónico y Edificación, Comisión Canaria para la Conmemoración V Centenario, Las Palmas, T-1, 118-122. I.

**ESBERT R.M., ORDAZ J., ALONSO F.J. y SUÁREZ DEL RÍO L.M. (1992). "Estudio diagnóstico del deterioro de las piedras de la fachada del antiguo Hospicio Provincial de Oviedo." En: Cong. Int. Rehabilitación del Patrimonio Arquitectónico y Edificación, Comisión Canaria para la Conmemoración V Centenario, Las Palmas, T-1, 123-126.

GROSSI C.M. (1992). Cristalización de sales en rocas monumentales porosas y su auscultación mediante emisión acústica. Tesis doctoral, Departamento de Geología, Universidad de Oviedo.

MARCOS R.M. (1992). Tratamientos de conservación aplicados a rocas carbonatadas. Catedral de León. Tesis doctoral, Departamento de Geología, Universidad de Oviedo.

MODESTO M. et al. (1992). Auscultación de la estabilidad de la catedral de Palma de Mallorca mediante técnicas de emisión acústical actividad microsísmica. Fases I, II y III. Informe de proyecto, Departamento de Geología, Universidad de Oviedo.

MONTOTO M., ESBERT R.M., SUÁREZ DEL RÍO L.M., RUIZ DE ARGANDOÑA V.G., CALLEJA L. y GROSSI C.M. (1992). "Acoustic emission/microseismic activity monitoring of salt crystallization for stone conservation" Journal of Acoustic Emission, 10 (1-2): s35s41.

VALDEÓN L., ESBERT R.M. y GROSSI C.M. (1992). “Hydric properties of some spanish building stones: a petrophysical interpretation". En: Druzik J.R., Freestone I.V.,Vandiver P.B. and Wheeler G.S. (Eds.), Materials Issues in Art and Archaeology, MRS Proc. 267: 911 916.

VALDEÓN L., GROSSI C.M, MARCOS R.M. y ESBERT R.M. (1992). "Influence of conservation treatments on hydric properties of stones". En: Delgado J., Henriques F. and Jeremias F.T. (Eds.), 7th. Int. Cong. Deterioration and Conservation of Stone, Laboratório Nacional de Engenharia Civil, Lisboa, V-2, 1073-1081.

1993

**ALONSO F.J., CHINCHÓN J.S., ORDAZ J., HERNANDEZ E., ALASTUEY A. y ESBERT R.M. (1993). "Las piedras de construcción de la Seu Vella de Lérida: Tipos, petrografía y propiedades físicas". Boletín Geológico y Minero (IGME), 104-4: 431-438.

**ESBERT R.M. (1993). “Utilización de protectores superficiales para la conservación de la piedra: situación actual en España. (The use of surface protectants: the current situation in Spain)". Materiales de Construcción (CSIC), 43 (229): 5-15.

ESBERT R.M. (1993). "The use of surface protectans: The current situation in Spain, Portugal and South America". Science and Technology for Cultural Heritage (Journal of the Comitato nazionale per la scienza e la tecnologia dei beni culturali), 2: 183-189.

ESBERT R.M., ALONSO F.J. y ORDAZ J. (1993). “Utilización de consolidantes e hidrofugantes de la piedra monumental", V Congreso de Geoquímica de España, Soria.

ESBERT R.M. et al. (1993). Determinación de las propiedades físicas de la piedra utilizada en la catedral de Almería y estado de deterior de la misma en las portadas de la de lo Pendones y Principal. Informe de proyecto, Departamento de Geología, Universidad de Oviedo.

ESBERT R.M. et al. (1993). Incidencia del ambiente en el deterioro de la piedra de la catedral de Burgos: Cimborrio y fachada de la Coronería. Informe de proyecto, Departamento de Geología, Universi- 
dad de Oviedo.

**ESBERT R.M., DÍAZ-PACHE F. (1993). "Influencia de las características petrofísicas en la penetración de consolidantes en rocas monumentales porosas. (Influence of petrographical characterístics in the penetration of consolidantsin porous building stones)". Materiales de Construcción (CSIC), 43 (230): 25-36.

HAMMECKER C. (1993). Importance des transferts d'eau dans le dègradation des pierres en oeuvre. Tesis doctoral, Departamento de Geología, Universidad de Oviedo.

**MARCOS R., ESBERT R.M., ALONSO F.J. y DÍAZ-PACHE F. (1993). "Características que condicionan el comportamiento de la caliza de Hontoria (Burgos) como piedra de edificación". Boletín Geológico y Minero (IGME), 104-5: 587-597.

PÉREZ A. (1993). Granitos de Axeitos: petrografía, fisuración y propiedades físicas. Tesis de licenciatura, Departamento de Geología, Universidad de Oviedo.

\section{4}

ALONSO J. (1994). Propiedades que controlan la hidrorrepelencia de rocas carbonatadas tratadas con productos silicoorgánicos. Tesis de licenciatura. Departamento de Geología. Universidad de Oviedo.

**ALONSO F.J., ARECES J.L., TORAÑO J., RODRÍGUEZ R., GROSSI C. y ESBERT R.M. (1994). “Descripción y cuantificación de los espacios vacíos de algunas rocas detríticas carboníferas de la mina "La Camocha" (Gijón)". Boletín Geológico y Minero (IGME), 105-3: 306-317.

ALONSO F.J., ESBERT R.M., ALONSO J. y ORDAZ J. (1994). “Saline spray action on a treated dolomitic stone". En: Fassina V., Ott H. and Zezza F. (Eds), $3^{\circ}$ Int. Symp. The Conservation of Monuments in the Mediterranean Basin, Soprintendenza ai Beni Artistici e Storici, Venecia, ICRROM, 867-870.

**ALONSO F.J., ESBERT R.M. y ORDAZ J. (1994). “Estado de alteración de la piedra de los capiteles del monasterio de Santo Domingo de Silos". Ingeniería Civil (CEDEX), 96: 15-24.

**ALONSO F.J., DÍAZ-PACHE F. y ESBERT R.M. (1994). "Interacción piedra-ambiente, $1^{\text {a }}$ parte: Formas de alteración desarrolladas sobre la piedra de la catedral de Burgos". Informes de la Construcción (CSIC), 46 (433): 5-18.

DÍAZ-PACHE F. (1994). Formas de alteración y partículas sólidas de contaminación en la piedra de la catedral de Burgos. Seminario de investigación, Departamento de Geología. Universidad de Oviedo.

DÍAZ-PACHE, F., ESBERT, R.M. (1994). "Técnicas instrumentales aplicadas al control de la penetración de tratamientos de consolidación en piedra“. Ingeniería Civil (CEDEX), 96: 117-124.

ESBERT R.M. et al. (1994). Estudio sobre: Protección frente a la hu- medad de la piedra de revestimiento del edificio de la Presidencia del Gobierno de Canarias. Informe de proyecto, Departamento de Geología, Universidad de Oviedo.

ESBERT R.M. et al. (1994). Depósito de partículas sólidas de contaminación en rocas monumentales, ubicadas en ambientes urbanos. Incidencia en su conservación. Programa de Investigación. Departamento de Geología. Universidad de Oviedo.

ESBERT R.M., GROSSI C., ORDAZ J. y ALONSO F.J. (1994). “Características petrofísicas, deterioro y ensayos de conservación de la piedra de la catedral de Murcia“. En: La catedral de Murcia y su plan (Dirección General de Cultura de Murcia).

ESBERT R.M., PÉREZ-ORTIZ A., ORDAZ J. y ALONSO F.J. (1994). "Intrinsic factors influencing the decay of the granite as a building stone". En: Oliveira R., Rodrigues L.F., Coelho A.G. and Cunha A.P. (Eds.), A.A. Balkema, 7th Int. Cong. International Association of Engineering Geology, Lisboa, 3659-3665.

**GROSSI C.M., ESBERT R.M. (1994). "Las sales solubles en el deterioro de rocas monumentales. Revisión bibliográfica". Materiales de construcción (CSIC), 44 (235): 15-20.

GROSSI C.M., ESBERT R.M., LEWRY A.J. y BUTLIN R.N. (1994). "Weathering of building carbonate rocks under $\mathrm{SO}_{2}$ polluted atmospheres". En: Oliveira R., Rodrigues L.F., Coelho A.G. and Cunha A.P. (Eds.), A.A. Balkema, 7th Int. Cong. International Association of Engineering Geology, Lisboa, 3573-3582.

GROSSI C.M., LEWRY A.J., BUTLIN R.N. y ESBERT R.M. (1994). "Laboratory studies on interaction between $\mathrm{SO}_{2}$ polluted atmospheres and dolomitic building stone". En: Fassina V., Ott H. and Zezza F. (Eds), $3^{\circ}$ Int. Symp. The Conservation of Monuments in the Mediterranean Basin, Soprintendenza ai Beni Artistici e Storici, Venecia, ICRROM, 227-232.

MARCOS R.M., ALONSO F.J. (1994). “Identificación petrográfica de teselas de mosaicos romanos zamoranos (España), con vistas a su conservación". V Conf. Int. Committee for the Conservation of Mosaics, ICCM, Faro e Conimbriga, 203-212.

PÉREZ ORTIZ A., ORDAZ J., ESBERT R.M. y ALONSO F.J. (1994). "Microfissuring evolution of the granite from the Axeitos dolmen along the salt crystallization test". En: Fassina V., Ott H. and Zezza F. (Eds), $3^{\circ}$ Int. Symp. The Conservation of Monuments in the Mediterranean Basin, Soprintendenza ai Beni Artistici e Storici, Venecia, ICRROM, 115-119.

1995

ALONSO et al. (1995). Estudio petrográfico de un mármol blanco de Italia. Informe de proyecto, Departamento de Geología, Universidad de Oviedo.

ALONSO et al. (1995). Estudio petrográfico de la piedra "Crema Cenia". Informe de proyecto, Departamento de Geología, Universidad de Oviedo. 
ALONSO F.J., DÍAZ-PACHE F., ESBERT R.M. y QUINTANA A. (1995). "Aplicación del SEM-EDX al estudio de costras y partículas sólidas de contaminación en piedras monumentales". En: Microscopia Electrónica, XVII Reunión Bienal Sociedad Española de Microscopía Electrónica, Universidad de Oviedo, 308-309.

**ESBERT R.M., ALONSO J. (1995). “Hidrofugación de rocas carbonatadas porosas: Propiedades que controlan su eficacia (Waterproofing of porous carbonate rocks: Efficiency-controlling its properties)". Materiales de Construcción (CSIC), 45 (237): 15-30.

ESBERT R.M., ALONSO J., ALONSO F.J. y ORDAZ J. (1995). "Suggested properties for evaluating the behaviour of a waterproofed limestone under aggressive environmental conditions". En: Methods of Evaluating Products for the Conservation of Porous Building Materials in Monuments, Int. Colloquium, ICCROM, Roma, 331339.

ESBERT R.M. et al. (1995). Caracterización de la piedra de Tindaya para su estudio como loseta de revestimiento. Informe de proyecto, Departamento de Geología, Universidad de Oviedo.

ESBERT R.M. et al. (1995). Limpieza y conservación de la piedra de la fachada del Ayuntamiento de Ponferrada. Informe de proyecto, Departamento de Geología, Universidad de Oviedo.

ESBERT R.M. et al. (1995). Análisis y propuesta de tratamientos en la piedra de Hontoria: Fachada de Santa María (Catedral de Burgos). I Estudio alterológico de la piedra en vistas a su conservación. Planteamiento de las etapas de intervención. II Tratamiento de piedra in situ y en laboratorio. Informe de proyecto, Departamento de Geología, Universidad de Oviedo.

GROSSI C.M., MURRAY M. y BUTLIN R.N. (1995). "Response of porous building stone to acid deposition". Water, Air and Soil Pollution, 85: 2718-2731.

MONTOTO M., ESBERT R.M., SUÁREZ DEL RÍO L.M, RUÍZ DE ARGANDOÑA V.G., CALLEJA L, y GROSSI C.M. (1995). "Acoustic emision in stone conservation". Acoustic emisión / Microseismic activity in geological structures and material, V. Trans. Tech. Public. (USA), 665-684.

1996

ALONSO et al. (1996). Alteración de la piedra en edificios de Aite (San Sebastián). Caracterización petrográfica y análisis de sales solubles. Informe de proyecto, Departamento de Geología, Universidad de Oviedo.

**ALONSO F.J., ORDAZ J. y ESBERT R.M. (1996). “Deterioro selectivo de la piedra de construcción de la catedral de Palma de Mallorca“. Geogaceta (SGE), 20-5: 1228-1231.

**DÍAZ-PACHE F., ALONSO F.J. y ESBERT R.M. (1996). "La microscopía electrónica de barrido aplicada al estudio de partículas sólidas de contaminación depositadas sobre la piedra monumental“. Ingeniería Civil (CEDEX), 101: 29-36.
ESBERT R.M., ALONSO F.J., DÍAZ-PACHE F., ORDAZ J. y PÉREZORTIZ A. (1996). "Superficial protection of granite face to saline spray". En: EC workshop Degradation and Conservation of granitic rocks in monuments. European Commission, Protection and Conservation of European Cultural Heritage, research report 5, Santiago de Compostela, 337-342.

ESBERT R.M., DÍAZ-PACHE F., ALONSO F.J., ORDAZ J. y GROSSI C.M. (1996). "Solid particles of atmospheric pollution found on the Hontoria limestone of Burgos cathedral". En: Proceedings, 8th. Int. Cong. Deterioration and Conservation of Stone, V-1, Berín, $393-$ 399.

ESBERT R.M. et al. (1996). Palacio del Duque del Parque (Oviedo). Estudios previos a la limpieza de la fachada. Informe de proyecto, Departamento de Geología, Universidad de Oviedo.

ESBERT R.M. et al. (1996). Estudio alterológico de la piedra de la fachada de San Isidoro (Oviedo). Planteamiento de las etapas de intervención. Informe de proyecto, Departamento de Geología, Universidad de Oviedo.

GROSSI C.M., ESBERT R.M. y SUÁREZ DEL RÍO L.M. (1996). “The application of the acoustic emission technique to stone decay by sodium sulphate in laboratory tests". En: Origen, mechanisms and effects of salts on degradation of monuments in marine and continental environments. European Commission Research Workshop.

ORDAZ J., PÉREZ-ORTIZ A., ESBERT R.M., MARTÍNEZ-NISTAL A. y ALONSO F.J. (1996). "Study of the granite crack network by means of digital image processing". En: EC workshop Degradation and Conservation of granitic rocks in monuments. European Commission, Protection and Conservation of European Cultural Heritage, research report 5, Santiago de Compostela, 249-254.

PÉREZ A. (1996). Características intrínsecas y parámetros fractográficos que condicionan la alteración del granito. Tesis doctoral, Departamento de Geología, Universidad de Oviedo.

PÉREZ-ORTIZ A., ORDAZ J., ESBERT R.M., ALONSO F.J. y DÍAZPACHE F. (1996). "Physical behaviour and degradation trends in anisotropic granite". En: Proceedings, 8th. Int. Cong. Deterioration and Conservation of Stone, V-1, Berín, 205-209.

\section{7}

ESBERT R.M. et al. (1997). Características petrofísicas las dos piedras seleccionadas para el revestimiento de las fachadas del Gran Teatre del Liceu. Crema Ámbar, Verde Guatemala. Informe de proyecto, Departamento de Geología, Universidad de Oviedo.

ESBERT R.M. et al. (1997). Estudio de la durabilidad de las piedras preseleccionadas para el revestimiento de las fachadas del Gran Teatre del Liceu. Informe de proyecto, Departamento de Geología, Universidad de Oviedo.

ESBERT R.M., ORDAZ J., ALONSO F.J., MONTOTO M., GONZÁLEZ LIMÓN T. y ÁLVAREZ DE BUERGO M. (1997). Manual de diagnosis y tratamiento de materiales pétreos y cerámicos. Colegio de Apare- 
jadores y Arquitectos Técnicos de Barcelona, Barcelona.

ESBERT R.M. y VALDEÓN L. (1997). Estudio sobre las piedras del Cosolat del Mar (Palma de Mallorca). Informe de proyecto, Departamento de Geología, Universidad de Oviedo.

ESBERT R.M. y VALDEÓN L. (1997). Estudio de deterioro y sugerencias para la conservación de la piedra de las fachadas del Cosolat del Mar (Palma de Mallorca). Informe de proyecto, Departamento de Geología, Universidad de Oviedo.

**ESBERT R.M., VALDEÓN L., DÍAZ-PACHE F., ORDAZ J. y ALONSO F.J. (1997). "La fachada de la iglesia de San Isidoro de Oviedo. Etapas de intervención y sugerencias para su conservación y limpieza". Loggia: Arquitectura y Restauración, 3: 82-89.

**GROSSI C.M., ESBERT R.M. y SUÁREZ DEL RÍO L.M. (1997). “La emisión acústica aplicada al estudio del deterioro de la piedra en ensayos de cristalización con sulfato de sodio. (The application of the acoustic emission technique to Stone decay by sodium sulphate in laboratory test)". Materiales de Construcción (CSIC), 47 (425): 5-15.

*GROSSI C.M., ESBERT R.M., SUÁREZ DEL RÍO L.M., MONTOTO M. y LAURENZI-TABASSO M. (1997). "Acoustic emission monitoring to study sodium sulphate crystallization in monumental porous carbonate stones". Studies in Conservation, 42 (2): 115-125.

**VALDEÓN L., MONTOTO M., CALLEJA L., ESBERT R.M., CORRAL N. y LÓPEZ T. (1997). "A method to assess spatial coordinates in art and archaeological objects: application of tomography to a dolmen". J. of Archaeological Sciences, 24 (4): 337-346.

\section{8}

ALONSO F.J. (1998). Las partículas de contaminación atmosférica en la alteración de la piedra. Documento interno, Departamento de Geología, Universidad de Oviedo.

ALONSO et al. (1998). Caracterización petrográfica de la piedra de Igueldo. Informe de proyecto, Departamento de Geología, Universidad de Oviedo.

ALONSO F.J., ORDAZ J., DÍAZ-PACHE F. y ESBERT R.M. (1998). "Características petrográficas que condicionan la durabilidad de la piedra natural". En: /l Congreso Internacional de la Piedra (CDROM), Madrid.

ESBERT R.M. (1998). “Técnicas de consolidación y protección de la piedra". En: Tratado de Rehabilitación: Patología y técnicas de intervención. Elementos estructurales. Munilla-Leria, Madrid, 153-160.

ESBERT R.M. et al. (1995). Análisis y propuesta de tratamientos en la piedra de Hontoria: Fachada de Santa María (Catedral de Burgos). I Comportamiento hídrico de una pátina artificial aplicada a la piedra. II Evolución de la pátina artificial aplicada a la piedra frente a atmósferas contaminadas. Informe de proyecto, Departamento de Geología, Universidad de Oviedo.
ESBERT R.M. et al. (1998). Seguimiento de las labores de restauración de la iglesia de San Isidoro (Oviedo). Informe de proyecto, Departamento de Geología, Universidad de Oviedo.

ESBERT R.M. et al. (1998). Deterioro/Conservación de la piedra del monasterio de San Pelayo (Oviedo). 1 a Parte: Deterioro de las piedras: sus causas. Anexo: La iglesia de la Corte. 2a Parte: Conservación: Métodos y productos. Informe de proyecto, Departamento de Geología, Universidad de Oviedo.

ESBERT R.M. et al. (1998). Análisis y pautas de actuaciones en los elementos de piedra de las fachadas del Eixample de Barcelona. Informe de proyecto, Departamento de Geología, Universidad de Oviedo.

ESBERT R.M. et al. (1998). Caracterización de la piedra de Briviesca. Deterioro en el trasaltar de la catedral de Burgos. Informe de proyecto, Departamento de Geología, Universidad de Oviedo.

ESBERT R.M. et al. (1998). Deterioro y conservación de la piedra del teatro Victoria Eugenia de San Sebastián. Informe de proyecto, Departamento de Geología, Universidad de Oviedo.

**GROSSI C.M., ESBERT R.M. y DÍAZ-PACHE F. (1998). “Degradación y durabilidad de materiales rocosos de edificación en ambientes urbanos. (Decay and durability of building stones in urban envionments)". Materiales de Construcción (CSIC), 48 (252): 5-12.

\section{9}

**ALONSO F.J., ORDAZ J., VALDEÓN L., ROJO A., DÍAZ-PACHE F. y ESBERT R.M. (1999). “Caracterización petrofísica de la caliza de Piedramuelle (Oviedo, Asturias)". Trabajos de Geología, 21: 25-31.

DÍAZ-PACHE, F. GROSSI, C.M. y ESBERT, R.M. (1999). "Automated characterization of solid particles in urban environment using SEM and EDX". Microscopy and Analysis, 3: 19-21.

ESBERT R.M. et al. (1999). Análisis y propuesta de tratamientos en la piedra de Hontoria: Fachada de Santa María (Catedral de Burgos). III Seguimiento de los trabajos de conservación. Informe de proyecto, Departamento de Geología, Universidad de Oviedo.

ESBERT R.M. et al. (1999). Caracterización petrofísica y sugerencias de intervención en la piedra del palacio de Revillagigedo (Gijón). I Avance. II Informe. Informe de proyecto, Departamento de Geología, Universidad de Oviedo.

ESBERT R.M. et al. (1999). Diagnóstico de lesiones y sugerencias de intervención en la piedra de la fachada principal de la catedral de Girona. Primera parte: Diagnóstico de lesiones. Segunda parte: Sugerencias de intervención. Informe de proyecto, Departamento de Geología, Universidad de Oviedo.

ESBERT R.M. et al. (1999). Estudio del deterioro y sugerencias de intervención en la iglesia de Santa María de Castro Urdiales. Informe de proyecto, Departamento de Geología, Universidad de Oviedo. 
ESBERT R.M. et al. (1999). Estudio del deterioro y sugerencias de intervención en la iglesia de Santa María de Laredo. Informe de proyecto, Departamento de Geología, Universidad de Oviedo.

ESBERT R.M., ORDAZ J. y ALONSO F.J. (1999). Anális i pautes d'actuacions en els elements de pedra de les façaces de l'Eixample de Barcelona. ProEixample (Col•lecció Estudis Tècnics). Barcelona.

*GROSSI C.M., MURRAY M. (1999). "Characteristic of carbonate building stone that influence the dry deposition of acid gases". Construction and Building Material, 13: 101-108.

**MONTOTO M., ESBERT R.M. (1999). "Petrofísica de la roca matriz". Trabajos de Geología, 21: 239-252.

ROJO A. (1999). Propiedades hídricas de granitos ornamentales con distintos acabados superficiales. Tesis de licenciatura, Departamento de Geología, Universidad de Oviedo.

\section{0}

ALONSO F.J. (2003). "El agua en las rocas. Porosidad, permeabilidad y propiedades asociadas". En: I Curso sobre hidrogeología y medio ambiente. Departamento de Geología. Universidad de Oviedo.

ALONSO et al. (2000). Estudio petrográfico de rocas de Navarra. I Mendillorri. II Muralla y Mendillorri. Informe de proyecto, Departamento de Geología, Universidad de Oviedo.

**ALONSO F.J., ROJO A. y ESBERT R.M. (2000). “Deterioro de la piedra en la iglesia de Santa María de Castro Urdiales (Cantabria)". En: Geotemas, V Congreso Geológico de España, Alicante, V-1 (3), 191-195.

ALONSO F.J., VALDEÓN L. (2000). Estudio del puente de piedra de Puente Agüero (Cantabria). Informe de proyecto, Departamento de Geología, Universidad de Oviedo.

ESBERT R.M. et al. (2000). Deterioro y conservación de la piedra del monasterio de San Salvador de Oña (Burgos). Informe de proyecto, Departamento de Geología, Universidad de Oviedo.

ESBERT R.M. et al. (2000). Deterioro petrofísicos y alterológicos previos a la intervención en el palacio Mayoralgo de Cáceres. Informe de proyecto, Departamento de Geología, Universidad de Oviedo.

ESBERT R.M. et al. (2000). Pruebas de laboratorio para evaluar la durabilidad de un granito y un mortero a utilizar en paramentos exteriores del templo expiatorio de la Sagrada Familia (Barcelona). Informe de proyecto, Departamento de Geología, Universidad de Oviedo.

ESBERT R.M., ALONSO F.J., DÍAZ-PACHE F. y ORDAZ J. (2000). "Técnicas microscópicas aplicadas al estudio de recubrimientos artificiales de la piedra de los monumentos". En: 5th Int. Symp. The Conservation of Monuments in the Meditterranean Basin, Universidad de Sevilla, 234-235.
GROSSI C.M., ESBERT R.M., ALONSO F.J., VALDEÓN L., ORDAZ J. y DÍAZ-PACHE F. (2000). "Colour changes and reactivity to $\mathrm{SO}_{2}$, of some cladding stones at the "Gran Teatre del Liceu" (Barcelona, Spain)". En: Fassina V. 9th Int. Cong. Deterioration and Conservation of Stone, (Ed.), Elsevier, Venecia V-1, 323-328.

ROJO A. (2000). Estudio de los cambios inducidos en la superficie de la piedra por limpieza con energía láser. Trabajo de investigación, Departamento de Geología, Universidad de Oviedo.

${ }^{* *}$ ROJO A., ALONSO F.J. y ESBERT R.M. (2000). "Influencia de las características mineralógicas y texturales en el comportamiento hídrico de rocas graníticas". En: Geotemas, V Congreso Geológico de España, Alicante V-1 (1), 281-286.

SUÁREZ DEL RÍO L.M., CALLEJA L., RUIZ DE ARGANDOÑA V.G., RODRÍGUEZ REY A. Y ALONSO F.J. y DÍEZ SARRIÁ I., (2000). Caracterización tecnológica de rocas ornamentales de Asturias. CD-ROM, Universidad de Oviedo, Principado de Asturias.

VALDEÓN L., ESBERT R.M. (2000). “Seguimiento de los trabajos de conservación de la piedra. La fachada de la iglesia de San Isidoro de Oviedo". Loggia, 10: 88-93.

2001

ALONSO F.J. (2001). “Ensayos físicos de caracterización y comportamiento de materiales". En: Curso sobre Caracterización y restauración de materiales pétreos en arquitectura, escultura y arqueología. Fundación Uncastillo. Departamento de Geología. Universidad de Zaragoza, T-1, 189-201.

**ALONSO F.J., ESBERT R.M. y ROJO A. (2001). “Deterioro de la piedra en la iglesia de Santa María de Castro Urdiales (Cantabria)". RocMáquina ,(Elsevier) 66, 12-16.

ALONSO F.J. et al. (2001). Estudio del mármol del mausoleo del obispo Rodrigo Mercado de Zuazola, capilla de la Piedad, Oñate (Guipuzcoa). Informe de proyecto, Departamento de Geología, Universidad de Oviedo.

DÍAZ-PACHE F. (2001). Estudio de las partículas de contaminación depositadas sobre muestras expuestas en ambiente urbano. Su interacción con la piedra de edificación. (Catedrales de Burgos y Oviedo). Tesis doctoral, Departamento de Geología, Universidad de Oviedo.

*ESBERT R.M., DÍAZ-PACHE F., GROSSI C.M., ALONSO F.J. y ORDAZ J. (2001). "Airborne particulate matter around the cathedral of Burgos (Castilla y León, Spain)". Atmospheric Environment 35, 441-452.

ESBERT R.M. et al. (2001). Pruebas de laboratorio para evaluar la durabilidad de diversos materiales pétreos a utilizar en paramentos exteriores del templo expiatorio de la Sagrada Familia (Barcelona). Informe de proyecto, Departamento de Geología, Universidad de Oviedo.

ESBERT R.M. et al. (2001). Pruebas de laboratorio para evaluar la 
durabilidad del granito Silvestre Sagayo a utilizar en paramentos exteriores del templo expiatorio de la Sagrada Familia (Barcelona). Informe de proyecto, Departamento de Geología, Universidad de Oviedo.

ESBERT R.M., GROSSI C.M., ROJO A., ALONSO F.J., MONTOTO M., ORDAZ J., PÉREZ DE ANDRÉS M.C., ESCUDERO C., SEBASTIÁN E., RODRÍGUEZ-NAVARRO C. y ELERT K. (2001). "The effect of laser radiation used for cleaning purposes on different building stones". En: LACONA IV, Int. Conf. Lasers in the Conservation of Artworks, (ICOMOS), Paris, 255-258.

ESBERT R.M., ORDAZ J., ALONSO F.J., DÍAZ-PACHE F. y MATEOS F. (2001). "Caracterització petrofísica de la pedra de Girona: el seu ús en edificació". La Punxa (Col•legi d'Aparelladors i Arquitectes Tècnics de Girona) 31, 30-44.

**ESBERT R.M., ORDAZ J., ALONSO F.J., MONTOTO M., VALDEÓN L., GROSSI C.M., DÍAZ-PACHE F. y ROJO A. (2001). "Materiales pétreos. Metodología de diagnosis y tratamiento". Restauración \& Rehabilitación (América Ibérica, Madrid) 50, 42-47.

**ROJO A., ALONSO F.J. y ESBERT R.M. (2001). "Influencia de las características mineralógicas y texturales en el comportamiento hídrico de rocas graníticas". RocMáquina, Elsevier, 67, 38-41.

RODRÍGUEZ-NAVARRO C., ELERT K., SEBASTIÁN E., ESBERT R.M., GROSSI C.M., ROJO A., MONTOTO M., ORDAZ J., ALONSO F.J., ESCUDERO C. y PÉREZ DE ANDRÉs M.C. (2001). “Q-switched NdYAG laser cleaning of white marble: Induced damage evaluation through combined use of XRD and SEM". En: LACONA IV Int. Conf. Laser in the Conservation of Artworks, (ICOMOS), París, 49-52.

2002

**ALONSO F.J. (2002). Porosimetría de inyección de mercurio: Procedimiento de ensayo. Documento interno, Departamento de Geología, Universidad de Oviedo.

ALONSO et al. (2002). Estudio petrográfico de rocas de Navarra. III Monasterio de Sta. María de Irache. Informe de proyecto, Departamento de Geología, Universidad de Oviedo.

ESBERT R.M. et al. (2002). Pruebas de laboratorio para evaluar la durabilidad de material granítico de cantera (Pena da Croa, Santa María). Informe de proyecto, Departamento de Geología, Universidad de Oviedo.

ESBERT R.M. et al. (2002). Claustro de la catedral de Oviedo. I Pruebas de limpieza: estudio morfoquímico de la superficie limpiada. II. Estado de alteración de los capiteles del claustro bajo y sugerencias de intervención. Informe de proyecto, Departamento de Geología, Universidad de Oviedo.

**ESBERT R.M, GROSSI C.M., ALONSO F.J., ORDAZ J. y ROJO A. (2002). "Características de la piedra que permiten valorar los efectos de la limpieza con láser". En: Conservación del Patrimonio: Evolución y Nuevas Perspectivas, GEIIC, I Congreso Grupo Español del IIC, Valencia, 363-367.
ESBERT R.M, ORDAZ J. y ALONSO F.J. (2002). “Caracterización, durabilidad y conservación de materiales pétreos". Il Jornadas Empresariales de Trasferencia de Tecnología y Conocimiento. Universidad de Oviedo.

LOSADA J.M., ESBERT R.M. (2002). “Criterios de intervención en materiales pétreos (I) y (II)». Roc Máquina, Elsevier 75: 20-26 y 76: 24-30.

**SUÁREZ DEL RÍO L.M., CALLEJA L., DÍEZ SARRIÁ I., RUIZ DE ARGANDOÑA V.G., RODRÍGUEZ REY A. y ALONSO F.J. (2002). “Las rocas ornamentales de Asturias". Roc Máquina , Elsevier, 75: 30-38.

**SUÁREZ DEL RÍO L.M., CALLEJA L., DÍEZ SARRIÁ I., RUIZ DE ARGANDOÑA V.G., RODRÍGUEZ REY A. y ALONSO F.J. (2002). “Características tecnológicas de las rocas ornamentales de Asturias». Trabajos de Geología, 23: 73-84.

2003

ALONSO et al. (2003). Estudio petrográfico de rocas de Navarra. IV Monasterio de Sta. María de Irache. V Cuzcurrita (La Rioja). Informe de proyecto, Departamento de Geología, Universidad de Oviedo.

ESBERT R.M. et al. (2003). Claustro de la catedral de Oviedo. III La piedra del claustro, variedades y características. IV Estado de alteración de los las galerías del claustro bajo y sugerencias de intervención. V Pruebas de limpieza con el láser EOS1000 en el claustro bajo. VI Estado de alteración y sugerencias de intervención en el tambor de la capilla de Santa María del Rey Casto. VII Experimentación de tratamientos para aplicar a la piedra. VIII Inscripciones epigráficas: Criterios de intervención. IX. Estatua de Alfonso XI: Análisis de pinturas y piedra. Informe de proyecto, Departamento de Geología, Universidad de Oviedo.

*ESBERT R.M., GROSSI C.M., ROJO A., ALONSO F.J., MONTOTO M., ORDAZ J., PÉREZ DE ANDRÉS C.M., ESCUDERO C., BARRERA M., SEBASTIÁN E., RODRÍGUEZ-NAVARRO C. y ELERT K. (2003). “Application limits of Q-switched Nd:YAG laser irradiation for stone cleaning based on colour measurements". Journal of Cultural Heritage, 4 (S.1): 50s-55s.

**GROSSI C.M., ESBERT R.M., DÍAZ-PACHE F. y ALONSO F.J. (2003). "Soiling of building stone in urban environments". Building and Environment, 38: 147-159.

**LOSADA, J.M., ESBERT, R.M. (2003). “Criterios de intervención en materiales pétreos. (Conclusiones de las Jornadas celebradas en febrero de 2002)". Bienes Culturales, Revista del Instituto del Patrimonio Histórico Español, 2, Anexo, 34 p.

RODRÍGUEZ-NAVARRO C., ELERT K., SEBASTIÁN E., ESBERT R.M., GROSSI C.M., ROJO A., ALONSO F.J., MONTOTO M. y ORDAZ J. (2003). "Laser cleaning of stone materials: an overview of current research". Reviews in conservation (IIC), 4: 65-82.

**ROJO A., ALONSO F.J. y ESBERT R.M. (2003). "Propiedades hídricas de algunos granitos ornamentales de la península ibérica con distintos acabados superficiales: interpretación petrofísica. (Hid- 
ric properties of some iberian ornamental granites with different superficial finishes: a petrophysical interpretation)". Materiales de Construcción (CSIC), 53: 61-72.

**SUÁREZ DEL RÍO L.M., CALLEJA L., DÍEZ SARRIÁ I., RUIZ DE ARGANDOÑA V.G., RODRÍGUEZ REY A. y ALONSO F.J. (2003). “La caliza Griotte de Asturias (España) cómo roca ornamental". Boletín Geológico y Minero (IGME), 114: 463-471.

**VALDEÓN L., ROJO A., MATEOS F.J., ALONSO F.J., ORDAZ J. y ESBERT R.M. (2003). “La limpieza con láser de la piedra del claustro de la catedral de Oviedo". Restauración\&Rehabilitación, 81: 4247.

\section{4}

**ALONSO F.J., ESBERT R.M., ORDAZ J. y GROSSI C.M. (2004). “Reactividad frente al $\mathrm{SO}_{2}$ de piedras limpiadas con laser. (Reactivity of laser-cleaned stones to a $\mathrm{SO}_{2}$ ageing test)". Materiales de Construcción (CSIC), 54: 45-55.

**ÁLVAREZ S., ESBERT R.M., DÍAZ-PACHE F., ALONSO F.J., ORDAZ J., SUÁREZ DEL RÍO L.M., RODRÍGUEZ REY A. y RUIZ DE ARGANDOÑA V.G. (2004). "San Julián de los Prados (Oviedo). Agresiones, estado actual y propuestas para la conservación de un monumento singular del prerrománico asturiano". Restauración\&Rehabilitación. América Ibérica, Madrid, 85: 52-57.

ESBERT R.M., ALONSO F.J., ORDAZ J., VALDEÓN L., ROJO A. y MATEOS F.J. (2004). "La conservación de la piedra del claustro de la catedral de Oviedo". VII Cong. Int. Rehabilitación del Patrimonio Arquitectónico y Edificación, Lanzarote, 477.

ESBERT R.M. et al. (2004). Claustro de la catedral de Oviedo. X Etapas de intervención: Seguimiento y control de obra. Mantenimiento. Informe de proyecto, Departamento de Geología, Universidad de Oviedo.

ESBERT R.M. et al. (2004). Pruebas de laboratorio para evaluar la durabilidad de tres rocas ornamentales. Arenisca de los Pinares, Crema Teruel y Travertino Teruel. Informe de proyecto, Departamento de Geología, Universidad de Oviedo.

ESBERT R.M., ORDAZ J., ALONSO F.J., VALDEÓN L., ROJO A. y MATEOS F.J. (2004). "Cleaning of the capitals of Oviedo cathedral cloister". En: Proceeding 10th Int. Cong. Deterioration and Conservation of Stone, ICOMOS, Stockholm, V-2, 939-946.

ESBERT R.M., ROJO A., ALONSO F.J., MATEOS F.J., ORDAZ J. y VALDEÓN L. (2004). "La conservación de la piedra del claustro". En: VV.AA. La restauración de la torre y el claustro de la catedral de Oviedo, Ediciones Nobel, Oviedo, 284-302.

GROSSI C.M. (2004). “La limpieza de la piedra con el láser Nd:YAG” Investigación y Ciencia, 339: 280-281.

**MATEOS F.J., VALDEÓN L. y ROJO A. (2004). "Piedras de construcción de la fuente prerrománica de Foncalada: tipos y origen". Trabajos de Geología, 24: 107-118.
ORDAZ J., ALONSO F.J., ESBERT R.M., MATEOS F.J., VALDEÓN L. y ROJO A. (2004). “La intervención en la piedra del claustro de la catedral de Oviedo". Menhir. Derio, Vizcaya, 16: 72-85.

ROJO A., MATEOS F.J. y VALDEÓN L. (2004). "Patologías que afectan a los materiales pétreos". RocMáquina, Elsevier, 91: 4651.

**ROJO A., MATEOS F.J. y VALDEÓN, L. (2004). “Caracterización petrológica de los morteros de la fuente prerrománica de Foncalada, Oviedo". Trabajos de Geología, 24: 165-175.

ROJO A., MATEOS F.J., VALDEÓN L. y ESBERT R.M. (2004). “La intervención en la capilla de San Lorenzo de Gijón (Asturias-España): Seguimiento petrológico". Menhir. Derio, Vizcaya, 15: 30-39.

VALDEÓN L. (2004). “La conservación de las fábricas de sillería de la torre gótica". En: VV.AA , La restauración de la torre y el claustro de la catedral de Oviedo, Ediciones Nobel, Oviedo, 111-142.

\section{5}

**ÁLVAREZ S., ESBERT R.M., ARIAS L., SÁEZ R., ALONSO F.J., ORDAZ J., DÍAZ-PACHE F., RUIZ DE ARGANDOÑA V.G., CALLEJA L., RODRÍGUEZ REY A. y SUÁREZ DEL RÍO L.M. (2005). “Santa Cristina de Lena, un monumento enigmático del prerrománico asturiano: piedras, deterioro y sugerencias de conservación". Loggia, 18: 7087.

ALONSO et al. (2005). Estudio petrográfico de rocas de Navarra. VI Monasterio de Sta. María de la Oliva y Baluarte (auditorio de Pamplona). VII Artarraga. Informe de proyecto, Departamento de Geología, Universidad de Oviedo.

ESBERT R.M. et al. (2005). Caracterización de la durabilidad de la arenisca Dorada Urbión. Informe de proyecto, Departamento de Geología, Universidad de Oviedo.

ESBERT R.M. et al. (2005). Evaluación de productos de tratamiento aplicados a la superficie del material de revestimiento del edificio anexo al del Cabildo Insular en Santa Cruz de Tenerife. Informe de proyecto, Departamento de Geología, Universidad de Oviedo.

ESBERT R.M. et al. (2005). Informe sobre el estado de las fachadas del teatro Victoria Eugenia de San Sebastián. Informe de proyecto, Departamento de Geología, Universidad de Oviedo.

ESBERT R.M. et al. (2005). Palau de la Música de Barcelona. Caracterización petrofísica de los materiales constructivos utilizados en la fachada. Informe de proyecto, Departamento de Geología, Universidad de Oviedo.

ESBERT, R.M., MONTOTO, M., TIANO, P. y FRATINI, F.L. (2005). “The specific problems of monuments and art works and the contribution offered by characterization". En: Finished product characteristics and uses: a guide. OSNET Editions, 18: 89-106.

MATEOS F.J. (2005). Durabilidad de rocas graníticas sometidas a la acción de los aerosoles salinos: Características petrofísicas y me- 
canismos implicados. Trabajo de investigación, Departamento de Geología, Universidad de Oviedo.

**MATEOS F., ROJO A., VALDEÓN L., ALONSO F.J., ESBERT R.M. y ORDAZ J. (2005). "Influencia del grado de deterioro de la piedra en la limpieza de los capiteles del claustro de la catedral de Oviedo". En: Conservación y Restauración, II Cong. Grupo Español del IIC, GEIIC, Barcelona, 141-145.

\section{6}

**ALONSO F.J. (2006). La porosidad como componente petrográfico: La porosidad de las rocas carbonatadas. Documento interno, Departamento de Geología, Universidad de Oviedo.

**ALONSO F.J. (2006). Técnicas de estudio de la porosidad. Documento interno, Departamento de Geología, Universidad de Oviedo.

ALONSO F.J., DÍAZ-PACHE F., GROSSI C.M. y ESBERT R.M. (2006). "Atmospheric particles in an urban background: damage to building stone". En: Heritage, Weathering and Conservation, Int. Conf. Heritage, Weathering and Conservation, Madrid. Taylor \& Francis.

**ALONSO F.J., ESBERT, R.M., ORDAZ J. y VÁZQUEZ P. (2006). "Análisis del deterioro de los materiales pétreos de edificación". ReCoPaR (revista electrónica), 3: 23-32.

ALONSO et al. (2006). Estudio petrográfico de suelos y morteros de San Miguel de Lillo (Oviedo). Informe de proyecto, Departamento de Geología, Universidad de Oviedo.

ESBERT R.M. et al. (2006). Litologías, deterioro y sugerencias de conservación de la piedra y morteros de la casa de La Rúa de Oviedo. Informe de proyecto, Departamento de Geología, Universidad de Oviedo.

ESBERT R.M. et al. (2006). Palau de la Música de Barcelona. I Estado de conservación de los materiales de la fachada histórica. II Productos de conservación experimentados para utilizar en la fachada histórica. III Durabilidad de las posibles pinturas a aplicar en la fachada. Informe de proyecto, Departamento de Geología, Universidad de Oviedo.

**MARTOS E., ALONSO F.J., JIMÉNEZ-SÁNCHEZ y TORRES ALONSO M. (2006). "El monasterio de Raíces (Castrillón, Asturias): Estudio petrográfico de los materiales de construcción". Geogaceta (SGE), 40: 299-302.

**MATEOS, F.J., ESBERT, R.M., ROJO, A. y VALDEÓN, L. (2006). "Evaluación del grado de penetración de tratamientos consolidantes mediante la determinación de las variaciones en la velocidad de propagación de ondas longitudinales". ReCoPaR (revista electrónica), 3: 33-38.

ORDAZ et al. (2006). Estudio petrográfico y porométrico de las piedras Iroko y Kafé/Wengué para su uso como roca ornamental. Informe de proyecto, Departamento de Geología, Universidad de Oviedo.
ROJO A., ESBERT R.M., VALDEÓN L., ALONSO F.J., MATEOS F.J. y ORDAZ J. (2006). "La conservación de la piedra del claustro de la catedral de Oviedo". Loggia, 19: 96-107.

\section{7}

**ALONSO F.J., ESBERT R.M., ORDAZ J., VALDEÓN L., ROJO A. y MATEOS F.J. (2007). “El claustro de la catedral de Oviedo: conservación de la piedra". En: Ciencia, Tecnología y Sociedad para una Conservación Sostenible del Patrimonio Pétreo. Restauradores sin fronteras y CSIC-UCM, Madrid, 13-21.

**ALONSO F.J., VÁZQUEZ P., ESBERT R.M. y ORDAZ J. (2007). "Influence of measuring conditions on roughness parameters of ornamental rock". En: Preservation of Natural Stone and Rock Weathering, Int. Workshop Preservation of Natural Stone and Rock Weathering, Lisboa/Madrid. Taylor \& Francis, 13-16.

**ESBERT, R.M. (2007). “Alteración de rocas graníticas utilizadas en edificación. (Alteration of granite stone used in building construction)". Materiales de Construcción (CSIC), 57 (288): 77-89.

**ESBERT R.M. (2007). “Una aproximación a la conservación de la piedra en España en los últimos 25 años". En: La conservación infalible: de la teoría a la realidad, GEIIC, conferencia inaugural. III Cong. Grupo Español del IIC, Oviedo.

ESBERT R.M. et al. (2007). Estudio del deterioro del arco de Carlos III (La Cavada, Cantabria). Informe de proyecto, Departamento de Geología, Universidad de Oviedo.

ESBERT R.M. et al. (2007). Palau de la Música de Barcelona. IV Permeabilidad al vapor de agua de las posibles pinturas a aplicar en la fachada. VUtilización de veladuras a base de pigmentos minerales a aplicar en la fachada. Informe de proyecto, Departamento de Geología, Universidad de Oviedo.

ESBERT R.M. et al. (2007). Estudio del deterioro del deterioro de la piedra de las fachadas y capilla del palacio de Sobrellano (Comillas). Informe de proyecto, Departamento de Geología, Universidad de Oviedo.

**GROSSI C.M., ALONSO F.J., ESBERT R.M. y ROJO A. (2007). “Effect of laser cleaning on granite color". Color Research and Application, 32: 152-159.

**GROSSI C.M., BENAVENTE D., ESBERT R.M., ALONSO F.J., BRIMBLECOMBE P. y GARCÍA DEL CURA M.A. (2007). "Studies of colour changes by laser irradiation of reddish building limestone by $X$ ray photoelectron spectroscopy". En: LACONA VII, Int. Conf. Lasers in the Conservation of Artworks, (CSIC). Madrid, 129.

**GROSSI C.M., BRIMBLECOMBE P., ESBERT R.M. y ALONSO F.J. (2007). "Color changes in architectural limestones from pollution and cleaning". Color Research and Application, 32: 320-331.

VÁZQUEZ, P. (2007). Efectos de la cristalización de sulfato sódico en granitos ornamentales. Trabajo de investigación, Departamento de Geología, Universidad de Oviedo. 
**VÁZQUEZ P., LUQUE A., ALONSO F.J., ORDAZ J. y SEBASTIÁN E. (2007). "Diferencias de rugosidad en granitos y mármoles pulidos". Macla 7, XXVII. Reunión Sociedad Española de Mineralogía, Jaén, 99.

\section{8}

ALONSO F.J. et al. (2008). Oviedo Redondo. Estudio petrográfico de rocas. Informe de proyecto, Departamento de Geología, Universidad de Oviedo.

ALONSO F.J. et al. (2008). Oviedo Redondo. Estudio petrográfico de morteros. I Santa Ana, Cimadevilla y Rúa. Il Catedral, San Juan. III Museo arqueológico. IV Ayuntamiento, Universidad, Jovellanos, Lillo, Colloto. Informe de proyecto, Departamento de Geología, Universidad de Oviedo.

ALONSO F.J. et al. (2008). Oviedo Redondo. Estudio petrográfico de rocas y morteros. Glosario, metodología y protocolo de muestreo. Informe de proyecto, Departamento de Geología, Universidad de Oviedo.

**ALONSO F.J., VÁZQUEZ P., ESBERT R.M. y ORDAZ J. (2008) “Durabilidad de granitos ornamentales: valoración de los daños inducidos por el ensayo de cristalización de sales (Ornamental granite durability: evaluation of damage caused by salt crystallization test)". Materiales de Construcción (CSIC), 58: 191-201.

**ESBERT R.M., ALONSO F.J. y ORDAZ J. (2008). "La petrofísica en la interpretación del deterioro y la conservación de la piedra de edificación". Trabajos de Geología, 28: 87-95.

ESBERT R.M. et al. (2008). Pruebas de laboratorio para evaluar la durabilidad de dos rocas ornamentales a utilizar en la Sagrada Familia (Barcelona). Informe de proyecto, Departamento de Geología, Universidad de Oviedo.

ESBERT R.M., MATEOS F., ORDAZ J. y ALONSO F.J. (2008). “Estudios previos a la intervención en las fachadas del Palau de la Música Catalana (Barcelona)". IX Cong. Int. Rehabilitación del Patrimonio Arquitectónico y Edificación, Sevilla, 425-430.

ROJO A., MATEOS F.J. y VALDEÓN L. (2008). “Consolidation of granite building stones used in continental climates: San Juan de los Reyes Church in Toledo, Spain". En: Delgado J. and Mumoso J.M. (Eds.), Stone consolidation in cultural heritage: research and practice, Int. Symp. Stone consolidation in cultural heritage, Lisboa, 213-222.

VÁZQUEZ P., ESBERT R.M., ALONSO F.J. y ORDAZ J. (2008). “Evaluation of damage salt crystallization in granitic building stones". V-I, 11th. Int. Congress on Deterioration and Conservation of Stone, Torun, 325-331.

\section{9}

**ALONSO F.J., BUSTAMANTE R., DÍAZ C., MONJO J. y SALTO I. (2009). "Glosario de morteros". ReCoPaR (revista electrónica), 6:
$33-40$.

ALONSO F.J. et al. (2009). Análisis de materiales cerámicos constructivos de yacimientos romanos. I Hornos La Venta del Gallo, Cayés (Llanera). II Hornos PK 15 Veranes (Gijón). III Villa romana de Priañes, Nora (Oviedo). IV Necrópolis romana de Paredes (Siero). Informe de proyecto, Departamento de Geología, Universidad de Oviedo.

ALONSO F.J. et al. (2009). Mortero romano. Casas del Puente, Salas. Informe de proyecto, Departamento de Geología, Universidad de Oviedo.

ALONSO F.J. et al. (2009). Cerámica vidriada. Torre Gascona, Oviedo. Informe de proyecto, Departamento de Geología, Universidad de Oviedo.

CARRIZO L. (2009). Caracterización y alteración de la piedra de la fachada de la iglesia de los Padres Franciscanos de Avilés. Propuesta de conservación. Tesis de máster, Departamento de Geología, Universidad de Oviedo.

ESBERT R.M. et al. (2009). El deterioro de la piedra de las fachadas y capilla del palacio de Sobrellano (Comillas). Sugerencias de actuaciones urgentes. Informe de proyecto, Departamento de Geología, Universidad de Oviedo.

KOVÁCS T. (2009). Durability of crystalline monumental Stone in terms of their petrophysical characteristics. Tesis doctoral, PhD Thesis, Departamento de Geología, Universidad de Oviedo/ Universidad de Bolonia.

**REQUEJO O., CALLEJA S. y ALONSO F.J. (2009). “Intercambios comerciales en el Arco Atlántico: Producciones cerámicas francesas (siglos XIII-XV) en yacimientos asturianos: Torre Gascona de Oviedo y Palacio Camposagrado de Avilés (Principado de Asturias)“. En: Historia y arqueología en el litoral del Arco Atlántico. I Symp. Int. Gentes del Mar, Luanco.

**REQUEJO O., JIMÉNEZ M. y ALONSO F.J. (2009). “La iglesia de San Miguel de Lillo, Oviedo. Obras de conservación y actuación arqueológica (2005-2006)“. En: Excavaciones Arqueológicas en Asturias 2003-2006 (Principado de Asturias) 338-346.

\section{0}

**ALONSO F.J. (2010). La porosidad como propiedad física: Densidad y porosidad. Documento interno, Departamento de Geología, Universidad de Oviedo.

ALONSO F.J. et al. (2010). Análisis de materiales cerámicos constructivos de yacimientos romanos. Conclusiones. Informe de proyecto, Departamento de Geología, Universidad de Oviedo.

**ALONSO F.J., REQUEJO O. FERNÁNDEZ-CRESPO M. y CARRIZO L. (2010). "Caracterización petrográfica de morteros del conjunto medieval de la ciudad de Oviedo". Trabajos de Geología, 30: 337349. 
ÁLVAREZ E.M. (2010). Caracterización físico-mecánica y alterabilidad de los materiales pétreos empleados en la construcción de la catedral de Santa María de Astorga (León). Tesis de máster, Departamento de Geología, Universidad de Oviedo.

ESBERT et al. (2010). Estudios previos de los materiales de las fachadas del edificio de la Biblioteca Nacional y el Museo Arqueológico Nacional. Informe de proyecto, Departamento de Geología, Universidad de Oviedo.

ESBERT et al. (2010). Análisis petrológico del deterioro y conservación de las fachadas del Palacio de Sobrellano (Comillas). Informe de proyecto, Departamento de Geología, Universidad de Oviedo.

**GÓMEZ-HERAS M., VÁZQUEZ P., FORT R., CARRIZO L. y ALONSO F.J. (2010). "Effects of high temperatures in building granites: Micro-cracking patterns and ultrasound velocity attenuation". XIX Cong. of the Carpathian Balkan Geological Association, Tesalónica.

**LUQUE A., VÁZQUEZ P., ARIZZI A., CULTRONE G., SEBASTIÁN E. y ALONSO F.J. (2010). "Cambios de permeabilidad observados en mármoles tratados térmicamente". Macla (SEM) 13, XXX Reunión Sociedad Española de Mineralogía, Madrid 139-140.

SUAREZ DEL RÍO L.M., RUIZ DE ARGANDOÑA V.G., CALLEJA L., RODRÍGUEZ-REY A., GROSSI C.M. y MONTOTO M. (2010). "Acoustic emission monitoring of the cathedral of Palma de Mallorca (Spain)". En: Bostenaru-Dan M., Prikyl R. y Török (Eds), Material, technologies and practice in historic heritage structures, Springer, 351-365.

VÁZQUEZ P. (2010). Granitos ornamentales: Caracterización, durabilidad y sugerencias de uso. Tesis doctoral, Departamento de Geología, Universidad de Oviedo.

**VÁZQUEZ P. y ALONSO F.J. (2010). "SO 2 exposure effect in monumental granitic stones". The 20th General Meeting of the International Mineralogical Association, Budapest.

*VÁZQUEZ P., ALONSO F.J., ESBERT R.M. y ORDAZ J. (2010). “Ornamental granites: Relationships between P-wave velocity, water capillary absorption and crack network". Construction and Building Materials, 24: 2536-2541.

**VÁZQUEZ P., CARRIZO L., FERNÁNDEZ M. y ALONSO F.J. (2010). "Cambios en la superficie de rocas sedimentarias tras su exposición a $\mathrm{HNO}_{3}$ ". Macla (SEM) 13, XXX Reunión Sociedad Española de Mineralogía, Madrid, 219-220.

2011

ACUÑA M. (2011). Cambios en la superficie de granitos ornamentales sometidos a diferentes temperaturas. Tesis de máster, Departamento de Geología, Universidad de Oviedo.

ALONSO L. (2011). Anisotropía en el comportamiento hídrico de las rocas sedimentarias. Tesis de máster, Departamento de Geología, Universidad de Oviedo.
**ALONSO F.J. (2011). El agua en los materiales rocosos. Documento interno, Departamento de Geología, Universidad de Oviedo.

**CARRIZO L., ALONSO F.J. y ESBERT R.M. (2011). “Piedras de edificación: canteras, petrografía y deterioro. Fachada de la iglesia de los Padres Franciscanos de Avilés (Asturias)". Boletín Geológico y Minero (IGME), 122-1: 37-48.

FÉRNÁNDEZ M. (2011). Comportamiento hídrico de areniscas ornamentales. Tesis de máster, Departamento de Geología, Universidad de Oviedo.

MATEOS F.J. (2011). Petrofísica de la roca matriz del acuífero costero de Campos (Mallorca): Funcionalidad hidráulica de su porosidad. Tesis doctoral, Departamento de Geología, Universidad de Oviedo.

**MOLINA E., CULTRONE G., SEBASTIÁN E., ALONSO F.J., CARRIZO L., GISBERT J. y BUJ O. (2011). "The pore system of sedimentary rocks as key factor in the durability of building materials". Engineering Geology, 118: 110-121.

ROJO A., ESBERT R.M, VALDEÓN L., ALONSO F.J., MATEOS F. y ORDAZ J. (2011). “Limpieza láser en el mármol: Pruebas de limpieza láser en el mármol de la biblioteca nacional y museo arqueológico nacional". Restauro (Revista Internacional del Patrimonio Histórico), 10: 34-39.

VÁZQUEZ P. y ALONSO F.J. (2011). "Weathering of dimensional granitic stone used as cladding". In: Matthew J. Colon (Ed), Weathering: types, processes and effects. Nova Sci. Publ, 167-188.

**VÁZQUEZ P., SIEGESMUND S. y ALONSO F.J. (2011). "Bowing of dimensional granitic stones". Environ Earth Sci, 63 (7-8): 16031612.

2012

**ALONSO F.J., ALONSO L. y VÁZQUEZ P. (2012). “Propiedades hídricas y anisotropía en rocas sedimentarias porosas". Geotemas (SGE) 13, VIII Congreso Geológico de España. Oviedo, 249.

**BUSTAMANTE R. y ALONSO F.J. (2012). “Normalización del análisis de la piedra y conservación del patrimonio cultural". Geotemas (SGE) 13, VIII Congreso Geológico de España. Oviedo, 252.

COTO I. (2012). Inventario y caracterización de los materiales pétreos utilizados en el patrimonio monumental del centro de Asturias. Tesis de máster, Departamento de Geología. Universidad de Oviedo.

PÉREZ A. (2012). Caracterización petrofísica de rocas de facies Jurásico-Cretácicas, sus posibilidades para almacenamiento de $\mathrm{CO}_{2}$. Tesis de máster, Departamento de Geología, Universidad de Oviedo.

**ORDAZ J., ALONSO F.J.VALDEÓN L. y PRENDES N. (2012). “Rosa María Esbert Alemany. In memoriam. (1942-2011)". Materiales de Construcción (CSIC), 62 (305): 38. 
2013

**ALONSO F.J. (2013). Durabilidad de materiales rocosos. Documento interno, Departamento de Geología, Universidad de Oviedo.

**ALONSO F.J., LOZANO A., DEL COZ J.J. y NAVARRO A. (2013). "Los ENS'S y ED'S aplicados a la patrología de humedades de fachadas", Jornadas Internacionales de Investigación en la Construcción, Eduardo Torroja, Madrid.

**ALONSO F.J., ORDAZ J. y Esbert R.M. (2013). "Indicadores del deterioro de los materiales pétreos de edificación. Clasificación y análisis de los daños". En: Ana Laborde (Coord.). Proyecto COREMANS: Criterios de intervención en materiales pétreos. Ministerio de Educación, Cultura y Deporte (IPCE), Madrid, 109-207.

**FERNÁNDEZ-IRIGOYEN J., RUIZ-FERNÁNDEZ J. GARCÍA C. y ALONSO F.J. (2013). “Explotación de los recursos líticos durante el Paleolítico antiguo en el oriente de Asturias". En: Baena R., Fernández J.J. y Guerrero I. (Eds.), El Cuaternario Ibérico: Investigación en el S. XXI, AEQUA Sevilla, 300-305. VIII Reunión del Cuaternario
Ibérico, Sevilla.

**MOLINA E., CULTRONE G., SEBASTIÁN E. y ALONSO F.J. (2013). "Evaluation of stone durability using a combination of ultrasound, mechanical and accelerates ageing test". Journal of Geophysics and Engineering, 10: 035003.

*VÁZQUEZ P., ALONSO F.J., CARRIZO L., MOLINA E., CULTRONE G., BLANCO M. y ZAMORA I. (2013). "Evaluation of the petrophysical properties of sedimentary building stones in order to establish quality criteria". Construction and Building Materials, 41: 868-878.

**VÁZQUEZ P., LUQUE A., ALONSO F.J. y Grossı C. (2013). "Surface changes on crystalline stones due to salt crystallization". Environmental Earth Sciences, 69 (4): 1237-1248.

* Documento digital.

**Documento digital de libre acceso en la red.

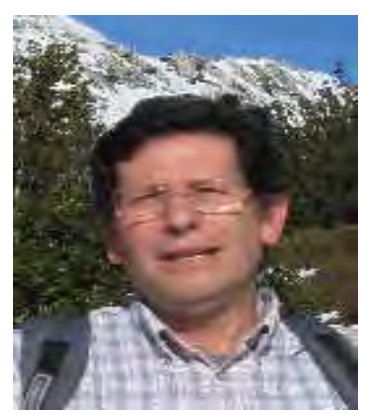

\section{Fco. Javier Alonso Rodríguez}

Departamento de Geología de la Universidad de Oviedo jalonso@geol.uniovi.es

Licenciado y doctor en Geología por la Universidad de Oviedo. Profesor Titular de Petrología y Geoquímica en el Departamento de Geología de la Universidad de Oviedo. Investigador en los siguientes temas: caracterización e interpretación petrofísica de materiales rocosos, alteración y durabilidad de rocas, deterioro y conservación de materiales pétreos usados en edificación, en particular en el patrimonio monumental. Miembro del "Grupo de Alteración” del Departamento Geología de Oviedo desde su formación en los años 80. He colaborado en diferentes proyectos: "Protección de rocas monumentales emplazadas en ambientes urbanos", "Efectos de la limpieza láser sobre la piedra monumental", "Estudio de las rocas utilizadas en los monumentos asturianos", y dirigido: "Durabilidad de rocas ornamentales cristalinas utilizadas en revestimientos exteriores"; "Acabado superficial y durabilidad de rocas porosas empleadas con fines ornamentales", entre otros. He participado en trabajos de intervención en edificaciones monumentales: "Fachada de la iglesia de San Isidoro (Oviedo)", "Teatro Victoria Eugenia (San Sebastián)", “Fachadas del Eixample de Barcelona”," "Iglesia de Sta. María de Castro Urdiales", “Claustro de la Catedral de Oviedo," “Palau de la Música Catalana”, “Casa de la Rúa (Oviedo), “Palacio de Sobrellano en Comillas”, etc. Evaluador de proyectos de investigación de: ANEPA, Agencia para la Calidad del Sistema Universitario de Castilla y León, Agencia Andaluza de Evaluación de la Calidad y Acreditación Universitaria. Miembro de: "Sociedad Geológica de España”, “Asociación Española para la Enseñanza de las Ciencias de la Tierra", "International Institute for Conservation of Historic and Artistic Works (IIC)", "AENOR, vocal en el Subcomite AEN/CTN 41/SC 8: Conservación, restauración y rehabilitación de edificios". 


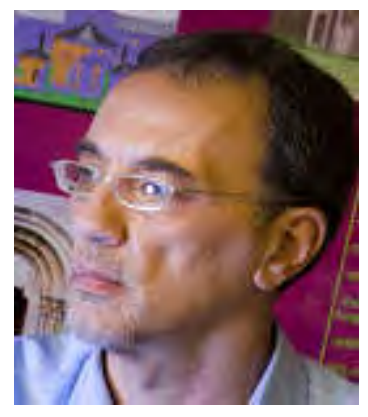

\author{
Luis Valdeón \\ GEA asesoría geológica \\ correo@geaasesoriageologica.com
}

Luis Valdeón ha desarrollado toda su carrera profesional en el ámbito de la conservación de patrimonio histórico-arqueológico y evaluación de materiales pétreos, combinando una completa base de formación científico-técnica con una dilatada experiencia profesional a pie de obra. Tras doctorarse en Geología en la Universidad de Oviedo en1989, realizó estudios postdoctorales en el Imperial College de Londres (1989-2001) donde se especializó en la aplicación de técnicas no destructivas a materiales pétreos. En estos ámbitos posee más de cuarenta publicaciones en congresos y revistas nacionales e internacionales. Ha realizado cientos de trabajos en intervenciones de patrimonio monumental o estudios previos a las mismas, investigando asimismo el comportamiento de materiales constructivos y ornamentales en, por ejemplo, excavaciones arqueológicas, como las del yacimiento de Contrebia Leucade (La Rioja), o sobre bienes declarados patrimonio de la Humanidad, como el prerrománico asturiano (Monumentos de Oviedo y del Reino de Asturias), o Monasterio de Yuso (La Rioja), así como en catedrales, capillas y monumentos civiles de todo el país.

Desde 2001 es socio fundador, de la empresa GEA asesoría geológica especializada en estudios sobre Conservación y Restauración de Patrimonio y la caracterización de todo tipo de materiales. Es miembro activo del Grupo Español del International Institute for Conservation (GE-IIC) en donde ha formado parte de los comités científicos del grupo de trabajo "piedra".

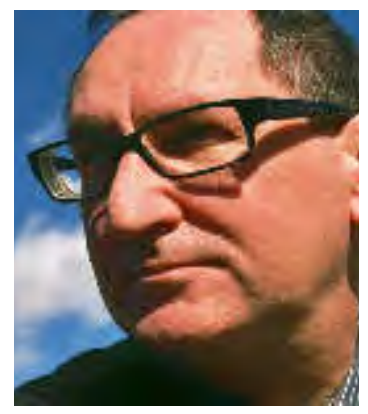

\title{
Jorge Ordaz
}

Departamento de Geología de la Universidad de Oviedo

Licenciado en Ciencias Geológicas por la Universidad de Barcelona se doctoró en la Universidad de Oviedo en 1973. Ha realizado su actividad docente y profesional como profesor en esta última universidad hasta su jubilación en 2011 . Su campo de trabajo se ha centrado en el estudio sobre caracterización, deterioro, durabilidad y conservación de los materiales rocosos, en especial de las piedras de los edificios y monumentos. En este sentido ha participado en la mayoría de proyectos e informes llevados a cabo por el "Grupo de Alteración" del Departamento de Geología de la Universidad de Oviedo, del que ha sido miembro desde su creación. Ha realizado también estudios sobre la historia de la geología en España. Ha dirigido tesinas y tesis doctorales y es autor, solo o en colaboración, de más de un centenar de publicaciones, entre libros y artículos en revistas nacionales e internacionales, así como de numerosas comunicaciones a congresos. Es miembro del Instituto Feijoo de Estudios del Siglo XVIII y del International Committee on the History of Geological Sciences (INHIGEO) 


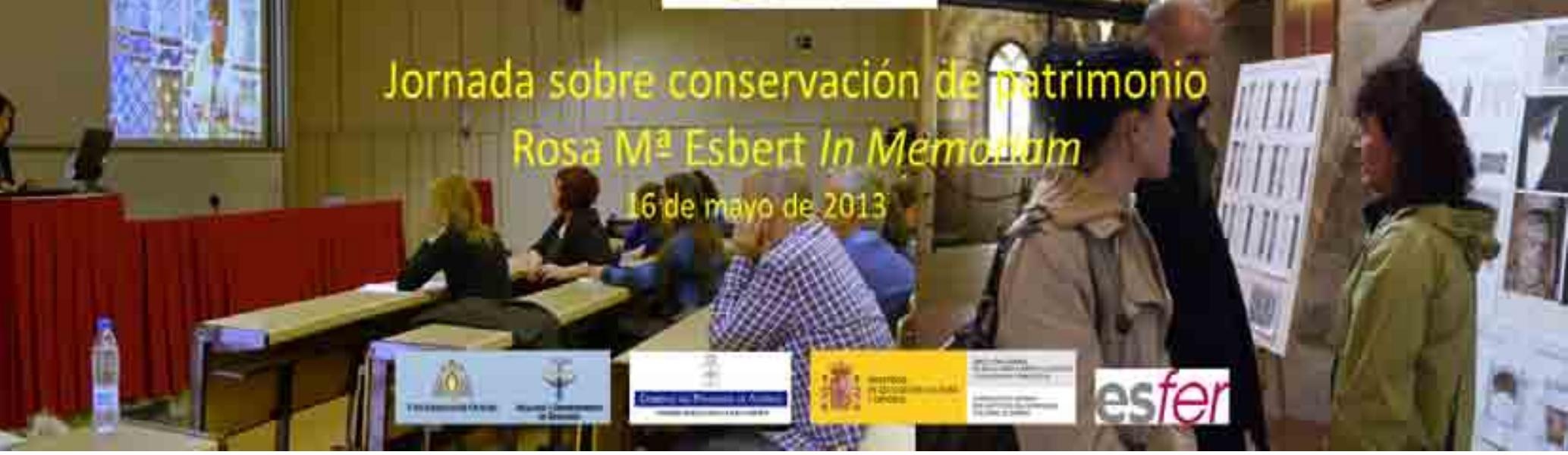

\title{
Los estudios complementarios sobre la Cámara Santa de la catedral de Oviedo.
}

\author{
Cosme Cuenca y Jorge Hevia
}

Resumen: Los estudios complementarios se desarrollan como una completa documentación gráfica, en la que se incluyen los textos alusivos a cada tema, a fin de hacer posible, al final del proceso restauratorio, una exposición divulgativa sobre la intervención realizada. Tras la ejecución de la 1a Fase de las obras de la Cámara Santa (la correspondiente a la envolvente exterior, a la cripta de Santa Leocadia, a la Antecámara y a las portadas de acceso), y antes de acometer las relativas a la $2^{\text {a }}$ Fase (las actuaciones pendientes del exterior y las relativas al interior de la Cámara Santa y a la nueva forma de exposición de sus contenidos), es cuando se llevan a cabo estos estudios complementarios, junto con los trabajos pluridisciplinares de los petrólogos Araceli Rojo, Luis Valdeón y Félix Mateos, y los restauradores Luís Suárez Saro y Pablo Klett Fernández.

Palabras clave: estudios complementarios, cámara santa, catedral oviedo, apostolado, restauración, limpieza y tratamiento

\section{Complementary studies of the Cámara Santa of the Oviedo Cathedral.}

Abstract: Complementary studies are developed as a complete graphical documentation in which the related texts for each topic are included, in order to make possible, at the end of restoration process, an informative presentation of the intervention. Following the implementation of the 1st phase of the works of Cámara Santa (corresponding to the building envelope, the crypt of Santa Leocadia, to the Antechamber and the doorways), and before embarking on the 2 nd phase (exterior outstanding works, the interior of Cámara Santa and the new form of exposure of its contents), is when we conduct these additional studies along with multidisciplinary work of petrologists Araceli Rojo, Luis Valdeón and Felix Mateos, and restorers Luis Suárez Saro and Pablo Klett Fernández.

Key words: complementary studies, cámara santa, catedral oviedo, postolote, restoration, cleaning and treatment

\section{Antecedentes}

Los estudios complementarios histórico-constructivoarquitectónicos, sobre la Cámara Santa de la Catedral de Oviedo, se realizaron por encargo de la Consejería de Educación, Cultura y Deporte del Gobierno del Principado de Asturias, siguiendo las recomendaciones del instituto del Patrimonio Cultural de España y con el fin de completar los ya realizados anteriormente con motivo de la redacción del "Proyecto básico y de ejecución de obras de restauración en la Cámara Santa de la Catedral de Oviedo", de junio de 2011. Simultáneamente también se coordinaron los trabajos auxiliares en los que participaron los petrólogos Araceli Rojo, Luis Valdeón y Félix Mateos (GEA, Asesoría Geológica), y los restauradores Luís Suárez Saro y Pablo Klett Fernández, que se concretaron en los siguientes estudios:
Estudio higrotermométrico de la Cámara Santa de la Catedral de Oviedo, de Félix J. Mateos.

Estudio de materiales del Apostolado de la Cámara Santa de la Catedral de Oviedo, de Araceli Rojo.

- Las alteraciones en la Cámara Santa de la Catedral de Oviedo, de Luis Valdeón.

Análisis de los tratamientos y sistemas de limpieza sobre los materiales de la Cámara Santa, de Luís Suárez Saro.

Los estudios complementarios se desarrollan como una completa documentación gráfica, en la que se incluyen los textos alusivos a cada tema, a fin de hacer posible, al final del proceso restauratorio, una exposición divulgativa so- 
bre la intervención realizada. Ya se ha concluido la $1^{\text {a }}$ Fase de las obras de la Cámara Santa (la correspondiente a la envolvente exterior, a la cripta de Santa Leocadia, a la Antecámara y a las portadas de acceso) y se ha confeccionado un panel divulgativo de las mismas que se ha colocado en la girola de la catedral. Tras la ejecución de estas obras, y antes de acometer las relativas a la $2^{\text {a }}$ Fase (las actuaciones pendientes del exterior y las relativas al interior de la Cámara Santa y a la nueva forma de exposición de sus contenidos), es cuando se llevan a cabo estos estudios complementarios por el equipo técnico pluridisciplinar aludido.

En muestra de agradecimiento queremos dejar constancia de la generosa aportación de fotografías históricas que nos han facilitado D. Alfonso Suárez Saro, D. Pedro Díaz Gómez, la Hermandad de Defensores de Oviedo y el Museo de Bellas Artes de Asturias.

Para una mejor identificación de los elementos de la Cámara Santa se dividen los seis elementos verticales de sustentación de los arcos fajones, que contienen el apostolado, en:

\section{COLUMNA}

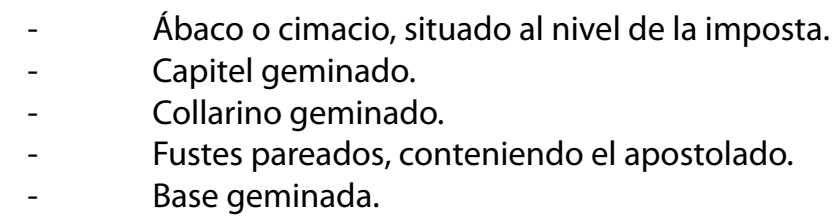

\section{PEDESTAL.}

Y, en función de su posición en planta, los seis elementos de apoyo se agrupan en:

Costado norte (lado del evangelio): A, B y C. Costado sur (lado de la epístola): D, E y F.

Iconográficamente tienen la siguiente correspondencia:

$\begin{array}{lll}- & \text { A: } & \text { San Simón y San Judas Tadeo } \\ \text { - } & \text { B: } & \text { Santiago y San Juan (Hijos de Zebedeo). } \\ \text { - } & \text { C: } & \text { San Andrés y San Mateo. } \\ \text { - } & \text { D: } & \text { Santiago el Menor y San Felipe. } \\ \text { - } & \text { E: } & \text { San Pedro y San Pablo (Príncipes de los } \\ & & \text { Apóstoles). } \\ \text { - } & \text { F: } & \text { Santo Tomás y San Bartolomé. }\end{array}$

En base a esta identificación de elementos, que se adopta por todo el equipo pluridisciplinar, se desarrollaron los planos-documentos gráficos del estudio complementario que a continuación enumeramos:

\section{PLANOS-DOCUMENTOS.}

No 1 El Apostolado de la Cámara Santa. Costado norte
(A-B-C) y costado sur (D-E-F).

Disposición, pedestales y eje jerárquico.

Leyenda del pedestal común, eje jerárquico trans versal, sistema de identificación y leyenda con los santorales apostólicos.

No 2 El Apostolado de la Cámara Santa. Costado norte (A-B-C) y costado sur (D-E-F).

Despiece pétreo de pedestales y columnas.

Despiece de los distintos elementos pétreos, mar cas de cantero, y herramientas de cantero utiliza das durante el románico.

No 3 El Apostolado de la Cámara Santa. Costado norte (A-B-C) y costado sur (D-E-F).

Repertorio iconográfico de los elementos de las columnas.

Repertorio iconográfico detallado de ábacos, ca piteles, collarinos, fustes y basas.

No 4 El Apostolado de la Cámara Santa. Costado norte (A-B-C) y costado sur (D-E-F).

Repertorio iconográfico de los capiteles de las co lumnillas de los pedestales.

Repertorio iconográfico detallado y paralelismos con otros capiteles románicos.

No 5 El Apostolado de la Cámara Santa. Costado norte (A-B-C).

Detalle de ábacos, capiteles, cabezas y basas de las columnas.

Detalle a escala $1 / 5$ de los elementos de las co lumnas del costado norte.

No 6 El Apostolado de la Cámara Santa. Costado sur (D-E-F).

Destalle de los ábacos, capiteles, cabezas y basas de las columnas.

Detalle a escala $1 / 5$ de los elementos de las co lumnas del costado sur.

No 7 Cabezas del apostolado. Costado norte (A-B-C). 
Comparativo años 1941-2012.

Evolución de las cabezas restauradas en 71 años.

No 8 Cabezas del apostolado. Costado sur (D-E-F).

Comparativo años 1941-2012.

Evolución de las cabezas restauradas en 71 años. Ojos de Santo Tomás: iris con emplaste de azaba che, pupilas realizadas con zafiros azules.

No 9 Cabezas del calvario coetáneo al apostolado.

Repertorio iconográfico de las tres efigies. Com parativo 1918-2012.

Repertorio iconográfico detallado; estados com parativos entre los años 1918 (antes de la voladu ra de 1934) y 2012.

No 10 La Cámara Santa de la catedral de Oviedo.

Daños de 1934 y método utilizado en su recons trucción.

Documentación fotográfica histórica con los da ños en general, en el costado norte y el costado sur. Documentación fotográfica histórica con la clasificación y montaje en seco de los restos. Le yenda con los daños en las fábricas y los conteni dos. Leyenda con los daños en el calvario. Leyen da con los daños en el apostolado. Leyenda con el método de reconstrucción de los elementos ar tísticos.

No 11 Columnas del apostolado. Costado norte (A-B-C).

Comparativo años 1918-1941-2012.

Evolución de las columnas del costado norte en 94 años, con referencia a su situación antes de la voladura de 1934.

No 12 Columnas del apostolado. Costado sur (D-E-F).

Comparativo años 1918-1941-2012.

Evolución de las columnas del costado sur en 94 años, con referencia a su situación antes de la vo ladura de 1934.

No 13 Pedestales del apostolado. Costado norte (A-B-C) y costado sur (D-E-F).
Estado actual y marcas de cantero.

Registro fotográfico detallado del estado actual tanto de los frontales como de los laterales.

No 14 Capiteles y ábacos del apostolado. Costado norte (A-B-C).

La materialidad perdida en 1934. Comparativo 1918-1941.

Registro fotográfico comparativo entre los años 1918 y 1941, grafiando sobre el dibujo la materia lidad perdida en la voladura de 1934 y que no se repuso.

No 15 Capiteles y ábacos del apostolado. Costado sur (D-E-F).

La materialidad perdida en 1934. Comparativo 1918-1941.

Registro fotográfico comparativo entre los años 1918 y 1941, grafiando sobre el dibujo la materia lidad perdida en la voladura de 1934 y que no se repuso.

No 16 Basas del apostolado. Costado norte (A-B-C).

La materialidad perdida en 1934. Comparativo 1918-1941.

Registro fotográfico comparativo entre los años 1918 y 1941, grafiando sobre el dibujo la materia lidad perdida en la voladura de 1934 y que no se repuso.

No 17 Basas del apostolado. Costado sur (D-E-F).

La materialidad perdida en 1934. Comparativo 1918-1941.

Registro fotográfico comparativo entre los años 1918 y 1941, grafiando sobre el dibujo la materia lidad perdida en la voladura de 1934 y que no se repuso.

No 18 El interior de la Cámara Santa. Costado norte.

Estado actual de paramentos.

Inserción en plano a escala 1/25 de ortofotogra fías de los paramentos entre el apostolado. Foto general del interior hacia el camarín.

No 19 El interior de la Cámara Santa. Costado sur. 
Estado actual de paramentos.

Inserción en plano a escala 1/25 de ortofotogra fías de los paramentos entre el apostolado. Foto general del interior hacia la antecámara.

№ 20 El interior de la Cámara Santa. Costados este y oeste.

Estado actual de paramentos.

Inserción en planos a escala 1/25 de ortofotogra fías de los paramentos. Foto general de la bóveda.

\section{No 21 El interior de la Cámara Santa.}

Elementos metálicos de hierro, cobre y bronce.

Situación en planta o alzado de los distintos ele mentos metálicos de hierro, cobre o bronce, y jus tificación de su procedencia.

No 22 El Apostolado de la Cámara Santa. Costado norte (A-B-C) y costado sur (D-E-F).

Mapeo de faltas, adiciones y patologías.

Mapeo detallado de las reintegraciones de Víctor Hevia Granda en 1939-1942, fracturas por la vo ladura de 1934, falta de volumen pétreo no rein tegrado, morteros industriales añadidos, frag mento de fuste distinto y refuerzos con barras de cobre. Leyenda sobre la eliminación de la pintura al óleo que cubría el apostolado y que fue elimi nada por Víctor Hevia en 1919-1920.

\section{№ 23 El interior de la Cámara Santa.}

Contenidos artísticos vinculados.

Cuatro relieves en madera dorada y policromada del s.XVI, de la escuela castellana. Cuatro óleos so bre lienzo oval del s.XIX (1815-1817) de Carlos García Muñiz. Contextualización de los conteni dos según dibujo de Jenaro Pérez Villamil de 1846, según grabado de José María Avrial de 1847, y según fotografía de 1886 de Laurent.

№ 24 Tesoro de la Cámara Santa.

Cruces y Caja de las ágatas.

Fotografías actuales de alta resolución de la Cruz de la Victoria, Cruz de los Ángeles, Caja de las Ágatas y Cristo de Nicodemo, tanto del anverso como del reverso. Textos sintéticos sobre data ción, materialidad, peso y dimensiones.
No 25 Tesoro de la Cámara Santa.

Arquetas de plata.

Fotografías actuales de alta resolución de la arqueta gótica de San Eulogio de Córdoba y San ta Lucrecia, s.XIV (1305); la arqueta de San Julián y San Serrano, s.XVl; la arqueta barroca de San Vi cente abad, de León, s.XVIII (1753); y la arqueta moderna de plata del s.XX (1989). Textos sintéti cos sobre datación, materialidad y dimensiones, y foto de la visita del Papa Juan Pablo II en 1989.

№ 26 Tesoro de la Cámara Santa.

Arca Santa.

Registro fotográfico comparativo entre los años 1918 y 2012 . Texto sintético sobre datación, mate rialidad y dimensiones.

NN27 Reliquias de la Cámara Santa.

Santo Sudario.

Fotografías actuales de alta resolución con el an verso y el reverso y foto del marco de plata. Texto con dimensiones del lienzo y el marco de plata que lo contiene.

No 28 El conjunto de la Cámara Santa.

Posibles elementos divulgativos. Formato peque ño.

Propuesta de marca libros y postales para reno var las existentes.

№ 29 El conjunto de la Cámara Santa.

Posibles elementos divulgativos. Formato medio.

Propuesta de un nuevo material gráfico en un ta maño superior al de las postales (DIN A-6). Tama ños doble postal y trípticos en DIN-A4.

\section{MONTAJES.}

M-1 Cartel del Camino de Santiago.

Montaje del Salvador y los Apóstoles.

Comparativo a la misma escala del Colegio Apos tólico de la Cámara Santa y el Salvador.

Texto relativo al romancero medieval francés.

Alusión al Camino de Santiago español y euro 
peo con representación gráfica del "Primer itinerario cultural europeo" declarado en 1987 por el CONSEJO DE EUROPA.

Boceto de cartel para su posible divulgación.

\section{M-2 Planta y sección de la Cámara Santa.}

Detalle de paramentos interiores.

Detalle de capiteles y cabezas del apostolado.

Detalle del tesoro y las reliquias.

M-3 Columnas del apostolado.

Comparativo 1918 - $1941-2012$.

\section{TRÍPTICOS.}

T-1 Tríptico del Apostolado de la Cámara Santa.

Costado norte (A-B-C).

T-2 Tríptico del Apostolado de la Cámara Santa.

Costado sur (D-E-F).

\section{Propuesta de sistemas de limpieza, integración cromá- tica y protección}

Tras los análisis realizados por los petrólogos en relación con las patologías superficiales, humedades, eflorescencias salinas, restos de policromías y pátinas, arenizaciones, disgregaciones, etc., así como con la monitorización de las condiciones ambientales del interior de la Cámara Santa, se han llevado a cabo unos estudios metodológicos sobre las pruebas de limpieza por el restaurador Luís Suárez Saro. Una vez probados los distintos métodos de limpieza, reintegración cromática y protección, (cuyos resultados se reflejan en documento independiente elaborado por los petrólogos y restauradores) se ha llegado a la siguiente conclusión inicial, pendiente aún del resultado de algunos análisis:

- Para la limpieza de la sillería escultórica y decorativa (constituida por ábacos, capiteles, fustes con el apostolado, basas y las cabezas del calvario) utilizar la metodología láser con los siguientes parámetros:

- Longitud de onda: 1064nm.

- Energía máxima de impulso: $150 \mathrm{~mJ}$.

- Frecuencia: 1 - 5-10-15-20 Hz.

- Potencia: 3W.
- Modo de salida: Multimodo circular.

- Divergencia: 5 mrad máx.

- Diámetro del foco en salida: $4 \mathrm{~mm}$.

- Duración del impulso: 8ns.

La limpieza láser se llevó a cabo sobre el apostolado, realizando diferentes catas programando el láser desde energías de $50 \mathrm{mj}$. a $150 \mathrm{mj}$. y frecuencias de 5 hz. a 20 hz.

- Para la limpieza de la sillería arquitectónica (constituida por pedestales, recercados de puertas y ventanas y fustes lisos) utilizar el sistema mecánico de proyección con micropartículas de piedra pómez pulverizada, con los siguientes parámetros:

- Presión en boquilla de 0,5 a 1,5 bares.

- Distancia a la superficie entre 25 y $40 \mathrm{~cm}$.

- Ángulo respecto a la superficie entre 45 y $60^{\circ}$.

- Pistola M500 con boquilla de $2 \mathrm{~mm}$.

- Para la limpieza de los revocos de bóvedas y paramentos utilizar también el sistema mecánico de proyección de micropartículas de piedra pómez pulverizada con los siguientes parámetros:

- Presión en boquilla de 0,5 a 1,5 bares.

- Distancia a la superficie entre 25 y $40 \mathrm{~cm}$.

- Ángulo respecto a la superficie entre 45 y $60^{\circ}$.

- Pistola M500 con boquilla de $5 \mathrm{~mm}$.

- Para la limpieza de las columnas y capiteles altomedievales utilizar un método químico mediante un disolvente universal inocuo tipo White Spirit, aplicado con hisopo de algodón tras el reblandecimiento de la cera superficial con pistola de aire caliente tipo Bosch regulada a $70-80^{\circ} \mathrm{C}$.

En cuanto a la integración cromática, sobre piedra, tanto de las escamaciones como de los morteros de restauración que restañaron los daños provocados en octubre de 1934, se probó el buen comportamiento de agua de cal 100 cc., pigmento ocre avana de CTS 3 grs., pigmento giallio ocre de CTS 1 gr., y pigmento nero fumo de CTS 0,5 grs., aplicado exclusivamente sobre las lagunas existentes en la pátina de la piedra y las reintegraciones volumétricas realizadas en la intervención de Víctor Hevia, con pinceles de pelo de marta del no $0-1-3$. También se pueden utilizar pigmentaciones de acuarela de la casa W\&N (Windsor and Newton).

Similar técnica de integración cromática se puede utilizar en los revocos de reposición para que no difieran tanto de los originales que pervivieron a la voladura de la Cámara Santa, empleándose en este caso pigmentos minerales naturales y fotoestables de la casa Keim.

Como capas de protección se probaron:

- Tecnadis PRS EFFECT, hidrofugante basado en nanopartículas de alta repelencia al agua que permite la transpirabilidad del material y no altera el brillo, tono, color y textura 
de la superficie tratada. No reacciona con el sustrato y es altamente resistente frente a los rayos UVA.

- Tecnadis PRS PERFOMANCE, hidrofugante y antimanchas basado en nanopartículas con excelentes propiedades de hidrofobicidad y oleofobicidad que permite la transpirabilidad del material y no altera el brillo, tono, color y textura de la superficie tratada. No reacciona con el sustrato y es altamente resistente a los rayos UVA y a la abrasión.

Ambos se aplicaron por separado con pulverizador y brocha en elementos pétreos, revocos y morteros.

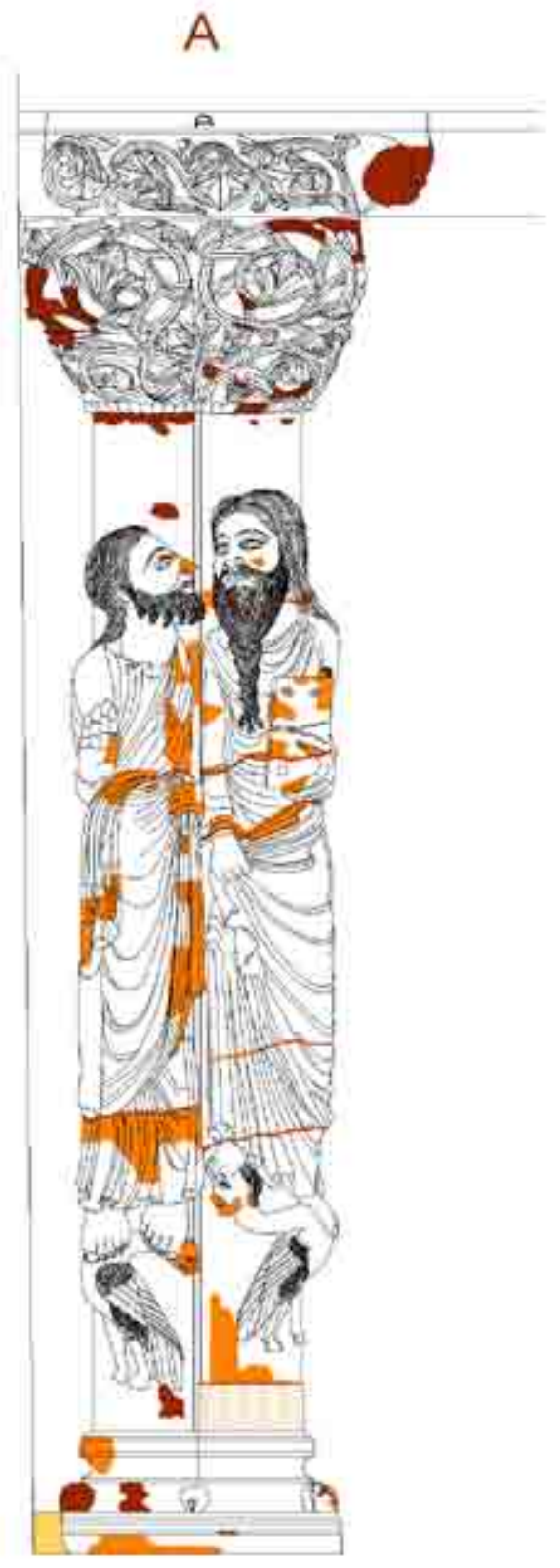

IEYENDA

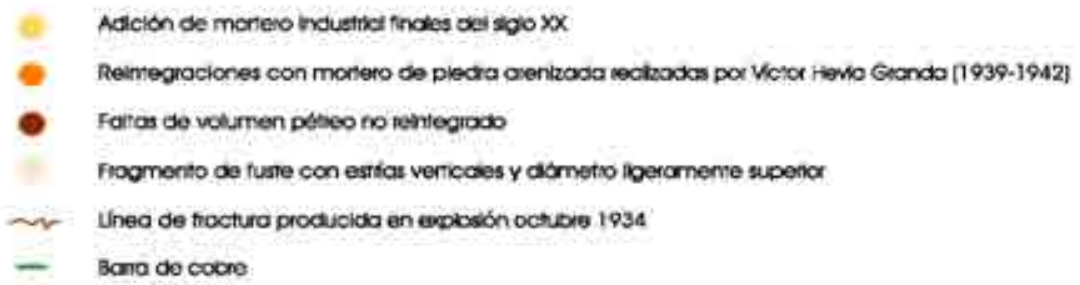

SAN SIMÓN Y SAN JUDAS TADEO

Figura 1: Mapeo de faltas, adiciones y patologías del Apostolado de la Cámara Santa: San Simón y San Judas Tadeo.. 
B

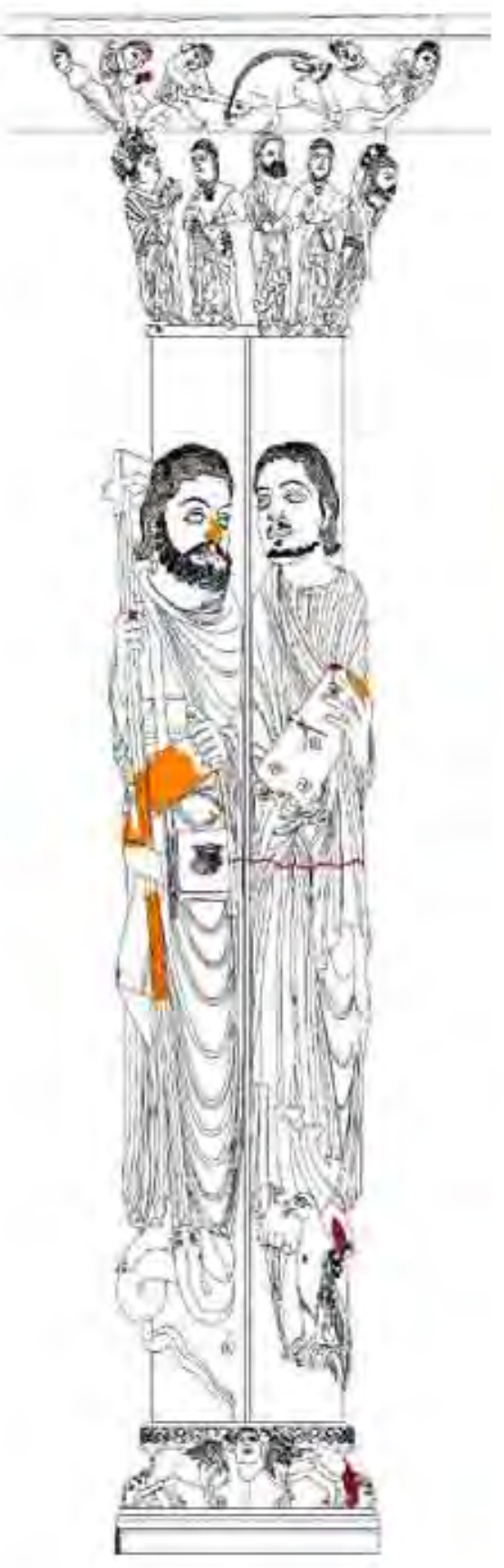

COSTADO NORTE

\section{LEYENDA}

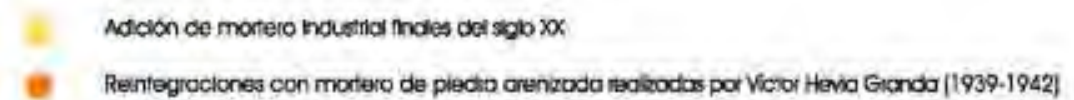

- Foras de volumen peseo no vertegrodo.

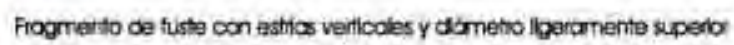

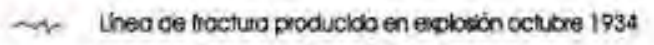

- Bana de corre

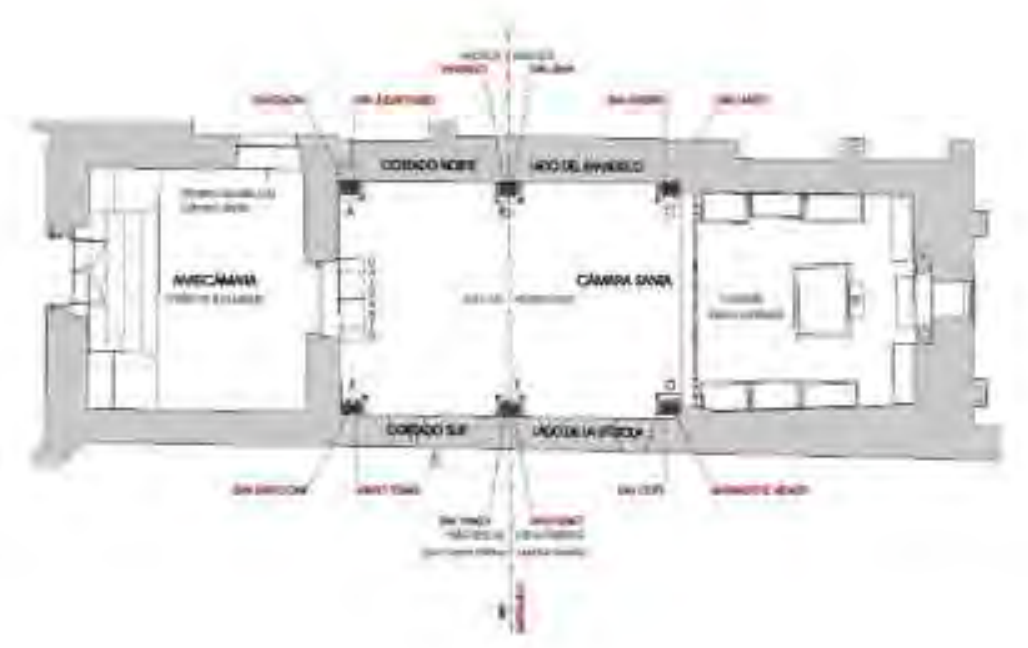

SANTIAGO Y SAN JUAN

Figura 2: Mapeo de faltas, adiciones y patologías del Apostolado de la Cámara Santa: Santiago y San Juan.. 


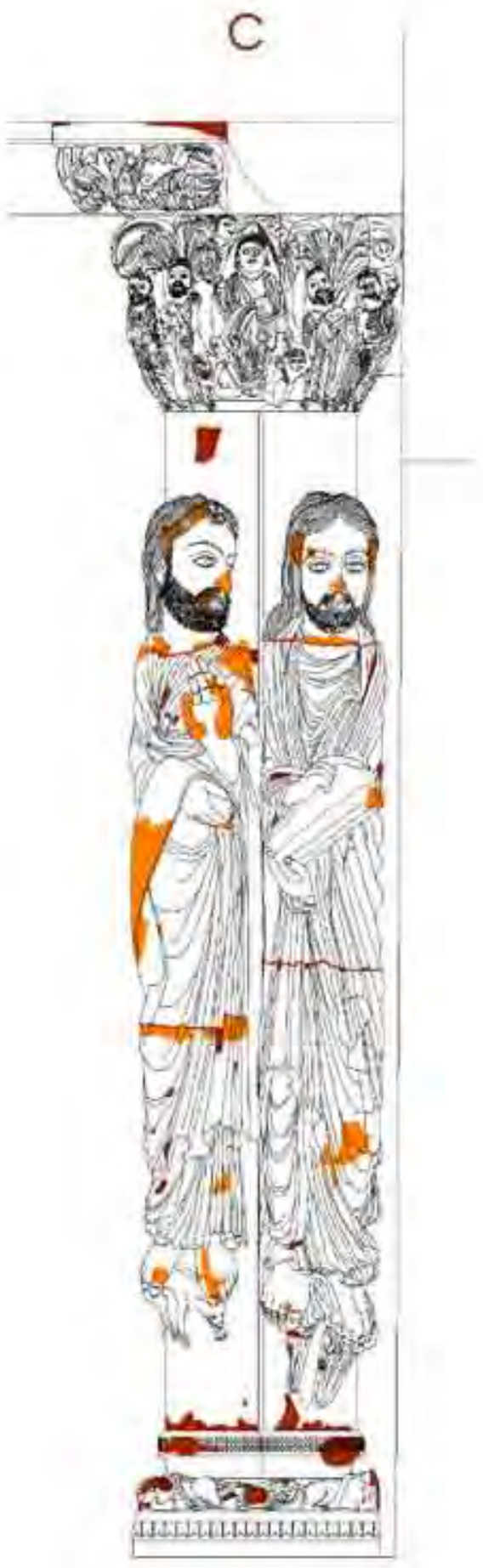

LEYENDA

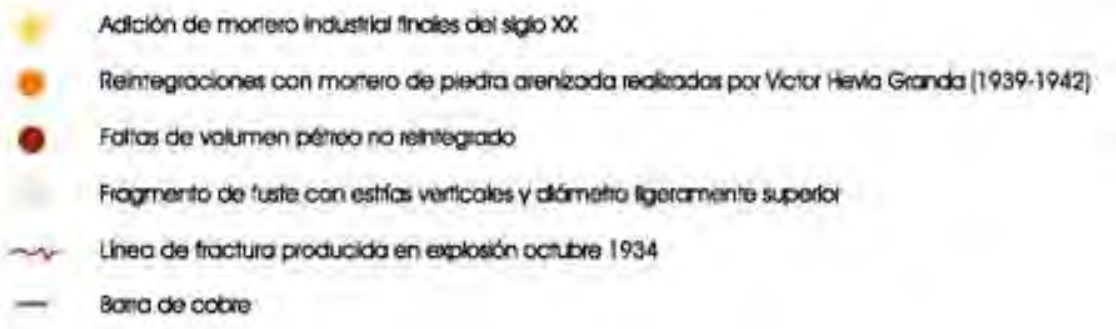

SAN ANDRÉS Y SAN MATEO

Figura 3: Mapeo de faltas, adiciones y patologías del Apostolado de la Cámara Santa: San Andrés y San Mateo. 
D

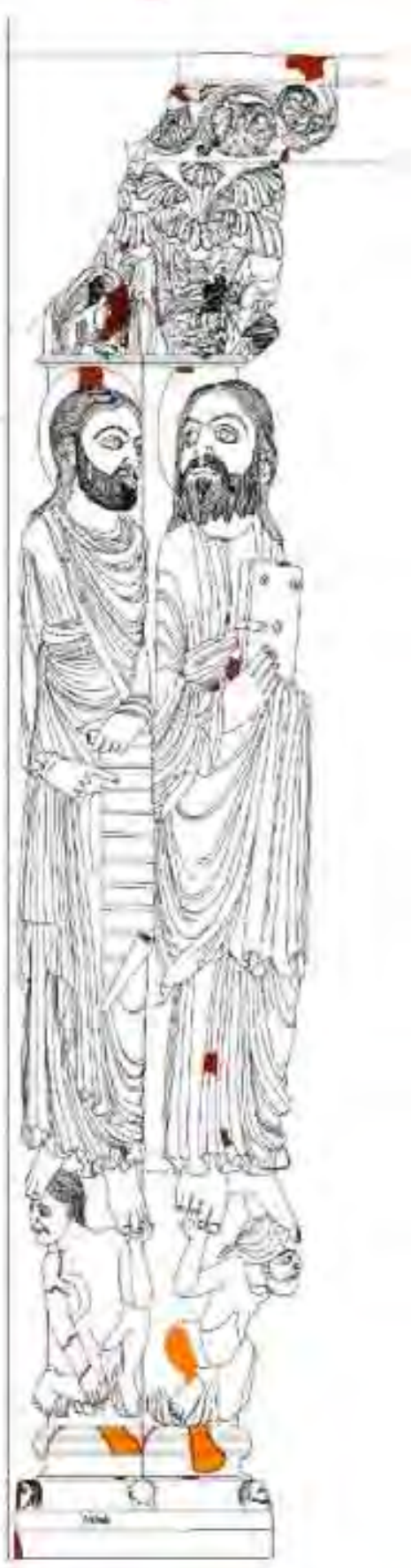

COSTADO SUR

\section{LEYENDA}

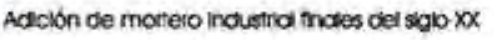

Reintegraciones con modero de piedra arenzada rechocoss por Vctox Hevia Ganda (1939-1942)

- Foras de voumen peneo no velntegrodo

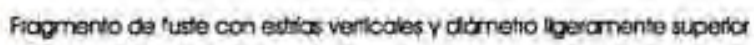

N. Inea de froctura pioctucida en explosidn octubue 1934

- Bana de cocre

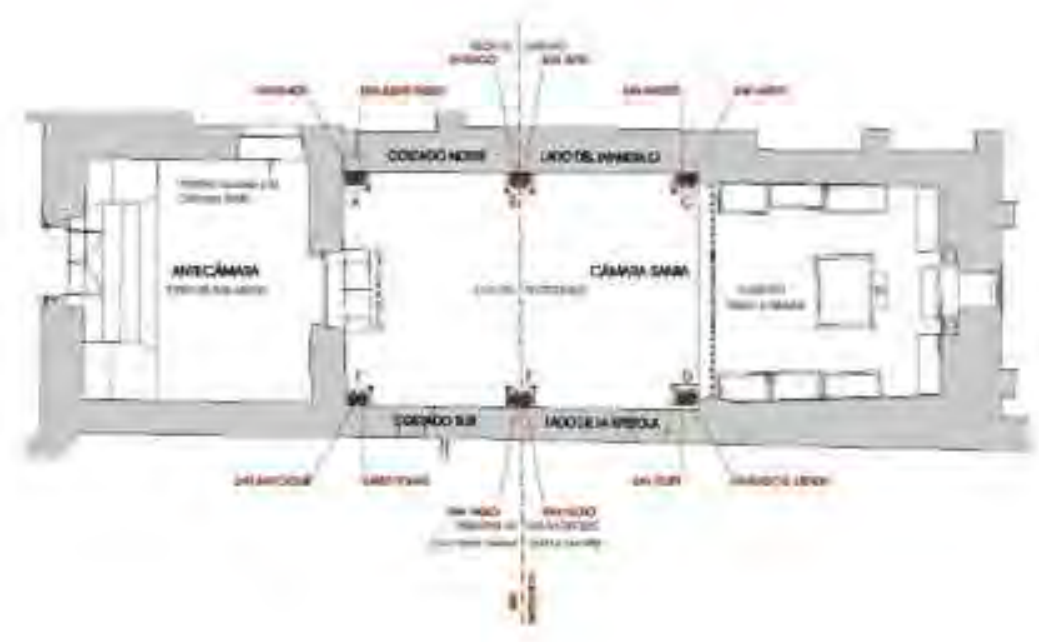

\section{SANTIAGO EL MENOR Y SAN FELIPE}

Figura 4: Mapeo de faltas, adiciones y patologías del Apostolado de la Cámara Santa: Santiago El Menor y San Felipe. 
E

COSTADO SUR

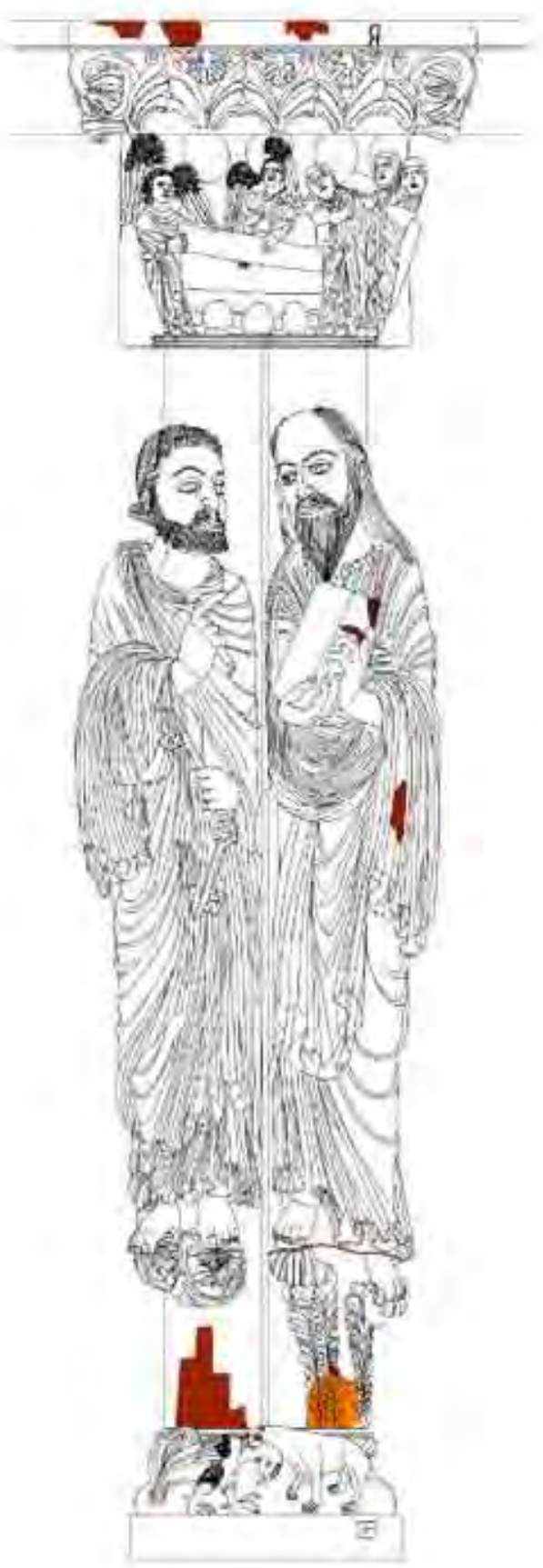

\section{LEYENDA}

\section{Adicion de monero houstial incles del spoo $x x$}

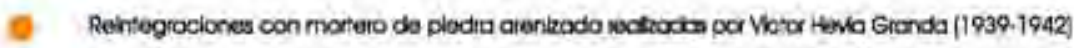

- fahtos de volumen petiec na rehtegrads.

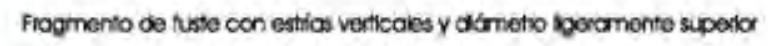

in thea de froctura producida en explosion octubie 1934

- Barid de cobro

\section{SAN PEDRO Y SAN PABLO}

Figura 5: Mapeo de faltas, adiciones y patologías del Apostolado de la Cámara Santa: San Pedro y San Pablo. 


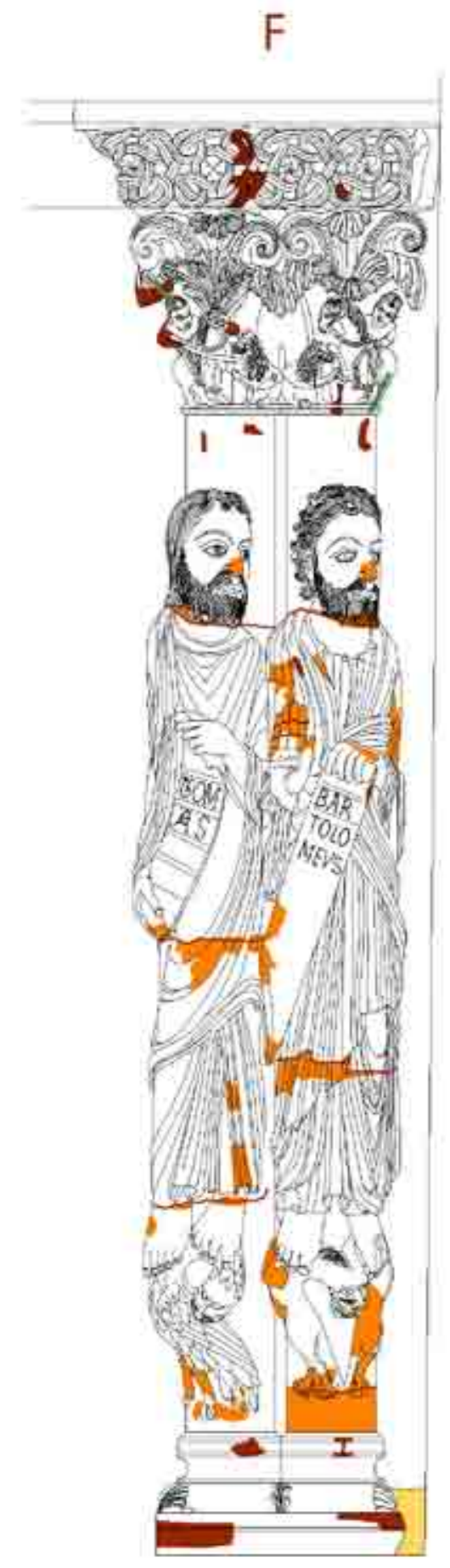

\section{COSTADO SUR}

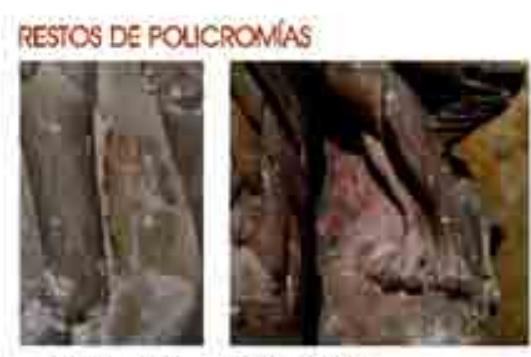

Fuste bavierdo

Fuste derecho

\section{LEYENDA}

\section{- Adclón de mortero industria males del sigo $\mathrm{xx}$}

- Reintegraciones con motero de piedra aranzada realzadas por Victar Hevia Gicnda [1939-1942]

- Fartas de volumen petreo no reintegrodo.

Fiogrnento de Nuste con estícs vericoles y darnetro lgercrnente supertor

Mr thed de froctura producido en explosḱn octubre 1934

- sana de cobre

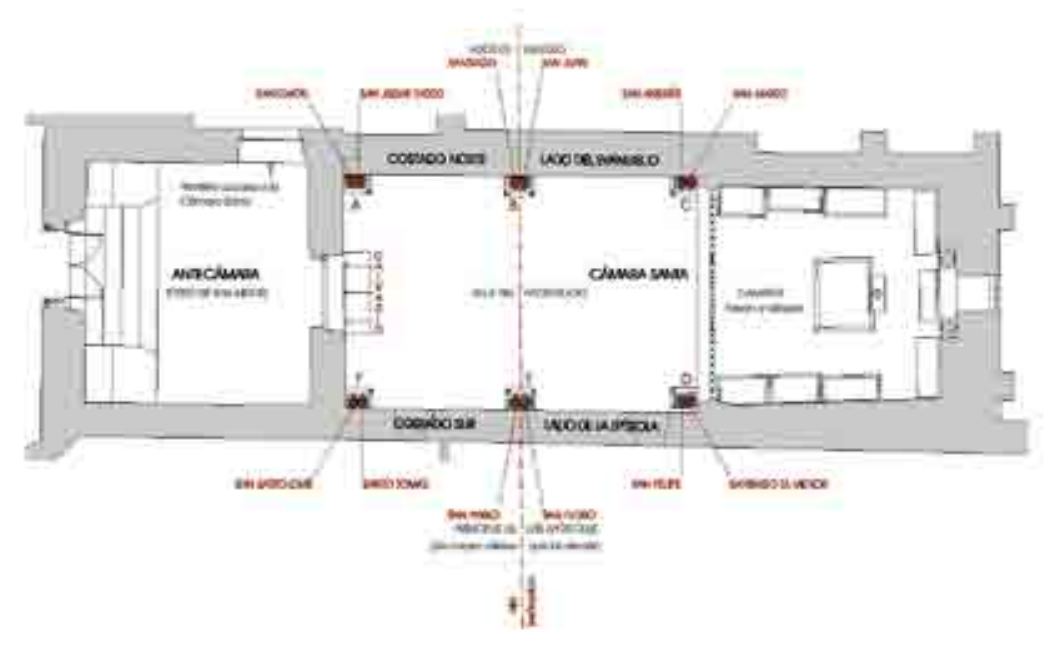

\section{SANTO TOMÁS Y SAN BARTOLOMÉ}

Figura 6: Mapeo de faltas, adiciones y patologías del Apostolado de la Cámara Santa: Santo Tomás y San Bartolomé.

*Todas las imágenes son propiedad de los autores del texto y fueron realizadas por encargo de la Consejería de Educación, Cultura y Deporte del Gobierno del Principado de Asturias. 


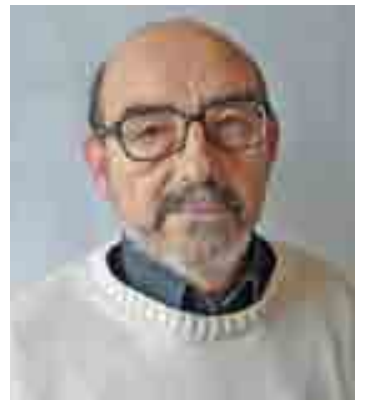

\section{Cosme Cuenca}

Arquitectos Cosme Cuenca y Jorge Hevia S.L.P.

C/ Marqués de San Esteban 1, 5 - 33206 Gijón (Asturias). 985347 357;

estudio@cuencahevia.com; www.cuencahevia.com

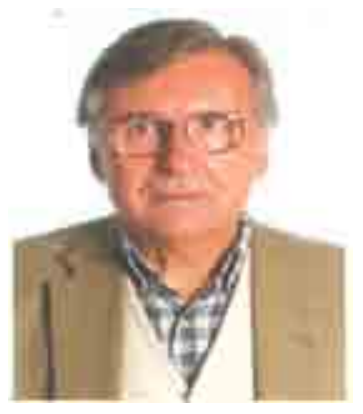

\section{Jorge Hevia}

Arquitectos Cosme Cuenca y Jorge Hevia S.L.P.

C/ Marqués de San Esteban 1, 5 - 33206 Gijón (Asturias)985 347 357;

estudio@cuencahevia.com; www.cuencahevia.com

1974- 1975 Titulados por la E.T.S. de Arquitectura de Sevilla. A partir de 1976 inician su actividad profesional, conjuntamente, hasta la fecha, en su estudio de Gijón, bajo la sociedad: Arquitectos Cosme Cuenca y Jorge Hevia S.L.P.

En más de 35 años de profesión han realizado trabajos muy diversos y han colaborado con técnicos y especialistas de diferentes disciplinas. La vivienda, tanto de promoción privada como pública, y los equipamientos de índole cultural, docente, administrativa, hotelera o religiosa han sido frecuente objeto de su trabajo.

También han realizado intervenciones de rehabilitación o restauración en muy diversos ejemplos del patrimonio edificado asturiano, sin excluir planes directores como el de la Catedral de Oviedo o planes especiales de protección de conjuntos como el del Real Sitio de Covadonga, de los que son autores.Su principal actividad docente fue la de dirigir los ocho Cursos de Extensión Universitaria de la Universidad de Oviedo dedicados a la Intervención en el Patrimonio Arquitectónico Asturiano (1993 - 2000), habiendo participado, recientemente, en el primer curso de Especialista impartido en Asturias sobre el mismo tema por la Universidad Politécnica de Madrid junto con la Universidad de Oviedo. 


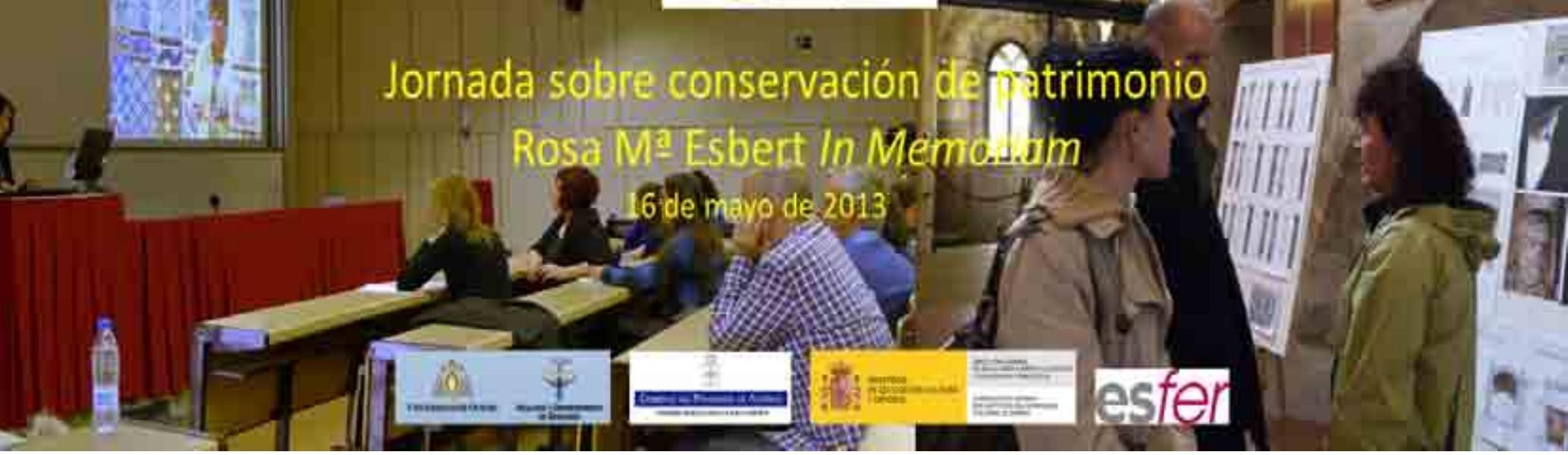

\title{
La alteración en la Cámara Santa de la Catedral de Oviedo
}

\author{
Luis Valdeón Menéndez
}

\begin{abstract}
Resumen: El estado de alteración que se encontró en el interior de la Cámara Santa al iniciar esta serie de estudios estaba netamente influenciado por las dramáticas vicisitudes del pasado siglo que se superpusieron a la evolución natural de los materiales en el medio ambiente característico del interior de este pequeño recinto. En efecto, hay que destacar los daños producidos por la deflagración de octubre de 1934 que afectaron, desde la estructura y cubiertas que se vinieron abajo, hasta la integridad de las excepcionales piezas escultóricas románicas y demás ornamentos pétreos, así como a extensos fragmentos de los muros con sus revestimientos históricos. La complicada y minuciosa reconstrucción de todo el conjunto y la restauración de los elementos dañados, materializada por el escultor Víctor Hevia Granda durante los años 1938 a 1942, hizo posible la recuperación del espacio y la salvaguardia de la materia histórica, dejando a su vez, sus propias huellas en las superficies recién restauradas. Este artículo, centrado en los elementos pétreos, discrimina las alteraciones inducidas en aquella época, o sus consecuencias, de otros procesos de alteración ligados a la evolución de los materiales en el medio ambiente de la Cámara Santa a lo largo de los siglos.
\end{abstract}

Palabras clave: Alteración de materiales, piedra de Laspra, restauración de patrimonio, formas de alteración, Cámara Santa, Catedral de Oviedo.

\section{The alteration in the Holy Chamber of Oviedo Cathedral}

Abstract: When the present studies were initiated, the deterioration state of the so called "Cámara Santa" (The Holy Chamber) was heavily affected by the consequences of its recent history, especially by the effects of a deflagration inside the chamber in 1934 which caused the collapse of the whole structure and great damage to the sculptures and other stone pieces inside. The meticulous reconstruction of the chamber and restoration of valuable sculptures were undertaken by Víctor Hevia Granda (1938-1942), who made possible its recovery as a whole, but also leaving signals of that restoration. This article tries to separate deterioration caused by historical events from those due to the natural evolution of the materials in its proper environment.

Key words: Materials deterioration, Laspra stone, heritage restoration, weathering forms, Cámara Santa, Cathedral of Oviedo.

\section{Introducción}

Los estudios de la alteración del interior de la Cámara Santa formaron parte de los denominados "Estudios Complementarios de la Cámara Santa" (Cuenca y Hevia, en prensa), algunos de los cuales se presentan en otros artículos de esta misma revista. Son los estudios de los materiales del apostolado (Rojo Álvarez, en prensa), que exponen la completa secuencia de capas que los recubren y los estudios de humedades (Mateos Redondo, en prensa), que resultaron imprescindibles para realizar una interpretación de los procesos de alteración y para señalar las medidas ambientales correctoras que palien los efectos de la humedad.

\section{Estado de conservación de la Cámara Santa}

La Cámara Santa de la catedral de San Salvador de Oviedo corresponde a una pequeña capilla con cripta, adosada a una torre anterior, atribuida a la época de Alfonso II. Fue reformada en el siglo XII, añadiendo una bóveda de cañón con sus arcos fajones y fue entonces cuando se colocaron las seis columnas pareadas con los doce apóstoles, joya de la escultura románica hispánica.

Al acceder al interior de la Cámara Santa lo primero que llama la atención es que las superficies de los muros, bóvedas y elementos escultóricos y ornamentales, están recubier- 


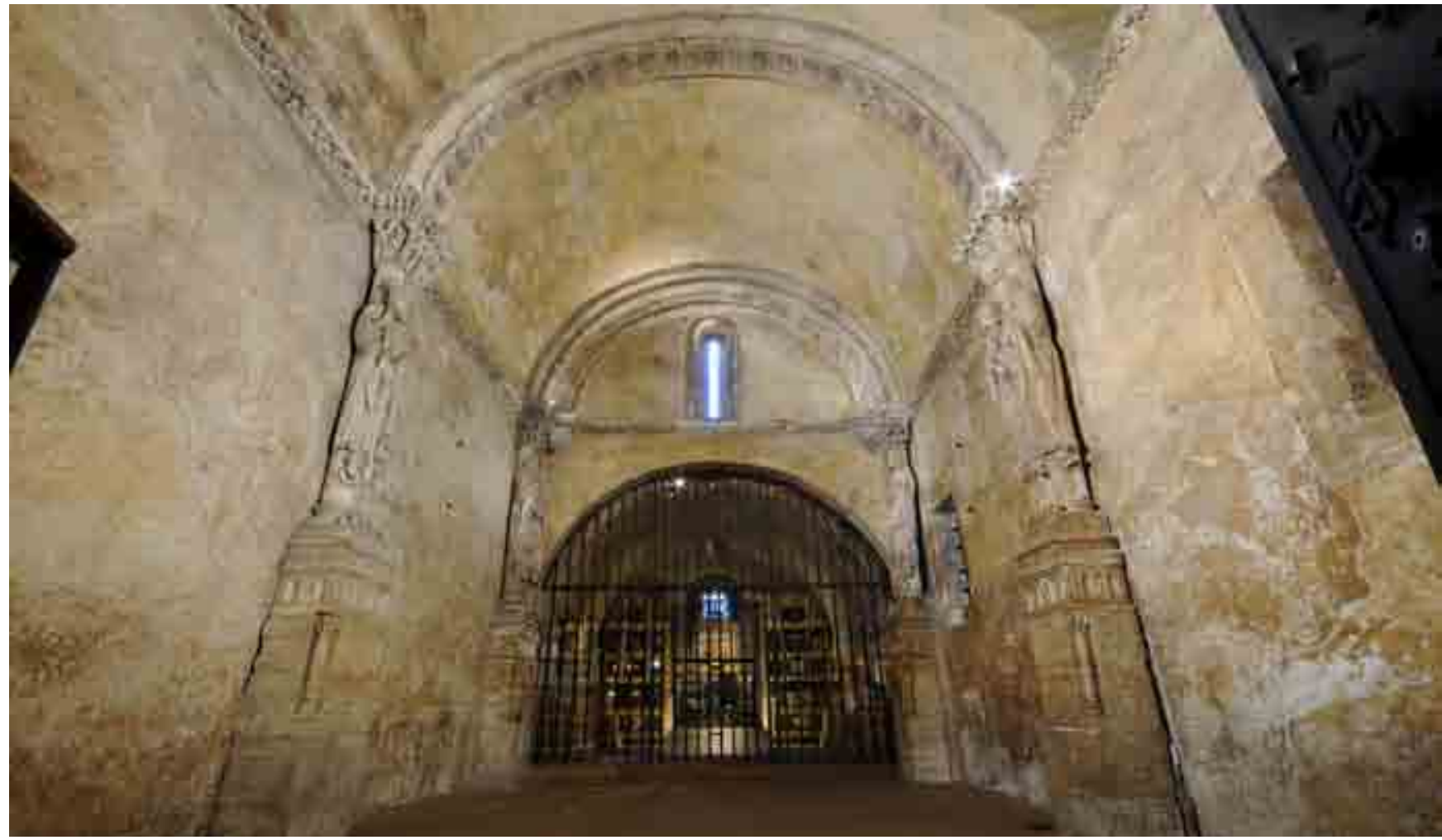

Figura 1. Aspecto general del interior de la Cámara Santa. Una heterogénea pátina amarillenta cubre la mayor parte de los materiales y contribuye en gran manera a la particular percepción de este reducido espacio, hasta este momento.

tas de una heterogénea pero persistente pátina en la que predominan una variedad de tonos ocres y amarillentos [figura 1].

Con relación a los materiales pétreos propiamente dichos, el estudio del recinto permite diferenciar entre los daños traumáticos provocados por la destrucción de la Cámara Santa en 1934, las modificaciones introducidas con la restauración posterior y el desarrollo de otras formas de alteración relacionadas con el medio ambiente del recinto.

Respecto a la alteración propiamente dicha, en este caso más centrada en los elementos pétreos, con la destrucción de la Cámara Santa en 1934, debían quedar bien separados esos daños traumáticos inducidos y las modificaciones experimentadas tras la restauración posterior, del desarrollo de otras formas de alteración propiamente relacionadas con la interacción de los materiales constructivos con el ambiente climático del recinto.

\section{Lesiones traumáticas de origen antrópico}

La explosión de 1934 originada en la cripta, justo por debajo de la propia cámara, ocasionó severos y muy traumáticos destrozos en los grupos escultóricos, bien como consecuencia de su caída directa tras la deflagración, bien por efecto de la onda expansiva o el impacto de todo tipo de escombros. La minuciosa inspección que se llevó a cabo de los elementos escultóricos, permitió dejar identificadas las zonas con fragmentos desaparecidos y zonas similares, reintegradas con morteros de Víctor Hevia, ya que la evolución diferencial de ese nuevo material permitió discriminar los elementos reintegrados. Este sería el caso de muchos apéndices nasales, dedos, fragmentos de mantos, etc. tal como ha quedado reflejado en los mapas de daños que aparecen en el primer artículo de esta serie 1. En ellos,

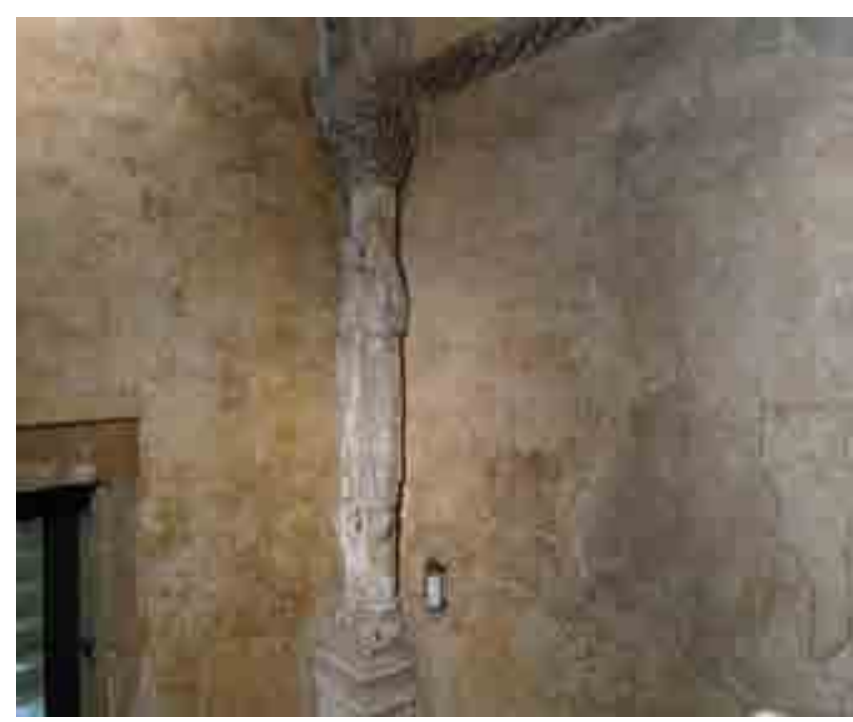

Figura 2. Aspecto heterogéneo de las patinaciones sobre diversos elementos del ángulo noroeste de la Cámara Santa. 
quedaron señaladas las faltas no reintegradas y los volúmenes rehechos con un mortero que terminó modificando su apariencia respecto a la piedra que lo engloba [figura 3]. Estas dos alternativas son las que manejó Víctor Hevia y el criterio para elegir entre una y otra debió haber sido bien meditado por él para, por ejemplo, facilitar la lectura artística integral de las esculturas. Pero una interpretación sistemática y completa de estas modificaciones, basada en conocimientos artísticos y en la propia figura de Víctor Hevia, aún está pendiente de completarse.
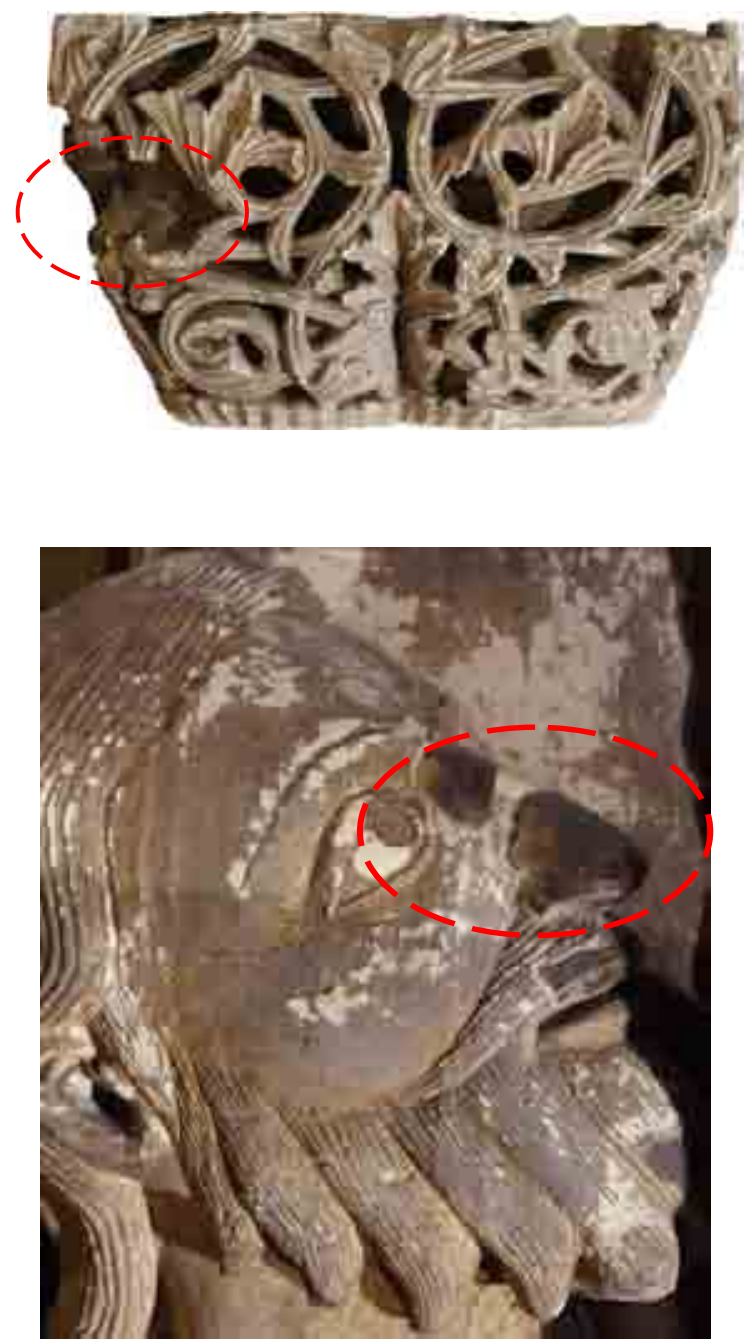

Figura 3. Izquierda, ejemplo de caída de material pétreo que permanece sin reintegrar (capitel grupo A); derecha, rotura de apéndice nasal seguida de su reintegración durante las restauraciones inmediatas a la guerra. La evolución del mortero ha sido diferente de la de la piedra patinada lo que facilitó su reconocimiento.

\section{Alteraciones ligadas al ambiente}

Acotadas las lesiones traumáticas originadas por la explosión, se expone el estado de las superficies escultóricas en el momento de la realización de estos estudios.
Para ello también se cuenta con los estudios de caracterización que se presentan en el artículo posterior a este, referidos al apostolado (Rojo Álvarez, en prensa).

A primera vista, destaca la presencia o ausencia de esas pátinas superficiales de tonos ocre, más o menos intensos. Su conservación sobre las esculturas es muy variable y cuando han saltado dejan numerosas lagunas en las que queda visible una piedra de color blanco, la dolomía de Laspra, utilizada en la decoración ornamental y escultórica e interiores de la catedral en casi todas las épocas constructivas.

La presencia o ausencia de pátina va cambiando por zonas o motivos escultóricos, ya que hay columnas donde se conserva más pátina, por ejemplo en el grupo de San Pedro y San Pablo y otras en la que ha desaparecido, quedando la piedra al descubierto, como ocurre en el grupo adyacente de Santo Tomás y San Bartolomé [figura 4].

Las observaciones y analítica realizadas ponen de manifiesto que, de modo general, tanto la piedra como la pátina, se encontraban en una situación bastante estable desde el punto de vista físico-químico, ambas mecánicamente coherentes y sin disgregaciones llamativas. Sin embargo hay una zona donde esto no es así, es en la parte central y oriental del muro norte a la altura de capiteles, cimacio e imposta. Aquí las superficies blanquecinas que afloran cuando la pátina ya ha caído presentan una disgregación pulverulenta acusada. Los análisis químicos muestran que las disgregaciones blanquecinas presentan elevados contenidos en yeso mezclado con los minerales propios de la piedra (dolomita y algo de cuarzo). Por tanto, se trata de una mezcla de dolomía y yeso neoformado, que es quien está produciendo esa disgregación mediante mecanismos de alteración ligados a la acción de sales solubles. [figura 5].

Justo en la zona izquierda del caso anterior, en el grupo $B$ del costado norte, también se observan pulverulencias en las lagunas con piedra, pero además se ha constatado que la propia pátina aunque no se ha desprendido de la piedra soporte, ya está muy debilitada, los colores son más pálidos y es un material que se descohesiona con facilidad [Figura 6].

En definitiva, en la zona medio oriental del costado norte, y en general alrededor de la imposta se detecta un notable incremento de la alteración físico-química con pulverulencias y aparición de yeso de neoformación. El reciente estudio de humedades, con datos recogidos durante todo un año, muestra que las condensaciones por exceso de humedad son posibles en esa zona (Mateos Redondo, en prensa).

Además hay que pensar que la pared exterior orientada al norte ha tenido que sufrir durante siglos las consecuencias del impacto directo de la lluvia en los muros y también las escorrentías desde la cubierta, lo que ha tenido que debilitar y alterar los materiales. Como se asume que todas 

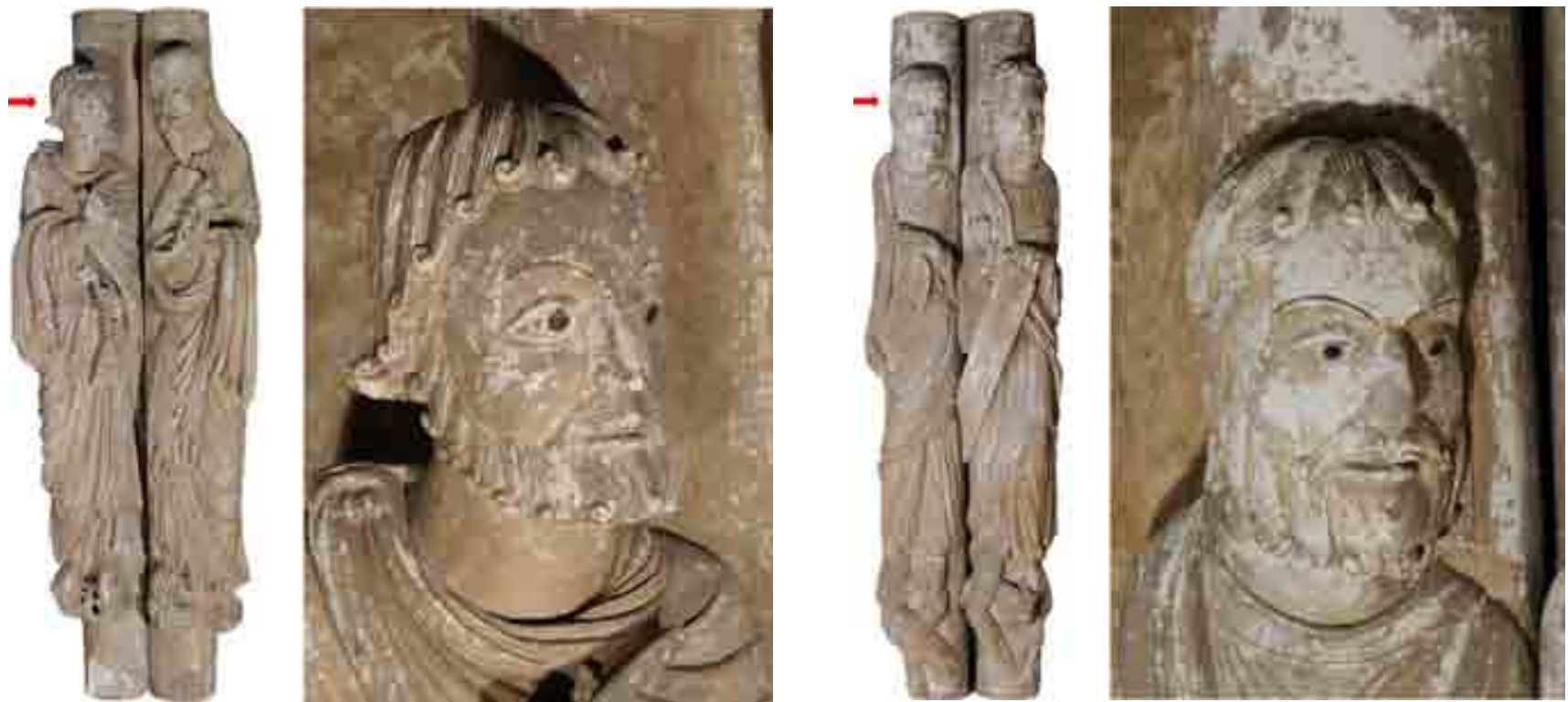

Figura 4. Hay figuras escultóricas que presentan más superficie patinada (izquierda, grupo E San Pedro y San Pablo) y otras donde ha caído quedando la piedra blanquecina al descubierto (derecha, grupo F Santo Tomás y San Bartolomé).
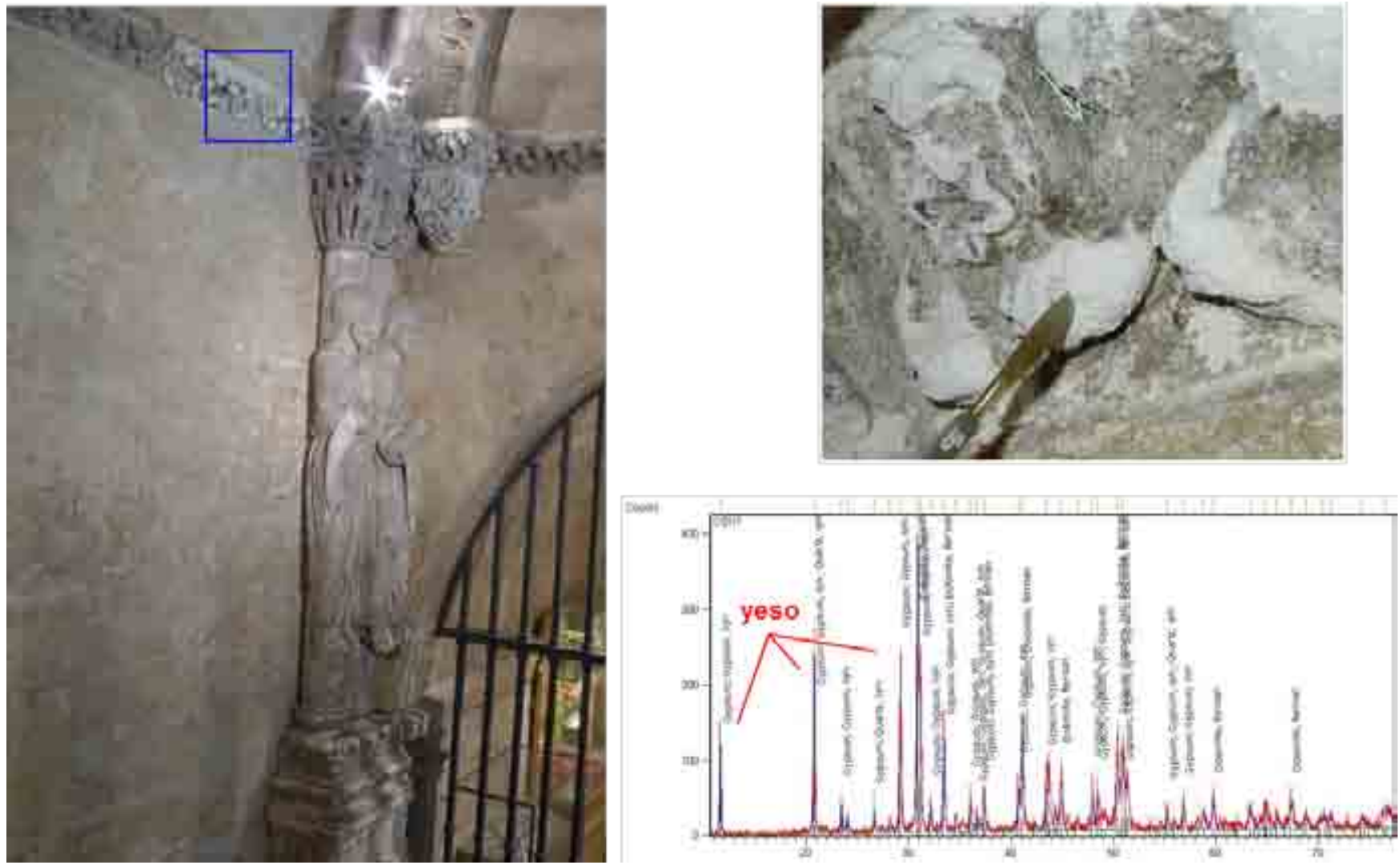

Figura 5. Imposta al lado del grupo escultórico C en el costado norte, con disgregación pulverulenta de la piedra que contiene yeso de neoformación.

las pátinas tenían tonos ocre desde la restauración de los años cuarenta, se deduce que los deterioros de la zona norte también se han estado produciendo en los últimos setenta años, aunque en el momento actual estos proce- sos estén ya controlados. Otros aspectos de la evolución de los materiales en estas últimas décadas puede seguirse en el próximo apartado. 


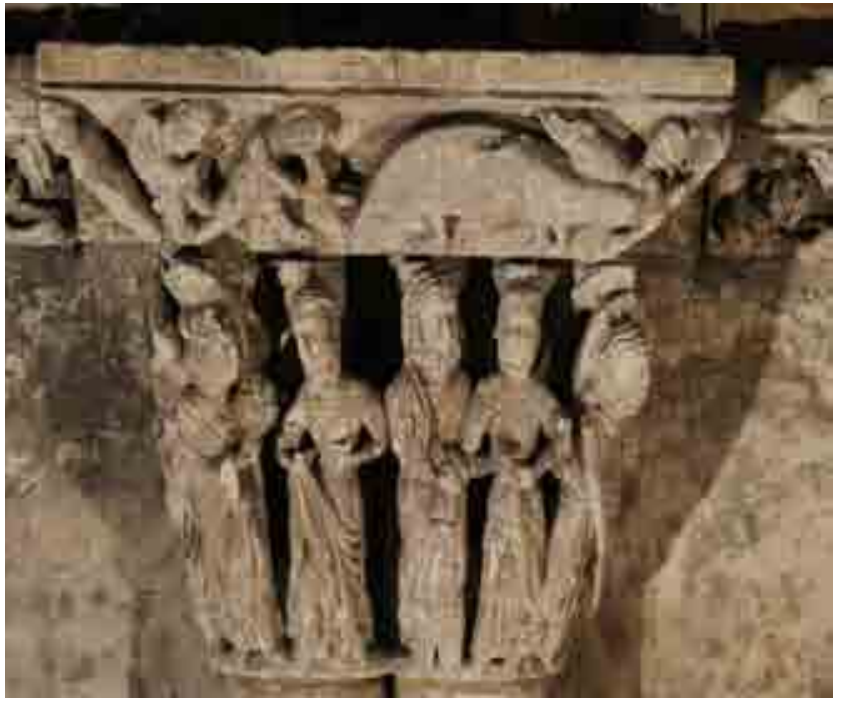

Figura 6. Pátinas incoherentes y decoloradas en el capitel decorado de la columna $\mathrm{B}$, en el medio del costado norte.

\section{Evolución de las superficies: 1942-2012}

Es posible comparar el estado diferencial de las superficies pétreas entre estas siete décadas al contar con series fotográficas similares actuales y de entonces. Teniendo en cuenta las limitaciones perceptivas de las fotografías, puede deducirse que en muchos casos se observan patrones muy parecidos en las morfologías pátina superficial/laguna pétrea, entre ambos momentos. En estos casos puede deducirse que hay zonas en las que no se han producido cambios importantes en estas siete décadas, ya que esa impronta ya existía entonces [figura 7].
Sin embargo, son más frecuentes las modificaciones superficiales durante estos años. Lo que se aprecia es un aumento de la superficie de las lagunas blancas, incluso en las zonas más estables como en el grupo $E$ del costado sur. En la figura 8 puede apreciarse que las lagunas blancas han aumentado de superficie, lo que es debido a un incremento de las saltaciones de las pátinas a lo largo de estas décadas.

Considerando que las morfologías de las lagunas son muy irregulares y para ayudar a diferenciar mejor sus modificaciones se han coloreado artificialmente en un ejemplo. En el rostro de la figura 9 se han representado las lagunas de cada época: trama azul en 1942, trama roja en 2012. Al superponerlas se aprecia un aumento de la superficie vista de la piedra. Por el contrario, también quedan de manifiesto algunos retoques en las pátinas (aunque minoritarios). Por ejemplo, en la figura se han enmarcado en verde zonas que en 1942 presentaban lagunas y que aparecen recubiertas en la actualidad, lo que indica retoques.

En resumen, en el momento de estos estudios, en 2012, buena parte de las superficies de la Cámara Santa se encontraron patinadas con recubrimientos de tonos ocres diversos, con un aspecto muy heterogéneo y numerosas saltaciones que dejaban al descubierto los materiales subyacentes, morteros en los muros o la piedra blanca de Laspra en los elementos escultóricos y ornamentales (impostas y arcos fajones).

Las observaciones y análisis realizados permitieron localizar las lesiones ocasionadas por la deflagración de 1934, y también los trabajos posteriores de restauración, principalmente con recuperación de volúmenes escultóricos y adhesión de fragmentos (mapas de lesiones en el artículo primero de esta serie 1).
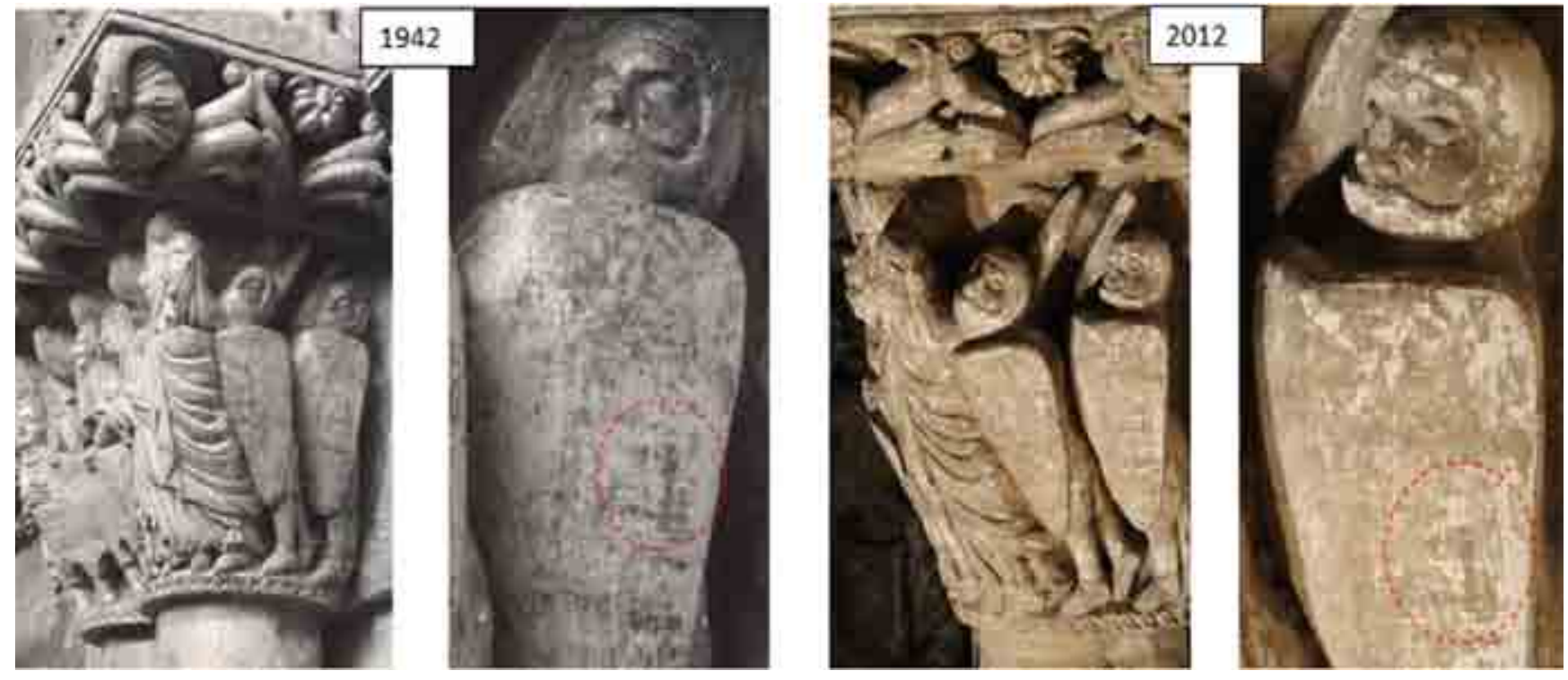

Figura 7. Permanencia de la morfología de improntas aparentes de pátinas que ya existían hace siete décadas. 

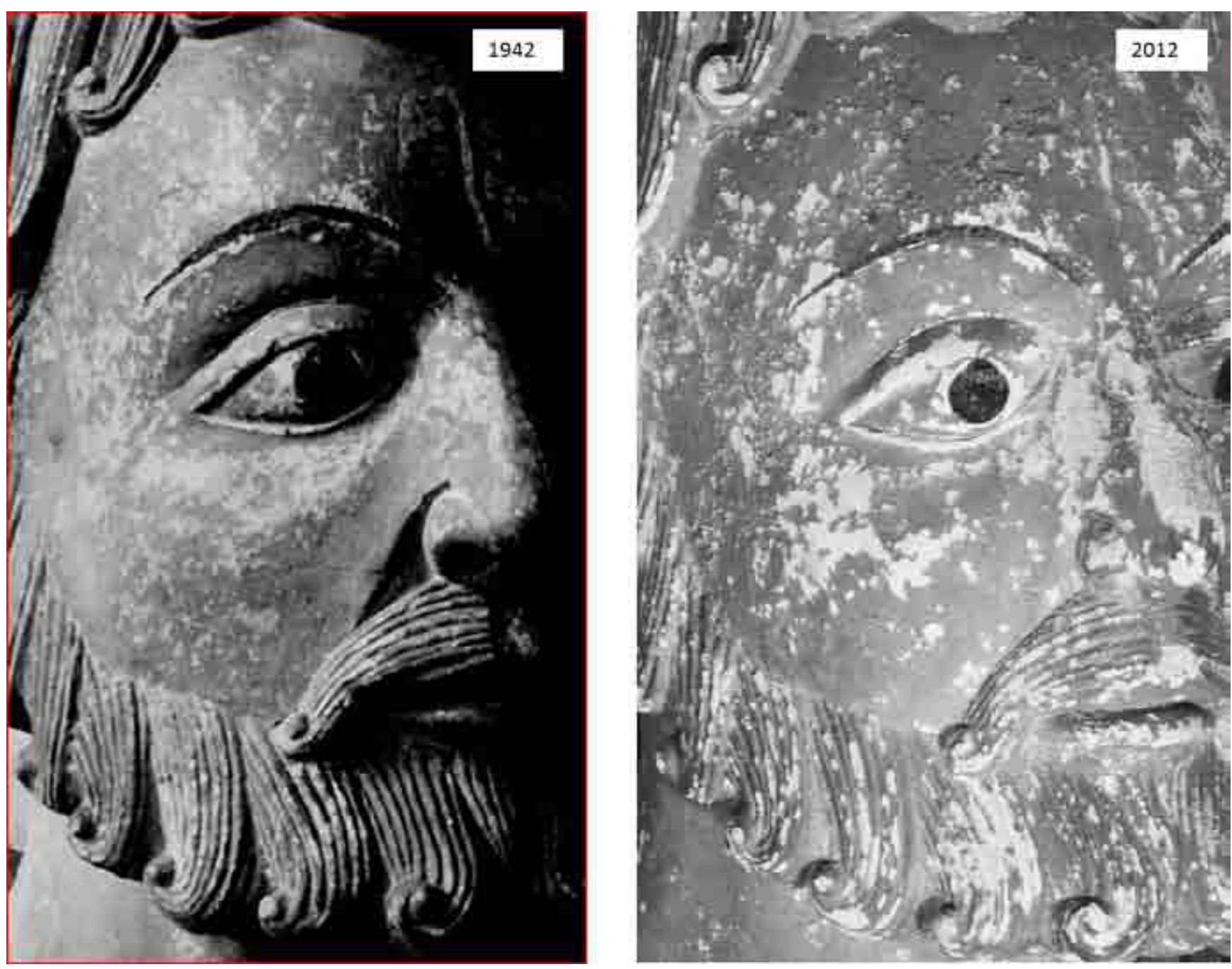

Figura 8. Aspecto comparativo del rostro de San Pedro con diferencias en la morfología y extensión de las lagunas blancas por caída de pátina entre los años señalados.
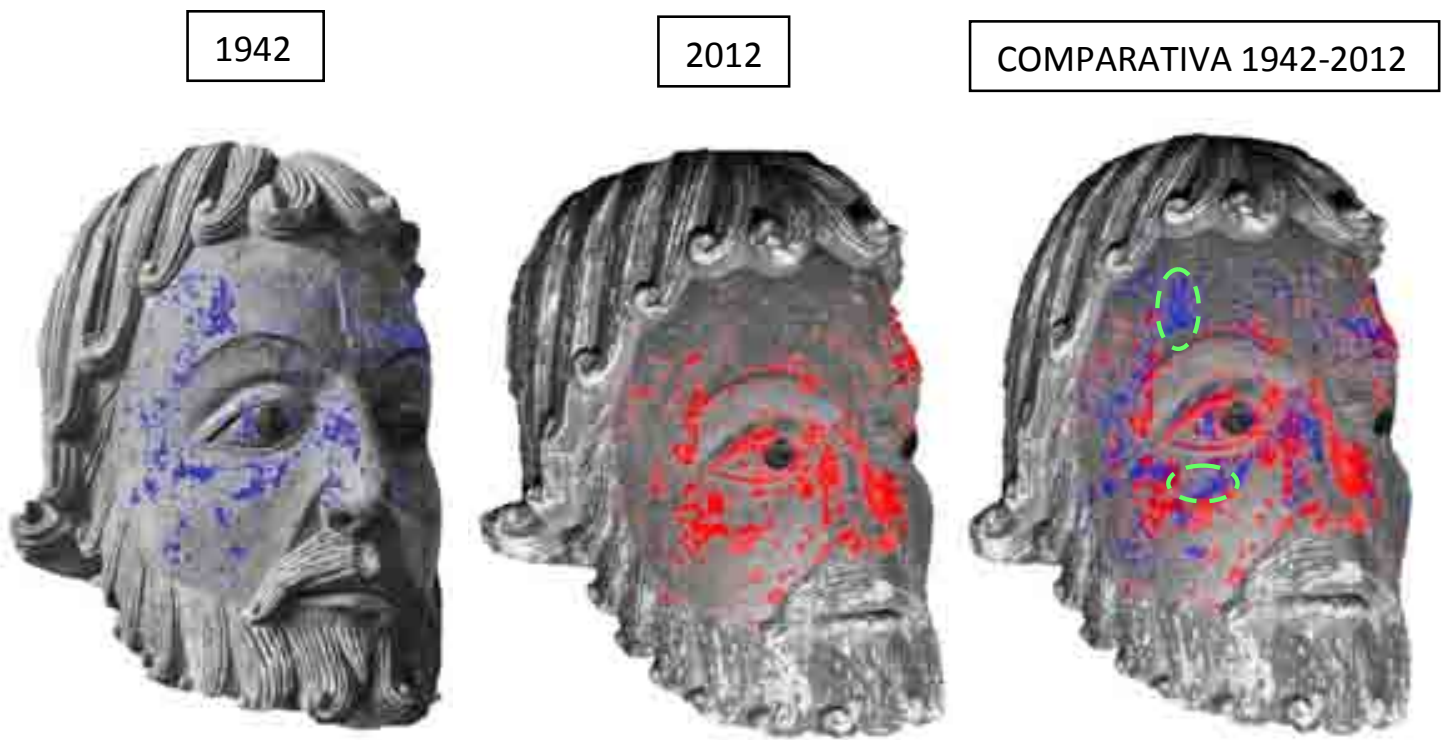

Figura 9. Se ha coloreado artificialmente las faltas de pátinas o lagunas (zonas más claras) en las dos épocas y al superponerlas se aprecia una mayor extensión de las lagunas en la actualidad. También ocurre lo contrario y las zonas enmarcadas en verde señalan posibles retoques que se han añadido, ya que no estaban en 1942. 
También se ha visto que los materiales, piedra o pátinas, presentan mayor alteración a la altura media del costado norte, con disgregación pulverulenta acusada y presencia de sales solubles. Estos procesos son independientes de los sucesos de 1934 y se deben más a las humedades que han podido penetrar desde el exterior por el muro y a los efectos de las condensaciones, tal como se aclara en los estudios de humedades dentro de esta misma tanda de estudios 3.

Gracias a los registros fotográficos que se hicieron a partir de la reconstrucción de los años cuarenta se ha podido comparar la evolución del estado de conservación de algunas superficies escultóricas. Se puede detectar que buena parte de las pátinas que llegaron a la actualidad ya estaban presentes, pero que también parte de ellas han ido saltando por efecto de los mecanismos de deterioro.
Asimismo se han detectado ciertos retoques que implicaron la aportación de nuevas pátinas, quizás para compensar las caídas que se estaban produciendo.

\section{Bibliografía}

CUENCA BUSTO, C. y HEVIA BLANCO, J. (en prensa). Los estudios complementarios sobre la Cámara Santa de la Catedral de Oviedo.

MATEOS REDONDO, F.J. (en prensa). Estudio higrotermométrico de la Cámara Santa de la Catedral de Oviedo.

ROJO ÁlVAREZ, A. (en prensa). El Apostolado de la Cámara Santa de la Catedral de Oviedo: Estudio de materiales.

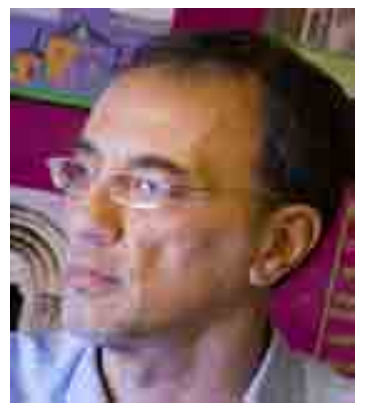

\author{
Luis Valdeón Menéndez \\ GEA asesoría geológica \\ correo@geaasesoriageologica.com
}

Luis Valdeón ha desarrollado toda su carrera profesional en el ámbito de la conservación de patrimonio histórico-arqueológico y evaluación de materiales pétreos, combinando una completa base de formación científico-técnica con una dilatada experiencia profesional a pie de obra. Tras doctorarse en Geología en la Universidad de Oviedo, en 1989, realizó estudios postdoctorales en el Imperial College de Londres (1989-2001) donde se especializó en la aplicación de técnicas no destructivas para la evaluación de materiales pétreos. En estos ámbitos posee más de cuarenta publicaciones en congresos y revistas nacionales e internacionales.

Ha realizado cientos de trabajos en intervenciones de patrimonio monumental o estudios previos a las mismas, investigando asimismo el comportamiento de materiales constructivos y ornamentales en, por ejemplo, excavaciones arqueológicas, como las del yacimiento de Contrebia Leucade (La Rioja), o sobre bienes declarados patrimonio de la Humanidad, como el prerrománico asturiano (Monumentos de Oviedo y del Reino de Asturias), o Monasterio de Yuso (La Rioja), así como en catedrales, capillas y monumentos civiles de todo el país.

Desde 2001 es socio fundador, de la empresa GEA asesoría geológica especializada en estudios sobre Conservación y Restauración de Patrimonio y la caracterización de todo tipo de materiales. Es miembro activo del Grupo Español del International Institute for Conservation (GE-IIC) del que ocasionalmente forma parte de comités científicos del grupo de trabajo "piedra". 


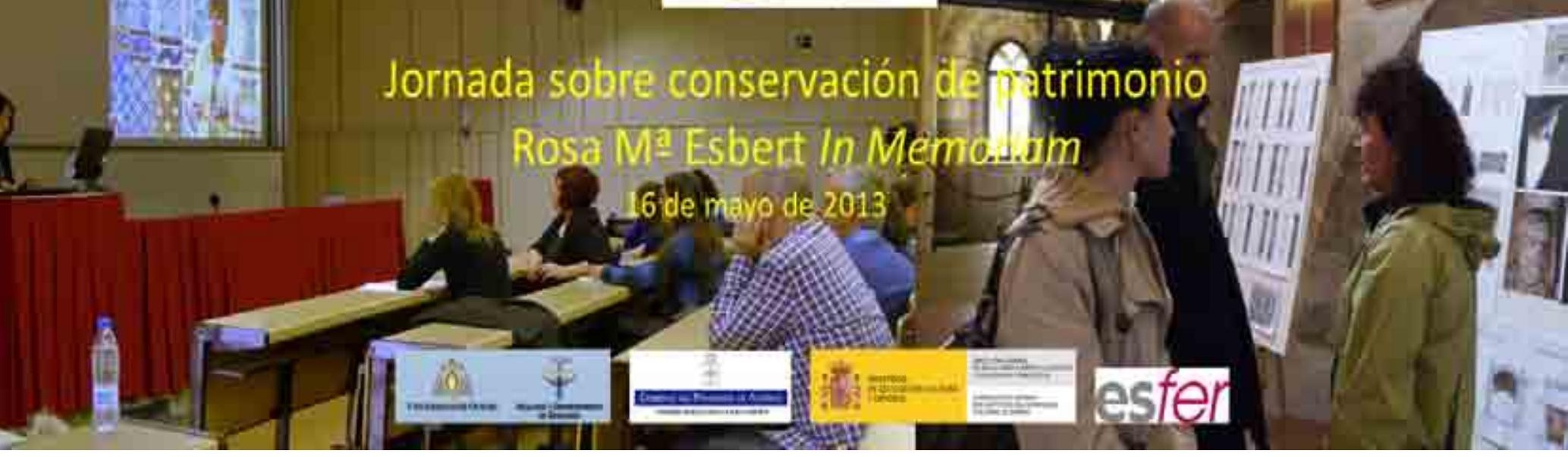

\title{
Análisis de los tratamientos y sistemas de limpieza de los mate- riales de la Cámara Santa.
}

\author{
Luis Suárez Saro; Araceli Rojo Álvarez; Luis Valdeón Menéndez; Félix J. Mateos Redondo; Ve- \\ rónica Fernández Cuesta y Pablo Klett Fernández
}

Resumen: Identificadas las patologías y caracterizados los materiales presentes en la Cámara Santa, se han diseñado una serie de pruebas destinadas a la limpieza de los revocos, morteros y elementos pétreos, eliminando pátinas de ennegrecimiento, eflorescencias salinas y recubrimientos superficiales, que pudieran estar resultando perjudiciales para la correcta conservación de estos materiales.

Las catas realizadas han perseguido la representatividad de cada casuística ajustando al mínimo las dimensiones de las pruebas y tratando de evitar el impacto visual que pudieran producir.

El objetivo primordial de estas pruebas es buscar la máxima inocuidad del método a emplear en cada caso, en relación a su máxima eficacia.

Las pruebas han sido realizadas por Luis Suárez Saro y supervisadas y analizadas por el equipo de petrólogos de GEA asesoría geológica. La metodología de trabajo seguida durante la realización de las mismas ha consistido en la toma de muestras antes y después de la realización de cada cata. Posteriormente, se ha procedido al análisis morfoquímico de las superficies (SEM - EDX), buscando posibles modificaciones inducidas sobre las superficies limpiadas. Del análisis de estos resultados se ha perseguido la selección de uno o varios métodos, más adecuados para cada material (piedra, mortero, capa pictórica, etc.), teniendo en cuenta su naturaleza y estado de deterioro

Palabras clave: métodos de limpieza, láser, análisis morfoquímico, SEM-EDX.

\section{Analysis of treatment and cleaning systems of the materials of the Cámara Santa}

Abstract: Once the pathology in the Cámara Santa has been identified and the materials characterized, a series of tests has been designed to clean the plasters, mortars and stone elements, removing blackening patina, saline efflorescence and surface coatings which could be damaging for the proper preservation of these materials.

These tests pursued the representativeness of each different case reducing as much as possible the size of the exam area and trying to avoid the visual impact they might have produced.

The main aim of these tests is to find the safest and most effective method for each case.

All tests have been carried out by Luis Suárez Saro and supervised and analysed by the team of GEA asesoría geológica. The working methodology followed has involved sampling before and after the execution of each case. Subsequently, morpho-chemical surface analysis (SEM - EDX) has been performed, searching possible modifications on the cleaned surfaces. Finally, after analysing these results, one or more methods have been selected as most appropriate for each material (stone, mortar, paint layer...) taking into account their composition and state of deterioration.

Key words: cleaning methods, laser, morpho-chemical analysis, SEM-EDX 


\section{Selección de métodos y ajuste de parámetros instru- mentales.}

Los métodos empleados en las pruebas han sido mecánicos, químicos y físicos (láser).

Dentro de los métodos mecánicos se han seleccionado dos tipos:

- Manuales: Cepillos y brochas de pelo suave, goma de borrar exenta de grasa "Archival Aids", bisturí y lápiz de fibra de vidrio.

-Instrumentales: Microproyección con pistola M500 y boquilla de $2 \mathrm{~mm}$ (en los elementos pétreos) y de $5 \mathrm{~mm}$ (en los revocos), adaptada a un compresor eléctrico con calderín de 200 litros (Incoimsa de $2 \mathrm{hp}$ ) y presión regulable de 0,1 a 8 bares. Entre ambos se ha dispuesto un postenfriador RA 20-E.

Los microabrasivos empleados han sido microesferas de vidrio $(180-300 \mu \mathrm{m})$, bicarbonato Armex $(90-250 \mu \mathrm{m})$ y piedra pómez $(0-89 \mu \mathrm{m})$.

La presión en boquila ha sido de 0,5 a 1,5 bares, la distancia a la superficie entre 25 y $40 \mathrm{cms}$ y el ángulo respecto a esta última entre 45 y $60^{\circ}$.

Entre los métodos químicos también se han seleccionado dos tipos:

-White spirit aplicado con hisopo de algodón, tras reblandecimiento de la cera superficial con pistola de aire caliente Bosch regulada a $70-80^{\circ} \mathrm{C}$.

-Crema de latex "Arte Mundit" de la casa FTB (Tipos Arte Mundit I, III y V), con dos aplicaciones separadas en intervalos de 48 horas.

La limpieza láser utiliza la energía fotónica para la eliminación de los depósitos de suciedad sobre la superficie de la piedra, morteros y revocos.

El láser de Nd:YAG empleado es un láser de estado sólido cuyo medio activo es un cristal de granate de ytrio y aluminio, dopado con neodimio; modelo ArtLaser II, de la casa CTS.

\begin{tabular}{|l|l|}
\hline Longitud de Onda & $1064 \mathrm{~nm}$ \\
\hline Duración del pulso & $8 \mathrm{~ns}$ \\
\hline Frecuencia del pulso & $1,5,10,15 \mathrm{y} 20 \mathrm{~Hz}$ \\
\hline Potencia del equipo & $3 \mathrm{w}$ \\
\hline Energía máxima del pulso & $150 \mathrm{~mJ}$ \\
\hline Diámetro del haz (colimado) & $4 \mathrm{~mm}$. \\
\hline Densidad de energía (fluencia) & $0,3-113,2 \mathrm{~J} / \mathrm{cm} 2$ \\
\hline
\end{tabular}

Tabla I. Características de la radiación
El equipo consta además de otra fuente láser de HeNe que emite dentro del espectro visible por el ojo humano y su función es la de iluminar la zona de trabajo. Posee un brazo de fibra óptica, que confiere al sistema una gran movilidad. Las características de la radiación láser se presentan en la tabla I.

Las pruebas de limpieza láser sobre el apostolado se llevaran a cabo variando las energías del láser desde 50 a 150 $\mathrm{mJ}$ y las frecuencias de $5 \mathrm{a} 20 \mathrm{~Hz}$.

La selección del método de limpieza empleado ha estado condicionado por:

- La naturaleza y espesor del material a eliminar

- $\quad$ El grado de cohesión y adherencia de la suciedad al sustrato pétreo

- $\quad$ La naturaleza y grado de cohesión del sustrato pétreo sobre el que se deposita la suciedad

- El valor artístico del elemento a limpiar

En lo que se refiere a los métodos acuosos, que utilizan el agua como disolvente, su empleo en la Cámara Santa se ha desestimado por el escaso grado de cohesión de alguna de las superficies y la presencia de sales solubles. Este tipo de limpieza puede generar productos de neoformación nocivos y provocar, a medio plazo, cambios de color y opacidad en las superficies intervenidas.

Durante las pruebas de limpieza realizadas se han ido ajustado las variables que intervienen en cada método con el fin de establecer un protocolo de actuación que garantice la integridad de las superficies.

El control del método de limpieza empleado se realiza mediante un estudio morfoquímico sistemático de las superficies limpiadas, al microscopio electrónico de barrido con microsonda por energía dispersiva de rayos $\mathrm{X}$.

La limpieza facilita la preparación del soporte pétreo para posteriores tratamientos de conservación.

\section{Análisis morfoquímicos de las superficies limpiadas: Resultados}

Con objeto de detectar posibles modificaciones superficiales inducidas durante la limpieza, se han recogido muestras antes y después de las mismas, las cuales han sido observadas al microscopio electrónico de barrido. El análisis morfoquímico de estas superficies permite valorar la efectividad e inocuidad de los métodos empleados.

A continuación se presenta un resumen de los resultados obtenidos para cada método aplicado. 


\section{Limpieza LÁSER}

Los parámetros que se han ido ajustando durante las pruebas de limpieza láser han sido la energía del equipo y la frecuencia. Tal como se observa en la imagen de la figura 1 las catas de limpieza han sido realizadas con frecuencias comprendidas entre 15 y $20 \mathrm{~Hz}$ y energías de 100, 150, 200 y $250 \mathrm{~mJ}$.
A continuación en la tabla II se recogen los resultados obtenidos en los análisis realizados al SEM - EDX.

De lo anterior se deduce que los parámetros más adecuados para la limpieza láser del soporte pétreo son $100 \mathrm{~mJ}$ de energía y $20 \mathrm{~Hz}$ de frecuencia (Figs. 2-4). En el caso del mortero de reintegración, y para no insistir sobre las zonas limpiadas, podrían emplearse $125 \mathrm{~mJ}$ de energía y $20 \mathrm{~Hz}$ de frecuencia.

\begin{tabular}{|c|c|c|c|c|c|}
\hline \multirow{2}{*}{ SOPORTE } & \multirow{2}{*}{ MUESTRA } & \multirow{2}{*}{ TÉCNICA } & \multicolumn{2}{|c|}{ PARÁMETROS } & \multirow{2}{*}{ RESULTADOS } \\
\hline & & & $\begin{array}{c}\text { Energía } \\
\text { (mij) }\end{array}$ & $\begin{array}{c}\text { Frecuencia } \\
(\mathrm{Hz})\end{array}$ & \\
\hline \multirow{6}{*}{$\begin{array}{l}\frac{\pi}{0} \\
\frac{0}{0} \\
\frac{g}{0} \\
\frac{\pi}{8} \\
\frac{\pi}{8}\end{array}$} & PL1 & \multirow{8}{*}{$\begin{array}{l}\text { 㟔 } \\
\stackrel{s}{s}\end{array}$} & 100 & 15 & $\begin{array}{l}\text { En zonas puntuales se elimina el } \\
\text { recubrimiento (cera de abeja), } \\
\text { aflorando la pátina de cal y yeso. }\end{array}$ \\
\hline & $\mathrm{PL} 2$ & & 150 & 15 & $\begin{array}{c}\text { Seelimina gran parte del recubrimiento } \\
\text { (cera de abeja), aflorando la pátina de } \\
\text { cal y yeso y el sustrato base (Piedra de } \\
\text { Laspra). }\end{array}$ \\
\hline & PL3 & & 150 & 20 & $\begin{array}{c}\text { Se elimina parte del recubrimiento } \\
\text { (cera de abeja), aflorando la pátina de } \\
\text { cal y yeso y el sustrato base (Piedra de } \\
\text { Laspra). }\end{array}$ \\
\hline & PL4 & & 100 & 20 & $\begin{array}{c}\text { El recubrimiento (cera de abeja) ha } \\
\text { desaparecido, dejando al descubierto } \\
\text { algún resto de la capa pictórica de } \\
\text { albayaldey el sustrato base (Piedra de } \\
\text { Laspra). }\end{array}$ \\
\hline & PL5 & & 100 & 20 & $\begin{array}{l}\text { Seelimina gran partedel recubrimiento } \\
\text { (cera de abeja), dejando al descubierto } \\
\text { restos de la capa pictórica de albayalde } \\
\text { y el sustrato base (Piedra de Laspra). }\end{array}$ \\
\hline & PL6 & & 100 & 20 & $\begin{array}{c}\text { Seelimina la mayoría del recubrimiento } \\
\text { (cera deabeja), aflorando gran parte de } \\
\text { la capa pictórica dealbayaldey algo del } \\
\text { sustrato base (Piedra de Laspra). }\end{array}$ \\
\hline \multirow{2}{*}{ 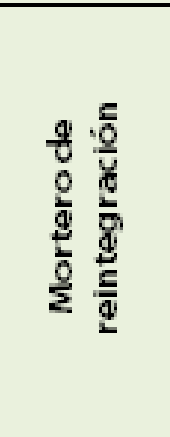 } & PL8B & & 100 & 20 & $\begin{array}{c}\text { Apenas se elimina el recubrimiento } \\
\text { (cera de abeja) y donde no lo hay } \\
\text { afloran restos de una pátina de yeso } \\
\text { situada sobreel sustrato base (mortero } \\
\text { de cal). }\end{array}$ \\
\hline & PL11B & & 125 & 20 & $\begin{array}{l}\text { El recubrimiento (cera de abeja) ha } \\
\text { desaparecido, dejando al descubierto } \\
\text { una pátina de cal y yeso, situada sobre } \\
\text { el sustrato base (mortero de cal). }\end{array}$ \\
\hline
\end{tabular}

Tabla II. Análisis morfoquímico de las superficies limpiadas con láser. 

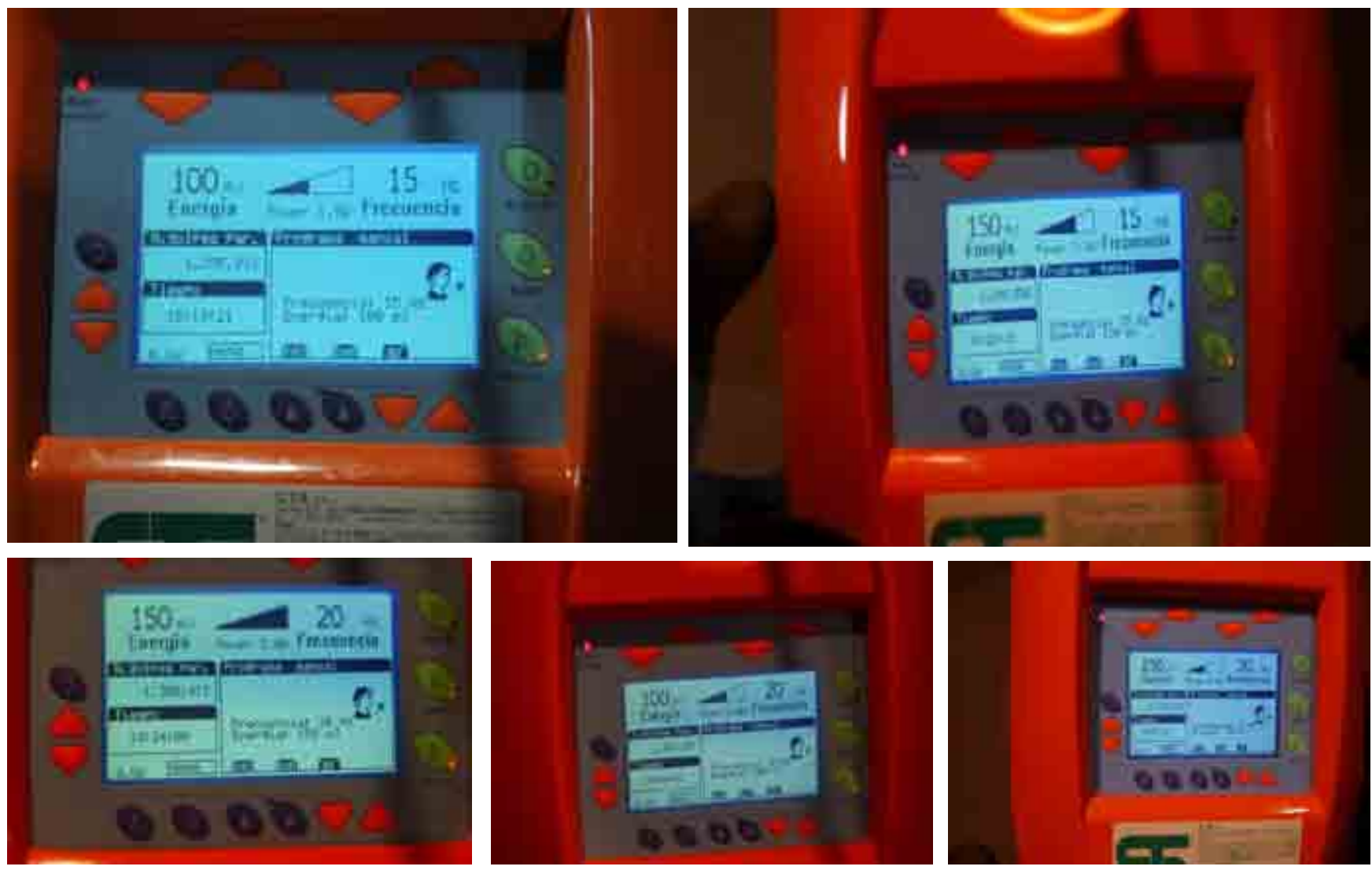

Figura 1. Imágenes de las pantallas del equipo láser durante algunas de las pruebas de limpieza realizadas.

\section{Limpieza química con crema látex "Art Mundi"}

Se lleva a cabo mediante dos aplicaciones sucesivas de la crema con espátula, transcurridas 48 horas se retira la primera y se aplica la segunda que permanece otras 48 horas. Los resultados se presentan en la tabla III y en las figuras 5 y 6

Arte Mundit ${ }^{\circledR}$, de la casa FTB, es una crema - pasta que elimina las manchas, polvo y suciedad. Está disponible en diversos tipos (I, II, III, IV y V) dependiendo de la superficie a aplicar y del grado de contaminación y consiste en una

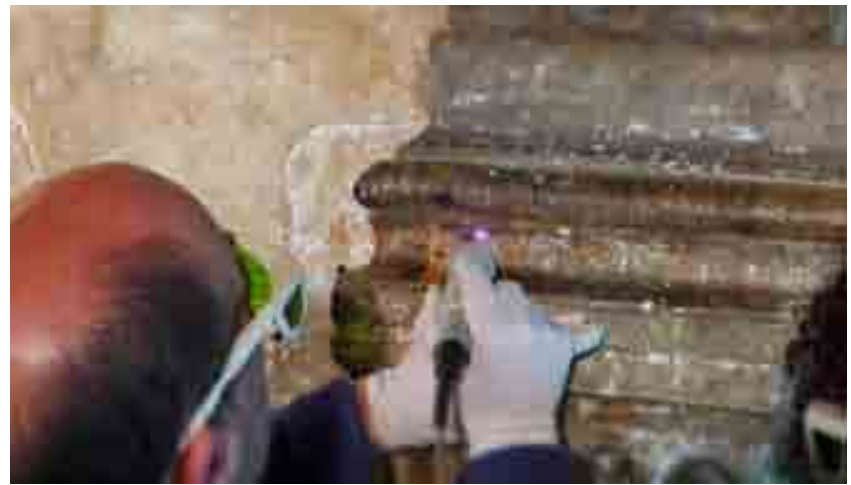

Figura 2. Realización de catas de limpieza Láser a diferentes energías y frecuencias.

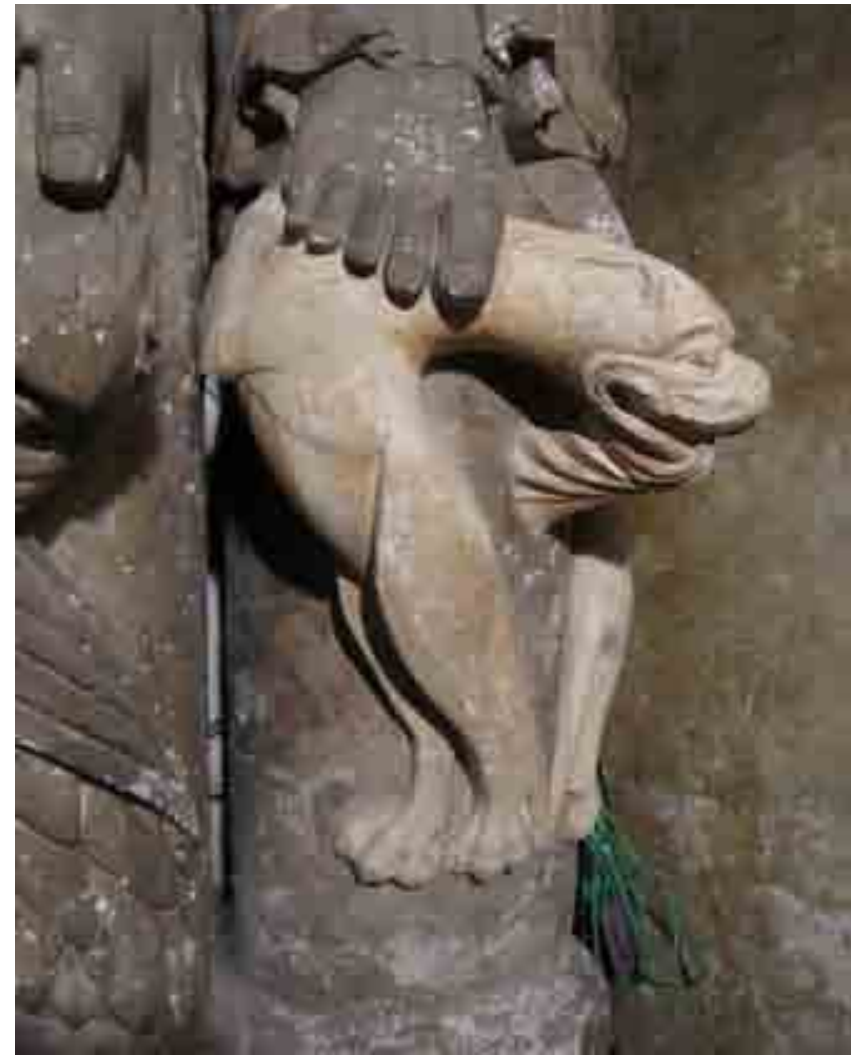

Figura 3. Resultado de la limpieza Láser en la columna de San Bartolomé y Santo Tomás. 

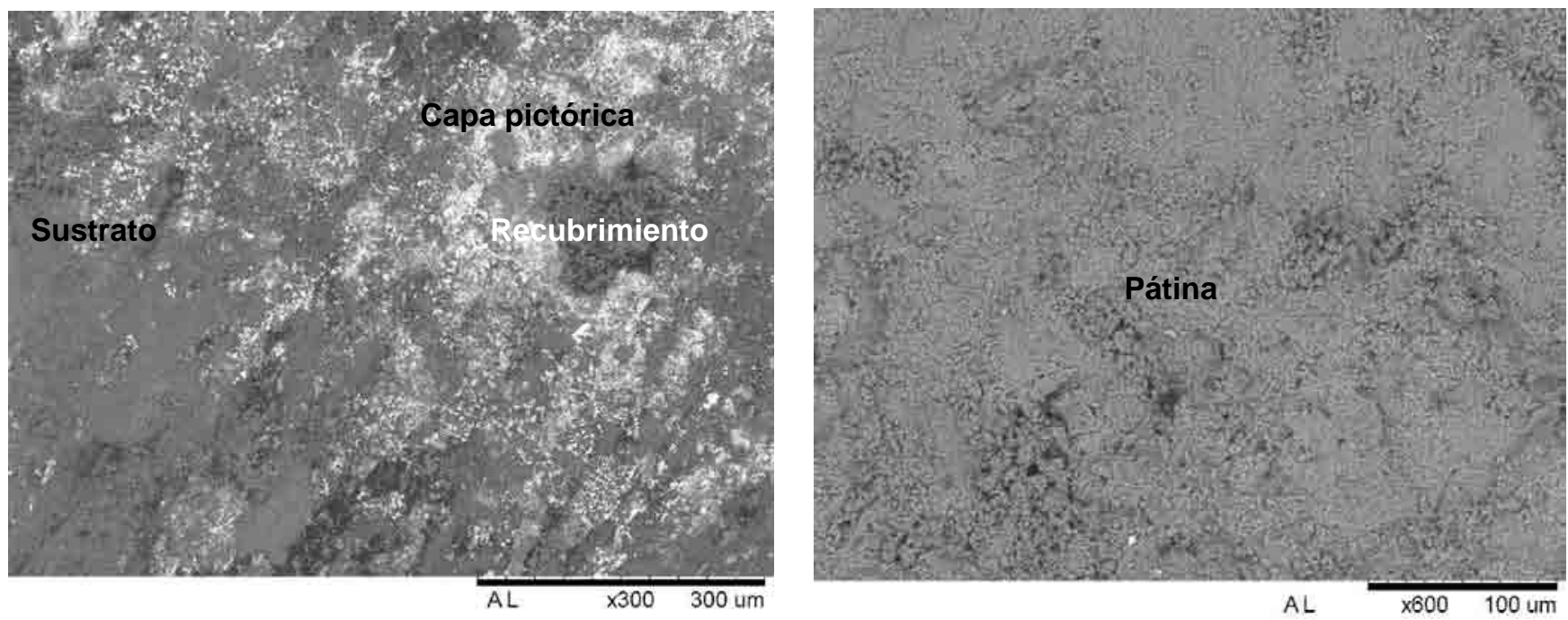

Figura 4. Detalles de las superficies de mortero limpiadas con láser. En ambos casos la frecuencia seleccionada ha sido $20 \mathrm{~Hz}$ pero la energía ha sido en un caso de $100 \mathrm{~mJ}$ (izquierda) y en otro de $125 \mathrm{~mJ}$ (derecha). En la imagen de la izquierda no se conservan restos del recubrimiento orgánico de cera de abeja.

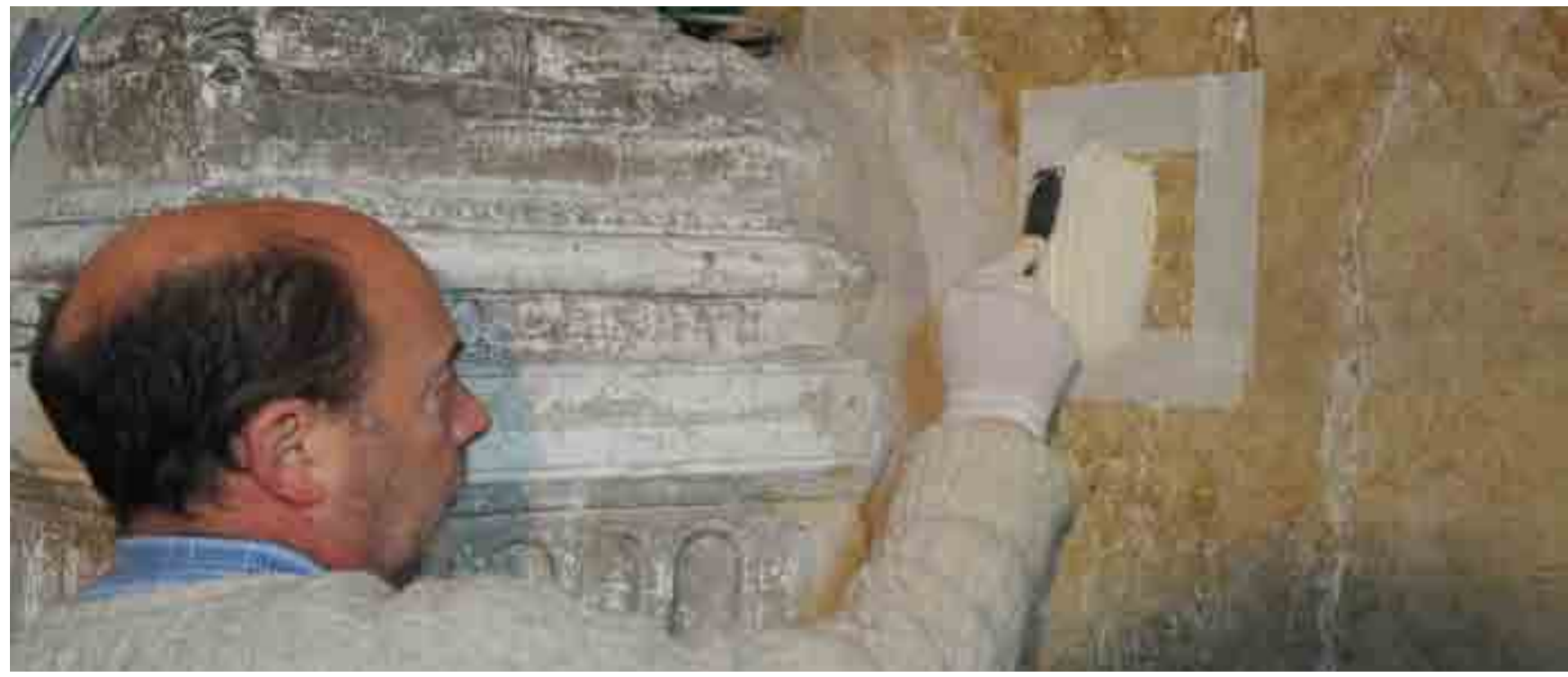

Figura 5. Aplicación de la crema "Arts Mundi" sobre el revoco de la pared sur de la Cámara Santa

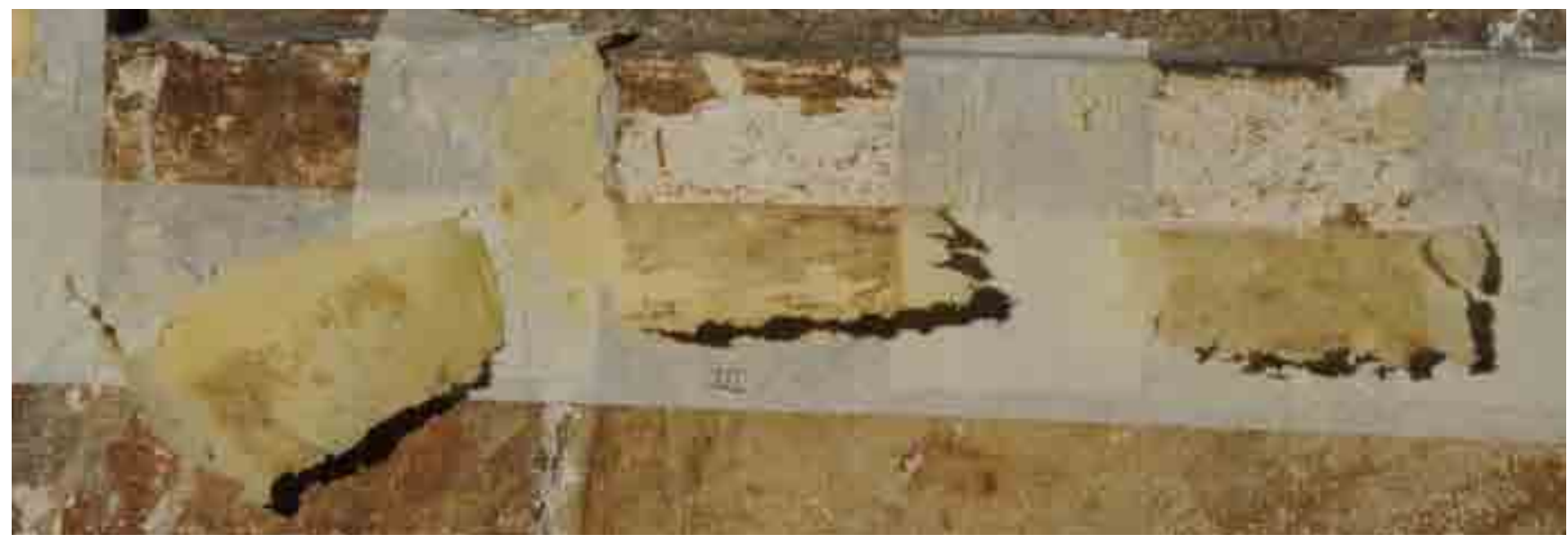

Figura 6. Detalles de tres catas de limpieza, realizadas sobre revoco con los látex del tipo I, tipo III y tipo V, después de la segunda aplicación. 


\begin{tabular}{|c|c|c|c|c|c|c|}
\hline \multicolumn{2}{|c|}{ SOPORTE } & \multirow{2}{*}{ MUESTRA } & \multirow{2}{*}{ TECNICA } & \multicolumn{2}{|c|}{ PARAMETROS } & \multirow{2}{*}{ COMENTARIOS } \\
\hline & & & & Tipo & Aplicaciones & \\
\hline \multirow[b]{2}{*}{ 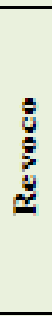 } & Látex & PL12a & \multirow{10}{*}{ 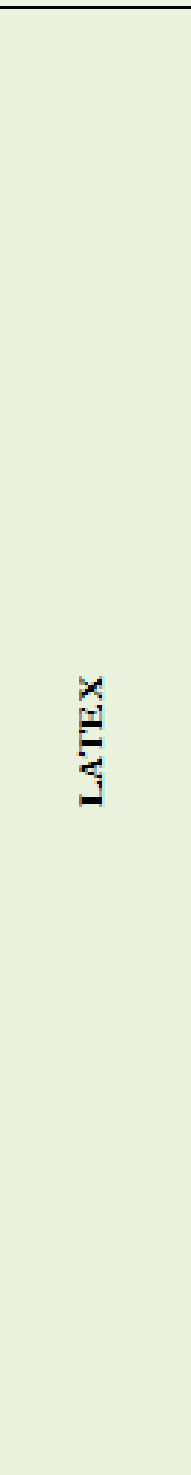 } & & & $\begin{array}{l}\text { Sobre el látex se identifican cristales de un } \\
\text { compuesto sódico. }\end{array}$ \\
\hline & Revoco & PL12b & & I & 1 & $\begin{array}{l}\text { La mayoría del recubrimiento (cera de } \\
\text { abeja) se mantiene y sobre él se observan } \\
\text { cristales de sulfato } y / \text { o carbonato de } \\
\text { sodio, resultado de la reacción del látex y } \\
\text { la superficie del revoco. }\end{array}$ \\
\hline \multicolumn{2}{|c|}{ Revoco } & PL16 & & II & 1 & $\begin{array}{c}\text { El recubrimiento (cera de abeja) se } \\
\text { mantiene } y \text { se identifican cristales de } \\
\text { sodio. }\end{array}$ \\
\hline \multirow{3}{*}{$\underset{\Xi}{\mathscr{E}}$} & Látex & PL13a & & & & $\begin{array}{l}\text { Sobre el látex se identifican cristales de } \\
\text { sodio y aluminosilicatos. }\end{array}$ \\
\hline & Revoco & PL1วิb & & & & $\begin{array}{c}\text { El recubrimiento (cera de abeja) se } \\
\text { mantiene y sobre él se identifican cristales } \\
\text { de sodio. }\end{array}$ \\
\hline & Laspra & PL19 & & III & 1 & $\begin{array}{c}\text { El recubrimiento (cera de abeja) se } \\
\text { mantiene } y \text { sobre él se identifican cristales } \\
\text { de sodio. }\end{array}$ \\
\hline \multirow{2}{*}{\multicolumn{2}{|c|}{ Revoco }} & PL20 & & & & $\begin{array}{l}\text { Parte del recubrimiento (cera de abeja) es } \\
\text { eliminado, dejando al descubierto el } \\
\text { sustrato base (revoco de cal). En ambas } \\
\text { zonas se identifican cristales de sodio. }\end{array}$ \\
\hline & & PL17 & & III & 2 & $\begin{array}{l}\text { Parte del recubrimiento (cera de abeja) es } \\
\text { eliminado, dejando al descubierto el } \\
\text { sustrato base (revoco de cal y cuarzo). En } \\
\text { ambas zonas se identifican cristales de } \\
\text { sodio. }\end{array}$ \\
\hline \multirow{2}{*}{$\stackrel{8}{\mathscr{E}}$} & Látex & PL14a & & \multirow[b]{2}{*}{$\mathrm{V}$} & \multirow[b]{2}{*}{1} & $\begin{array}{c}\text { Sobre el látex se identifican cristales de } \\
\text { sodio. }\end{array}$ \\
\hline & Reroco & PL14b & & & & $\begin{array}{l}\text { La mayoría del recubrimiento (cera de } \\
\text { abeja) se mantiene y sobre él se observan } \\
\text { cristales de sodio. }\end{array}$ \\
\hline
\end{tabular}

Tabla III. Análisis morfoquímico de las superficies limpiadas con látex.

emulsión de látex (> $90 \%$ ), AEDT (ácido etilendiaminatetraasético), sal de tetrasodio (3 - 10\%) y amoníaco en solución acuosa $(<0,005 \%)$.

Tal como se comprueba en la tabla III, independientemente de que se analice soporte pétreo, mortero o el propio látex, sobre las superficies estudiadas se detectan compuestos de sodio, presumiblemente carbonatos y/o sulfatos sódicos (Fig. 7).

La presencia de elementos exógenos a los materiales originales o de reposición desaconseja el empleo de esta técnica.

\section{Limpieza química con white spirit y pistola de aire caliente.}

Este tipo de limpieza se ha restringido a superficies pétreas con recubrimientos orgánicos de cera de abeja de elevado espesor (Figs. 8 - 9). La metodología consiste en el precalentamiento de la zona a tratar con pistola de aire caliente regulada a $70 / 80^{\circ} \mathrm{C}$ y posterior eliminación de las ceras con hisopos de algodón embebidos en white spirit. El resultado de los análisis de las superficies limpiadas con este método se presentan en la tabla IV y en la figura 10. 

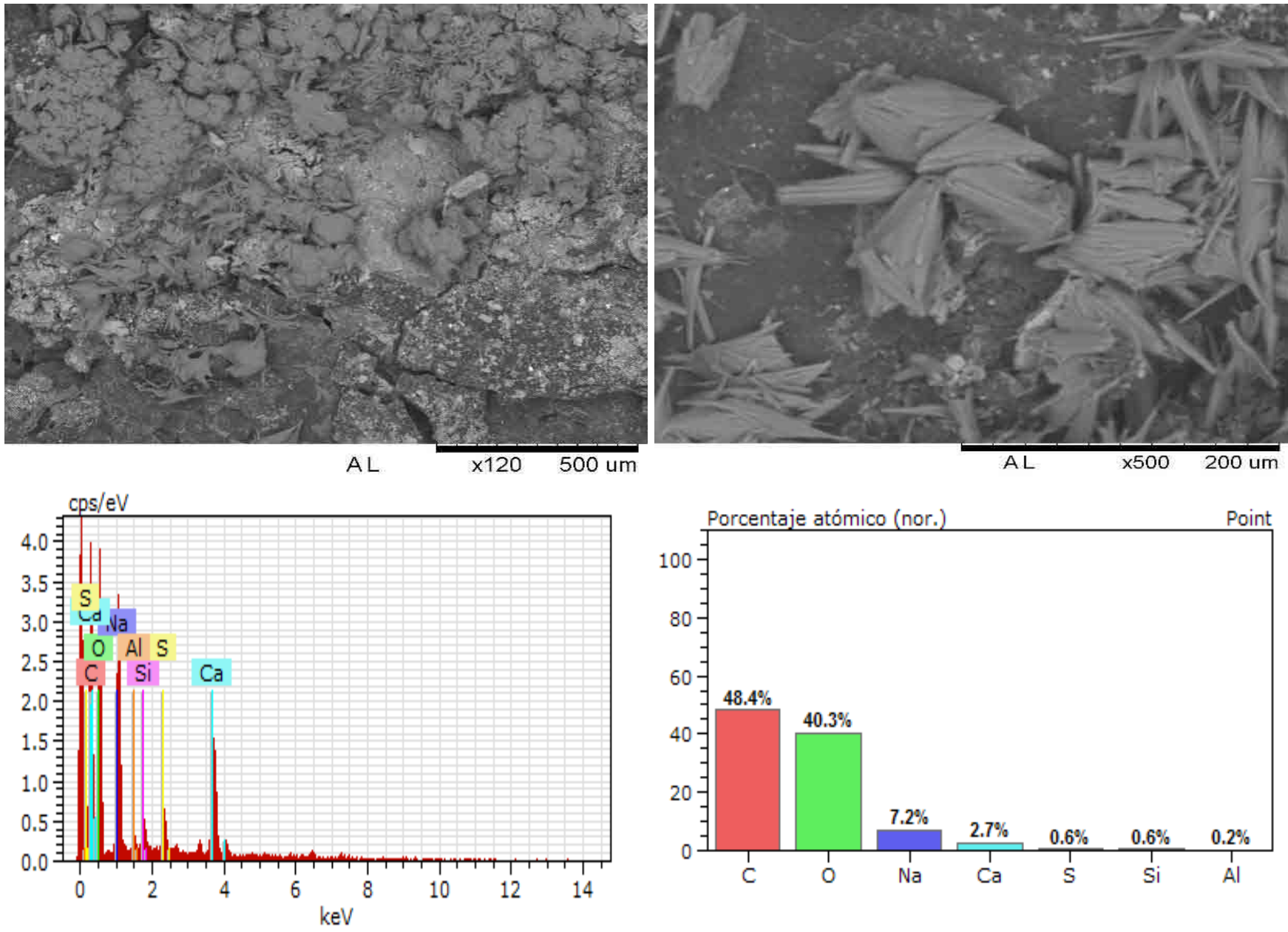

Figura 7. Micrografías al SEM, espectro EDX e histograma de porcentajes atómicos de los cristales detectados en las zonas de revoco limpiadas con el látex "Art Mundit". Además del carbono y el oxígeno, el sodio es el elemento mayoritario. En mucha menor proporción se detecta calcio, azufre, silicio y algo de aluminio.

\section{Limpieza mecánica instrumental: Microproyección.}

En lo que se refiere a la limpieza mecánica cabe resaltar que los métodos manuales no han sido eficaces en la eliminación del recubrimiento orgánico de cera de abeja.

Las pruebas de microproyección con bicarbonato y piedra pómez han sido realizadas tanto sobre el sustrato pétreo de podios, como sobre los revocos.

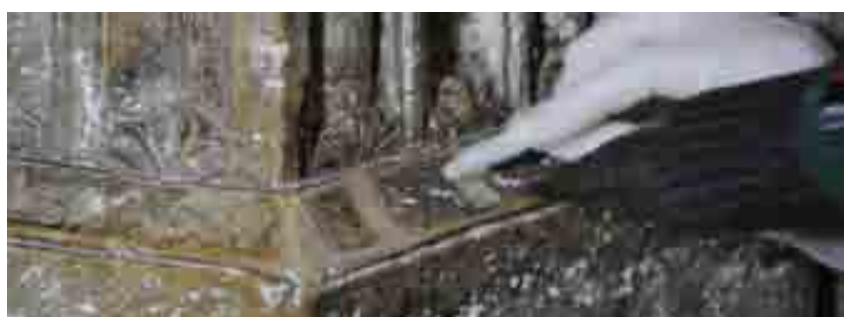

Figura 8. Catas de limpieza con aire caliente y white spirit realizadas en el pedestal de la columna de San Pedro y San Pablo.

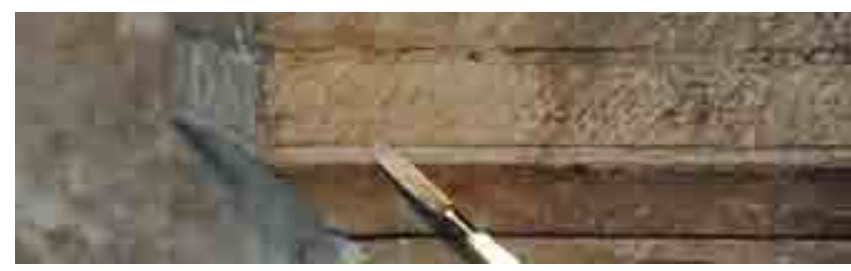

Figura 9. Aspecto de la superficie una vez aplicado el tratamiento en el pedestal de la columna de Santiago el Mayor y San Juan.

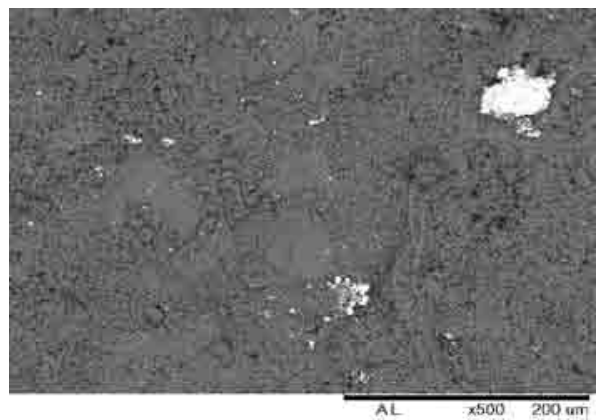

Figura 10. Aspecto morfológico al SEM de la superficie pétrea limpiada con White spirit y aire caliente. El recubrimiento de cera de abeja ha desaparecido durante el proceso de limpieza. 


\begin{tabular}{|c|c|c|c|c|c|}
\hline \multirow{2}{*}{ SOPORTE } & \multirow{2}{*}{ MUESTRA } & \multirow{2}{*}{ TËCNICA } & \multicolumn{2}{|c|}{ PARÁMETROS } & \multirow{2}{*}{ COMENTARIOS } \\
\hline & & & Producto & Aire caliente & \\
\hline \multirow{2}{*}{ 芴 } & PL15a & \multirow{2}{*}{ 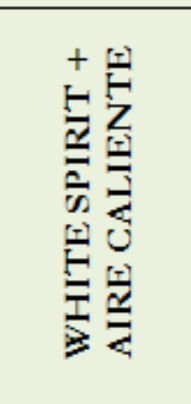 } & \multirow[b]{2}{*}{ White Spirit } & \multirow[b]{2}{*}{$70-80^{\circ} \mathrm{C}$} & $\begin{array}{l}\text { La mayoría del recubrimiento } \\
\text { (cera de abeja) es eliminado, } \\
\text { dejando al descubierto el } \\
\text { sustrato base (Piedra de Laspra). }\end{array}$ \\
\hline & PL15b & & & & $\begin{array}{l}\text { El recubrimiento (cera de abeja) } \\
\text { ha desaparecido, dejando al } \\
\text { descubierto restos de la capa } \\
\text { pictórica de albayalde y el } \\
\text { sustrato base (Piedra de Laspra). }\end{array}$ \\
\hline
\end{tabular}

Tabla IV. Análisis morfoquímico de las superficies limpiadas con White spirit y pistola de aire caliente.

En la tabla $V$ se resumen los resultados obtenidos del análisis morfoquímico de las superficies limpiadas con este método.

De los análisis morfoquímicos realizados sobre las superficies limpiadas mediante microproyección se deduce que la piedra pómez es más efectiva en la eliminación de la suciedad y los recubrimientos orgánicos de cera de abeja, tanto sobre sustrato pétreo como sobre revocos (Figs. 11 $-12)$.

Respecto al bicarbonato llama la atención que algunos de los microabrasivos analizados, adheridos a la micromuestras, presentaban elevados contenidos en sílice, a pesar de que la ficha técnica del Armex recoge que se trata de un abrasivo formulado a base de bicarbonato sódico natural tratado (99\% mínimo de $\mathrm{CO}_{3} \mathrm{HNa}$ ) (Fig. 13). Además, durante las pruebas realizadas se comprobó que, empleando este microabrasivo, era necesario insistir varias veces sobre la superficie a limpiar para eliminar los recubrimientos ennegrecidos.

De las pruebas de limpieza realizadas se concluye lo siguiente:

- $\quad$ La limpieza láser es el método más adecuado para las superficies pétreas de labra escultórica, siempre y cuando, se realice a energías inferiores a $100 \mathrm{~mJ}$ y frecuencias de $20 \mathrm{~Hz}$.

- $\quad$ El empleo de White spirit combinado con una pistola de aire caliente puede resultar adecuado para la limpieza de superficies sin labra escultórica, siempre y cuan-

\begin{tabular}{|c|c|c|c|c|c|c|}
\hline \multirow{2}{*}{ SOPORTE } & \multirow{2}{*}{ MUESTRA } & \multirow{2}{*}{ TÉCNICA } & \multicolumn{3}{|c|}{ PARÁMETROS } & \multirow{2}{*}{ COMENTARIOS } \\
\hline & & & Abrasivo & $\begin{array}{l}\text { Presión } \\
\text { (bares) }\end{array}$ & $\begin{array}{l}\text { Granulometría } \\
(\mu \mathrm{m})\end{array}$ & \\
\hline \multirow{4}{*}{ 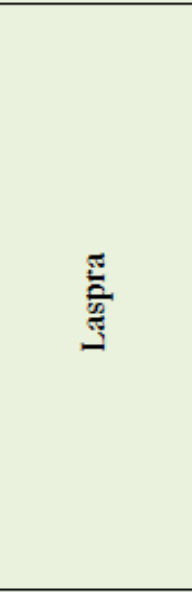 } & PL21a & \multirow{5}{*}{ 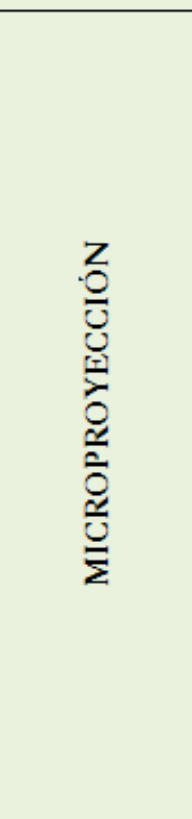 } & \multirow[t]{2}{*}{ 总 } & \multirow{5}{*}{$0,5-1,5$} & \multirow[t]{2}{*}{$90-250$} & $\begin{array}{c}\text { El recubrimiento (cera de } \\
\text { abeja) ha sido eliminado } \\
\text { dejando al descubierto el } \\
\text { sustrato base (Piedra de } \\
\text { Laspra). }\end{array}$ \\
\hline & PL21b & & & & & \\
\hline & PL22a & & \multirow{3}{*}{ 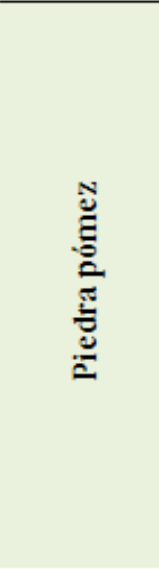 } & & \multirow[t]{2}{*}{$0-89$} & $\begin{array}{l}\text { Parte del recubrimiento } \\
\text { (cera de abeja) es } \\
\text { eliminado, dejando al } \\
\text { descubierto restos de la } \\
\text { capa pictórica de albayalde } \\
\text { y el sustrato base (Piedra } \\
\text { de Laspra). }\end{array}$ \\
\hline & PL22b & & & & & $\begin{array}{l}\text { Restos del recubrimiento } \\
\text { (cera de abeja). }\end{array}$ \\
\hline Revoco & PL23 & & & & $0-89$ & $\begin{array}{l}\text { La mayor parte de las } \\
\text { eflorescencias de yeso y del } \\
\text { recubrimiento (cera de } \\
\text { abeja), han sido eliminadas, } \\
\text { dejando al descubierto el } \\
\text { sustrato base (revoco). }\end{array}$ \\
\hline
\end{tabular}

Tabla V. Análisis morfoquímico de las superficies limpiadas con microproyección. 


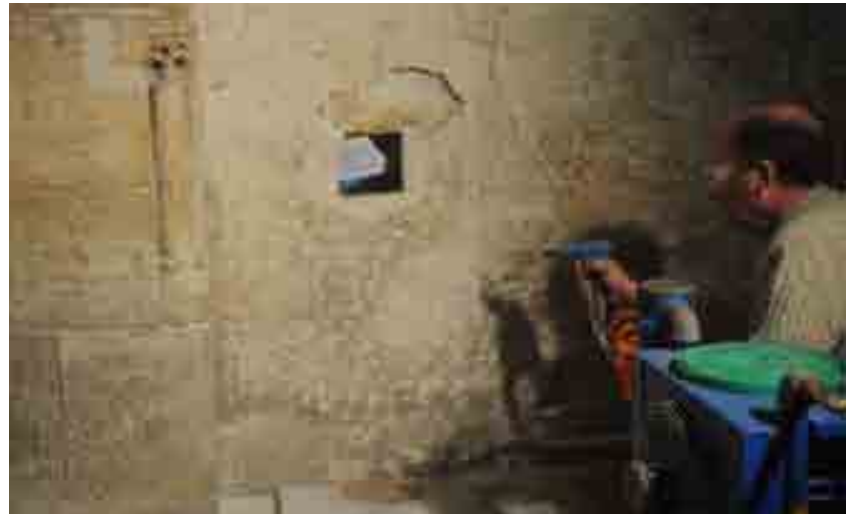

Figura 11. Aplicación de microabrasivo de piedra pómez en el revoco de la pared norte de la Cámara Santa.

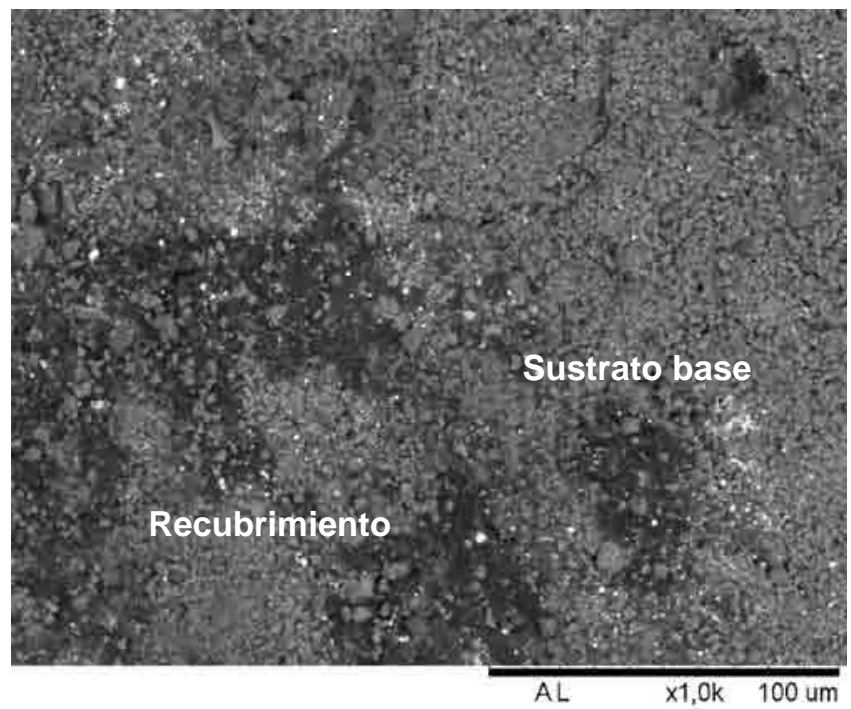

Figura 12. Aspecto morfológico al SEM de la superficie pétrea limpiada con piedra pómez.

do, el espesor del recubrimiento orgánico de cera de abeja sea elevado.

- La limpieza mecánica, mediante microproyección, resulta adecuada para la limpieza de paramentos lisos y superficies pétreas sin labra escultórica, siempre y cuando, el microabrasivo empleado sea la piedra pómez, proyectada a presiones comprendidas entre 0,5 y 1,5 bares.

- Se desaconseja el empleo del látex "Art Mundit" para la limpieza de cualquier tipo de superficie, al haberse detectado compuestos formados a base de carbonato sódico, en las micromuestras procedentes de las catas de limpieza.

A pesar de estas afirmaciones, durante las labores de seguimiento petrológico de la restauración, habrá que ir ajustando la combinación de estos métodos ensayados para garantizar la correcta limpieza de las superficies, preservando los restos pictóricos
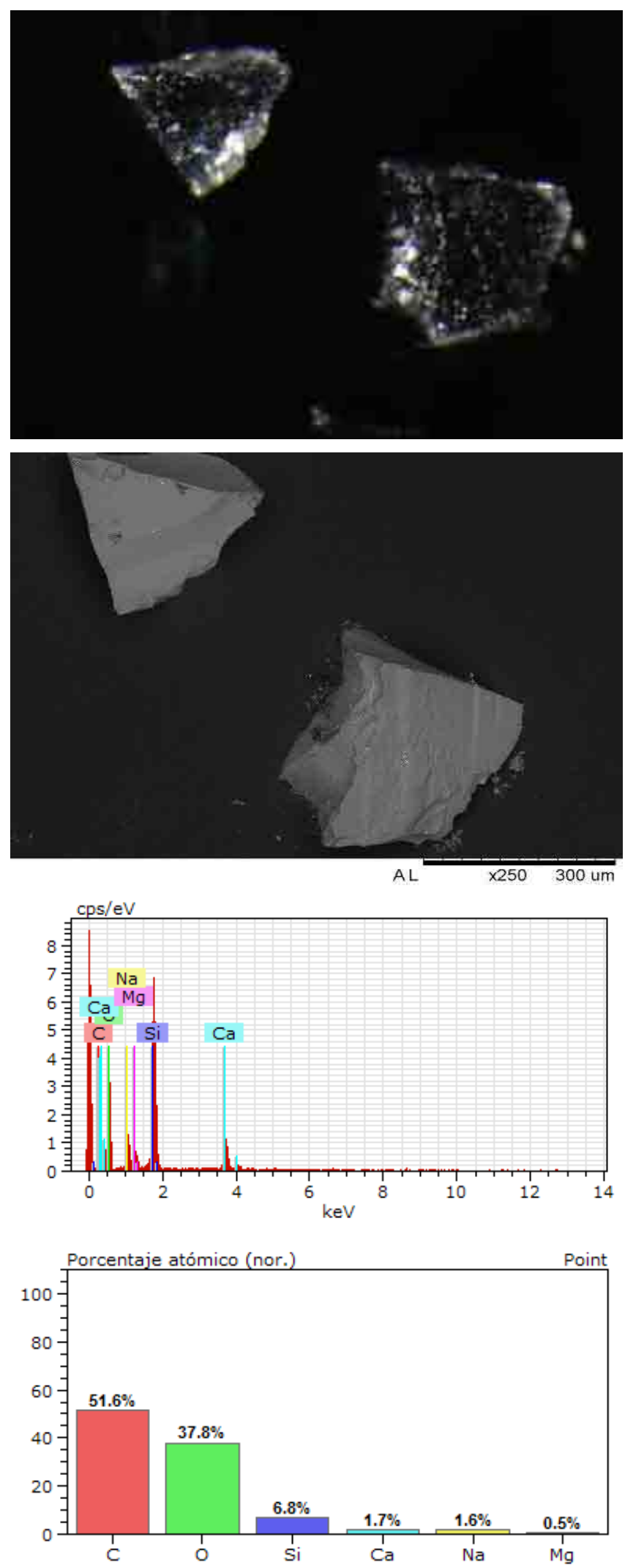

Figura 13. Aspecto macroscópico, microscópico, espectro EDX e histograma de porcentajes atómicos. Como elementos mayoritarios se ha detectado carbono, oxígeno y silicio. Como elementos minoritarios aparece calcio, sodio y magnesio. 


\section{Bibliografía.}

Asociación de congresos de conservación y restauración de bienes culturales, Actas de los congresos VI, VII, VIII, IX, X, XI, XII, XII, XIV XV, XVI y XVII. 1986 - 2010.

BALDINI, U. (1978). Teoría del Restauro, e unita' di metodología, (Volúmenes I y II), Florencia, Nardini Editore.

BRANDI, C. (1988). Teoría de la Restauración, (Edición española), Madrid, Alianza Editorial.

BELMUNT, O. y CANELLA, F. (1985).“Asturias" Tomo I Tip. De Octavio Bellmunt, Gijón, págs. 216.

CENINI, C. (1988). El libro del arte. Ed. Akal.

GARATE ROJAS, Y. (1994). Artes de la Cal, Ministerio de Cultura, Madrid.

GARCIA DE MIGUEL, JM. (2009). Tratamiento y conservación de la piedra, el ladrillo y los morteros. Consejo General de la arquitectura técnica en España, Madrid.

Ge IIC, Actas de los congresos I, II,III, IV y V Valencia 2002 y Barcelona 2005, Oviedo 2007, Cáceres 2009 y Madrid 2012.

GOMEZ GONZALEZ, M. L. (1994). Examen científico aplicado a la conservación de obras de Arte, Madrid, Ministerio de Cultura.

IPHE (2008). La ciencia y el arte, Madrid, IPHE.
LOPEZ ROMAN, A. (1999). Prevención de riesgos laborales en la investigación e intervención en Patrimonio Histórico, Granada, Cuadernos Técnicos.

MATTEINI - MOLES. (2001.) La química en la restauración, Hondarribia, Guipúzcoa, Editorial Nerea.

PRINCIPADO DE ASTURIAS (2001). Ley del Principado de Asturias de Patrimonio Cultural, Oviedo.

VERA BOTI, A. (2003). La Conservación del Patrimonio Arquitectónico, Murcia, Diego Martín editor.

VIGIL, CIRIACO M. (1987) Asturias, monumental, epigráfica y diplomática. Oviedo. Principado de Asturias.

VVAA (2012). Canteras Históricas de Oviedo. Oviedo, Hércules Astur Ediciones.

VVAA (2004). La restauración de la torre y el claustro de la catedral de Oviedo, Oviedo, Ediciones Nobel.

VVAA (2004). Intervención en el Patrimonio Cultural, creación y gestión de Proyectos, Madrid, editorial Síntesis.

VVAA (1997). Manual de diagnosis y tratamiento de materiales pétreos y cerámicos, Barcelona, Colegio de Aparejadores.

VVAA (2003). Una mirada hacia la conservación preventiva del patrimonio cultural., Valencia, UPV.

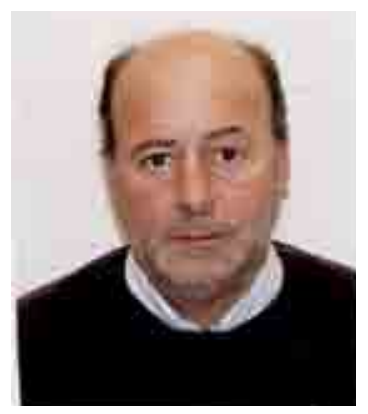

Luis Suárez Saro

Isaro@telecable.es

Inicia como autónomo la profesión de conservación y restauración de BBCC en el año 1986 tras superar sus estudios en Bellas Artes (licenciado por la Universidad del País Vasco). Bajo las normas establecidas en la Ley del Principado de Asturias de Patrimonio Cultural (1/2001, de 6 de marzo), su equipo, configurado multidisciplinarmente, interviene en la conservación y restauración de diferentes tipos de bienes culturales. Actualmente pertenece al equipo multidisciplinar, constituido por la Consejería de Educación y Cultura del Principado de Asturias para la realización de los "Estudios complementarios petrológicos de la Cámara Santa de la Catedral de Oviedo". Además, también imparte clases en la Escuela Superior de Arte del Principado de Asturias y ocupa el puesto de co-director (con D. Avelino Gutiérrez) del curso de postgrado en calidad de experto de la Universidad de Oviedo "Gestión y Conservación de bienes arqueológicos". 


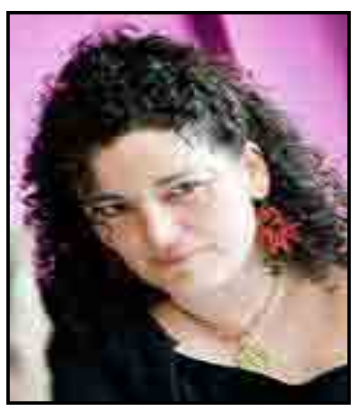

\section{Araceli Rojo Álvarez}

Ha obtenido su licenciatura en la Geología en 1996 y su grado (Tesis de licenciatura) en el año 2000, ambas por la Universidad de Oviedo, habiendo realizado los cursos de doctorado entre los años 1996 - 1998. Ha participado en 9 proyectos de investigación, ha publicado 26 documentos científicos en revistas nacionales e internacionales y ha asistido a 12 congresos relacionados con diversos aspectos de la geología. Ha realizado labores docentes impartiendo clases prácticas de Petrología Aplicada y Rocas Industriales en la Facultad de Geología de la Universidad de Oviedo durante los años 1997 2000. Ha participado en 4 cursos de verano de la Universidad de Oviedo (2003, 2005, 2006 y 2012), llevando la dirección/ coordinación del organizado en 2012. Ha impartido docencia en un curso experto de la Universidad de Oviedo (2007 - 2008) y en 3 másteres organizados por la Fundación Laboral de La Construcción de Asturias (2011 - 2012).

Es uno de los socios fundadores de GEA asesoría geológica, desarrollando su actividad profesional en esta empresa desde 2001, con una experiencia 12 años en diversos campos de geología como la petrofísica, la caracterización de materiales, la restauración, la geotécnica, el I+D+i, y la formación. Como miembro de esta empresa ha participado en más de 200 proyectos ligados a la caracterización de materiales aplicados al patrimonio arquitectónico, la construcción e ingeniería.

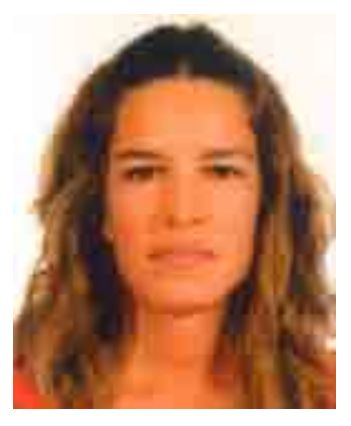

\section{Verónica Fernández Cuesta}

Licenciada en Geología por la Universidad de Oviedo (2010). Durante el segundo ciclo de la licenciatura ya fue becaria en la Universidad de Oviedo en diversos proyectos, como por ejemplo INTERFASE y I-STONE, así como becaria en la empresa GEA asesoría geológica. Al obtener la licenciatura fue becada por La Fundación Universidad de Oviedo para iniciar trabajos de laboratorio en la empresa GEA asesoría geológica, donde está contratada en la actualidad.

En esta empresa realiza estudios de caracterización, diagnosis y conservación de todo tipo de materiales constructivos pertenecientes al patrimonio histórico y arqueológico, así como actuales. Asimismo se ocupa de la puesta a punto y mantenimiento del equipamiento instrumental de laboratorio. 


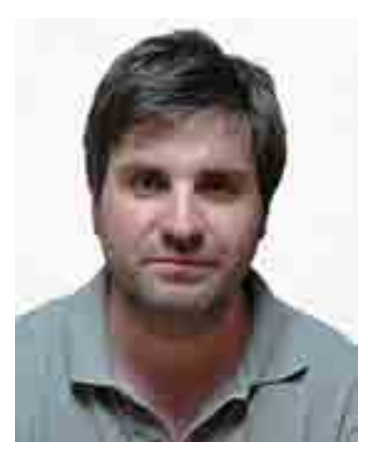

\title{
Pablo Klett Fernández
}

Licenciado en Bellas Artes, Especializado en Restauración de BBCC. Universidad Complutense de Madrid (1994-1999). Participó como colaborador honorífico en el equipo investigador en diversos estudios realizados en el Departamento de Restauración de Universidad de BBAA. de la UCM.

Comenzó su actividad profesional en el campo de la restauración, por cuenta propia en 1999. En diciembre 2002 pasó a formar parte de la plantilla de la empresa Técnicas de Arquitectura Monumental, S.A., siendo designado en 2004 Responsable del Departamento de Restauración de Bienes Muebles. Participó como miembro del equipo multidisciplinar que realizó los “Estudios complementarios petrológicos de la Cámara Santa de la Catedral de Oviedo" y actualmente interviene en su restauración.

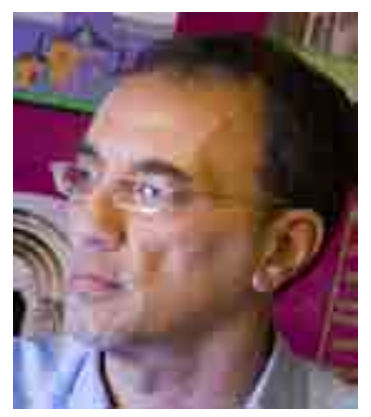

\author{
Luis Valdeón Menéndez \\ GEA asesoría geológica \\ correo@geaasesoriageologica.com
}

Luis Valdeón ha desarrollado toda su carrera profesional en el ámbito de la conservación de patrimonio histórico-arqueológico y evaluación de materiales pétreos, combinando una completa base de formación científico-técnica con una dilatada experiencia profesional a pie de obra. Tras doctorarse en Geología en la Universidad de Oviedo en1989, realizó estudios postdoctorales en el Imperial College de Londres (1989-2001) donde se especializó en la aplicación de técnicas no destructivas a materiales pétreos. En estos ámbitos posee más de cuarenta publicaciones en congresos y revistas nacionales e internacionales. Ha realizado cientos de trabajos en intervenciones de patrimonio monumental o estudios previos a las mismas, investigando asimismo el comportamiento de materiales constructivos y ornamentales en, por ejemplo, excavaciones arqueológicas, como las del yacimiento de Contrebia Leucade (La Rioja), o sobre bienes declarados patrimonio de la Humanidad, como el prerrománico asturiano (Monumentos de Oviedo y del Reino de Asturias), o Monasterio de Yuso (La Rioja), así como en catedrales, capillas y monumentos civiles de todo el país.

Desde 2001 es socio fundador, de la empresa GEA asesoría geológica especializada en estudios sobre Conservación y Restauración de Patrimonio y la caracterización de todo tipo de materiales. Es miembro activo del Grupo Español del International Institute for Conservation (GE-IIC) en donde ha formado parte de los comités científicos del grupo de trabajo "piedra". 


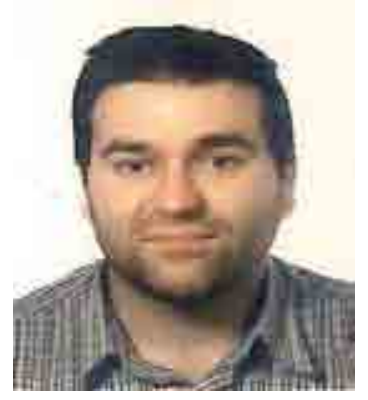

Félix Javier Mateos Redondo

Licenciado y Doctor en Ciencias Geológicas por la Universidad de Oviedo (1995-1999; 2011), en el año 1999 comienza su andadura profesional como investigador contratado dentro de los grupos de "Alteración y Durabilidad" y "Petrofísica" del Departamento de Geología de la Universidad de Oviedo, donde durante más de una década (1999-2010) ha participado en numerosos proyectos de investigación de ámbito internacional (CONNET, ALIANCE, MCDUR, CURRIC, FUNMIG, I-STONE, EPISCON..) y nacional (INTERFASE, NANOROCK, PERDURABLE..), así como decenas de contratos de investigación y/o servicios con empresas, fundaciones y organismos públicos.

Paralelamente a su actividad universitaria, en el año 2001 pasa a formar parte como Socio Fundador de la empresa GEA asesoría geológica, con sede en Oviedo, consultora especializada en campos como la conservación del patrimonio histórico-artístico, caracterización de materiales y petrofísica. 


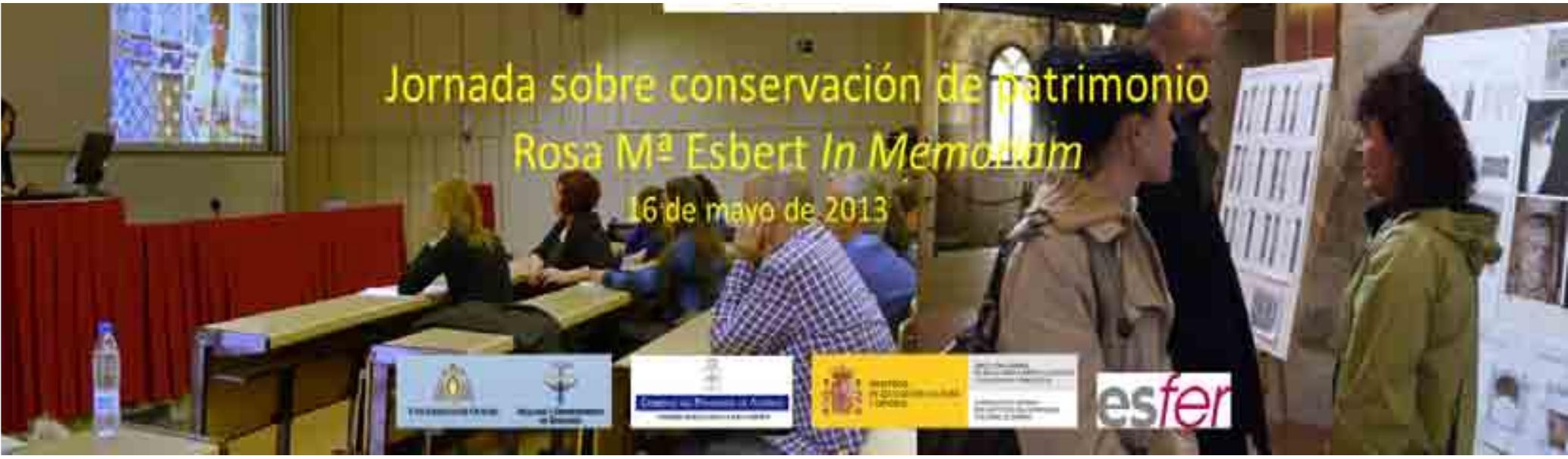

\title{
El apostolado de la Cámara Santa de la catedral de Oviedo: estudio de materiales
}

\author{
Araceli Rojo Álvarez
}

Resumen: El apostolado de la cámara Santa de la catedral de San Salvador de Oviedo es uno de los grupos escultóricos más representativos del románico asturiano. Este apostolado se adosó a la capilla prerrománica, en el siglo XII, con un nuevo enlucido pictórico. En este trabajo se caracterizó el soporte pétreo y se identificó la posible policromía original. El apostolado está labrado en dolomía de Laspra y de los restos pictóricos analizados se deduce que la técnica utilizada ha sido la pintura al óleo. Se identificaron capas de imprimación previas a la aplicación del color. Las bases de preparación están elaboradas con pigmentos secantes de blanco de plomo y tierras y otras con blanco de huesos mezclado con blanco de plomo. Se conocen intervenciones similares a éstas, anteriores al siglo XIV, en otras catedrales españolas. También aparecen repintes posteriores, elaborados a base de blanco de plomo y tierras rojas.

Palabras clave: Cámara santa, Catedral de Oviedo, Prerrománico, Dolomía de Laspra, Pigmentos.

\section{The Holy Chamber apostolate of the Cathedral of Oviedo: study materials}

\begin{abstract}
The Holly Chamber apostolate of the cathedral of San Salvador de Oviedo is one of the more representative sculptural groups of the Romanesque period. This apostolate was attached to the pre-Romanesque chapel in the XII century, with a new pictorial plaster. In this research, the stone support was characterized and the possible original polychrome was identified. The apostolate is carved in Laspra dolomite and after the analysis of the pictorial remains it could be deduced that oil painting was the used technique. Moreover, we have found that primer coatings were applied before the application of color. The base coats are made with drying pigments of white lead and clay earth, and others with bone white mixed with white lead. Similar interventions are known, prior to the fourteenth century, in other Spanish cathedrals. Overpainting also appears, prepared from white lead and red earth.
\end{abstract}

Key words: Holly chamber, Oviedo Cathedral, Laspra Stone, pigments.

\section{Introducción}

La Cámara Santa, emplazada en la catedral de San Salvador de Oviedo e incluida en el conjunto Monumentos de Oviedo y del Reino de Asturias, bienes declarados como Patrimonio Mundial, corresponde a una capilla doble con cripta, adosada a una torre anterior, de la época paleocristiana.

En el último tercio del siglo XII, el piso superior de la Cámara Santa sufrió una modificación en la nave (García de Castro 2012: 43). Se desmonta la primitiva techumbre de madera y se habilita un nuevo plano de imposta sobre el que se eleva una bóveda de cañón, construida en mampostería de arenisca y toba calcárea [figura 1]. Las impostas laterales descasan sobre columnas con pedestales, en cuyos fustes, en piedra de Laspra, ha sido labrado un apostolado que constituye uno de los grupos escultóricos más significativos del románico hispánico [figura 2].

La reforma de la Cámara Santa, tres siglos después de su construcción, conlleva la aplicación de un nuevo enlucido pictórico sobre el programa iconográfico altomedieval. Los espacios pintados alcanzarían a toda la estancia de la 

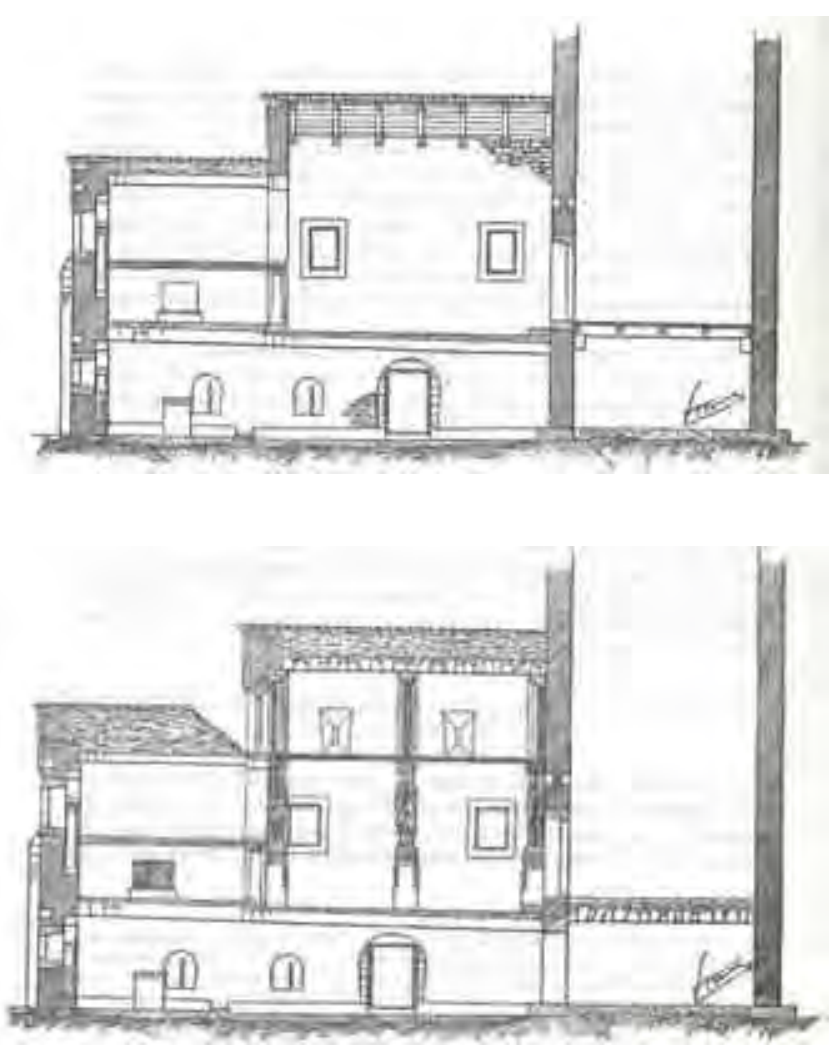

Figura 1. Corte longitudinal de la Cámara Santa antes (arriba) y después (abajo) de la reforma efectuada en el siglo XII (Dibujo y Estudio de Víctor Hevia, Fernández y Hevia, 1984: 96).

capilla y, por tanto, al conjunto escultórico del apostolado (Arias 2013: 13).

Durante la revolución de Asturias de 1934, se intentó destruir la torre gótica de la catedral, colocando una carga de dinamita en el interior de la cripta (Menéndez 1960: 3). Esta explosión destruyó casi por completo la Cámara Santa, quedando solo en pie aquello que tenía detrás algún agregado o refuerzo.

Los trabajos Ilevados a cabo por el arquitecto Alejandro Ferrant y el arqueólogo Manuel Gómez Moreno, permitieron recuperar las joyas que atesoraba la Cámara Santa, encargándose el escultor Víctor Hevia de la clasificación de los materiales constructivos mutilados (Hevia 2006: 168).

Finalizada la Guerra Civil, Luis Menéndez Pidal llegó a Oviedo con el encargo oficial de la restauración de la Cámara Santa, pero el Patronato de Reconstrucción de la Catedral ya había iniciado unos trabajos de urgencia, adjudicando las labores de restauración a Víctor Hevia (Fernández y Hevia 1984: 126).

Resulta evidente que ante las innumerables vicisitudes ocurridas a lo largo de los años, la dolomía de Laspra, piedra mayoritaria en el interior de la Cámara Santa, haya podido sufrir diferentes policromías, repolicromías y/o re- pintes, sin olvidar la presencia de pátinas, imprimaciones, revestimientos $y / 0$ recubrimientos, aplicados con fines estéticos y/o protectores. La correcta lectura de las superficies originales condicionará las futuras labores de restauración y las estrategias preventivas previstas para la conservación y mantenimiento de este conjunto escultórico.

El objetivo de este estudio se centra en caracterizar el sustrato pétreo, la policromía original y las capas superpuestas, así como la extensión y estado de conservación de las mismas.

\section{Análisis de materiales}

Los estudios que a continuación se presentan, se articulan en tres apartados: sustrato pétreo, capas pictóricas y revestimientos y morteros de reposición.

El criterio seguido en el muestreo parte de un examen minucioso preliminar de las superficies del apostolado, para posteriormente centrarse en dos grupos escultóricos; uno caído tras la voladura de 1934 y otro mantenido en posición original. Tales grupos han sido los formados por San Pedro y San Pablo y por San Simón y San Judas Tadeo. Esta elección ha estado también condicionada por su localización en el interior de capilla; costado norte (San Simón y San Judas) y costado sur (San Pedro y San Pablo). El muro norte, sometido a la acción directa del agua, presenta un mayor grado de deterioro que el observado en el muro sur, protegido de las inclemencias meteorológicas por el ala norte del claustro de la catedral.

Simultáneamente se han recogido muestras complementarias, en otros grupos escultóricos, con objeto de constatar los datos analíticos obtenidos en las zonas de control.

La nomenclatura seguida en el muestreo asigna letras de la $A$ a la $F$ para indicar cada grupo apostólico pareado [figura 3], seguido de las letras $\mathrm{Ar}, \mathrm{C}, \mathrm{C}, \mathrm{F}, \mathrm{p}$ y Pa correspondientes a arco fajón, cimacio, capitel, fuste, podio y paramento, respectivamente, seguido de un número de referencia correlativo. Así, a modo de ejemplo, la micromuestra ArEB12 ha sido recogida en el arco fajón, localizado entre San Pedro y San Pablo (E) y Santiago y San Juan (B).

\section{1.- Sustrato pétreo}

Menéndez Pidal, en 1960, identifica la piedra blanca "de la Sierra", posteriormente denominada Piedra de Laspra (Esbert 2004: 284), como material de labra, empleado en el conjunto escultórico del siglo XII. Se trata de una dolomía del Terciario inferior, explotada en la ciudad de Oviedo y alrededores, constituida en un $95 \%$ por dolomita.

Esta roca aflora en el "Picu Sierra", próximo a la estación de Viella (Granda), con labores de extracción recientes (Esbert y Marcos 1983: 55). Debieron de existir varias zonas de ex- 

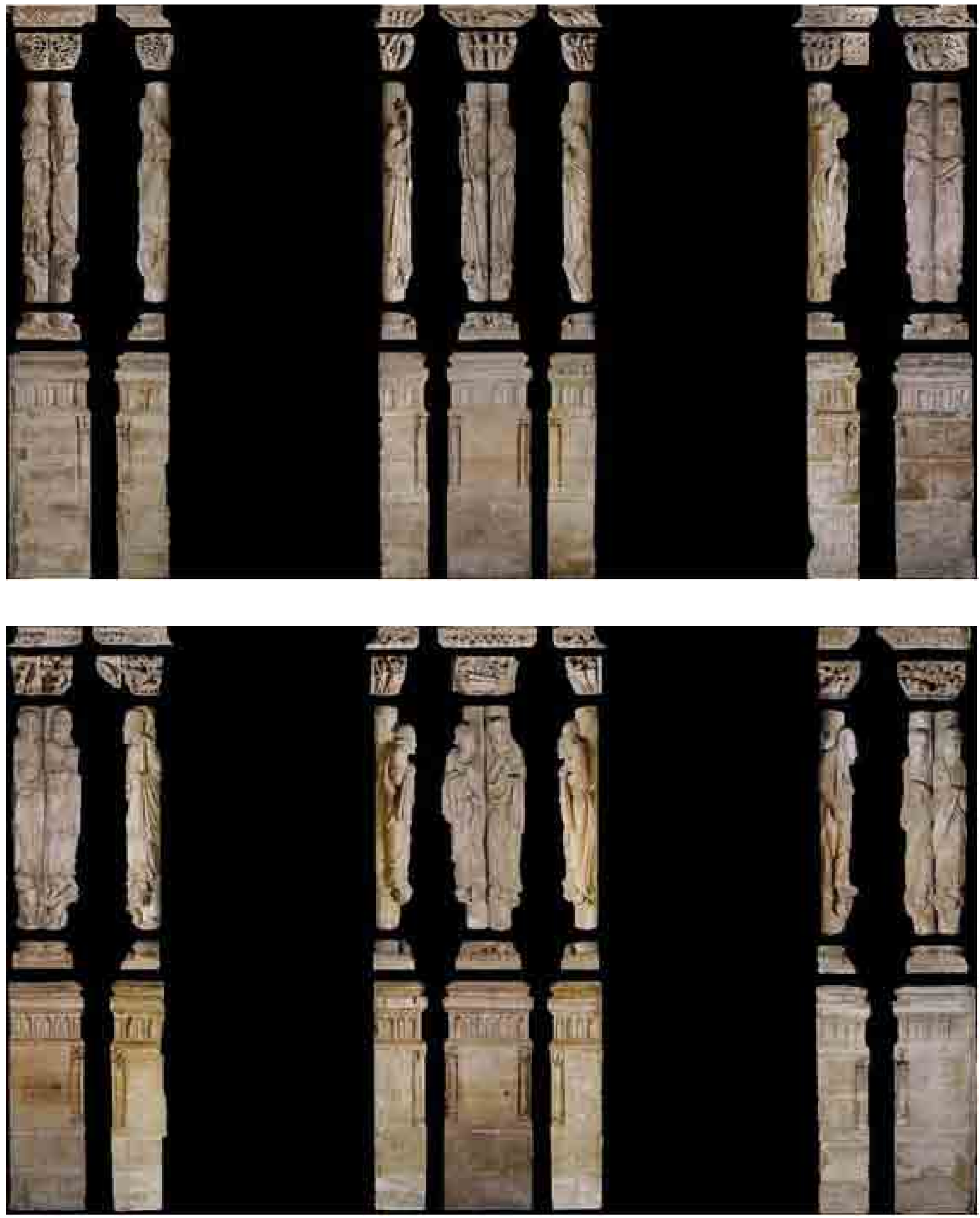

Figura 2. Arriba: Costado Norte, de izquierda a derecha; San Simón, San Judas, Santiago, San Juan, San Andrés y San Mateo. Abajo: Costado sur, de izquierda a derecha; Santiago el menor y San Felipe, San Pedro y San Pablo, Santo Tomás y San Bartolomé 

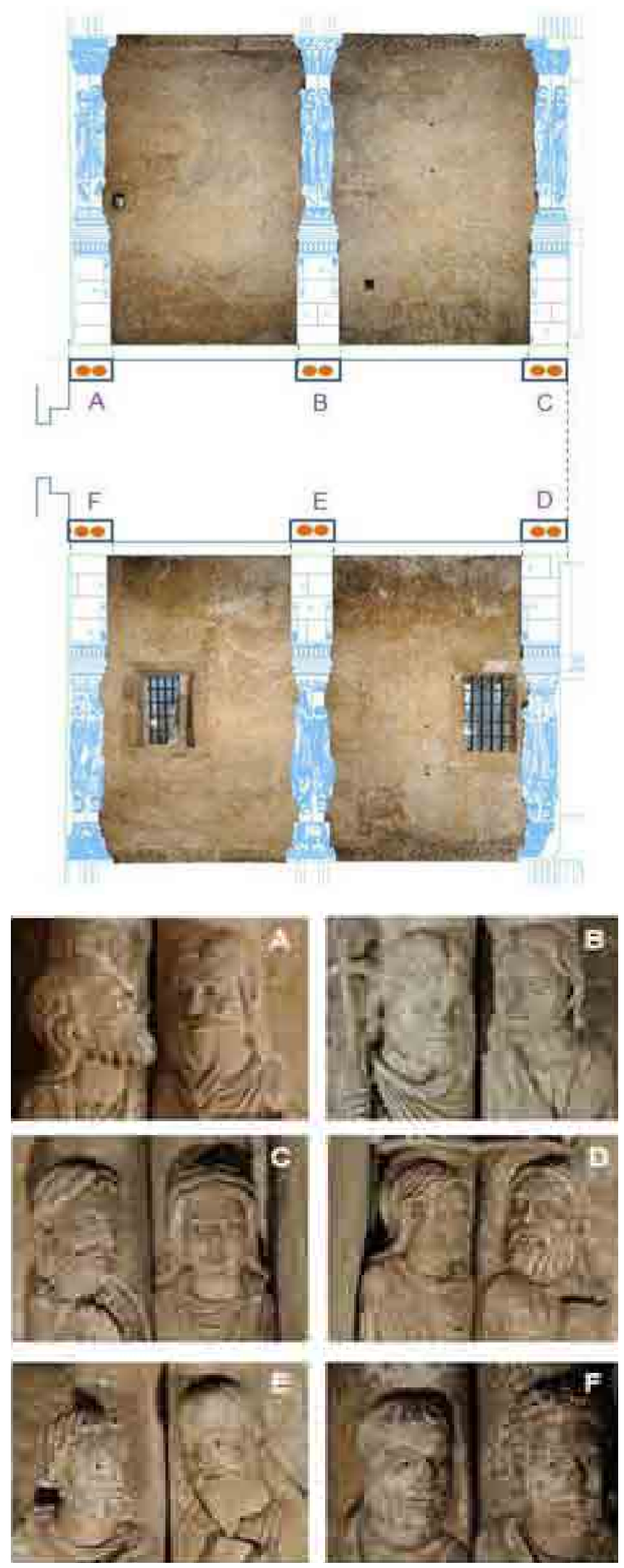

Figura 3. Esquema en planta con sus correspondientes alzados (norte y sur) donde se adjudica una letra a cada grupo escultórico aparejado. De izquierda a derecha la correspondencia es la siguiente: A - San Simón y San Judas, B - Santiago y San Juan, C - San Andrés y San Mateo, D - Santiago el menor y San Felipe, E - San Pedro y San Pablo, F - Santo Tomás y San Bartolomé. plotación de esta dolomía (Amilladoiro en 1473, Omilladoiro en 1493, Milladoiro en 1505 y Santa Olalla de Colloto en 1520), localizándose la principal en el barrio del Cristo (Esbert y Marcos 1983: 54) y en La Canterona, lugar que ocupa actualmente el barrio de Montecerrao (Gutierrez y Torres 1995: 197).

Menéndez Pidal también hace referencia al tipo de labra al afirmar que la piedra primitiva fue trabajada a pica fina y trinchante, alcanzándose el pulido en las columnas, capiteles y cimacios aprovechados y haciendo hincapié que en la obra escultórica del siglo XII, el trabajo de labra es aún más delicado, realizándose con instrumentos cortantes (Menéndez Pidal 1960: 13).

En lo que respecta a la superficie de labra de esta piedra dolomítica, Cuesta y Sandoval citan la presencia de signaturas o marcas especiales románicas que posteriormente desaparecen en el Renacimiento (Cuesta y Sandoval 1920: 14). Estos signos lapidarios se atribuyen a antiguos gremios del siglo XI, realizados para reconocer la obra ejecutada por cada uno de los obreros y poder así liquidar sus jornales (marcas de propiedad) o para marcar la orientación y posición de los bloques y facilitar así su colocación (marcas de posición y ensamblado) (Pardo, Cortázar y Sanz 2009: 149), aunque en ocasiones, estos signos podían tener un significado simbólico.

Cuesta y Sandoval (1920:16) añaden que muchos artistas centroeuropeos abandonaban sus hogares para convertirse en propagadores del nuevo arte, añadiendo ciertas señales para identificar sus obras. Un ejemplo son los círculos cortados por un diámetro horizontal, correspondientes a artistas franceses de Chartres y las marcas de seis remates (estrella de Salomón) que indican nacionalidad alemana de Hamburgo.

Gutiérrez y sus colaboradores (2013: 20-21), en su libro sobre las canteras históricas de Oviedo, recogen la relación de pedreros del municipio de Oviedo en el siglo XIII, así como el nombre y residencia de los canteros de las explotaciones de Piedramuelle y Laspra, en el primer tercio del siglo XVI.

En los estudios complementarios de la Cámara Santa, se recogen sobre los planos las herramientas empleadas por los canteros de la época (Cuenca y Hevia 2012: plano-documento $n^{\circ} 2$ ), así como algunas de las marcas observadas en podios y cimacios (Cuenca y Hevia 2012: plano-documento $n^{\circ} 13$ ).

Durante las labores de restauración de la Cámara Santa será posible registrar aquellos signos que pudieran haber pasado desapercibidos por el grado de ensuciamiento y descohesión de algunas de las superficies pétreas.

La dolomía de Laspra es una roca bastante homogénea constituida por dolomita, cuarzo y filosilicatos [figura 4]. El tamaño de grano de esta dolomia $(<4 \mu \mathrm{m})$ condicio- 
na la textura y homogeneidad de este material [figura 4], convirtiéndolo en una roca compacta pero relativamente blanda, muy adecuada para trabajos escultóricos de labra fina.

\section{2.- Capas pictóricas y revestimientos}

Las pinturas se presentan como una superposición constituida por una o más capas de preparación; blancas o coloreadas (Gómez 2004: 19), seguidas de una o varias capas pictóricas coloreadas que pueden aparecer recubiertas por una capa de protección, en este caso aplicadas sobre dolomía de Laspra.

La relación de pigmentos y metales identificados en el estudio estratigráfico de las micromuestras analizadas, se presenta a continuación:

\section{(a) Blanco de Plomo}

También conocido como albayalde, es el pigmento más importante en la pintura occidental desde la antigüedad hasta el siglo XX. De color blanco, está constituido por carbonato básico de plomo $\left[2 \mathrm{PbCO}_{3} \cdot \mathrm{Pb}(\mathrm{OH})_{2}\right]$.

Es el pigmento más frecuente en el apostolado y ha sido identificado en 23 muestras. En la mayoría de los casos aparece aplicado directamente sobre la piedra de Laspra, en una o varias manos y casi siempre acompañado de calcita y en ocasiones también de yeso.

En las muestras analizadas se detectan diferentes tipos de albayalde: aplicados en una mano, con calcita y/o yeso, aplicados en dos y tres manos, en capas superpuestas, mezclados con tierras rojas, aplicados sobre estucos, aplicados con, sobre y bajo negro carbón, aplicados con aceite secante, con resina de colofonia y con cera de abeja (en superficie).

En base a estas particularidades, se establecen 5 tipos de albayalde, con diferentes coloraciones [figura 5], presumiblemente aplicados en diferentes momentos históricos o en distintas intervenciones. A continuación exponemos los distintos tipos y sus características fundamentales:
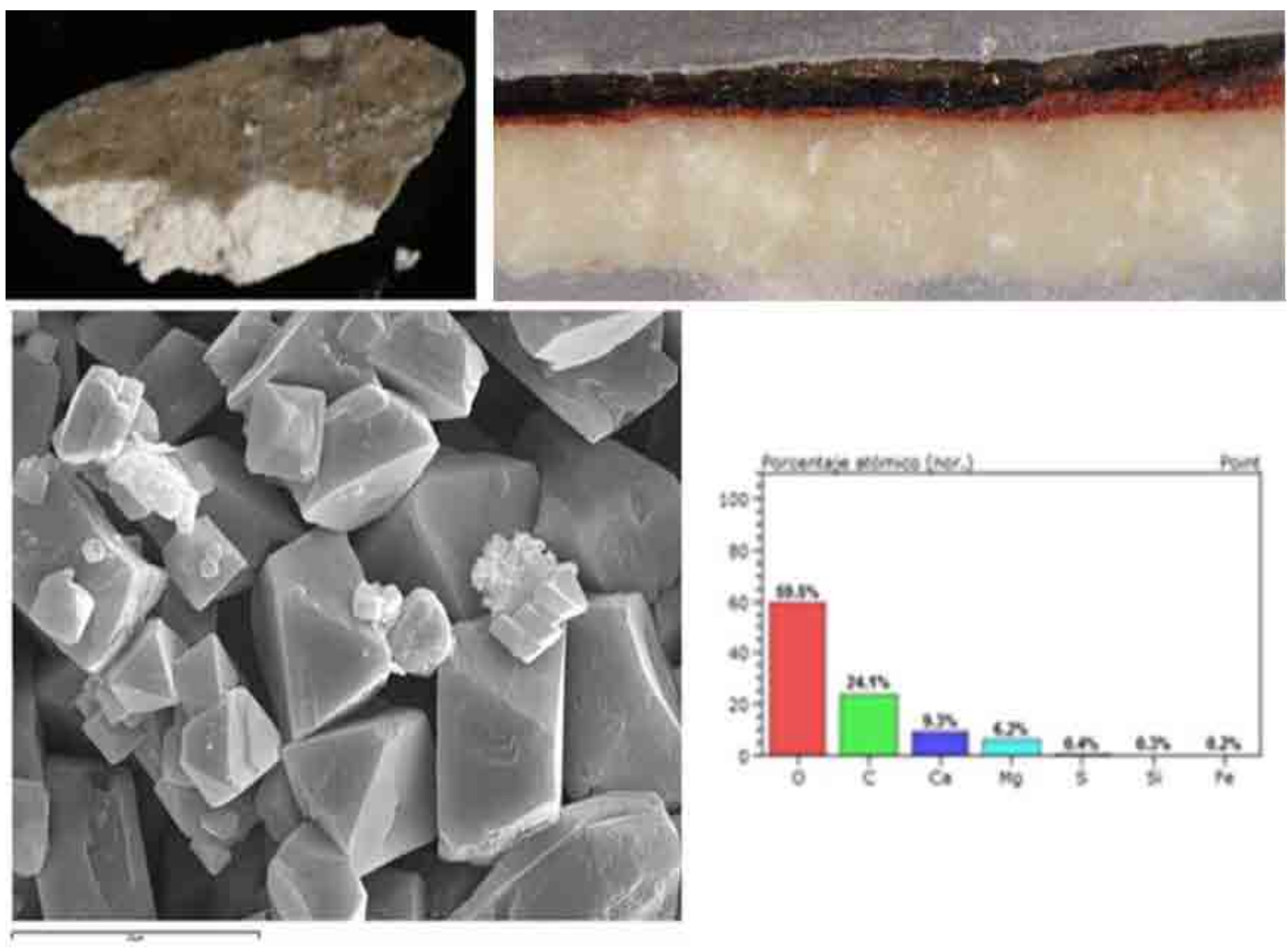

Figura 4. Arriba: Aspecto macroscópico y sección estratigráfica de una muestra recogida en el apostolado de la Cámara Santa. Abajo: Micrografía al microscopio electrónico de barrido (SEM) de la dolomía de Laspra e histograma de porcentajes atómicos de los elementos químicos analizados al SEM -EDX. Tal como se deduce del histograma esta roca está constituida por dolomita, algo de calcita, cuarzo $\left(\mathrm{SiO}_{2}\right)$ y óxidos o hidróxidos de hierro. 
Albayalde de color ocre: Se detecta en 5 muestras y pudiera tratarse de una de las capas más antiguas presentes en el apostolado.

\section{- $\quad$ Siempre aparece mezclado con carbonato cálcico} (calcita) y a veces, con silicatos.

- $\quad$ Aparece directamente aplicado sobre la piedra de Laspra.

- $\quad$ Suele llevar por encima una o dos capas de albayalde blanco o albayalde rojo.

- Se ha detectado en capiteles, podios y arcos fajones.

Se ha identificado en los grupos E (San Pedro y San Pablo) y D (Santiago el menor y San Felipe).

- Siempre aparece acompañado de aceite secante y resina de colofonia.

- En ocasiones, aplicado en 2 manos, presenta espesores medios de $100 \mu \mathrm{m}$ que aumentan en función del número de aplicaciones.

Albayalde de color rojo: Se detecta en 10 de las muestras analizadas y su disposición, incluso sobre superficies de rotura de piedra de Laspra, descarta que corresponda a una pintura de factura original. Además, la proliferación de estos restos pictóricos sobre mantos, fustes y podios, sin ningún criterio cromático, hace pensar que corresponda a una base de preparación de una posterior aplicación pictórica.

- $\quad$ Siempre aparece mezclado con tierras rojas, sulfato cálcico (yeso), carbonato cálcico (calcita) y carbonato cálcico - magnésico (dolomita).

Aparece directamente aplicado sobre la piedra de
Laspra.

- A veces presenta sobreimpuesto una de capa albayalde de color blanco sin negro carbón o con negro carbón. cos fajones.

Se ha detectado en capiteles, fustes, podios y ar-

- Se ha identificado en los grupos A (San Simón y San Judas), C (San Andrés y San Mateo), E (San Pedro y San Pablo) y F (Santo Tomás y San Bartolomé).

- Siempre aparece acompañado de aceite secante y resina de colofonia.

- $\quad$ Sus espesores medios rondan las $20 \mu \mathrm{m}$.

Albayalde sobre estuco: Se ha detectado en 3 muestras y al igual que el albayalde rojo, podría tratarse de una base de preparación para una posterior aplicación de un repinte, del cual no quedan restos en la actualidad.

- $\quad$ Siempre aparece aplicado sobre una capa de estuco elaborada a base de cuarzo, aluminosilicatos, sulfato cálcico (yeso), carbonato cálcico (calcita) y óxidos de hierro.

Se ha detectado en capiteles, cimacios y fustes.

- $\quad$ Se ha identificado en los grupos A (San Simón y San Judas) y E (San Pedro y San Pablo).

No presenta aceite secante, ni resina de colofonia.

Muestra espesores medios de $20 \mu \mathrm{m}$.

Albayalde de color gris: Se ha detectado en 4 muestras y corresponde a un repinte.

\begin{tabular}{|c|c|c|c|}
\hline Capa pictórica 6 & & Albayalde y calcita & Albayalde y calcita \\
\hline Capa pictórica 5 & & Albayalde y calcita & \\
\hline Capa pictórica 4 & Albayalde y calcita & Albayalde y calcita & Albayalde y calcita \\
\hline Capa pictórica 3 & $\begin{array}{l}\text { Calcita, dolomita, yeso, cuarzo } \\
\text { y albayalde }\end{array}$ & Cal y albayalde & Calcita y albayalde \\
\hline Capa pictórica 2 & $\begin{array}{l}\text { Calcita, tierra roja, dolomita, } \\
\text { albayalde y yeso }\end{array}$ & & $\begin{array}{l}\text { Calcita, yeso, tierra roja, dolo- } \\
\text { mita y albayalde }\end{array}$ \\
\hline Capa pictórica 1 & $\begin{array}{l}\text { Calcita y albayalde, dolomita, } \\
\text { cloruros, yeso, óxidos de hierro } \\
\text { y cuarzo }\end{array}$ & & Albayalde y calcita \\
\hline Muestras & ArEB13a & ArEB13b & ArEB13c \\
\hline
\end{tabular}

Tabla I. Estratigrafía de la muestra ArEB13 

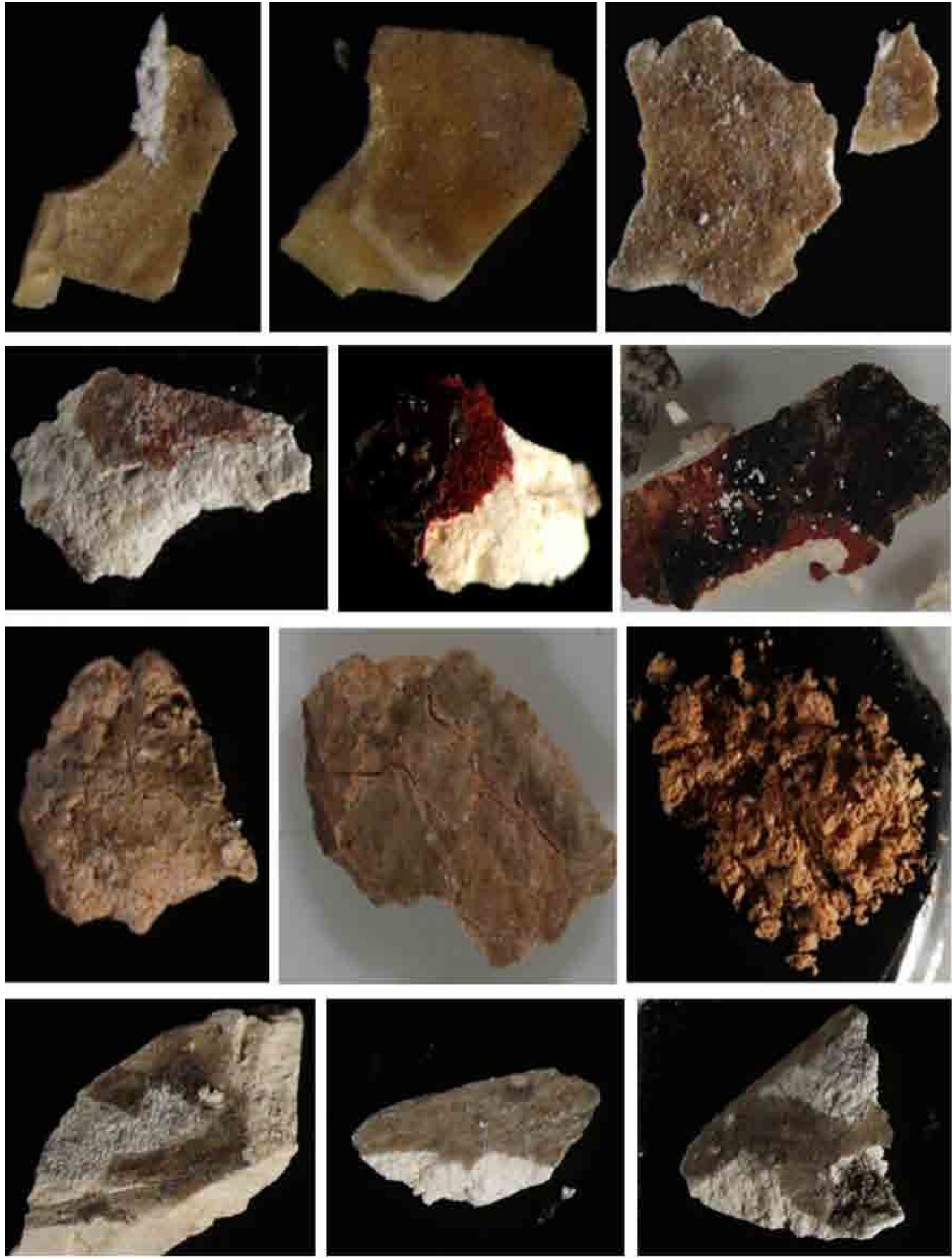

Figura 5. Aspecto macroscópico de las muestras de albayalde, recogidas en el apostolado de la cámara Santa. De arriba abajo: albayalde ocre, albayalde rojo, albayalde sobre estuco y albayalde gris. 
- Siempre aparece mezclado con sulfato cálcico y carbonato cálcico, en similar proporción, con o sin carbonato cálcico - magnésico.

- $\quad$ Aparece directamente aplicado sobre la piedra de Laspra.

- Se ha detectado en capiteles y fustes.

- $\quad$ Se ha identificado en los grupos C (San Andrés y San Mateo) y E (San Pedro y San Pablo).

- $\quad$ Siempre aparece asociado a aceite secante, sin resina de colofonia.

Sus espesores máximos rondan las $10 \mu \mathrm{m}$.

Albayalde de color blanco: Se ha detectado en 2 muestras y corresponde a un repinte. y silicatos.

Siempre aparece mezclado con carbonato cálcico

- $\quad$ Puede aparecer directamente aplicado sobre la piedra de Laspra o sobre alguno de los albayaldes anteriores; ocre (EC1 y Ep19) o rojo (EF7, EF8, EF16, AC22, y ArEB13). cos fajones.

Se ha detectado en fustes, capiteles, podios y ar-

Se ha identificado en los grupos escultóricos $E$ (San Pedro y San Pablo) y A (San Simón y San Judas). de colofonia.

Establecidos estos grupos, cabe mencionar que ha habido una única muestra donde se ha detectado una secuencia de superposición de hasta 6 capas pictóricas con el consiguiente orden de aparición, del interior al exterior: albayalde ocre, albayalde rojo y albayalde blanco [tabla 1]

\section{(b) Tierra roja}

Constituye un óxido impuro de hierro, también denominado ocre rojo, que ha sido empleado desde la antigüedad. Después del albayalde es el pigmento más común en las muestras analizadas y siempre aparece acompañado de éste.

Se utiliza en todas las técnicas pictóricas (óleo, temple, en el fresco), siendo frecuente en las carnaciones al temple o para pulimento en el óleo (Pacheco 2001: 465). Palomino (1947:91) añade que por su fina textura puede aplicarse para iluminaciones o en las primeras manos en el fresco.

\section{(c) Negro carbón}

Corresponde a carbono amorfo de naturaleza vegetal y/o animal. Ha sido detectado en dos muestras, sólo o mezclado con albayalde.

\section{(d) Blanco de hueso}

El fosfato tricálcico $\mathrm{Ca}_{3}(\mathrm{PO} 4)_{2}$, obtenido a partir de huesos calcinados, ha sido usado raramente en la antigüedad (Mateini y Moles 2001: 51) aunque se conoce su uso en la pintura como estabilizante del blanco de plomo (Cabrera 2010: 22).

En el capitel del grupo escultórico correspondiente a San Pedro y San Pablo se ha detectado una capa de pintura de aspecto blanquecino - ocre, elaborada a base de albayalde, silicatos y blanco de huesos [figura 6]. Esta capa apare-
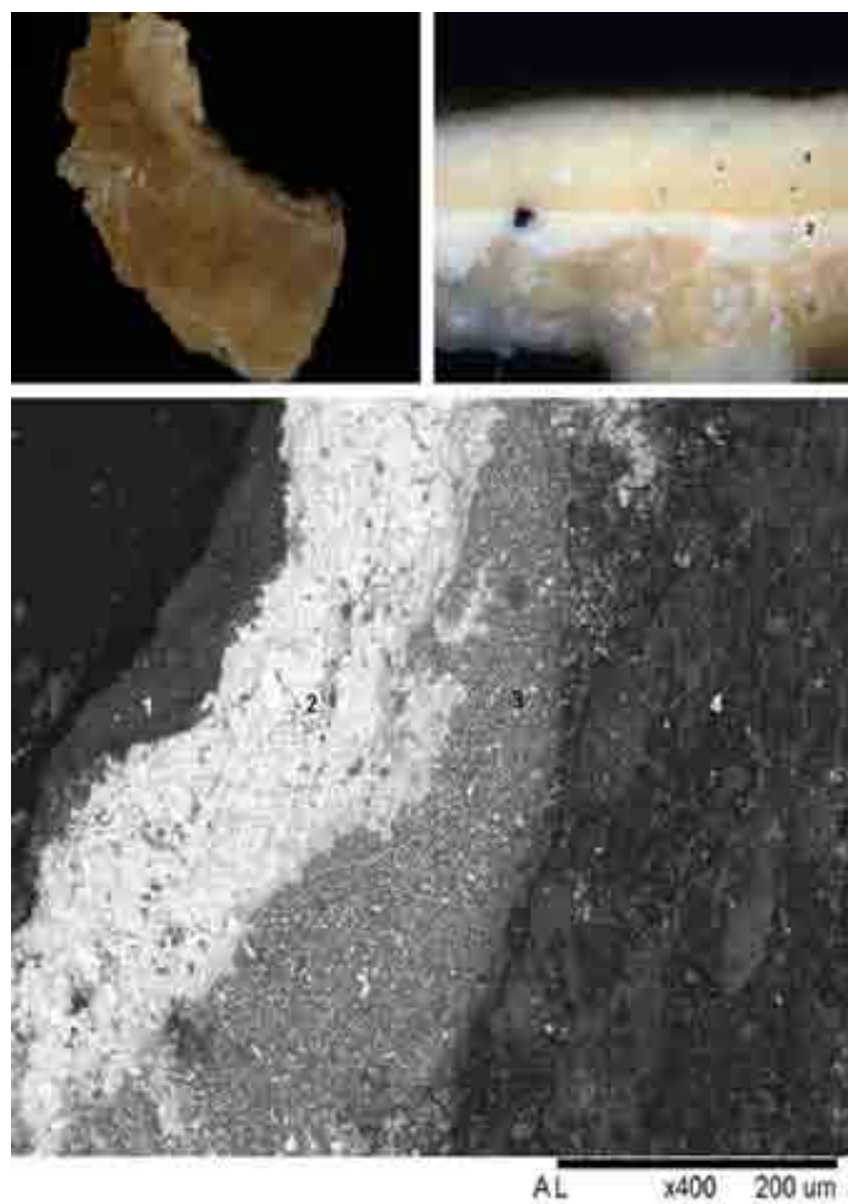

Figura 6. Arriba: Aspecto macroscópico y estratigrafía de la muestra EC5. Sobre la dolomía de Laspra (1) se detecta una capa pictórica de $40 \mu \mathrm{m}$ de espesor, elaborada a base de albayalde, calcita y silicatos (2). Sobre ésta se dispone una capa ocre - blanquecina, de $110 \mu \mathrm{m}$ de espesor, que presenta como pigmentos y/o cargas albayalde, silicatos y blanco de hueso (3). Abajo: Micrografía al SEM del aspecto morfológico y textura de la secuencia estratigráfica. 
ce aplicada sobre otra inferior elaborada a base de albayalde, calcita y silicatos, en contacto directo con la piedra de Laspra. Por su rareza y disposición podría tratarse de una de las capas pictóricas más antiguas, o quizás se trate de la original. Además es la única en la que se ha identificado aceite de lino como aglutinante orgánico.

\section{(e) Minio}

Al igual que el blanco de hueso, ha sido exclusivamente identificado en una muestra recogida en un fuste [figura 7] y podría tratarse de una de las capas pictóricas más antiguas que se conserva sobre la superficie del apostolado.

También denominado rojo de plomo, corresponde a un óxido mixto de plomo que se conoce y utiliza desde la antigüedad en todas las técnicas pictóricas y presenta un color anaranjado, con buen poder cubriente.
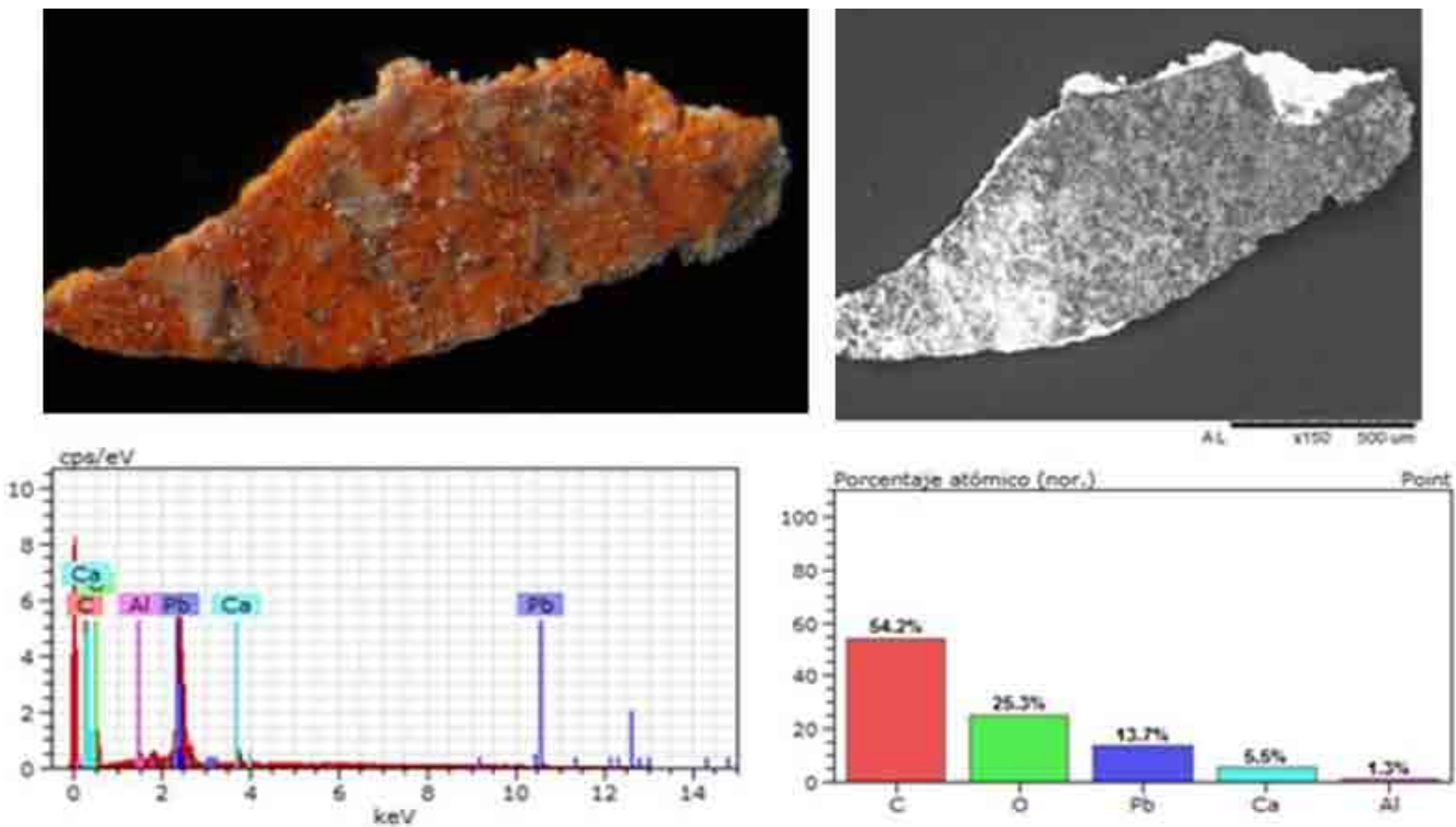

Figura 7.- Aspecto macroscópico y microscópico de la muestra EF25 con su correspondiente espectro EDX y su tabla de porcentajes atómicos. De estos últimos se deduce la presencia de minio como pigmento responsable del color de esta capa pictórica.
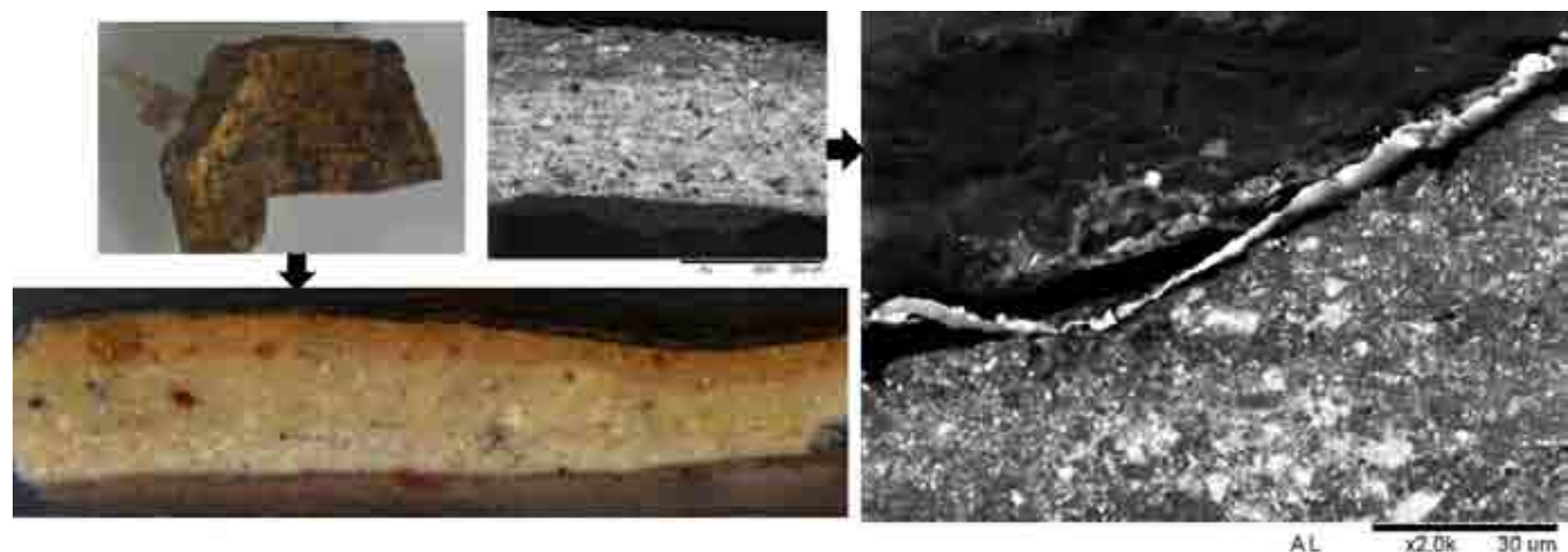

Figura 8. Aspecto macroscópico, microscópico de una lámina de oro, detectada en la muestra ArEB12. 


\section{(f) Oro}

Se incluye en este apartado una muestra en la cual se ha identificado una lámina de oro, aplicada sobre tres capas pictóricas de albayalde [figura 8].

Además de los pigmentos, en el estudio estratigráfico se han identificado dos tipos de estucos que se describen a continuación.

\section{(a) Estuco rojo}

Este estuco ya ha sido descrito en el apartado anterior, al haberse empleado como base de preparación de una capa de albayalde (albayalde sobre estuco). Se trata de una capa de color asalmonado, con un espesor medio de $900 \mu \mathrm{m}$, elaborada a base de cuarzo, aluminosilicatos, yeso, calcita y óxidos de hierro que se ha detectado en los párpados de la escultura de San Pedro y en la superficie de algún capitel.

\section{(b) Estuco negro}

Este tipo de estuco se localiza en los ojos de las esculturas, excepto en Santo Tomás, y ha sido descrito por Fernández Buelta y Hevia (1984: 113) como empaste de estuco negro. Hevia es el primero en mencionar la presencia de zafiros en los ojos de santo Tomás al levantar las pinturas que cubrían las esculturas entre los años 1919 y 1920 y defiende que todos los apóstoles tuvieron piedras preciosas en las pupilas, restringiendo el estuco negro al iris, quedando la huella de las mismas en los restos de pasta que él pudo observar.

Cuesta y Sandoval (1919: 13) también hacen referencia en sus memorias al hecho de que las estatuas tenían vista, que los ojos estaban admirablemente trabajados al igual que las cejas, apareciendo las cavidades o cajas cubiertas de algo negro como esmalte.

Se han identificado distintos tipos de ojos, aquellos que constan de pupilas de zafiro y otros en los que las pupilas e iris están elaboradas con un estuco negro mate o negro brillante [figura 9].

Para conocer la evolución que han sufrido los ojos se han examinado imágenes de los diferentes grupos escultóricos apeados o "in situ” después de la destrucción de la Cámara Santa. La falta de algunos resulta evidente en las fotografías, como es el caso de San Simón, San Juan, San Pablo y San Bartolomé, aunque podría ser que alguno de ellos haya sido repuesto con anterioridad a la realización del reportaje fotográfico. Durante este estudio se han analizado cuatro ojos correspondientes a las pupilas de San Pedro, San Simón y San Mateo y al iris de Santo Tomás.

El estuco negro mate ha sido muestreado en las pupilas de San Simón y San Mateo y en el iris de Santo Tomás [figura 9]. Este estuco mate está elaborado a base de yeso, calcita y aluminosilicatos. En la superficie de las muestras se detectan contenidos muy elevados en carbono, originados por la presencia de un recubrimiento orgánico.

El estuco negro brillante ha sido recogido en uno de los ojos de San Pedro y en una de las cejas de San Pablo. En este caso, el componente mayoritario es el azabache, cuyos cristales aparecen aglutinados con una pasta de yeso, calcita y dolomita [figura 9].

Observando los dos tipos de estuco se comprueba que la superficie interna de los mismos presentan estrías de agarre distintas, diseñadas para favorecer su adhesión a la cavidad ocular [figura 9].

Se desconoce si en origen todas las pupilas llevaban incrustaciones de piedras preciosas o vidrios pero, en la actualidad, a excepción de Santo Tomás, las pupilas están elaboradas con estucos negros, probablemente los de color negro brillante que presentan cristales de azabache sean más antiguos, mientras que los de color negro mate, más modernos, podrían corresponder a la restauración de Víctor Hevia. Sin embargo, no se descarta que los ojos elaborados a base de cristales de azabache sean de factura original.

\section{Revestimientos o recubrimientos orgánicos}

Se incluyen en este apartado los compuestos orgánicos aplicados con fines aglutinantes, consolidantes o protectores. Las técnicas de estudio empleadas en este tipo de análisis han sido la espectroscopía infrarroja por transformada de Fourier (FTIR por transmisión y FTIR-ATR) y la cromatografía de gases - espectrometría de masas (GC-MS).

De manera general puede decirse que todas las muestras presentan un recubrimiento superficial de cera de abeja que en algunos casos resulta extremadamente abundante. Sólo se ha encontrado una muestra en la que no aparece cera $^{1}$ y es en ella donde se ha identificado el blanco de hueso.

Esta cera aparece en la mayoría de los casos asociada con resina de colofonia. Sólo en las muestras de albayalde gris y de albayalde sobre estucos no se detecta este tipo de resina.

Otro compuesto orgánico detectado en las muestras es el aceite secante aunque sólo en una muestra este aceite ha podido identificarse como aceite de lino. El tipo de aceite empleado en las pinturas se calcula a partir de las proporciones de los ácidos grasos azelaico, palmítico y esteárico, las cuales marcan las pautas para saber si los aceites son de lino, nueces o adormidera. El problema se produce cuando hay ceras mezcladas ya que al presentar éstas elevadas proporciones de estos ácidos, distorsionan los resultados, impidiendo asignar el aceite a un tipo específico. En este caso sólo es correcto hablar de aceite secante. El aceite se- 

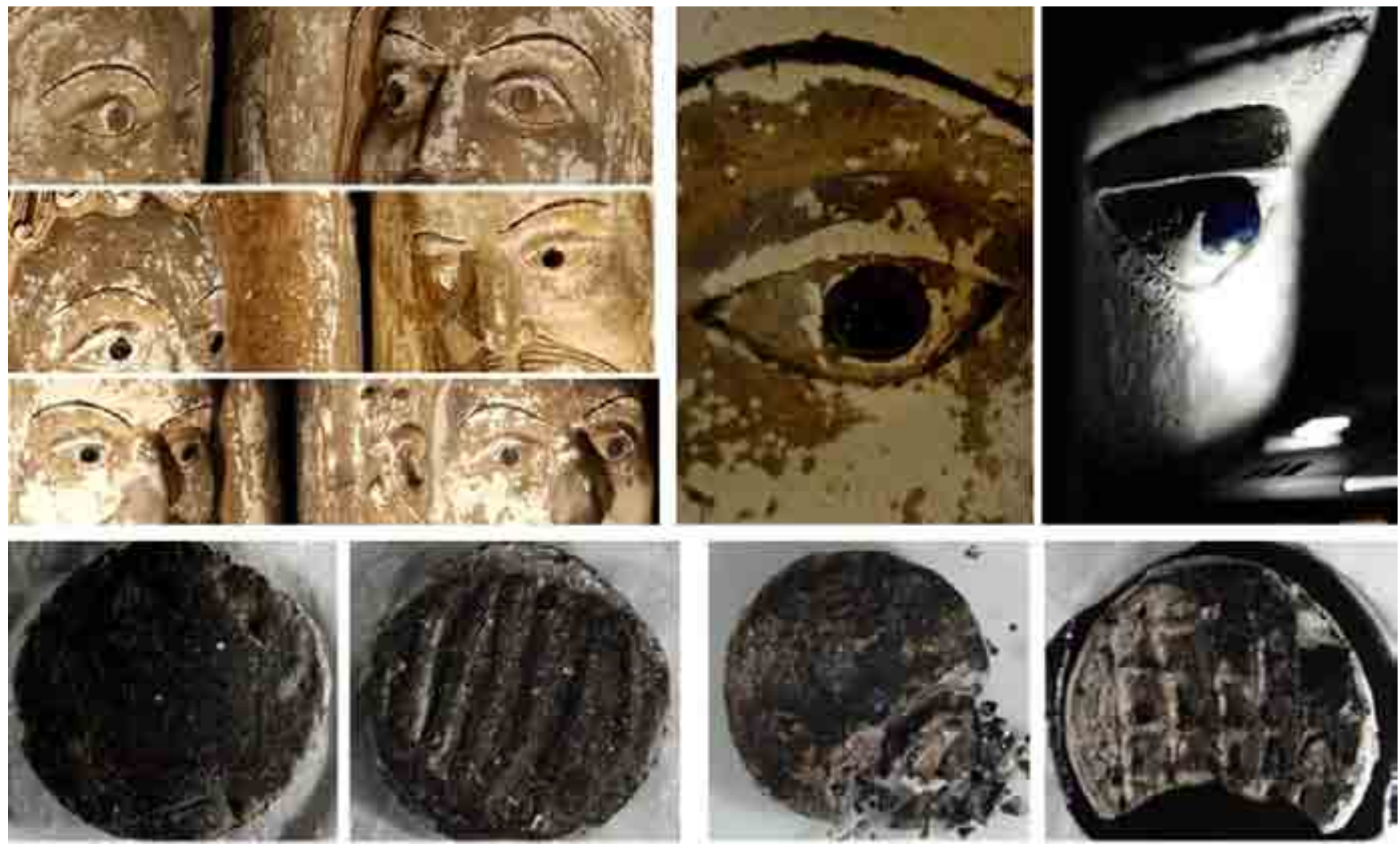

Figura 9. Superior izquierda: De arriba abajo, detalles de los ojos de los grupos escultóricos D (Santiago el menor y San Felipe), B (San Pedro y San Pablo) y C (Santo Tomás y San Bartolomé). Superior derecha: Detalles de los ojos de Santo Tomás. Inferior: Aspecto macroscópico de los ojos de San Simón (izqda.) y de San Pedro (dcha.) en superficie externa e interna.

cante ha sido identificado en varias muestras, sólo o acompañado de resina de colofonia.

Los aceites se utilizan en las técnicas al óleo $\mathrm{u}$ óleo-resinosas; mezclados con proteínas desde el siglo XII, formando emulsiones en técnicas mixtas o témperas, o solos, fundamentalmente desde el siglo XVII en la pintura al óleo, propiamente dicha.

Cabe mencionar que en la mayoría de las muestras también se han detectado oxalatos, originados por la actividad de microorganismos o por degradación oxidativa de los componentes orgánicos de la pintura.

\section{3.- Morteros de reintegración}

El mortero de reintegración, objeto de este estudio es el que, presumiblemente, ha empleado Víctor Hevia para la reconstrucción de volúmenes perdidos tras la destrucción de la Cámara Santa en 1934. La restauración del apostolado duró 10 meses, durante los cuales Hevia dibujó, modeló fragmentos que luego vaciaba, pulverizó piedra de la misma calidad que la original, manipuló, amasó y colocó pruebas para estudiar el fraguado de cada una de ellas. Menéndez Pidal hace referencia en sus escritos a que en la Cámara Santa fueron empleados todos los elementos del monumento derruido, previamente recogidos y clasificados, y que se buscaban entre los restos los fragmentos que posteriormente eran unidos con grapas y mortero de ligadura (Menéndez Pidal 1960: 14).

Sobre los criterios de restauración asumidos por Víctor Hevia, Fernando Señas Encina explica que «un observador atento descubre bajo la pátina que cubre los muros, los puntos restaurados para no dar lugar a confusiones cuando alguien quiera estudiar la vicisitudes que ha pasado este monumento» (Hevia y Hevia 2006:193). Ya en ese momento, el escultor huye de la creación de reintegraciones formales ideales, algo asumido actualmente como uno de los criterio básicos de la intervención en materiales pétreos (Esbert y Losada 2003: 26).

Del mortero empleado en las reintegraciones se han recogido dos muestras en dos ubicaciones diferentes; San Pablo y San Judas Tadeo. Se trata de un mortero elaborado a base de cal, molienda de piedra de Laspra y algo de cuarzo. En superficie presenta un recubrimiento pictórico de yeso, calcita y aluminosilicatos.

Los compuestos orgánicos detectados en este recubrimiento superficial son aceite secante, resina de colofonia y cera de abeja. Estos compuestos son los mismos que se han venido detectando en las muestras correspondientes 
a las capas pictóricas, recogidas en el apostolado. Este hecho complica la interpretación de los datos obtenidos en los análisis, ya que resulta imposible discernir si la mayoría de los aceites, resinas y ceras detectadas en las muestras, son productos empleados en anteriores intervenciones, proceden de la utilización de la técnica encáustica o corresponden a aglutinantes originales.

\section{3.- Discusión y conclusiones}

Del estudio de los escasos restos pictóricos conservados en el Apostolado de la Cámara Santa se deduce que la técnica pictórica utilizada ha sido la de pintura al óleo, mayoritariamente empleada a partir de la segunda mitad del siglo XVI.

Se conocen intervenciones de pintura al aceite sobre elementos de piedra labrada anteriores al siglo XIV en otras catedrales como la de Santa María de Vitoria (Cortazar et al., 2009: 173). En el pórtico de ésta, desde el siglo XV al $X X$, cuando se realizó la última policromía, los pigmentos han sido diluidos en aceite secante (de linaza) y en todos los casos donde la técnica empleada ha sido al óleo, se aprecia una secuencia estratigráfica concreta. Siempre se identifica una capa de imprimación, previa a la aplicación del color; bien elaborada con blanco de plomo, amarillos y tierras o con blanco de hueso mezclado con albayalde. Ambos tipos de imprimación han sido identificados en el grupo escultórico del apostolado, recubiertos en ocasiones por otros, aplicados en épocas posteriores y elaborados con albayalde y tierras rojas.

Estableciendo similitudes con el pórtico de la catedral de Vitoria, también se ha observado que la aplicación de láminas de oro está relacionada con la técnica al óleo, encontrándose la lámina metálica mate sin bruñir, dispuesta sobre una capa de asiento oleosa con carga de pigmentos. Estos últimos le dan consistencia y cuerpo, acelerando además su secado.

El análisis de las técnicas y pigmentos identificados en el Pórtico de la Gloria de la catedral de Santiago de Compostela, en fase de realización, permitirán establecer, si cabe, comparativas o correlaciones entre muestras pictóricas.

Paralelamente a los estudios de la cámara Santa, se ha procedido al análisis de micromuestras recogidas en la escultura de San Salvador de la catedral de Oviedo, encontrándose cierto paralelismo en el empleo del albayalde y las tierras rojas como base de preparación de otras capas pictóricas. También se ha detectado, en esta escultura, un recubrimiento de cera de abeja con resina de colofonia.

\section{Notas:}

[1] Las ceras son sólidos blandos que se usan mezclados con resinas para rebajar el punto de fusión de la mezcla adhesiva formada. Se utilizan como espesantes del óleo o como consolidantes y adhesivos, solas o mezcladas con resinas terpénicas y como aglutinantes en la encáustica. La encáustica emplea cera sola o mezclada con resina y se utiliza desde la antigüedad. Esta técnica, usada por griegos y romanos hasta la caída del Imperio, se aplica en caliente (Calvo, 1997: 84). En los siglos XVIII y XIX vuelve a ponerse de moda con los descubrimientos arqueológicos del momento (Ramer, 1977: 122). En su Historia natural (siglo I d. C.), Plinio la describe distinguiendo entre pintura a la cera y pintura al encausto (Giannini, 2008:51). Esta última consiste en extender una capa de cera sobre la pintura o el intonaco y después pulirla con trapos de lino. Su aplicación ha tenido fines estéticos para abrillantar la superficie de las pinturas.

\section{Bibliografía}

ARIAS, L. (2013). “Pérdida y conservación de la policromía del apostolado de la Cámara Santa. 70 Aniversario de su destrucción y posterior reconstrucción". Liño: Revista anual de historia del arte, n० 19 , págs. 9-22

CABRERA J.Ma. (2010). “La pátina como lenguaje de la piel en el patrimonio construido. Primeras referencias a la Santa Iglesia Catedral de Mallorca". Encuentro científico de conservación y restauración del patrimonio arquitectónico. Palma 11 - 13 febrero de 2010. pp $11-31$

CALVO, A. (1997). Conservación y Restauración. Materiales, técnicas y procedimientos De la A a la Z. Ediciones del Serbal. Cultura Artística

CORTÁZAR, M.; PARDO, D. y SANZ, D. (2009). Estudios y restauración del pórtico. Catedral de Santa María de Vitoria - Gasteiz. Fundación Catedral de Santa María.

CUENCA C. y HEVIA J. (2012). Estudios complementarios de la Cámara Santa de la Catedral de Oviedo, Planos. Documentos no 1- $\mathrm{n}^{\circ}$ 29.

CUESTA, J. y SANDOVAL, A. (1919). Cámara Santa. Memoria I, presentada al Excmo. Cabildo por los M.I. Sres. D. José Cuesta, Arcipreste y D. Arturo Sandoval, Canónigo Archivero. Oviedo, Imp. La Cruz. San Vicente, num. 10

CUESTA, J. y SANDOVAL, A. (1920). Cámara Santa. Memoria ll, presentada al Excmo. Cabildo por los M.I. Sres. D. José Cuesta, Arcipreste y D. Arturo Sandoval, Canónigo Archivero. Oviedo, Imp. La Cruz. San Vicente, num. 10

ESBERT, R. Ma y MARCOS, R. (1983). Las piedras de la catedral de Oviedo y su deterioración. Colegio Oficial de Aparejadores y Arquitectos Técnicos de Asturias.

ESBERT R.Ma y LOSADA J.Ma (2003). "Intervention criteria in masonry materials". Revista del Instituto de Patrimonio Histórico Espa$\tilde{n} \mathrm{ol}, \mathrm{n}^{\circ} 2$, 2003. P. 26

ESBERT, R.Ma; ROJO, A.; ALONSO F.J.; MATEOS, F.J.; ORDAZ, J. y 
VALDEÓN, L. (2004). "La conservación de la piedra del Claustro" en La restauración de la torre y el claustro de la catedral de Oviedo. Ed. Nobel, P. 284 - 299.

FERNÁNDEZ BUELTA, J. y HEVIA GRANDA, V. (1984). Ruinas del Oviedo primitivo. Instituto de estudios asturianos (I.D.E.A). Principado de Asturias. P. 90.

GARCÍA DE CASTRO, C. (2012). La reforma románica de la Cámara Santa de la catedral de San Salvador de Oviedo. Monumentos singulares del románico. Nuevas lecturas sobre formas y usos. Fundación Santa María la Real - C.E.R. pp. 43 - 89

GIANNINI, C. y ROANI, R. 2008. Diccionario de restauración y diagnóstico. Ed. Nerea.

GÓMEZ, Ma.L. (2004). La restauración. Examen científico aplicado a la conservación de obras de arte. Cuadernos Arte Cátedra. Instituto del Patrimonio Histórico Español.

GUTIÉRREZ, M. y TORRES, M. (1995). Geología de Oviedo. Descripción, recursos y aplicaciones. Ed. Paraíso. P 197.

GUTIÉRREZ M.; LUQUE C., PANDO L.A. (2012). Canteras históricas de Oviedo. Aportación al patrimonio arquitectónico. Hercules Astur Ediciones, pp. 20 - 21.

HEVIA OJANGUREN, P. (2006). “Oviedo: Centro artístico y cultural en la primera mitad del siglo XX. El entorno creativo de un escultor: Víctor Hevia". I Congreso de Estudios Asturianos. Tomo V. Comisión de Artes, Arquitectura y Urbanismo. Real Instituto de Estudios Asturianos, pp. $151-175$.

HEVIA OJANGUREN, P. Y HEVIA RODRÍGUEZ, V. (2006). “Víctor Hevia: El estudio y los talleres del artista. Claustro de San Vicente Cámara Santa - Sala Capitular". I Congreso de Estudios Asturianos. Tomo V.

MATEINNI, M y MOLES, A. 2001. La química en la restauración. NEREA. Junta de Andalucía - Consejería de Cultura - IAPH.

MENÉNDEZ PIDAL, L. (1960). “La Cámara Santa de Oviedo. Su destrucción y reconstrucción". Boletín del Instituto de Estudios Asturianos. $n^{\circ}$ XXXIX

PACHECO, F. (2001). El arte de la pintura. Cátedra, Madrid

PALOMINO DE CASTRO y VELASCO, A. (1947). El museo pictórico y la escala óptica. Aguilar. Madrid.

PARRILLA, Ma A. (2007). El arte de los pigmentos. Análisis histórico - artístico de su evolución a partir de los tratados españoles de Francisco Pacheco y Antonio Palomino. Tesis doctoral. Departamento Historia del Arte. Universitat de Valencia.

RAMER, B. (1977). "Encaustic paintings in the Petrie Museum: their techonology, examination and conservation". Studies in Conservation. London

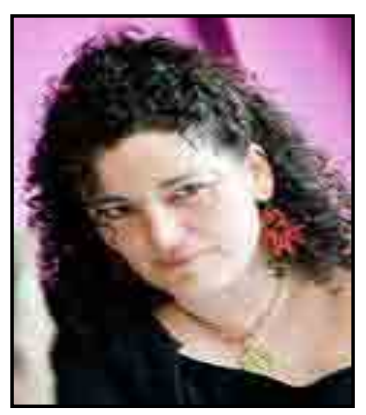

\section{Araceli Rojo Álvarez}

Araceli Rojo / GEA asesoría geológica

correo@geaasesoría geológica.com

Ha obtenido su licenciatura en la Geología en 1996 y su grado (Tesis de licenciatura) en el año 2000, ambas por la Universidad de Oviedo, habiendo realizado los cursos de doctorado entre los años 1996 - 1998. Ha participado en 9 proyectos de investigación, ha publicado 26 documentos científicos en revistas nacionales e internacionales y ha asistido a 12 congresos relacionados con diversos aspectos de la geología. Ha realizado labores docentes impartiendo clases prácticas de Petrología Aplicada y Rocas Industriales en la Facultad de Geología de la Universidad de Oviedo durante los años1997 - 2000. Ha participado en 4 cursos de verano de la Universidad de Oviedo (2003, 2005, 2006 y 2012), Ilevando la dirección/coordinación del organizado en 2012. Ha impartido docencia en un curso experto de la Universidad de Oviedo (2007 - 2008) y en 3 másteres organizados por la Fundación Laboral de La Construcción de Asturias $(2011-2012)$.

Es uno de los socios fundadores de GEA asesoría geológica, desarrollando su actividad profesional en esta empresa desde 2001, con una experiencia 12 años en diversos campos de geología como la petrofísica, la caracterización de materiales, la restauración, la geotécnica, el I+D+i, y la formación. Como miembro de GEA ha participado en más de 200 proyectos ligados a la caracterización de materiales aplicados al patrimonio arquitectónico, la construcción e ingeniería. 


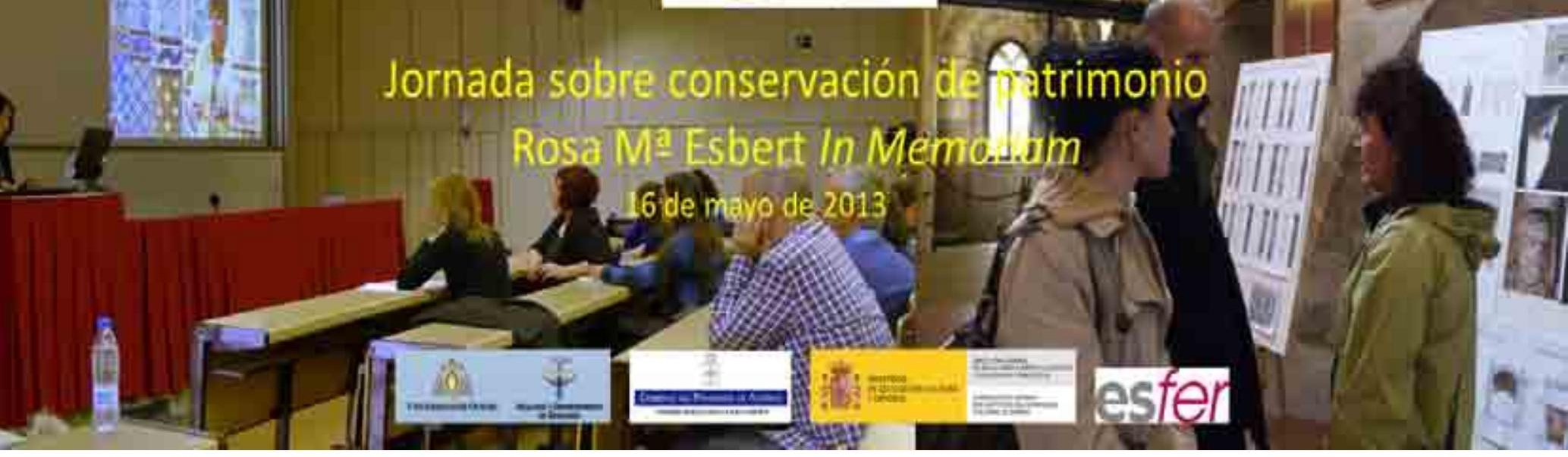

\section{Estudio higrotermométrico en la Cámara Santa de la Catedral de Oviedo.}

\section{Félix Javier Mateos Redondo}

Resumen: La Cámara Santa presenta una serie de patologías, muchas de las cuales se encuentran en mayor o en menor medida relacionadas con la presencia de humedad. Las sucesivas pérdidas de las pátinas históricas aplicadas sobre las superficies pétreas del conjunto escultórico, claramente relacionadas con la acción del agua líquida o en forma de vapor, están provocando una aceleración en la degradación del conjunto. Ante esta situación, y de cara a su futura intervención, se ha realizado un estudio de humedades que ha permitido conocer el estado higrotermométrico de la Cámara Santa, y plantear una serie de medidas correctoras encaminadas a eliminar o minimizar los mecanismos de deterioro relacionados con la presencia de dicha humedad.

Palabras clave: conservación preventiva, piedra, humedad, temperatura, condensación, higrotermométrico, alteración, punto de rocío

\section{Hygrothermometrical Study in the Holy Chamber of Oviedo Cathedral.}

Abstract: The Holy Chamber presents a series of pathologies, many of them related to the humidity presence. The successive losses of historical patinas applied on the sculpture set, clearly related to the action of the liquid or vapor water form, are causing an acceleration in the degradation of the sculptures. In this situation, and in relation to its future intervention, a humidity study has been performed that has allowed to know the Holy Chamber hygrothermometrical conditions, and to propose a series of correctives measures oriented to eliminate or to diminish the mechanisms of deterioration related to the presence of humidity.

Key words: preventive conservation, stone, humidity, temperature, condensation, hygrothermometrical conditions, alteration, dew point

\section{Objetivos}

El objetivo del estudio ha sido determinar los principales focos de humedad presentes en el interior de la Cámara Santa, estableciendo en la medida de lo posible sus orígenes. Se ha prestado especial atención al conjunto escultórico, donde los problemas se hacen patentes a simple vista.

Para alcanzar dicho objetivo y, por un periodo de 12 meses (ciclo climático anual), se han llevado a cabo en el interior de la Cámara Santa, mediciones en continuo de temperatura y humedad ambiental, temperatura y contenido en humedad de la superficie de los materiales pétreos, y el cálculo de las temperaturas de rocío.

\section{Metodología}

Con el fin de monitorizar las condiciones ambientales existentes en el interior de la Cámara Santa se instalaron un total de 4 equipos de medida Data Logger Testo 177-H1, ocupando diferentes orientaciones y alturas (Figs. 1 y 2). Cada uno de estos equipos registra la temperatura y la humedad relativa del ambiente en el entorno de ubicación del aparato. Con estos dos datos el equipo determina directamente la temperatura del punto de rocío " $\mathrm{Td}^{\text {", }}$ utilizando para ello transformaciones psicométricas. Finalmente, el equipo lleva conectado a su canal externo una sonda de temperatura superficial cuyos datos son igualmente registrados y almacenados por el Data-Logger. 
De la misma manera, la temperatura de las fábricas y del propio apostolado ha sido monitorizada mediante la utilización de un total de 24 sondas de temperatura superficial (Figs. 1 y 2), que fueron distribuidas abarcando los 4 muros de la Cámara Santa, diferentes alturas (suelo hasta el techo) y los distintos soportes (muros cargados de mortero y soportes pétreos). Las sondas se encuentran conectadas a 5 equipos Data Logger Testo 177-T4 (4 sondas por equipo), correspondiendo las 4 sondas restantes con los canales
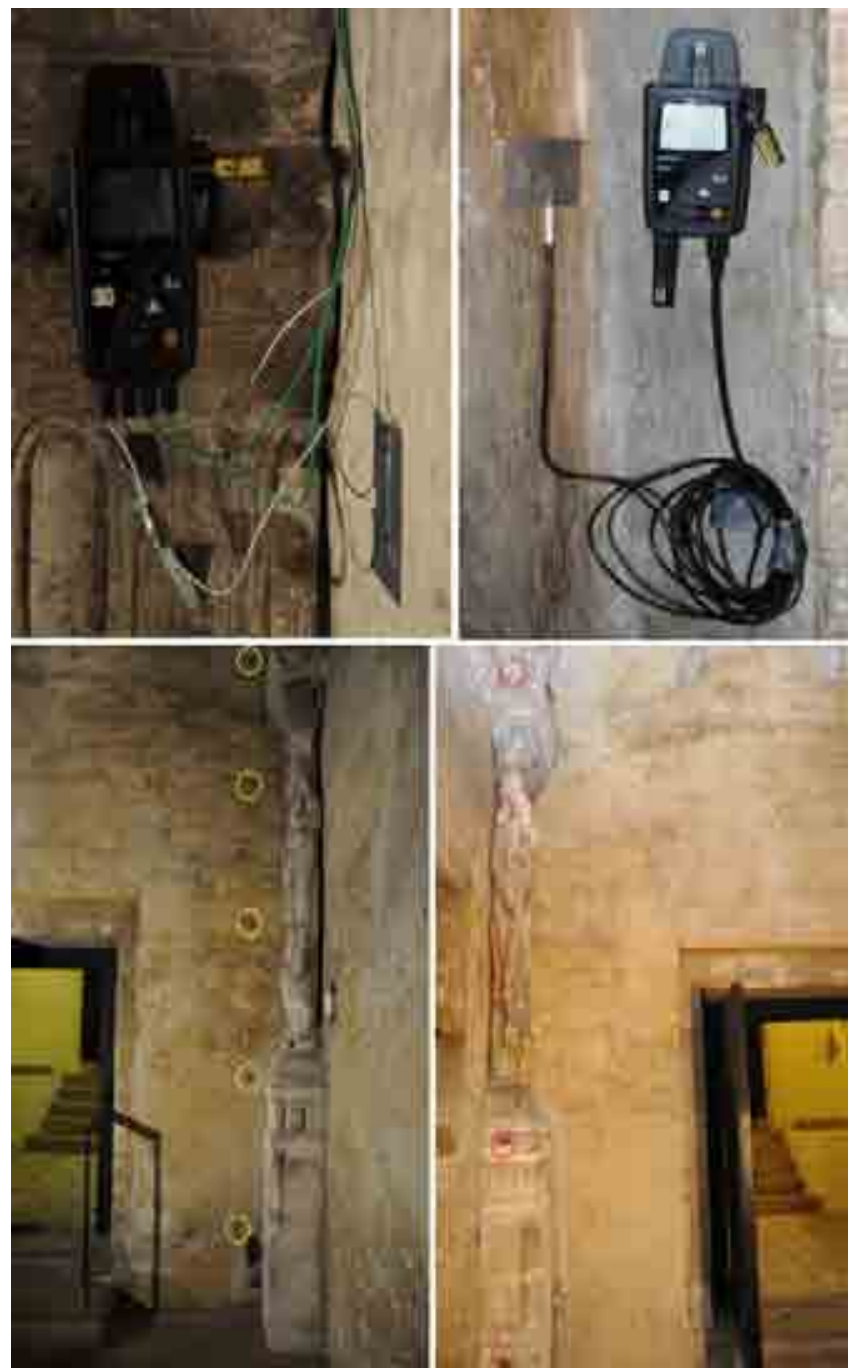

Figura 1. Arriba: Equipos instalados en la Cámara Santa de la catedral de Oviedo. Izquierda; Data Logger Testo177-T4 que dispone de cuatro sondas para la medida de la temperatura superficial. Derecha; Data Logger Testo177-H1 para la medición de la temperatura y humedad relativa del ambiente. Dispone adicionalmente de una sonda para la medida de la temperatura superficial. Abajo: Detalle de dos de los 5 perfiles verticales de temperatura superficial monitorizados en la Cámara Santa. A la izquierda se enmarcan en un círculo amarillo las cinco sondas de temperatura superficial que a diferentes alturas fueron colocadas en el muro Oeste. A la derecha, perfil vertical constituido por cinco puntos de medida (círculos rojos), en esta ocasión, sobre uno de los apóstoles (Santo Tomás), con el fin de controlar los efectos que la humedad puede generar en estos elementos exentos de los muros y de las posibles aportaciones de humedad ligados a éstos.
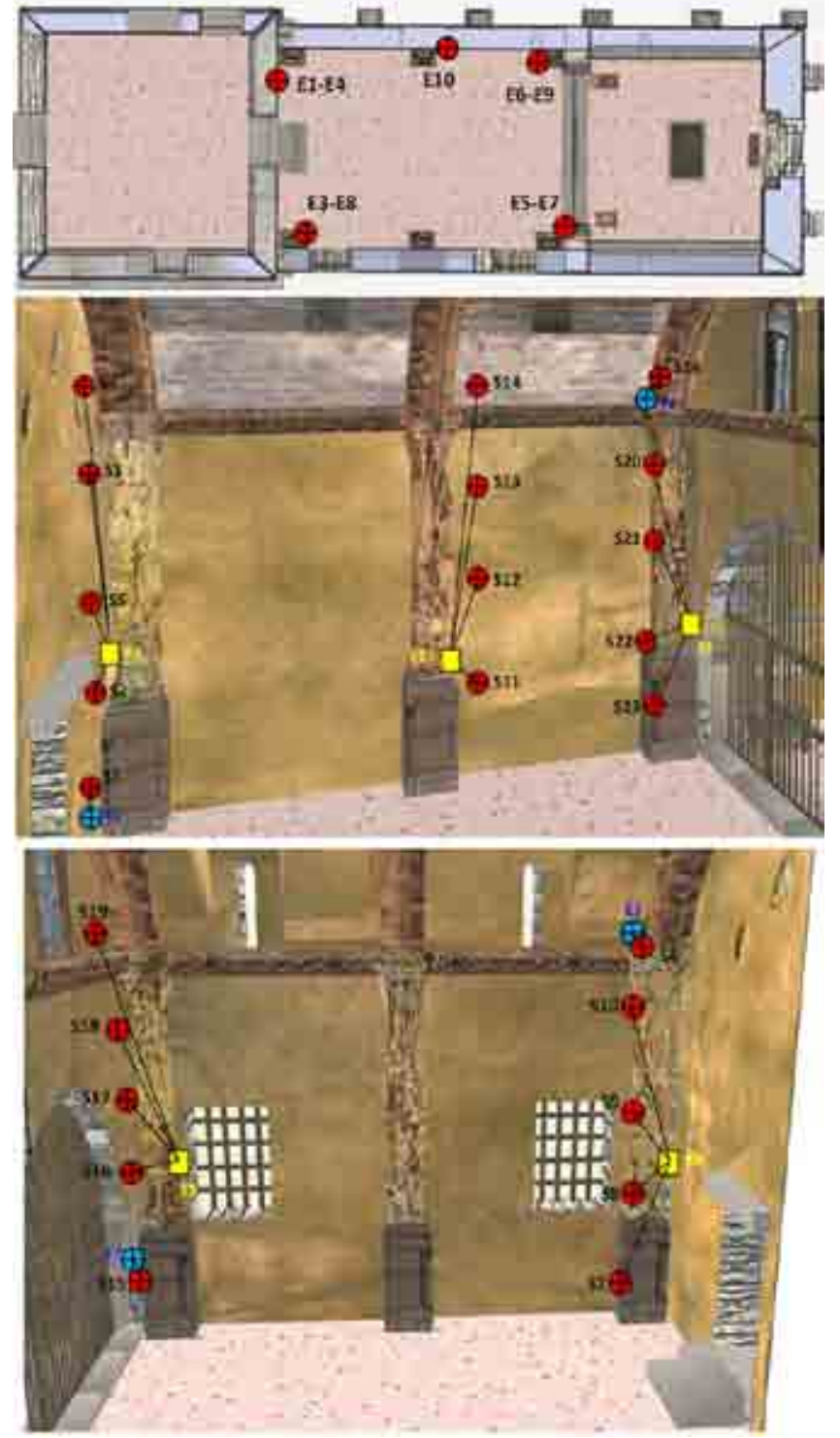

Figura 2. Localización de las diferentes sondas instaladas en la Cámara Santa. Arriba: Localización sobre planta de la ubicación de los diferentes Data-Logger instalados. Medio: Localización sobre reconstrucción virtual 3D (tomado de F.J. Borge Cordovilla) de los distintos equipos y sondas colocadas en el muro Norte y Oeste de la Cámara Santa. Uno de los perfiles verticales de sondas de temperatura superficial fue ubicado en el trasdós de San Andrés. Abajo: Localización sobre reconstrucción virtual 3D (tomado de F.J. Borge Cordovilla)de los diferentes Data Logger instalados en el muros Sur y en el de separación del Camarín. En amarillo se identifican los Data-Logger de los equipos 177-T4 que registran los datos procedentes de 4 sondas de temperatura superficial. En azul se identifican los equipos Data-Logger 177-T1 que además de tomar datos de humedad, temperatura ambiental y punto de rocío, registra los datos medidos por una sonda de temperatura superficial. Uno de los perfiles verticales de sondas de temperatura superficial fue ubicado en el trasdós de Santo Tomás.

externos de los equipos Data-Logger 177-H1 de control ambiental anteriormente descritos (1 sonda por equipo). 
Ambos equipos han registrado y almacenado en su memoria interna los datos obtenidos, procediendo a una toma de datos cada 5 minutos.

La medición del contenido en humedad superficial ha sido llevada a cabo sobre las fábricas y elementos escultóricos (apostolado) existentes en el interior de la Cámara Santa. Se diseñó una malla de 24 estaciones de medida, distribuidas a modo de 5 perfiles verticales (Fig. 3), coincidentes con las estaciones de temperatura superficial. La altura máxima alcanzada por esta malla se situó próxima a los 5,5 metros.

El principio de funcionamiento del instrumento es la medición por métodos no destructivos de una impedancia. El aparato de medida dispone de 2 electrodos coplanarios. Durante el período de medición una señal de baja frecuencia es transmitida a la superficie del material para medir el cambio en la impedancia provocado por la presencia de humedad.
La toma de datos ha sido realizada de manera mensual, procediendo a la medición de la humedad superficial de las fábricas y del apostolado una vez cada 30 días aproximadamente. Se anotan además las condiciones climatológicas existentes el día de medición y los días previos.

\section{Resultados obtenidos}

Los datos recogidos durante los 12 meses de estudio han sido procesados, agrupados por meses naturales y orientación de los muros, analizados estadísticamente y finalmente graficados, a fin de facilitar posteriores labores de interpretación. Fundamentalmente se han elaborado: a) Gráficos mensuales individuales y proyecciones conjuntas de $\mathrm{T}^{\mathrm{a}}$ ambiental, humedad relativa ambiental y $\mathrm{T}^{\mathrm{a}}$ del punto de rocío, a partir de los datos registrados por los distintos Data Logger Testo 177-H1 (Fig. 4); b) Gráficos mensuales individuales de $T^{a}$ superficial vs Ta $^{\mathrm{a}}$ del punto de rocío (monitorización de los episodios de condensación), a par-

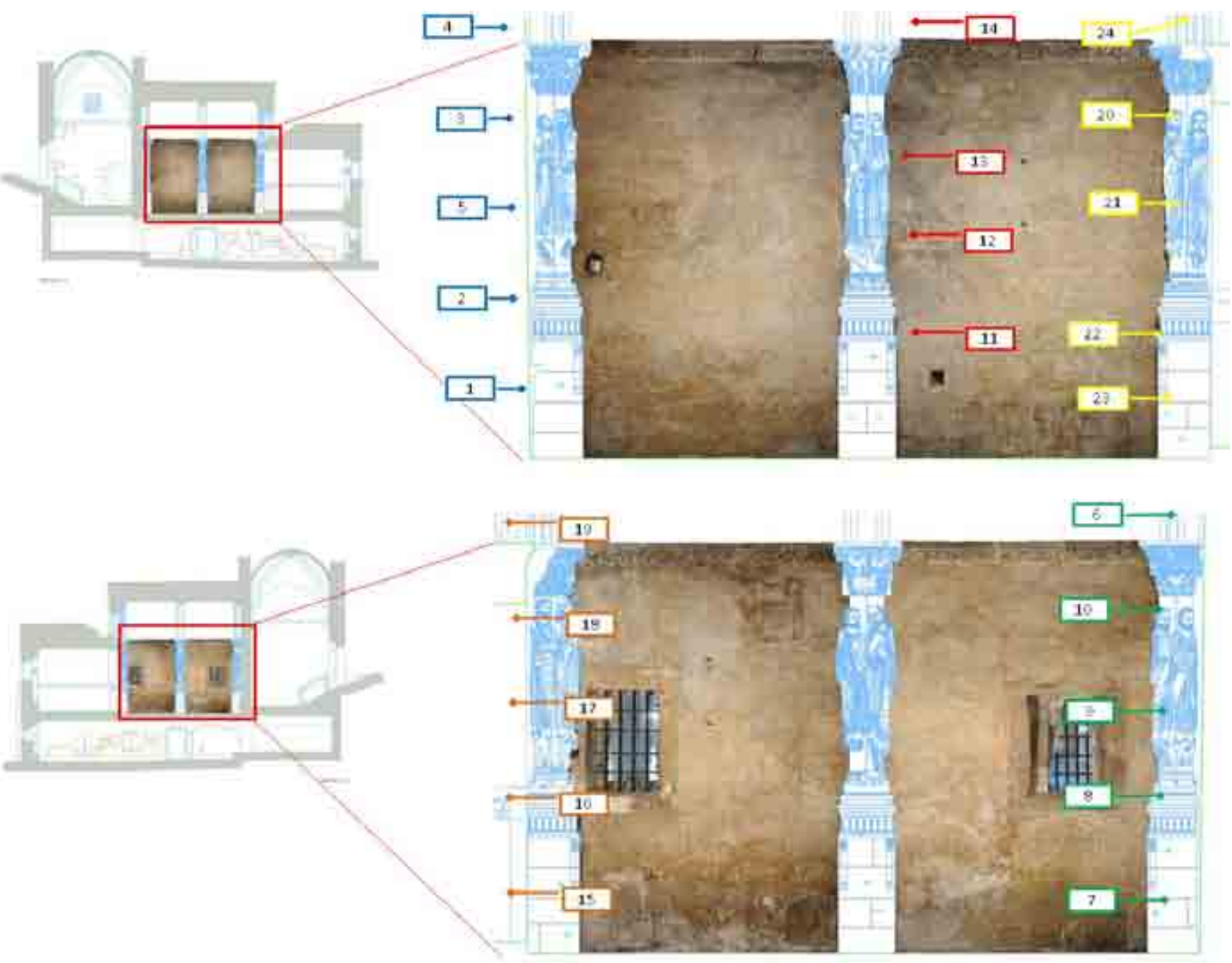

Figura 3. Arriba: Localización de las 14 estaciones de medida de la humedad superficial establecidas en el muro Norte y Oeste de la Cámara Santa, que han sido distribuidas en 3 perfiles verticales. Abajo: Localización de las 10 estaciones de medida de la humedad superficial establecidas en el muro Sur y Este (al Camarín) de la Cámara Santa, que han sido distribuidas en 2 perfiles verticales 


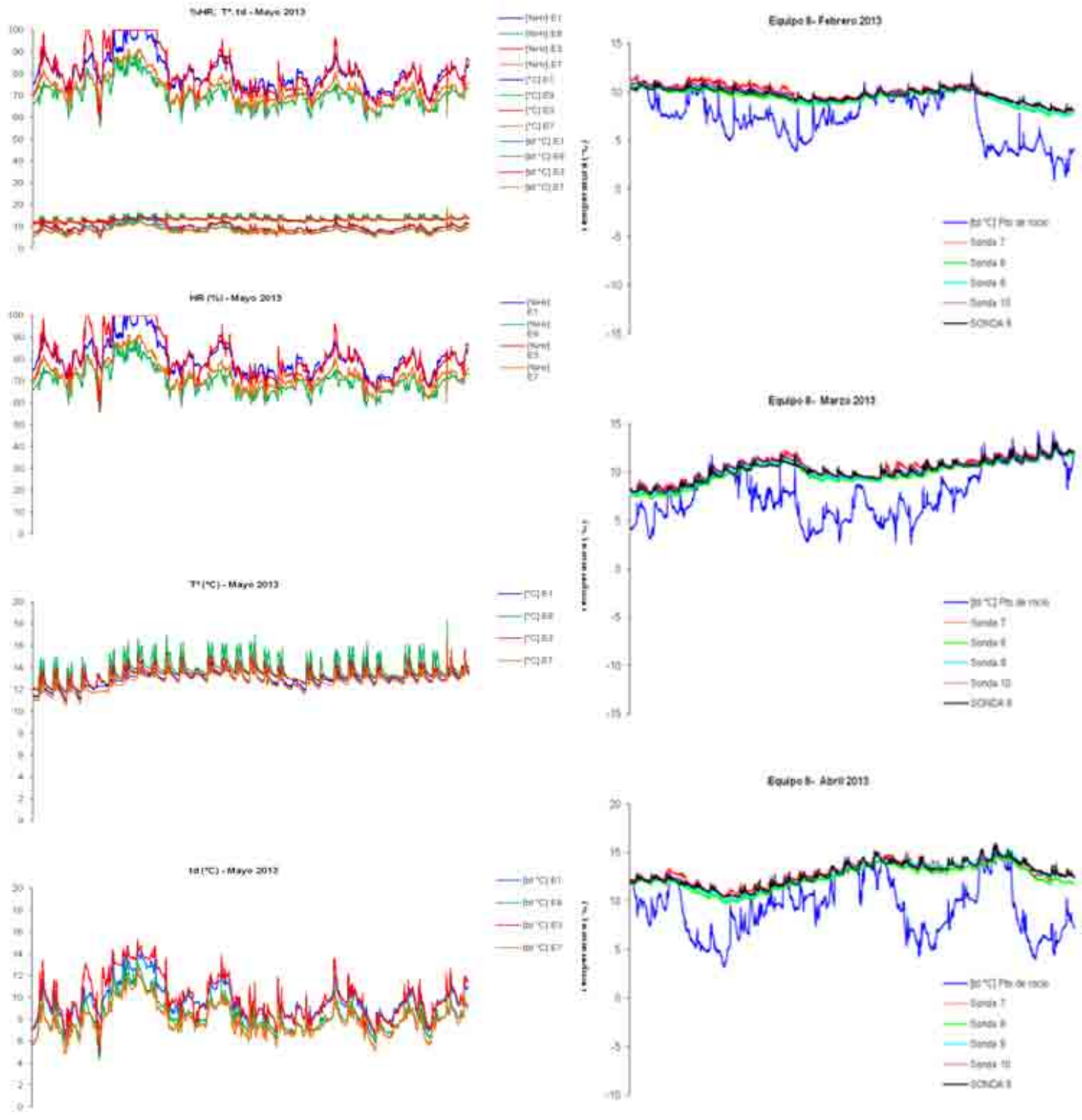

Figura 4. Ejemplo de los centenares de gráficos elaborados a partir de los datos recopilados en la Cámara Santa durante los 12 meses de estudio. Izquierda: Gráficas de humedad ambiental (\%), temperatura ambiental $\mathrm{Ta}^{\circ}\left({ }^{\circ} \mathrm{C}\right)$ y punto de rocío " $\mathrm{Td}$ " $\left({ }^{\circ} \mathrm{C}\right)$ en el interior de la Cámara Santa correspondientes al mes de mayo de 2013 . Derecha: Gráficas de temperatura superficial $\left({ }^{\circ} \mathrm{C}\right)$ vs punto de rocío $\left(\mathrm{Td}{ }^{\circ} \mathrm{C}\right)$ a lo largo de los meses de Febrero, Marzo y Abril de 2013 correspondiente a uno de los puntos de control del muro Sur interior.

tir de los datos registrados por los distintos Data Logger Testo 177-H1 y Testo 177-H4 (Fig. 4) y; c) Tablas de humedad superficial de las superficies pétreas (Tabla I).

\section{Análisis e interpretación de los resultados obtenidos}

La monitorización de las condiciones ambientales en el interior de la Cámara Santa de la Catedral de Oviedo, y el posterior análisis e interpretación de los datos recopilados a lo largo de 12 meses, ha puesto de manifiesto la existencia de abundantes episodios donde las temperaturas de las superficies pétreas son inferiores al punto de rocío, lo que se traduce en la aparición de fenómenos de condensación de agua sobre fábricas y apostolado.
En relación a la distribución temporal de estos fenómenos de condensación, cabe citar las siguientes observaciones:

- Se ha podido comprobar que los fenómenos de condensación en el interior de la Cámara Santa tienen lugar en cualquier mes de año (Tabla II), si bien, su manifestación es más frecuente a lo largo de los meses de primavera y verano.

- De manera general la condensación de agua sobre las superficies pétreas tiene lugar durante el día (10$11 \mathrm{~h}$ a 19-20h predominantemente), en relación con un rápido ascenso de las temperaturas diurnas tras un descenso nocturno más o menos importante, mientras que, las superficies pétreas, que igualmente han sufrido un descenso 


\begin{tabular}{|c|c|c|c|c|c|c|c|c|c|c|c|c|c|}
\hline & & \begin{tabular}{|l|} 
Fecha \\
Hora \\
\end{tabular} & $\begin{array}{c}12 / 11 / 2012 \\
11: 00\end{array}$ & $\begin{array}{c}27 / 12 / 2012 \\
13: 00\end{array}$ & $\begin{array}{c}30 / 01 / 2013 \\
12: 15\end{array}$ & $\begin{array}{c}11 / 03 / 2013 \\
11: 00\end{array}$ & $\begin{array}{c}19 / 04 / 2013 \\
14: 00\end{array}$ & $\begin{array}{c}30 / 05 / 2013 \\
11: 00\end{array}$ & $\begin{array}{c}04 / 07 / 2013 \\
10: 30\end{array}$ & $\begin{array}{c}13 / 08 / 2013 \\
11: 00\end{array}$ & $\begin{array}{c}17 / 09 / 2013 \\
11: 00\end{array}$ & $\begin{array}{c}24 / 10 / 2013 \\
11: 00\end{array}$ & $\begin{array}{c}30 / 11 / 2013 \\
10: 30\end{array}$ \\
\hline Logger & Altura (cm) & SONDA & \multicolumn{11}{|c|}{$\begin{array}{ll}\text { Humedad relativa (\%) } \\
\end{array}$} \\
\hline E1 & 53 & Abajo 1 & 13 & 17 & 14 & 20 & 15 & \begin{tabular}{|r|}
15 \\
\end{tabular} & 16 & 17 & 14 & 17 & 16 \\
\hline \multirow{4}{*}{ E4 } & 150 & & 13 & 15 & 15 & 15 & 16 & 14 & 20 & 18 & 18 & 15 & 17 \\
\hline & 254 & 5 & 10 & 13 & 18 & 11 & 9 & 9 & 11 & 13 & 10 & 12 & 11 \\
\hline & 356 & & 11 & 8 & 12 & 13 & 13 & 12 & 17 & 13 & 14 & 14 & 12 \\
\hline & 453 & Arriba 4 & 10 & 11 & 12 & 14 & 12 & 11 & 16 & 15 & 13 & 13 & 12 \\
\hline \multirow{4}{*}{ E10 } & 141 & Abajo 11 & 12 & 20 & 24 & 17 & 17 & 21 & 24 & 25 & 25 & 25 & 24 \\
\hline & 236 & 12 & 18 & 20 & 23 & 22 & 19 & 22 & 30 & 30 & 23 & 22 & 20 \\
\hline & 326 & & 20 & 17 & 20 & 15 & 18 & 19 & 25 & 24 & 20 & 18 & 17 \\
\hline & 455 & Arriba 14 & 21 & 10 & 10 & 14 & 11 & 12 & 16 & 13 & 9 & 15 & 13 \\
\hline \multirow{4}{*}{ E6 } & 53 & Abajo 23 & 17 & 18 & 21 & 22. & 17 & 15 & 25 & 22 & 20 & 24 & 21 \\
\hline & 154 & 22 & 18 & 14 & 16 & 19 & 14 & 17 & 20 & 25 & 19 & 19 & 20 \\
\hline & 254 & 21 & 23 & 17 & 18 & 19 & 16 & 18 & 24 & 23 & 22 & 24 & 21 \\
\hline & 348 & 20 & 20 & 20 & 19 & 21 & 19 & 22 & 25 & 22 & 21 & 22 & 20 \\
\hline E9 & 440 & Arriba 24 & 16 & 14 & 14 & 17 & 11 & 19 & 24 & 23 & 14 & 17 & 17 \\
\hline & & \begin{tabular}{|l|} 
Fecha \\
\end{tabular} & $12 / 11 / 2012$ & $27 / 12 / 2012$ & \begin{tabular}{|l|}
$30 / 01 / 2013$ \\
\end{tabular} & \begin{tabular}{|l|}
$11 / 03 / 2013$ \\
\end{tabular} & $19 / 04 / 2013$ & $30 / 05 / 2013$ & \begin{tabular}{|l|}
$04 / 07 / 2013$ \\
\end{tabular} & $13 / 08 / 2013$ & $17 / 09 / 2013$ & \begin{tabular}{|l|}
$24 / 10 / 2013$ \\
\end{tabular} & $30 / 11 / 2013$ \\
\hline & & Hora & 11:00 & 13:00 & 12:15 & \begin{tabular}{|c|}
$11: 00$ \\
\end{tabular} & 13:45 & \begin{tabular}{|l|}
$11: 00$ \\
\end{tabular} & \begin{tabular}{|c|}
$10: 30$ \\
\end{tabular} & 10:30 & \begin{tabular}{|l|}
$11: 00$ \\
\end{tabular} & \begin{tabular}{|c|}
$11: 00$ \\
\end{tabular} & $10: 30$ \\
\hline Logger & Altura $(\mathrm{cm})$ & SONDA & \multicolumn{8}{|c|}{ umedad relativa (\%) } & & & \\
\hline \multirow{4}{*}{ E8 } & 49 & Abajo 7 & 13 & 14 & 19 & 15 & 14 & 17 & 25 & 19 & 17 & 15 & 15 \\
\hline & 155 & 8 & 18 & 17 & 17 & 17 & 15 & 17 & 19 & 22 & 16 & 17 & 19 \\
\hline & 238 & 9 & 9 & 10 & 11 & 14 & 9 & 13 & 16 & 20 & 10 & 11 & 14 \\
\hline & 348 & 10 & 16 & 17 & 11 & 16 & 16 & 19 & 22 & 23 & 15 & 15 & 15 \\
\hline E3 & 444 & Arriba 6 & 13 & 14 & 14 & 12. & 11 & 15 & 17 & 18 & 14 & 14 & 15 \\
\hline E7 & 48 & Abajo 15 & 18 & 9 & 11 & 11 & 7 & 9 & 14 & 13 & 10 & 12 & 9 \\
\hline \multirow{4}{*}{ E5 } & 177 & 16 & 10 & 9 & 11 & 12 & 8 & 10 & 16 & 13 & 12 & 11 & 13 \\
\hline & 275 & 17 & 16 & 21 & 21 & 21 & 16 & 18 & 24 & 22 & 20 & 19 & 17 \\
\hline & 348 & & 14 & 15 & 16 & 16 & 16 & 14 & 22 & 18 & 14 & 15 & 13 \\
\hline & 451 & Arriba 19 & 14 & 13 & 14 & 14 & 11 & 16 & 19 & 15 & 14 & 14 & 17 \\
\hline
\end{tabular}

Tabla I. Valores de humedad superficial (WME-\%-) obtenidos a lo largo de los 12 meses de monitorización para cada uno de los 5 perfiles establecidos; 3 en el muro norte (arriba) y 2 en el muro Sur (abajo).

\begin{tabular}{|c|c|c|c|c|c|c|c|c|c|c|c|c|c|}
\hline & \multicolumn{13}{|c|}{ MURO NORTE } \\
\hline & Nov. & Dic. & Ene. & Feb. & Mar. & Abri. & Mave & Jun. & Jul. & Ago. & Sep. & Oct. & Nov. \\
\hline E1-E4 & - & - & 1 & - & 7 & 2 & 6 & 10 & 12 & 2 & - & 3 & 1 \\
\hline E10 & - & - & 2 & 1 & 7 & - & 4 & 4 & 10 & 2 & - & 3 & 1 \\
\hline \multirow[t]{3}{*}{ E6-E9 } & - & - & - & - & 1 & - & 1 & - & - & - & - & - & - \\
\hline & \multicolumn{12}{|c|}{ MURO SUR } & \\
\hline & Nov. & Dic. & Ene. & Feb. & Mar. & Abri. & Mays & Jun. & Jul. & Ago. & Sep. & Oct. & Nov. \\
\hline E5-E7 & - & - & - & - & - & - & - & - & - & - & - & - & - \\
\hline E3-E8 & 8 & 6 & 9 & 15 & 15 & 7 & 8 & 13 & 15 & 4 & 3 & 5 & 3 \\
\hline
\end{tabular}

Tabla II. Número aproximado de días por mes monitorizado en el que se han detectado fenómenos de condensación en cada uno de los equipos instalados sobre los materiales constructivos de la Cámara Santa.

térmico durante la noche, elevan su temperatura de una manera mucho más lenta ya que se encuentran en el interior protegidas de la acción de los rayos solares, situándose por debajo del punto de rocío ambiental.

Este salto térmico es más importante durante la primavera y más aún durante el verano, razón por la cual, en estas dos estaciones se concentran el mayor número de días de condensación. Destaca igualmente la ocurrencia que ha tenido lugar en la última semana de marzo, coincidiendo con una semana muy calurosa. Este hecho confirma el potencial aumento de los fenómenos de condensación durante episodios de altas temperaturas ambientales en el exterior.
Sin embargo, durante estos periodos anteriormente citados, donde aumenta la frecuencia de los días en que se produce condensación, ésta puede tener lugar durante todo el día de manera continuada, incluso llegando a prolongarse varios días.

A los aspectos térmicos anteriormente descritos, hay que sumar la importante acción de la humedad ambiental que, como se explicará más adelante, es muy elevada en determinadas zonas de la Cámara Santa, contribuyendo notablemente a la generación y focalización de las condensaciones en estas zonas más húmedas.

Finalmente, cabe citar, que se ha podido compro- 
bar tanto en vivo, como con el análisis detallado de los datos obtenidos, que durante las visitas turísticas a la Cámara Santa, y sobre todo, cuando se realizan visitas secuenciales de varios grupos numerosos en un periodo concentrado de tiempo (1-2 horas), se produce un aumento de la humedad (8-10\%) y la temperatura $\left(3-4^{\circ} \mathrm{C}\right)$ en el interior de la Cámara Santa, generando a su vez un aumento instantáneo del punto de rocío.

En relación a la distribución espacial de estos fenómenos de condensación, cabe citar las siguientes observaciones:

- $\quad$ Se concentran fundamentalmente en la esquina Suroeste de la Cámara Santa (muro Sur), coincidiendo con los apóstoles Santo Tomás y San Bartolomé, lo que justificaría en gran medida el deterioro observado en éstos (Fig. 5). En esta zona, se han detectado procesos de condensación de agua durante todos los meses del año, alcanzando en el periodo estival ocurrencias superiores a 15 días/mes donde en mayor o menor medida se ha producido condensación. Por su parte, la esquina Sureste (muro Sur), no muestra ninguna evidencia de condensación de agua sobre las superficies pétreas lo que pone de manifiesto una clara zonificación ambiental del espacio interior de la Cámara Santa, tal y como se describe más adelante.

- $\quad$ En el muro Norte, aunque los episodios de condensación han acontecido con una frecuencia ligeramente menor, han de considerarse igualmente importantes. De manera similar al caso anterior, se han concentrado predominantemente en la esquina Noroeste, y en este caso en la zona central del muro, pudiendo considerarse anecdóticos las manifestaciones de condensación en la esquina Noreste.

En ambos casos, se puede afirmar que los fenó- menos de condensación han sido observados para cualquiera de las alturas estudiadas.

- $\quad$ La humedad medida en los muros es en general baja, dada la naturaleza de los materiales constructivos y la presencia de acabados o tratamientos superficiales impermeabilizantes (pátinas, ceras y veladuras). En las superficies desnudas, donde los fenómenos de alteración han provocado la saltación de estos acabados superficiales, los valores de humedad superficial han sido medidos puntualmente, comprobando que son mucho más elevados.

Cabe destacar un aumento relativamente importante en los valores de humedad superficial coincidiendo con los periodos donde los fenómenos de condensación ocurren de manera continuada durante varios días (verano), demostrando una vez más, la incidencia de los fenómenos de condensación con la humectación de las fábricas y su consiguiente alteración.

En relación a la zonificación ambiental de la Cámara Santa, cabe citar las siguientes observaciones:

- $\quad$ En base a los valores medios en humedad ambiental, temperatura ambiental y punto de rocío se puede afirmar que, pese a la pequeña superficie y volumen del interior de la Cámara Santa, existe una importante zonificación ambiental (Fig. 6).

- Las esquinas Suroeste y Noroeste, zonas mayor condensación, coinciden con las zonas con mayor humedad, detectándose frecuentes periodos prolongados de humedad ambiental del $100 \%$ (días a semanas).

En estas mismas áreas se han medido los puntos de rocío más elevados, lo que facilita la aparición de fenómenos de

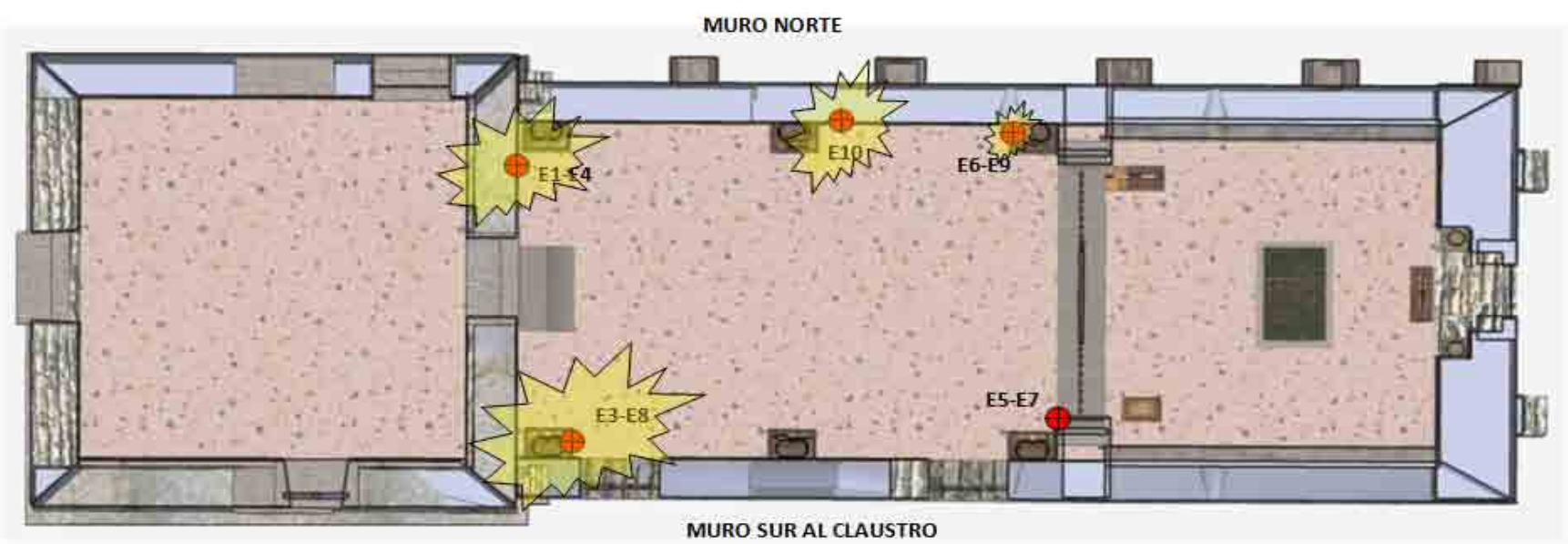

Figura 5. Localización en planta de las zonas donde se han detectado fenómenos de condensación durante los 12 meses de monitorización. El tamaño de la simbología indica la importancia del fenómeno. Las condensaciones detectadas en la esquina Suroeste han tenido lugar en todos los meses, siendo frecuentes los períodos de condensación de 24 horas que se prolongan durante 4-5 días. Destaca igualmente la relevancia de las condensaciones observadas en la esquina Noroeste y zona central del muro Norte, con importantes episodios de condensación en primavera y verano. 

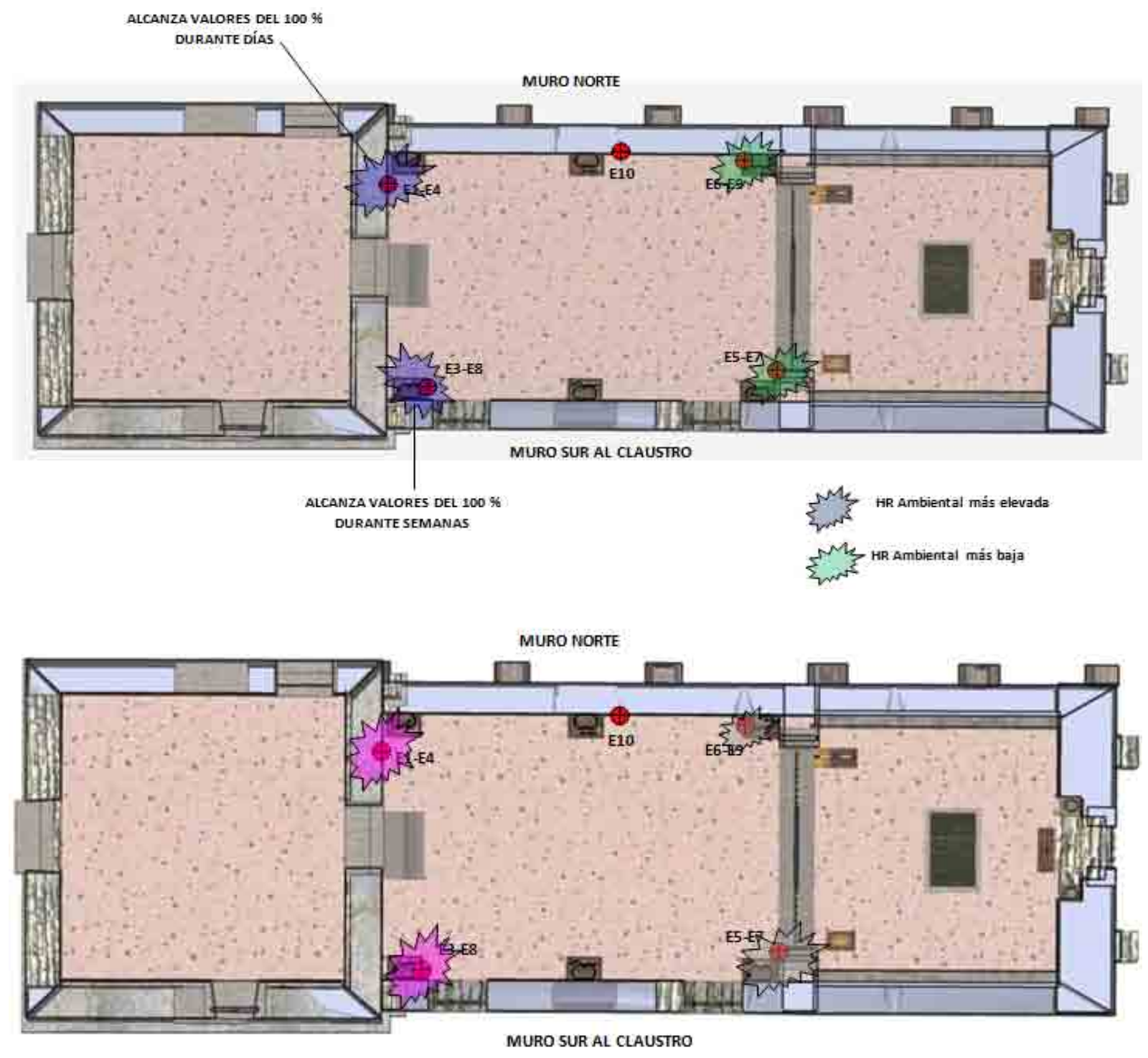

int más bajo I

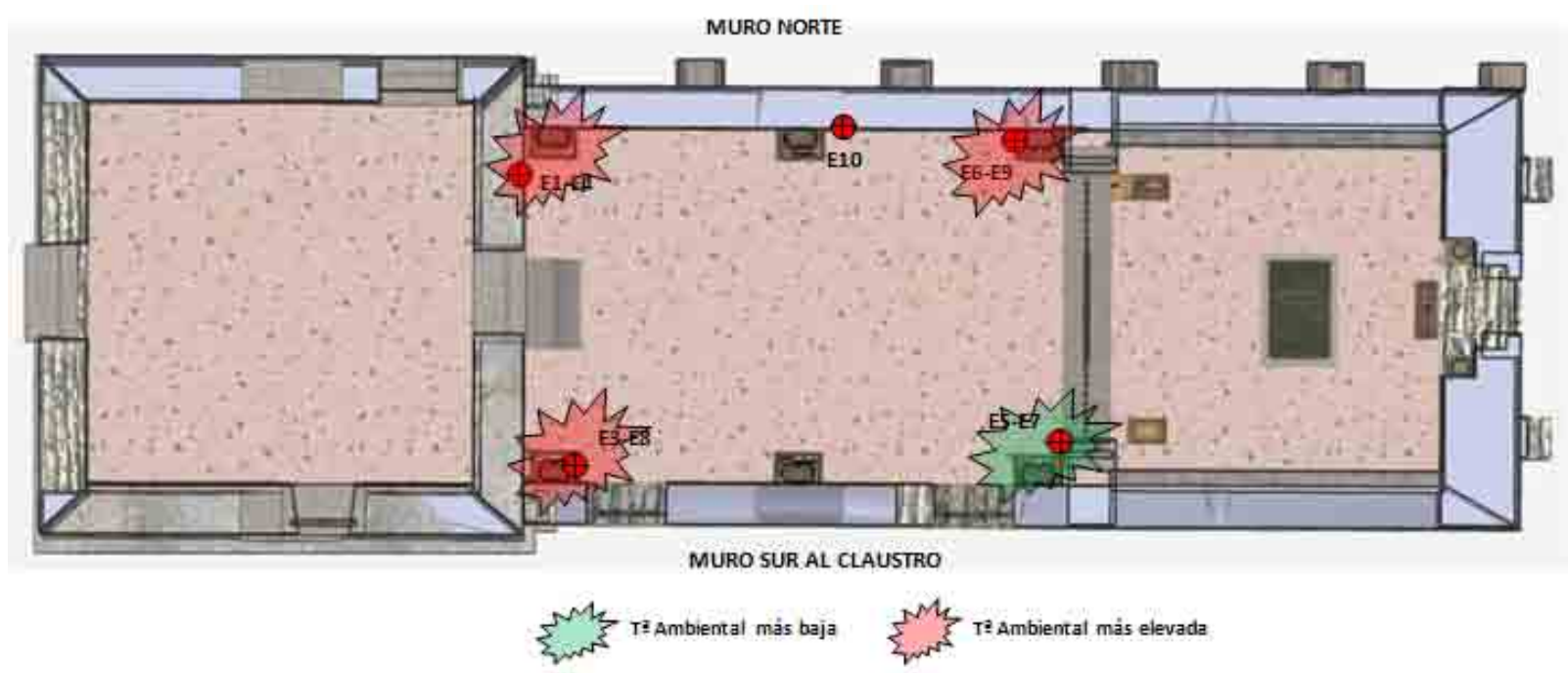

Figura 6. Localización en planta de las zonas donde, durante los 12 meses de monitorización, se detectan los mayores/menores valores de humedad ambiental media (arriba), temperatura ambiental media (medio) y puntos de rocío medio (abajo). 

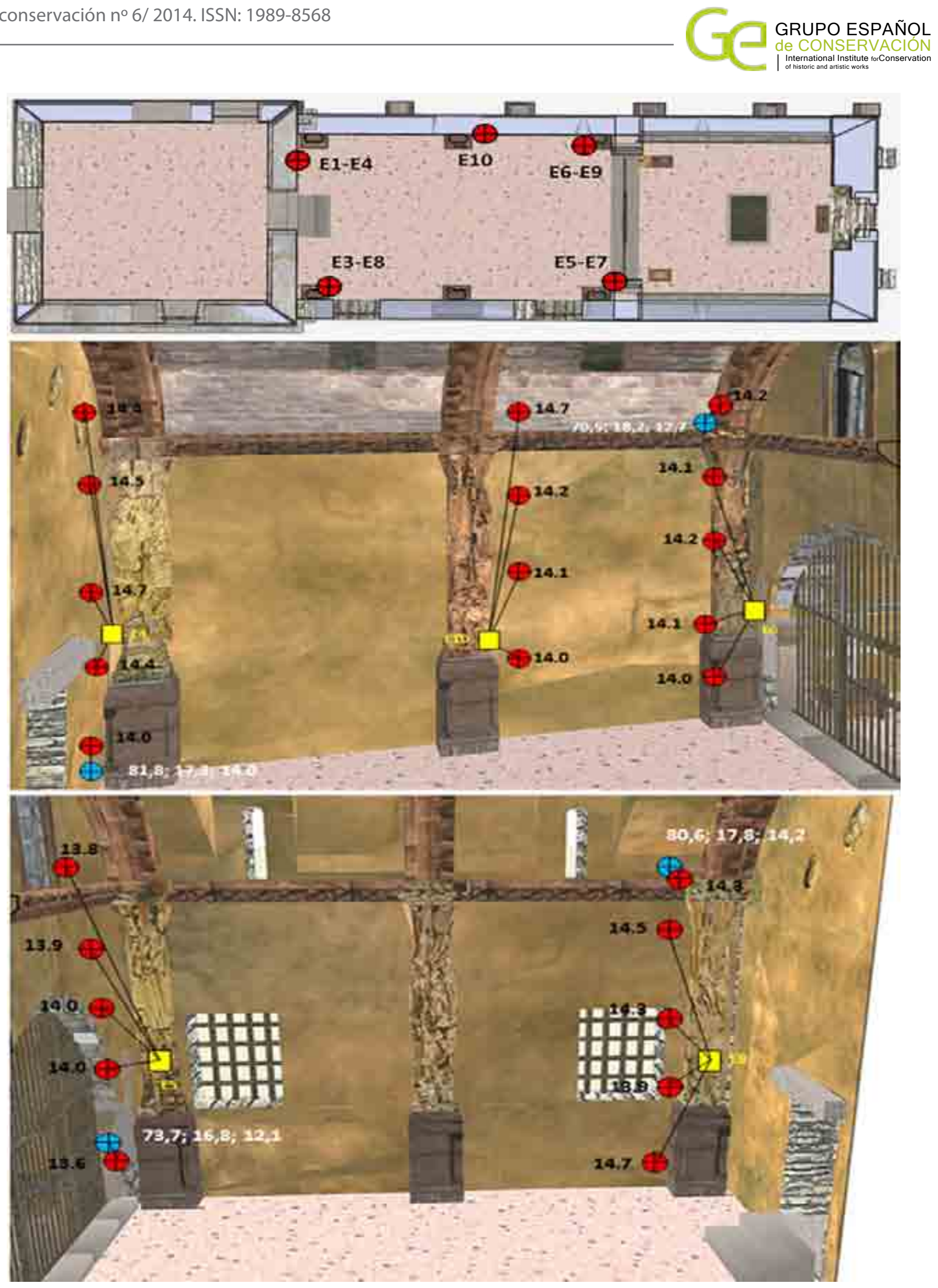

Figura 7. Valores medios obtenidos para los diferentes parámetros monitorizados representados sobre reconstrucción virtual 3D (tomado de F.J. Borge Cordovilla). Datos correspondientes al muro Norte (medio) y al muro Sur (abajo). Las mayores diferencias corresponden a las medias de datos de humedad y puntos de rocío, mientras que las temperaturas ambientales y superficiales muestran menores diferencias. En negro: temperaturas superficiales medias anuales medida en cada sonda. En blanco: humedad ambiental, temperatura ambiental y punto de rocío medios anuales medidos en los respectivos equipos.. 
condensación. Las diferencias térmicas (ambientales y de superficie) son menos relevantes situándose en todos los casos por debajo de $1^{\circ} \mathrm{C}$ (Figura 7).

\section{Conclusiones}

A tenor de las causas y mecanismos de deterioro establecidos en este estudio, cabe concluir que las posibles soluciones para minimizar la elevada humedad detectada y los episodios de condensación pasan por tomar medidas de control ambiental. En este sentido, el control de la humedad ambiental de la Cámara Santa parece la solución más viable técnica y económicamente, dado que, por un lado se eliminarían los estadios de alta humedad ambiental, y por otro lado, descendería el punto de rocío lo que limitaría la posibilidad de producirse condensaciones.

A este fin, se recomienda la instalación de un equipo de des humidificación automatizado con higrómetro digital, que permita fijar una humedad ambiental de referencia para el interior de la Cámara Santa, activándose el equipo de manera automática si la humedad ambiental se dispara por encima de dicho valor. Se recomienda tomar como humedad ambiental de referencia un valor del $70 \%$, si bien, será necesaria su validación durante los primeros meses mediante un pequeño control higrotermométrico.

El equipo a instalar debe estar dimensionado en relación a las necesidades volumétricas de evacuación del interior de la Cámara Santa y deberá ser lo más silencioso posible.

Dada la zonificación ambiental detectada en la Cámara Santa, se recomienda colocar el deshumidificador en la esquina Suroeste, o bien, a fin de salvaguardar el aspecto estético, colocar un higrómetro inalámbrico en esta zona, situando físicamente el equipo de deshumidificación en una zona más discreta no visible para los visitantes. Igualmente se recomienda un equipo que permita la evacuación directa mediante tubería de goma del agua condensada, conectando a un sistema de recogida de aguas.

Para que este sistema de control de humedad ambiental sea efectivo, se hace necesario eliminar o minimizar todas las posibles entradas al interior de la Cámara Santa de aire húmedo procedente directamente de zonas externas. Por esta razón, se recomienda cerrar completamente las ventanas existentes en la Cámara Santa mediante la instalación de cristales de vidrio, y el cegado de los diferentes agujeros localizados en los muros.

Tan sólo, y a fin de evitar una acumulación de dióxido de carbono (CO2) durante los momentos de mayor afluencia de visitantes, se recomienda dejar sin acristalamiento la ventana enrejada situada en el muro suprayacente a la actual reja de entrada al camarín. Esta ventana, actuará a modo de tiro, permitiendo la evacuación del dióxido de carbono acumulado, a la vez que, por su situación elevada, no representará un aporte importante de aire húmedo exterior en los periodos cálidos, por ser este de menor densidad que el presente en el interior.

Finalmente, cabe recomendar el control del número de personas que simultáneamente acceden al interior de la Cámara Santa durante las visitas guiadas en grupo, a fin de evitar la influencia de los mismos en las condiciones higrotermométricas.

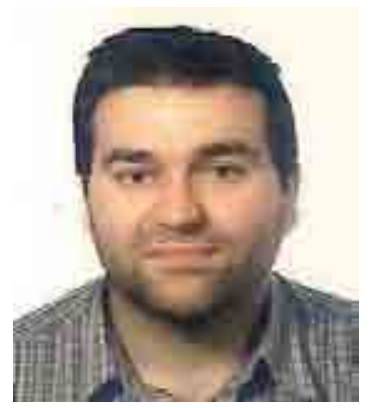

Félix Javier Mateos Redondo

GEA asesoría geológica

felix@geaasesoriageologica.com

Félix Javier Mateos Redondo (1975): Licenciado y Doctor en Ciencias Geológicas por la Universidad de Oviedo (1995-1999; 2011), en el año 1999 comienza su andadura profesional como investigador contratado dentro de los grupos de "Alteración y Durabilidad" y "Petrofísica" del Departamento de Geología de la Universidad de Oviedo, donde durante más de una década (1999-2010) ha participado en numerosos proyectos de investigación de ámbito internacional (CONNET, ALIANCE, MCDUR, CURRIC, FUNMIG, I-STONE, EPISCON..) y nacional (INTERFASE, NANOROCK, PERDURABLE..), así como decenas de contratos de investigación y/o servicios con empresas, fundaciones y organismos públicos.

Paralelamente a su andadura universitaria, en el año 2001 pasa a formar parte como Socio Fundador de la empresa GEA asesoría geológica, con sede en Oviedo, consultora especializada en campos como la conservación del patrimonio histórico-artístico, caracterización de materiales y petrofísica. 


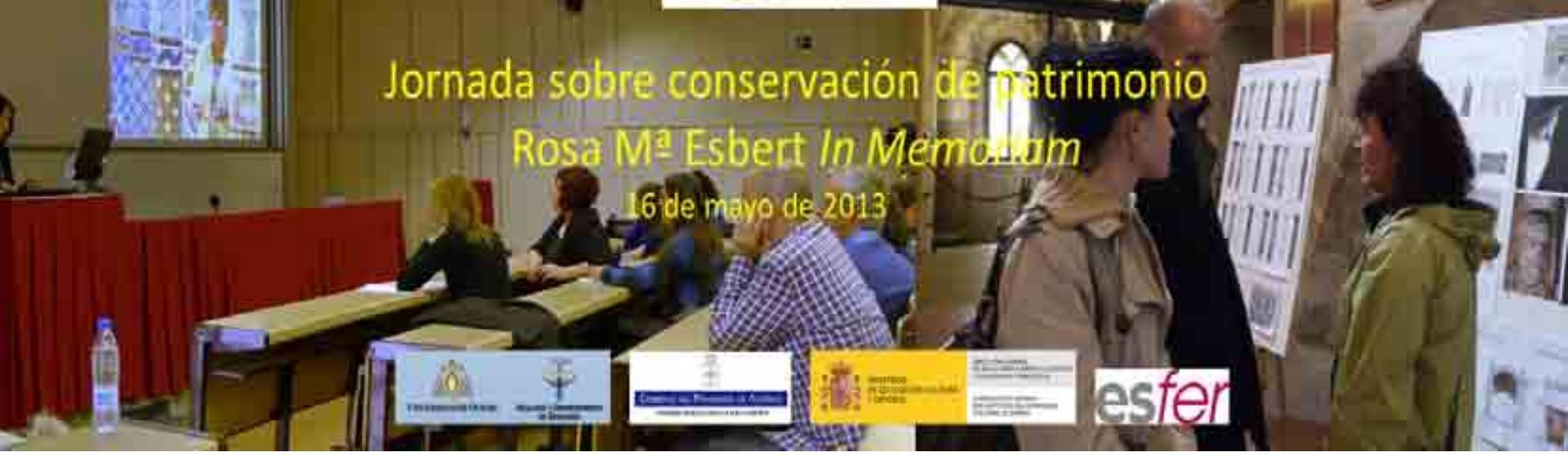

\title{
Cualidades y empleo del ciclododecano durante el proceso de moldeado de frag- mentos y originales de soporte pétreo. Casos prácticos.
}

\author{
Xavier Mas-Barberà , Stephan Kröner, José Vicente Grafiá Sales y Javier Orozco Messana.
}

\begin{abstract}
Resumen: Este trabajo presenta el uso del ciclododecano utilizado en el sistema bicapa durante el proceso de moldeado de esculturas y ornamentos labrados en material pétreo con diferente porosidad y textura. En este sentido, se expone el trabajo experimental previo desarrollado con probetas de mármol de Macael y probetas de caliza travertínica Tosca de Rocafort. Los cambios morfológicos y la presencia de residuos han sido observados a través del microscopio estereoscópico y el espectroscopio infrarrojo por transformada de Fourier (FTIR). Los resultados más significativos han sido aplicados en dos obras originales donde se ha mostrado eficaz el uso del ciclododecano y, por tanto, del sistema bicapa. En definitiva, se trata de una técnica alternativa a las nuevas tecnologías y accesible para todos los profesionales de la conservación y restauración.
\end{abstract}

Palabras clave: ciclododecano, reproducción, soporte pétreo, separador temporal, copia parcial.

\section{Qualities and use of cyclododecane during molding and original stone fragments support. Case Studies.}

\begin{abstract}
This work presents the use of the cyclododecane used in the double layer system during the process of molding of sculptures and ornaments stone material with different porosities and textures. In this regard, the previous experimental work developed with specimens of Macael marble and specimens of calcareous stone Tosca de Rocafort have been studied. The morphological changes and the presence of residuals have been examined through the stereoscope microscope and the Fourier transform infrared spectroscopy (FTIR). Similarly, the most significant results have been applied in two original artworks, where it has been shown the effectiveness of the use of ciclododecano and, therefore, of the double layer system. In short, it is an alternative technique to other new technologies and accessible for all the professionals of the conservation and restoration.
\end{abstract}

Key words: cyclododecane, reproduction, stone material, temporary barrier film, partial copy.

\section{Introducción}

Actualmente, las técnicas de moldeo siguen usándose como medio para acometer actuaciones de conservación y restauración. Se dan casos en los que la obra está expuesta a la intemperie, sometida a factores ambientales y actos antisociales, susceptible al deterioro o que por razones de seguridad y conservación, se hace imprescindible la realización de una reproducción que conserve el original en condiciones controladas de preservación, es decir, en un museo (Roig 1995; Mas 2006). En otros casos, el préstamo del original para exposiciones, la transferencia de piezas y/o la cesión permanente obligan a valorar la realización de copias y sustituciones análogas al original. Este hecho pone de manifiesto la necesidad de estudiar y desarrollar nuevos materiales y medios accesibles que así lo permitan.

Cuando alrededor de 1995 Hangleiter propuso el uso del ciclododecano ${ }^{1}$ como un material susceptible de aplicarse en determinadas actuaciones de conservación y restauración, no se sabía a ciencia cierta la repercusión que tendría en un mundo prácticamente cambiante y, a la vez, técnicamente encorsetado. Tras varios años de estudios y 
aplicaciones diversas, son muchos los estudiosos y grupos a nivel internacional que están analizando y evaluando las cualidades de esta sustancia polivalente y temporal (Hangleiter 1999; Bruckle et al. 1999; Cagna y Riggiardi 2006; Mas et al. 2006; Riggiardi et al. 2010; Mas et al. 2013).

Particularmente, y desde que empezamos a estudiarlo a finales del 2004, el objetivo del uso del ciclododecano se centró en evaluar su compatibilidad con el soporte y la afinidad con determinadas sustancias, durante el proceso de moldeado de obras originales. En este sentido, el ciclododecano se ha utilizado como capa de separación temporal dado que no requiere ninguna fase de remoción superficial tras el proceso de desmoldado del original. Solamente debe tenerse en cuenta el tiempo de sublimación, propiedad que lo hace muy idóneo para ser usado en el campo de la conservación y restauración, donde los restauradores se ven obligados a respetar el original sin someterlo a cambios formales o estéticos (Tosini 1999; Grafiá y Mas 2004; Mas et al. 2006; Pereira 2008).

Las cualidades que presenta el ciclododecano cumplen con los requisitos más importantes que debe reunir un separador y que son, entre otros, la capacidad de formar una película protectora que conserva y respeta la textura del soporte, la facilidad de desmoldeo y la eliminación sin medios químicos o físico-mecánicos (Stein et al. 2000; Mas et al. 2006 y 2010), sin que se produzca el manchado de la pieza original (Matteini et al. 1990; Pereira 2008; Mas et al. 2012).

Los estudios sobre la aplicación del ciclododecano durante el moldeado de piezas escultóricas en materiales pétreos son escasísimos (Maish y Risser 2002; Mas et al. 2008). Hasta la fecha, estos estudios han demostrado la capacidad del ciclododecano de crear capas provisionales, homogéneas e impermeables al agua, dependiendo de las condiciones ambientales de aplicación y de la dilución empleada. Lo que realmente hace interesante al ciclododecano, como separador temporal, es su aplicabilidad en materiales con elevada porosidad y rugosidad. La problemática se centra en el peligro de retención de residuos en la pieza original. Para mitigar este aspecto, desde 2010 se está llevando a cabo, desde el Instituto Universitario de Restauración del Patrimonio de la Universidad Politécnica de Valencia, una línea de estudio centrada en el moldeado de soportes pétreos macroporosos (Mas et al. 2012 y 2013) con resultados prometedores, aplicables a casos reales y como una alternativa accesible ${ }^{2}$ para todos los profesionales de la restauración.

Los resultados más innovadores son que se ha conseguido optimizar el sistema bicapa, a modo de sistema sándwich (apolar-polar-apolar), lo que da respuesta al problema de afinidad entre la película de ciclododecano y los elastómeros RTV. Éste es uno de mayores inconvenientes, pues se trata de dos sustancias apolares, siendo el ciclododecano soluble en los aceites no polares de la silicona. Este dato ya fue considerado por Bruckle et al. (1999) cuando ma- nifestaron que "el manchado (por parte del "elastómero") era muy severo tanto con película de ciclododecano, como sin ella".

Este trabajo muestra, la idoneidad del ciclododecano combinado con una sustancia polar, el látex, a partir del sistema bicapa, aplicado tanto al moldeado de soportes pétreos macroporosos, como a otros de reducida porosidad [Figura 1].

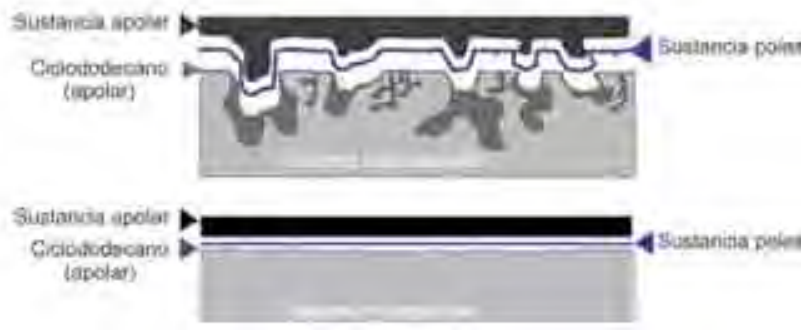

Figura 1. Esquema del procedimiento de aplicación de las capas.

\section{Casos de estudio}

A continuación se expone el procedimiento seguido en dos piezas de material pétreo con textura y porosidad diferentes.

En el primero de los casos, la realización del molde viene obligada por el estado de conservación de la pieza. La obra en cuestión, es originaria de la Iglesia de San Juan de la Cruz (Valencia) y como se aprecia en la figura 2, se encuentra totalmente fragmentada y descontextualizada funcional y estéticamente. Se trata de una pileta de santiguarse de dimensiones $125 \times 80 \times 80 \mathrm{~cm}$ aprox. y tallada en mármol blanco. La propuesta de intervención consistió en unir y coser internamente todos los fragmentos y en reconstruir las lagunas, mediante el sistema de prótesis y reproducciones parciales, con morteros de matriz inorgánica. Dado que existía un modelo idéntico en el propio edificio [Figura 3] se llevó a cabo el moldeado del fuste con el ciclodecano y el sistema bicapa para, obtener una copia que resistiera el peso de la pileta. Las dimensiones del fuste son $75 \times 24 \times 24 \mathrm{~cm}$ aprox.

El segundo caso, hace referencia a una dovela heráldica que contiene un detalle de una cruz templaria tallada en travertino, conocido en la zona levantina como piedra Tosca de Rocafort (Valencia) (Roig 1995; Mas 2006). Se trata de una piedra de dureza media, macroporosa, de elevada rugosidad y color crema tostada [Figura 4]. El motivo de la intervención fue la sustitución del original por la copia moldeada, como medida de conservación preventiva. La pieza tiene unas medidas de $49 \times 23 \times 15 \mathrm{~cm}$ aprox. y es de propiedad particular. 

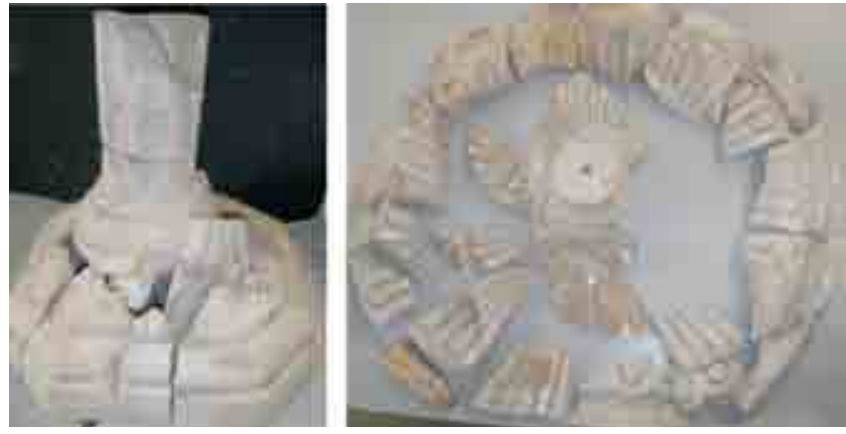

Figura 2. Vista general del estado de conservación de la base, fuste y taza que conforman la pileta, objeto de estudio.
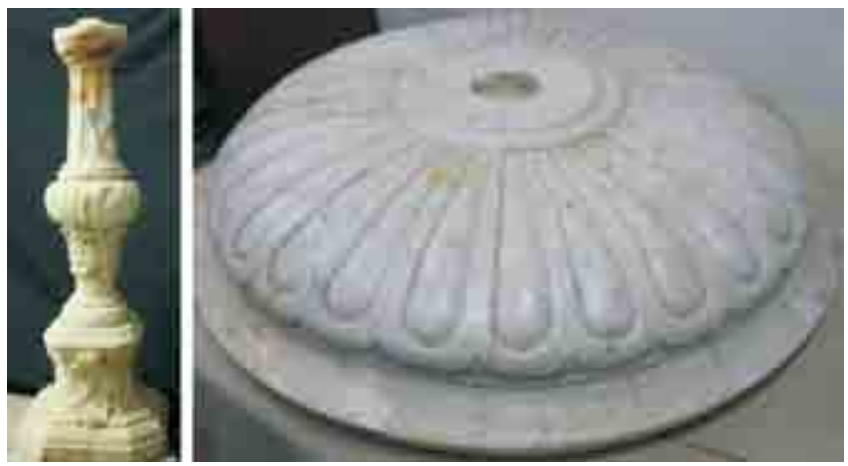

Figura 3. Vista general de la pileta gemela, ubicada en las dependencias eclesiásticas, tomada como modelo y referente para el proceso de moldeado del fuste.
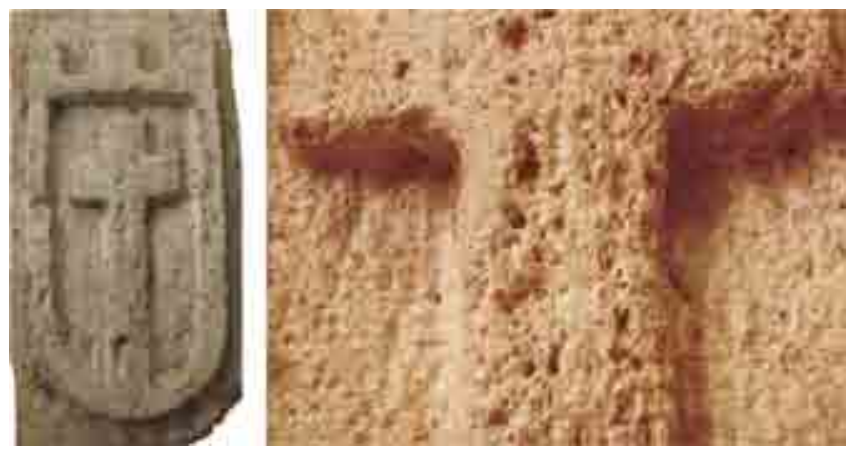

Figura 4. Vista general de la obra objeto de estudio. Obsérvese en la figura de detalle la macroporosidad de la piedra Tosca de Rocafort.

\section{Materiales y métodos experimentados}

Materiales de moldeo. Los productos empleados en este trabajo han sido los siguientes:

El ciclododecano (de ahora en adelante CDD) se ha empleado como separador apolar o barrera provisional en el proceso de moldeado. Se trata de un hidrocarburo cíclico $\left(\mathrm{C}_{12} \mathrm{H}_{24}\right)$, insaturado y químicamente estable. Posee la particularidad de sublimar a temperatura ambiente y presenta baja toxicidad. Su punto de fusión entre $58^{\circ}$ y $61^{\circ} \mathrm{C}$ lo convierte en una sustancia manejable. Este producto es suministrado por AgarAgar.
El White Spirit D40 desnaturalizado, necesario para preparar las disoluciones del CDD. Se trata de una mezcla de hidrocarburos alifáticos desnaturalizados con dicloropropano. Es un líquido incoloro con un punto de ebullición entre $145^{\circ}$ y $250^{\circ} \mathrm{C}$ e inflamabilidad de $36^{\circ} \mathrm{C}$. Este producto es suministrado por CTS España.

El látex de goma 5602 se ha utilizado como sustancia polar, aplicada entre el CDD y los elastómeros en el sistema bicapa. Se trata de una goma natural, un copolímero en dispersión acuosa. La película obtenida resulta estable a la luz, transparente, flexible y elástica. Se presenta como un líquido lechoso blanco, con un contenido en amoníaco $<1 \%$, con $\mathrm{pH}$ 10,5 y una viscosidad de $35 \mathrm{cps}$. Este producto es suministrado por CTS España.

El elastómero SILASTIC 3483 RTV ha actuado como estrato y nivelación/refuerzo, aplicado sobre el látex. Es un caucho de silicona de color blanco con excelentes propiedades mecánicas, resistente y de elevada fluidez. Es un producto bicomponente, compuesto por una base fluida y un endurecedor, agente de curado SILASTIC 83 que al mezclarse, vulcanizan a temperatura ambiente $\left(22^{\circ}-25^{\circ} \mathrm{C}\right)$, mediante una reacción de condensación, alcanzando unas propiedades mecánicas óptimas frente al desgarro y flexión (dureza shore A 13, resistencia a tracción 3,5 $\mathrm{MPa}$ ). Este producto es suministrado por Dow Corning.

La silicona Silical 110 plasmable, aplicada de igual modo que la anterior, es una goma de silicona tixotrópica con buenas propiedades mecánicas (dureza shore $A$ 21). Es un producto bicomponente, compuesto por una base y un catalizador, agente de curado Silical 115 que al mezclarse, vulcanizan a temperatura ambiente $\left(23^{\circ} \mathrm{C}\right)$. Es suministrado por CTS España.

La Putti Soft Fast ${ }^{\circledast}$ es una silicona de adición proveniente de la industria dental. Es un producto bicomponente, compuesto por una base y un catalizador que al mezclarse endurecen a los dos minutos, alcanzando unas propiedades mecánicas óptimas (dureza shore A 67). Se trata de un compuesto de polivinil-siloxano. Se ha experimentado en este trabajo por su escaso tiempo de manipulación y por su limpieza en la ejecución. Este producto es suministrado por Gerho Magazine.

El mat de superficie o velo de fibra de vidrio se ha usado para reforzar y mitigar los cambios dimensionales de la capa de látex. Son fieltros de hilos de fibra de vidrio cortados, aglomerados fuertemente entre sí, mediante un ligante químico y calandrados. De gramaje $50 \mathrm{~g} / \mathrm{m} 2$. Este producto es suministrado por Glaspol Composites España. 


\section{Preparación y aplicación de materiales}

Partiendo de los resultados obtenidos hasta la fecha (Mas et al. 2010, 2012 y 2013), este estudio se amplia con el uso de diversas siliconas de vulcanización rápida que minimizan el tiempo de manipulación y contacto.

Como paso previo a la intervención sobre los casos de estudio, se cortaron probetas de $6 \times 5 \times 3 \mathrm{~cm}$ de piedra Tosca de Rocafort y mármol Macael. Asimismo, se preparó el CDD al 50\% con White Spirit D40. Las sustancias empleadas como capa interfaz polar entre las capas apolares de CDD y del elastómero silicónico fueron el Látex de goma 5602 y la Putti Soft Fast ${ }^{\circledR}$. Todas las capas, tanto polares como apolares, fueron aplicadas según indicaciones de la ficha técnica y mediante pincel de cerdas, creando un film uniforme [Tabla 1]. El estudio se completó a través de observaciones superficiales con el microscopio óptico y análisis por espectroscopia FT-IR de muestras extraídas de la superficie de las probetas. El total de probetas estudiadas fue de 36 unidades.

La metodología experimental ha sido la siguiente:

1. Aplicación del separador apolar CDD. Preparación en baño maría y aplicado a pincel entre 40 y $45^{\circ} \mathrm{C}$ aprox., dependiendo de la textura y porosidad de la zona a tratar.

2. Aplicación del separador polar Látex de goma S602 y Putti Soft Fast ${ }^{\oplus}$, transcurridos 90 min. de la aplicación del CDD.
3. Aplicación del estrato de nivelación. Silicona SILASTIC 3483 (con propiedades tixotrópicas) y la silicona Silical 110 plasmable, transcurrido el secado de la capa polar de látex de goma 5602 (aprox. $120 \mathrm{~min}$ ).

4. Desmoldado, transcurrido el tiempo reseñado según la ficha técnica.

5. Observación visual directa, mediante microscopio óptico y análisis FTIR de las probetas tras la sublimación del CDD.

\section{Instrumentación}

El microscopio estereoscópico permitió observar en la superficie de las probetas la presencia de residuos y la evolución de la sublimación del ciclododecano. El equipo utilizado ha sido una lupa marca Leica, modelo MZ APO, de 8-80X aumentos, con sistema fotográfico digital acoplado e iluminación por fibra óptica bilateral. La espectroscopía infrarroja por transformada de Fourier (FTIR) permitió detectar los residuos en las probetas, tras el desmoldado. El equipo usado ha sido un espectrómetro VERTEX 70, operando con sistema de reflexión ATR (Attenuated Total Reflection) y contando con un detector FR-DTGS con recubrimiento para la estabilización de la temperatura. Las condiciones operativas fueron: número de barridos acumulados de 32 , y resolución de $4 \mathrm{~cm}-1$. Los datos fueron procesados con el sistema software OPUS, versión 5.0.

\begin{tabular}{|c|c|c|c|c|}
\hline \multirow{2}{*}{ SOPORTE PÉTREO } & \multicolumn{2}{|c|}{$\begin{array}{l}\text { SISTEMA BICAPA } \\
\text {-Separadores- }\end{array}$} & \multirow{2}{*}{$\begin{array}{c}\text { ELASTÓMERO } \\
\text { Estrato nivelación }\end{array}$} & \multirow{2}{*}{ INSTRUMENTACIÓN } \\
\hline & APOLAR & POLAR & & \\
\hline
\end{tabular}

Tosca de Rocafort (TR) CDD (50\%)
+ White Spirit D40 Látex de goma S602+mat de superficie

Putti Soft Fast ${ }^{\circledast}$

Mármol Macael (MM)
Microscopio

estereoscópico

\author{
Putti Soft Fast ${ }^{\circledast}$ \\ Silastic 3483 RTV
} 1 aplicación en
MM

Metodología

3 aplicaciones de látex sobre el CDD

Capa tixotrópica y plasmable

Observación de la varia-

Hasta obturación

del poro en TR

FTIR

Tabla 1. Materiales y metodología empleada en el desarrollo del estudio. 


\section{Resultados y discusión}

\section{Aproximación organoléptica}

Desde el punto de vista de la conservación y restauración hay dos aspectos fundamentales a considerar: la total inocuidad de los materiales con respecto al original y la facilidad de manipulación.

Los efectos visuales más significativos observados en la sustancia Putti Soft Fast ${ }^{\oplus}$, aplicada directamente sobre el CDD, en cualquiera de los soportes pétreos estudiados (TR y MM), han sido que deja residuo y modifica cromáticamente la superficie, siendo mayor este cambio en el soporte más poroso (TR) (Fig. 5). Esto podría deberse al contacto entre el CDD y los vapores de white Spirit, pues la Putti Soft Fast ${ }^{\oplus}$, al ser una sustancia, diseñada para el uso en medio acuoso, no resulta eficaz en presencia de sustancias apolares -hidrocarburos-. Esto ya ha sido apuntado por Bruckle en 1999. Este mismo resultado se ha observado con el empleo del elastómero plasmable Silical 110 [Figura 6 y 7]. Este manchado resulta más evidente en el material pétreo con mayor porosidad y rugosidad y es más sutil en el de menor rugosidad, tal como se ha comprobado con el FTIR.

Con el látex de goma S602 aplicado sobre el CDD no se han observado modificaciones. Después de treinta días, las probetas no exhiben cambios de color, ni apariencia de residuos [Figura 8]. Asimismo, el uso del mat de superficie evita modificaciones dimensionales y deformaciones durante el secado del látex y permite que todos los detalles de la superficie sean registrados correctamente.

En cuanto al estrato de acoplamiento y nivelación ${ }^{3}$, de los tres productos practicados (Silastic 3483 RTV, Silical 110 y Putti Soft Fast ${ }^{\circledR}$ ), el Silastic 3483 resulta ser más flexible y se adapta correctamente a la capa de látex. Sin embargo, la Silical 110 y la Putti Soft son más rígidas, quebradizas y el contacto con el látex es menor, hecho que imposibilitará los trabajos en piezas de gran formato.

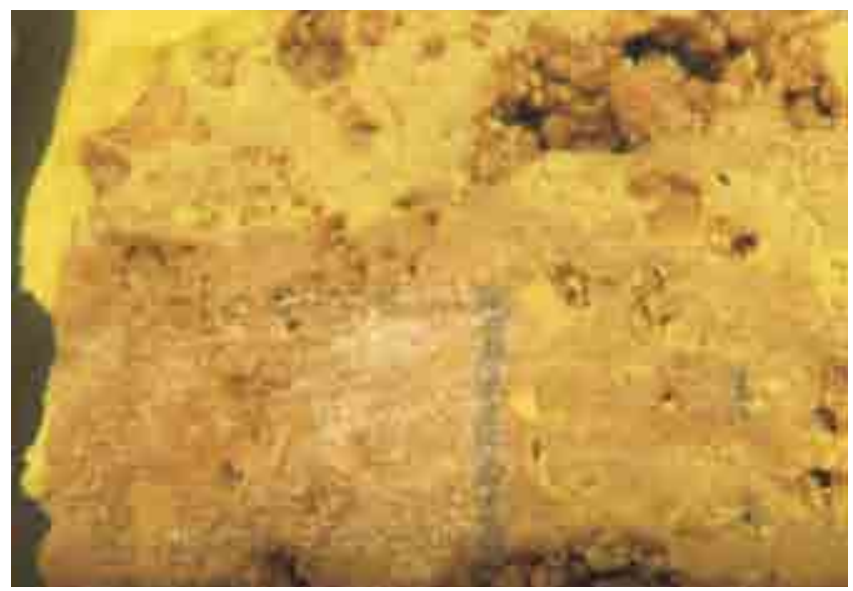

Figura 5. Soporte pétreo travertino TR. Obsérvese la presencia de residuos en el interior de los poros. La cata de remoción indica la eliminación de la mancha en zonas lisas, sin embargo los poros mantienen restos de la sustancia Putti Soft Fast ${ }^{\oplus}$.

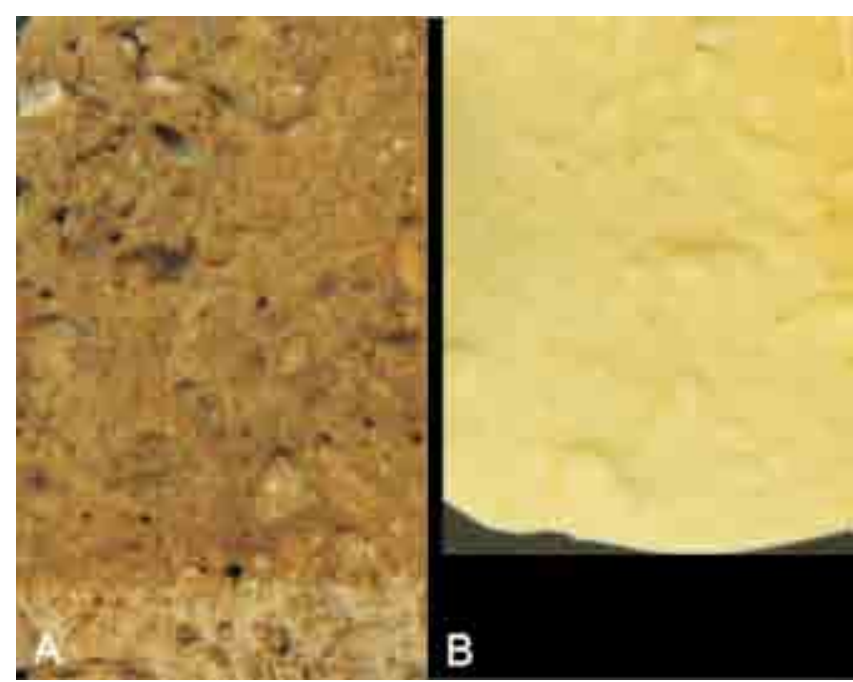

Figura 6. A. Soporte pétreo travertino TR después de 3 días del levantamiento del elastómero plasmable Silical 110. Se observa aún la presencia de CDD y el manchado de la superficie. B. Detalle de la impronta retenida en el elastómero Silical 110. A pesar de que retiene los detalles perfectamente, no resulta viable en cuanto a su inocuidad.

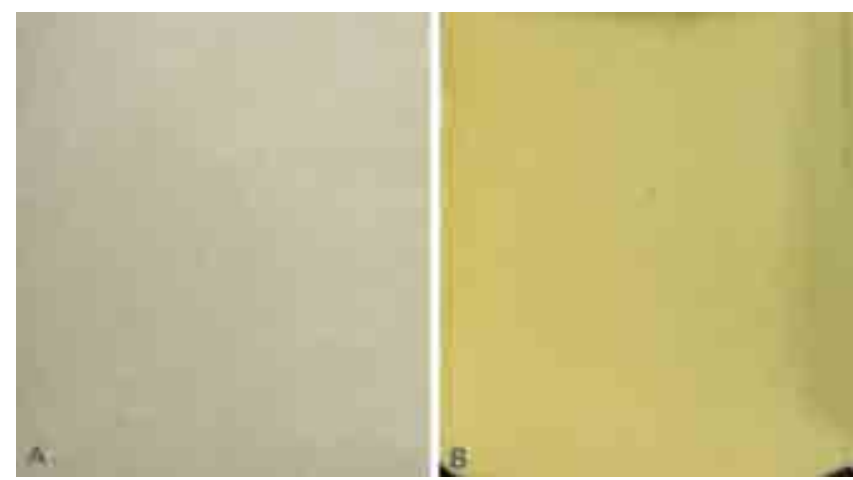

Figura 7. A. Soporte pétreo mármol Macael después de 3 días del levantamiento del elastómero plasmable Silical 110. Se observa de manera sutil el manchado de la superficie. B. Detalle de la impronta retenida en el elastómero Silical 110.

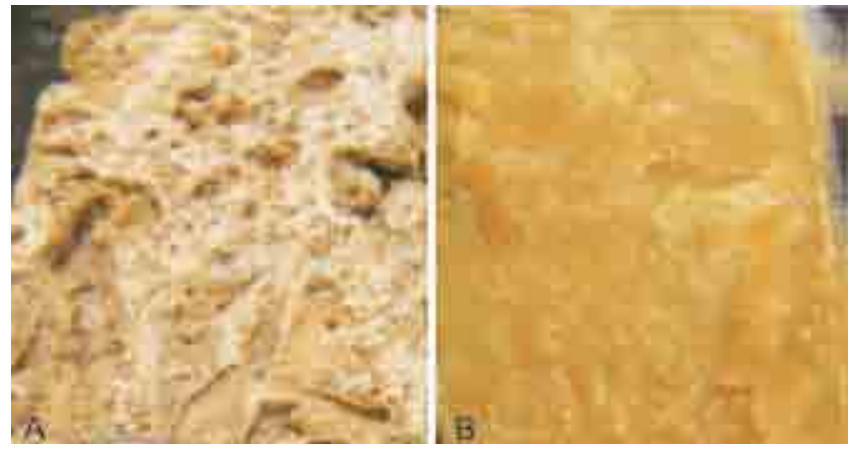

Figura 8. A. Soporte pétreo travertino TR después de 30 días del levantamiento del látex de goma $\mathrm{S602}$. No se observa manchado de la superficie. B. Detalle de la impronta retenida en el látex de goma 5602 y reforzado con mat de superficie. Los detalles de los poros son retenidos fielmente conforme al original. 

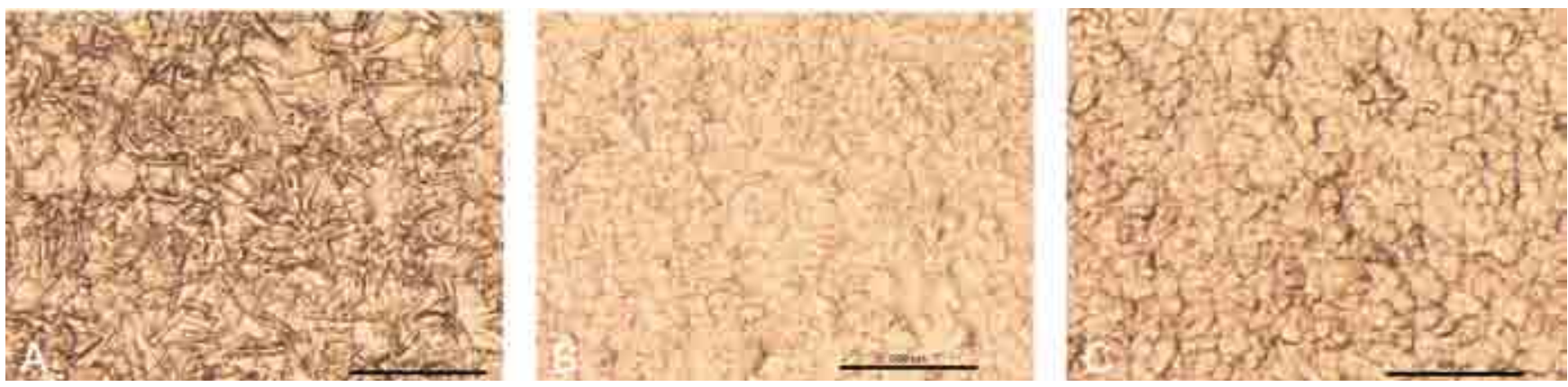

Figura 9. Aplicación de CDD sobre vidrios porta objetos. A. Disolución de CDD al $40 \%$ con White Spirit. B. Disolución de CDD al 50\% con White Spirit. C. Disolución de CDD al 60\% con White Spirit.

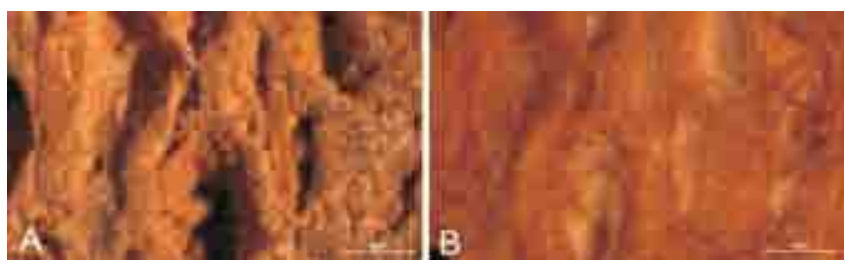

Figura 10. Soporte pétreo travertino TR. A. Vista de detalle en superficie de la red porosa. B. Aplicación de CDD hasta la saturación.

\section{Microscopía estereoscópica}

A través de esta técnica se observó la capa creada por varias disoluciones de $\operatorname{CDD}(40,50$ y $60 \%)$ aplicadas sobre vidrios porta objeto. La disolución de CDD al 50\% forma una capa sutil, homogénea y lo suficientemente cerrada para impedir el manchado de las aplicaciones de látex de goma posteriores [Figura 9]. Además, los detalles superficiales son copiados sin interferencias.

En el caso de las probetas con macroporos, la aplicación de CDD se lleva hasta la saturación impidiendo que el resto de estratos penetren y manchen el soporte, como se aprecia en la figura 10. El CDD experimenta una sublimación gradual que varía en función de la concentración de CDD, del solvente utilizado y de las condiciones ambiéntales de temperatura y humedad relativa Para una disolución de CDD al 50\% con White Spirit $D 40$, en condiciones de $21^{\circ} \mathrm{C}$ de temperatura y $35 \%$ de humedad relativa y para una superficie (vidrio porta objeto) tratada de $1 \mathrm{~cm}$ de diámetro y $0,5 \mathrm{~mm}$ de espesor, el tiempo de sublimación es de 9 horas aprox.

\section{Espectroscopía infrarroja por transformada de Fourier (FTIR)}

En la figura 11 se observa el espectro FTIR resultante del análisis de probetas de TR. Se detectan bandas características a $\sim 2920 \mathrm{~cm}-1, \sim 2860 \mathrm{~cm}-1 \sim 1200 \mathrm{~cm}-1$, $\sim 1000 \mathrm{~cm}-1$ y $\sim 800 \mathrm{~cm}-1$ en las probetas donde ha sido aplicado la silicona Silical 110 y Putti Soft Fast ${ }^{\circledast}$ que no deberían estar presentes en el soporte pétreo. Estos datos nos indica la existencia de residuos tras el des-

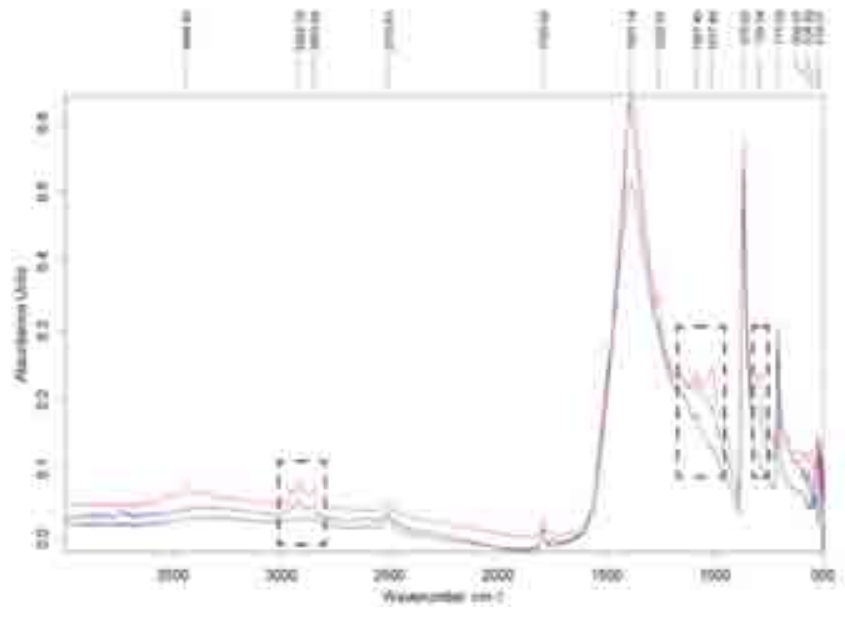

Figura 11. Espectro FTIR obtenido del análisis de muestras extraídas de probetas de soporte travertino TR. La línea superior corresponde a la silicona Silical 110, la línea intermedia a la silicona Putti Soft Fast ${ }^{\oplus}$ y la línea inferior al látex de goma 5602.

moldado de las probetas y la sublimación del CDD. Sin embargo, para el látex de goma S602, la banda detectada es inapreciable y apunta la ausencia de residuos en las probetas, o niveles de los mismos muy bajos, inferiores al límite de detección del instrumental. Algo similar ocurre con las probetas de mármol Macael. Los datos obtenidos exhiben ausencia de residuos para el caso del látex de goma 5602 y pequeñas proporciones de residuos para el caso de la silicona Silical 110 y ${ }^{\circledR}$, inferiores a los detectados en la piedra Tosca. Todo ello indica que la rugosidad y el grado de porosidad del soporte pétreo son aspectos a considerar a la hora de desarrollar un molde sobre un original.

\section{Aplicación del sistema bicapa a los casos reales}

El proceso de moldeado de una obra real supone un amplio conocimiento no sólo de los materiales y las técnicas necesarias para la intervención, sino también de todo aquello que afecta directamente a la pieza; tipo 
de soporte, textura, porosidad, color, estado de alteración, condiciones ambientales del entorno y objetivos y criterio de la intervención. En este sentido, el responsable de la intervención debe ser capaz de evaluar correctamente la viabilidad del proceso sin someter a la obra a daños innecesarios. Por este motivo, la realización de moldes sobre originales debe estar siempre justificada, debe ser viable, con garantías y llevada a cabo por personal cualificado que velará por la integridad de la obra. Actualmente, con el avance de los materiales, el proceso de moldeado sigue siendo la alternativa a las nuevas tecnologías de reproducción aún destinadas a casos extraordinarios. Por tanto, el moldeado mediante el sistema bicapa resuelve una problemática importante dado que respeta la obra, no mancha y es accesible para todos los profesionales de la conservación y restauración.

En las figuras 12 y 13 se muestran los pasos llevados a cabo en el proceso de moldeado de las dos piezas, anteriormente mencionadas. El paso previo es la reconstrucción de volúmenes que, originados por varios motivos, rompen la lectura del conjunto. La reconstrucción sigue la forma y detalles de la zona a tratar [Figura 12. A], dependiendo del criterio de intervención.

Otra consideración importante es delimitar las partes que constituirán el molde, es decir las zonas por donde se abrirá sin contener contrasalidas o enganches. Generalmente, suelen ser dos, una del anverso y otra de reverso; no obstante el despiece del molde viene condicionado por el estado de conservación, la forma, el tamaño y el peso de la obra que, en ocasiones podría ser numeroso y de medidas dispares.

La siguiente fase se centra en la aplicación de la sustancia separadora. El CDD impedirá que la pieza entre en contacto con las sucesivas capas responsables de contener la impronta. El número de aplicaciones de la primera capa dependerá de las propiedades del original. Si la superficie es lisa y con una porosidad reducida bastará con una aplicación; si por el contrario, la textura es rugosa y muy porosa, las aplicaciones variarán entre dos y cinco (hasta saturación) [Figura 13. B], con control de la temperatura de la disolución y otros parámetros ambientales del taller.

La siguiente capa, la aplicación del látex de goma S602, debe respetar el tiempo de evaporación del disolvente White Spirit. A partir de los datos analizados, el margen se sitúa entre 90 y 120min, dependiendo de las características del soporte pétreo. La primera capa de látex de goma debe recoger todos los detalles [Figura 12. C], la segunda y tercera irá reforzada con mat de superficie [Figura 12. D]. Las capas deben aplicarse una tras otra, en mordiente.

La última fase corresponde a la aplicación de la silicona Silastic 3483 RTV. Se practica el estrato de acopla-
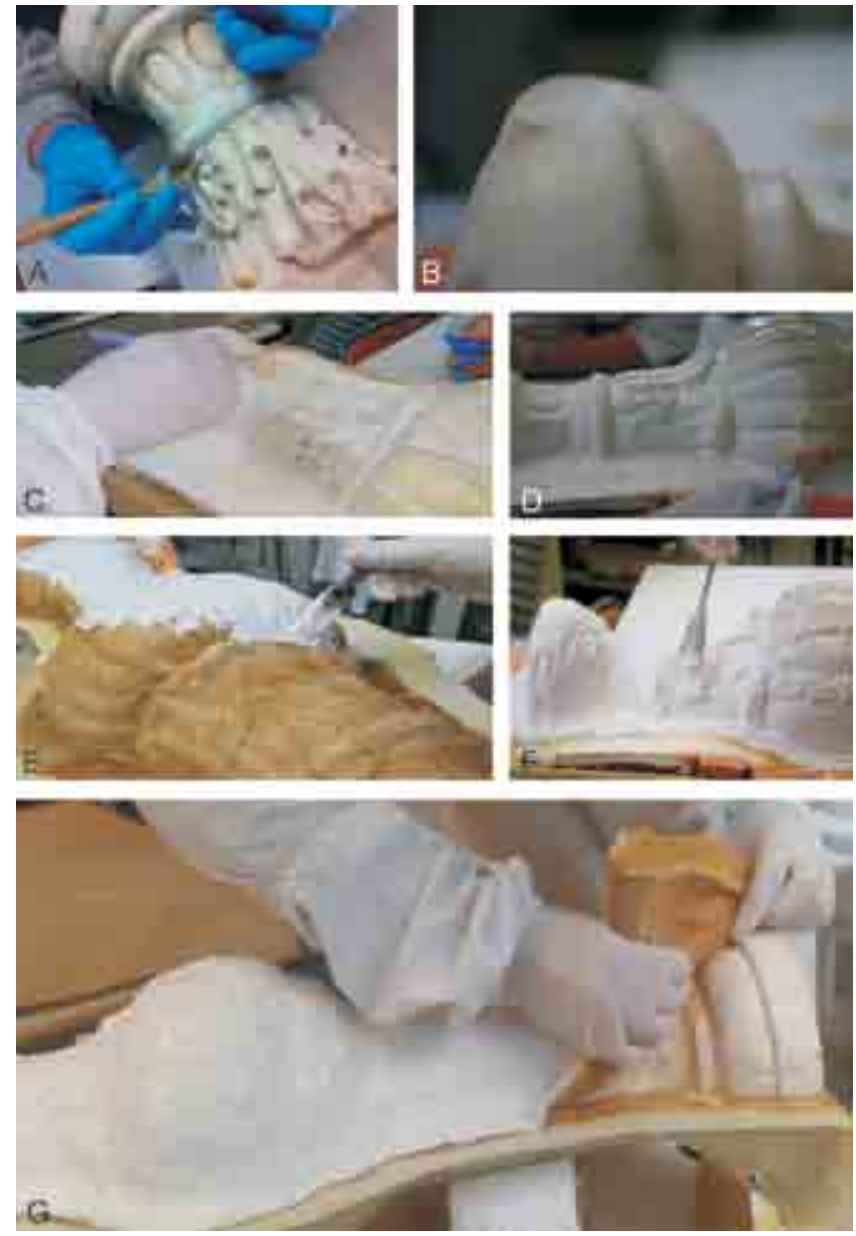

Figura 12. Proceso de preparación y moldeado del fuste; A. Reconstrucción de pequeñas pérdidas de volumen de la decoración mediante plastilina; B. Detalle de los cristales formados sobre la superficie del mármol tras la aplicación del ciclododecano al 50\% con White Spirit D40; C. Aplicación de la primera capa de látex sobre la capa de ciclododecano; $D$. Segunda capa de látex reforzada con mat de superficie; E. Aplicación del estrato de acoplamiento mediante silicona Silastic 3483 RTV; F. Aplicación del estrato de nivelación con silicona Silastic 3483 RTV tixotrópica; G. Fase de desmoldado. Obsérvese que, tanto la capa de látex como los estratos de silicona, forman un todo unitario.

miento [Figura 13. E] que requiere el contacto perfecto del elastómero con el látex. Transcurridas seis horas, se añade el estrato de nivelación. La silicona empleada es la Silastic 3483 a la que se le añade un aditivo tixotrópico que le confiere propiedades antidescolgantes [Figura 13. F]. Finalmente, y transcurridas aprox. doce horas, se realiza la caja rígida contenedora de todas las capas y estratos descritos. Generalmente suelen usarse resinas acrílica y/o de poliéster reforzadas con mat de fibra de vidrio. Endurecida la caja rígida, se lleva a cabo el proceso de apertura de las partes que conforman el molde. Por un lado la caja, por otro la capa elástica que contiene la impronta (combinación del látex de goma más la silicona) [Figura 13. G] y por otro, la pieza con el CDD en fase de sublimación. 

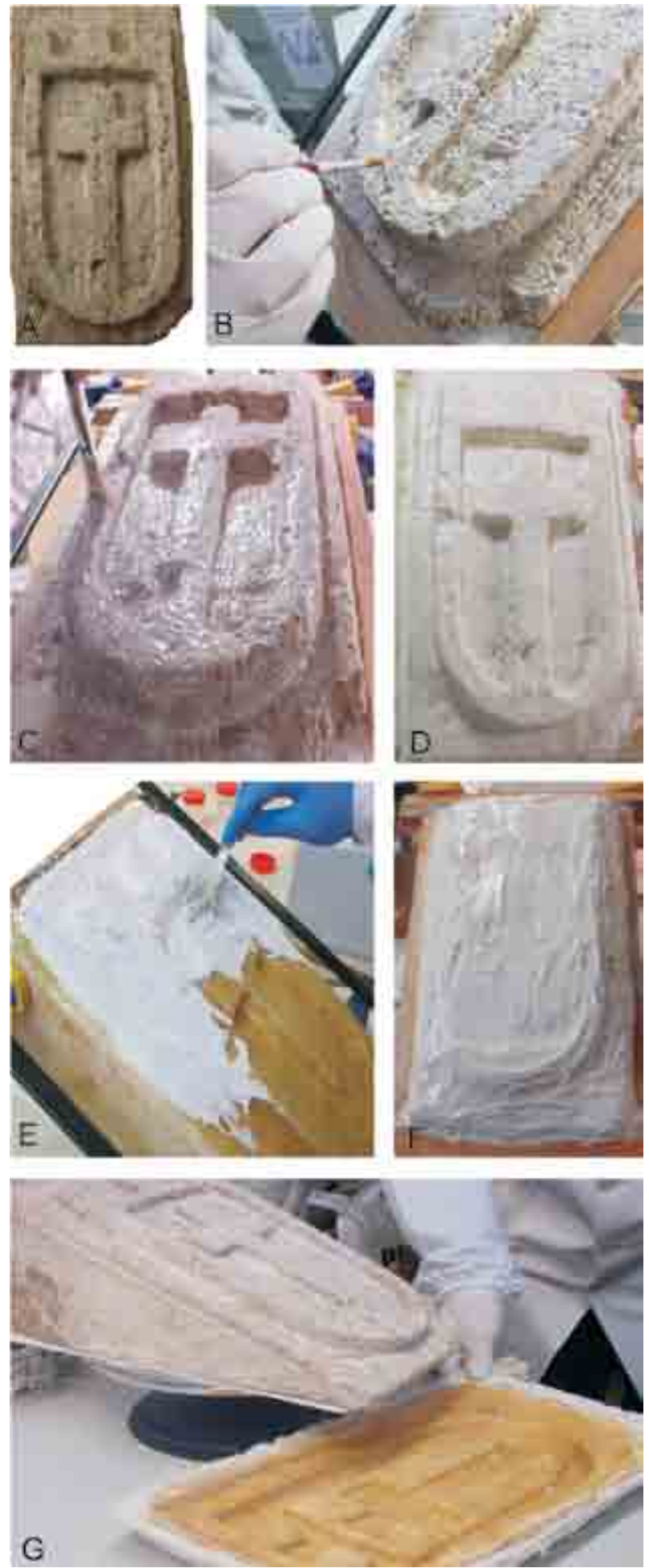

Figura 13. Proceso de preparación y moldeado de la dovela heráldica con cruz templaria. A. Vista general de la pieza; B. Detalle de la aplicación del ciclododecano al 50\% con White Spirit D40 hasta la saturación del poro; C. Aplicación de la primera capa de látex sobre la capa de CDD; D. Tercera capa de látex reforzada con mat de superficie; E. Aplicación del estrato de acoplamiento mediante silicona Silastic 3483 RTV; F. Aplicación del estrato de nivelación con silicona Silastic 3483 RTV tixotrópica; G. Vista general de la obra, del molde en negativo donde se aprecia el detalle de la textura, y del contramolde que contiene el conjunto. Obsérvese el CDD presente en la superficie de la obra. Durante las siguientes ocho semanas el CDD sublimará totalmente.

\section{Conclusiones}

Las conclusiones más sobresalientes extraídas de esta investigación demuestran que el CDD al 50\% con White Spirit $\mathrm{D} 40$ es una sustancia ideal como separador temporal. Permite una manipulación correcta y no requiere de una remoción mecánica ni química, dado que sublima a temperatura ambiente.

Asimismo, el moldeado de originales mediante este sistema bicapa en el que se combina el CDD, el látex de goma S602 -reforzado con mat de superficie- y el elastómero Silastic 3483 RTV -como estrato de acoplamiento y nivelación-, resulta eficaz para ambos soportes pétreos. Es una alternativa innovadora en casos donde no se requiera de un gran aporte científico y tecnológico. En este sentido, se trata de una técnica relativamente rápida, fácilmente controlable por el restaurador y que evita el manchado del original, sin retener residuos y siendo económicamente viable. Estos resultados quedan demostrados con la obtención de improntas idénticas al original, con empleo de materiales de toxicidad muy baja.

En definitiva, el sistema CDD y látex de goma 5602 aglutina las diez propiedades fundamentales que debe reunir un buen separador y que son:

1. Formación de una película aislante -capa interfaz homogénea- que facilita la separación entre el molde y el modelo.

2. Compatibilidad del separador con el material constituyente del modelo-obra de arte.

3. Adaptación de la capa interfaz a la superficie del modelo.

\section{Protección integral del modelo.}

5. Facilidad y control en el método de aplicación.

6. Estabilidad química.

7. Creación de un film sutil que posibilita el registro fiel de los detalles del modelo.

8. Reversibilidad del separador tras el desmoldeado sin causar deterioro alguno en el original.

\section{Ausencia de residuos.}

10. Baja o nula toxicidad.

\section{Agradecimientos}

Este trabajo ha sido financiado por el proyecto HAR201129538 del Ministerio de Ciencia e Innovación Español. 


\section{Notas}

[1] Ciclododecano (CDD). Características físico-químicas: Fórmula: $\mathrm{C} 12 \mathrm{H} 24$; Punto de fusión: $58^{\circ}$ a $61^{\circ} \mathrm{C}$; Punto de ebullición: $243^{\circ} \mathrm{C}$; Peso específico: 0,83 kg/dm3; Solubilidad: disolventes apolares, insoluble en agua y alcoholes. Usos en restauración: separador, consolidante, fijativo, protectivo y adhesivo temporales. Aplicación: fundido, aerosol y disolución. Parámetros a controlar: a) el método y cantidad aplicada, b) la temperatura de la sustancia de CDD fundida, c) la temperatura del soporte, d) profundidad de penetración deseada, e) cantidad de solvente añadido a la sustancia $\mathrm{CDD}$ y, f) velocidad de evaporación del solvente y de la disolución del CDD.

[2] Se muestra el moldeado de originales a través de moldes flexibles como una alternativa a determinadas técnicas más sofisticadas e inaccesibles como son la fotogrametría, el escáner láser y la fotodigitalización 3D combinada con el pantógrafo computerizado/impresoras 3D o electrolitografía y relegadas éstas a casos VIP. Esta técnica del moldeado permite obtener prótesis, reproducciones, copias parciales y totales idénticas al original con unos recursos humanos y económicos accesibles.

[3] Estrato de nivelación. Capa de material diverso y de grosor variable preparada con el fin dar volumen, incrementar espesores entre materiales y dar continuidad espacial al conjunto.

\section{Referencias}

BRUCKLE, I., THORNTON, J., NICHOLS, K. y STRINCKLER G., (1999). "Cyclododecane: Technical note on some uses in paper and objects conservation" Journal of the American Institute for Conservation. Volume 38, Number 2, Article 4, 162.

CAGNA. M. y RIGGIARDI, D., (2006). 'Control of sublimation time of Cyclododecane used as a temporary fixative", in the Care of Painted Surfaces: Materials and methods for consolidation, and scientific methods to evaluate their effectiveness,.Third International Conference, Colour and Conservation. 10-11 November, ed. CESMAR7, Milan.

GRAFÍA SALES, J. y MAS-BARBERÀ, J., (2004). "Proceso de reproducción de nuestra señora de aguas vivas debido a las alteraciones causadas por su funcionalidad. Idoneidad en la ejecución del molde y obtención de la réplica", in XV Congreso Internacional de Conservación y Restauración de Bienes Culturales, 21-24 Octubre, Murcia, Ligia Comunicación y Tecnología, Vol. l, 607-616.

HANGLEITER, H. M. (1999). Volatile binding media. www.hangleiter.com

MAISH, J. y RISSER, E., (2002):. "A case study in the use of cyclododecane and latex rubber in the molding of marble"'. Journal of the American Institute for Conservation, Volume 41, Number 2, Article 3.

MASI BARBERÀ, J., GRAFÍA SALES, J., SANMIGUEL SAMPEDRO, L., MARCO GISBERT, S., ORTÍ MATEU, V. y ROIG SALOM, J.L., (2006). "Application of new material release agent - interface support / silicone rubber - in the reproduction of porous pieces", in 16th International Meeting on Heritage Conservation, 2-4 Noviembre,
Valencia, Editorial UPV, Valencia Vol. I, 655-664.

MAS I BARBERÀ, X. (2006). Estudio y caracterización de morteros compuestos, para su aplicación en intervenciones de sellados, reposiciones y réplicas, de elementos pétreos escultórico-ornamentales. Tesis doctoral. Departamento de Conservación y Restauración de Bienes Culturales, Universidad Politécnica de Valencia.

MAS I BARBERÀ, X., VAN UDEN, ANA; KRONER, S.; MARTÍNEZ BAZÁN, M.; DOMÉNECH CARBO, M.T. y DE LA CRUZ CAÑIZARES, J. (2008). "Study of the cyclododecane as a temporary barrier in the moulding of sculpture and ornamental stone pieces". Arché Número 3, pp. 179-184.

MAS I BARBERÀ, X., RODRÍGUEZ IZQUIERDO, A.; KRONER, S.; MARTÍNEZ BAZÁN, M. y DOMÉNECH CARBO, M.T. (2010). "Análisis y aplicación de separadores en el moldeado de originales. El busto fenicio de Puig dels Molins, Ibiza". Arché, Número 4-5, pp. 43-50.

MAS I BARBERÀ, X.; KRONER, S., MARTÍNEZ BAZÁN, M; OROZCO MESANA, J. y GRAFIÁ SALES, J.V. (2012). “Estudio del ciclododecano como separador temporal en el proceso de moldeado de materiales pétreos macroporosos", Arché, Vol. 6 y 7, pp 279-284

MAS I BARBERÀ, X.; KRONER, S., MARTÍNEZ BAZÁN, M; OROZCO MESANA, J. y GRAFIÁ SALES, J.V. (2013). "Application of the double layer system as preventive method in the moulding process of sculptures and ornament", In Science and technology for the conservation of cultural heritage. CRC Press Taylor and Francis, pp 329-332

MATTEINI, M.; MOLES, A. y TOSINI, I. (1990). "Interazioni tra i materiali costitutivi dei manuffati e le sostanze utilizzate per il calco: controllo di alcune procedure", in De Sculture da Conservare. Ministero per i Beni Culturali a Ambientali, Orificio delle Pietre Dure e Laboratori di Restauro di Firenze. Edito da Vallardi \& Associati, Firenze.

PEREIRA, C., (2008). Conservar la información. Clones y documentación. Universidad Complutense de Madrid. Facultad de Bellas Artes.

ROIG SALOM, J. L. (1995). Estudio de la alteración de materiales pétreos en los monumentos de la ciudad de Valencia. Posibles tratamientos de conservación. Tesis doctoral. Facultad de Bellas Artes. Departamento de Conservación y Restauración de Bienes Culturales. Universidad Politécnica de Valencia.

RIGGIARDI, et al. (2010)::"Il ciclododecano nel restauro dei manufatti artistici", Cuaderno n॰8, Cesmar 7, II Prato.

STEIN, R., KIMMEL, J., MARINCOLA, M. y KLEMM, F., (2000). “Observations on Cyclododecane as a Temporary Consolidante for Stone". Journal of the American Institute for Conservation, Volume 39, Number 3, Article 4.

TOSINI, I. (1999):."II calco dei manufatti storico-artistici mediante elastomeri siliconici". Revista dell'Opificio delle Pietre Dure e Labo- 


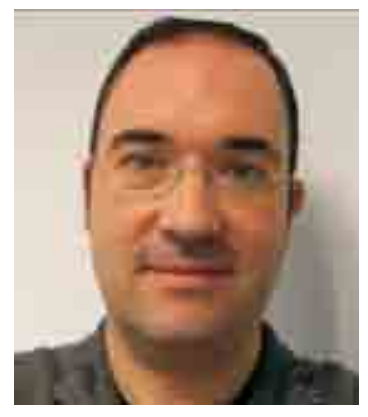

\section{Xavier Mas-Barberà}

Instituto Universitario de Restauración del Patrimonio, Universitat Politècnica de València, Camino de vera s/n 46022 Valencia

jamasbar@upvnet.upv.es.

ratori de restauro di Firenze, no 11.

Doctor en Bellas Artes, en la especialidad de Conservación y Restauración de Bienes Culturales (Universitat Politècnica de València, Valencia, 2006). Es profesor de conservación y restauración de escultura y ornamentos en la Facultad de Bellas Artes y, su investigación la realiza en el Instituto Universitario de Restauración del Patrimonio (Universitat Politècnica de València); concretamente centrada en el estudio de materiales pétreos empleados en Patrimonio, su diagnóstico y el desarrollo de nuevos métodos para el tratamiento de esculturas y ornamentos labrados en piedra.

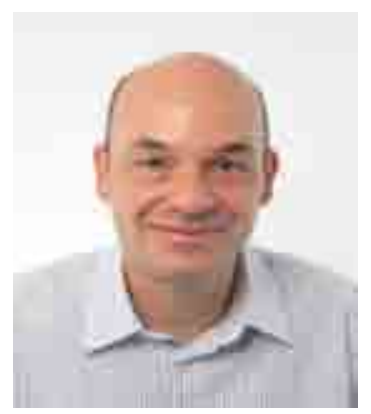

\section{Stephan Kröner}

Instituto Universitario de Restauración del Patrimonio, Universitat Politècnica de València, Camino de vera s/n 46022 Valencia

ustephan@upvnet.upv.es

Doctor en Geología (Johannes Gutenberg University Mainz, 2005). Hizo la primera parte de sus estudios de geología (Vordiplom-Examen intermedio) en el Instituto de Tecnología de Karlsruhe (Alemania) y, posteriormente, se traslada y los completa (Diploma-Licenciatura, con trabajo final de la carrera) en la Universidad de Lausana (Suiza). Durante su carrera se especializó en el campo de la geología estructural (Alpes). En la etapa de tesis doctoral se especializa en la geoquímica (geología de isótopos, geocronología) con el fin de entender los procesos de formación de las cordilleras montañosas del Damara Orogen (Namibia). Finalmente, en 2007, accede al Instituto Universitario de Restauración del Patrimonio (Universitat Politècnica de València) y se responsabiliza del área de caracterización de materiales inorgánicos (materiales pétreos, cerámicos, pigmentos y morteros, entre otros). 


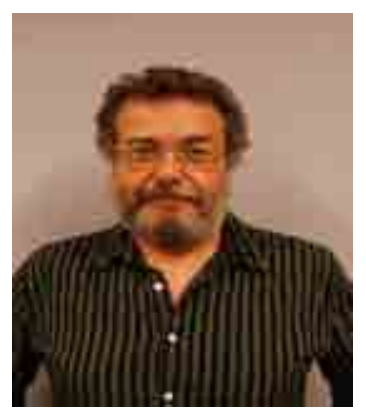

\section{José Vicente Grafiá Sales}

Departamento de Conservación y Restauración de Bienes Culturales, Camino de Vera s/n, 46022 Valencia

jograsa@crbc.upv.es

Doctor en Bellas Artes por la Universidad Politécnica de Valencia. Desarrolla su actividad docente en la Facultad de Bellas Artes, en el Departamento de Conservación y Restauración de Bienes Culturales y su faceta investigadora en el Instituto de Restauración del Patrimonio de la Universidad Politécnica de Valencia. Sus líneas de investigación versan sobre la comparativa de distintos adhesivos orgánicos e inorgánicos sobre soporte lígneo y sobre aspectos de etnología de objetos de de madera.

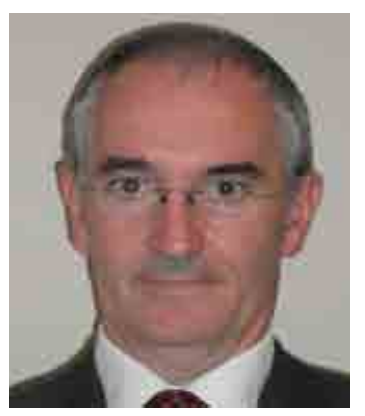

\section{Javier Orozco Messana}

Universitat Politecnica de Valencia;Edificio “Nexus" 6G, 4ª planta; Camino de Vera s/n; 46022 Valencia

jaormes@cst.upv.es

Doctor Ingeniero Industrial. Desarrolla su actividad docente en la Escuela Técnica Superior de Ingeniería de la Edificación en la Universitat Politécnica de Valencia y su faceta investigadora en el Instituto de Tecnología de Materiales en la propia universidad. Sus líneas de trabajo se centran en el estudio y análisis de materiales fotovoltaicos, desarrollo de sostenibilidad a través de los materiales y el tratamiento de hormigones reforzados con fibras. Dirección Universitat Politecnica de Valencia;Edificio “Nexus" 6G, 4a planta; Camino de Vera s/n; 46022 Valencia, Spain. Correo: 


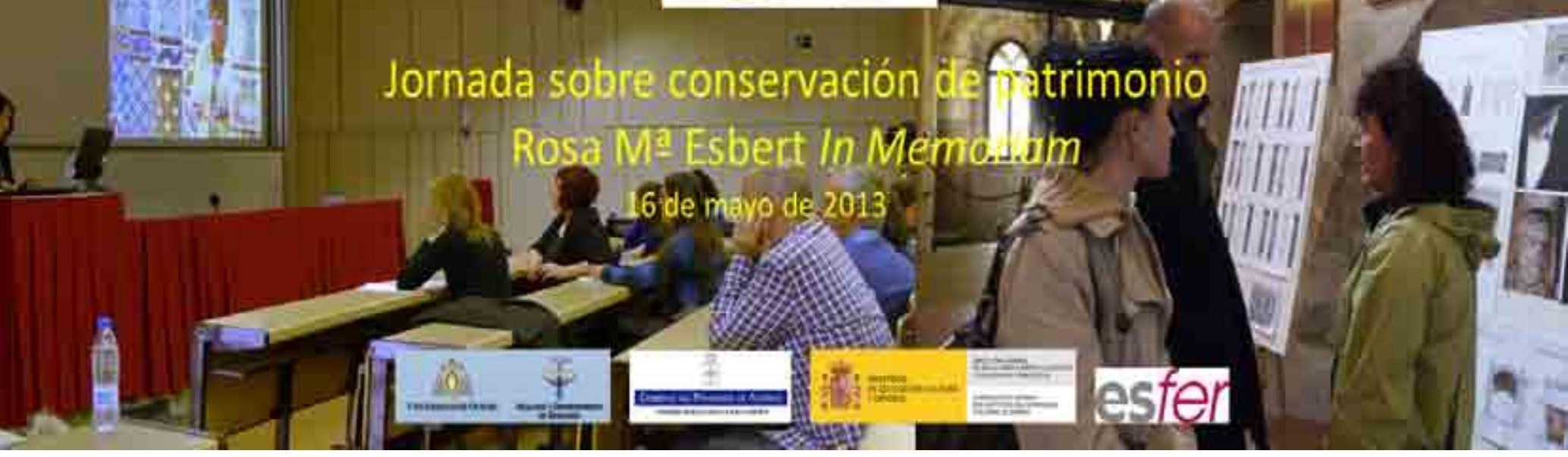

\title{
Cruz de término y fuente de mármol en uso: exposición de ambos casos.
}

\author{
Núria Avecilla Palau, Marta Llach Berné y Manuel Ángel Iglesias Campos
}

Resumen: La cruz de término de El Masnou y la fuente de mármol del Palau Mercader de Cornellá del Llobregat son dos intervenciones sobre material pétreo in situ del programa de conservación y restauración que la Diputación de Barcelona creó como soporte técnico, de colaboración y cooperación con los museos adheridos a la Xarxa de Museus Locals. Este programa, cuyo objetivo es establecer planes de conservación preventiva y de seguimiento a medio y largo plazo con los que controlar, mantener y conservar el patrimonio cultural local en las mejores condiciones posibles, supone además, en algunos casos, intervenir in situ con personal propio de la Oficina de Patrimonio Cultural. Con esta metodología, adaptada a los medios técnicos y económicos disponibles en la actualidad, se prevé llevar el seguimiento de los bienes intervenidos y la eficacia de los tratamientos y materiales utilizados.

Palabras clave: Crucero/cruz de término, fuente de mármol, arenisca silícea, conservación preventiva in situ, restauración de piedra in situ, alveolización, costra negra, aerosol marino, biodeterioro, concreción calcárea.

\section{Case study: a wayside cross and a marble fourtain in use.}

\begin{abstract}
The wayside cross in El Masnou and the Palau Mercader marble fountain in Cornellá de Llobregat are two on-site interventions on stone objects within the conservation and restoration program created by the Diputació de Barcelona as technical support in partnership and cooperation with the local municipal museums network. This article presents the beginning of on-site restoration work with our own Cultural Heritage Office staff, the purpose of which is to establish medium and long-term follow-up preventive conservation plans to control, maintain and preserve the local cultural heritage in the best possible conditions. These programs will allow degradation processes of the objects to be evaluated, and the efficiency of the treatments and materials used to be determined. At the same time, these programs should be viable and adapt to the existing available technical and economic resources.
\end{abstract}

Key words: Wayside cross, fountain, siliceous sandstone, marble, in situ preventive conservation, alveolization, black crust, biodeterioration, sea spray, calacareous crust

\section{Cruz de Término}

Esta propuesta de intervención ha sido realizada a instancia del Museo de la Náutica de El Masnou -municipio de la costa a $17 \mathrm{~km}$ al noroeste de Barcelona-, para determinar el estado de conservación de la cruz y los tratamientos necesarios para su preservación in situ.

La cruz de término, declarada Bien Cultural de Interés Nacional en 1963, es uno de los elementos patrimoniales con mayor valor histórico y artístico del municipio. Se trata de uno de los pocos testimonios medievales que allí se conservan. La inscripción ANNO CHRISTI MD que aparece en la base la dataría en 1500. Antiguamente se encontraba en la actual avenida Joan XXIII, en el camino de Alella, delimitando los términos territoriales de Teià y Alella, cuando El Masnou aún no existía como municipio. Su ubicación cambió hacia el año 1818, cuando en la necrópolis de la iglesia de Sant Pere se construyó el conocido como cementerio 
viejo y allí fue trasladada. En 1868 con la construcción del actual cementerio proyectado por el arquitecto municipal Miquel Garriga i Roca, la cruz fue trasladada de nuevo y se colocó sobre un basamento de mampostería en el centro del recinto, como emblema religioso. A lo largo del siglo $X X$, en el parterre que la rodea, fueron colocadas tres placas conmemorativas que recogen diferentes hechos históricos del Masnou.

El cementerio cuenta además con panteones de gran valor artístico en los que participaron importantes arquitectos catalanes de los siglos XIX y XX como Bonaventura Bas-

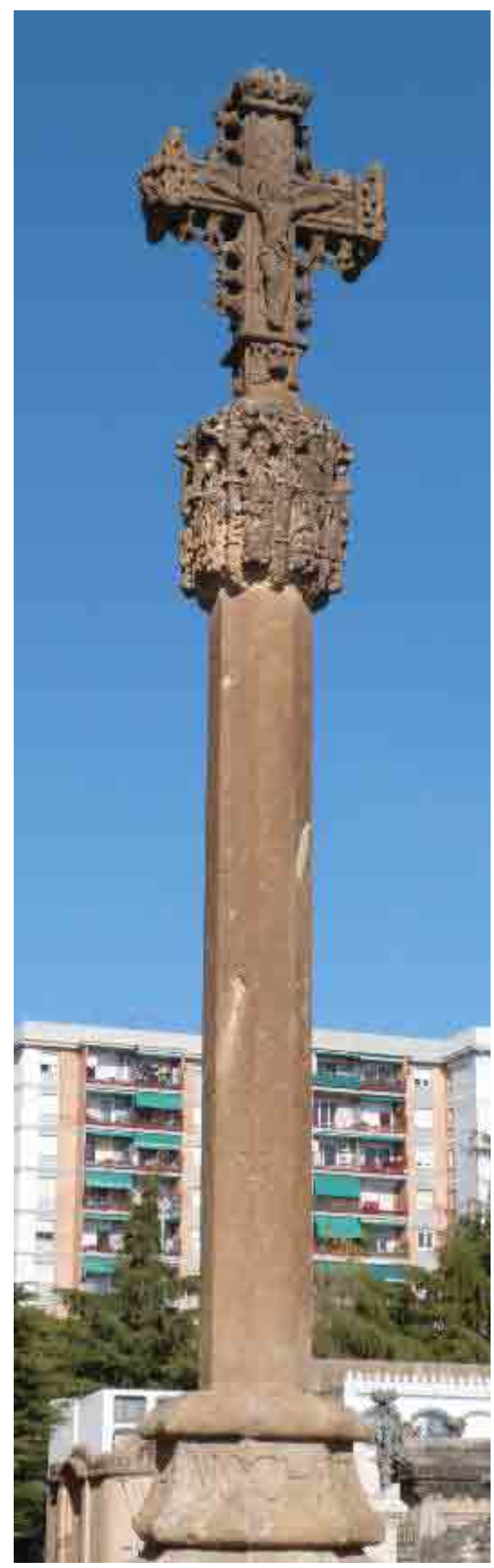

Figura 1. Vista general de la cruz segoda, Pere Jordi Bassegoda o Josep Llinàs, y escultores como Josep Llimona, Frederic Marés, Rafael Atché o Josep Maria Subirachs entre otros.

El cementerio es para el municipio un testimonio de parte de su historia, un bien artístico y un lugar de interés histórico cultural local en proceso de recuperación y de dinamización.

A pesar del mal estado de conservación del capitel, con alveolizaciones y pérdidas de volumen acentuadas, la voluntad del consistorio de conservar la cruz en su contexto histórico fundamenta este proyecto de restauración. La intervención se proyecta como un primer paso dirigido a frenar los procesos de alteración para posteriormente implantar un plan de conservación preventiva. Este programa de control y mantenimiento servirá para evaluar la nueva situación, determinar si el proceso de degradación continúa y a qué velocidad lo hace, y servirá para aportar soluciones que prolonguen su conservación en su ubicación actual.

\section{Datos técnicos y estilísticos:}

Nombre: Cruz de término

Material: Arenisca silícea

Datación: 1500 según la inscripción MD

Medidas: Aproximadamente 3,60 m de altura y de base octogonal

Localización: Cementerio del Masnou

Protección: Bien Cultural de Interés Nacional el 1963, según Decreto 14/3/1963 número 571/63. Decreto de protección de los escudos, emblemas piedras heráldicas, rollos de justicia, cruces de término y piezas similares de interés histórico/artístico.

La Cruz de término [figura 1], compuesta por base, fuste, capitel y cruz, es de estilo gótico tardío y presenta características parecidas a las localizadas en los municipios colindantes de Teià y Alella.

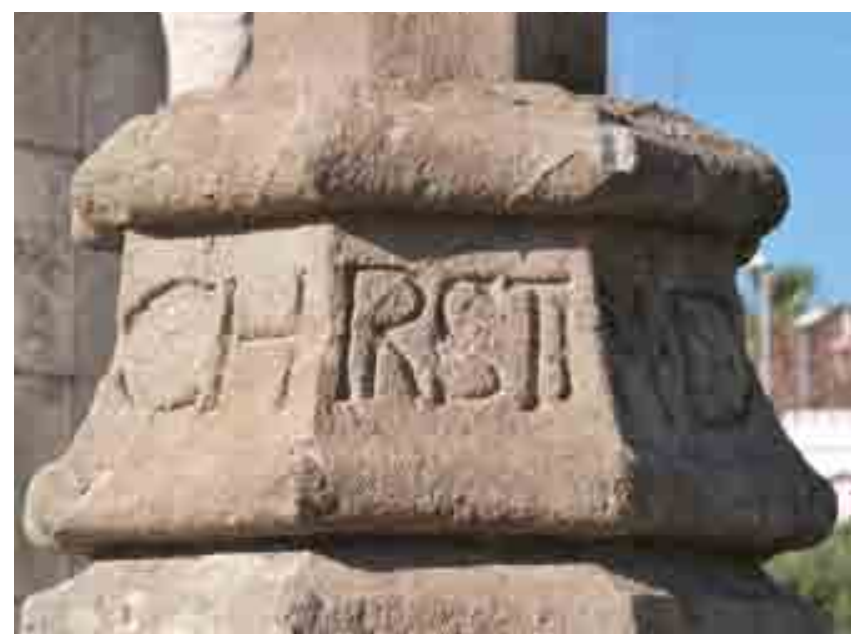

Figura 2. Base de la cruz donde aparece la inscripción ANNO CHRISTI MD 
La base es octogonal y está decorada por una moldura, con la inscripción ANNO CHRISTI MD [figura 2]. El fuste, también octogonal, se remata con un capitel esculpido con la imagen de ocho santos no identificados debido al mal estado de conservación dentro de hornacinas de factura gótica. La cruz, decorada con motivos vegetales y hojas de acanto, tiene dos relieves dispuestos en cada una de sus caras: en una, la imagen de Cristo crucificado con la calavera a los pies; en la otra, la imagen de la Virgen con el Niño en brazos.

\section{Descripción y diagnostico del estado de conservación}

El material pétreo natural en el que está construida esta Cruz es una arenisca silícea, con ligeras variaciones de composición según la pieza concreta, que presenta ligera descohesión. Existen diferentes tipologías de morteros de cal aérea e hidráulica que parecen relacionarse con los diferentes traslados y montajes que ha tenido la pieza, así como diferentes morteros de cemento, localizados principalmente en el basamento de mampostería. Los morteros de cal presentan en general un buen estado de conservación y no se aprecian degradaciones significativas.

Se conservan, además, dos cromatizaciones artificiales que se corresponden a dos momentos diferentes: una ocre y otra rosa. La ocre, localizada principalmente en el capitel, parece estar hecha de pigmentos tierras y ser la más antigua de las conservadas. La de color rosa recubre de manera casi general zonas con suciedad y morteros de juntas; en la mayoría de los casos, sobretodo en la cruz, tiene un aspecto de veladura y por su ubicación podría considerarse la más moderna de las dos.

El conjunto presenta un estado de conservación muy desigual según la pieza concreta y su orientación. Las alteraciones principales se localizan sobretodo en el capitel y la cruz de coronamiento y se relacionan con pérdidas de volumen, pequeñas descamaciones, costras de suciedad compactada, recubrimientos biogénicos y costra negra dendrítica localizada; además el capitel tiene alveolizaciones importantes.

Existe una gran diferencia de suciedad y acumulación de depósitos superficiales entre la zona superior (cruz y capitel) y la inferior (fuste y base). Los primeros tienen costras de suciedad compactada y el capitel, además, costra negra dendrítica puntual en zonas donde se conserva la cromatización ocre. El fuste tiene una capa de suciedad muy superficial y la base está limpia, lo que por comparación con las partes superiores podría indicar que el fuste tuvo un tratamiento de limpieza quizás en algunos de los traslados y montajes, y que la base, a parte de una posible limpieza como el fuste, recibe agua en su superficie durante el riego de mantenimiento del parterre en el que se encuentra el conjunto.

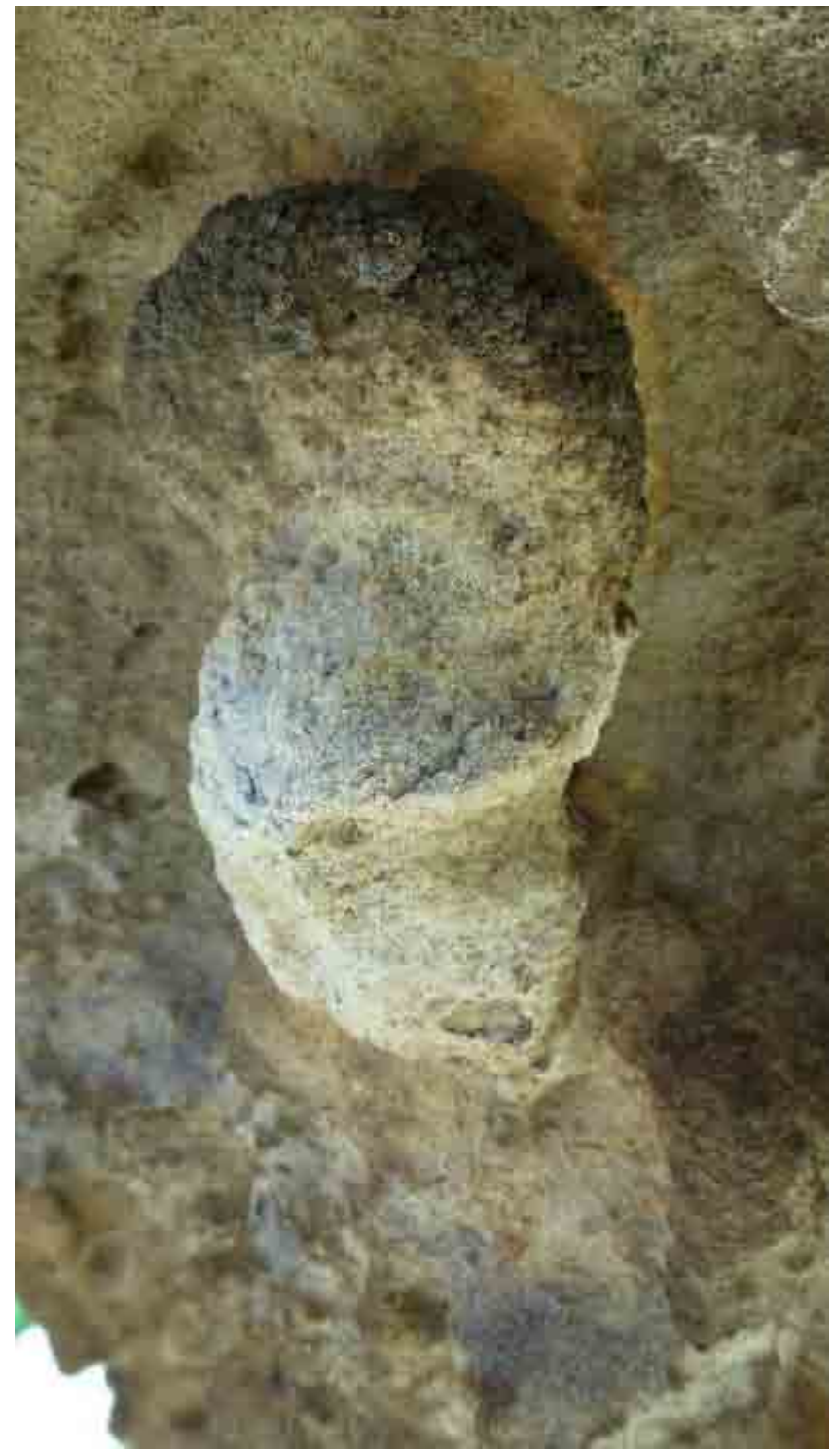

Figura 3. Detalle del santo de la cara sudeste en peor estado de conservación

Además de la suciedad superficial, la base y el fuste se encuentran en buen estado de conservación y sólo presentan algunas pérdidas puntuales de materia por disyunción, abrasión o golpes.

En el capitel existe una clara diferencia entre el grado de degradación que presentan la Cara Este y la Cara Noroeste debido a los factores de alteración que les afectan, propios de su ubicación a la intemperie.

La Cara Este está más expuesta a los agentes meteorológicos y ambientales (sol, lluvia, viento y aerosol marino) y presenta alveolización, erosión y arenización localizada en una de las figuras de los santos. [Figura 3]

La Cara Noroeste: más sombría y no tan expuesta, presenta estratos de suciedad acumulada en forma de costras y ataque biológico. La pérdida de detalles escultóricos y decorativos también es evidente aunque el grado de erosión es 


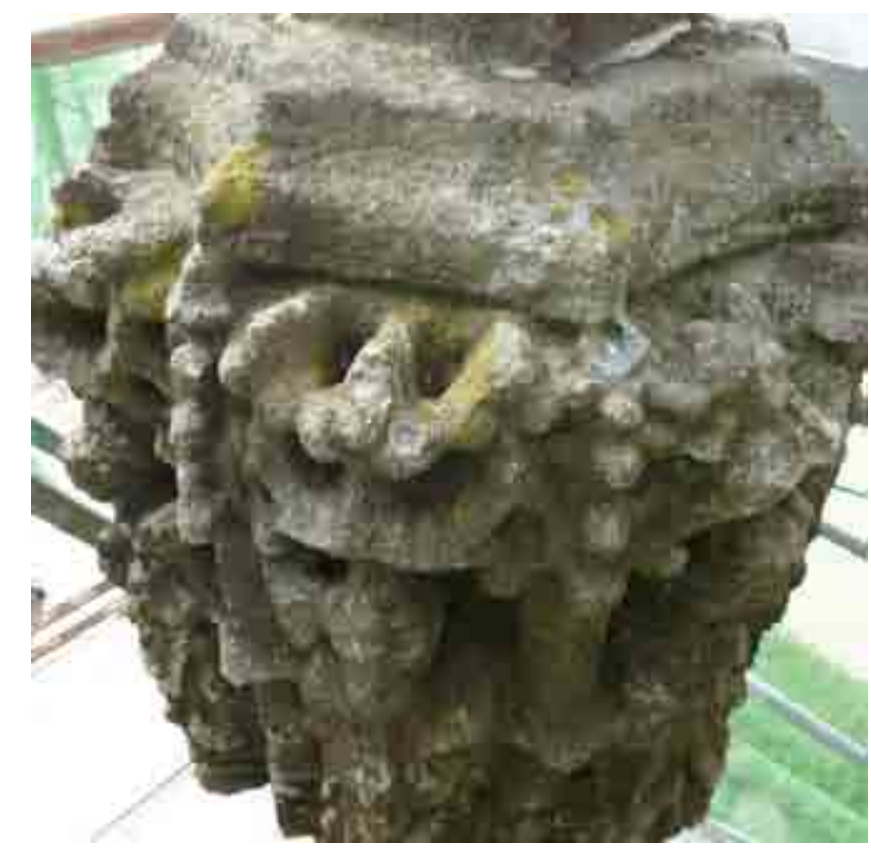

Figura 4. Vista del capitel por la cara Noroeste, más sombría, con presencia de costra y biodeterioro

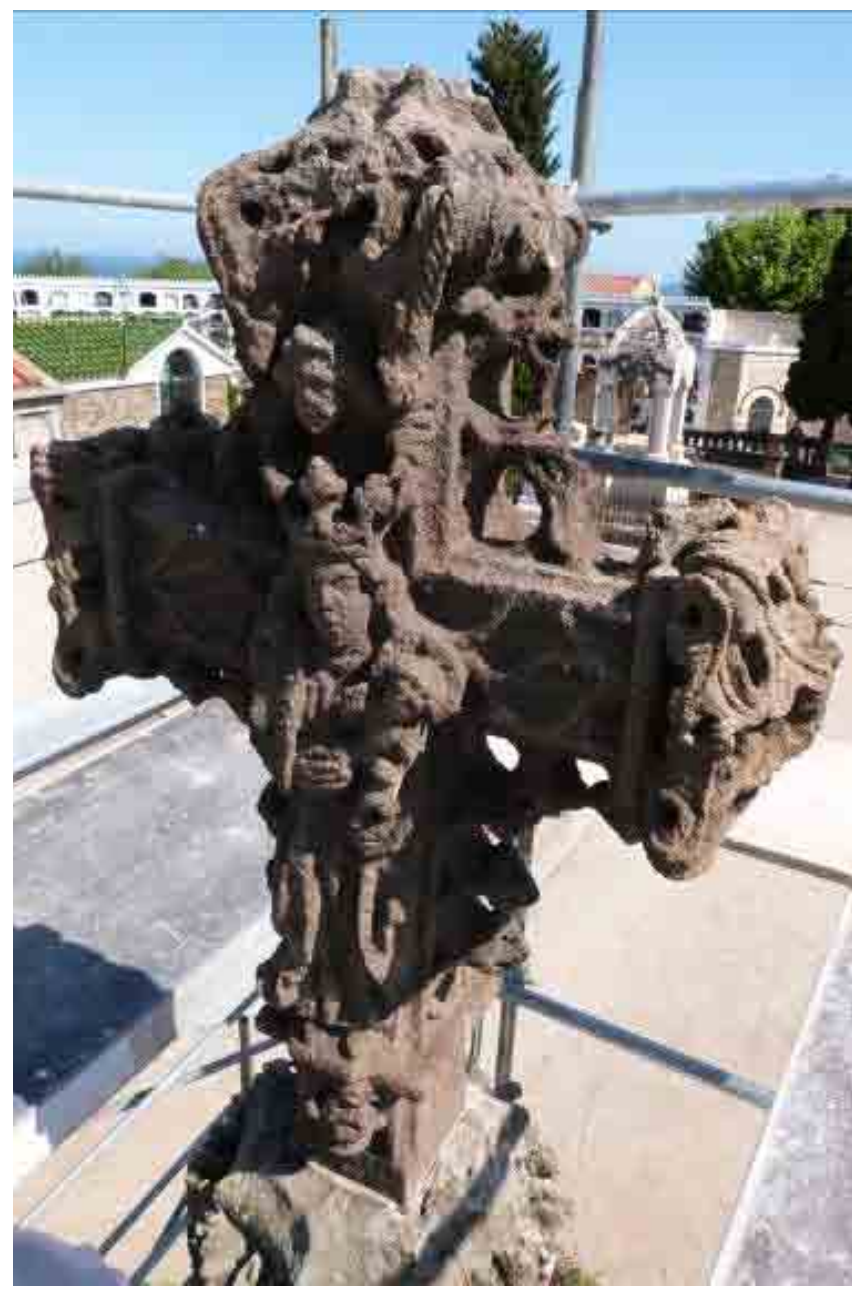

Figura 5. Vista de la cruz y el capitel desde el lado Noreste. menor que el de la Cara Este y, a simple vista, no se aprecia arenización ni descohesión de la piedra. [Figura 4]

La Cruz, con un estado de conservación regular, presenta depósitos y costras superficiales y no se aprecian alteraciones que indiquen pérdida de cohesión de la piedra. [Figura 5]

\section{Propuesta de conservación y restauración}

Está prevista una fase previa de estudios con la que, a partir de unos análisis mínimos que faciliten la información imprescindible para la toma de decisiones y con un coste reducido, poder establecer los tratamientos necesarios para su conservación. A falta de los resultados de este estudio, los tratamientos que se proponen contemplan la estabilización y protección de la piedra, el saneamiento y la eliminación de los productos de alteración, así como un posterior control y seguimiento de los posibles agentes de degradación.

Los trabajos previstos consistirán en:

Desalación si los análisis confirman la presencia de sales solubles.

Preconsolidación antes de la limpieza en caso que exista un alto grado de descohesión de la piedra.

Limpieza. Como ya ha sido indicado, la agresión del ambiente sobre la cruz es diversa y depende tanto de la zona como de su orientación geográfica y espacial. Por ello, antes de iniciar la limpieza, se diferenciarán con mayor exactitud los diferentes grados de deterioro para poder seleccionar el método más efectivo y menos agresivo con el soporte pétreo. Para la eliminación de la suciedad y las costras se priorizará la limpieza manual y mecánica, con el uso de bisturí, micromotores o microproyección de abrasivos. Se realizará limpieza química cuando la limpieza mecánica no sea efectiva, previa realización de pruebas y catas.

Consolidación con producto inorgánico exclusivamente en las zonas que lo requieran y cuando el sustrato se muestre descohesionado.

Reintegración con mortero de cal hidráulica como medida preventiva; se realizará principalmente en las zonas con pérdidas volumétricas del capitel y del fuste. Su función será la de sellado para evitar la retención del agua y la erosión del viento.

Protección de la piedra con hidrofugante si al terminar la intervención se considera que la acción del agua de la lluvia puede incrementar su deterioro. 


\section{FUENTE DE MÁRMOL EN USO}

La intervención en esta fuente de mármol, solicitada por el Museo Palau Mercader de Cornellá del Llobregat, tiene como objetivo recuperar su aspecto y función originales. Can Mercader es un palacio de estilo romántico construido en 1865 por la familia Mercader-Bell•|loc, perteneciente a la nobleza catalana. Los condes de Bell-lloc trasladaron allí las colecciones que tenían en sus otras residencias y las distribuyeron por las salas con una intención marcadamente expositiva.

El ayuntamiento de Cornellá del Llobregat adquirió la finca en 1974 y tras un período de rehabilitación, la abrió al público como museo en 1995. El Palau Can Mercader es hoy un museo que muestra las afinidades y los gustos artísticos de una familia aristocrática de finales del siglo XIX.

La fuente se debió construir al mismo tiempo que el palacio y está ubicada delante de la entrada principal del museo en el centro de un pequeño estanque.

\section{Datos técnicos y estilísticos:}

Nombre: Fuente

Material: Mármol blanco

Datación: hacia 1865

Medidas: $2,23 \times 1,40 \mathrm{~m}$

Ubicación: Parque público Can Mercader, Cornellá del Llobregat, Barcelona

La fuente consta de dos platos circulares decorados en la cara inferior con molduras y soportados por un eje formado por 3 tres balaustres, el inferior decorado con hojas y molduras, el central sólo molduras, el superior es liso y termina en surtidor de agua.

\section{Diagnóstico del estado de conservación:}

Presentaba una gruesa estratificación de concreciones calcáreas de diferentes durezas debido a la falta de limpieza durante más de 50 años. Es necesario remarcar que el agua que abastecía la fuente procedía de una mina, hasta que hacia el año 2000 pasó a suministrarse con la red de agua potable.

El grosor y peso de las concreciones, además de formar una cobertura exterior con musgo y plantas superiores que le dieron un aspecto parecido a un árbol, también ponían en peligro la estabilidad e integridad de la fuente. [Figura 6]

En 1999/2000 debido a problemas con el surtidor, se instaló un tubo de cobre externo, agujereando los dos platos de mármol y cubriendo el tubo con cemento rápido. Las concreciones calcáreas se dejaron intactas.

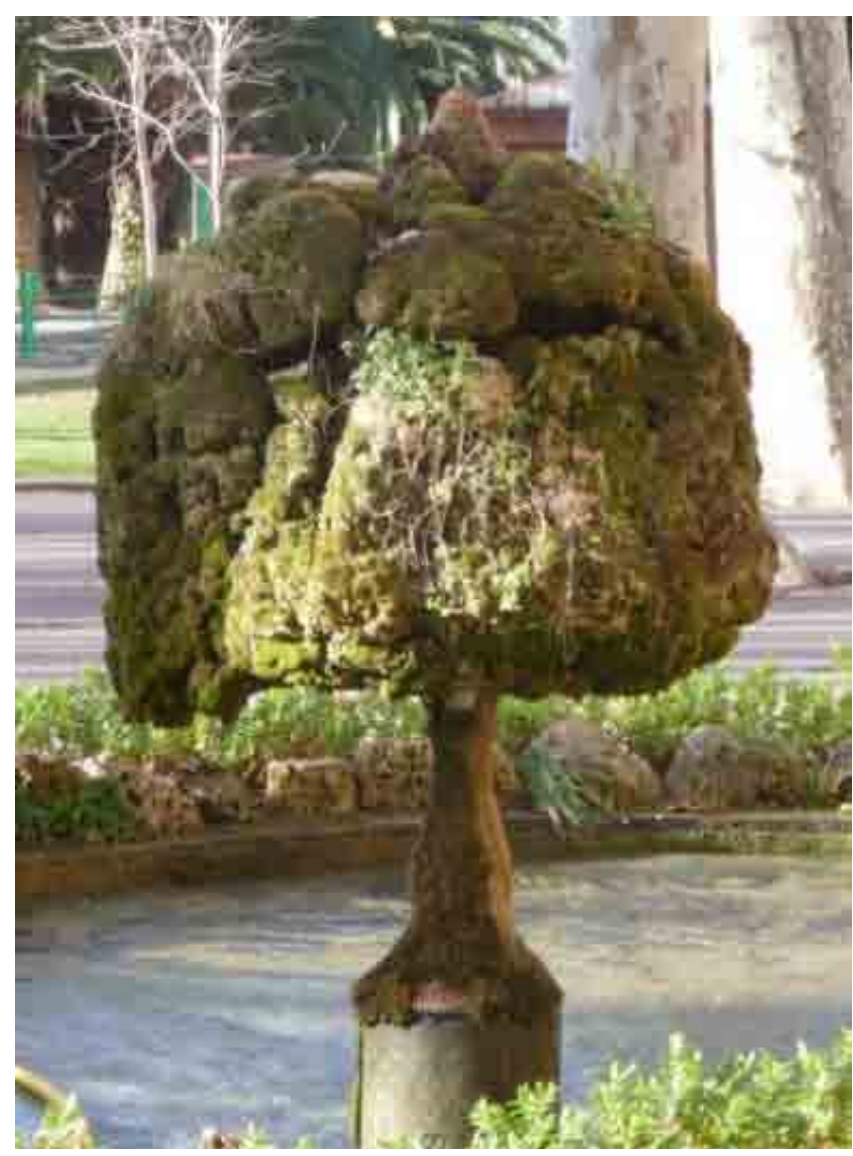

Figura 6. La fuente del Palau Mercader antes de la $1^{\text {a }}$ fase de la intervención

\section{Proceso de intervención}

Eliminación de las concreciones. En la primera fase de intervención se empezó eliminando manualmente la capa externa de musgo y vegetación. Debajo de esta aparecieron las raíces de musgo, con estratos arenosos de sedimentación muy compactos y concreciones calcáreas formadas por precipitación del carbonato cálcico del agua de mina, de durezas, formas y grosores muy diferentes; algunas de ellas, sobre todo las que cubrían el plato inferior, alcanzaban los $50 \mathrm{~cm}$ de espesor. También se encontraron otros elementos vegetales fosilizados o carbonatados como hojas de plátano y estalagmitas con formas coralinas. [figura 7]

La retirada de todos estos recubrimientos calcáreos junto con otros elementos, como piedras y restos de materiales, se hizo manual y mecánicamente, utilizado martillos y escarpas en combinación con radiales y martillos neumáticos eléctricos [figura 8]. Una vez extraídos llenaron 1 saco y medio de escombros, lo que equivale a aproximadamente $1 \mathrm{~m}^{3}$ de volumen y $1000 \mathrm{Kg}$. de peso.

Cuando se alcanzaron las capas más internas y cercanas a la superficie del mármol se utilizaron micromotores eléc- 


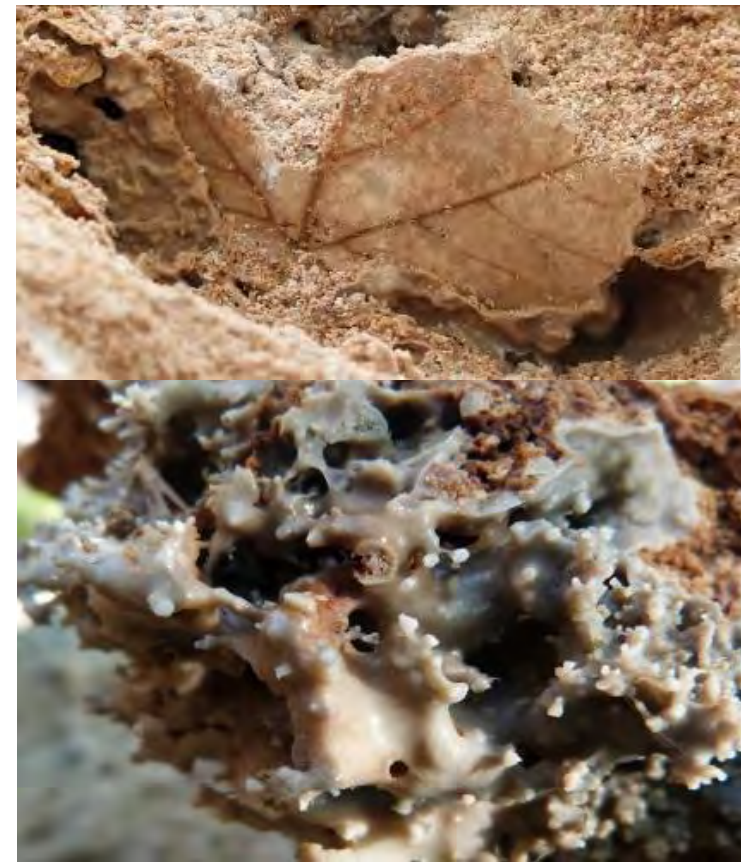

Figura 7. Elementos vegetales fosilizados o carbonatados

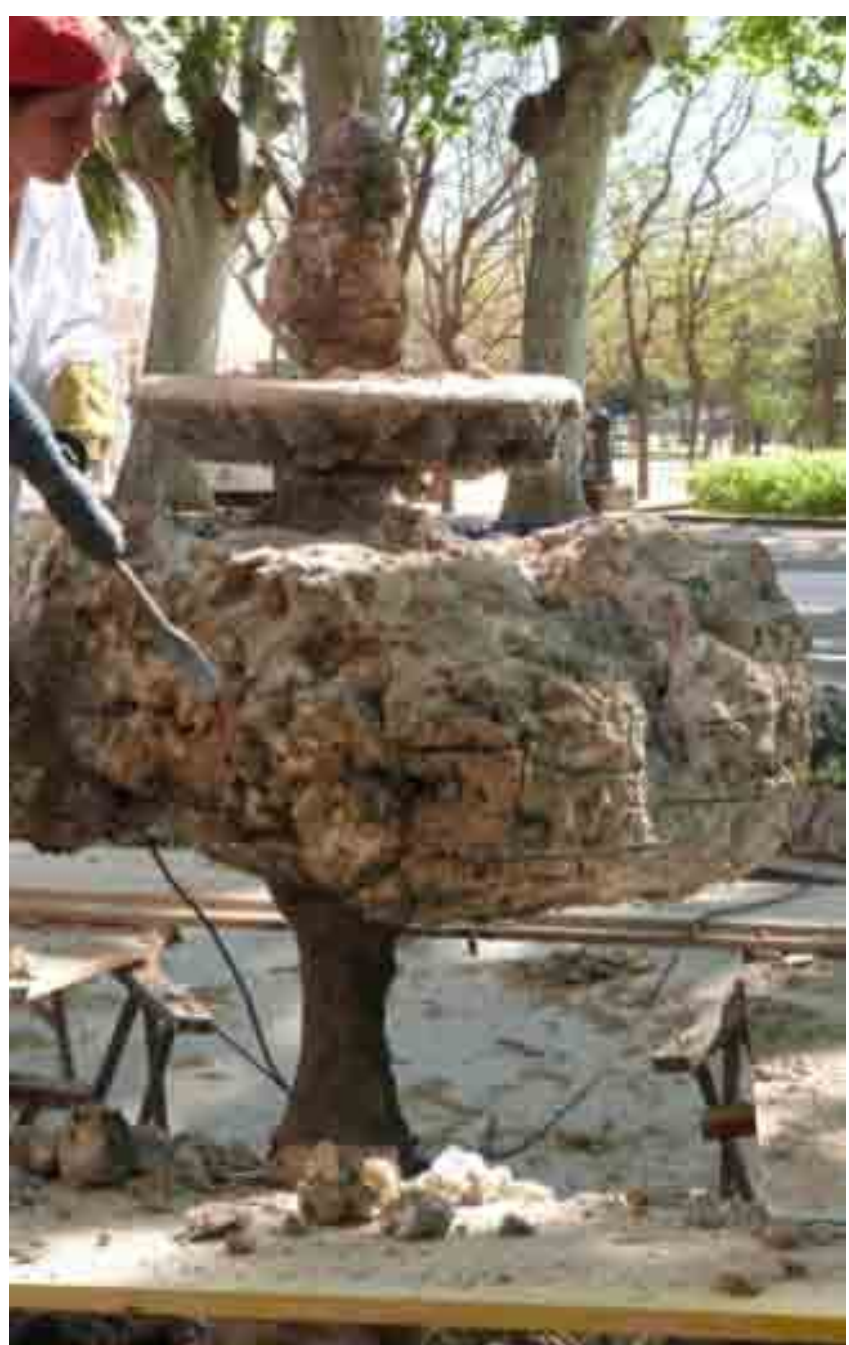

Figura 8. La fuente del Palau Mercader durante la $1^{\text {a }}$ fase de intervención

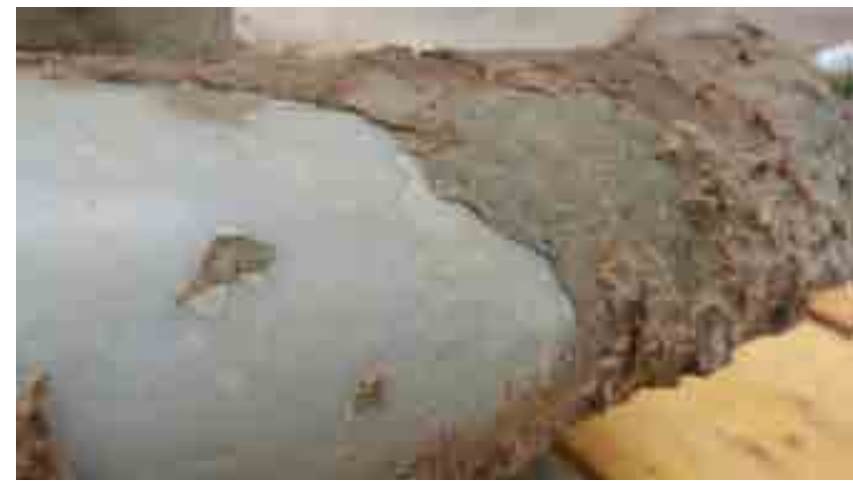

Figura 9. Estratos calcáreos en la superficie

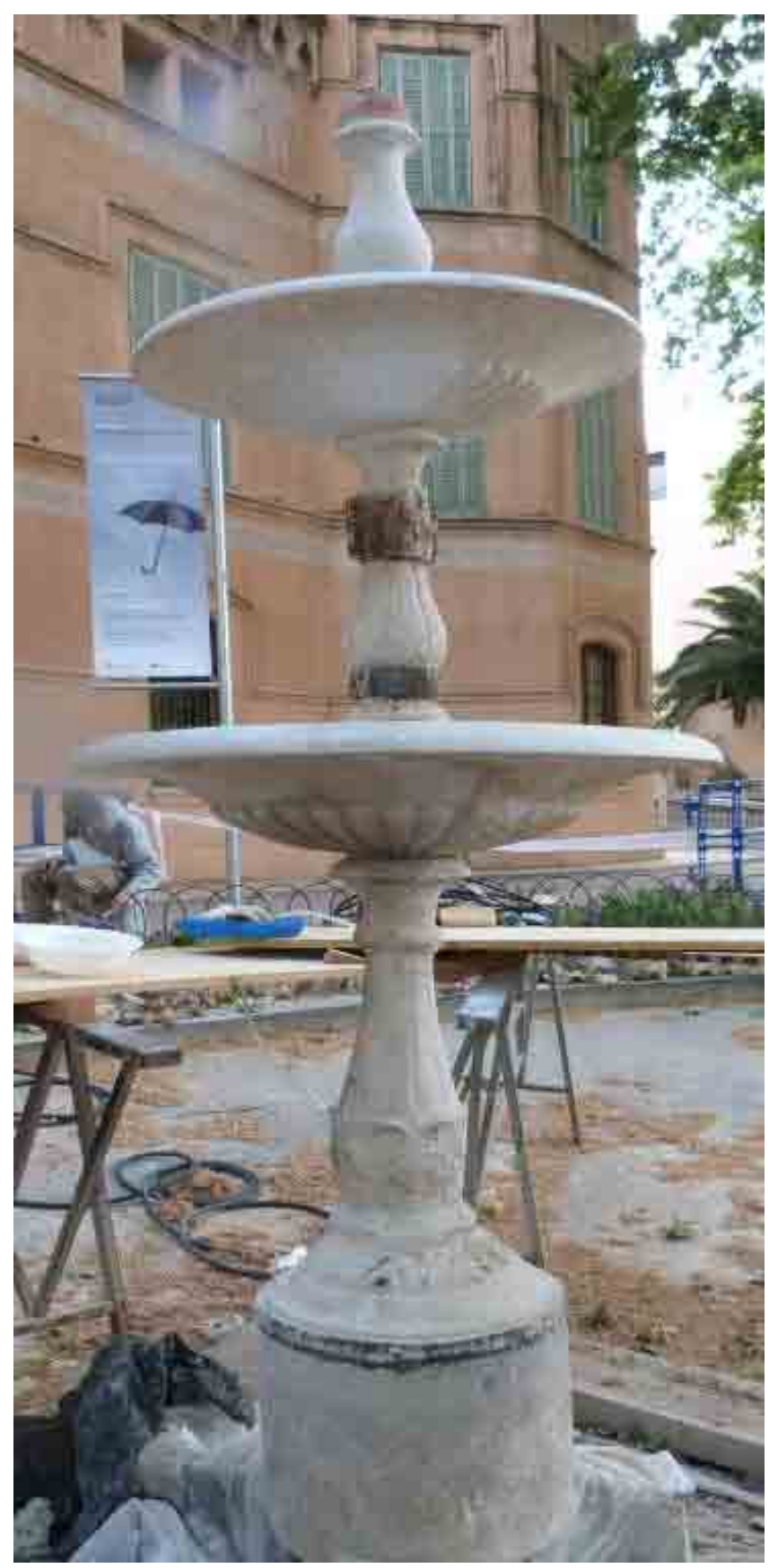

Figura 10. La fuente del Palau Mercader después de la 1a fase de intervención 
tricos y micromartillos neumáticos de mayor precisión.

Por último, ya en contacto con la superficie del mármol, se identificaron cuatro estratos calcáreos muy finos [figura 9]. Para su eliminación se usaron bisturís y cepillos metálicos en combinación con apósitos de carbonato de amonio y EDTA al 10\%, en intervalos de 10 minutos para reblandecer las capas. Con ello se consiguió una limpieza de la superficie del mármol hasta recuperar los volúmenes y formas decorativas. Además se pudieron identificar algunas de las juntas de unión de los elementos escultóricos, lo cual ayudó a entender su estructura y sistema de montaje.

En la parte superior de los platos se consiguió un grado de limpieza uniforme, aunque no exhaustiva, y parcialmente se llegó al nivel del mármol. Sin embargo, en la parte inferior de los platos y en las balaustradas no fue posible la eliminación total de las capas.

En el balaustre central, entre los dos platos, aparecieron dos pernos de hierro soldados que esconden una reparación anterior o una posible fractura de la pieza. Estos elementos metálicos se limpiaron con micromotor y se les dio un tratamiento antioxidante con ácido tánico como estabilizador y una protección antihumedad con dos capas de resina epoxi.

Una vez recuperada la visión de la fuente en su totalidad se observó que estaba mal montada; así como también desplazada del eje central y que el plato superior estaba ligeramente inclinado.
Por su complejidad, después de consensuarlo con los responsables del Museo y de la Diputación, se creyó conveniente interrumpir la restauración en esta primera fase dejando la fuente presentable al público e in situ. [figura 10] Tras este proceso queda pendiente una segunda fase en la cual se estudiará la posibilidad de desmontar la fuente y restaurarla en laboratorio para volverla a colocar en su ubicación original. Para ello será necesario localizar todas las juntas de unión de las diferentes piezas que componen la fuente y la naturaleza y grado de dureza y reversibilidad de las mismas. Se realizarán pruebas de eliminación que nos ayudarán a valorar la viabilidad o no del desmontaje completo.

Si esto fuera posible nos permitiría realizar la limpieza exhaustiva de todas las piezas y quizás recuperar el conducto original de canalización del agua; también se intentará extraer los pernos de hierro del balaustre reparado y valorar el estado de conservación del mismo.

Si esta intervención pudiera suponer algún riesgo para la fuente, deberán ser estudiadas otras opciones como, por ejemplo, desmontarla parcialmente o incluso no desmontarla y realizar in situ la restauración final.

\section{Bibliografía}

BASTARDES, A. (1983). Les Creus al Vent, Col•lecció Aire Lliure-1, Barcelona, Editorial Milla.

RICO VÁZQUEZ, M., ROIG LERONE, M. (2008). “El cementiri del Masnou, un museu a l'aire lliure (segles XVIII-XXI)". III Beca d'Investigació i de Recerca Local del Masnou, 2006. Roca de Xeix, número 27. Ajuntament del Masnou, Patronat Municipal

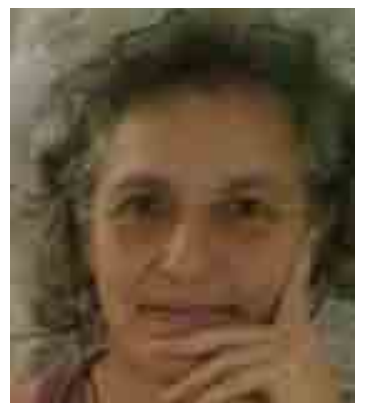

Núria Avecilla Palau

Diputación de Barcelona avecillapn@diba.cat

Licenciada en Conservación-Restauración por la Universidad de Barcelona. Profesora de Restauración Arqueológica en la Escuela de Artes y Oficios de la Diputación de Barcelona (1988-2010). Imparte clases de Técnicas Artísticas en el Grado de Historia del Arte de la Universidad Autónoma de Barcelona. Técnica de la Oficina de Patrimonio Cultural de la Diputación de Barcelona. Conservadora Restauradora de Vidrio, Mosaico, Piedra y Pintura Mural Romana. 


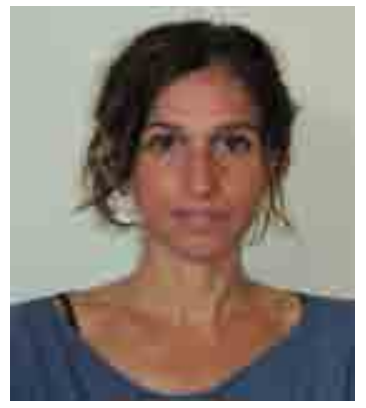

\title{
Marta Llach Berné
}

Diputación de Barcelona

Ilachbm@diba.cat

Licenciada en Historia del Arte por la Universidad de Barcelona. Diplomada en Restauración de Cerámica y Materiales Pétreos por l'Istituto per l'Arte e il Restauro Palazzo Spinelli de Florencia. Postgrado en Gestión de Empresas Culturales y en Gestión de Proyectos Culturales por la UOC (Universitat Oberta de Catalunya). Técnica de la Oficina de Patrimonio Cultural de la Diputación de Barcelona.

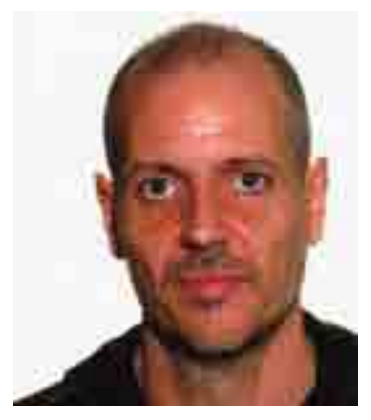

\author{
Manuel Ángel Iglesias Campos, \\ Universidad de Barcelona \\ manuel.iglesias@ub.edu
}

Doctor en Conservación-Restauración por la Universidad de Barcelona. Miembro de los grupos de investigación CETECPatrimoni (UAB-IQS) y Conservació-Restauració del Patrimoni (UB). Actualmente es profesor de la Secció de ConservacióRestauració de la Facultat de Belles Arts (Universitat de Barcelona). Su línea de investigación se centra en el tratamiento de materiales del Patrimonio Arquitectónico y Monumental. 


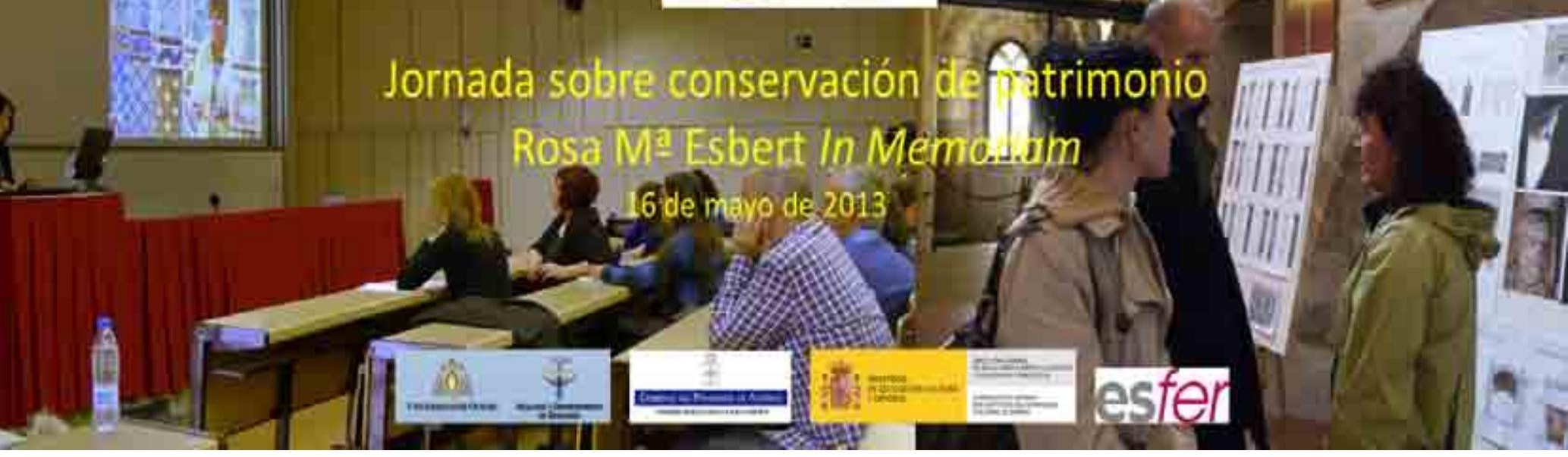

\title{
Intervención sobre el revoco decorativo de la muralla romano- medieval de León.
}

\author{
Aránzazu Álvarez Villalibre.
}

Resumen: En este artículo se presenta la restauración de un elemento singular por ser uno de los pocos ejemplos existentes conservados en la actualidad. La mayor parte de nuestro Patrimonio inmueble ha llegado a nuestros días con sus paramentos limpios, cuando, en realidad, estaban dotados de una epidermis que cumplía una doble función: protectora y decorativa. La desaparición de estos revocos ha conllevado la pérdida de elementos artísticos tanto pictóricos como escultóricos, y la desaparición de una valiosa información para el estudio histórico. Aunque hay algunos artículos referidos al revoco de la muralla, aún no se ha estudiado con la profundidad necesaria.

Palabras clave: Restauración, mortero, revoco, muralla, arquitectura, decoración, medieval.

\section{Intervention on the wall decorative plastering roman medieval of León.}

\begin{abstract}
The wayside cross in El Masnou and the Palau Mercader marble fountain in Cornellá de Llobregat are two on-site interventions on stone objects within the conservation and restoration program created by the Diputació de Barcelona as technical support in partnership and cooperation with the local municipal museums network. This article presents the beginning of on-site restoration work with our own Cultural Heritage Office staff, the purpose of which is to establish medium and long-term follow-up preventive conservation plans to control, maintain and preserve the local cultural heritage in the best possible conditions. These programs will allow degradation processes of the objects to be evaluated, and the efficiency of the treatments and materials used to be determined. At the same time, these programs should be viable and adapt to the existing available technical and economic resources.
\end{abstract}

Key words: Restoration, morter, plastering, wall, architecture, decoration, Medieval

\section{Introducción}

La Muralla Medieval de León en su origen debía estar totalmente revocada. En la actualidad dicho revoco se conserva en contados puntos de la misma, ha desaparecido, en su mayoría, por su abandono y posterior deterioro o ha sido eliminado durante las intervenciones que ésta ha sufrido a lo largo del tiempo, por no considerarlo de la suficiente entidad e importancia.

Gracias a los esfuerzos de, entre otros, el arqueólogo Julio M. Vidal Encinas, con sus estudios y publicaciones referentes a este revoco, se le ha devuelto la importancia y relevancia que merece.
Con las obras de emergencia ya iniciadas sobre los cubos denominados E5 y E6 del tramo de la carretera de los Cubos de León se decidió sobre la marcha la conservación del revoco situado en el cubo E6, para lo cual la empresa adjudicataria de la obra me solicitó elaborar la propuesta de tratamiento.

\section{Reseña histórica. Aspectos técnicos del revoco}

Como ya es bien sabido por todos, desde la Antigüedad las arquitecturas se han cubierto con decoraciones de múltiples maneras y formas. Desgraciadamente, la mayoría de estos recubrimientos no han llegado hasta nuestros días 
por diversas razones, con lo cual, nos hemos acostumbrado a ver los muros de los monumentos desnudos, con la piedra vista.

En los libros miniados la arquitectura es un tema constante, así que, gracias a los ejemplos que se conservan y al estudio de esas iluminaciones podemos conocer mucho mejor cómo eran esas ricas ornamentaciones.

La Muralla de León data de época romana, pero según consta en la documentación histórica se realizaron reconstrucciones a comienzos del siglo XIII. Para ello emplearon una fábrica de cal y canto rodado, que se diferencia al primer golpe de vista de la fábrica original romana con paramentos de opus incertum formados por bloques de cuarcita, caliza y arenisca. Además de cantos rodados, en el cubo, también colocaron grandes sillares de conglomerado, que en la zona del revoco se dejan totalmente vistos.

Es en ese momento del siglo XIII donde hay que situar este revoco decorativo. Se encuentra a unos 8 metros de altura [Figura 1]. Ocupa una superficie de 36 metros cuadrados, que rodea por completo el cubo, salvo por una gran laguna. Mide 19 metros de largo y 1.90 de ancho. No se han tomado muestras para analíticas pero a simple vista se aprecia que el mortero está básicamente realizado con cal y áridos de diferentes granulometrías, además de ladrillo machacado y cenizas de madera. Tiene un grosor variable entre 2 y $4 \mathrm{~cm}$. Visto de cerca es un mortero de textura muy rugosa debido al grosor del árido, aunque por otro lado, es muy apropiado para el monumento en el que se encuentra por su función defensiva.

El revoco cubre casi en su totalidad la mampostería. La técnica que emplearon para la decoración fue la incisión
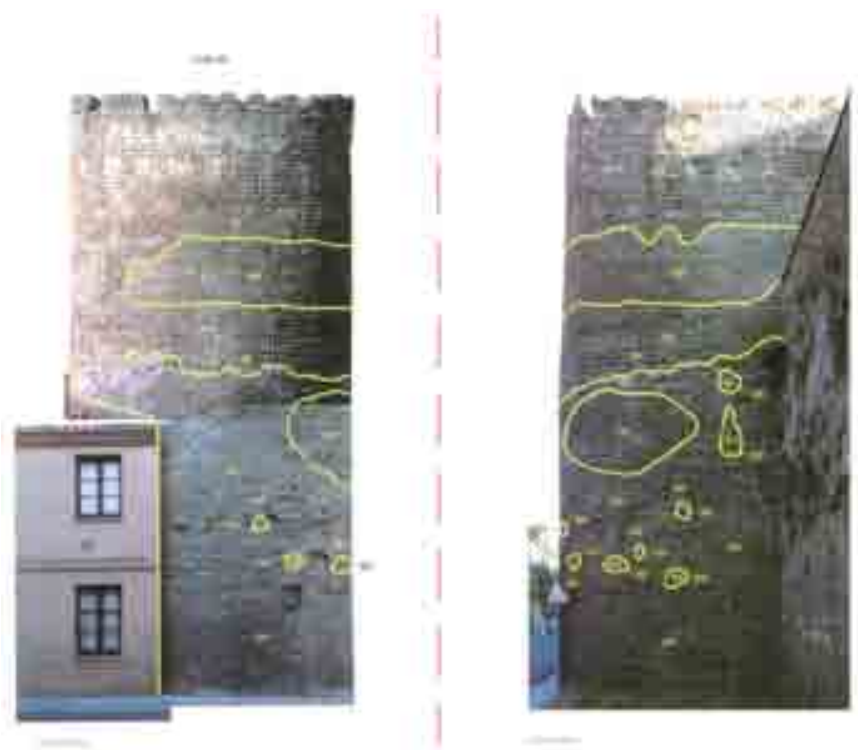

Figura 1. Revoco decorativo de la muralla de una de sus herramientas de trabajo, probablemente la paleta, sobre el mortero aún fresco. La decoración es de tipo geométrico bastante sencilla. Se basa en una serie de líneas horizontales paralelas conformando bandas dentro de las cuales se hicieron otras líneas oblicuas que se intercalan entre los cantos rodados que han dejado descubiertos a propósito y que, con sus diferentes colores, lo enriquecen desde el punto de vista estético. La ejecución no es muy fina, tampoco demasiado regular, pero se consigue un gran efecto plástico, ya que se podría llegar a pensar al verla desde lejos que todas esas líneas conforman paralelepípedos oblicuos de piedra labrada, material de mayor categoría que el canto rodado.

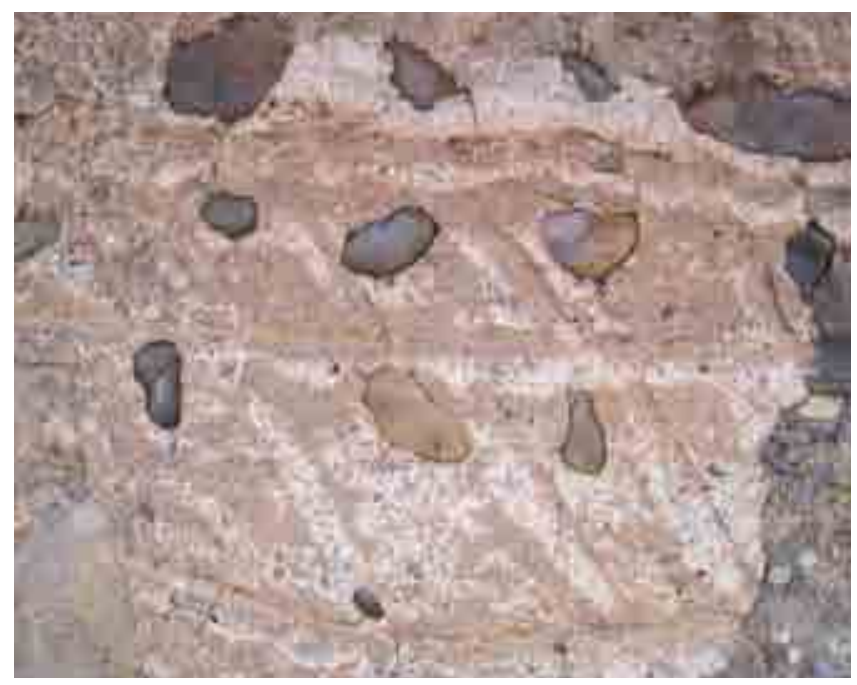

Figura 2. Jornadas de trabajo o las tongadas

Las pérdidas de volumen del revoco dejan ver claramente las jornadas de trabajo o las tongadas [figura 2] que se suceden cada tres líneas horizontales o cada dos franjas. Lo fueron revocando de abajo hacia arriba, dejando un bisel curvado en la parte superior para que montara encima la siguiente tongada. Cada una de estas jornadas mide aproximadamente $43 \mathrm{~cm}$ de anchura; las dos bandas se reparten esos centímetros de forma desigual ya que la banda inferior tiene unos $25 \mathrm{~cm}$ de ancho, mientras que la superior es de $18 \mathrm{~cm}$.

Además de cumplir una función decorativa, aportando una mayor riqueza y dignidad al monumento, el revoco tiene una función protectora, a modo de epidermis, aísla a la muralla de las condiciones climáticas adversas.

\section{Estado de conservación}

El revoco decorativo se encontraba en un estado de deterioro bastante grave y avanzado; con peligro de desprendimiento y pérdida de grandes zonas.

Desde el punto de vista estructural y material parece que no ha perdido gran parte de sus propiedades físicas, su 
consistencia y dureza son más que aceptables, no se aprecia disgregación de los materiales constituyentes, salvo en zonas concretas.

Las alteraciones que se aprecian en el revoco son distintas en función de su ubicación en el cubo, siendo los factores ambientales determinantes.

El lado orientado hacia el Sur presenta una deformación plástica muy acusada [figura 3], existiendo un grave riesgo de desprendimiento por el combamiento del revoco. De hecho la gran laguna que existe en esta zona se ha deprendido por esta causa. Este lado del revoco ha sufrido en mayor medida las condiciones climáticas adversas, en este sentido las oscilaciones térmicas han sido cruciales para el desarrollo de esta alteración. León se caracteriza por tener contrastes de temperatura bastante acusados, helar durante la noche y a mediodía llegar hasta los $18^{\circ} \mathrm{C}$. Teniendo en cuenta que el sol está incidiendo directamente sobre este lado del revoco durante casi todo el día, la temperatura que realmente tiene que soportar el mortero se multiplica. Además de las oscilaciones térmicas, otro factor que influye en el combamiento del revoco es el coeficiente de dilatación térmica, diferente para cada uno de los materiales que componen la muralla.
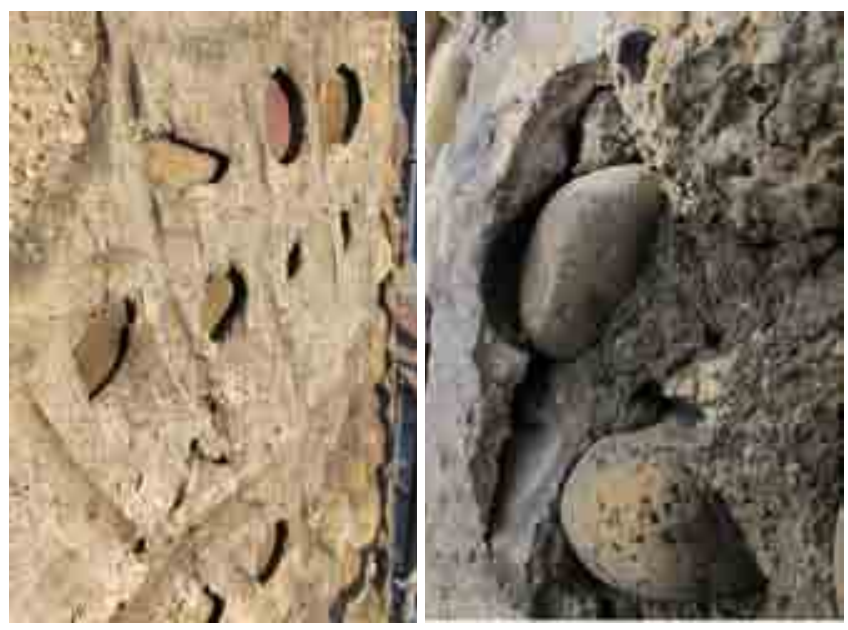

Figura 3. Lado orientado hacia el Sur

Otra de las alteraciones presentes en el revoco, aunque más acusada en este lado Sur es la ruptura del mortero [figura 4] en forma de grietas, fisuras, etc. Esta alteración es provocada por el agua de lluvia que penetra hacia el interior, con la bajada de las temperaturas el agua se hiela produciendo estas rupturas que cada vez van a más.

Este lado Sur, también sufre más la acción del viento, erosionando su superficie. Esto se manifiesta en alteraciones como estriado vermicular, picados y perdidas de volumen superficiales.

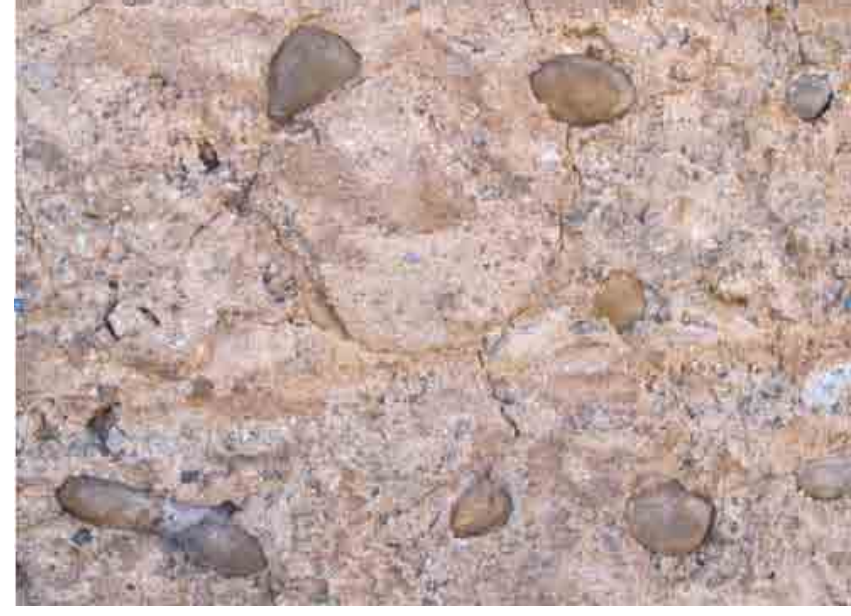

Figura 4. Alteraciones del revoco en forma de grietas, fisuras, etc

El lado que se orienta hacia el Norte, se encuentra más protegido del viento, tampoco sufre de grandes oscilaciones térmicas ya que no recibe los rayos solares, por lo que no adolece de estas patologías. En cambio sufre otra no menos grave, la costra negra, originada por la contaminación atmosférica de origen antropogénico. La muralla se encuentra pegada a una vía muy transitada, la acción de los contaminantes emitidos por el tráfico rodado, junto con las partículas y aerosoles en suspensión que contienen carbón, polvo, hollín sulfatos o nitratos ha formado depósitos muy adheridos a la superficie y de bastante dureza, que desembocan en la degradación del material ya que retienen la humedad y facilitan las reacciones químicas con el mortero y los contaminantes. El hollín, producto de la incompleta combustión de varios tipos de combustibles, contiene materias oleosas o alquitranadas que hacen que se adhiera a la superficie del revoco, que como además es bastante rugosa lo hace más fácil. El hollín también es portador de sustancias corrosivas como el ácido sulfúrico, por lo que se forman depósitos de suciedad ácidos y ennegrecidos. La costra negra se concentra en mayor medida sobre las zonas cóncavas, tanto de las incisiones que marcan la decoración del revoco como del mortero que rodea los cantos rodados [figura 5]. Otra razón de por qué la costra negra se concentra en esta parte pueden ser los vientos dominantes, que no llegan a esta zona por estar más protegida facilitando la acumulación de los depósitos.

\section{Tratamiento realizado}

Como ocurre en muchas ocasiones, para la realización de este trabajo hubo una serie de condicionantes. Por un lado el presupuesto con el que se contaba para la restauración del revoco era muy limitado. Como no se contemplaba su restauración en el proyecto inicial, se decidió destinar el dinero dedicado a toma de muestras y analíticas para realizar este trabajo. Aunque los estudios analíticos son de gran importancia la dirección facultativa optó por suprimirlos al disponer de estudios ya realizados en otras intervenciones 


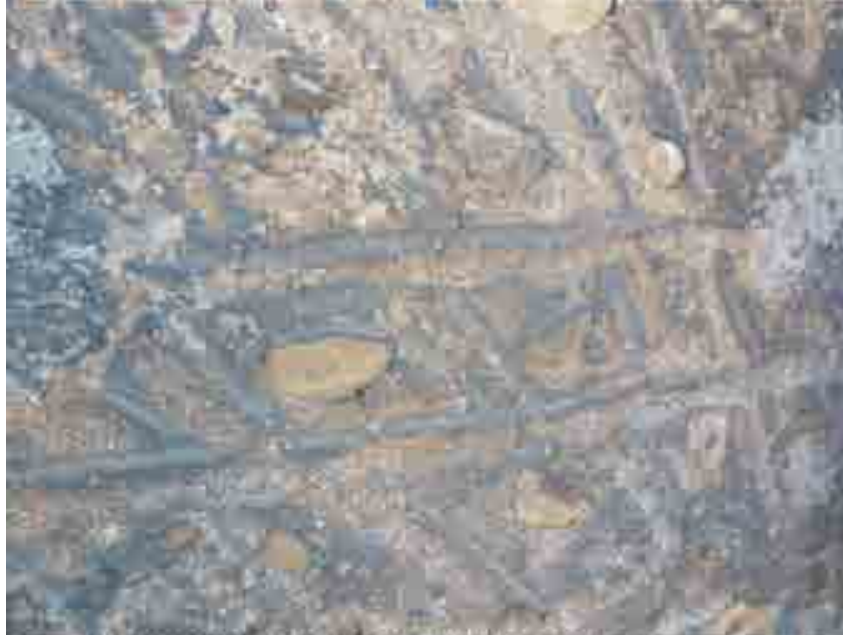

Figura 5. Costra negra se concentra en mayor medida sobre las zonas cóncavas, tanto de las incisiones que marcan la decoración del revoco como del mortero que rodea los cantos rodados

de la muralla. Por otro lado el tiempo del que se disponía para la realización de los trabajos era de tan sólo un mes. Ambos aspectos, pero sobre todo el económico, hicieron que la propuesta inicial planteada con respecto al método de limpieza (sistema mecánico asistido por abrasión con microchorro y árido) fuera modificada con la obra ya comenzada. Sin disponer de tiempo para plantear alternativas, se decidió utilizar un producto con el que no estaba conforme; su uso se justificó contando con la aprobación de la dirección facultativa al haberse empleado en otras fases de intervención sobre la muralla.

Para afrontar la limpieza del revoco con las suficientes garantías era prioritario comenzar por su consolidación estructural. Previamente se realizaron numerosas muestras de morteros con diferentes proporciones y áridos para elegir los más adecuados tanto para la inyección como para el sellado superficial.

Se han empleado dos tipos de cal diferentes según su finalidad:

- Cal en pasta grasa Decorchaux de la casa Naturcal, para el sellado tanto de los huecos entre el revoco y los cantos, como de sus bordes perimetrales.

- Cal hidráulica NHL 3'5 de la casa Naturcal, para el relleno de los huecos internos. Esta cal se caracteriza porque no necesita de la presencia de oxígeno para su fraguado. Endurece por reacción química con el agua.

Los áridos empleados son una arena de río lavada, mezcla de árido fino con pequeñas piedras; y un árido más fino de arena de sílice de Soto y Amío.

Se comenzó por sellar los huecos por donde se podría escapar el mortero de inyección, dejándolos a bajo nivel ya que era un sellado provisional. Para el relleno de las zonas abombadas, se inyectó el mortero fluidificado con una jeringuilla grande acoplada a una cánula de plástico para poder acceder a las zonas más difíciles [figura 6]. En este paso es muy importante seguir un orden a la hora de rellenar, comenzando por las zonas más bajas para ir ascendiendo poco a poco, asegurándose de que todos los espacios internos queden rellenados. En los lugares en los que el espacio lo permitía se iba batiendo el mortero inyectado para facilitar su penetración y eliminar las posibles burbujas.

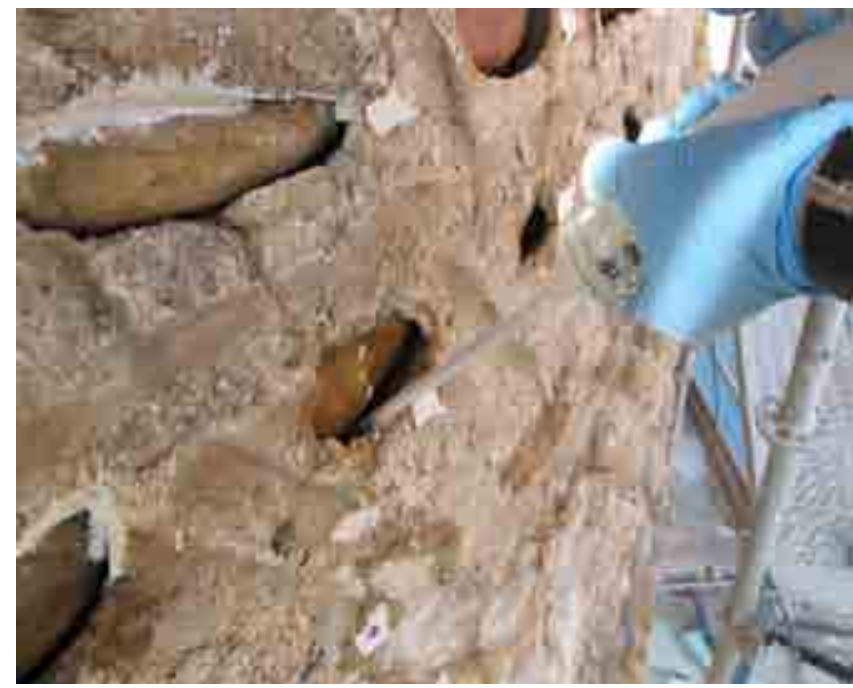

Figura 6. Inyección del mortero fluidificado con una jeringuilla grande acoplada a una cánula de plástico

En las zonas donde la separación del revoco era leve y apenas había hueco para la cánula se inyecto cal sin carga con la jeringuilla.

Una vez consolidado el revoco se procedió a la limpieza. El producto empleado fue Desichem Gel Piedra, un producto comercial de la casa Chempro diseñado para la limpieza de polución ambiental sobre piedra ornamental y mampostería.

El peligro de estos productos industriales es que la casa no da ninguna información sobre su composición y consecuencias. Es de composición alcalino-caústica, por lo que es un producto muy agresivo y del que se desconoce los efectos secundarios que puede tener a posteriori sobre los materiales de los que se compone el revoco y la propia muralla. Se insistió sobre este aspecto a la dirección facultativa en sus visitas de obra para que consideraran otras posibilidades de limpieza en posteriores fases de restauración de la muralla.

Antes de comenzar con la limpieza química se realizó una limpieza acuosa combinada con una limpieza mecánica 
por medio de cepillos de cerda sintética de dureza media, ya que el estado del mortero así lo permitía. Con ello se ablandaron y eliminaron los depósitos de suciedad muy adheridos y se dejaba más a la vista los depósitos de costra negra.

Es entonces cuando se inicia la limpieza química. Previamente se realizaron pruebas para ver cuánto tiempo se tenía que dejar actuar el producto para que fuera efectivo y se vio que 20 minutos era suficiente. El producto se aplicó con un pincel haciendo una capa de cierto grosor y sólo se limitaba a las zonas negras; el área de aplicación se limitó a 1 metro cuadrado de cada vez, para evitar que el producto se secase y hubiera que repetir la aplicación [figura 7]

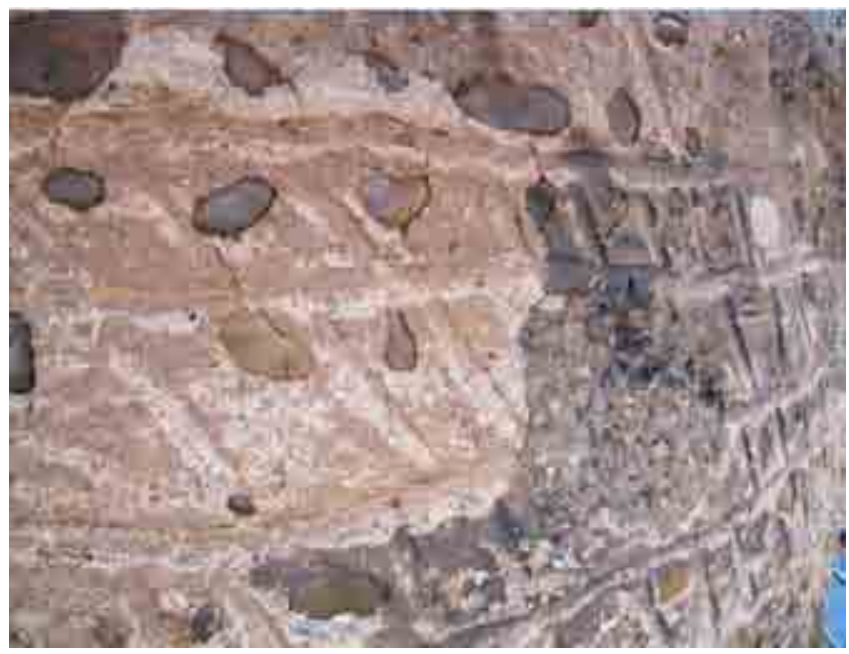

Figura 7. Área de aplicación

Una vez pasado el tiempo de actuación se frotaron esas zonas con cepillos de cerda sintética para finalizar con un lavado con agua a baja presión. Para tratar de eliminar lo máximo posible todos los residuos y sales solubles que pudieran aparecer consecuencia de esta limpieza se repitieron los lavados con agua a baja presión varias veces al día durante el tiempo que duró la limpieza y días posteriores. Esto ha sido bastante efectivo, aunque ha aparecido de manera puntual algún velo blanquecino producto de las eflorescencias.

Finalizada la limpieza sólo quedaba el sellado y rejuntado del revoco. La laguna grande no se ha reintegrado ya que estructuralmente no suponía peligro para la estabilidad del revoco conservado. Se han recrecido pequeños volúmenes que ayudaban a su conservación, siempre evitando el estancamiento y la penetración del agua, y los que han sido necesarios por motivos estructurales.

El mortero empleado en proporción 1:4 se tiñó con pigmentos minerales en polvo de la casa CTS, se hicieron las pruebas pertinentes hasta dar con el color apropiado.
Como el revoco tiene una pátina anaranjada de oxalatos no demasiado uniforme se decidió emplear dos tonos diferentes, uno más claro y otro más oscuro, en función de la zona donde se iba a aplicar.

Las grietas, oquedades y zonas picadas se han sellado dejándolas a nivel. Los bordes perimetrales del revoco se realizaron a bisel, al igual que el rejuntado de los cantos rodados en las zonas donde el revoco se había abombado y separado de los cantos rodados. Todo esto, con el fin de minimizar el daño que pudiera hacer el agua, evitando su estancamiento y tapando sus puntos de acceso [figura 8].
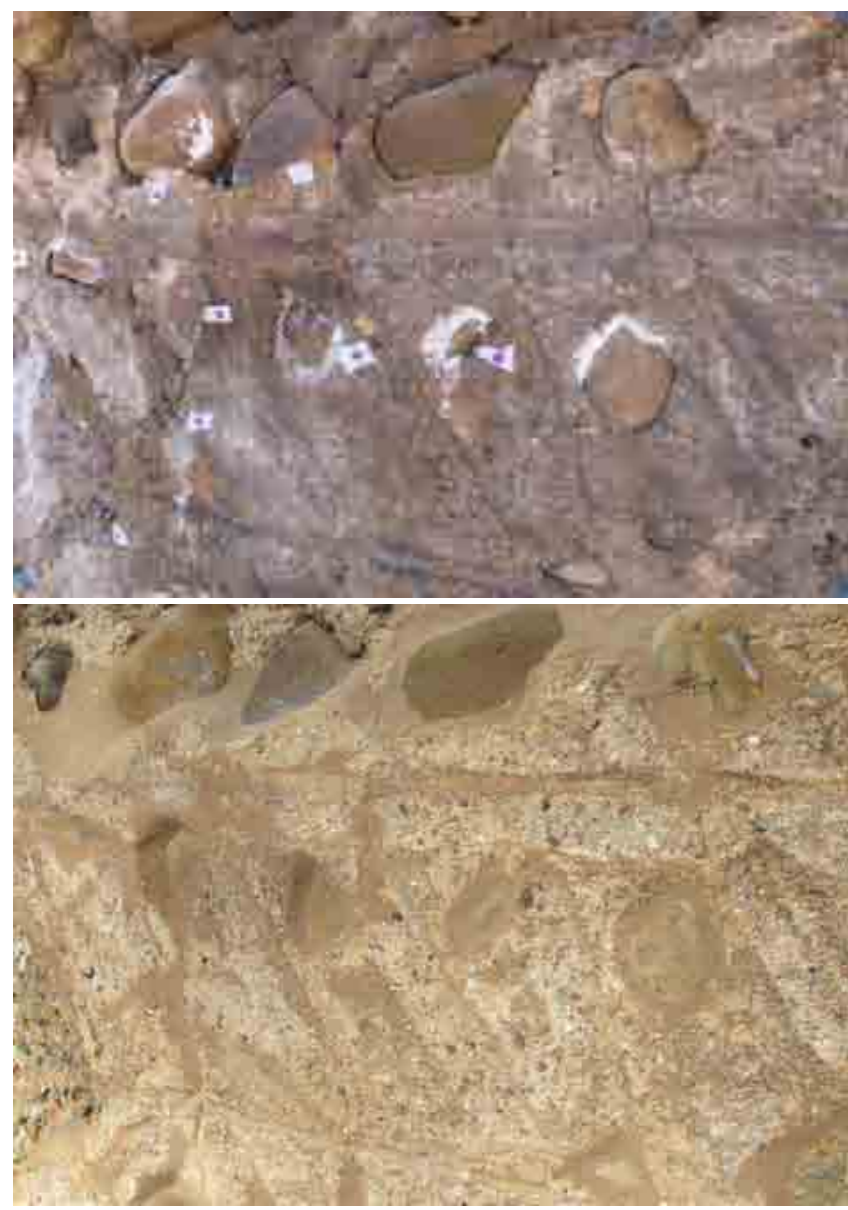

Figura 8. Grietas, oquedades y zonas picadas que se han sellado.

\section{Conservación preventiva}

Dentro del informe se aportaban una serie de recomendaciones encaminadas a la conservación preventiva del revoco y la muralla en general.

El seguimiento y mantenimiento de una obra al aire libre restaurada es primordial. En este caso la vigilancia o revisión periódica visual, sobre todo, para controlar el crecimiento de plantas y poder eliminarlas a tiempo, antes de que dañen más gravemente el revoco. 
Las condiciones ambientales no se pueden modificar o controlar tan fácilmente como dentro de un espacio cerrado, pero sí que hay aspectos de su entorno que si se cambian pueden repercutir en el riesgo de deterioro.

Es el caso de la contaminación ambiental, lo más idóneo sería que se limitara el tráfico rodado por esta calle haciéndola peatonal.

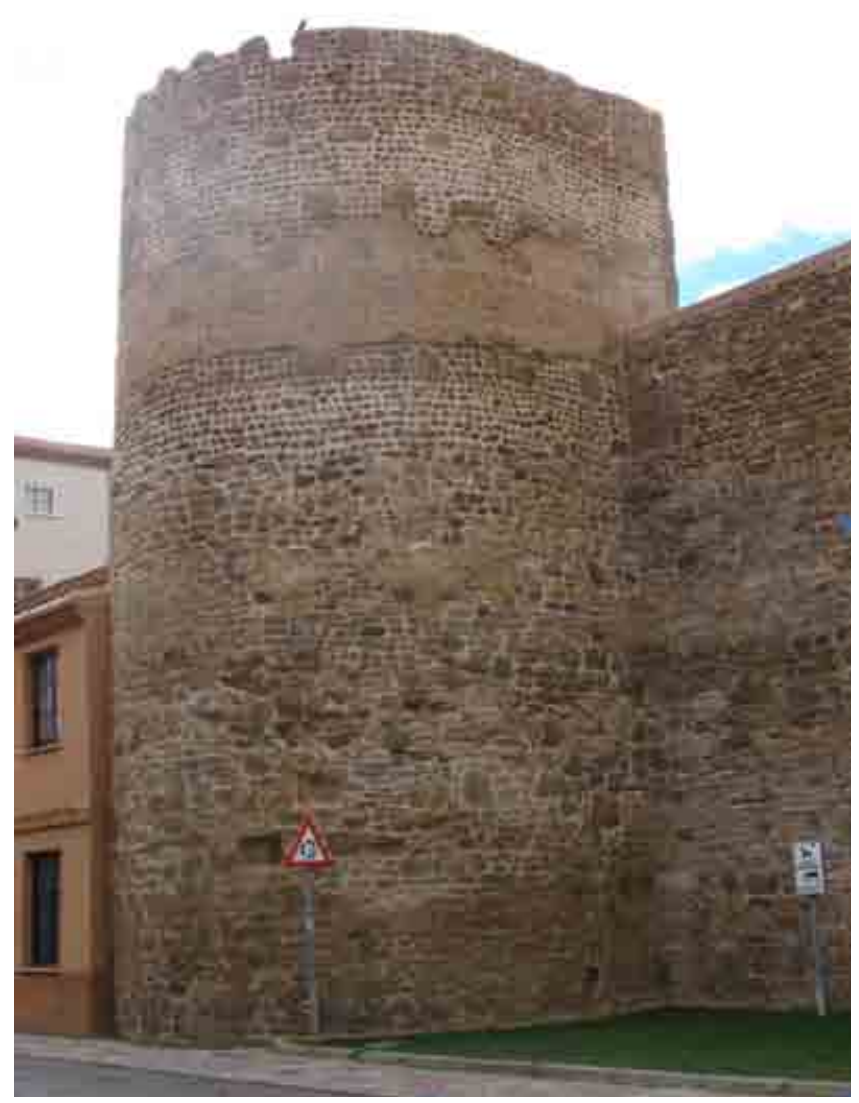

Figura 9. Imágen de la muralla

\section{Bibliografía}

ALCALDE MORENO, M. y VILLEGAS SÁNCHEZ, R. (2003). “Indicadores de alteración de los materiales pétreos", Cuadernos técnicos, N8, pp. 168-193.

ALCALDE MORENO, M. y VILLEGAS SÁNCHEZ, R. (2007). Actas de la jornada técnica "Tratamientos de conservación aplicados a materiales pétreos". Cáceres. Junta de Extremadura.

CABRERA GARRIDO, J. M. (1996). “Estudios de recubrimientos de fachadas antiguas: la pátina de la piedra y el color de la arquitectura", en XI Congreso de Conservación y Restauración de Bienes Culturales: Castellón, 3, 4, 5 y 6 de octubre de 1996, pp. 869-877.

CAMPOMANES ALVAREDO, E. (2001). "Introducción al estudio estratigráfico murario de la muralla de León" Actas del IV Curso de Cultura Medieval seminario, La fortificación medieval de la Península Ibérica", pp. 351-360. Aguilar de Campoo: Fundación Santa María la Real, Centro de estudios del Románico.

ESBERT ALEMANY, R. M. y LOSADA ARANGUREN, J. M. (2003). "Criterios de intervención sobre materiales pétreos", Bienes Culturales, No2, pp.1-34.

FERNÁNDEZ GONZÁLEZ, E. y GALVÁN FREILE, F. (2008). "Pintando arquitecturas/arquitecturas pintadas: las construcciones figuradas en el Códice Albeldense", De Arte, № 7, pp. 51-60. León: Universidad de León, Facultad de Filosofía y Letras.

FERRER MORALES, A. (1996). “Decoración de muros en castillos califales de Andalucía Oriental", Atrio, 8/9, pp. 3-18. Sevilla: Universidad Pablo Olavide. Disponible en: http:// www.upo.es/depa/webdhuma/areas/arte/atrio8/1.pdf

VIDAL ENCINAS, J. et al. (2002). “Un asunto superficial: el revoco decorativo del recinto amurallado romano-medieval de León", De Arte, № 1, pp. 11-20. León: Universidad de León, Facultad de Filosofía y Letras.

VILLEGAS SÁNCHEZ, R., BAGLIONI, R. y SAMEÑO PUERTO, M. (2003). "Tipología de materiales para tratamiento", Cuadernos técnicos, N8, pp. 168-193. 


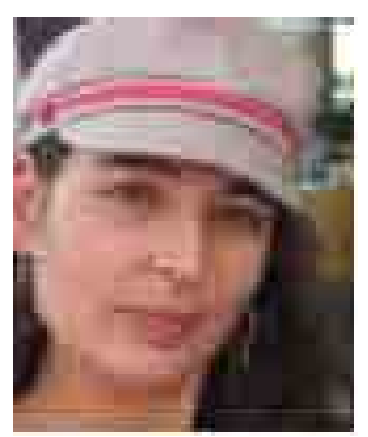

\section{Aránzazu Álvarez Villalibre}

Arancha.villalibre@gmail.com

Licenciada en Historia del Arte por la Universidad de León y Diplomada en Conservación y Restauración de B. C. en la especialidad de escultura por la E.C.R.B.C.de Madrid. Miembro del Grupo de trabajo de piedra del GEllC. Desde el año 2000 que finalizó sus estudios oficiales se ha dedicado por completo al campo de la restauración trabajando para diferentes empresas y desde el año 2010 de manera autónoma. 


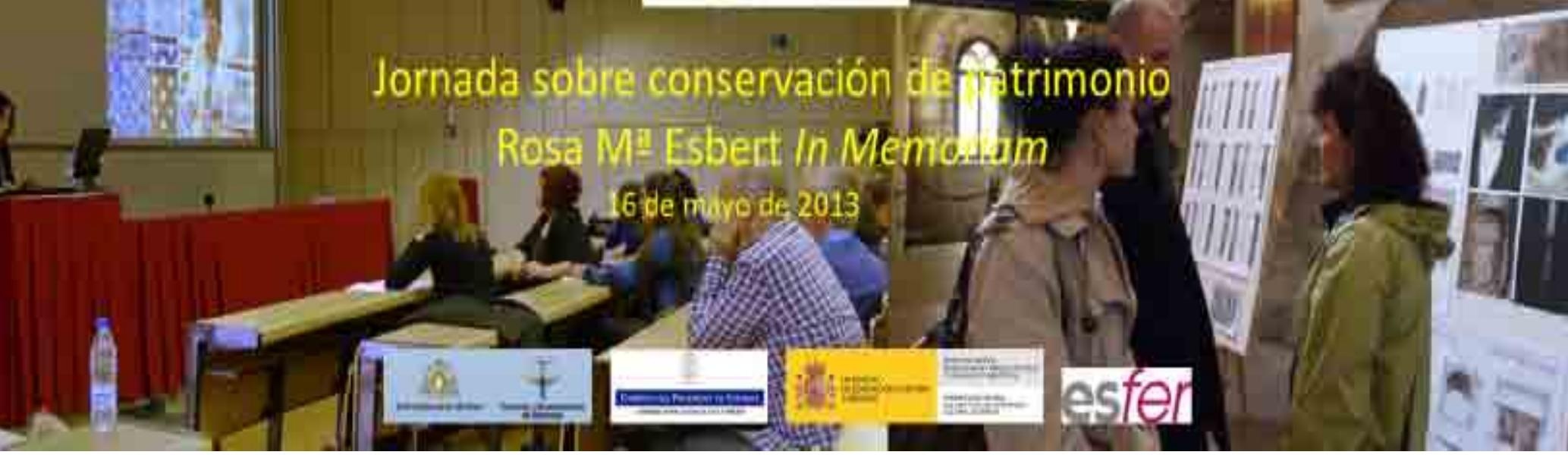

\title{
Catedral de Tudela. Los problemas de conservación de la piedra campanil.
}

\author{
Alicia Ancho Villanueva
}

Resumen: La catedral de Tudela es uno de los edificios históricos más destacados de Navarra, tanto por el interés arquitectónico del templo y de sus dependencias, como por los bienes que contiene y por las dimensiones del conjunto. Muestra un magnífico repertorio escultórico románico distribuido entre sus edificaciones, especialmente rico en el claustro y en las tres portadas que dan acceso al templo. Actualmente la escultura monumental presenta graves problemas de conservación que no sólo encontramos en la catedral de Tudela. Está presente en todas las construcciones realizadas con el mismo tipo de piedra en la Ribera de Navarra y afecta a elementos tan lejanos de Tudela como el trasaltar de la Catedral de Burgos, por lo que nos encontramos con un problema de dimensiones y consecuencias para la conservación de nuestro patrimonio realmente de calado. El artículo se centra en el claustro, y presenta un resumen de su historia material, de los estudios previos realizados, los proyectos a desarrollar y las perspectivas de actuación para mejorar las condiciones de conservación de uno de los mejores conjuntos de escultura del siglo.

Palabras clave: Piedra caliza campanil, conservación preventiva, expansión por secado, estudios previos, escultura monumental, restauraciones antiguas, investigación, detector de metales.

\section{Tudela Cathedral. The problems of conservation of stone campanile.}

\begin{abstract}
The Tudela cathedral is one of Navarre more outstanding historical buildings, so much because of the temple architectonic interest and its dependencies, as for the architectural goods and the dimensions of the ensemble. The cathedral exhibits a magnificent Romanic sculptural repertoire distributed among its contractions. It is especially rich in the cloister and the three portals to access to the temple. At the present time the monumental sculpture displays serious conservation problems found not only in the Tudela cathedral. These problems are manifested in all the constructions made with the same kind of stone in the Navarre Ribera and they are affecting so distant sculptural elements as the trasaltar of Burgos cathedral. So we are facing a problem of big dimension and with dire consequences to the conservation of our patrimony.
\end{abstract}

Key words: Campanil limestone, preventive conservation, expansion by drying, previous studies, monumental sculpture, old restorations, investigation, metal detector.

La catedral de Tudela, uno de los primeros edificios de Navarra en ser declarado Monumento Nacional en el siglo $\mathrm{XIX}^{1}$ ha sido objeto de gran valoración desde hace más de un siglo, y tanto por su riqueza patrimonial como por la alta valoración de que es objeto, se han realizado en ella desde entonces diversas obras de restauración y conservación. Su magnífica escultura románica presenta graves problemas de conservación, y no los encontramos sólo en la catedral de Tudela. Afecta en mayor o menor medida a todas las construcciones realizadas con el mismo tipo de piedra en la Ribera de Navarra, por lo que nos encontra- mos con un problema grave, de enormes dimensiones y consecuencias para la conservación de nuestro patrimonio. [Figura 1]

Desde 2003 la Dirección General de Cultura/Institución Príncipe de Viana, viene realizando un seguimiento de la evolución de la escultura monumental del claustro de Tudela, que sufre un proceso de deterioro importante ya detectado a mediados del pasado siglo, pero que en los últimos años se muestra más agresivo en algunas zonas. [Figura 2 y 3 ] 


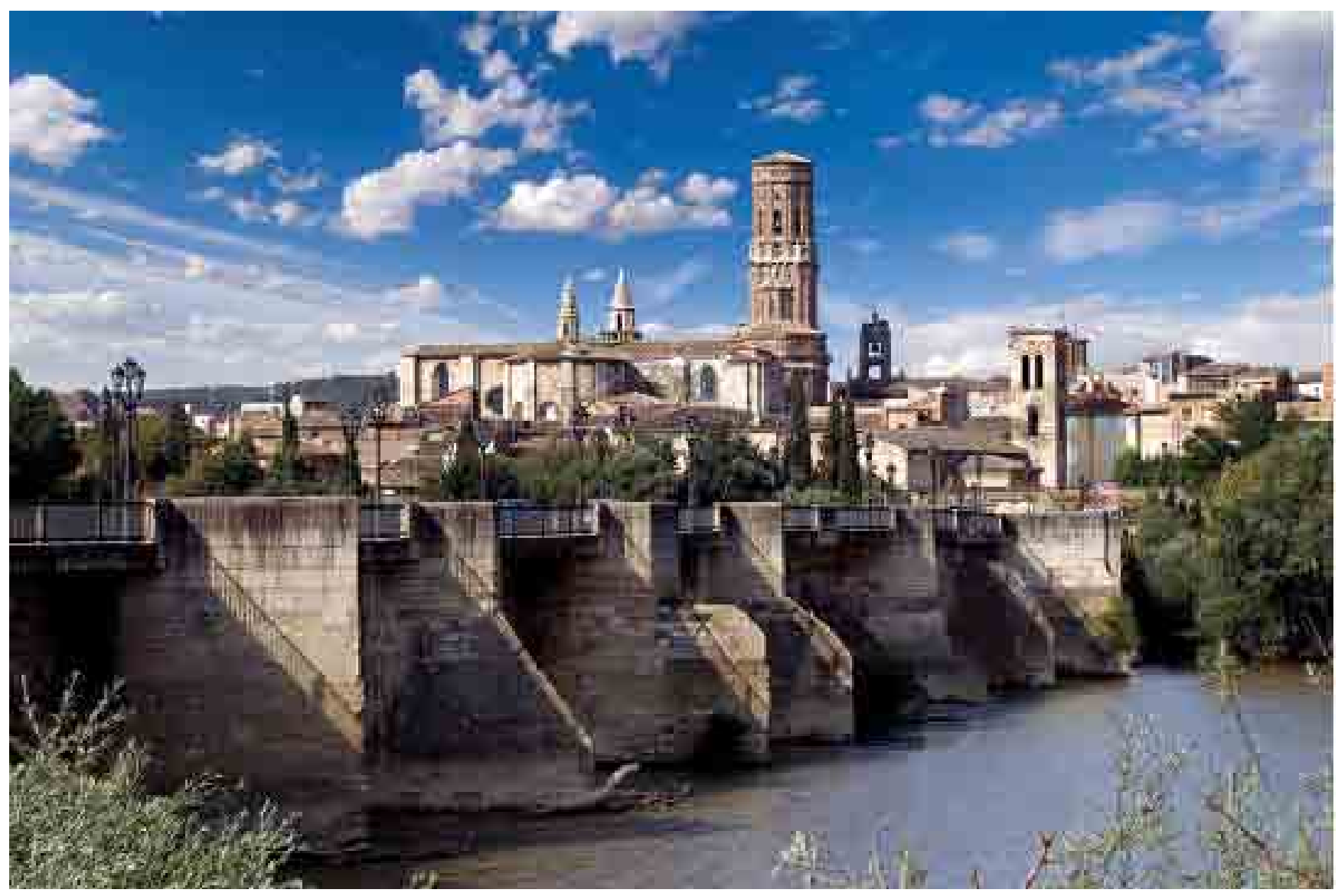

Figura 1.Vista general de la catedral de Tudela e iglesia de la Magdalena desde el puente del Ebro.
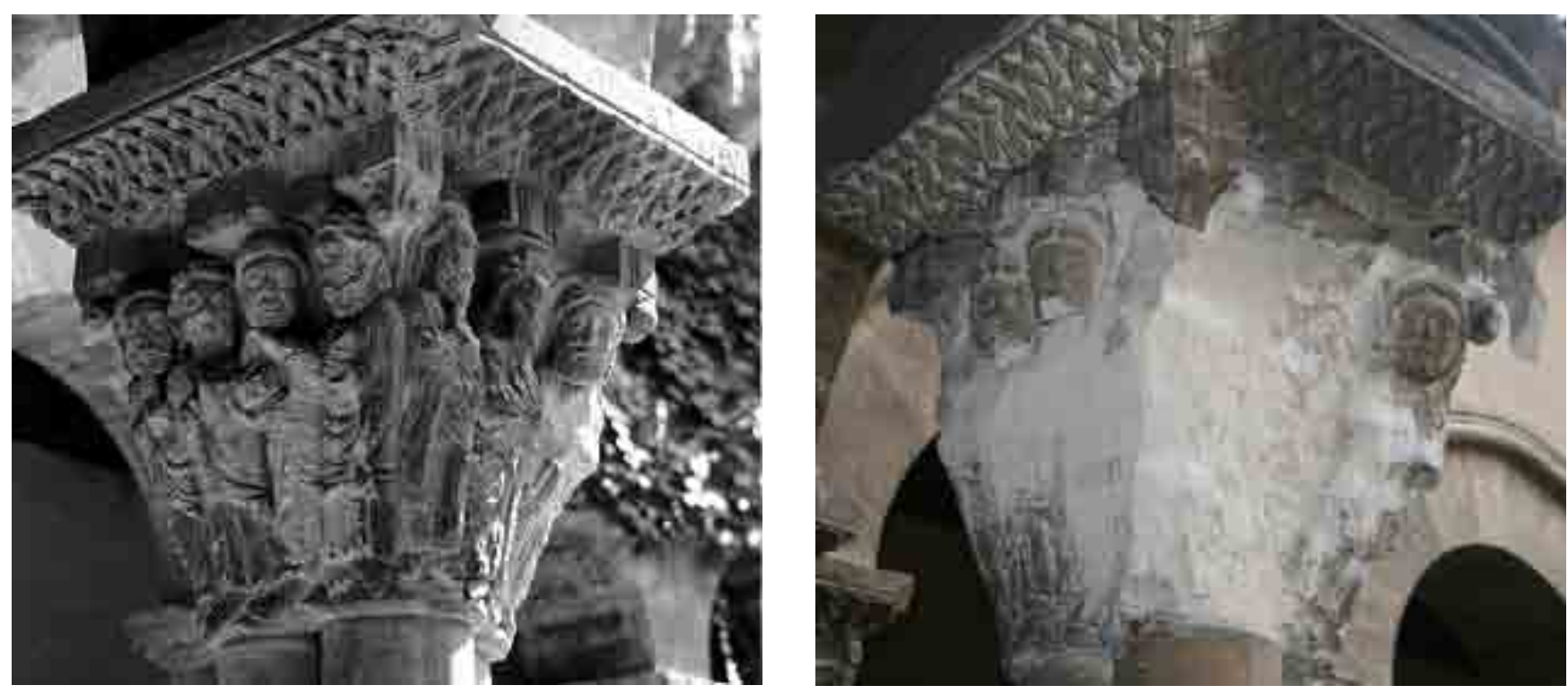

Figuras 2 y 3. Comparativa de la evolución de daños en un mismo capitel entre 1960 y 2005.

La piedra se fractura por sí misma, dando el aspecto de una rotura mecánica, por compresión o por golpe, pero no existen tales detonantes. Hay elementos que presentan lesiones muy antiguas que no han progresado desde hace un siglo. $Y$ encontramos otros elementos donde el deterioro es evidente de semana en semana: aparecen mi- crofisuras, la grieta se va abriendo, y finalmente salta un fragmento por si solo. La piedra continúa siendo dura, los filos de la fractura son cortantes, no hay material friable. Los fragmentos desprendidos pueden ser de unos pocos milímetros o de tamaño considerable y un peso de hasta varios kilos. El proceso generalmente no termina ahí. 
Podemos retirar un elemento desprendido (por ejemplo una cabeza o un torso) y en unos meses ese fragmento puede convertirse en tres o cuatro, lo que dificulta su recolocación futura. En otros casos el elemento recogido no continúa fragmentándose, pese a estar guardado en el mismo entorno que el que sí lo hace.

Los estudios encaminados al conocimiento de las causas del deterioro que está sufriendo el claustro, de cara a plantear la intervención restauradora más correcta posible, son interdisciplinares y muy exhaustivos, llevados a cabo por un equipo de especialistas, entre los que destacan Artelan, empresa de restauración que ha hecho las intervenciones de urgencia, estudios de estado de conservación y estudios previos y el equipo Arbotante, geólogos de la Universidad de Zaragoza dirigidos por Josep Gisbert, quien describió por primera vez la patología que presenta la piedra campanil con la que está construida la catedral de Tudela. El objetivo es concretar qué mecanismos operan para provocar el nivel de destrucción que padece la piedra y la forma adecuada de tratarla para evitar su avance. Pese a los años de estudio y los diferentes profesionales que están aportando sus conocimientos para salvar la escultura monumental tudelana, la solución no está clara todavía.

Paralelamente a los estudios, se han realizado varias campañas de intervención de urgencia para frenar la pérdida de escultura, pero el deterioro continúa. En ellas se actúa puntualmente asegurando mediante colocación de tiras de engasado las zonas afectadas por la patología activa para evitar su pérdida, o retirando los fragmentos con peligro de caída, o incluso protegiendo los capiteles con una malla para evitar mayores pérdidas. La empresa Artelan ha realizado cuatro campañas (en 2004, 2005, 2007 y 2013) presentando al finalizar cada trabajo un "Estudio del estado de conservación del claustro de la catedral de Tudela" correspondiente a cada año, cuyas fotos y gráficos corroboran la aceleración que vive el deterioro de la escultura monumental románica del claustro de la catedral de Tudela. Además, técnicos de la Sección de Bienes Muebles de la Dirección General de Cultura han intervenido de urgencia en varias ocasiones para asegurar puntos extremadamente frágiles o retirar elementos con alto riesgo de desprendimiento.

\section{La Catedral de Tudela. Descripción.}

La catedral de Tudela se construyó sobre el solar que acogía a la mezquita mayor. Entre 1180-1200 se levanta el claustro. Las obras empiezan en crujía norte y continúan por este y sur, finalizando en el lado oeste. Entre 1190 y 1195 se levanta la portada sur, y entre 1200 y 1204 se alza la portada norte. Finalmente entre 1200 y 1210 se levanta la maravillosa Puerta del Juicio, citada en documentación de la época como "puerta pintada".

El claustro se encuentra al sur del templo. La planta de las arquerías es un rectángulo casi regular, con lados mayores orientados al este y al oeste. Las arquerías son de medio punto hay nueve en los lados menores y doce en los mayores y apean en triples y dobles columnas alternativamente, casi todas ellas repuestas en los años 40 por columnas lisas de arenisca. En el centro de los lados, marcando los ejes del jardín interior, hay pilares rectangulares con dobles columnas adosadas a cada intradós. En los ángulos del claustro también hay pilares, con columnas pareadas en sus frentes y semicolumnas en los chaflanes. En el interior de los ángulos hay otro orden de columnas a la altura de los arcos con algunas escenas en relieve en el ángulo sureste. Hacia el jardín las arcadas son sencillas, limitadas con una moldura de baquetón. Por el interior las arquivoltas se decoran con líneas geométricas y en los lados menores se desarrollan dientes de sierra adaptados al medio punto.

El verdadero interés de este claustro reside en los capiteles figurados que coronan las columnas. De los 58 capiteles que componían originalmente el claustro (42 en columnas y 16 en los pilares de esquina) han desaparecido completamente 16 y no tenemos referencia sobre las figuras representadas en ellos. Actualmente se encuentran en buen estado 24 , y padecen daños de mayor o menor gravedad 18; 5 de ellos en estado tan grave que su lectura se va haciendo muy difícil. En los capiteles predominan las figuras robustas, de grandes cabezas y ojos marcados, vestidas con pesados plegados curvos que resaltan sus miembros. Sus cabellos y barbas son muy variados, detallados y minuciosos, con rizos y trenzados. Sus gestos muy expresivos. La figura principal suele aparecer en un ángulo, mientras que las otras se sitúan en los lados, dirigiéndose a ella, aunque en ocasiones el protagonista ocupa el centro de la cara del capitel. A las figuras se añaden fondos arquitectónicos, árboles o follaje que dan idea de un desarrollo paisajístico. Encontramos también volutas con follaje y frutos que recuerdan los clásicos elementos del capitel. A pesar de la importancia de la figura, en algunos capiteles el follaje y la decoración vegetal estilizada se hace predominante y también pueden aparecer junto al follaje seres monstruosos o animales. Los cimacios mezclan motivos vegetales y entrelazos geométricos.

En cuanto a la iconografía, desarrollan fundamentalmente escenas bíblicas y neotestamentarias, aunque también hay representaciones de la vida de la época, como la cacería del jabalí, y otras escenas simbólicas con animales y seres fantásticos ${ }^{2}$. Los capiteles todavía conservan restos de policromía en ojos y cejas, e inscripciones relativas a los personajes representados. Las arquerías del claustro están construidas con piedra caliza campanil, denominada así por la especial sonoridad que produce al golpear un fragmento con otro. También hay algunos elementos de arenisca, pero son los menos (sólo los tres primeros capiteles). Todas las piezas introducidas en la restauración de 1940 son de piedra arenisca, precisamente para evitar sufrir los problemas de la campanil. 


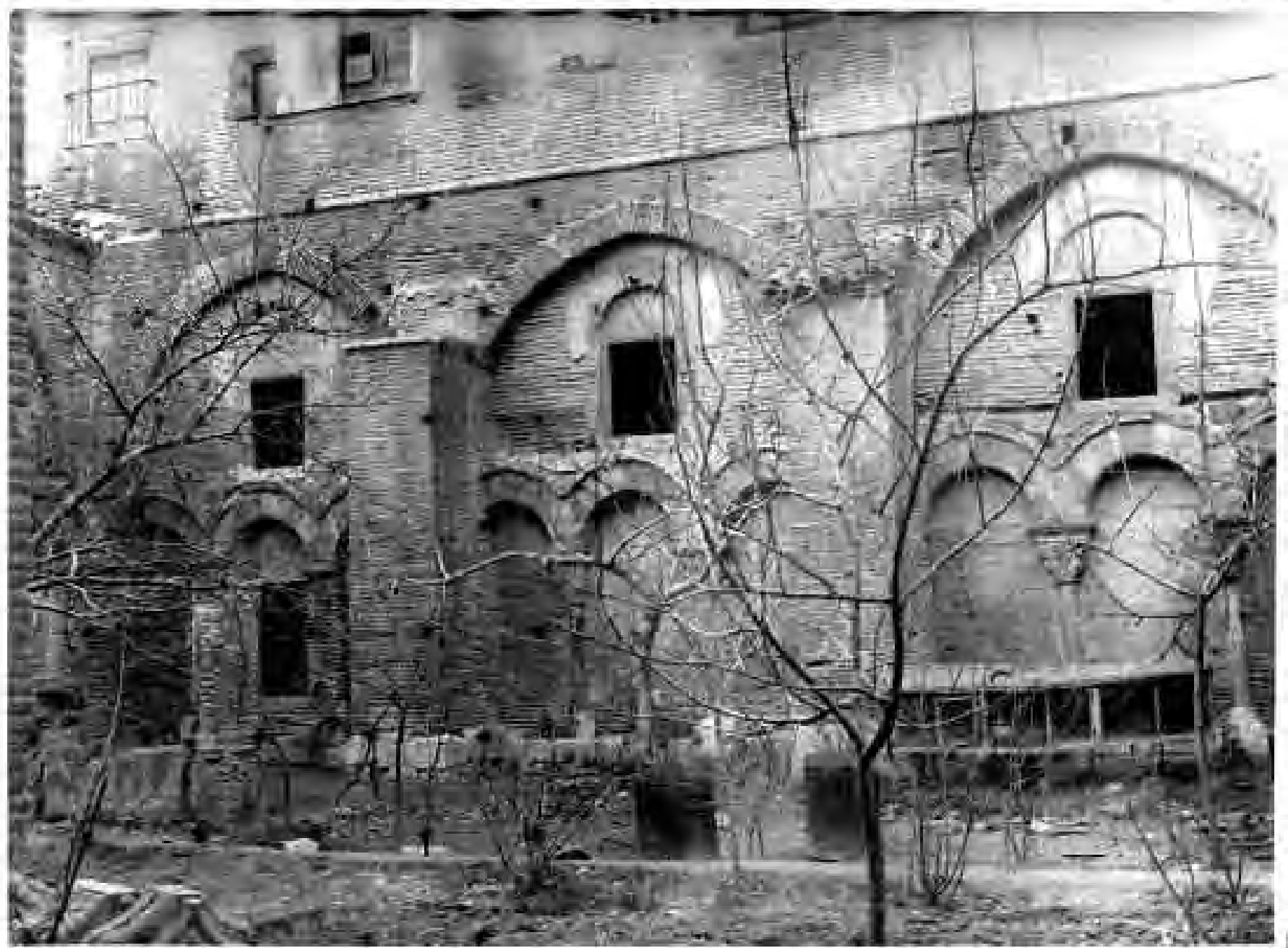

Figura 4. Vista general del claustro desde el huerto, en 1916

\section{El Claustro a través de los siglos. Historia material.}

Las obras en el claustro han sido relativamente pocas en sus más de ocho siglos de existencia, pero hay dos intervenciones, la del siglo XVI y la del XX que han sido cruciales para entender su situación hoy en día. En síntesis, estos son los datos conocidos:

\section{S. XVI}

- Remodelación del claustro. Se cubre con bóvedas de ladrillo y yeso, que sustituyen a la cubierta original. Cada tres arcos románicos se levanta un arco al interior y un contrafuerte al exterior, ambos de ladrillo. Se ciegan las arquerías. En el lado oeste se levanta un sobrepiso de ladrillo. En el lado sur se construye una galería - solana ${ }^{3}$ [Figura 4]

1879

- Se construye una galería perimetral sobre el claustro.

$1941-1950$

- Restauración del claustro:
- Desmontado del claustro y de las edificaciones que tenía encima y posterior montaje conforme a su disposición original. Cimentado, reposición de arquerías, introducción de basas, columnas, capiteles y arcos desaparecidos o deteriorados en piedra arenisca. Las arquerías fueron completadas hacia arriba con tres hiladas de sillares lisos de arenisca de escaso grosor y relleno de hormigón. Las cubiertas se hicieron nuevas. [Figura 5]

\section{$1953-1954$}

- Pavimentación del claustro con losa de piedra arenisca y rectángulos de canto rodado, y arreglo del jardín con aceras enlosadas y plantación de cuatro cedros.

\section{5}

— Sustitución del ruejo del pavimento por ladrillo.

\section{0}

- Aplicación de Poimate SIL-19 como consolidante. En documentación consta que se aplicó en las portadas, pero debió darse también en los capiteles del claustro 


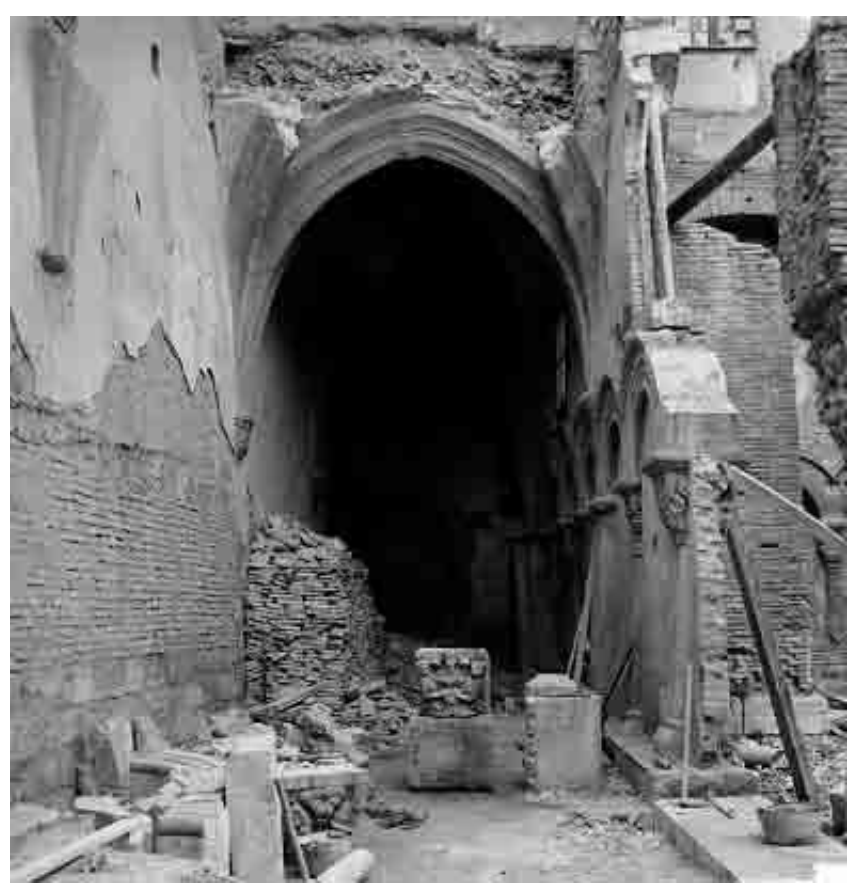

Figura 5. Proceso de desmontaje en 1940.

porque se ha encontrado en los análisis de películas de revestimiento. Al parecer el tratamiento consistió en una limpieza ácida, lechada de yeso, tratamiento con silicato potásico y aplicación de Poimate, producto con propiedades hidrofugantes.

\section{2 y 1989}

Limpieza de cubiertas. Las cigüeñas y palomas obligan al mantenimiento constante, pero no siempre se cumple. En el 89 se talan los cedros del jardín del claustro porque sus raíces y ramas dañaban la estructura.

1997 - 1998

- Rehabilitación del Palacio Decanal.

- Sustitución del cañizo que soportaba las tejas en la cubierta oeste del claustro por tabla.

— Estudio del clima por TSA.

\section{3}

- Estudio del terreno por Antonio Aretxabala, de la Escuela de Arquitectura de la Universidad de Navarra.

- Estudio de la piedra por Arbotante, de la Universidad de Zaragoza. Descripción de la EPS. Litologías, cartografía de sales, síntesis documental, estudio comparativo de fotos históricas, geoquímica, mineralogía de sales y caracterización del comportamiento de la roca.

\section{4}

- Estudio y tratamiento de urgencia (sujeción y protección de los capiteles del claustro) por Artelan. Colocan contramoldes parciales a tres capiteles con grave riesgo de desprendimiento y malla ventilada en cuatro capiteles para evitar caídas de piedra.

— Fijaciones puntuales de capiteles por técnicos de Pa- trimonio Histórico.

2005

- Nuevo tratamiento de urgencia y estudio de la evolución del deterioro de los capiteles del claustro por Artelan. Retirada de los contramoldes y colocación de malla ventilada a un capitel más.

— Fijaciones puntuales de capiteles por técnicos de $\mathrm{Pa}$ trimonio Histórico.

- Análisis de material de escorrentía en capiteles y fustes por Artelab.

2006

— Fijaciones puntuales de capiteles por técnicos de Patrimonio Histórico.

- Se repasan algunas goteras del claustro.

\section{7}

- Inicio de estudios previos Artelan - Arbotante de cara a la redacción del proyecto de intervención en el claustro. Nuevas fijaciones de urgencia, pruebas de limpieza y de desalación.

\section{8}

- Presentan el estudio y conclusiones Artelan y Arbotante.

- Se plantea reparar la cubierta y comprobar estado de la fábrica y el sistema de montaje de los capiteles mediante catas, pero no se lleva a efecto.

2009

- Arbotante desarrolla en laboratorio y presenta un protocolo de extracción de sales.

\section{2}

- Se convoca una jornada de trabajo de especialistas en Tudela para avanzar en la solución, ante las dudas que plantea la redacción del proyecto. La jornada de trabajo se desarrolla in situ, y asisten a ella:

Concha Cirujano Gutiérrez. Restauradora de materiales pétreos. IPCE

José Vicente Navarro. Geólogo. IPCE

Pedro Pablo Pérez García. Geólogo.

Javier Sancho Domingo. Arquitecto. IPV

Alicia Ancho Villanueva. Restauradora. IPV

Violeta Romero Barrios. Restauradora. IPV

Berta Balduz Azcárate. Restauradora. Museo de Navarra

Diana Pardo Gil. Restauradora. Diputación Foral de Álava

Cristina Escudero Remirez. Restauradora. CyL Pep Gisbert. Geólogo. Universidad Zaragoza. Arbotante

Raquel Sanz Falcón. Restauradora. Arbotante Javier Latorre Zubiri. Restaurador. Artelan.

\section{3}

- Técnicos restauradores y arqueólogos del Servicio 
de Patrimonio Histórico, realizan un estudio con detector de metales para localizar los elementos metálicos existentes en el claustro. A la vista de los resultados, se descarta desalar o desmontar el claustro.

- Encuentro del Grupo de Piedra del GE-IIC en Oviedo, con motivo del homenaje a Rosa Esbert. Se presenta el tema del claustro de Tudela y la piedra campanil. La opinión general de los geólogos presentes es que el problema está en la propia piedra, pero hay que dar con el mecanismo de activación.

- Estudio y tratamientos de urgencia de los capiteles por Artelan, previo a la instalación de protecciones de cara a las obras de reparación de cubierta y ampliación del alero del claustro.

- Sustitución de la cubierta de 1940, conservando la estructura de madera, ampliando el alero y mejorando el sistema de evacuación de aguas.

- Programa de colaboración con el Museo de Navarra, donde Arbotante lleva a cabo más estudios sobre elementos esculpidos en piedra campanil, que pese a estar en un entorno de museo, seguro y controlado, presentan los mismos daños que la escultura monumental in situ, y la patología se encuentra muy activa.

\section{Metodología de estudios previos.}

En el archivo de Patrimonio Arquitectónico se conservan planos de la restauración de 1940-50 del claustro (estado previo y restauración). En la última década se ha realizado el levantamiento de planos de la catedral, que incluye plantas del claustro, secciones de todas las crujías y alzados de las arquerías desde el jardín. Todos esos alzados y secciones cuentan con representación detallada de las arquerías y los capiteles. Estos planos han servido para marcar las litologías, estudios de distribución de sales, patologías e intervención, y van a servir de base para un próximo proyecto de estudio de insolación.

Conservamos fotografías históricas ${ }^{4}$ de las galerías y del jardín (huerto en este caso), anteriores a las obras de 1940 y de la propia obra, que constituyen unos datos muy valiosos, dada la poca documentación del estado previo y de las obras. Hay vistas generales del claustro desde 1916, y una serie completa de los capiteles, cara por cara, una vez terminada la restauración del siglo pasado. Otra serie completa es la constituida por el fondo del Catálogo Monumental de Navarra, publicado en 1980. De fechas recientes hay series fotográficas completas de los capiteles, realizadas con cámara digital para los estudios del estado de conservación y para el levantamiento de planos. Estamos trabajando en un proyecto de colaboración con el Departamento de Ingeniería de la Universidad Pública de Navarra - Campus de Tudela para el escaneo de los capiteles y elementos escultóricos en 3D. Factum Arte escaneó en 2012 dos capiteles y realizó la reproducción en escayola de una de las caras de un capitel ${ }^{5}$.

Se ha establecido un sistema de siglado único de los ele- mentos del claustro, que facilite la localización de cualquier elemento y permita a todos los especialistas implicados trabajar con la documentación generada, ya que el claustro es muy complejo y resulta evidente que avanzaremos mejor si todos hablamos el mismo idioma. Sirve para la identificación, descripción y localización de capiteles, arcos, pilares, fustes, basas y zócalos del claustro.

A lo largo de estos años han pasado por el claustro varios equipos de restauradores, que han recogido los datos de estado de conservación de los elementos escultóricos. Todos ellos debían conocer y utilizar el mismo lenguaje para referirse a las patologías presentes en la piedra o en las películas de revestimiento. Por ello se fijó un glosario ilustrado de las patologías encontradas, que han ido manejando, y en ocasiones ampliando, los sucesivos equipos. Cada patología cuenta con una breve descripción, una fotografía que la identifica claramente, y la trama elegida para su representación gráfica sobre plano. Hay diversos deterioros: fisuras, fracturas, pulverización, descamación, picoteado, escorrentías y pátinas de enmugrecimiento. Tiene especial importancia la que el equipo de geólogos ha denominado patología de expansión por secado (EPS), que ha sido estudiada con detalle.

\section{Estudios previos específicos}

\section{1.-El terreno de la catedral de Tudela}

La catedral de Tudela se asienta junto al lecho del Ebro, de cuyo cauce actual se encuentra relativamente cerca. Los terrenos atravesados son rellenos antrópicos, arcillas marrones con gravas y gravillas, gravas redondeadas en matriz arenosa, y a más de $10 \mathrm{~m}$ margas grises y formaciones arcillosas impermeables al paso del agua. Hay agua a partir de $6 \mathrm{~m}$ de profundidad, asociada al cauce del Ebro a través del estrato de gravas. En momentos puntuales de inundación, que pueden llegar a ocurrir anualmente en otoño y/o primavera, el nivel varía poco más de $20 \mathrm{~cm}$, por lo que la afección en el claustro es inapreciable.

\section{2.-La piedra de la catedral de Tudela: caracterización de la patología EPS}

En 2003 el arquitecto del Servicio de Patrimonio Histórico, Javier Sancho, solicita un estudio que explique determinadas patologías que presenta la catedral de Tudela, aparentemente con aspecto de problemas de cargas, pero que no pueden explicarse por este motivo. El estudio se realizó sobre los materiales pétreos del interior de la catedral y del claustro, con algunas observaciones sobre las portadas. En la catedral encontramos caliza campanil, arenisca utilizada en la construcción y arenisca utilizada en las restauraciones del siglo XX. La primera es la más abundante y su deterioro más grave, por lo que requiere más atención. Se efectuó la caracterización de la piedra campanil y su 
comportamiento en laboratorio. Se realizaron mapas de distribución de sales de las arquerías del claustro y esto se combinó con el estudio del deterioro in situ. La patología más evidente se manifiesta en fracturas debidas a expansión de la piedra, que se origina en condiciones de secado extremo generalmente en presencia de sales de magnesio, aunque no siempre. La patología es antigua y en algunos puntos ha llegado a un punto de estabilización o latencia. El aumento de los efectos de esta patología en los últimos decenios parecía en principio debida a la lluvia ácida y al magnesio aportado por la arenisca y el cemento Pórtland introducido en la restauración, pero como iremos viendo esto no justifica todos los casos. En la piedra arenisca la degradación se debe a un mecanismo diferente, de arenización y desintegración granular, causada por la baja calidad de la piedra. Es una patología habitual de este tipo de piedra que no da mayores problemas a la hora de plantear tratamientos de conservación-restauración, por lo que no nos referiremos a ella en este trabajo.

La piedra campanil es una caliza lacustre de color blanco. Los términos litológicos varían desde wackstone hasta packstone bioclástico; variaciones que indican oscilaciones ambientales en el contexto lacustre, correspondiendo los términos wackstone a zonas más cercanas a la orilla del lago respecto a los términos packstone. El porcentaje medio de residuo insoluble es del 2,44\%, por lo que se trata de calizas muy puras. En el residuo soluble se encuentran al menos dos tipos de materia orgánica, una de las cuales corresponde a restos carbonosos visibles con lupa de mano. La comparación de resultados de los ensayos muestra que los sillares con mayor contenido de materia orgánica son los que presentan un peor comportamiento frente a la patología EPS. Se ha estudiado la configuración del sistema poroso por porosimetría de inyección de mercurio. Los ensayos de absorción, succión capilar y desorción indican un sistema poroso bien comunicado que permite un movimiento rápido del agua en su interior. La rápida desorción indica una baja permanencia de la humedad en su interior.

La patología EPS se caracteriza por provocar el agrietamiento de sillares y el desprendimiento de numerosos fragmentos. En función de la orientación del sillar y de la pieza litológica puede tener distinta expresión: en un sillar colocado con la estratificación vertical aparecen desprendimientos de escamas planas paralelas a la superficie del sillar; en un sillar colocado con la estratificación horizontal la fisuración afecta a todo el cuerpo del sillar; en capiteles y motivos escultóricos la fisuración afecta a los elementos en relieve con planos de rotura y desprendimiento paralelos al núcleo de la pieza. Pero se ha comprobado que también existen elementos de este tipo (capiteles, cimacios) conservados desde hace mucho tiempo exentos, que desde hace pocos años han empezado a mostrar desprendimientos en la cara superior, permaneciendo intacta la zona labrada. En casos más graves se ha observado la fractura completa en horizontal del elemento, quedando en dos mitades, ambas con un peso considerable. No siempre se ven eflorescencias donde se rompe la piedra y no se dis-

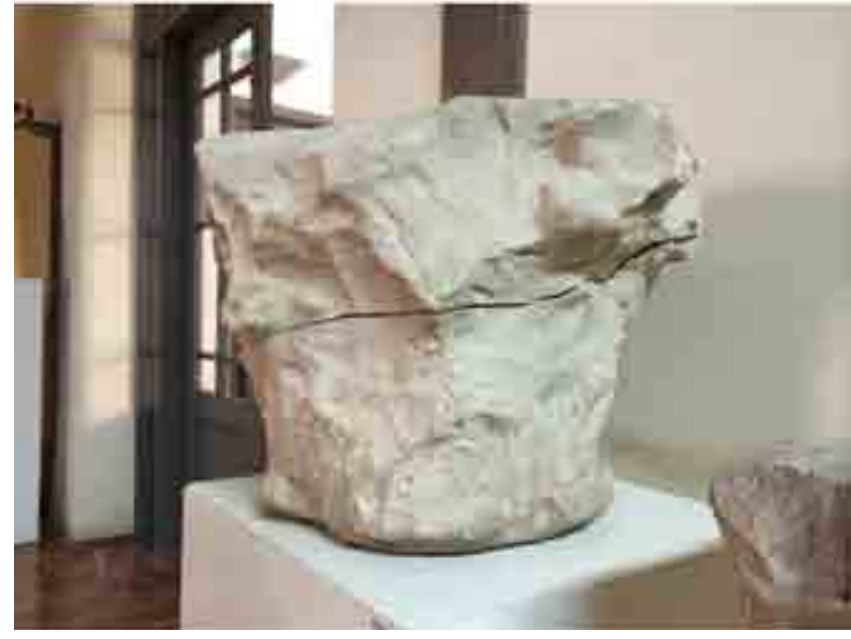

Figura 6. Capitel expuesto en el Archivo Municipal de Tudela, fractura horizontal abierta hace 3 años.

grega la piedra al tacto. [Figura 6]

La patología existió siempre en la catedral, como muestran las fotografías antiguas y reseñan los proyectos de reparación de finales del siglo XIX. Pero desde comienzo de los años 70 parece existir una generalización e incremento del deterioro. Este aumento puede ser consecuencia del uso del cemento Portland en las reparaciones, al menos desde 1930, y de la intercalación de sillares de arenisca en paramentos de caliza, dado que son dos fuentes de magnesio, cuyas sales provocan de forma especial la patología, por encima de otras sales que ya estaban presentes por lixiviados de guano, etc. La repetición de los ciclos de humectación y secado crea una fatiga en la roca que desencadena la fisuración del material.

Con independencia de su viabilidad en la práctica, el estudio de Arbotante proponía ampliar el alero del claustro para protegerlo del impacto directo de la lluvia, colocar un toldo que reduzca la insolación en la parte N, NE y NW, estudiar un sistema de humidificación que evite el secado extremo, sustituir los fustes de arenisca y piezas del mismo material próximas a la parte decorada por otros de caliza, retirada de morteros Portland, desmontar y desalar los elementos de mayor valor artístico: piezas escultóricas, capiteles, etc. Una vez desalados, tomar las medidas oportunas para que no se mojen ni sufran nuevas intrusiones salinas. También labrar y sellar juntas de $5-8 \mathrm{~cm}$ de profundidad que hagan de barrera a la difusión superficial de sales y realizar perforaciones rellenas con cartucho de resinas de intercambio que capturen cationes divalentes, especialmente magnesio. Además presentó el documento Protocolos para desalar la caliza campanil afectada por patología EPS, que aborda tanto la desalación en piezas desmontadas y sin desmontar. Se trata de procesos complejos y delicados, sobre todo los segundos, porque la piedra afectada por esta patología experimenta importantes cambios de volumen tanto al hidratarse como al deshidratarse, cambios que pueden fisurar la roca y desprender fragmentos. Por ello requieren un estudio y una evaluación mayores. 

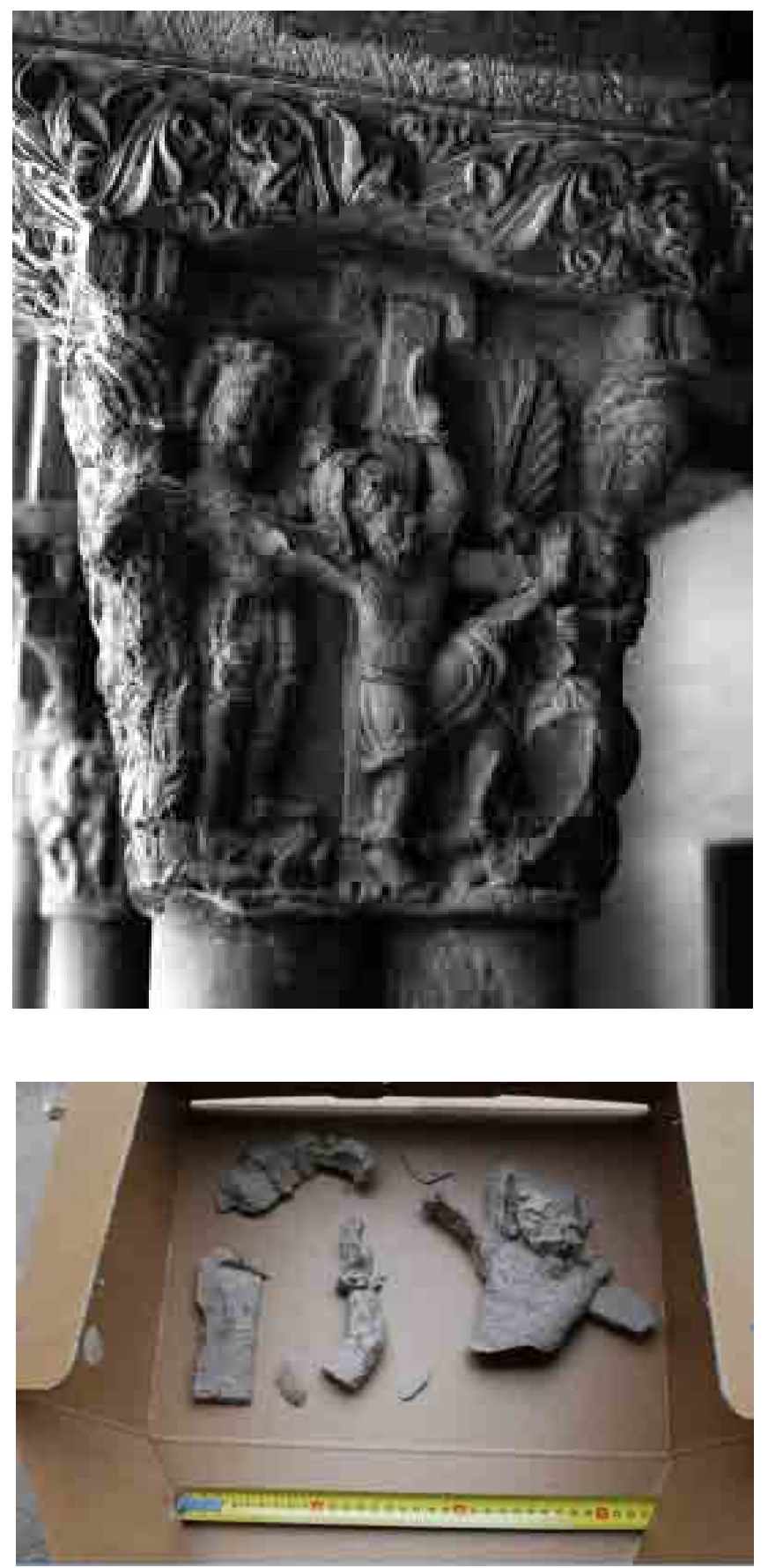

Figuras 7, 8 y 9. Proceso de destrucción de elementos escultóricos. Capitel de San Andrés entre 2007 y 2012, y fragmentos recuperados de la malla.

Además los ensayos realizados hasta ahora tras procesos de desalación no demuestran que detenga por completo la evolución de la patología.

\section{3.-Estudio sobre el estado de conservación del claustro ${ }^{8}$}

El estudio, realizado al mismo tiempo que un tratamiento de consolidación de urgencia, consistió en la realización de fichas individuales en las que se detalla el estado de conservación de cada uno de los capiteles. Se llevó a cabo

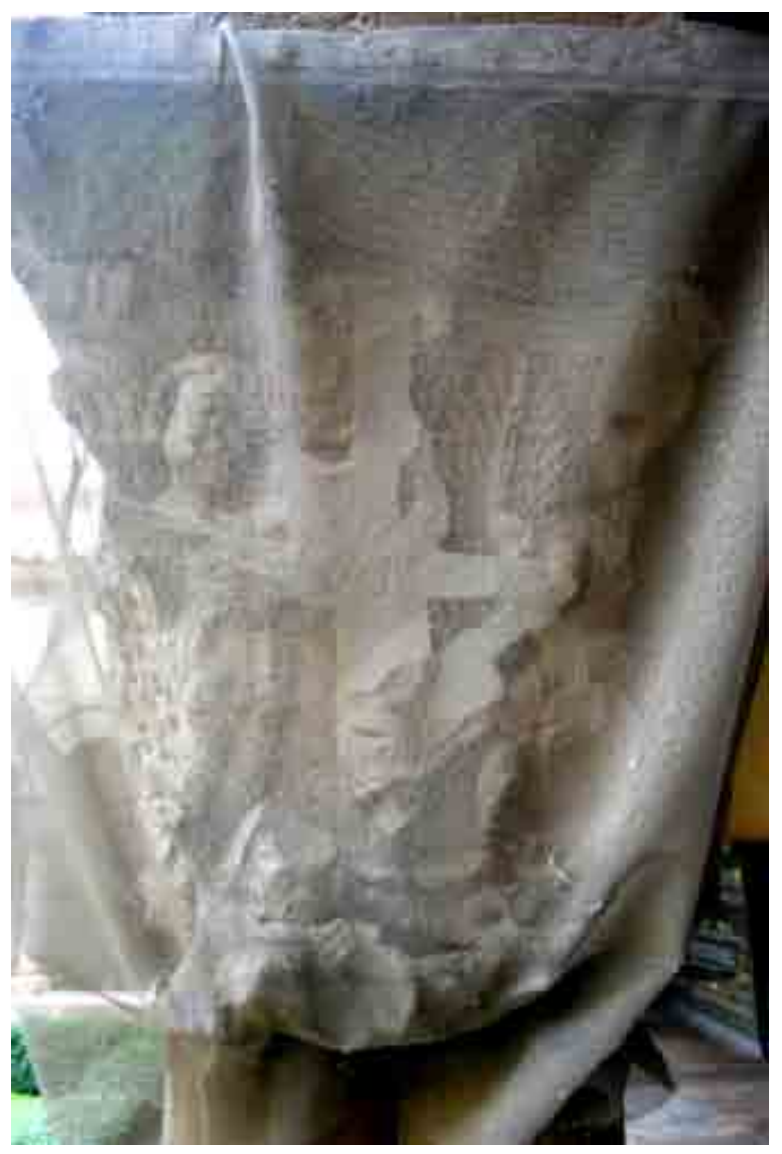

un proceso de recogida de datos, desarrollo de cartografía adecuada y normalización de descripciones de patologías presentes, siendo actualizado y ampliado posteriormente con el resto de elementos arquitectónicos: arcos, pilares, fustes, basas y zócalos. El primer tratamiento de urgencia se aplicó en 2004 en capiteles que presentaban riesgo de desprendimiento. En ellos se eliminó mecánicamente la suciedad superficial, se fijaron los fragmentos que amenazaban desprendimiento mediante tiritas de engasado adheridas con un homopolímero acetovinílico (Vinavil 59 ${ }^{\circledR}$ ) y resina acrílica en dispersión acuosa (Acril $33^{\circledR}$ ) al 50\%. Se realizaron contramoldes de espuma de poliuretano aislada de la superficie pétrea con papel Japón y Tyvek ${ }^{\circledast}$ para adaptar las fijaciones rígidas al capitel, y se instaló una malla ventilada recogiendo el contorno del capitel.

Un año más tarde la Institución encargó la revisión y actualización del Estudio, se realizaron nuevas fichas de cada elemento y se plasmó el avance del deterioro. La retirada de las protecciones provisionales rígidas colocadas el año anterior sirvió para comprobar que no habían aumentado los daños en las zonas protegidas por contramoldes. Se decidió mantener la red para la recogida de los fragmentos que pudieran desprenderse. Además se comprobó la buena reversibilidad de los engasados realizados en 2004 y se realizaron nuevos engasados junto con la revisión de los anteriores. [Figuras 7, 8 y 9]

En 2007 la Institución encargó un trabajo de Documentación y actuaciones previas en el claustro de la catedral, y 
una nueva intervención de urgencia. Este nuevo trabajo debería servir como estudio previo de cara a la redacción de un proyecto de intervención para acometer la restauración del claustro. Nuevamente se eliminó la suciedad superficial se colocaron más engasados de sujeción y se revisó la eficacia, el estado de conservación y la reversibilidad de los engasados realizados anteriormente, viendo que el sistema seguía siendo apropiado. Por último se reinstaló la malla ventilada.

Se realizaron pruebas de eliminación de juntas y reconstrucciones de cemento, y ensayos y pruebas de limpieza de la superficie de la piedra, tanto original como de reposición. En cuanto a la retirada de reconstrucciones con cemento, se observó un claro riesgo, ya que muchas de las zonas de reconstrucción están entre fragmentos originales o los sujetan, por lo que su eliminación podría conllevar la pérdida de soporte original. Se localizaron espigas metálicas incluidas en los morteros reforzando la unión entre la piedra original y la reconstrucción y complicando la retirada de las reconstrucciones.

Las pruebas de limpieza se realizaron con microproyección sobre los arcos, utilizando distintos áridos. Se llegó a la conclusión de que el más adecuado era el de piedra pómez, sobre todo en las piezas más erosionadas. También se realizaron pruebas de limpieza con carbonato de amonio en distintos tiempos sobre soporte original de caliza campanil, con la conclusión de que no era un sistema adecuado porque la actuación era mínima e irregular, a causa de la variabilidad de la capa de suciedad, así como por la dificultad de controlar la neutralización del producto y el problema de trabajar en húmedo en una roca muy sensible. Finalmente se realizaron pruebas de desincrustación fotónica en los capiteles con un equipo Art Laser ${ }^{\circledR}$, con resultados muy satisfactorios.

\section{Otros estudios}

En 1998 se había realizado un estudio del clima ${ }^{9}$. No es completo al registrar poco más de medio año, no ha quedado constancia de los puntos de colocación de los sensores, ni hay una valoración de resultados. No obstante, hemos podido comprobar que tiene más importancia el estudio de modelos de insolación y corrientes de aire que el del clima específicamente. En Tudela el clima es mediterráneo de estepa. La mayor parte de las lluvias proceden de temporales con viento del Sureste, y aportaciones de tormentas de finales de primavera y principios de otoño, alcanzando en total unos $400 \mathrm{~mm}$. La temperatura media anual ronda los $14^{\circ} \mathrm{C},\left(31^{\circ} \mathrm{C}\right.$ de media máxima y $2^{\circ} \mathrm{C}$ de media mínima), con más de 120 días despejados al año, y predominio de viento racheado del Noroeste (Cierzo). Hay una media de 25 días de helada y no llegan a tres los de nevada. Un fenómeno atmosférico importante en Tudela es la niebla típica del valle del Ebro. Se da en invierno, y aparece en condiciones de gran estabilidad atmosférica (anticiclón y ausencia de vientos), lo que da lugar a fenó- menos de inversión térmica. El ambiente húmedo del Ebro provoca una intensa condensación, produciéndose la niebla. La orografía de la zona hace que el fenómeno sea muy persistente, pasando días enteros y consecutivos bajo la niebla. En Tudela dicen que la niebla "arroja", es decir, moja. Esto es importante, ya que supone una vía de humedad a tener muy en cuenta, con aportación de agua micronizada difícilmente controlable.

Tras una fuerte tormenta advertimos unas llamativas manchas blancas de escorrentía tanto en el exterior como en el interior de las arquerías. En un primer momento parecía que el agua había arrastrado arena o polvo blanco. Pero una vez examinadas de cerca las zonas afectadas pudimos comprobar que no era una sustancia que ensuciaba la piedra, si no que algo arrastrado por la lluvia había lavado la piedra. En los fustes de las columnas se aprecia un rebaje microscópico: el agua se había llevado la pátina dejando la piedra desnuda. Esto era muy preocupante, porque además de dejar la piedra sin protección, afectaba a la escultura monumental de capiteles y arcos, que todavía conservan restos de policromía original. El tejado se encontraba en malas condiciones y ocupado por un palomar incontrolado, con la consiguiente acumulación de palomino. Este material orgánico se removía durante las tormentas y era arrastrado por el agua, escurriendo por el claustro. El guano contiene ácido nítrico, úrico y fosfórico, altamente agresivos. Los estudios de laboratorio ${ }^{10}$ confirmaron arrastre de estas sustancias y por consiguiente la urgencia de atajar estos factores de riesgo.

En 2012 se celebró en el Palacio Decanal una jornada de especialistas, con el fin de avanzar en el conocimiento de las posibles causas y soluciones al problema de la piedra campanil. Durante todo el día comentamos la situación del claustro y portadas, los estudios realizados y se realizaron nuevas propuestas. Fue un paso importante, ya que el círculo de profesionales implicados en el tema se abrió a otras experiencias y puntos de vista, lo que siempre es enriquecedor. Entre los asistentes había restauradores, geólogos, y el arquitecto responsable de las obras. Hubo nuevas preguntas que no nos habíamos planteado antes o que se podían contemplar desde otra perspectiva, y constituyó una ventana de aire fresco. Nuevas vías de investigación quedaron abiertas. La jornada se recogió en un acta donde quedaron plasmadas las dudas planteadas y sus respuestas desde varios puntos de vista, cuestiones pendientes, posibles soluciones y actuaciones. Algunas se han acometido, otras están en proyecto.

En 2013 se realizó por técnicos del Servicio de Patrimonio Histórico un estudio ${ }^{11}$ de la estructura interna de los elementos constructivos del claustro que supuso un cambio importante en cuanto a las posibilidades de intervenir en el claustro. Los estudios de Artelán dejaban constancia de la existencia de varillas de hierro que afloraban en varios capiteles. Sin embargo nunca había surgido la posibilidad de estudiar en qué elementos exactamente se emplearon vástagos de hierro en el montaje de la década de 1940. 
Acababa de volver de un curso de especialización en conservación de piedra policromada, organizado en Madrid por el Instituto de Patrimonio Cultural de España. En él Isabelle Pallot-Frossard, del Laboratoire de Recherche des Monuments Historiques de Francia presentó una ponencia sobre el proyecto de intervención en la portada de la catedral de Senlis. Explicó cómo habían conseguido distinguir las cabezas originales góticas de las reposiciones del siglo XIX utilizando un detector de metales para localizar vástagos de hierro colocados en las esculturas mutiladas durante la Revolución Francesa. Esta información me sugirió la posibilidad de emplear la misma técnica para "ver" cómo montaron el claustro de Tudela y hasta qué punto las varillas de hierro que se aprecian en los capiteles más dañados se encontrarían también en otros elementos.

Solicitamos colaboración a nuestros compañeros de la Sección de Arqueología y para mayor garantía el aparato lo manejó Jesús García Gazólaz, técnico arqueólogo, que conoce bien su manejo. En una mañana comprobamos todos los elementos del claustro. El estudio aporta datos hasta ahora desconocidos que condicionan cualquier intervención mecánica que se pretenda llevar a cabo en la estructura arquitectónica del claustro. Quedó en evidencia que el claustro está literalmente cosido con vástagos de hierro, y que embutida en la parte superior hay una estructura metálica interna que ata las cuatro arquerías. Con estos datos consideramos inviable realizar un desmontaje para proceder a su desalación o a su sustitución por réplicas. La piedra caliza de la catedral se denomina "campanil" por su especial sonoridad, es decir, transmite muy bien el sonido, y por ende cualquier vibración. Emplear cualquier herramienta de corte sería peligrosísimo dada la capacidad de transmitir vibraciones de esta piedra, las fisuras no tardarían en aparecer, abrirse y reventar la piedra a un ritmo aún mayor de lo que ya ocurre. [Figura 10]

En 2013 también se mantuvieron reuniones con el Departamento de Química y Edafología de la Universidad de Navarra ${ }^{12}$ y la colaboración puntual del Departamento de Química Orgánica y Farmacéutica de la misma universidad con el objetivo de caracterizar la materia orgánica existente en la piedra, cuestión que hasta la fecha no se había podido resolver en los diversos estudios realizados y se considera un punto clave para poder comprender el comportamiento del material pétreo en el desarrollo la patología EPS descrita por Arbotante. Se han realizado varias pruebas usando técnicas de solubilidad con espectroscopía infrarroja y resonancia magnética nuclear.

La Universidad Pública de Navarra ${ }^{13}$, colabora desarrollando un proyecto de escaneado y digitalización 3D de los capiteles de todo el claustro, así como un estudio de deformación de materiales y estructuras, y estudios complementarios de insolación, aplicando tecnología punta empleada en las estaciones fotovoltaicas. El escaneado en 3D tiene como objetivo documentar exhaustivamente el estado actual del claustro, lo que nos permitirá realizar comparaciones muy precisas de su evolución en los próximos
Claustro de rudela. Estudio con detector de metales.

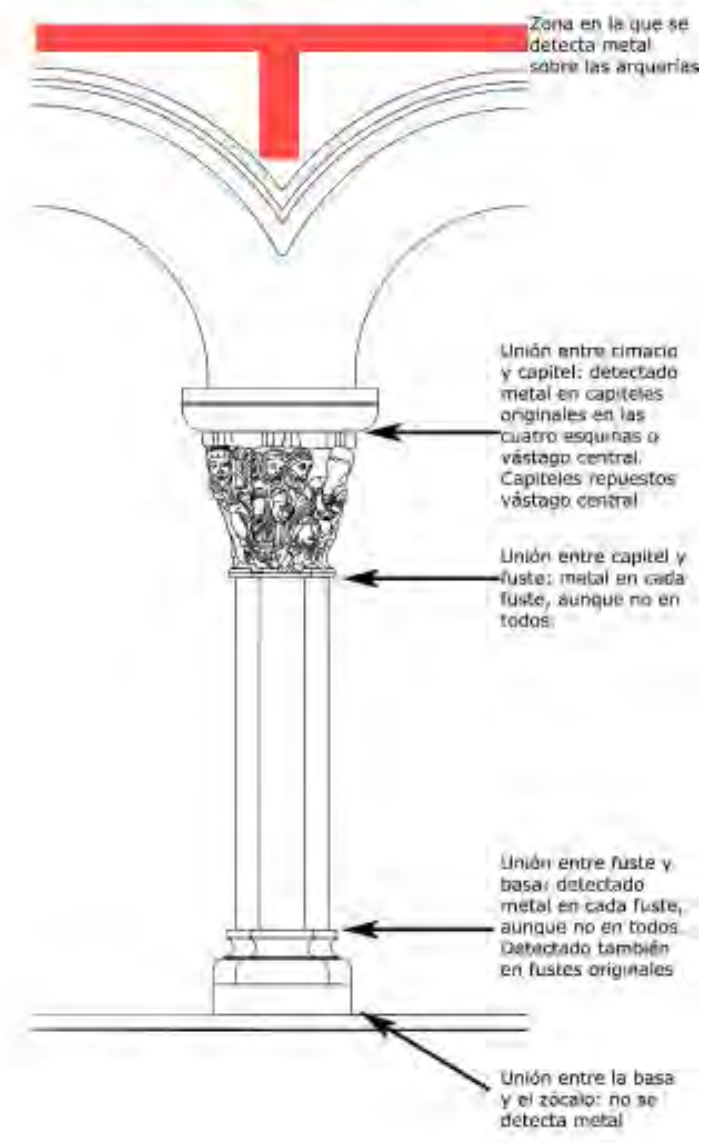

Figura 10. Gráfico mostrando la colocación de varillas de hierro.

años, servirá para documentar los capiteles más dañados ya que todavía no sabemos cómo detener su deterioro, y permitirá crear réplicas en un futuro. Descartamos la posibilidad de retirar los capiteles dañados y sustituirlos por réplicas por los problemas que su extracción podría producir en aquellos en buen estado, y porque hemos comprobado que trasladar este tipo de elementos con patología activa a un entorno seguro de museo no garantiza su conservación: los problemas continúan dentro.

\section{¿La excepción confirma la regla?}

El desarrollo de la patología en las portadas de Tudela (las tres de la catedral y la de la Iglesia de la Magdalena) coincide claramente con puntos de creación de corrientes de aire, escorrentía de agua por mal funcionamiento de los sistemas de evacuación de pluviales, y zonas de insolación vespertina. Este último agente resulta muy evidente, puede trazarse una línea recta coincidente con la línea de sol y sombra por la tarde en verano. Donde incide el sol se concentran los mayores daños, en el resto no es tan grave el deterioro o actúan otros agentes. La zona de incidencia del sol matutino no desarrolla EPS, la piedra guarda la frescura y humedad de la noche y resiste mejor el calentamiento. 
Por la tarde el sol incide sobre la roca ya seca y templada a lo largo del día, generando problemas.

Sin embargo en el claustro las cosas no están tan claras. El mapa general de patologías a simple vista es un caos donde no se observan patrones de sol y sombra, norte o sur, mojado o seco. La distribución de los daños parece absolutamente aleatoria. No se observa mayor deterioro en unas galerías u otras, por mayor efecto del viento o dependiendo de la orientación, por estar junto a piezas de arenisca o con cemento Pórtland, por estar en zonas muy secas o muy húmedas, con escorrentías de cubierta o en zonas de corriente. No obstante hay que buscar el detonante y las condiciones que lo provoca, y a ser posible qué hizo que en algunos elementos las lesiones entrasen en letargo o el deterioro parase por completo. Si la alteración de la piedra fuese únicamente debida a su propia naturaleza, el claustro habría desaparecido hace mucho tiempo.

Las imágenes del Archivo Mas muestran detalles de los capiteles embutidos en los muros de cierre, quedando exentas las caras interiores, hacia las galerías cerradas, y las exteriores, hacia el huerto. No hay diferencias entre las caras interiores, las embutidas o las exteriores, por ese lado no podemos establecer diferencias. Y hay que tener en cuenta que los capiteles permanecieron en aquellas condiciones más de 300 años. Encontramos capiteles en muy buen estado en todas sus caras independientemente de su orientación y situación mientras duró el claustro cegado.

Vamos acotando agentes muy poco a poco. Comparando las imágenes de antes de la intervención de 1940 con las actuales y con los planos de patologías, vemos claramente la explicación a la desaparición de 6 de los capiteles que ya fueron repuestos en 1940. Su ubicación coincide con los contrafuertes de ladrillo colocados en el siglo XVI, por lo que pudieron desaparecer entonces. En esas mismas imágenes se observa el claustro convertido en huerto, con jaulas para aves y conejos adosadas a las arquerías ya cegadas que producirían acumulaciones de excrementos que a su vez servirían para abonar el huerto. Esto constituye una fuente de sales extra que podría explicar porqué no se conserva más que una basa original y ningún fuste.

Hay imágenes de 1916 que muestran daños claros por EPS y hoy el área afectada sigue siendo la misma, no ha habido evolución, y las lesiones tienen aspecto de viejas. En otros casos se observa una mínima evolución. En cambio hay otros que parecen abocados a su desaparición.

En cuanto a la coexistencia con sillares de arenisca de reposición, en la esquina NW se colocó un sólido capaz sustituyendo a la mitad de un capitel que en 1940 estaría muy dañado, y actualmente su situación es estable, presenta lesiones viejas inactivas, y no parece afectarle negativamente el contacto con la arenisca. [Figura 11]

Se ha estudiado cómo rompe la roca en cantera, ya que en algunas piezas se ven fracturas que se explican por el pelo

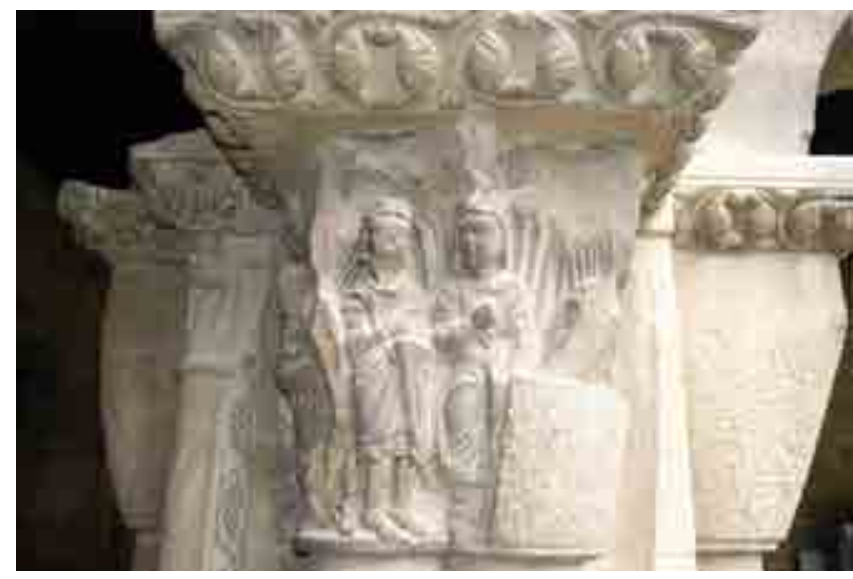

Figura 11. Lesiones antiguas estables en un capitel colocado con sólido capaz de arenisca en 1940.

de la piedra. Sale mucho material desechable, piezas que se cortan un día al siguiente (o poco más tarde) se han partido solas. No obstante en los estudios que se han hecho sobre probetas cuesta mucho reproducir la EPS en piedra de cantera, y poco hacerlo en piedra procedente de la catedral, lo que le hace pensar a los geólogos que hay una implicación de la fatiga acumulada.

Nos preocupa la evolución de elementos que desde hace décadas se encuentran en el interior de edificios y que en un momento dado han empezado a fracturarse, sin que las condiciones hayan variado sustancialmente. Es como si la piedra tuviese un periodo de garantía que una vez sobrepasado se desencadene el desastre. La esperanza está en que hay elementos en los que por algún motivo se ha detenido el avance de la patología. Ahí estará la solución.

\section{Estudios pendientes}

En estos años hemos avanzado mucho, pero queda mucho por hacer, y continuamente surgen nuevas posibilidades que abren nuevos campos. Actualmente trabajamos para completar el estudio de las fuentes documentales, y siguen abiertos los campos de investigación con las universidades. La jornada de especialistas celebrada en 2012 nos deja como tareas aún pendientes:

- Monitorización por sonido de las microfracturas para prevenir nuevas pérdidas, análisis microsísmico.

— Estudios de corrientes de aire, ya que hay más daños en las esquinas.

- Mapas de insolación tanto actuales como según las construcciones derribadas en el 40 y la disposición del arbolado entre 1950 y 1989.

- Termografía del claustro, especialmente interesantes los cambios interestacionales (hay más desprendimientos en octubre) y variaciones día/noche, por lo que se necesitan 2 tomas diarias durante muchos meses.

- Relacionar todos los mapas que se van realizando 
(insolación, termografías, humedades, evaporímetros...)

- Buscar casos similares fuera de nuestras fronteras.

No se ha hecho un estudio de biodeterioro para descartar contaminantes en los macroporos ya que el equipo de geólogos descarta que pueda existir. Tampoco se han hecho análisis de cementos, hay innumerables reparaciones con cementos diferentes, y tampoco parecen ser determinantes en el desarrollo de la patología.

\section{Situación actual}

El claustro de la catedral de Tudela tiene desde otoño de 2013 una nueva cubierta que aprovecha la estructura de madera de la anterior. Se ha prolongado el alero considerablemente y en las tormentas acaecidas en estos meses se ha comprobado que no se mojan los capiteles, por lo que la protección funciona bien a nivel de agua de lluvia. También es mayor la protección del sol, pero aún así hay horas de exposición directa. Este problema se intentará paliar con la colocación de un toldo de sombreo y arbolado de crecimiento controlado y hoja perenne que ayude a mantener sombra y un cierto grado de humedad en el claustro. Se ha proyectado una intervención de conservación y restauración que contempla la limpieza según las pruebas realizadas en los estudios previos, y la fijación de elementos con riesgo de caída, reponiendo todos aquellos de los recogidos en los últimos decenios que sea posible. Se tratarán los hierros expuestos al aire y se retirará todo el cemento que sea posible sin dañar a la piedra original. Se van a ensayar morteros de cal como cierre de superficies muy fragmentadas. Hemos visto que este tipo de soluciones, que se aplicaron con éxito hace décadas, puede minimizar los daños.

Sabemos que con esta intervención no termina nuestro trabajo en Tudela. Volveremos a intervenir el año próximo, pues no hemos dado con la solución y el caso no está cerrado. Seguimos investigando.

\section{Bibliografía}

BLANCO, M., COLUCCI, F., GISBERT, J. y LOPEZ P. (2009). Modelo de distribución de sales en materiales pétreos porosos. Universidad de Zaragoza. http://zaguan.unizar.es/record/4325/files/ART-2009-111.pdf

GISBERT AGUILAR J. (2012). "Piedra y patrimonio: patologías de la piedra campanil en la catedral y claustro románico de Tudela", en Románico: Revista de arte de amigos del románico, $n^{\circ} .14$, págs. 68-75.

GISBERT AGUILAR J., O. BUJ, F. COLUCCI (2007). "Automatización de los ensayos de absorción y desorción en materiales pétreos consolidados con el objetivo de valorar las variaciones en su sistema poroso. (Póster)", en La conservación infalible: de la teoría a la realidad, págs. 383-386.

GISBERT AGUILAR, J., MATEOS ROYO, I. y SOMOVILLA DE MIGUEL, I.A.. "Morteros de restauración", Zabaglia 14, Colegio Oficial de Aparejadores, Arquitectos Técnicos e Ingenieros de Edificación de Huesca http://www.catvalencia.es/articulos/2012/ VIR02126.pdf

MELERO MONEO, M L. (1997). Escultura románica y del primer gótico de Tudela, Tudela, p. 33-161

VV.AA. (1980). Catálogo Monumental de Navarra, v. I, p. 238-290

VVAA. (2002). El arte románico en Navarra, p. 223-231 у p. 371-378

VVAA. (2006). La catedral de Tudela, p. 159-189 y p. 191-223 у p. 399-417

VVAA. (2010). "Estudio y cartografía de sales en paramentos pétreos: innovaciones tecnológicas con este propósito", en La ciencia y el arte: ciencias experimentales y conservación del Patrimonio Histórico, Vol. 2, págs. 162-170.

\section{Notas}

[1] Declarada Monumento Nacional por Real Orden de 16 de Diciembre de 1884.

[2] VV.AA. Catálogo Monumental de Navarra, Pamplona 1980, v. I, p. 238-290.

[3] Julio Segura, archivero de Tudela, retrasó esta intervención hasta el siglo XVII.

[4] Archivo Mas, Archivo Institución Príncipe de Viana, Fondo Uranga.

[5] Actuación promovida por la Asociación de Amigos de la Catedral de Tudela.

[6] Se redactó en marzo de 2003 por el geólogo Antonio Aretxabala, del Laboratorio de Edificación de la Escuela de Arquitectura de la Universidad de Navarra, por encargo de la Institución Príncipe de Viana.

[7] Redactado por el equipo de investigación Arbotante, del Departamento de Geología de la Universidad de Zaragoza, dirigido por Josep Gisbert Aguilar, en mayo de 2003.

[8] Redactado por Artelan, en el año 2004, ampliado y actualizado en 2005, 2009 y 2013.

[9] Estudio encargado a TSA, S.L.

[10] Estudio encargado a Artelab S.L.

[11] Estudio inédito redactado por Violeta Romero BarriosTécnico Superior Restauradora. 
[12] Profesores Dr. Adrián Durán Benito y Dr. José Ignacio Álvarez Galindo

[13] José Ramón Alfaro, ingeniero, vicerrector del Campus de Tudela

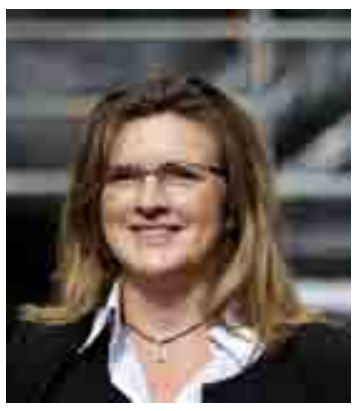

\section{Alicia Ancho Villanueva}

aanchovi@navarra.es

Licenciada en Bellas Artes, especialidad en Conservación y Restauración de Bienes Culturales, Universidad Politécnica de Valencia, 1994.

Trabajó como restauradora en empresa particular y como autónoma entre 1994 y 2003, fecha de ingreso en el Servicio de Patrimonio Histórico del Gobierno de Navarra. En la Administración ha ocupado desde 2003 plaza de Técnico Superior Restauradora y desde 2011 es Jefa de la Sección de Bienes Muebles y Registro del Patrimonio. Su labor se centra en la autorización de intervenciones en bienes tutelados, la redacción de Pliegos Técnicos y Proyectos de Conservación y Restauración, Dirección de obra, gestión de subvenciones y asesoramiento técnico a particulares, parroquias, ayuntamientos y otras entidades, realización de intervenciones de urgencia previas a la restauración y difusión de las actividades de la Sección: conferencias, sensibilización en localidades donde se interviene, redacción y coordinación de textos para su publicación. 


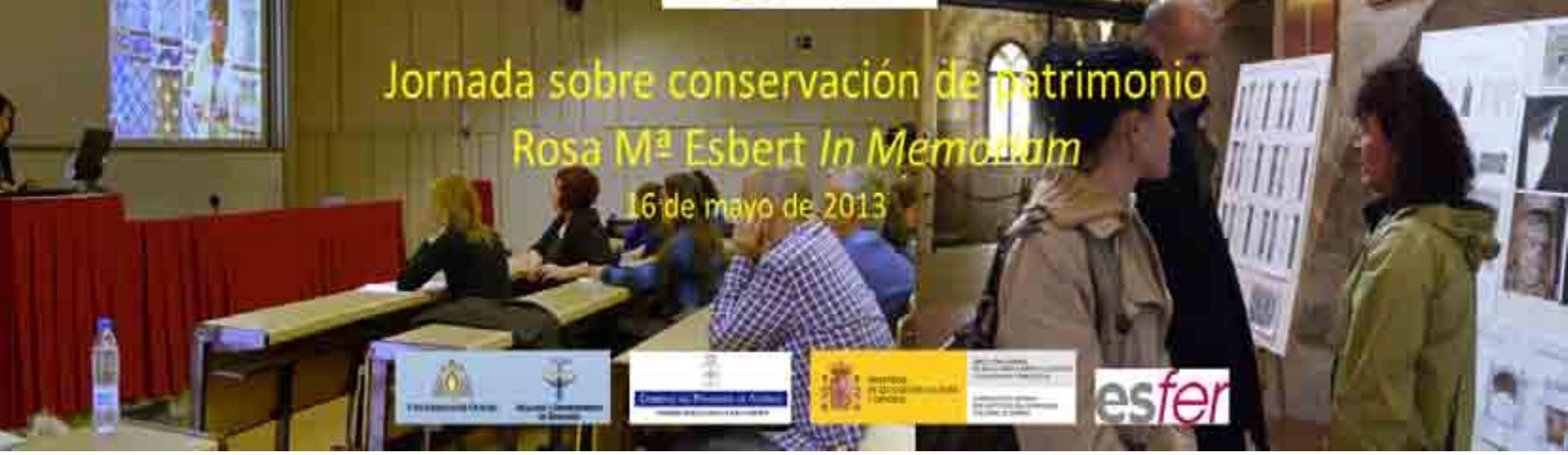

\title{
Aspectos relacionados con el Valle Salado de Añana: Sistemas constructivos de la eras, su evolución en el tiempo y criterios de conservación..
}

\author{
Azucena Prior Santamaría y Ángel Luis García Pérez
}

Resumen: El Valle Salado de Añana es una explotación minera a cielo abierto situado en la provincia de Álava. Destaca su sorprendente arquitectura, su interés histórico y arqueológico y su especial valor paisajístico y medioambiental. En el momento álgido de su actividad, en 1960, se explotaban en el valle salado unas 5000 eras para producción de sal, mientras que en el año 2000 apenas quedaban ya 42. Este vertiginoso ritmo de degradación, llevó a la Diputación Foral de Álava a impulsar la recuperación del conjunto patrimonial, para lo cual, se puso en marcha un Plan Director. Ártyco, empresa especializada en la recuperación de patrimonio monumental, lleva participando en los trabajos de recuperación del Valle de forma prácticamente continuada desde el año 2010, consolidando en unas ocasiones y en otras construyendo los entramados de madera, eras, muros de contención, pozos, almacenes..., siempre los antiguos sistemas constructivos, los mismos materiales tradicionales y con un respeto escrupuloso a las tipologías formales y constructivas existentes..

Palabras clave: Salinas de Añana, Paisaje Cultural, recuperación integral, materiales de acabado para las eras

\section{Aspects related to the Salt Valley Añana: Construction Systems eras, its evolution over time and conservation criteria.}

\begin{abstract}
Añana Salt Valley is a traditional opencast salt mine located in Álava, northern Spain province. This site stands out for its amazing architecture, its historical and archaeological interest and their special scenic and environmental value. At the height of its activity, in 1960, 5000 pools for salt production called eras, were exploited in the salt Valley, while in 2000 there were just 42 . This rapid rate of degradation, led to the Álava Provincial Council to promote the recovery of this unique industrial heritage, for which a Master Plan was launched. Ártyco which is a company specialiced in heritage recovery has been working steadily in the recovery efforts of mining structures since 2010, with works to consolidate structures, wooden palisades, walls, wells and storage places, always following the traditional building methods and materials and keeping a scrupulous respect for existing typologies.
\end{abstract}

Key words: Añana Salt Valley, Cultural Landscape, Integral restoration, Salt farm building materials

\section{Introducción}

El Valle Salado de Añana - actualmente candidato a Patrimonio Mundial dentro de la categoría de Paisaje Cultural de la UNESCO - está situado en la provincia de Álava, a 30 $\mathrm{km}$ al oeste de Vitoria.

El emplazamiento actual de las salinas estuvo cubierto hace más de 200 millones de años por un gran océano que, al secarse, dejó una capa de sal de varios kilómetros de espesor. Con el paso del tiempo, esta capa se fue cubriendo con nuevos estratos que la ocultaron definitivamente. La explotación de estos filones se realiza aprovechando los manantiales de agua salada (salmuera) que se crean tras el paso de corrientes de agua dulce por las capas de sal sólida. Estos manantiales suministran la muera a las eras a través de canales de madera y a nivel de superficie, de manera natural y continua, lo que permite su empleo sin 
necesidad de realizar perforaciones ni bombeos. Existe un gran número en el Valle Salado y su entorno, pero sólo cuatro de estos manantiales son aprovechables, pues su caudal es permanente y su grado de salinidad está cercano a la saturación (entre 210 y 250 gr. de sal por litro), aproximadamente 7 veces la concentración del mar. Proporcionan diariamente en torno a 260.000 litros de salmuera.

Haciendo un breve repaso a su historia, comentaremos que las primeras huellas de asentamiento en las cercanías de estos manantiales de agua salada, se remontan a hace unos 5.000 años, habiéndose descubierto vestigios de la Edad del Hierro, romanos y altomedievales, en cuyos textos se denominó el Valle de Haniana. En torno a 1114, Alfonso I el Batallador otorgó al valle el primer fuero real del País Vasco. En el siglo XIV estuvieron bajo el dominio del Monasterio de las Huelgas de Burgos y después bajo la autoridad de familias nobiliarias.

A mediados del siglo XVI Felipe II decretó el monopolio de la sal. Durante este periodo de control estatal, la corona obligó a los salineros a cambiar el sistema de producción empleado tradicionalmente. Esto provocó una profunda transformación de todo el valle salado, perteneciendo a esta época la mayor parte de las estructuras que hoy podemos contemplar. Por fin el Estado puso fin al monopolio y los productores recuperaron el control completo de la explotación, pero a mediados del siglo XX se inicia la decadencia de esta explotación salinera, debido entre otros factores, a la introducción de mejoras en la producción de las salinas costeras.

\section{La recuperación del valle}

La iniciativa y el interés de recuperación integral del Valle, se debió a su sorprendente arquitectura, su interés histórico y arqueológico, su gran valor paisajístico y su particular biotopo, con especies de animales y plantas únicas en estos ecosistemas.

En su momento álgido, en 1960, habían funcionado en el valle salado unas 5000 eras de hacer sal, y en el año 2000 apenas quedaban ya en explotación 42. Este vertiginoso ritmo de degradación, Ilevó a la Diputación Foral de Álava a impulsar la recuperación del conjunto patrimonial. Para ello, se puso en marcha un Plan Director cuyo principal objetivo era diagnosticar los problemas que ocasionaban la ruina del valle e indicar la forma y el modo más adecuados para rescatarlo del olvido al que había sido sometido durante los últimos cuarenta años, preservarlo, mantenerlo, cuidarlo, y, a través de su uso y explotación, garantizar su pervivencia.

Restaurar un complejo de estas características supone sumergirse en un modo de construir diferente, caracterizado no tanto por la complejidad técnica de las soluciones constructivas, sino por el carácter empírico de una arquitectura práctica, rural y tecnológicamente sencilla, que es fruto de una perfecta adaptación del hombre al medio que le rodea

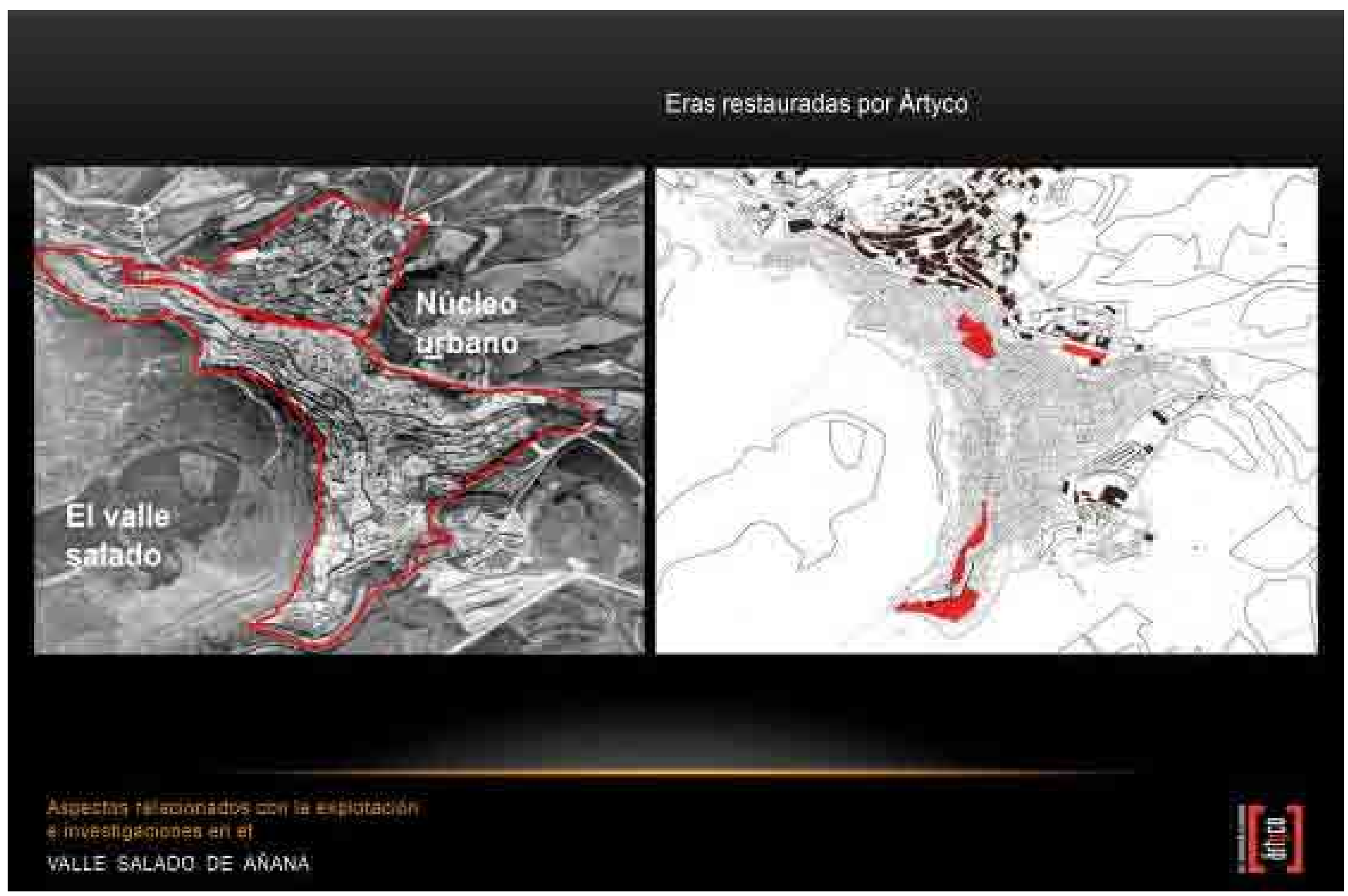




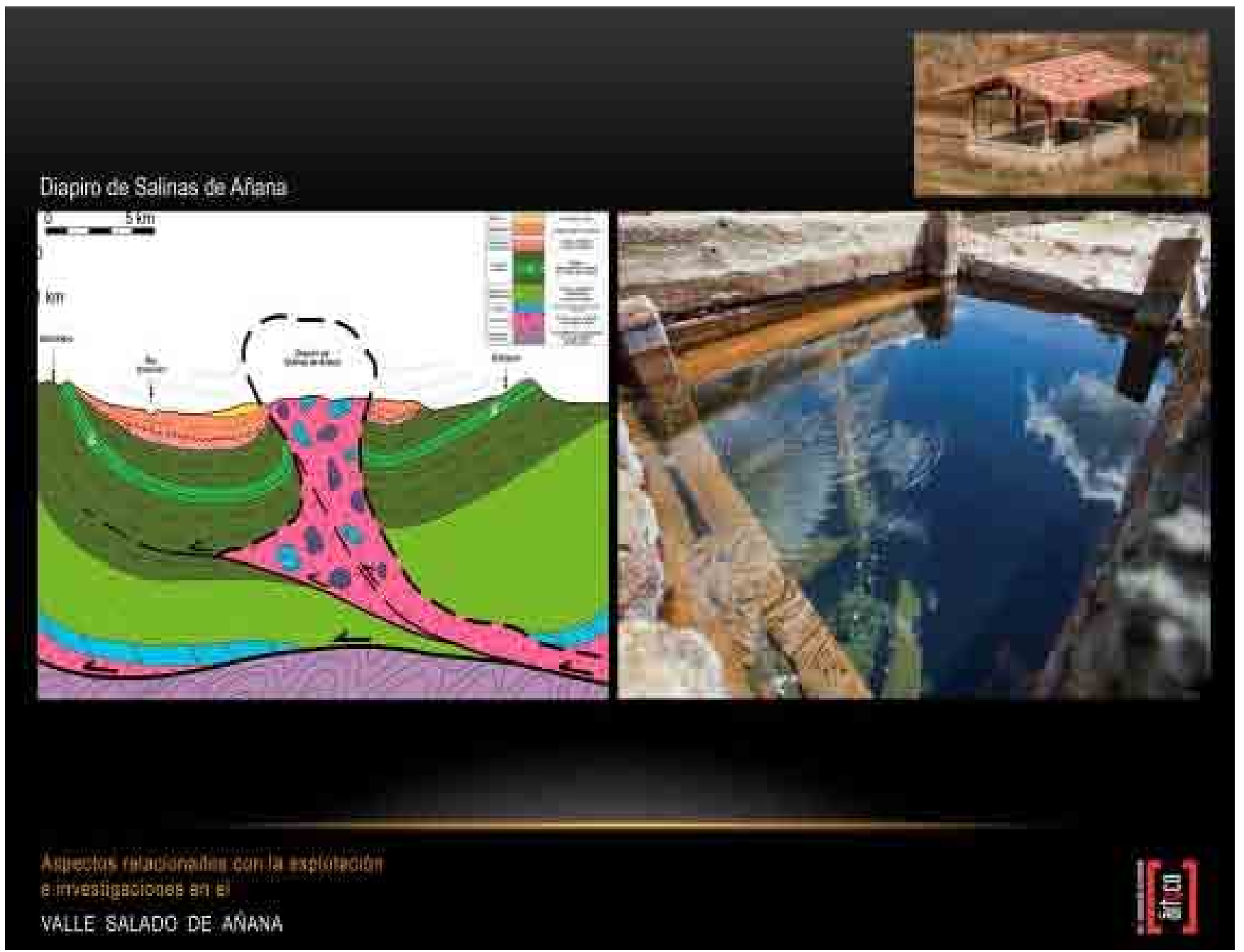

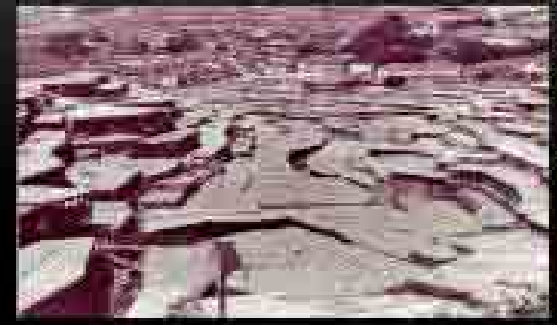

Inicia s. $x X$

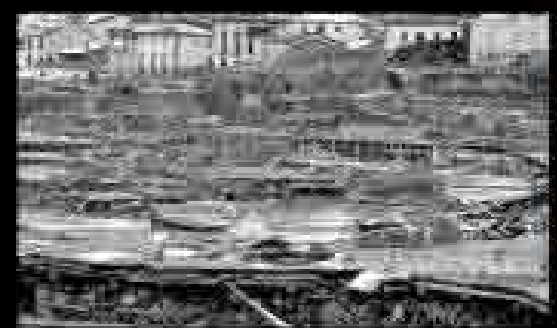

Finales s. $\mathrm{XX}$

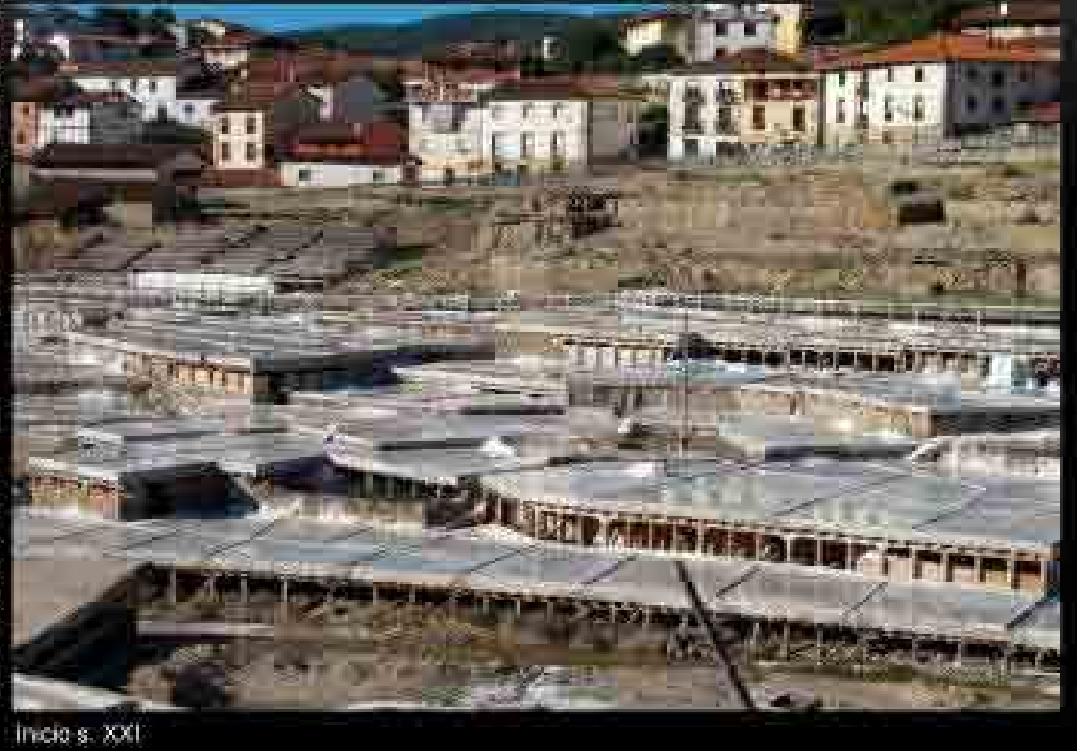

4 불유. 


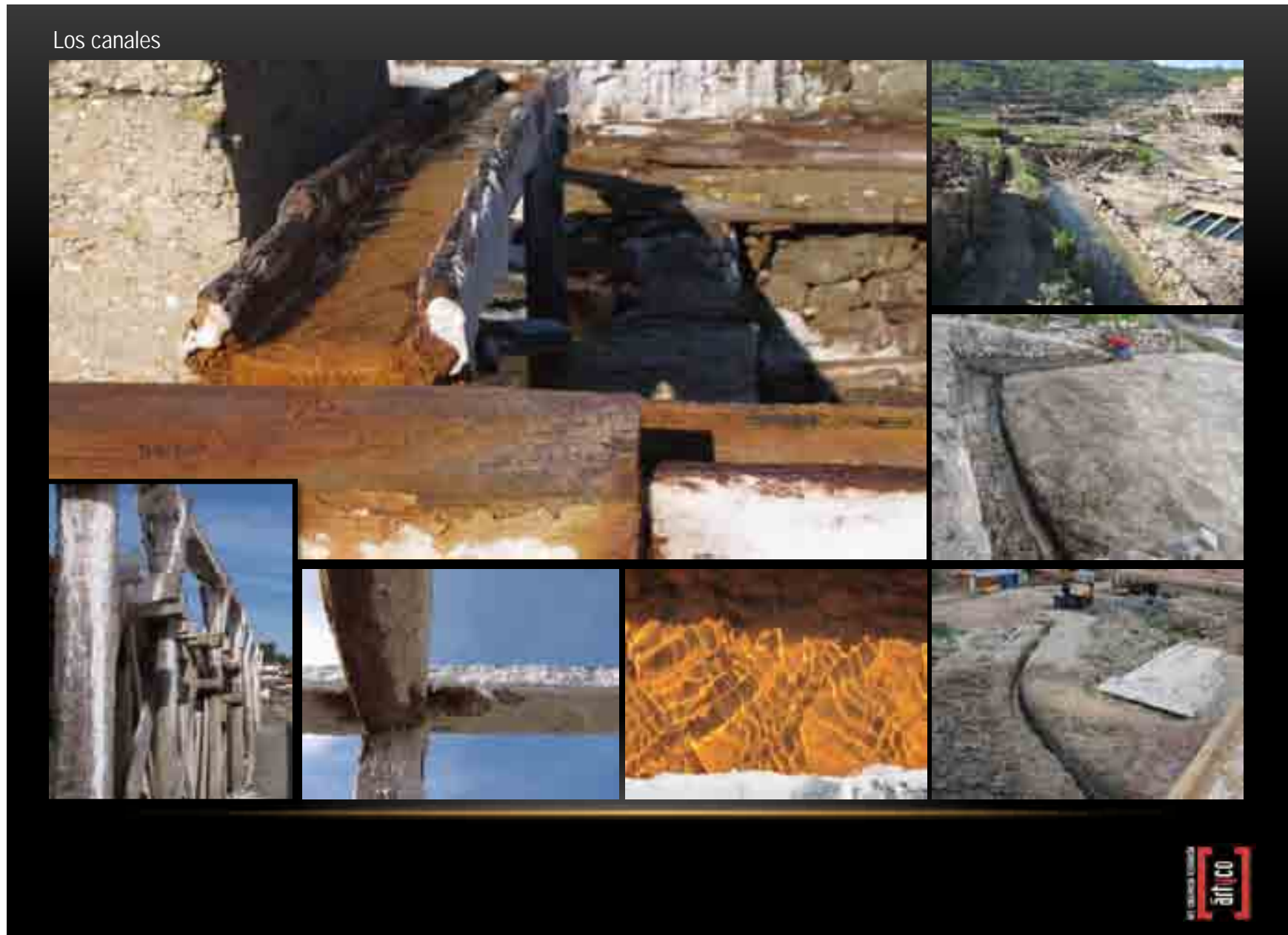

Los muros

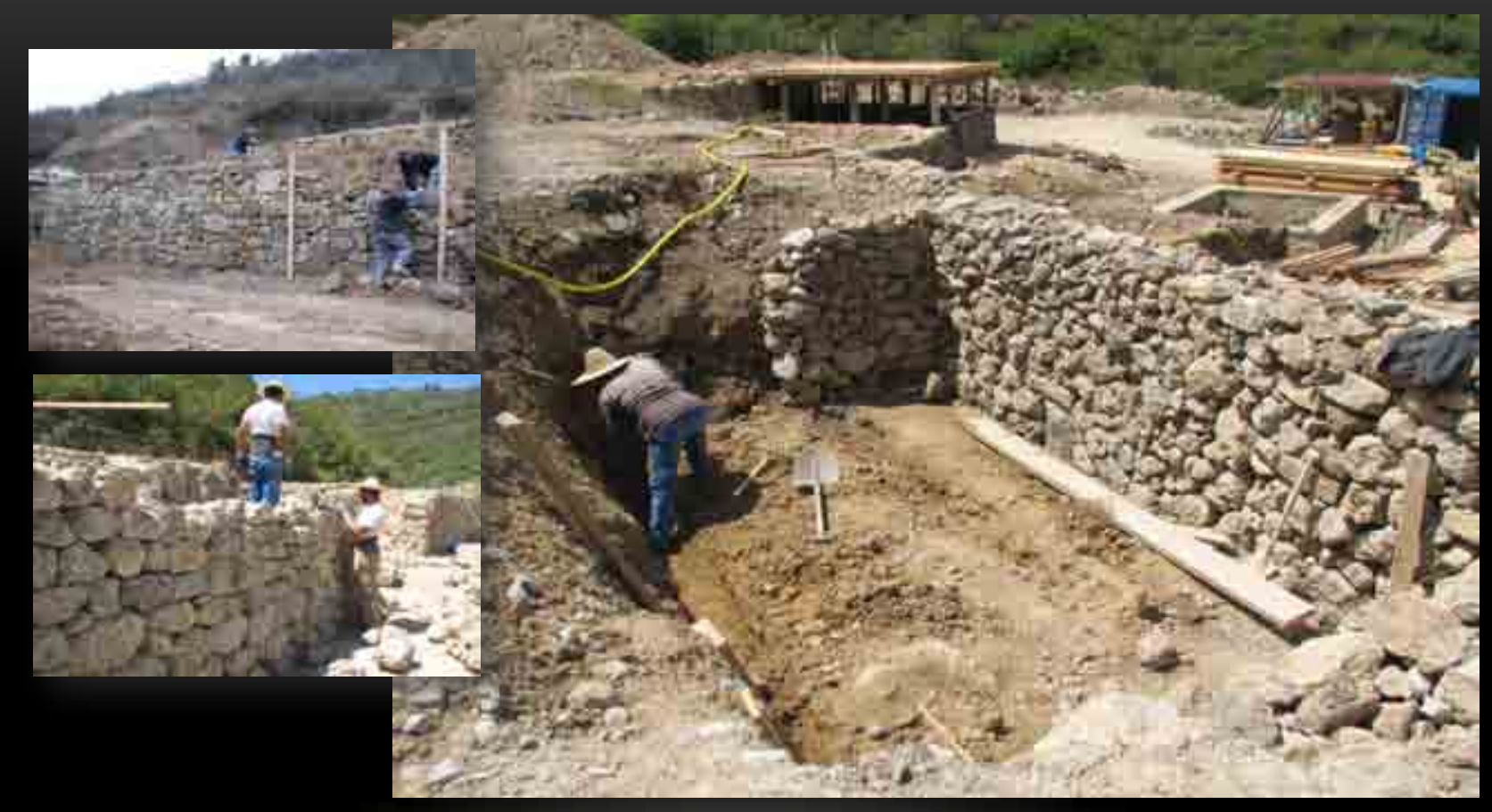


desarrollada durante miles de años. Es por ello por lo que es tan importante conocer la evolución histórica y arquitectónica de las salinas desde sus orígenes.

Ártyco lleva participando en los trabajos de recuperación del Valle de forma prácticamente continuada desde el año 2010, consolidando en unas ocasiones y en otras construyendo entramados, eras, muros de contención, pozos, almacenes..., siempre con los antiguos sistemas constructivos, con los mismos materiales tradicionales y con un respeto escrupuloso a las tipologías formales y constructivas existentes.

Los criterios generales de las actuaciones realizadas son por un lado respetar y asegurar la conservación de los elementos originales manteniendo los factores que determinan el carácter monumental del Valle y por otro trasladar y poner en uso una infraestructura productiva y de ocio. La mínima intervención, el respeto de todos los elementos en buen estado de conservación y la conveniencia de reutilizar al máximo los diferentes materiales existentes, son los objetivos y directrices del Plan Director para la recuperación de todas las estructuras y entramados originales.

\section{Elementos constructivos del valle}

Ni los elementos constructivos ni los materiales utilizados han variado apenas a lo largo de la historia del Valle. El contacto de los materiales con esa alta concentración de salinidad impide la introducción de nuevos materiales más modernos como los metales, que podían agilizar los procesos constructivos y los de explotación.

Así pues, el listado de materiales utilizados en el Valle ha sido y es muy reducido: madera de pino silvestre, mampuesto de la zona para los muros, canto rodado para la superficie de las plataformas y barro, utilizado como capa impermeable de pozos y eras, y NUNCA elementos metálicos.

\section{Los canales}

El transporte del agua salada desde los manantiales por gravedad se realiza a través de una red de canales llamados royos -con más de tres kilómetros de longitud total-. Si bien en origen gran parte de ellos eran simples zanjas excavadas en el terreno, con el tiempo fueron sustituidos por troncos de madera horadados, generalmente de pino

\section{Los pozos}

El agua de los canales se vierte en los pozos (actualmente 848), que son el corazón de las granjas de sal. La morfología de los pozos es muy variada, los hay exteriores, los de boquera bajo las eras, los calentadores..., pero todos ellos tienen la función de reservar la muera hasta que el sol y el calor permita la distribución de esta agua en las eras. Es- tos pozos están construidos exclusivamente con una capa de arcilla compactada. El barro y la propia muera impermeabilizan la superficie.

\section{Las eras}

La obtención de la sal en Añana se basa en la evaporación del agua contenida en la salmuera por medios naturales. Para conseguirlo, se vierte el agua salada en unas superficies horizontales llamadas eras cuya superficie varía entre doce y veinte metros cuadrados. Los grupos de eras trabajadas por un mismo propietario se denominan granjas. Éstas se van adaptando a la compleja topografía del lugar, tanto en forma como en altura, dando lugar esta particular e inimitable fisonomía del Valle.

\section{Los muros}

Esta superficie de las eras se obtuvo inicialmente mediante desmontes del terreno, aterrazando las laderas del valle para formar planos horizontales donde recoger la salmuera y facilitar su evaporación. Los muros de contención de tierras se realizan con piedras sin labrar de la zona de distintas variedades, pero resistentes a la sal (ofitas, tobas, ........), manejables por uno o dos hombres y colocadas unas sobre otras en seco, sin mortero de ningún tipo. Suelen tener cierto desplome hacia las tierras a contener $y$ pueden alcanzar alturas hasta de cuatro metros

\section{Las plataformas y los entramados}

Con objeto de mejorar la productividad y aumentar la superficie de eras que proporcionaban los desmontes del terreno, se construyeron multitud de entramados de madera de pino, que servían de base para la construcción de nuevas eras, de nuevos pozos de almacenamiento de muera y para la construcción de almacenes de sal, una vez evaporada y recogida la "cosecha".

Todos estos entramados están construidos con madera de pino silvestre, aprovechando troncos, vigas con secciones más o menos regulares y tablas, unidos todos los elementos entre sí por medio de ensambles de caja y espiga, media madera..., siendo todos ellos fijados con espigas de madera.

\section{Almacenes de sal}

Estos almacenes construidos de madera y de piedra permiten guardar y proteger la sal hasta el momento de su transporte a los almacenes públicos situados en el exterior de la explotación. Este tipo de estructuras se sitúan principalmente bajo las eras, aprovechando los huecos existentes entre los muros de las terrazas y las plataformas de evaporación. Esta técnica constructiva facilita en gran medida su llenado, pues la sal es simplemente vertida por unos pequeños huecos abiertos en la superficie de las eras 
llamados boqueras.

\section{Plataformas}

Lo que más cambios ha experimentado es el acabado de la superficie de las eras: en un primer momento el acabado de las eras consistía en un perímetro con tablas de madera, a modo de encofrado y en su interior una regularización y compactación de la superficie con arcilla o greda, como se llama allí. Con este sistema se recogía una sal "sucia", así que se optó por añadir sobre la greda una capa de canto rodado. De este modo se consigue una sal más limpia, pero todavía, a través de los cantos rodados, ascendía algo de arcilla y ensuciaba la sal.

El siglo XX y la introducción del hormigón en la nueva arquitectura hizo que los salineros incorporaran este material en el Valle, así que sobre el canto rodado ya instalado, se cubría la superficie con cemento, así se creaba una superficie continua, horizontal y resistente, e impedía que la greda aflorara a la superficie. El resultado era una sal BLANCA.

Pero este último sistema ha generado muchos problemas de mantenimiento y de "desescombro" del material, que se agrieta y necesita renovación continua, y por su rigidez y peso es muy difícil deshacerse de él. Esto genera graves problemas ya que los accesos del Valle son muy limitados y reducidos, y es muy difícil extraerlos. Durante mucho tiem- po se consideró el sistema idóneo y prácticamente TODAS las eras del Valle acabaron recubiertas por esta capa.

En la actualidad y definido en el Plan Director se plantea introducir otro sistema de construcción de acabados de eras que permita recoger una sal tan blanca como con el acabado de cemento, y se ha optado por el enlosado. El planteamiento es introducir un material pétreo nuevo, extraído fuera del Valle pero compatible y coherente con el entorno y con los materiales de origen, modulado en pequeñas losas de forma cuadrada instaladas sobre la arcilla, generando una superficie continua, como el hormigón, pero compartimentado, de manera que los trabajos de mantenimiento y sustitución de elementos se pueda llevar a cabo de forma individual.

Sin embargo, el nuevo planteamiento de acabado de eras plantea la introducción de un nuevo material -la piedra- un material tan variable que es necesario controlar su comportamiento en este medio tan particular para escoger el más apropiado. Por ello, antes de introducirlo en un sistema alternativo al tradicional y de forma general en todo el Valle, se decide ponerlo en práctica en unas zonas, para experimentarlo in situ y realizar análisis y estudios de eficacia e idoneidad, tanto del sistema constructivo como del material que ha de elegirse. Para cumplir con estos objetivos la Fundación Valle Salado, a través de Artyco, encarga estas investigaciones a la empresa GEA asesoría geológica.

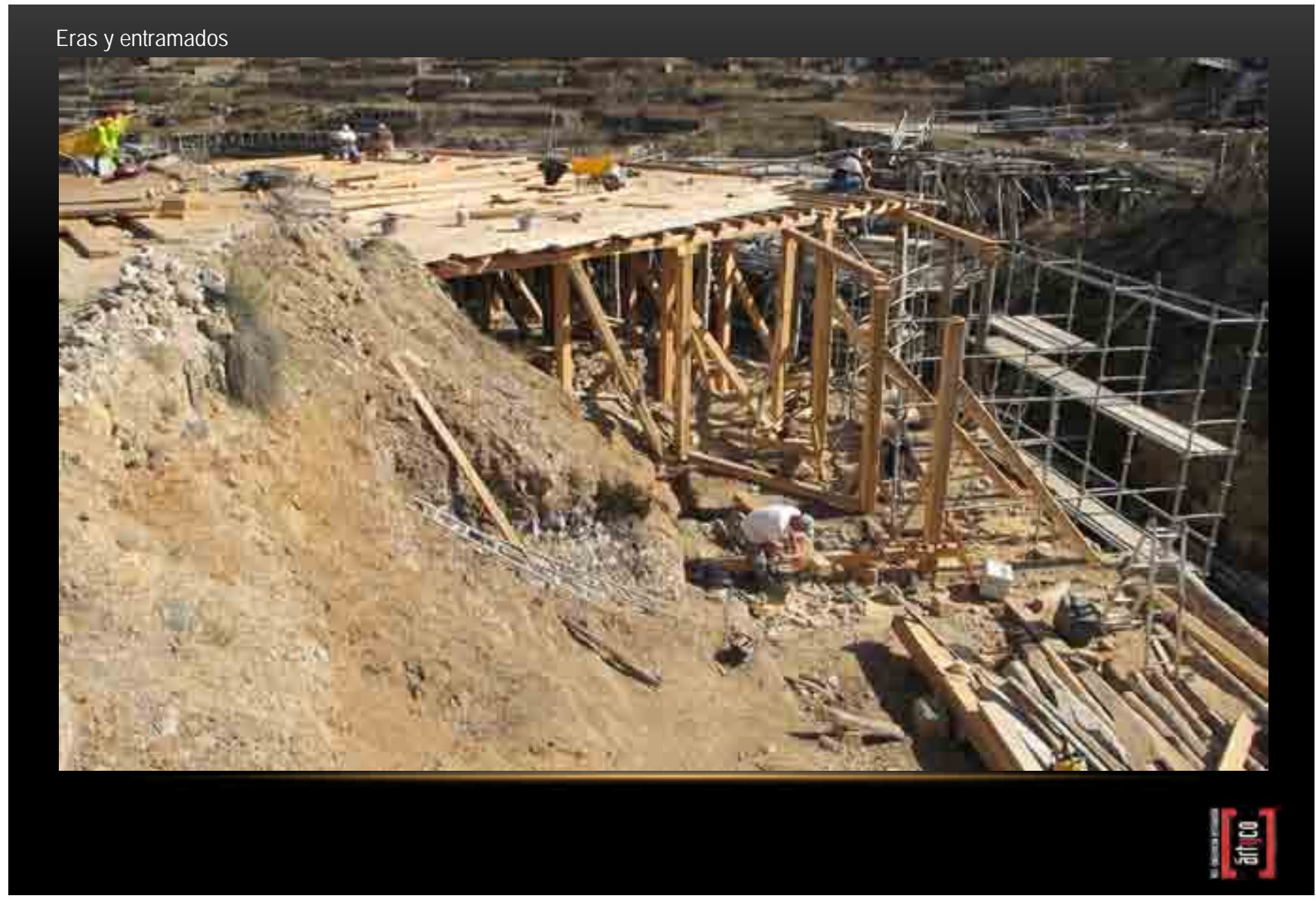



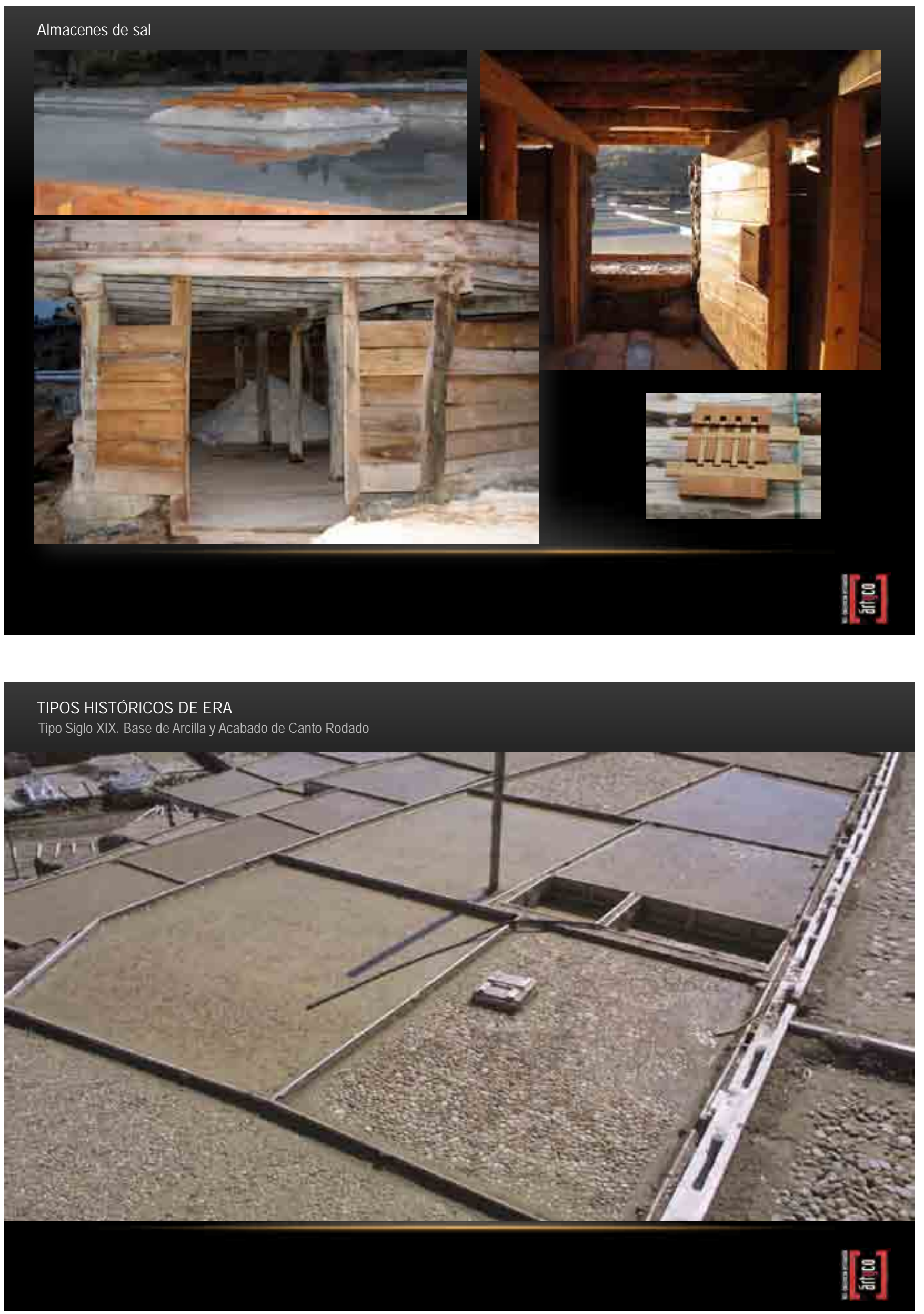


\section{TIPOS HISTÓRICOS DE ERA}

Tipo Siglo XX Base de Arcilla y Acabado de Cemento sobre Canto Rodado

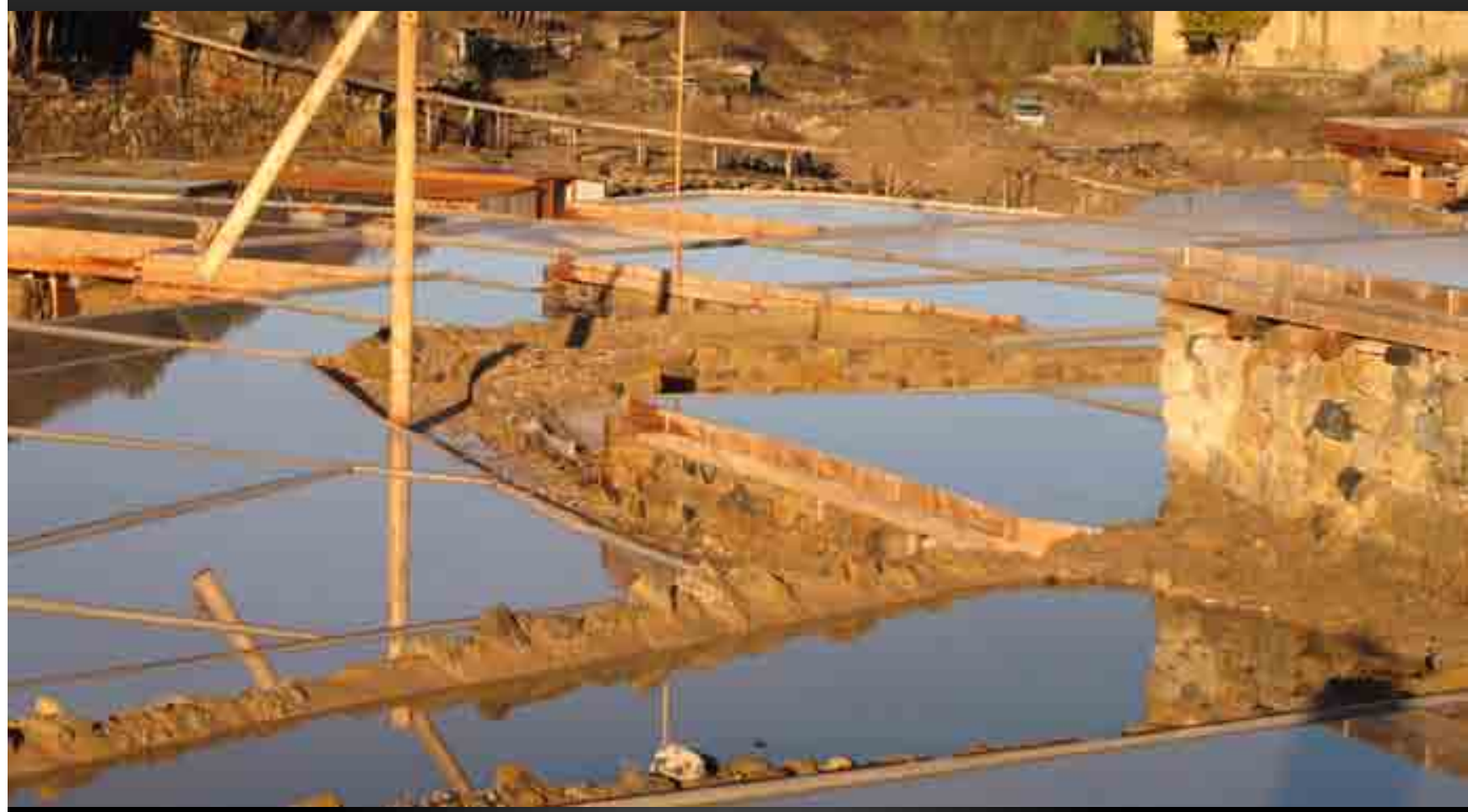

Tipo Siglo XXI. Base de Arcilla y Acabado de Piedra

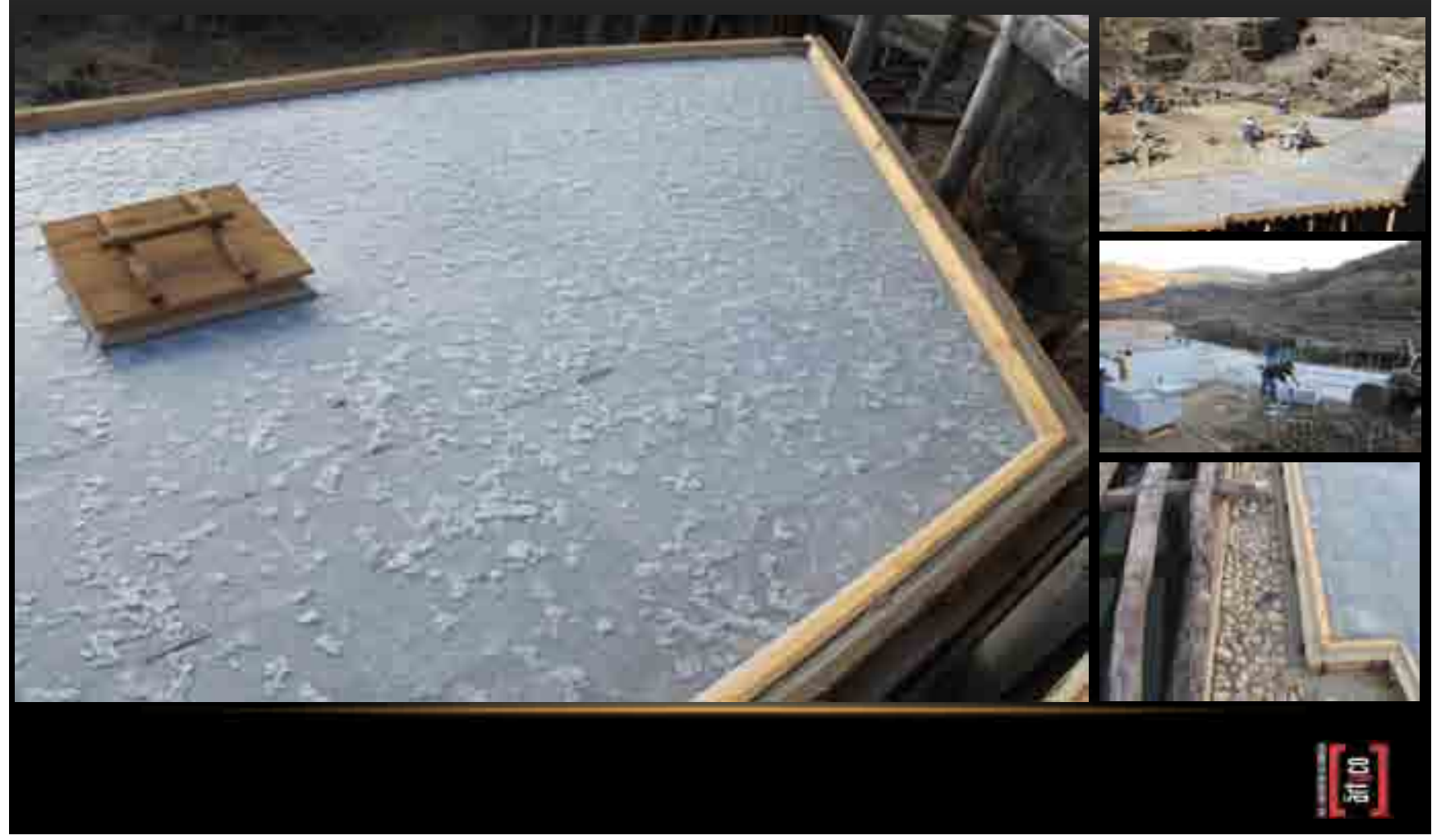




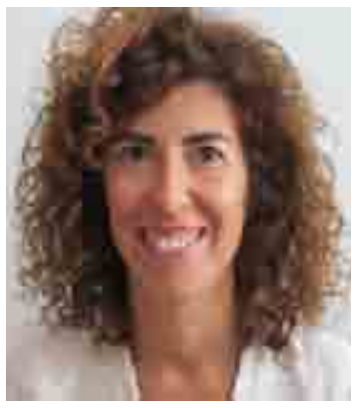

\section{Azucena Prior Santamaría \\ Artyco \\ artycorestaura@gmail.com}

Restauradora, licenciada en Bellas Artes por la Facultad de Bellas Artes de Barcelona en 1993 con la especialidad de Restauración. Interviniendo en obras de restauración de patrimonio desde el año 1993. Administradora de la empresa Ártyco desde el año 2005

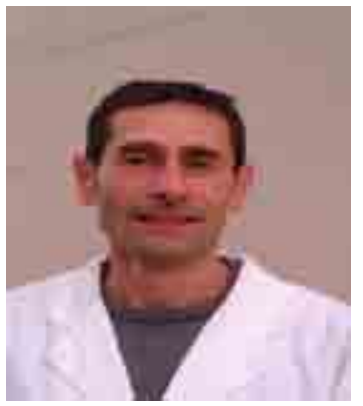

\section{Ángel Luis García Pérez}

Artyco

artycorestaura@gmail.com

Restaurador, diplomado en Conservación y Restauración de Bienes Culturales por la Escuela Superior de Conservación y Restauración de Bienes Culturales de Madrid en el año 1989 con la especialidad Arqueología.

Interviniendo en obras de restauración de Patrimonio desde el año 1987. Administrador de la empresa de restauración Ártyco desde el año 2005

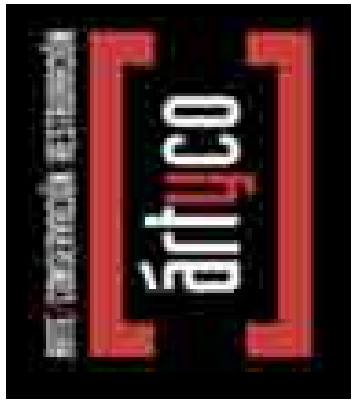

\section{Ártyco s.l.}

c/ Pintorería 41, bajo. 01001 VITORIA - GASTEIZ /ÁLAVA, Tfs: 945235239 / 652870034 / 652870035

artycorestaura@gmail.com

Empresa nacida en Vitoria en 2005, dedicada a la Restauración del Patrimonio Cultural.

Algunas obras destacadas: Portada de Campanilla en la Catedral de Sevilla; Capilla del Cristo y la bóveda del presbiterio de la Catedral de Vitoria; Recuperación de estructuras en el Valle salado de Añana; Lienzos de José María Sert en la iglesia del Museo de San Telmo de San Sebastián; Zócalos del Salon de los Reyes, Cubiertas y Artesonado del Oratorio del Partal en la Alhambra de Granada; Colección de Escultura Ibérica del Museo Arqueológico Nacional. 
que se dan en el valle de Añana, que sumadas a la persistente humedad suman nuevos procesos de deterioro.

Por todo ello se plantearon ensayos experimentales que pusiesen a prueba diversos tipos de piedra teniendo en cuenta las condiciones ambientales, el entorno salino y la repetitividad de los ciclos extractivos y poder así descartar variedades, o por el contrario tenerlas en cuenta como material de acabado. Se partía de la premisa de usar materiales oscuros por su mayor capacidad de absorción de calor. Consecuentemente se seleccionaron una serie de materiales pétreos, oscuros y poco porosos, dentro de la disponibilidad del mercado de piedra natural, para poder caracterizarlos y someterlos a ensayos de resistencia ambiental. Se concibieron dos fases experimentales bien diferenciadas, primero, ensayos en el laboratorio: deterioro inducido, para una primera criba de materiales y una segunda fase de experimentación in situ: deterioro natural, con observaciones experimentales en laboratorio de piedras expuestas durante todo un año en las eras salinas, tanto en época productiva (verano) como de reposo y mantenimiento. La metodología y resumen de resultados se exponen a continuación.

\section{Fase de ensayos de laboratorio: Deterioro inducido}

1) Preselección de litologías: propiedades petrofísicas. Dentro de la oferta comercial actual se escogieron siete litologías en función de las propiedades petrofísicas y de durabilidad que ofrecía cada casa comercializadora. Además se incluyeron otras dos calizas que ya estaban en fase de experimentación en las eras y otra caliza que se había contemplado con anterioridad. En total nueve litologías con las que se efectuaron los primeros estudios. Se evaluaron petrografía, porosidad, densidad, parámetros porométricos y resistencia mecánica. Correlacionando los valores obtenidos se efectuó una primera preselección de materiales y se descartaron los menos apropiados.

2) Selección final mediante ensayos de envejecimiento.

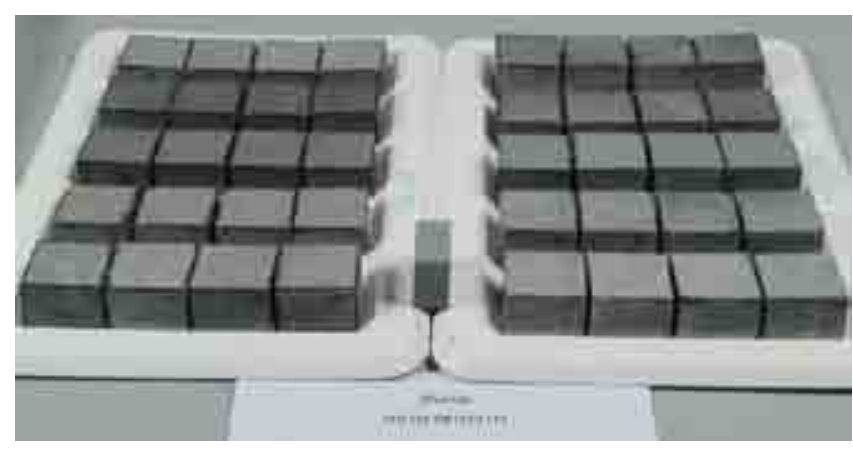

Figura 1. Aspecto general de probetas de todas las variedades antes del ensayo de alterabilidad de hielo-deshielo.

Después del primer corte se escogieron varias litologías entre las más aptas y se sometieron a ensayos de durabilidad o envejecimiento artificial acelerado y observar su comportamiento. Sus resultados darían las rocas más aptas para el fin propuesto.

Se utilizaron los siguientes ensayos de durabilidad teniendo presente las condiciones ambientales de las salinas [Figura 1]:

A.- Ensayo de heladicidad. 100 ciclos de hielo-deshielo. B.- Ensayos de cristalización de sales con 100 ciclos y dos modalidades:

- Ciclos de cristalización/hidratación con cloruro sódico

- Ciclos de cristalización/hidratación con sulfato sódico decahidratado

La evaluación de cada ensayo se determinó del siguiente modo (basado en la normativa UNE y ampliado): Modificaciones aspectuales: Desarrollo de formas de alteración, cambios de color y modificaciones físicas: Variaciones de masa y de velocidad ultrasónica.

También se experimentó la inmersión continua en solución saturada de cloruro sódico durante varios meses, evaluando modificaciones aspectuales.

Las litologías con las que se experimentó fueron las siguientes:

\begin{tabular}{llc} 
1: GRIS LIMAO & Caliza & China \\
\hline 2: ABSOLUTE BLACK o SHANXI BLACK & Gabro & China \\
\hline 3: NEGRO SUDAFRICA & Gabro & Zimbáfrica \\
\hline 4: NEGRO ZIMBAWE & Gabro & País Vasco \\
\hline 5: AÑANA ACTUAL X2 (CALIZA DE DEBA) & Caliza & Zaragoza \\
\hline 6: CALATORAO & Caliza & Badajoz \\
\hline 7: NEGRO VILLAR & Diabasa & País Vasco \\
\hline 8: CALIZA NEGRO & Caliza & País Vasco \\
\hline 9: CALIZA “GRIS MARQUINA” & Caliza &
\end{tabular}




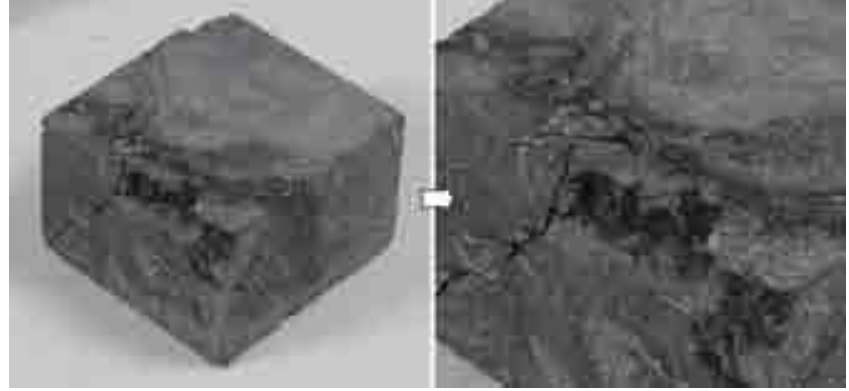

Figura 2. Concatenación de fisuras que lleva a la pérdida de pequeños fragmentos en la caliza de Calatorao.

Durante la fase de preselección se excluyeron en principio las rocas con menos de $1000 \mathrm{~kg} / \mathrm{cm} 2$ de resitencia a la compresión y con porosidades comunicadas por encima del $1 \%$ Se excluyeron las variedades $n^{\circ} 4$ y $n^{\circ} 6$ y las $n^{\circ} 5$ y la $n^{\circ} 9$ quedaron en el límite pero se incluyeron en los ensayos por su accesibilidad comercial y precio competitivo.

Durante las evaluaciones se utilizó como principal factor discriminante la observación del desarrollo de lesiones tipo fisura sobre la mera pérdida de masa, ya que se comprobó que frecuentemente en estas rocas se daba apertura de fisuras sin pérdida de masa mesurable. Sólo ocasionalmente la concatenación de fisuras degeneró en pérdida de pequeños fragmentos, como se aprecia en la figura 2.
Se comprobó que esta tendencia de deterioro quedaba reflejada en las variaciones de velocidad ultrasónica, lo que ayudó a discriminar bien el estado de las piedras después de los ensayos. Abajo se muestran las variaciones relativas de velocidad ultrasónica después de los ensayos de alterabilidad: hielo/deshielo, cristalización de la sal sulfato sódico y cristalización de cloruro sódico [Figura 3]. Las menores variaciones indican mejores comportamientos, como en el caso de la $n^{\circ} 7$, Negro Villar, aunque la valoración final tiene en cuenta toda la información acumulada.

Al final, las litologías evaluadas como más idóneas frente a deterioros como los que puedan presentarse en las salinas fueron, de más a menos idóneas (nombres comerciales): Absolute Black (gabro procedente de China), Negro Villar (diabasa extremeña), Gris Limao (caliza cristalina China) y algo menos aceptable pero con buen comportamiento una variedad de Gris Marquina -no confundir con la Negro Marquina- (calizas cristalinas vizcaínas).

Presentados nuestros trabajos en la primavera de 2011, por diversas razones, entre ellas, las económicas, en un momento dado se seleccionan para iniciar la recuperación y explotación de las eras, tres tipos de calizas cristalinas locales (de las que la Fundación Valle Salado de Añana encargó en su momento realizar una caracterización petrográfica). A resultas de esta situación en las eras, ya se planteó realizar la segunda fase de investigación in situ, cuyos resultados se resumen a continuación.

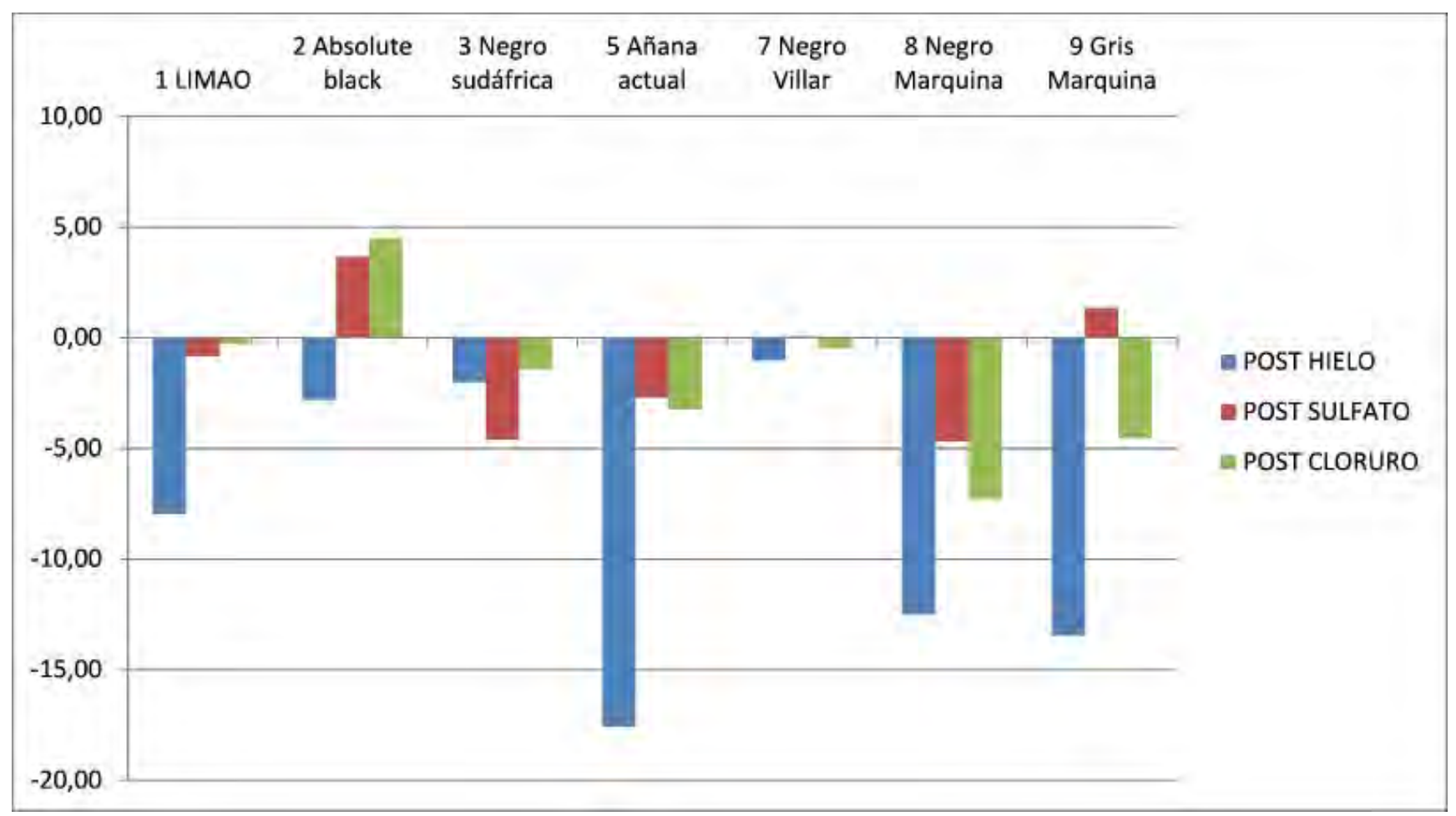

Figura 3. Variación de velocidades ultrasónicas tras los ensayos de alterabilidad mencionados. Las variaciones más negativas frente a un proceso suelen indicar pérdida de propiedades mecánicas del material. 


\section{Experimentación en las salinas: Deterioro natural}

Se evaluó el desarrollo de daños en las propias salinas de las tres litologías en experimentación, durante sus ciclos naturales de mantenimiento y explotación. Se acotaron tres momentos diferentes y se fueron separando las muestras correspondientes, en este caso fragmentos de las losetas: A, momento inicial sin alterar; $B$, al final de la etapa de mantenimiento, en primavera-verano, donde las losetas han permanecido a la intemperie con las condiciones ambientales de la temporada fría y sin labores de explotación; C, al final de la etapa de explotación, inicio de otoño, cuando las losetas ya han experimentado las consecuencias de las labores de explotación, con procesos cíclicos de inundación de las eras y posterior secado y cristalización de la sal seguida de su retirada.

En la figura 4 se muestra la secuencia de procesos desde la ubicación de la era con las losetas de un tipo hasta los fragmentos destinados a los estudios.

Las evaluaciones del deterioro en el laboratorio se realizaron del siguiente modo y con la aplicación de las siguientes técnicas:
Observaciones visuales. Valoración de daños en ubicaciones controladas de ciertas losetas (por ejemplo, esquinas, vértices, centro de losetas) partiendo del estado inicial de las losetas de control.

Cuantificación del deterioro por medio de la medición directa de características y propiedades físicas con probetas de roca extraídas de las losetas en cada una de las 3 fases señaladas:

1) Visualización y cuantificación de las modificaciones de las superficies. Técnicas de cuantificación semi automatizada de la topografía superficial o rugosidad de las superficies en cada momento $A, B$ y $C$ en que se han extraído las probetas. La técnica exige partir de imágenes de un estéreo microscopio óptico, en este caso un Leica M205FA, que captura imágenes secuenciales en la vertical de superficies topográficas, y la aplicación del software Leica Map, que calcula los parámetros de topografía superficial que se están generando, en este caso debido a la agresión ambiental en las eras.
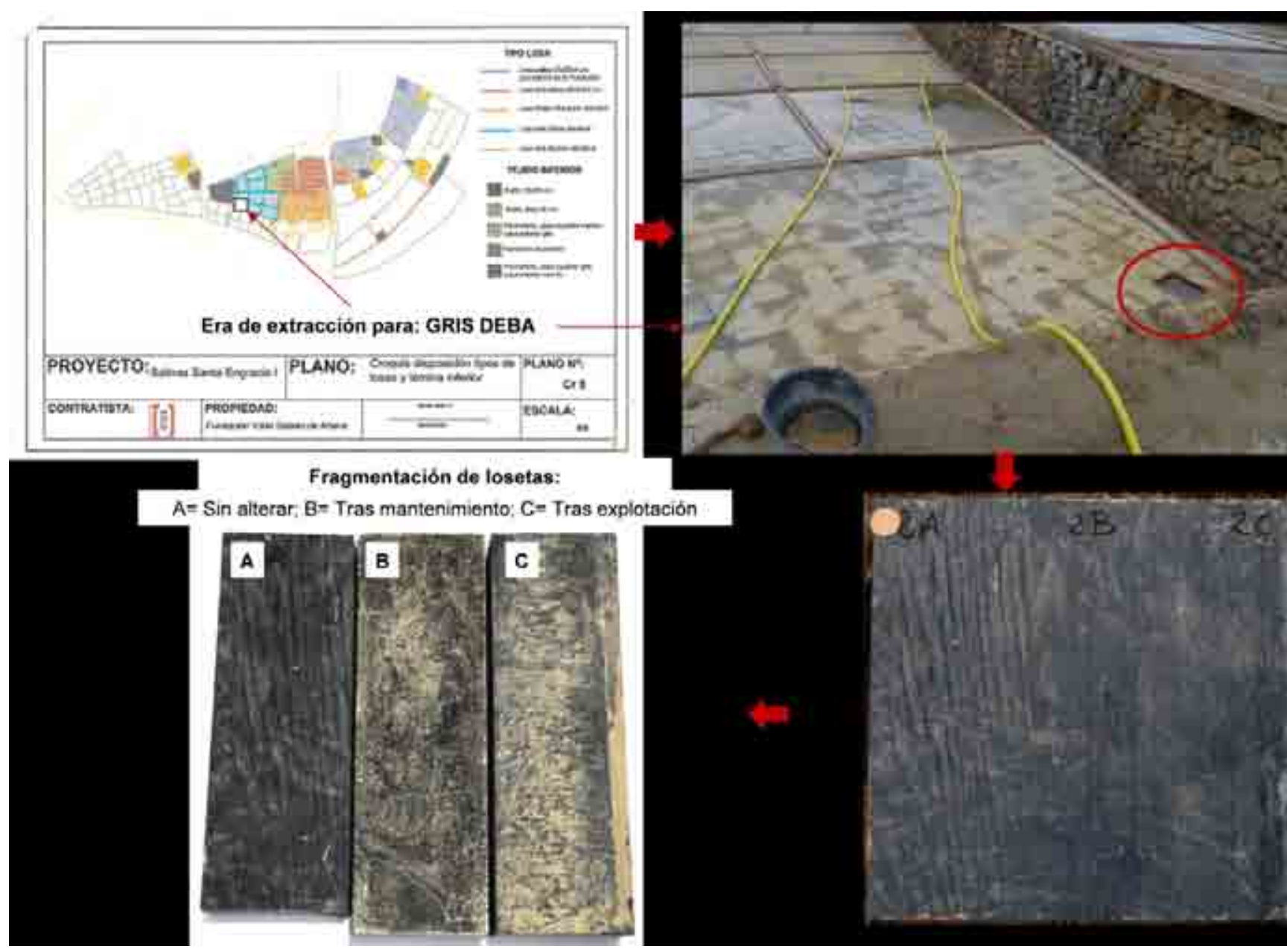

Fragmentación de losetas:

$A=\operatorname{Sin}$ alterar: $B=$ Tras mantenimiento; $C=$ Tras explotación
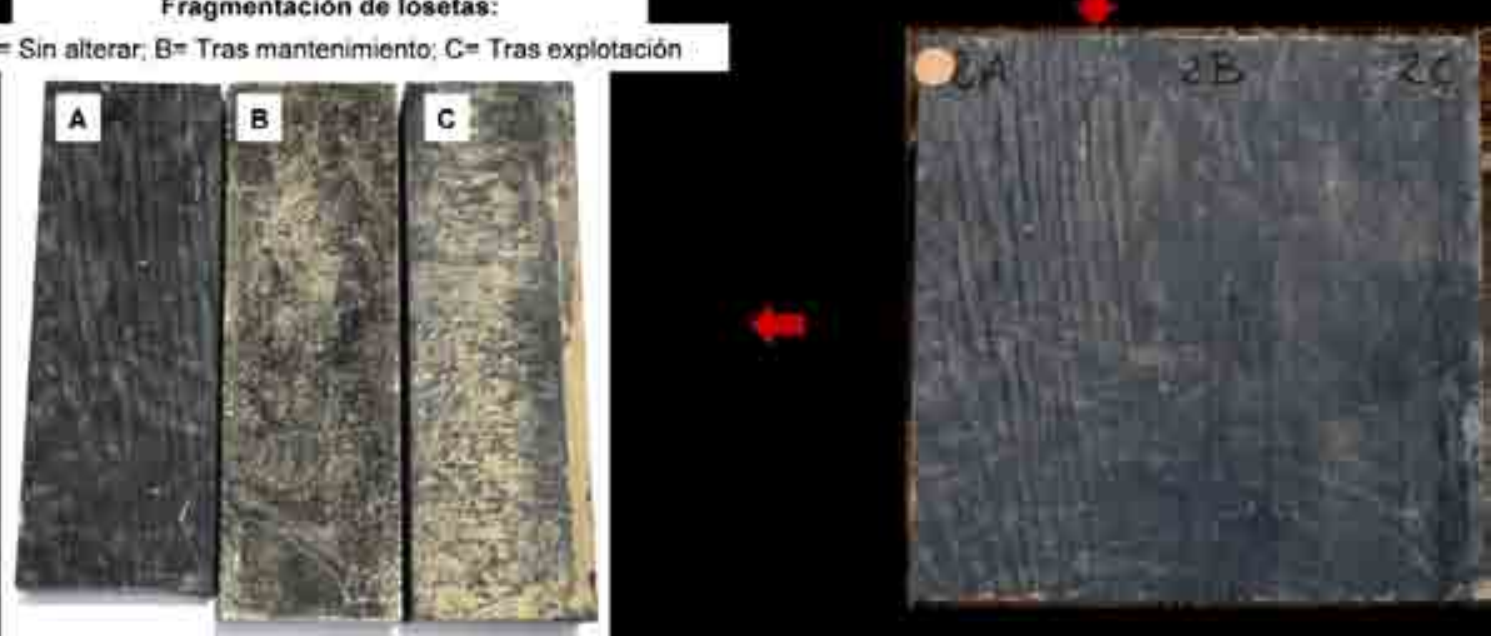

Figura 4. Localización y zona de extracción progresiva de fragmentos: $1^{\circ}$ inalteradas $(A)$, después del mantenimiento (B) y después de la fase de extracción (C), de una de los tipos de piedra, en este ejemplo de la caliza Gris Deba. 
2) Cuantificación del contenido en sal en el interior de la loseta, al menos a 2 profundidades desde la superficie de evaporación, $2 \mathrm{~mm}$-cerca de la superficie- y $20 \mathrm{~mm}$, en el corazón de la probeta. Se mide la conductividad eléctrica de cada zona.

3) Estudio de porosidad mediante porosímetro por inyección de mercurio. Se espera discriminar la evolución de la porosidad y la posible variación del tamaño de los poros durante los procesos.

Las características petrográficas básicas de las tres litologías en experimentación en las salinas y que ahora se evalúan son:

- GRIS DEBA: Caliza cristalina gris oscura muy coherente, con dos zonaciones texturales de límites muy irregulares, una formada por cristales de calcita tamaño esparita y otra por cristales de calcita tamaño microesparita. Porosidad $1,6 \%$.

- GRIS BAZTÁN: Caliza cristalina muy coherente de aspecto brechoide con colores grisáceos y bandeados rojizos. Presenta una mezcla de dos texturas, la formada por restos fósiles recristalizados y vetas, constituidos por cristales de calcita tamaño esparita, de tonalidades más claras, y la textura formada por cristales de calcita tamaño microesparita de color oscuro que constituye la fase de unión. Porosidad $1,1 \%$.

- NEGRO MARQUINA: Caliza cristalina gris oscuro y coherente. También con dos texturas diferenciadas. La formada por restos fósiles recristalizados (normalmente valvas) y vetas, constituidos por cristales de calcita tamaño esparita, zonas de color claro (30\%), y la formada por cristales tamaño micrita, de color más oscuro (70 \% del volumen total) que constituye la fase de unión de esta roca. Porosidad $1,8 \%$.
Como se ve, las tres son calizas cristalinas compactas, coherentes y de tonos grises o negros, con baja porosidad y además muy microporosas. Las escasas diferencias entre ellas las ocasionan la leve disminución del tamaño de grano de la textura más fina de la piedra Negro Marquina, que también presenta una porosidad ligeramente mayor.

Algunos resultados de los estudios se resumen a continuación en la tabla I. En ella se han reflejado la magnitud de las variaciones de parámetros físicos entre las probetas tras las etapas de mantenimiento y explotación en relación a las probetas inalteradas. En este caso se presentan: dos parámetros de las variaciones topográficas de las superficies pétreas originadas por el deterioro, diferencias de porosidad y diferencias de grado de salinidad. Respecto a la cuantificación de las variaciones topográficas (1) se han escogido para esta tabla dos parámetros estadísticos resultantes del rastreo y aplicación de software de análisis definido en la norma ISO 25178:

Sa: Media aritmética de la rugosidad de una superficie. Sv: Distancia entre el plano medio de una superficie y el valle más profundo.

Además se han tenido en cuenta las variaciones aspectuales de las probetas. Tras los análisis se puede comentar lo siguiente de cada piedra evaluada:

\section{Gris Deba}

Durante la evolución anual en las eras, no se detectaron variaciones superficiales significativas por observación visual directa y por otro lado, la cuantificación instrumental de la rugosidad tras cada etapa es muy moderada. Se han detectado variaciones topográficas medias de menos de diez micras, con saltos verticales máximos ocasionales del orden de 90 micras (apenas una décima de milímetro en

PROBETAS: $\mathrm{A}=$ INALTERADAS; $\mathrm{B}=$ TRAS ETAPA MANTENIMIENTO; $C=$ TRAS ETAPA DE EXPLOTACIÓN -

\begin{tabular}{|c|c|c|c|c|c|c|}
\hline \multirow{3}{*}{$\begin{array}{l}\text { Nombre } \\
\text { comercial }\end{array}$} & \multicolumn{3}{|c|}{ Variaciones probetas B / A } & \multicolumn{2}{|c|}{ Variaciones entre probetas $\mathrm{C} / \mathrm{A}$ : } & \multirow[b]{3}{*}{$\begin{array}{l}\text { Grado de sa- } \\
\text { linidad }(\mu \mathrm{S} / \mathrm{cm})\end{array}$} \\
\hline & \multicolumn{4}{|c|}{ PARÁMETROS DE TOPOGRAFÍA SUPERFICAL } & \multirow[b]{2}{*}{$\begin{array}{l}\text { Porosidad } \\
\text { (\%) }\end{array}$} & \\
\hline & $\begin{array}{l}\text { Sa }(\mu \mathrm{m}) \text { : Media } \\
\text { aritmética de } \\
\text { desviaciones } \\
\text { verticales }\end{array}$ & $\begin{array}{l}\text { Sv }(\mu \mathrm{m}) \text { : Dis- } \\
\text { tancia vertical } \\
\text { máxima }\end{array}$ & $\begin{array}{l}\text { Sa }(\mu \mathrm{m}) \text { : Media } \\
\text { aritmética de } \\
\text { desviaciones } \\
\text { verticales }\end{array}$ & $\begin{array}{l}\text { Sv }(\mu \mathrm{m}) \text { : Dis- } \\
\text { tancia vertical } \\
\text { máxima }\end{array}$ & & \\
\hline GRIS DEBA & $\mathrm{x} 1$ & $x 1,1$ & $x 4,3$ & $x 4,7$ & $\mathrm{x} 1$ & $x 3,6$ \\
\hline GRIS BAZTÁN & $x 10,2$ & $x 3,5$ & $x 16,7$ & $x 6,1$ & $x 1,5$ & $x 2,2$ \\
\hline $\begin{array}{l}\text { NEGRO } \\
\text { MARQUINA }\end{array}$ & $x 13,5$ & $x 8,9$ & $x 15,6$ & $x 6,4$ & $x 0,4$ & $x 1,5$ \\
\hline
\end{tabular}

Tabla I. Factor de variación de los parámetros físico topográficos, de porosidad y de grado de salinidad entre las probetas evaluadas tras las etapas de mantenimiento y explotación en relación a las inalteradas. 

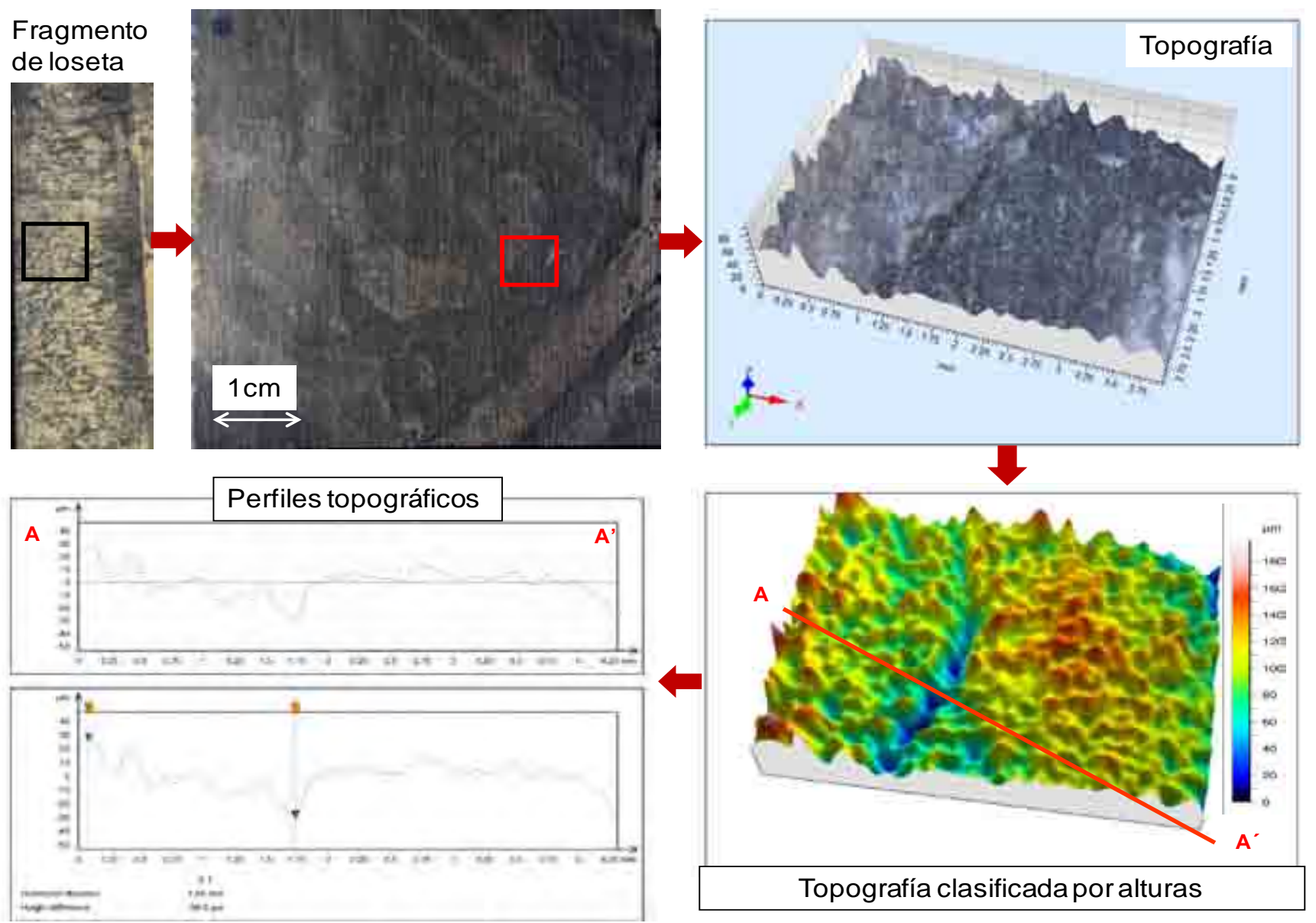

Figura 5. Análisis de las variaciones topográficas de las superficies del fragmento C, obtenido tras la etapa de explotación en la caliza Gris Deba. La rugosidad superficial provocada por la actividad en las salinas nunca llega a una décima de milímetro.

el peor de los casos). Es decir se pueden haber creado unos resaltes del orden de 4,3 veces superiores a las muestras sin alterar, pero siguen siendo mínimos. Por otra parte, la variación de porosidad es prácticamente nula y la de salinidad ha crecido unas 3 veces en las superficies sometidas a explotación, pero continua siendo muy baja. El comportamiento alterológico global tras el ciclo anual en las salinas puede considerarse muy bueno [figura 5]. El aspecto manchado de los fragmentos de esta loseta, por ejemplo en la parte superior izquierda de la figura 5 se reduce a la mera superficie, es aparente, sin que transciendan cambios significativos hacia el interior, de ahí su buen comportamiento.

\section{Gris Baztán}

En este caso, se han producido sutiles, pero perceptibles variaciones topográficas generadas por la actividad en las salinas, que incluso ya se generan tras la etapa de mantenimiento y por ello la magnitud de los parámetros físicos crece significativamente en todos los casos
[Tabla I]. Por ejemplo la variación aritmética media Sa, crece 10 veces tras la etapa de mantenimiento y al final ha crecido casi 17 veces. Sin embargo hay que resaltar que la coherencia integranular se mantiene perfectamente, así como el grado de compacidad global de las probetas.

Lo que ha ocurrido es que se produce un comportamiento diferencial de las dos texturas dominantes en la roca, ya que las zonas más finas, o de calcita microesparítica quedan ligeramente deprimidas respecto a las más cristalinas (calcita esparita) y esto es lo que ha detectado la técnica de cuantificación de rugosidad [Figura 6].

Por ello la apariencia de las muestras después de un año es la de presentar un cierto relieve cuando se contemplan con luz rasante, como ocurre en el ejemplo de la figura. Por otra parte la porosidad y la salinidad han crecido visiblemente respecto a las zonas inalteradas, pero se parte de valores realmente tan bajos que no son valores significativos. 


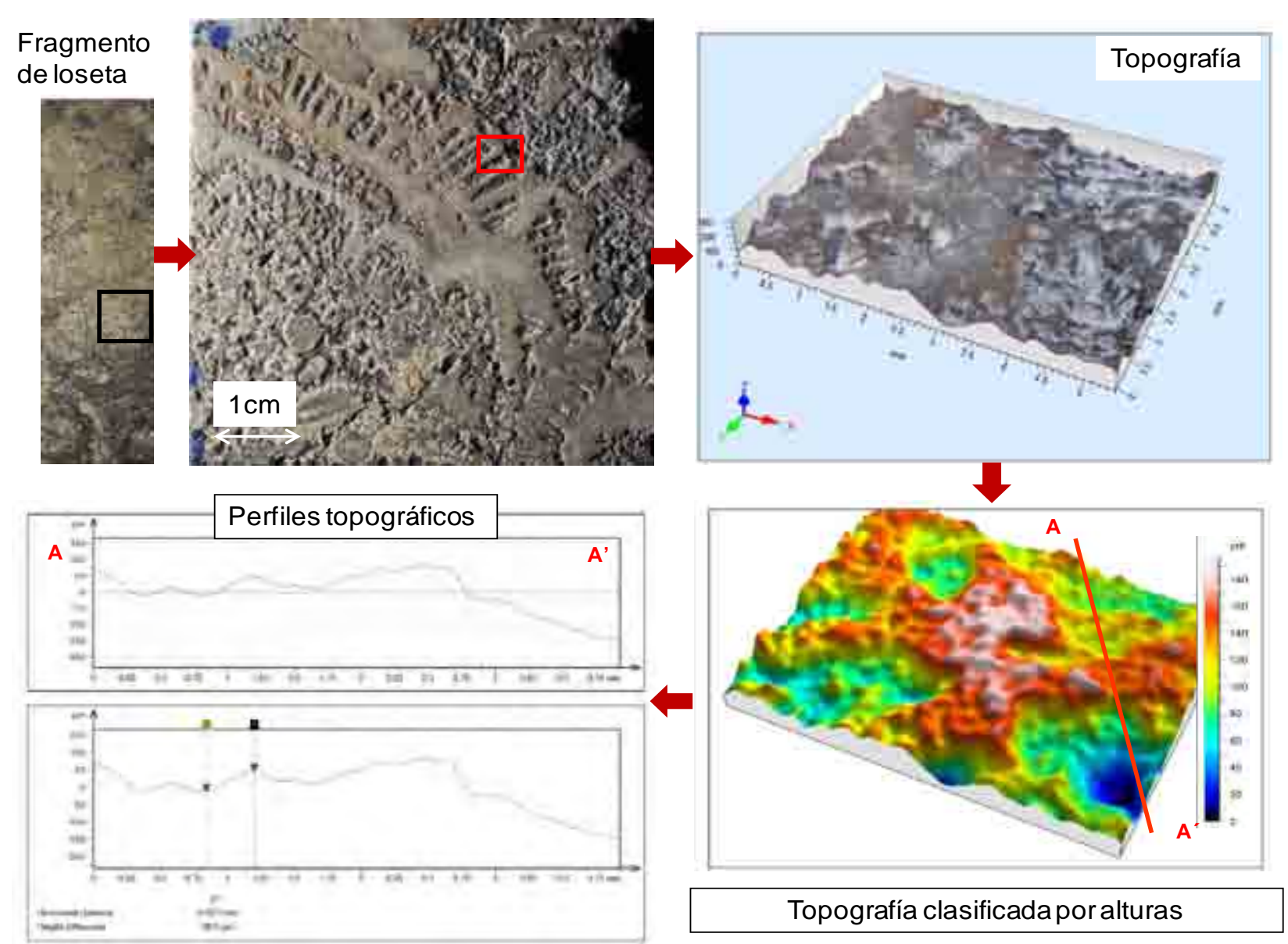

Figura 6. Análisis de las variaciones topográficas de las superficies del fragmento C, obtenido tras la etapa de explotación, en la caliza Gris Baztán. Se detecta un ligero aumento de la rugosidad provocada por la actividad salinera, pero no progresa con la actividad extractiva.

\section{Negro Marquina}

Ha sido la roca que más ha resultado afectada en las eras. En efecto, las variaciones topográficas originadas por las diferentes texturas son sólo ligeramente mayores que las que afectaron a Gris Baztán [Tabla I] y la apariencia de las muestras con luz rasante muestra esos resaltes [Figura 7].

Pero hay que añadir un factor determinante: se ha detectado que además se empiezan a producir pequeñas saltaciones de fragmentos que en las otras dos piedras nunca llegan a producirse (ver parte inferior izquierda de la probeta de la figura 8). Esta diferencia, independientemente de la magnitud de los resaltes topográficos medidos va acentuarse por el contacto cíclico con la sal y sólo por eso esta es la piedra, entre las ensayadas, que menos puede recomendarse para la actividad en las salinas.

\section{Consideraciones finales: recomendaciones de selec- ción}

Entre una serie de piedras comercializadas se han seleccionado mediante diversos ensayos aquéllas más idóneas para utilizar como material de acabado de las eras de producción de las salinas históricas del Valle Salado de Añana.

En una primera tanda de ensayos en laboratorio se ha encontrado un buen comportamiento alterológico en piedras comercializadas internacionalmente como Absolute Black (gabro procedente de China), Negro Villar (diabasa extremeña) o Gris Limao (caliza cristalina China) y algo menos aceptable pero con buen comportamiento una variedad de Gris Marquina.

En una segunda fase de experimentación in situ con calizas cristalinas locales: Gris Deba, Gris Baztán y Negro Marquina se encontraron como más idóneas las dos primeras, siendo menos recomendable para utilizar en las condiciones de estas salinas, la caliza Negro Marquina. 

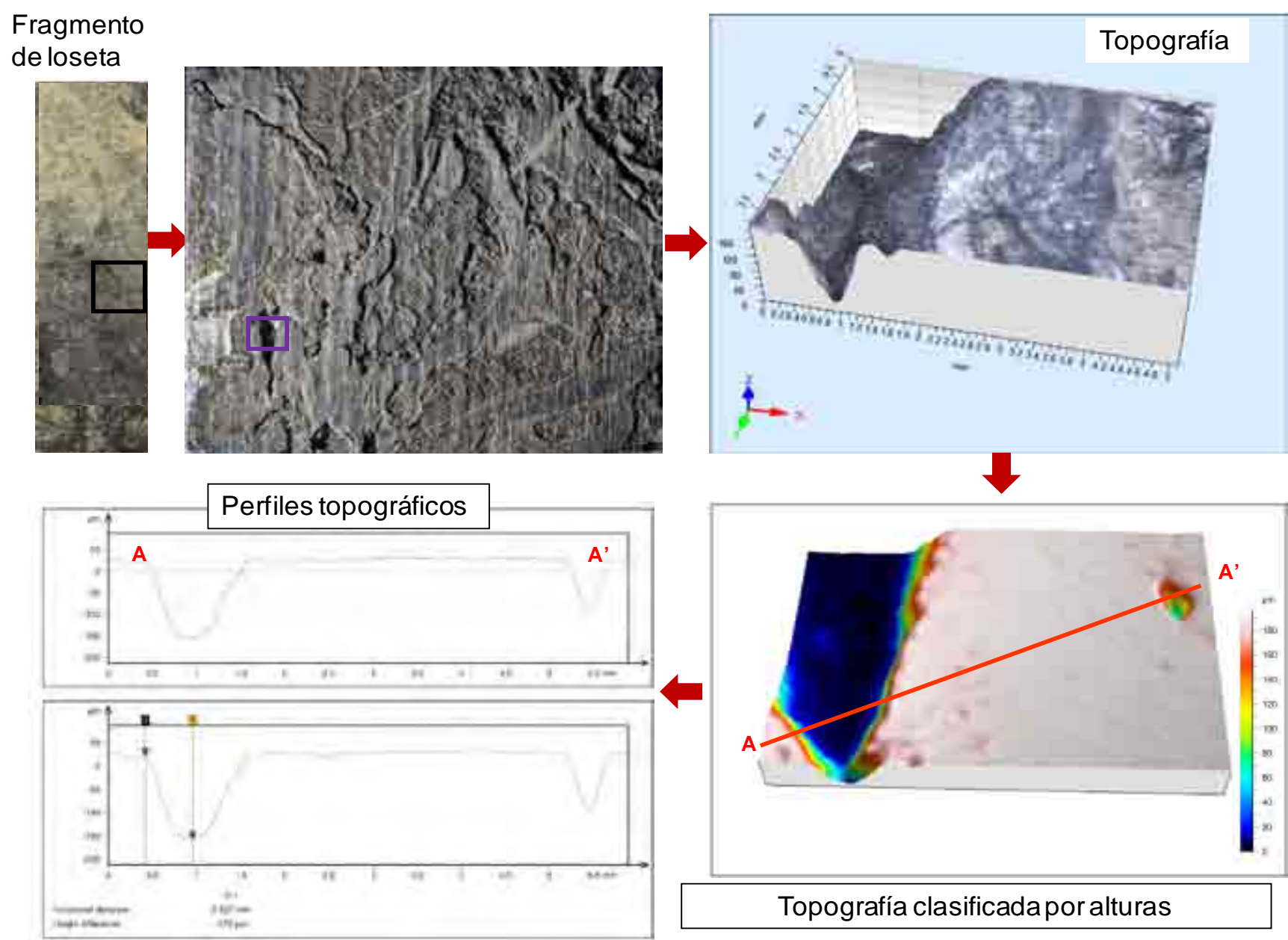

Figura 7. Análisis de las variaciones topográficas de las superficies del fragmento C, obtenido tras la etapa de explotación, en la caliza Negro Marquina. La rugosidad provocada por la actividad se incrementa, pero además se desprenden pequeños fragmentos como el señalado a la izquierda de la probeta.

La elección de una u otra litología puede venir determinada por diversos factores, como el económico, pero ahora se conoce mejor cada comportamiento de las piedras ensayadas.

\section{Notas}

[1] Artículo en este mismo número de la revista: Aspectos relacionados con la explotación en el Valle Salado de Añana: Las labores de restauración, por Ángel Luis García Pérez y Azucena Prior Santamaría. 


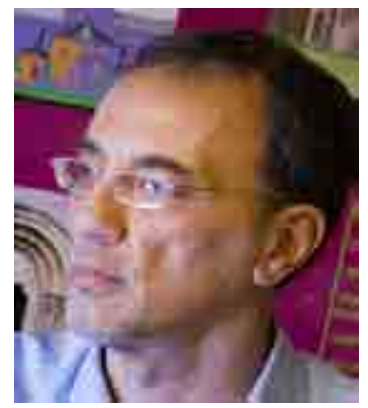

\author{
Luis Valdeón Menéndez \\ GEA asesoría geológica \\ correo@geaasesoriageologica.com
}

Luis Valdeón ha desarrollado toda su carrera profesional en el ámbito de la conservación de patrimonio histórico-arqueológico y evaluación de materiales pétreos, combinando una completa base de formación científico-técnica con una dilatada experiencia profesional a pie de obra. Tras doctorarse en Geología en la Universidad de Oviedo en1989, realizó estudios postdoctorales en el Imperial College de Londres (1989-2001) donde se especializó en la aplicación de técnicas no destructivas a materiales pétreos. En estos ámbitos posee más de cuarenta publicaciones en congresos y revistas nacionales e internacionales. Ha realizado cientos de trabajos en intervenciones de patrimonio monumental o estudios previos a las mismas, investigando asimismo el comportamiento de materiales constructivos $y$ ornamentales en, por ejemplo, excavaciones arqueológicas, como las del yacimiento de Contrebia Leucade (La Rioja), o sobre bienes declarados patrimonio de la Humanidad, como el prerrománico asturiano (Monumentos de Oviedo y del Reino de Asturias), o Monasterio de Yuso (La Rioja), así como en catedrales, capillas y monumentos civiles de todo el país.

Desde 2001 es socio fundador, de la empresa GEA asesoría geológica especializada en estudios sobre Conservación y Restauración de Patrimonio y la caracterización de todo tipo de materiales. Es miembro activo del Grupo Español del International Institute for Conservation (GE-IIC) en donde ha formado parte de los comités científicos del grupo de trabajo "piedra".

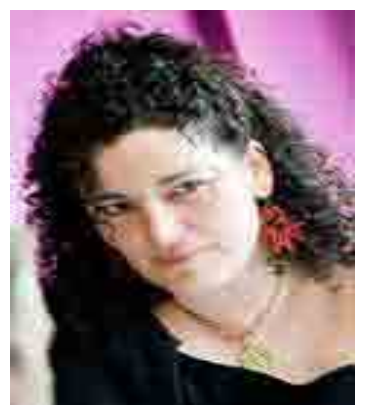

\author{
Araceli Rojo Álvarez \\ GEA asesoría geológica \\ correo@geaasesoriageologica.com
}

Ha obtenido su licenciatura en la Geología en 1996 y su grado (Tesis de licenciatura) en el año 2000, ambas por la Universidad de Oviedo, habiendo realizado los cursos de doctorado entre los años 1996 - 1998. Ha participado en 9 proyectos de investigación, ha publicado 26 documentos científicos en revistas nacionales e internacionales y ha asistido a 12 congresos relacionados con diversos aspectos de la geología. Ha realizado labores docentes impartiendo clases prácticas de Petrología Aplicada y Rocas Industriales en la Facultad de Geología de la Universidad de Oviedo durante los años1997 - 2000. Ha participado en 4 cursos de verano de la Universidad de Oviedo (2003, 2005, 2006 y 2012), llevando la dirección/coordinación del organizado en 2012. Ha impartido docencia en un curso experto de la Universidad de Oviedo (2007 - 2008) y en 3 másteres organizados por la Fundación Laboral de La Construcción de Asturias $(2011-2012)$.

Es uno de los socios fundadores de GEA asesoría geológica, desarrollando su actividad profesional en esta empresa desde 2001, con una experiencia de 12 años en diversos campos de geología como la petrofísica, la caracterización de materiales, la restauración, la geotécnica, el I+D+i, y la formación. Como miembro de esta empresa ha participado en más de 200 proyectos ligados a la caracterización de materiales aplicados al patrimonio arquitectónico, la construcción e ingeniería. 


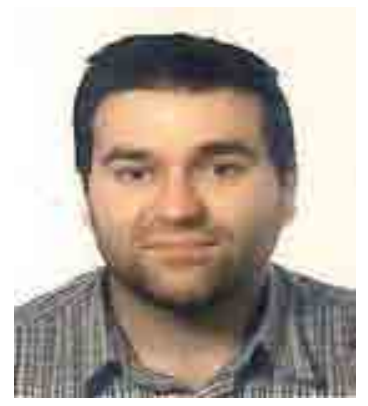

\title{
Félix Javier Mateos Redondo
}

GEA asesoría geológica

correo@geaasesoriageologica.com

Licenciado y Doctor en Ciencias Geológicas por la Universidad de Oviedo (1995-1999; 2011), en el año 1999 comienza su andadura profesional como investigador contratado dentro de los grupos de "Alteración y Durabilidad"y "Petrofísica" del Departamento de Geología de la Universidad de Oviedo, donde durante más de una década (1999-2010) ha participado en numerosos proyectos de investigación de ámbito internacional (CONNET, ALIANCE, MCDUR, CURRIC, FUNMIG, I-STONE, EPISCON..) y nacional (INTERFASE, NANOROCK, PERDURABLE..), así como decenas de contratos de investigación y/o servicios con empresas, fundaciones y organismos públicos.

Paralelamente a su actividad universitaria, en el año 2001 pasa a formar parte como Socio Fundador de la empresa GEA asesoría geológica, con sede en Oviedo, consultora especializada en campos como la conservación del patrimonio histórico-artístico, caracterización de materiales y petrofísica.

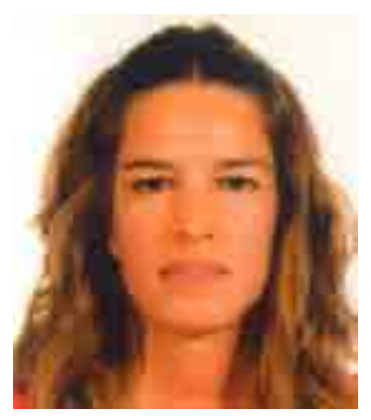

\author{
Verónica Fernández Cuesta \\ GEA asesoría geológica \\ correo@geaasesoriageologica.com
}

Licenciada en Geología por la Universidad de Oviedo (2010). Durante el segundo ciclo de la licenciatura ya fue becaria en la Universidad de Oviedo en diversos proyectos, como por ejemplo INTERFASE y I-STONE, así como becaria en la empresa GEA asesoría geológica. Al obtener la licenciatura fue becada por La Fundación Universidad de Oviedo para iniciar trabajos de laboratorio en la empresa GEA asesoría geológica, donde está contratada en la actualidad.

En esta empresa realiza estudios de caracterización, diagnosis y conservación de todo tipo de materiales constructivos pertenecientes al patrimonio histórico y arqueológico, así como actuales. Asimismo se ocupa de la puesta a punto y mantenimiento del equipamiento instrumental de laboratorio. 


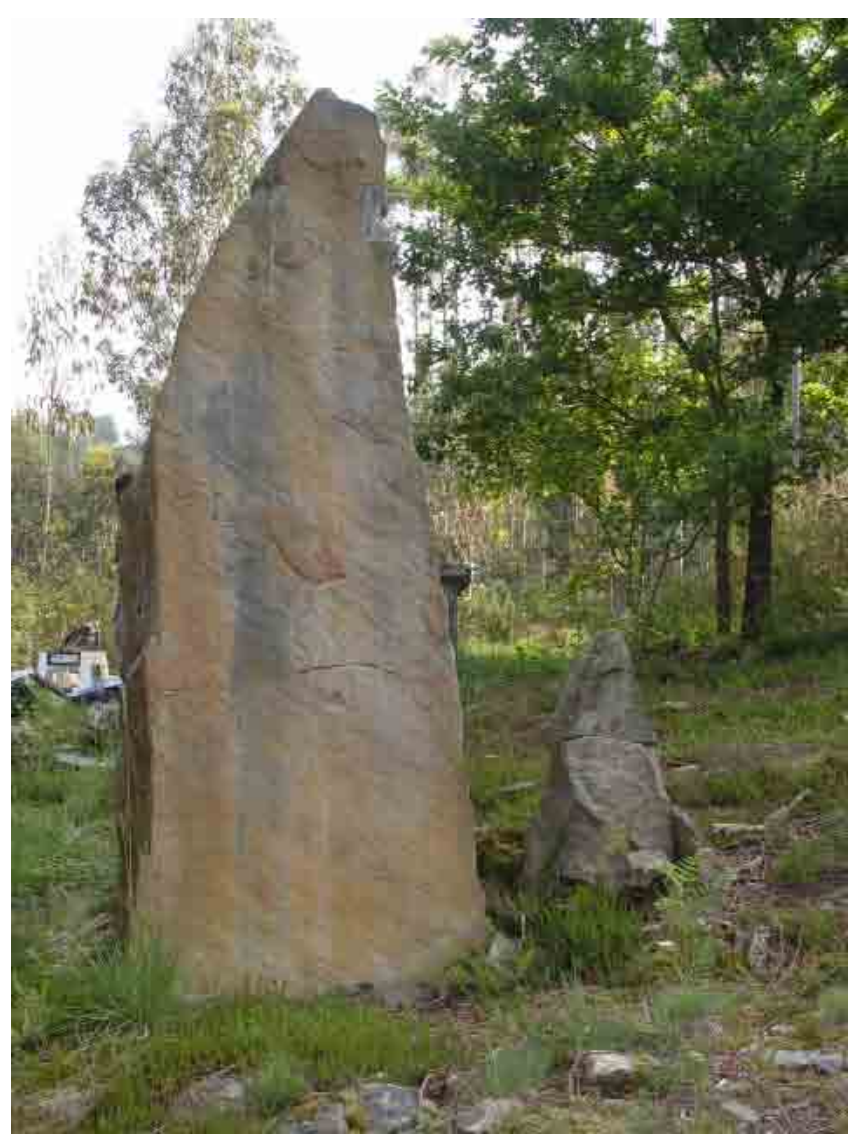

Figuras 1 y 2. Distintas vistas del monolito

Los incendios de 1989 afectaron al monolito fracturándolo longitudinalmente, por lo cual se programó una intervención arqueológica de urgencia (Pujana 1990). La directora de la excavación definió el yacimiento como un cromlech encuadrable en los inicios de la Edad del Hierro y el final el Bronce final.

Pese a las hipótesis planteadas, la ausencia de un contexto arqueológico neto impide, hoy por hoy, precisar la cronología y el significado de esta sugestiva pieza del Patrimonio Cultural de Urdaibai.

La intervención realizada en el monolito de SorbitzuagaArriatara abarcó cuatro fases:

(1) Desbroce de la vegetación que afectaba al monolito y del sendero de acceso;

(2) Retirada de los restos de plásticos y maderas con los que se había protegido el monolito tras la intervención arqueológica de 1990 (estos elementos, en un avanzado estado de deterioro, interferían en la percepción del monumento y en su integración en el paisaje);

(3) Creación de un anillo de protección del monolito a través de la intervención en el entorno vegetal;

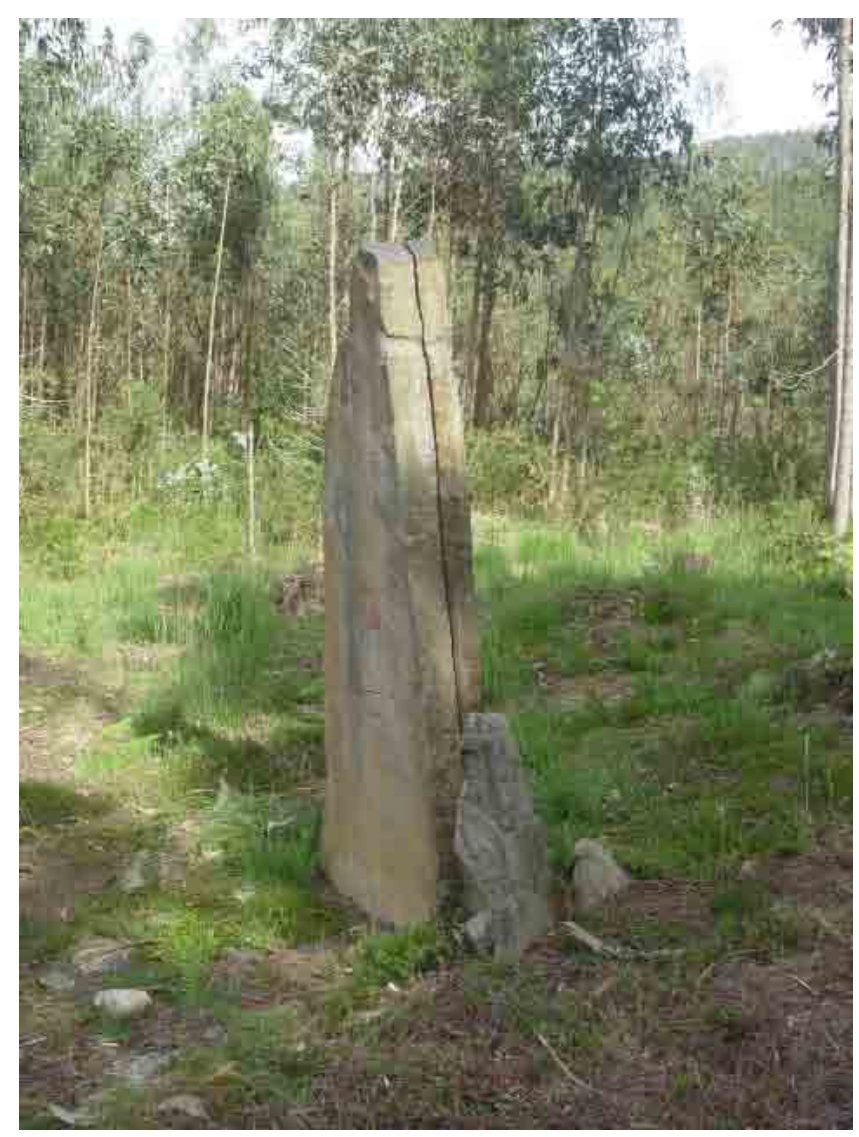

(4) Señalización del monumento con el hito oficial del Dpto. de Cultura del Gobierno Vasco;

(5) Elaboración de itinerario didáctico apoyado con una edición de carácter divulgativo: Urdaibaiko Kultur Ondarea zabaltzeko programa: SorbitzuagaArriatarako monolitoa (Busturia, Bizkaia) / Programa de difusión del Patrimonio Cultural de Urdaibai: el monolito de Sorbitzuaga-Arriatara (Busturia, Bizkaia).

(6) Intervención de consolidación a base de lecha das y morteros fluidos que se van a describir.

El estado de conservación que presentaba el menhir antes de la intervención de consolidación era el siguiente; las causas principales de los deterioros que presentaba el menhir habían sido provocadas por la naturaleza de la piedra, su exposición a todos los fenómenos atmosféricos (agua de lluvia, viento, heladas y horas de insolación), el paso del tiempo y los daños producidos por un incendio, además de los desniveles y asentamiento del terreno en el que se encontraba, por otra parte la superficie de ambos bloques de piedra presentaba colonización biológica y excrementos de ave y nidos de insecto, pequeñas fisuras transversales, desplacaciones en toda la superficie del menhir, debidas a la constitución propia del soporte y erosión generalizada. Presenta también una grieta longitudinal de gran tamaño, producida en los incendios de 1989. 
Esta grieta que atravesaba longitudinalmente el menhir con un espesor de unos centímetros, era el problema principal de conservación, ya que cada año aumentaba de tamaño debido a la ubicación del menhir y la constante filtración de aguas de lluvia y el desnivel del terreno. [Figuras $4,5,6$ y 7$]$

Tras el estudio del problema de la grieta longitudinal que ponía en peligro la integridad del conjunto del monolito se decidió, junto con la Dirección Facultativa de Juan Carlos López Quintana, el apuntalamiento del terreno del menhir con tierra y la consolidación de la grieta con lechadas y morteros sin la introducción de pernos, dada la fragilidad de la roca y por un criterio de intervención no invasivo.

Antes de la introducción de las lechadas se eliminó de manera puntual la presencia de colonización biológica superficial, ya que nuestra experiencia en casos similares, había constatado que en las zonas en las que no se eliminaba previamente la presencia de colonización biológica los morteros de cal no se adherían correctamente y acababan desprendiéndose. No se llevó a cabo una intervención drástica, se incidió sobre todo en las zonas en las que se iban a colocar morteros, ya que dada su ubicación, la presencia de la colonización biológica, era inevitable que se iba a volver a reproducir.

Antes de la inyección de las lechadas y morteros fluidos se procedió a la colocación de un mortero perimetral de cal hidráulica y arenas lavadas y a la colocación de cinchas para evitar roturas en la fase líquida de la aplicación de los mismos.

Tal y como nos indicó el Laboratorio General de la Diputación Foral de Álava, se respetaron los tiempos necesarios para que tanto los morteros de cierre como la aplicación de las lechadas entraran en carga y adquirieran la resistencia necesaria. Durante la realización de los trabajos de consolidación en el menhir, se pudo constatar un problema de asentamiento del mismo, por lo que para llevar a cabo correctamente el proceso de consolidación de la grieta longitudinal se realizó la operación de consolidación, teniendo en cuenta las resistencias a flexotracción-compresión de la cal hidráulica NHL 3,5 gris que se iba a emplear. Se aplicó la formulación de lechada fluida ensayada y recomendada por el Laboratorio General de la D.F.A.

Primero se inyectaron lechadas hidráulicas según formulación del Laboratorio General de la D.F.A para rellenar hasta los huecos más pequeños, posteriormente se inyectaron morteros fluidos. La primera inyección de consolidación se realizó el 16 de mayo, la segunda el 30 de mayo, la tercera el 7 de junio y la cuarta el 16 de agosto de 2012.

Este tipo de materiales (cal hidráulica NLH -3,5 gris ) adquieren su resistencia máxima a edades tardías, tras 2 años de curado, por lo que se consideró necesario dejar sobre el menhir las medidas de protección y sujeción (las cinchas) que se colocaron durante los trabajos, por espacio mínimo
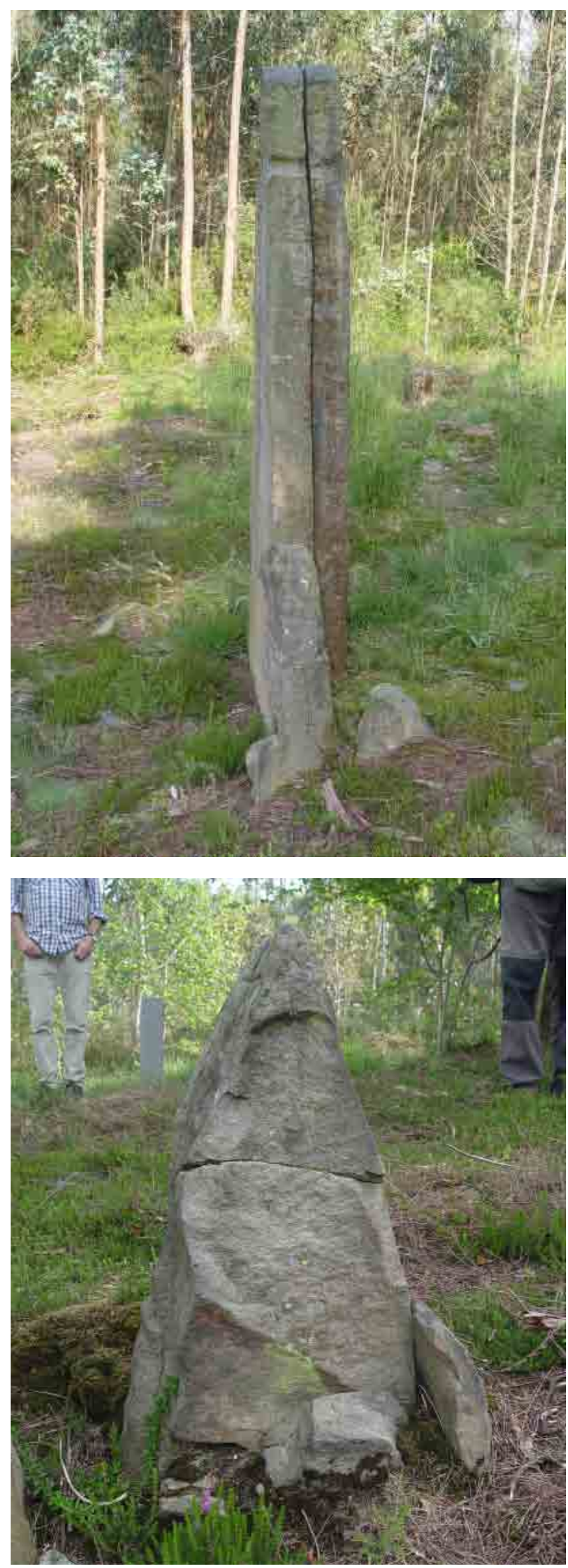

Figuras 3 y 4. Distintas vistas del monolito 


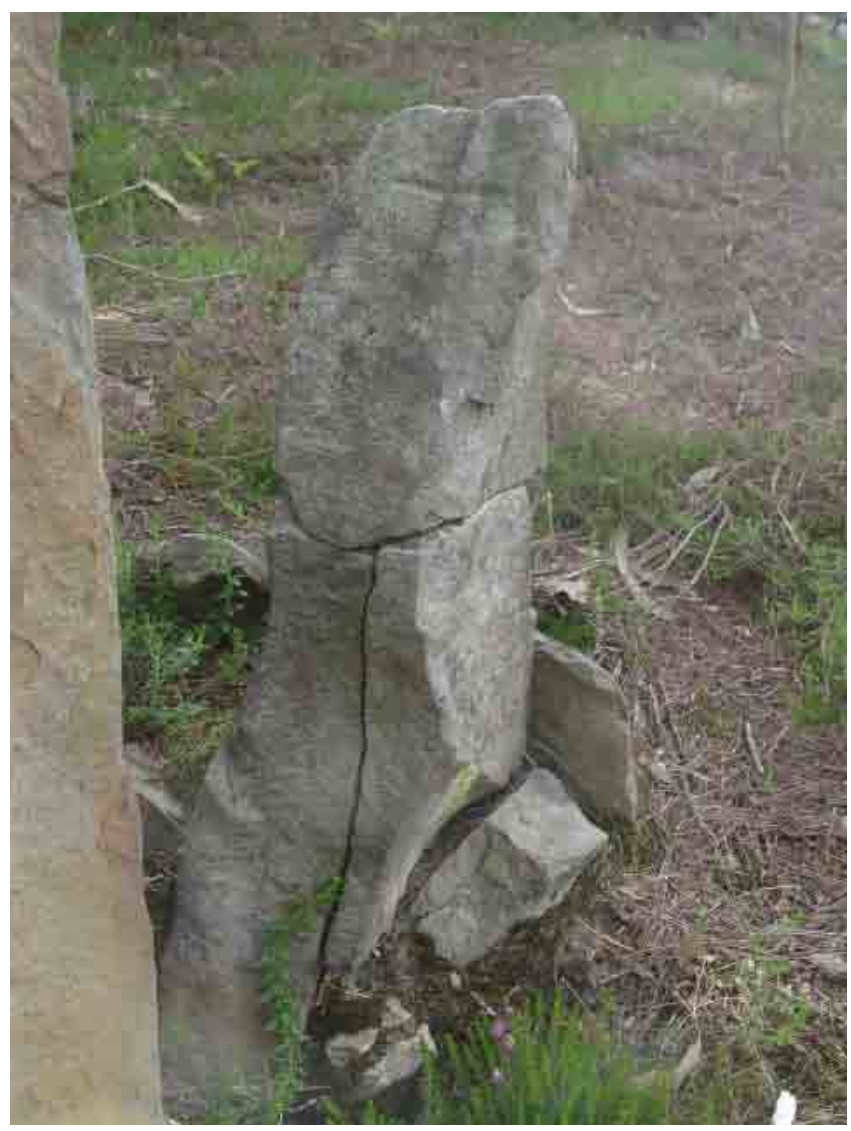

Figuras 5 y 6 . Distintas vistas del monolito

de 6 meses, hasta diciembre de 2012, para evitar posibles movimientos mientras se completaba el correcto fraguado de la cal y se adquiera una resistencia aceptable, para garantizar su estabilidad. La aplicación tanto de las lechadas como de los morteros fluidos se llevó a cabo de abajo a arriba.

Además de la consolidación se realizó también un fijado puntual de las lascas de piedra, pero se ha constatado que al ser lascas propias de la naturaleza de la piedra se han vuelto a producir, ya que el menhir se encontraba ubicado en el exterior, y se colocaron morteros de cierre en las grietas.

Tras la realización de la intervención de consolidación, al año siguiente se llevó a cabo una revisión del estado de conservación de la grieta, y como el terreno ya estaba asentado se sellaron las nuevas pequeñas fisuras aparecidas, para garantizar la conservación del conjunto. Después de este tipo de intervenciones, es necesario llevar a cabo controles periódicos de mantenimiento, ya que al encontrarse expuesto el monolito a los agentes atmosféricos, las variables de conservación son poco previsibles.

Actualmente la Dirección Facultativa, el arqueólogo J.C López Quintana, realiza visitas periódicas anuales y se encarga del mantenimiento del mismo junto con una asociación cultural de Busturia, lo que garantizará la conservación en el tiempo del mismo, ya que se realizan labores de elimina-

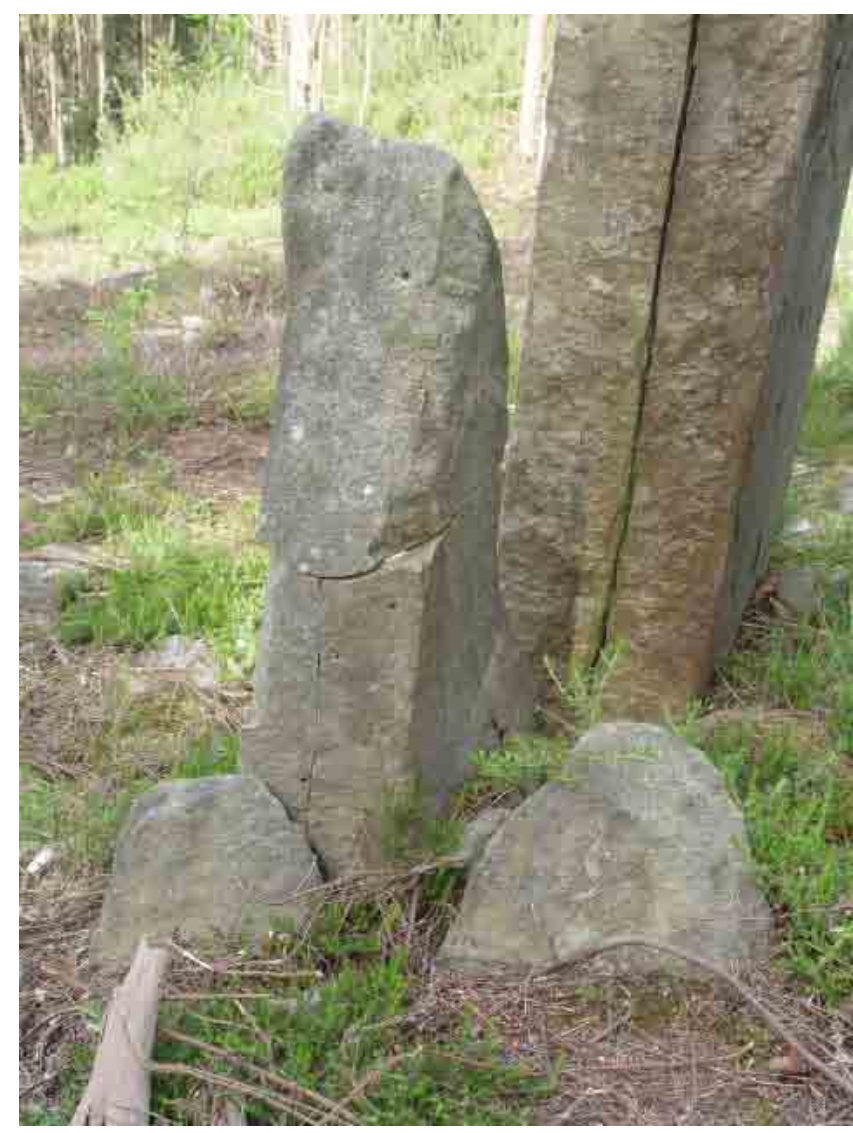

ción de plantas superiores cercanas al Menhir y se verifica la estabilidad del terreno. [Figuras $8,9,10,11,12$, 13 y 14]

\section{Datos técnicos relativos a la intervención de consolida- ción:}

- Tratamiento de eliminación puntual de la colonización biológica, se llevó a cabo mediante la aplicación del biocida, Botín T diluido en agua al $3 \%$ pulverizado, se realizaron cuatro aplicaciones con intervalos de más de una semana, realizándose entre éstas un cepillado en seco de la superficie en las zonas en las que se colocaron los morteros, con cepillos de cerdas sintéticas en función de la dureza de los restos a eliminar. Se realizó también un lavado de la superficie con agua pulverizada.

Sólo se eliminó la colonización biológica, en el menhir y en el hito mediane ro estrictamente en las zonas en las que se iban a colocar morteros.

- Tratamiento de fijado de lascas, tras la limpieza de la colonización biológica de la superficie con lascas, se colocaron unos morteros de cierre de baja granulometría para favorecer su aplicación en las fisuras.

- Tratamiento de colocación de morteros definitivos, para ello se realizaron pruebas de coloración, granulometría y textura. Las pruebas se llevaron 

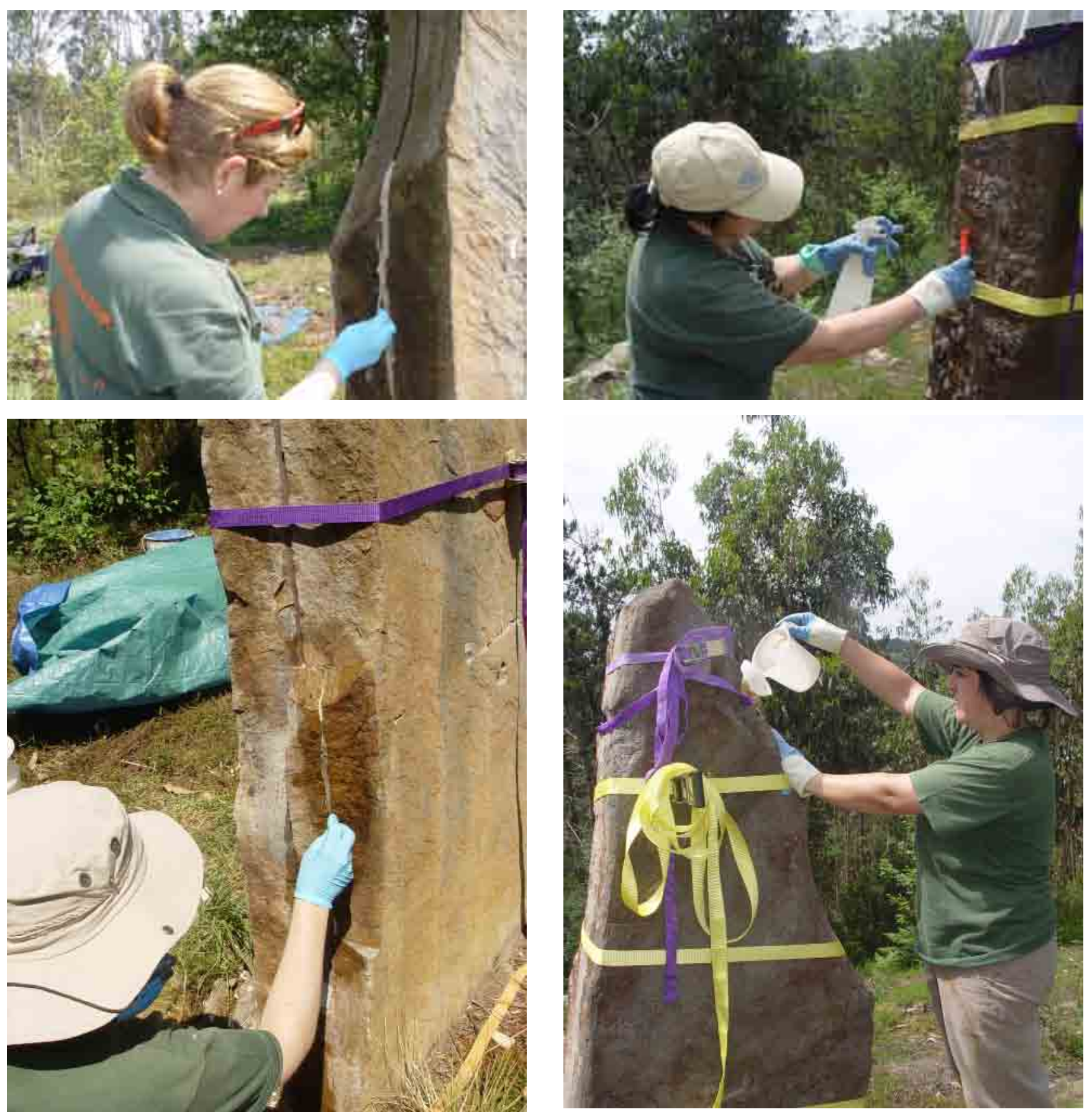

Figuras $\mathbf{7 , 8 , 9 , 1 0}$. Procesos de colocación de morteros de cierre, eliminación puntual de la colonización biológica y consolidación mediante inyecciones de lechadas hidráulicas.

a cabo con morteros de cal hidráulica NHL 3,5 gris y áridos de diferente granulometría y color con la dosificación cal: árido (1:3),confeccionados por nosotros. Antes de la colocación de los morteros definitivos se seleccionaron los más adecuados junto con la Dirección Facultativa.

\section{- Tratamiento de colocación de morteros de fondo} en la grieta longitudinal. Se colocaron morteros de fondo con cal hidráulica NHL 3,5 gris y áridos de gruesa granulometría con la dosificación cal: árido (1:3), confeccionados por nosotros. Estos morteros se pusieron para permitir la inyección de lechadas y morteros en el proceso de consolidación.

- Tratamiento de consolidación de la grieta longitudinal, tras el estudio de la grieta longitudinal que atravesaba y dividía en dos al menhir se optó, junto con la Dirección Facultativa por la realización de la consolidación de la misma mediante inyección de lechadas y morteros fluidos de cal hidráulica.

Las lechadas de inyección de la cal hidráulica NHL 3,5, no adquieren una resistencia mínima hasta pasados 28 días (ver tabla), por lo que fue necesario realizar una pausa de 28 días entre cada inyección realizar una pau- 

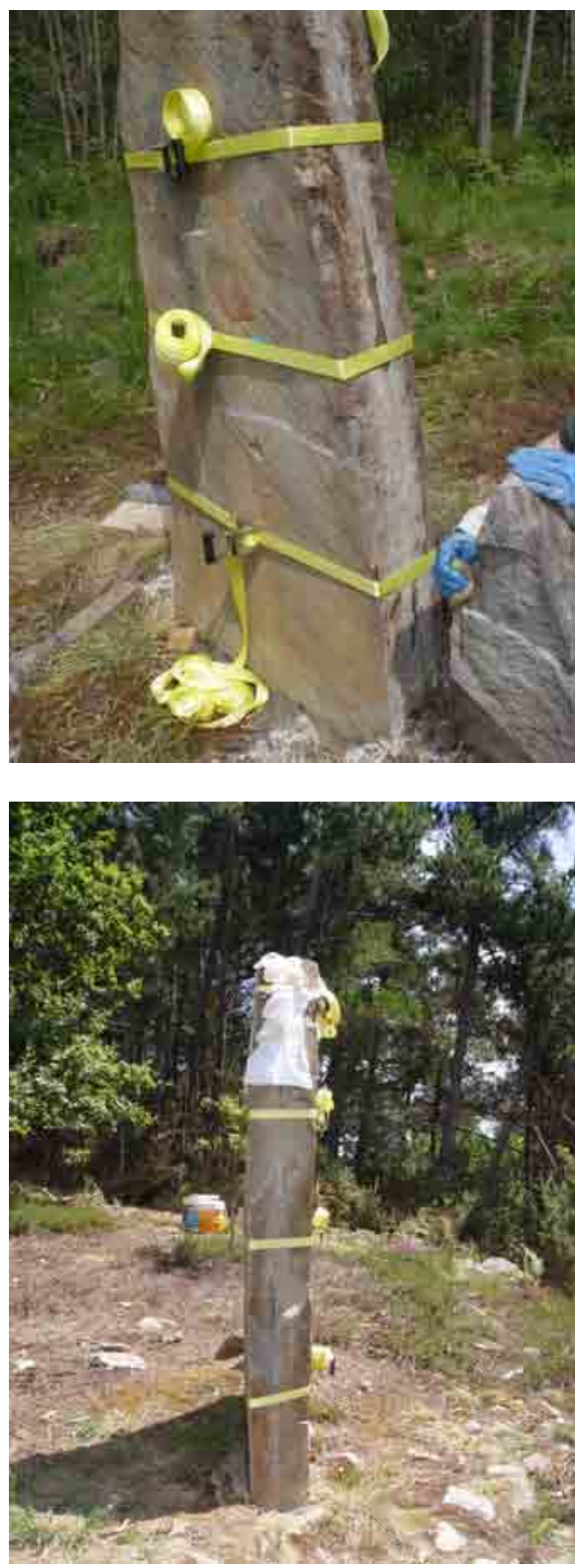

Figuras 11, 12, 13. Colocación de sistemas de sujeción, mientras se produce el correcto fraguado de la cal.

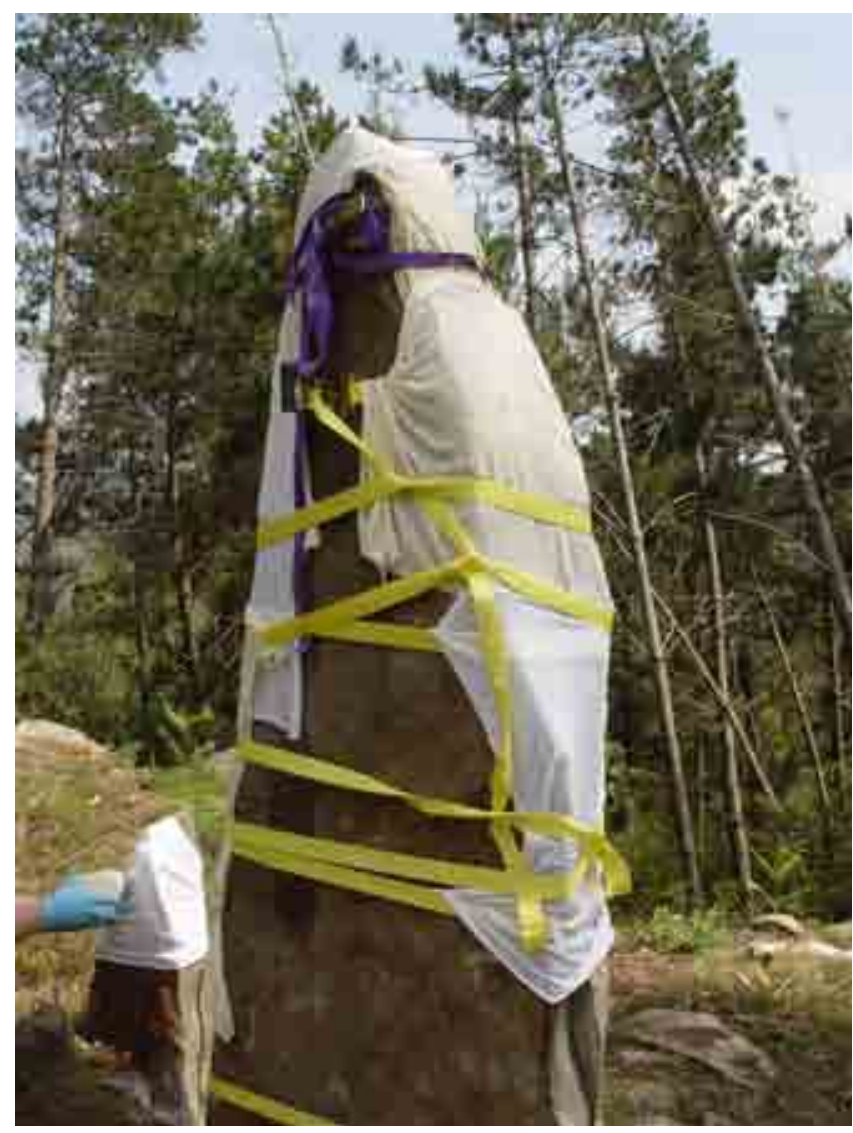

sa de 28 días entre cada inyección para desarrollar correctamente los trabajos de consolidación y garantizar su estabilidad en el tiempo. Además se colocaron las sujeciones correspondientes mediante colocación de cinco cinchas en torno al menhir para evitar los movimientos de flexo-tracción y la aparición de grietas en las fases húmedas y líquidas de inyección.

\section{- Tratamiento de sellado y micro-sellado de grietas} y fisuras, para el cierre de grietas y fisuras y de acabado final, tras la realización de las pruebas previas, se fabricó un mortero de cal hidráulica gris NHL 3,5 y arenas lavadas de diferente color y mármoles de colores de diferente granulometría, con el fin de conseguir un mortero lo más similar posible en color y textura a la piedra. La proporción cal/carga fue de 1:3. Para el sellado de la grieta principal se preparó un mortero de mayor granulometría para favorecer la adhesión entre capas y aumentar la resistencia. En cuanto al micro-sellado de las fisuras se creó un mortero de menor granulometría para favorecer la adhesión y la penetración en las fisuras.

En el hito medianero se colocaron morteros en las grietas y fisuras tras la eliminación puntual de la colonización biológica.

(*) Para evitar el rápido secado de los morteros, dadas las altas temperaturas existentes en el momento de su colocación, favorecer el correcto fraguado de los mismos y evitar grietas y fisuras, se cubrieron con trapos húmedos. 


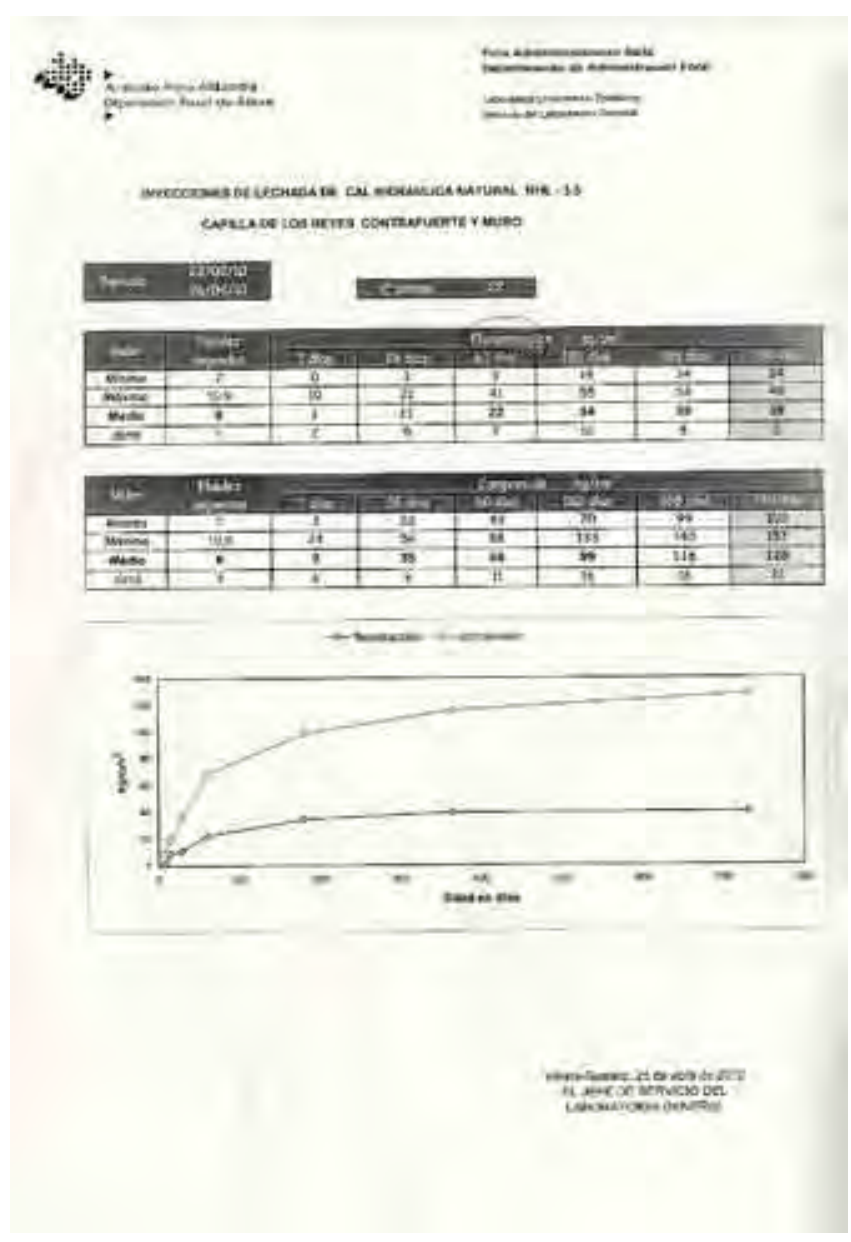

Tabla 1. justificación de resistencias

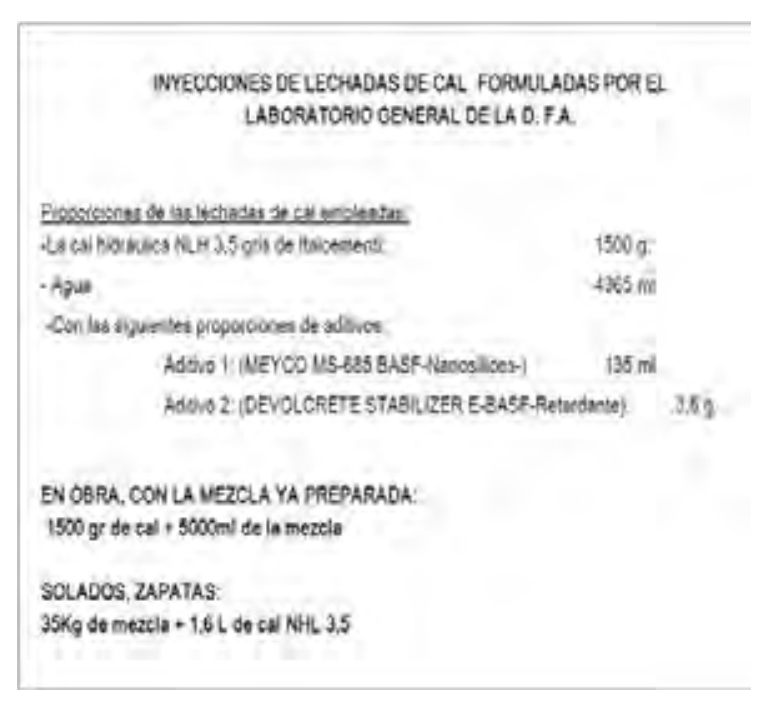

Tabla 2. Propoción de las lechadas de cal empleadas

Dosificaciones empleadas en los morteros: Mortero de fondo. Dosificación; (1:3), cal y áridos. Mortero de fisura. Dosificación; (1:3), cal y áridos.

\section{Bibliografía:}

BELL, O.; CÁMARA, L.; FERNÁNDEZ, M. Del C. ;GARCÍA, F. , GUARAS, B., KOROSO, I. y IGNACIO J. (2012). La inyección de cales en la consolidación de fábricas. Investigación aplicada. Santa Maria Katedrala Fundazioa - Fundación Catedral Santa María.

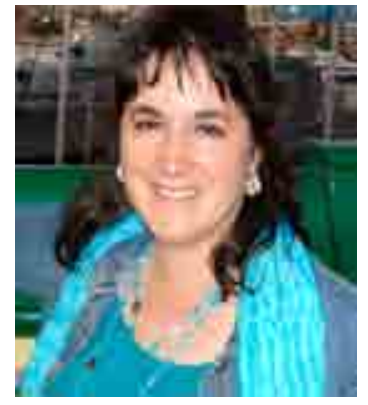

\title{
Ma Dolores Sanz Gómez de Segura , (Petra S.Coop.)
}

\author{
info@petrarestauracion.com
}

www.petrarestauracion.com

Diplomada en Restauración y Conservación de Bienes Culturales, especialidad escultura, Madrid, 1992; licenciada en B.AA., especialidad restauración de pintura, UCM 1996; becada por la Academia de España en Roma en la especialidad de Bienes Muebles, trabajo en los laboratorios del ICCROM bajo la dirección de Ernesto Borelli, 1992-1994. Actualmente está realizando su tesis doctoral en la UPV: "El color en la escultura pétrea y su secuencia en la diócesis de Vitoria, fines S. XV - S. XVIII" 
www.revista@ge-iic.com

Edición digital del GEIIC 